

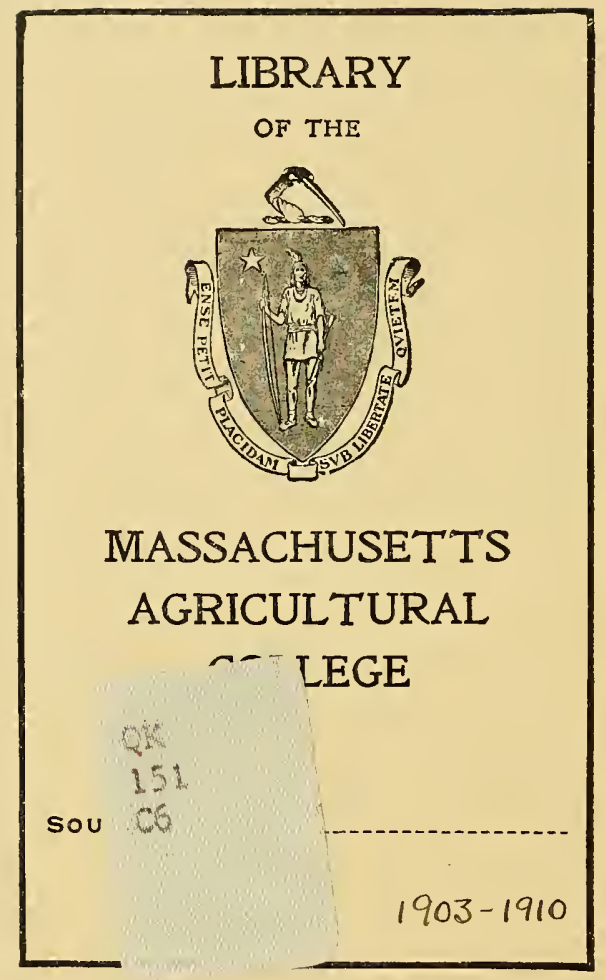








\section{IMETARY of $t$ \\ A. \\ MAR 171913 \\ As soiraltumal \\ Collorge}

\section{Itate of Connecticut}

ingragon in 1

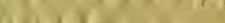

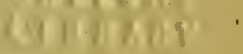

REPORT

OF

The Connecticut Agricultural Experiment Station

FOR THE YEAR 1903

PART IV.

REPORT OF THE STATION BOTANIST 



\section{CONNECTICUT}

AGRICULTURAL EXPERIMENT STATION

REPORT OF THE BOTANIST

G. P. CLINTON, S.D. 


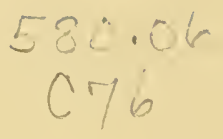

$1903-1910$

\section{EXPLANATION OF COLORTYPE}

Figures about natural size

I. Leaf Blight on Quince; see page . . . . . . 352

2. "Cedar Apple" on Cedar branch ; see page . . . . 301

3. Red Knot on bark of Kolveuteria; see page . . . . 328

4. Loose Smut in spike of Barley; see page . . . . 306

5. Anthracnose on leaf of Chestnut; see page . . . . 315

6. Black Dot on leaflets of Crimson Clover ; see page . . 316

7. Curl on Peach leaf; see page . . . . . . . 340

8. Leaf Spot on leaflet of Strawberry; see page . . . 360

9. Orange Rust on leaflets of Blackberry ; see page . . . 309

Io. Powdery Mildew on leaf of Indian Currant ; see page . . 327

Ir. Leaf Spot as seen on upper surface of Cherry leaf ; see page . 3 II

I2. Downy Mildew on Lima Bean Pod; see page . . . . 307

I3. Leaf Blight on Corn; see page . . . . . . 3 I7 


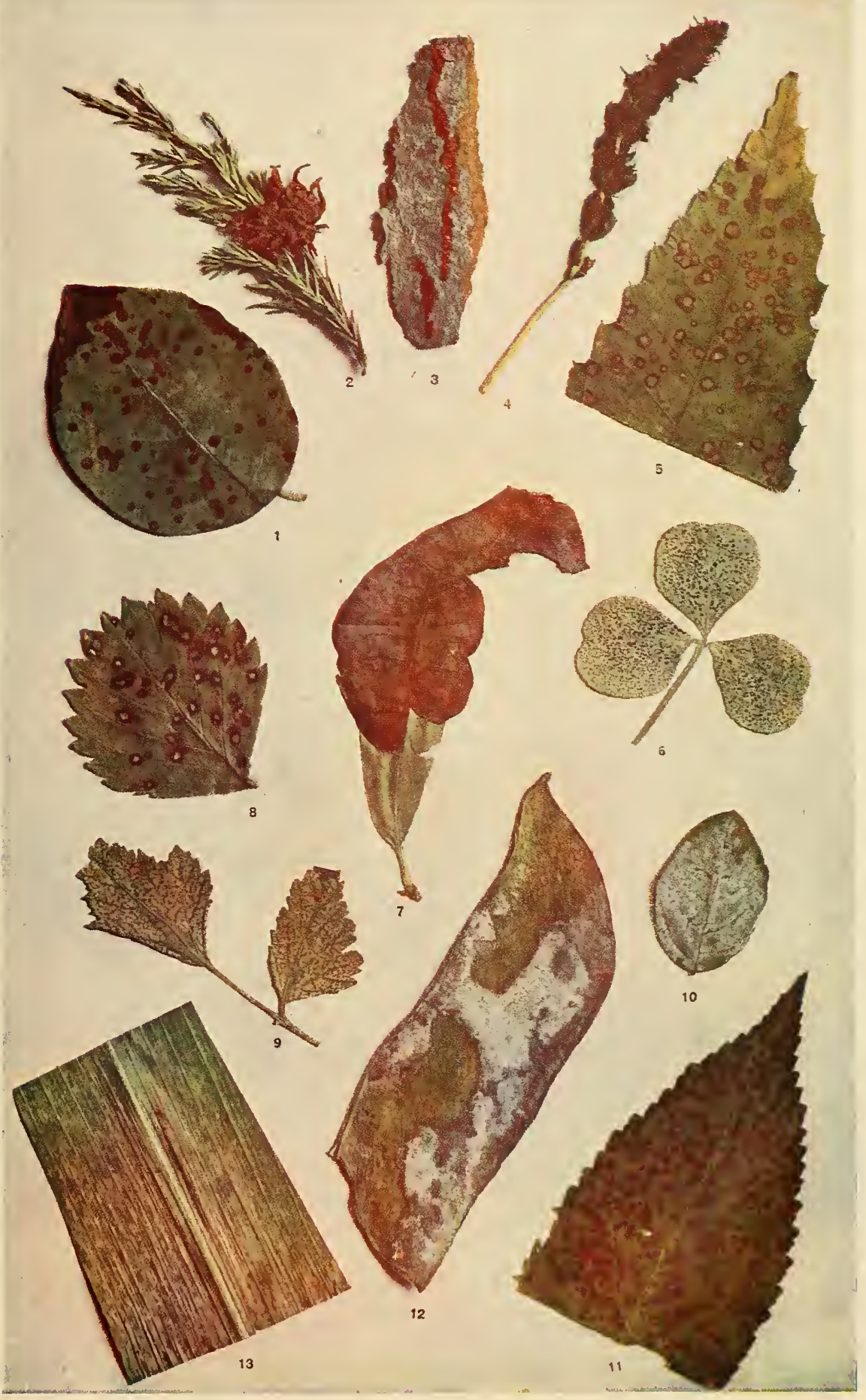





\title{
REPORT OF THE BOTANIST.
}

\section{DISEASES OF PLANTS CULTIVATED IN CON- NECTICUT.}

\author{
By G. P. Clinton.
}

Introduction. Since 1889 the botanists* connected with the Experiment Station have made studies of many of the troubles that assail our cultivated plants. The results of these investigations have been published in the annual reports or in bulletins, as short notes or as more extended treatises. During the past two seasons, the writer has made a special effort to gather together from different parts of the state information on all of the diseases of our cultivated plants, to use, with the previous data, as the basis of the present report. The cultivated plants of Connecticut fall under four general heads: viz., I. The general farm crops, 2. The horticultural or fruit crops, 3. The market garden crops, 4. The ornamental plants. Often the grower is interested only in one of these lines, but usually he specializes less and includes at least two. An attempt has been made to cover all of these industries in the notes reported.

\section{Causes.}

While the troubles to be discussed here are chiefly those produced by fungi, it will be well to note briefly the chief causes of injuries to plants. We can group these, somewhat arbitrarily, under the following four heads:

x. Mechanical Injuries. Under this head may be placed such injuries as result from some sudden mutilation of the plant. Damage by wind storms is of this character, and we had a good illustration of the injurious nature of such an agent to our fruit and shade trees in the gale of last September. Lightning is sometimes the cause of injury to shade or forest trees, opening the way, also, for future decay by timber-rotting fungi. Forest fires, while not occurring often on a large scale in this state, still, sometimes do considerable damage to local wood lots. Animals are agents of more or less damage to plants. Birds

\footnotetext{
* Prof. R. Thaxter, 1889-9I ; Dr. W. C. Sturgis, I89I-I9or.
} 
destroy considerable grain and fruit. Mice and rabbits often injure fruit trees by girdling. Sometimes cattle go where not wanted, with destructive results. In towns the injury to our street trees by horses is very evident. See Report 1900, p. 332. Man, himself, is often a mutilator under some conditions when installing city improvements.

2. Insect Injuries. These might be classed under animal injuries, but the damage insects cause in the way of chewing, sucking and stinging cultivated plants is so great that they deserve notice by themselves. It is not the purpose to treat of these here since the entomological reports issued from time to time by the Station deal with this subject. Since the fungi are occasionally classified by some persons as "bugs," I wish to call attention to the fact that insects as agents of injury to plants are entirely different from fungi as disease-producers. Usually the troubles caused by these two agents can be distinguished readily. Holes in the leaves or wood may generally be attributed to insects, dead spots to. the fungi. While insects by their stings, often cause a morbid growth, they are not true agents of decay as are the fungi and bacteria. The presence of an insect at the place of injury or of the spore stage of a fungus usually indicates the responsible agent.

3. Physiological Troubles. These are often obscure as to cause, being due to some disturbance of the natural surroundings of the plants, and are generally progressive in nature. Different conditions produce different troubles and as yet comparatively few have been studied or even noted. Cold weather is not an uncommon cause of trouble in plants. Injuries from this source usually result from a mild, late fall (in which the wood of plants fails to ripen thoroughly) followed by a sudden severe freeze, as that of December 9, 1902; or from an unusually severe winter, as has been the present; or from mild, open winter weather, inducing a flow of sap, followed by freezing weather; or from an early spring, inducing premature blossoming, followed by killing frosts, as illistrated somewhat by the spring of 1902 . The resulting injuries may be classed partially as mechanical, as the sudden death of the fruit buds, but chiefly as physiological. As yet we do not sufficiently know what troubles result from severe but not fatal injuries to the roots, wood and cambium. The primary effects of the cold 
are often manifest at once as a distinct injury, the secondary effects may be obscured in later developments, possibly covering a number of years. The effects of the sudden freeze of December 9, 1902, became evident at once or during the past year by the partial destruction of privet hedges ; by the almost total destruction of peach fruit buds, also by the death of some twigs and slight injury to the wood; by the girdled areas in the bark at the base of apple trees; and, in some nurseries, by the severe injury or death of the wood of young fruit trees, especially apples, without apparent injury to the bark or cambium. During the past severe winter, the injury, so far as observed, has been the partial destruction of the peach fruit buds and the very great injury, or even death in some orchards, of the wood, showing by its darkening color down to the snow line. Heat by affecting transpiration of moisture may produce wilting of foliage or tip burn; in greenhouses it may even burn spots in the leaves, probably in connection with imperfect glass or drops of water. Water when present in excess in the soil shuts out the proper circulation of air and thus causes a sickly yellowish plant growth or drowns it out entirely. In the shape of rain and dew it is the chief factor in the spreading of fungous diseases. Fertilizers, when used carelessly, sometimes burn the foliage, injure the roots or often kill the germinating seedlings. On the other hand, the lack of the proper elements of fertility in the soil manifests itself in a scanty or sickly plant growth. Enzyms, or chemical ferments, produced in plants through a disturbance of their normal activities and causing a diseased condition of the tissues containing them, are now given as the cause of such obscure troubles as peach yellows, calico tobacco, yellows of asters, etc. Such troubles are sometimes transmitted and are said to be produced by "running out of the stock," by unfavorable mechanical conditions in the soil, etc.

4. Fungous Diseases. It is the comparatively few physiological troubles and the very numerous fungous diseases that this article treats. The latter have, as the agents, what are commonly called parasitic fungi. A fungus is a plant as truly as are the flowering plants, but it is low down in the vegetable kingdom, lower even than is the insect in the animal world. Let us consider more fully the nature of these fungi, their 
effect upon vegetation as producers of disease, and the methods employed in combating them. [See Reports I889, pp. I27-9; I897, p. I82; I900, p. 255.]

\section{Parasitic Fungi.}

Nature of Fungi. As has just been stated, fungi are low in the plant kingdom, in fact, among the lowest and consequently of rather simple structure. Many of them are microscopic in size, while the largest are represented by the shelf fungi, toadstools and puffballs. They differ from the higher groups (the algæ, mosses, ferns and flowering plants) in that they lack chlorophyll or the green coloring matter that enables these other plants to manufacture their food directly out of the air, water and soil. They must in consequence, like animals, obtain their food already in an organized state from organic matter. When they obtain this from dead vegetable or animal matter, they are known as saprophytes, examples of which are the common household molds, puffballs and toadstools. When they get it from the living plant, or animal occasionally, they produce disease and are called parasitic fungi, as the various blights, rusts, smuts, mildews, leaf spots, etc. The line separating parasitic and saprophytic fungi is not very sharply marked, for many parasites have stages that are saprophytic, and some species, ordinarily saprophytes, may under certain conditions act as parasites. In general two structural parts are recognized in fungi; namely, the mycelium and the spores.

Mycelium. This is the vegetative part of the fungus (corresponding in function, in a general way, to the roots, stems and leaves of the higher plants) since it is largely concerned in gathering food. As stated before, it does not manufacture this food but gets it directly from the host (the plant or animal upon which it grows), either from food intended for the latter's use, or as the result of the disorganization of the plant's cells or cell contents by enzyms, or through the formation of morbid plant growths. The disease thus induced may be very local or widespread and it may become evident at once or only after considerable time.

In general the mycelium consists of microscopic threads, becoming more or less branched. The gross aspect is shown by the spawn that ramifies through the soil from the base of 
the toadstool. These threads are divided more or less by cross partitions into cells which are usually elongated. Generally the threads of the nycelium ramify loosely through the substratum but sometimes they are compacted into masses. The cells when young are filled with protoplasmic and other contents but with age the contents become limited to the walls or to scattered granules. The mycelium is generally colorless. Sometimes it is confined almost entirely to the exterior of the host, only sending short food-gathering branches, haustoria, within, as with the powdery mildews; but usually this condition is reversed and the mycelium is entirely concealed within the host, running between or often directly into the plant cells, and becoming evident on the exterior only when specially modified parts give rise to the spore stage. As a rule, then, the mycelium is not very evident or characteristic in the different fungi.

Spores. These are the reproductive bodies and, roughly speaking, correspond in function to the seeds of the flowering plants. They are formed on or from modified threads of the mycelium, usually at or on the surface of the host. While microscopic in size, the spores are usually produced in such abundance as to be evident to the naked eye. Thus in the rusts and smuts the reddish or blackish outbreaks are made up entirely of these bodies. Often they consist of a single cell, varying in shape, size and character of the wall in different species; not infrequently they are composed of two to many cells variously combined, of which, occasionally, only part are fertile. So great are these variations that those of each species usually have some individuality by which they can be recognized and it is chiefly upon these spore differences that the fungi are classified.

Very curiously each fungus generally has more than one kind of spores, sometimes as many as four or five kinds. These spores are of two types, summer and winter spores. The summer spores are usually thin-walled, germinate readily and are produced on the external parts of the host in great abundance, to be easily scattered. Their object is to spread the disease to the same or other plants during the growing season. The winter spores, on the other hand, are not produced so abundantly, are often buried more securely within the tissues, 
and if not thick-walled are formed within sacs and receptacles that protect them to a great degree from moisture and cold. Frequently they will not germinate until the following spring. Their evident function is to carry the fungus over the unfavorable period of winter weather. Mycelium in the perennial parts of the plant, also, may serve this same purpose, as in the case of the orange rust of blackberry.

The different kinds of spores are produced at different times of the year, usually the summer spores in spring and summer and the winter spores in summer and fall. Thus, the red (summer) stage of rusts precedes the black (winter) stage. This peculiarity is carried a step further when we find one spore stage developing parasitically and another saprophytically. Thus, in apple scab the summer spore stage exists as the "scab" of the living leaves and fruit while the winter stage develops on the dead leaves in the fall and following spring. The separation of the spore stages, however, becomes widest when they occur on entirely different host plants, one producing the other. Such is the case of the cedar-apple rusts and the barberrywheat rust.

To solve the complete life history of a fungus, therefore, often becomes a considerable problem. It is because of these complications that botanists have often described different stages of the same fungus as distinct. species. There are many parasitic fungi of which only the summer spore stages are known but which are suspected of having saprophytic winter spore stages, since detailed study of related forms has often brought these to light.

Fungi infect their host through the germination of the spores. Moisture in the shape of rain or dew is necessary to induce this. Usually the germination must take place on certain parts of the plant in order to secure entrance. Often the parts permitting infection are quite localized but more often it is a question of the tissues being in a young state and thus easy of penetration. The common method of infection is for the spore to send out a short germ thread which enters the plant through the stomates (breathing spores) or else bores directly through the tissues. Once inside, this thread, by growth, gives rise to the extended mycelium. Comparatively few spores meet conditions that insure infection of the host, hence the necessity to the fungus of great numbers of spores. 
Relation to weather. We have remarked on the importance of moisture to germination of spores and consequent infection of hosts. The character of the weather thus bears important relation to the spread of plant diseases, especially with certain kinds at special times. It is not the amount of rain that falls that is most important but the time it takes. For example, a few days of moist weather with comparatively little rain but also with little sunshine to dry away the moisture from the foliage is evidently more favorable for spreading these troubles than a violent rain storm followed the same day by bright sunshine. Cloudy weather, by hindering evaporation of the water transpired by the leaves, may aid in the spread of disease.

In its relation to different diseases of plants, the season of the moist weather is very important. For instance, a rainy April-May period is very favorable for apple rust; a cold, moist May or June aids decidedly the introduction and spread of apple or pear scab. The fruit grower dreads moist weather during the ripening and harvesting period of his peach and plum crop, since brown rot flourishes chiefly at this time. The market gardener is specially anxious about the rainy week that may come in July or August and blight his potato vines, and which, if followed with additional rainy weather, is likely to rot the tubers; or of wet August and September weather that produces stem rot in his onions. The downy mildews are especially lovers of moisture, and so the musk melons and cucumbers have suffered from one of these troubles during the past three years, because of their moist summers.

Water affects the spread of fungous diseases in three ways: First, many fungi, especially the stages producing thin-walled, ephemeral spores, produce these only or most vigorously during moist weather. Second, the rain, in a measure, acts as a distributing agent, washing the spores over different parts of the plant. Third, water, as has been stated before, is needed for the germination of the spores.

Injury and Loss. It is evident from what has been written that parasitic fungi often become agents of serious disease in plants and thus cause greater or less financial loss to the husbandman. It is not the intention to present an array of figures showing the losses caused by these parasites in Connecticut, for startling as these might look, they are not nearly so suggestive 
to the grower as some personal recollection he may have of local losses. Occasionally one hears the remark, "Fungous troubles are much worse than formerly. We never used to be bothered so by them." Very often this statement is incited by a season that has been especially favorable for such troubles, or is drawn forth by an unusual personal loss. Where plant growing is intensified, as it is in Connecticut, we may reasonably expect more trouble from fungous pests than occurred in the earlier days when farms were more scattered, importations limited and crops less specialized. We should bear in mind, however, that agitation and information now make losses seem more prominent than formerly, since then the grower knew less . of the why and wherefore of his troubles, attributing them, perhaps, wholly to season and luck.

Some of the pests causing serious loss during recent years may be briefly mentioned. Brown rot of peaches and plums is always present at harvest time, some seasons becoming so prevalent that it sweeps away a large part of the profits in a few days. The past year produced a small peach crop and this accounts in part for the small amount of rot, even in early varieties, as the fruit of heavily laden trees always rots more or less because of the facility for spreading the disease. Scab or black spot is another trouble of the peach that attracts the attention of the grower, for, while it is not primarily an agent of decay, it causes the fruit to become second class in appearance, often smaller in size or one-sided, and by cracking it, opens the way for decay. This trouble seemed to be worse than usual the past season. Black knot of plums and cherries is an old trouble that proved more prominent than usual last year. This is one of the few fungous diseases against which laws have been directed in some states. Downey mildew or blight of potatoes during the past two years has prematurely killed the vines in July or August, thus cutting down the crops of the late varieties 25 to 50 per cent., for the vines should have lived until killed by the September frosts. During the past season rot of the tubers, following the blight, added to the loss and attracted considerable attention among the growers. Stem rot of the White Globe onions has now been very bad for two years and has almost discouraged the growing of this popular and otherwise very profitable variety. In the vicinity of Green's Farms and Southport in 1902, the loss 
was reported to be in the vicinity of $\$ 50,000$, and last year some growers, after marketing part of the crop with returns little greater than the freight charges, threw away the remainder. The Dozmy Mildew and other troubles of the musk melon have proved so serious during recent years that many have given up growing this plant. The greenhouse man has his special troubles with the leaf spot of violets, rusts of carnation and chrysanthemum, mildew and leaf spot of rose and the various stem rots, and sometimes the local loss caused by one or more of these fungi becomes considerable.

Classification. Botanists have classified the fungi under various groups according to their relationships. Some of these groups contain only forms that are of little economic importance, but the chief divisions all contain at least some important parasitic forms. The scientific name of a plant conveys some idea of its nature and relationships. Dr. Sturgis in his Literature of Fungus Diseases [see Reports 1893, p. 253; I900, 255] aimed to apply the common names somewhat similarly, so that the terms rust, smut, blight are applied only to certain related forms and not used indiscriminately. Since in the following notes this plan has been largely followed, it may be profitable to discuss briefly a popular classification of these chief groups:

Slime Molds. Some scientists place these forms with the animals, and strictly considered they are related to rather than a group of true fungi. Ordinarily they occur as saprophytes that are found chiefly on decaying stumps in the woods during moist weather. At first they consist of brightly colored naked masses of protoplasm that ooze out in jelly-like masses on the wood, but in a dry atmosphere these soon change into clustered spore-bearing bodies. They are mentioned here because at least two forms are parasitic; viz., club-root of cruciferous plants and crown-gall of fruit trees. In both of these diseases there is a morbid growth of the infected tissues of the host but there is no evidence to the naked eye of the causal agent. See Plates $\mathrm{XV}, \mathrm{a} ; \mathrm{XXIV}, \mathrm{b}$.

Bacteria. These, also, are hardly true fungi but are very closely related to the lowest forms and for all practical purposes may be considered with them here. Bacteria as agents of contagious diseases in animals, especially in man, are 
recognized as very important organisms. While the diseases produced in plants are comparatively few, these are usually of importance and are very properly designated blights. They cause the death of the tissues invaded and these often assume a semi-water-soaked appearance. No sign of the bacteria is seen save occasionally in the sticky slime that oozes out on the surface. Examining this under the microscope, we see myriads of these smallest and simplest of living organisms-mere rounded or elongated cells too small to be seen save with the highest powers. Insects are very important factors in the distribution of these germs and they are among the most difficult troubles to control. Prominent examples are pear blight, bean leaf blight [Plate XIII, d], blight or wilt of cucurbits [Plate XXVI, a] and wet rot of potatoes [Plate XXII, a]. Some bacteria are useful, as soil bacteria, those producing root tubercles on leguminous plants, those giving flavor and aroma to butter, etc.

Thread Fungi (including Downy Mildews). This group includes a miscellaneous lot of fungi of which only the Downy Mildews are of economic importance in this state. These mildews are usually distinguished by the rather dense whitish growth they form on the outside of the infected parts. See Plate XIII, b. Examining this under the microscope, it is found to consist of erect fertile threads having a special, often tree-like, branching above, on the tips of which the thin-walled summer spores are borne singly. Less commonly, these fungi form large, thick-walled; dark colored winter spores embedded in the tissues, from which they are liberated only by decay. Prominent examples of the downy mildews are blight of potatoes [Plate XXIII, a], downy mildew, or blight of melons and cucumbers [Plate XVIII, b], and the downy mildews of lima beans [Plate XIII, b], and of grapes [XVII, b].

Smuts. The smuts cause very important diseases of the cereals, especially in the central and northwestern part of this country. As their name indicates, they are ordinarily distinguished by the "smutty" outbreaks on various parts of the host, most commonly occurring in the floral parts. Some species, the white smuts, of which few are of economic importance, are permanently embedded in the tissues and lack this dusty character. These outbreaks are made up entirely of the 
spores. The spores are usually single cells, but may consist of several cells united into a ball, which sometimes is covered with a coating of sterile cells. The spores in germinating often give rise to secondary spores, after the fashion and nature of the yeast fungus, and these help greatly in spreading the fungus. In the case of corn smut, for instance, these secondary spores are capable of existing and multiplying sapropyhytically in manure. In this state, the most injurious smuts are those of onion, corn [Plate XVI, b], oats [XIX, e] and barley [XIII, a].

Rusts. Rust is a term often used by growers to indicate any spotting of foliage, but as restricted here, it is applied to those small, reddish or blackish outbreaks on leaves and stems that are somewhat similar to the smuts but usually less dusty and often quite firm. They form a very common and large group, and include some of the most injurious of our parasites. In this state, the economic species include such examples as apple rust [Plate XI, c], oat rusts [Plate XIX, c-d], carnation [Plate XV, b] hollyhock [XVII, d], bean [Plate XIII, e] rusts, etc. The rusts are especially interesting because their spore forms may occur on different hosts. Let us illustrate this with the case of the black stem rust of oats: spermatia, inconspicuous, supposed spore stage, on upper surface of barberry leaves; I, aecidio-spores borne on the under surface, beneath the above, in the cluster cups; II, or uredo-spores, forming the reddish outbreaks on the stems of oats in early summer; III, or teleutospores, forming the black, less dusty, outbreaks on these same stems later in the season. Some rusts possess only one or two of these stages. In the case of the apple-leaf rust, the aecidial or summer spores occur on the apple leaves and the teleutal or winter spores on the cedar in the "cedar apples."

Fleshy Fungi. These are the most conspicuous fungi, including the toadstools, shelf fungi, puffballs, etc. The "spawn" of the cultivated toadstool is the mycelium, and it is perhaps chiefly by this that these fungi are carried over the winter. The toadstool itself is the fruiting body, bearing the thin-walled spores on the surface of the gills, that radiate out on the under side of the cap. In the puffballs, the dusty cloud that puffs out on pressure is composed of the spores. These forms are largely saprophytic, getting their food from the humus of the soil or dead wood. Some species are parasitic on trees; the 
injury done to trees and timber by the mycelium, causing dry rot, is very considerable.

Sac Fungi (including Powdery Mildews). Under this group come a great variety of fungi, including some of our most destructive parasites. They are distinguished microscopically by the fact that their winter spores, often eight in number, are borne inside of sacs or asci, and these in turn are enveloped, partially or wholly, by a special receptacle. The powdery mildews constitute one of the most distinct and important groups of this class. They are characterized by their mycelium developing on the exterior of the host, showing as a cobweb-like or cottony growth. The summer spores are produced on this in upright chains. The winter spores, asco-spores, are formed inside the small yellowish or blackish balls, perithecia, that can be seen with a lens, or often by the naked eye, embedded in the mycelium. See Plate XV, c. The great variation in the character of the sac fungi is shown by the following examples: powdery mildews of cherry [Plate XV,c], phlox [Plate XXIV, a], and rose [Plate XXV, a]; black knot [Plate XXIV, c], black rot [Plate XVII, a], ergot [Plate XXV, b]. Not uncommonly the summer spore stages of this class of fungi are serious parasites, while the winter spore stages develop merely as saprophytes, as in the case of apple scab, bitter rot and brown rot.

Imperfect Fungi. These are so-called because only summer spore stages are known. They are suspected, for the most part, to be merely stages of the sac fungi, and every once in a while these winter stages are found, as recently in the case of bitter rot of apples and brown rot of peaches. Under this group come many of the leaf blights, leaf spots, anthracnoses, molds, etc. Common examples are sooty blotch of apple [Plate XI, b], black rot of quince, anthracnose of bean [Plate XIII, c], potato scab [Plate XXII, c], leaf spot of violet [Plate XXVIII, d], etc.

\section{Prevention.}

It has become evident to the reader who has followed us thus far, that the fungous troubles of Connecticut are of sufficient importance to demand the efforts of the grower to lessen their ravages. What are some of the methods that may be employed to control them? 
Selection. The first requisite for good plants is Good seed, spelled with a capital $G$. Aside from any physiological advantage that large, plump, thoroughly matured seeds may have over smaller shrivelled ones, the former are less likely to come from diseased plants or to carry disease germs than are the latter. In some cases it is desirable to know the origin of the seed, for in the case of the grain smuts, the spores adhere mechanically to the seed. Evidently, seed from a field free from smut is to be preferred to that from a very smutty field, though the seed may look as good. Potato tubers, though not strictly seed, come under this class. Use scabby tubers and the resulting crop will be more or less scabby, according to the season. The same principle holds true of nursery stock. Buy of the most reliable firms, avoid purchase from nurseries where certain troubles are known to be bad; inspect the stock when it comes and discard the poor, especially if it shows knots or diseased areas. Selection of varieties may aid in some cases to keep down specific troubles, since it is well known that varieties vary in susceptibility to disease. For example, in a recent visit to a nursery, the writer saw Wealthy and Fallowater apples abundantly covered with leaf rust, while all of the other varieties in the same block of trees were free. Greenhouse growers well know that there is wide difference among the carnations in rusting. Our government botanists have even taken up the task of rearing disease proof varieties to certain diseases by selection and breeding. Along this line, the writer recalls what was told him by an eastern asparagus grower who was troubled with rust. He said he noticed in a certain spot of a neighbor's field that a few asparagus plants always remained green after the others were dying from the rust. He obtained plants from that place, and was gradually building up a bed to determine if he could secure exemption from the disease by obtaining a rust-proof variety. He may or may not succeed, but his experiment costs him little to determine this point. Selection of grouind certainly counts in those cases where disease has become established in the soil. A rational system of rotation must be adopted to prevent or lessen such troubles as onion smut, potato scab, club root, etc. Through continued use, especially with the same crop, the soil of the greenhouse may become infected with stem rot, drop and other fungous troubles. 
Cleanliness. It is easier to write about ideal farm methods than it is to carry them out; nevertheless, no one will deny that cleanly methods are the best. Thorough culture not only destroys weeds, conserves moisture, but it aids in the quicker destruction of old leaves, etc., that may be harboring the disease germs of last year's crop. Refuse of the present crop, especially when diseased, if left on the land, becomes a menace to succeeding crops of a similar nature. When one sees a turnip field in which the owner has very carefully gathered all of the roots except those "clubbed," he feels confident that the grower is helping along the trouble in the future use of that field for a similar crop. So, too, a field left covered with anthracnosed melons does not help the success of future crops. The manure pile is a very essential feature to sticcessful plant growing, but it should not be made a refuse pile upon which diseased vegetable matter is dumped. It will never do any harm to gather carefully all rotting fruit and refuse stems from the garden or orchard at the close of the season; it will do good, but the place to put them is in the bonfire.

Pruning. With certain diseases, the best treatment consists in the removal of the affected parts. In pruning pear trees for blight, or plums for black knot, one must cut off the infected branches so as to include all of the diseased wood. Aside from the removal of the diseased limbs, pruning is useful by letting in air and sunlight to aid in the rapid evaporation of moisture and thus hinder infection from germinating spores; it also lessens the work of spraying, where this is done. The thinning of fruit, when abundant, or the removal of decayed specimens, is a common practice that aids in minimizing most rot troubles. Greenhouse men fight many troubles, as leaf spot of violet, by picking off the diseased leaves as fast as they appear. As many of our greenhouse and garden troubles first get a foothold on a few leaves, the prompt removal of these is desirable. The place for all such refuse is the fire.

Fungicides. One of the most effective methods of fighting many fungous diseases is by the use of fungicides. These are prepared in such strengths that the spores adhering to the treated parts are either killed or prevented from germinating while the tissues of the plant are not injured. Such treatments are made in different ways to meet the requirements of various 
troubles. Seed treatment, for instance; where the seed is soaked or sprinkled with the mixture, has been found an effective method for preventing most of the cereal smuts. Applied to the tubers it is one of the ways of keeping down scab of potatoes. Soil treatment is sometimes given where the germs become established in the ground, as in the case of onion smut and club root, when lime and sulphur may be used.

Fungicides are most commonly applied as a spray. By means of spray pumps, the fungicide is distributed uniformly over all parts liable to infection as a fine mist. Upon drying, if the fungicide contains a sediment, this serves to destroy spores that are brought later. Spraying depends largely for its success on preventing rather than curing disease. The man who wins with this treatment is the one who anticipates and precedes his trouble rather than the one who follows along after the disease has gained a foothold. From the above consideration, it becomes apparent that there are two very important factors to successful spraying; namely, it must be done always with thoroughness and at the proper time, which varies with the disease to be treated. A great many substances have been tried as fungicides; a few of the most valuable are given here. Further information on this subject is given in Reports I890, p. IIo; I893, p. I03; I898, p. 266, and Bulletins III, II5, I25, I42 of this Station.

Bordeaux Mixture. 4 lbs. Copper Sulphate, 4 lbs. Fresh Lime, 40 to 50 gals. Water. Dissolve the copper sulphate in hot or cold water, suspending in a coarse bag. Slake the lime in a small amount of water and then strain into the spray barrel which is half filled with water. Dilute the copper sulphate to about half a barrel and then pour into the spray barrel, stirring the mixture. If necessary, add a little water to fill the barrel. Where large quantities are used, it is advisable to make stock solutions of the lime and the copper sulphate, each containing I lb. to I gal. of water. The proper proportions of each ( 4 gallons each per barrel) can then be used, as in the preceding account, when needed. Bordeaux mixture is the best fungicide and is to be used in all cases except when sediment on the sprayed parts is objectionable. The home-made mixture is preferable to anything bought in the market; and the dry powders used for dusting merit little attention as yet. 
Dilute Bordeaux. 2 lbs. Copper Sulphate, $4 \mathrm{lbs}$. Fresh Lime, 40 to 50 gals. Water. This is sometimes used when there is danger of burning the foliage by use of the stronger solution, as in the case of peach and Japanese plums. Caution, however, may be necessary even with this strength, especially on old foliage. Perhaps it is most useful for the second spraying, when necessary for peach curl.

Resin Bordeaux. 5 lbs. Resin, I lb.Soda lye, I pt. Fish Oil, 5 gals. Water. Dissolve the resin in the oil heated over fire; cool and add the lye, stirring slowly; then add water and boil until mixture will dissolve thoroughly in cold water. Use at rate of two gallons to a barrel of Bordeaux. This makes the Bordeaux mixture adhere better to smooth foliage and also to last longer. It will probably be found most efficient when used on such plants as carnations, onions, asparagus, etc.

Soda Bordeaux. I lb. Soda lye, 3 lbs. Copper Sulphate, 5 oz. Lime, 30 gals. ruater. Halsted, of New Jersey, gives this as a substitute for Bordeaux when one objects to much sediment. It requires more care in its preparation, as an excess of soda, or too little, will burn the foliage, so the formula calls for just enough soda to neutralize the copper, with a little lime added to make it slightly alkaline. Selby, of Ohio, used a slightly modified formula ( $4 \mathrm{lbs}$. copper sulphate, $\mathrm{I} / \mathrm{s}$ to $\mathrm{I} / 2 \mathrm{lbs}$. soda lye, 50 gals. water), which he preferred to Amm. Sol. Cop. Car. for the late sprayings against black rot of grapes. His formula, because of the omission of lime, leaves no sediment.

Amm. Sol. Cop. Carbonate. 5 ozs. Copper Carbonate, 3 pts. Ammonia, 45 gals. Water. Dilute the ammonia, if strong, with several volumes of water and use just enough to dissolve the copper carbonate; then dilute with water to 45 gallons. This fungicide is often used to replace Bordeaux when no sediment is desired on the sprayed plants. Because it lacks this sediment its fungicidal value is temporary and it has to be used more frequently. There is danger of burning the foliage if the solution is improperly prepared, so care is needed to use just enough but not too much of the ammonia. It is most frequently used in the later sprayings for bitter rot of apple, rots of grapes and celery leaf spots.

Copper Sulphate. 3 to $4 \mathrm{lbs}$. Copper Sulphate, 45 gals. Water. This strength is used as a winter spray, where it is 
desired to kill spores (or lichens) on the limbs. A weaker solution, I lb. to $250 \mathrm{gals}$., is sometimes advocated as a summer spray for peach rot; but the writer has not tried this strength.

Potassium Sulphide. 3 ozs. Potassium Sulphide, Io gals. Water. This fungicide has been found especially useful on the powdery mildews. Because it leaves no sediment, it is also adapted for greenhouse work in general but requires frequent applications. A different strength has been used for sprinkling grain to prevent smut.

Formalin. (A) I lb. ( I pt.) Formalin, 50 gals. Water. (B.) I $l b \cdot$ to 30 gals. Water. The $(A)$ formula is used for prevention of grain smuts, by thoroughly sprinkling a pile of the grain which is stirred so that all the seeds are wetted. The grain is left in piles or sacks over night before drying or planting. The (B.) formula is used for potato scab, the tubers being soaked in it $\mathrm{I}^{\mathrm{T} / 2}$ to 2 hours. Selby, of Ohio, also recommends its use for onion smut, the seed being sprinkled as it lies in the drills at planting.

Corrostve Sublimate. This is sometimes used instead of formalin for grain smuts or potato scab. In the latter case the tubers are soaked in a solution I $1 \mathrm{~b}$. to 50 gals. for $\mathrm{I} / 2$ hours. This is a poison and corrodes metals, hence care is needed in its use.

Sulphur. In the greenhouse this is used to check the powdery mildews. Most frequently the powder is sprinkled over the foliage. Sometimes the fumes produced by heating are used, but care should be exercised not to ignite the sulphur. A better method is to mix the sulphur with oil and paint this on the steam pipes. Sulphur is also used, sometimes with lime, on infected land to prevent onion smut. Stewart, of New York, recommends $100 \mathrm{lbs}$. mixed with $50 \mathrm{lbs}$. air-slaked lime per acre, used in the drills with the seed.

Lime. Occasionally this is put on land infested with certain fungi. For club root of cabbages, etc., 80 bushels per acre sown broadcast in the fall is recommended. For onion smut 75 to I25 bushels per acre drilled in with a fertilizer drill are required.

Hot WATER. For the grain smuts, soaking the seed Io to 15 minutes in hot water at $132-5^{\circ} \mathrm{F}$. is one of the most effective preventive treatments. Where large anounts of grain are to be treated, the cumbersomeness of the method and the trouble in drying the grain are the chief objections against its use. 


\section{Spray Machinery.}

For a general discussion of this subject and illustrations of types of pumps, see Bulletin I25 of this Station, also Reports I890, p. I04; I893, pp. 74, I05; I898, p. 266 . It is purposed here merely to mention the different kinds and indicate the field in which they are most useful.

Atomizers. These are bellows that produce the spray from a small cup containing the liquid at their tip. They are hard to work for any length of time and their usefulness is confined to the greenhouse or small beds of ornamental plants outdoors.

Powder Guns. These are used to dust dry mixtures over the surface of plants, usually when dew is on them. They are not of much value in fighting fungi.

Pail. Pumps. The best form is that in which the pump is inserted in any pail and held in place by the foot while one hand is used to pump and the other to direct the spray. These are of value around gardens or with small fruit grown on a limited scale. Effective pumps are likely to be expensive.

Knapsack Spravers. There are two types; those in which compressed air is first pumped into a reservoir and then used at will to force out the spray, and the common type in which the spray is forced out directly by pumping. These are useful on small fruit farms or in gardens where one can not use a barrel pump mounted in a wagon. It is rather hard work to carry one of these pumps on the back and spray for any length of time and so they are not very popular.

Barrel Pumps. When one wishes to get among plants where there is not room for a wagon, the small barrel pump mounted on two wheels is very handy and preferable to the knapsack sprayers. The ordinary pump mounted in a kerosene barrel and carried around in a cart or light wagon is the type in most common use. The style in which the air chamber is immersed in the barrel with only the handle protruding is now accepted as the best. In purchasing such a pump, one should select a durable rather than a cheàp make, and one that is strong enough to readily supply two lines of hose, each with a double nozzle. In commercial orchards force pumps are sometimes used in tanks of large capacity. For certain purposes, as potato spraying, an apparatus may be fitted up with stationary nozzles. See Report I893, p. 75 . 
Power Sprayers. In these machines the power is other than by hand. Steam is used in some cases, but such machines have scarcely obtained a foothold in this state. The most common type is where the power is supplied by the horses through gearing. This makes it necessary to keep the apparatus moving, and thus often prevents sufficient spray reaching the plants. Recently, machines in which the force is supplied by compressed air or by liquid carbonic acid gas have been placed on the market and are attracting attention. As yet, a perfect and cheap power sprayer does not seem to have been developed.

\section{NOTES ON SPECIFIC TROUBLES.}

The following notes are upon the specific troubles that have been reported in this state. Most of them have been seen the past two seasons. A few of the hosts, though economic, are not grown commercially in this state. Some of the fungi, while occurring on cultivated plants, are scarcely of economic importance. One can never be sure, however, that these may not at some time become troublesome. The few physiological troubles that are given are distinguished in the headings by the use of italicized common names. Specimens of all have been placed in the Station's herbarium and special mounts of the most important have been made for educational purposes. The hosts are arranged alphabetically.

ALFALFA, Medicago sativa.

LeAf Spot, Pseudopeziza Medicaginis (Lib.) Sacc. This is a common fungous trouble of alfalfa, though not so important in this state since the host, apparently, can not be extensively grown here. It shows as small reddish purple spots scattered over the leaves, which finally become yellowish. The only time the fungus has been reported as injurious was by Sturgis in the Report for I899, p. 28 I.

\section{APPLE, Pirus Malus.}

Bitter Rot, Glomerella rufomaculans (Berk.) Sp. \& von Schr. Plate XII, c. The summer spore stage (Gloosporium fructigenum) of this fungus is responsible for serious injury to apples, especially during recent years in the middle west. In Connecticut it does not seem to be nearly so troublesome. The 
fruit often begins to rot, while yet green, early in July, and if the season is moist from then on the trouble becomes greatly increased, even causing serious rotting after the apples are stored. Rotten sunken areas are formed which rapidly increase in size, and in moist weather produce numerous pinkish fruiting pustules arranged in concentric circles. The spores are viscid and so are easily carried by insects. Recently the fungus has been discovered on the branches, where it forms cankered areas often at the base of the old fruit spurs. It is in these that the mycelium passes the winter and produces spores for general infection another year. The winter or asco-spore stage is saprophytic and curiously enough was observed in artificial cultures of the fungus before found in nature. Besides the apple, this fungus has the pear, and probably the quince, for hosts in this state. The treatment given for apple scab, coupled with the pruning of diseased limbs and the gathering of rotting fruit, is apparently sufficient for Connecticut, but in more southerly states, where the trouble is often serions, the sprayings with Bordeaux are followed later in the season with Amm. Sol. Cop. Carbonate (Bulls. Irr, p. 5 ; I42, p. 2 ).

Black Mold, Fumago vagans Pers. See Pear.

Black Rot, Sphaeropsis Malorum Pk. Plate XI, a. One of the most common and universal troubles of the apple is black rot. Ordinarily this does not attack green fruit, except through insect injuries. It is most troublesome to the summer varieties at time of ripening and to fall and winter varieties after storage. The apples on rotting are brown at first, but usually blacken later, hence the common name. This fungus also occurs on the limbs, forming depressed, reddish, dead areas, or it may kill the young twigs by girdling. It is very common on the leaves, forming roundish or irregular reddish brown spots; and in this state most of the apple leaf spot troubles seem to be caused by it. So far only one spore stage has been found, and this places it with the imperfect fungi. The fruiting stage shows on the twigs as small black pustules, easily seen by the naked eye. The pear and quince are other hosts of the fungus. To fight this trouble, the trees should be thoroughly pruned of all dead limbs and twigs; the larger cankered areas, when found, should be scraped and painted; the trees should be given a winter spraying, followed by the ordinary treatment for scab. (Rep. I893, p. 9r ; Bull. r42, p. 2.) 
Blue Mold, Penicillium glaucum, Lk. This common saprophytic mold occasionally causes rot in storage apples. In a fruiting condition it is easily identified by the green blue spores that appear in clusters on the surface of the rotten fruit.

Brown Rot, Sclerotinia fructigena (Pers.) Schrt. Occasionally this causes rotting of ripe apples. It does not seem to be specifically different from the brown rot of peach, $q$. $v$.

CRown Gall. The crown galls on the apple have about the same appearance as those on the peach and plum, though it is not yet definitely known if they have the same cause. They form irregular knots or swellings at the crown or more commonly lower down on the roots. So far, in this state, the trouble has been seen only on young trees, chiefly nursery stock. There is some question just what the later effect is on the tree, but it is safest to reject all stock showing any signs of this trouble. In I899, Dr. Sturgis set out on the Station grounds ten young trees affected with knot; part of these had the knots cut off, others had knots cut off and roots then treated with copper sulphate, and some were left with knots on. After three seasons of growth, these trees were dug by the writer and the roots carefully examined. Very little difference could be seen in any of the trees at this time and the knots had spread very little, if any. (See Report Conn. Pom. Soc. 1903, p. 43.)

European Canker, Nectria ditissima Tul. Plate XII, d. This is found usually on old and neglected trees, where it gets started in the branches through wounds or possibly through winter killing. As it is perennial through its mycelium, the bark is prevented each year from forming over the wound, so that an enlarging canker is formed showing the annual layers of wood in concentric rings around the original starting point. If examined at the proper time with a hand lens, the small, red, globular fruiting bodies of this sac fungus can be seen clustered on the edges of the cankered area. All cankered limbs should be removed and the larger cut surfaces be given a coat of paint.

Fly Speck, Leptothyrimm Pomi (Mont. \& Fr.) Sacc. Plate $\mathrm{XI}$, d. The small black spots, similar to fly specks, produced by this fungus are usually clustered on the fruit in numbers from half a dozen to a hundred or more. The conditions favorable for sooty blotch also produce this fungus, so the two are 
often found together. The former trouble, however, proves to be the more serious as it is more abundant and evident. So far the writer has not found the fly speck fungus in a fruiting condition, though it is classified with the sac fungi. A similar fungus was sent to the Station on peach twigs in a fruiting condition, last year, so it is not unlikely that this fungus winters on the apple twigs.

Leaf Spots, Phyllosticta sps. Not unfrequently one finds species of the Phyllosticta fungi on the round brown spots on apple leaves and apparently the primary cause of these. As stated before, most of these leaf spots are caused by the black rot fungus. The fruiting stages of the two fungi are often found in the same spot. At yet little is known of the life history of these Phyllosticta fungi, but they are possibly summer stages of sac fungi.

Pink Mold, Cephalothecium rosenm Cda. During the fall of 1902, this fungus, which commonly occurs only on decaying vegetation, caused very serious loss to the apple growers of New York state and to a less extent in this state. The trouble developed after the apples were picked for storage. Its development was the direct result of badly scabbed apples, and a wet fall, since it was only through the scabby spots that the mold gained entrance to the fruit. These spots became covered with a luxuriant white growth of mycelial threads, which on producing the spores changed to a pinkish color. The mycelium also penetrated the tissues and caused the rot of the apple. Cold storage checked the trouble but did not prevent the rotting of the apples when again brought into a warm atmosphere. The prevention of this trouble requires a treatment that goes back to the prevention of scab.

Powdery Mildew, Podosphara lencotricha (Ell. \& Ev.) Salm. This is usually a pest only in nurseries, though occasionally found in orchards on sprouts at the base of the trees. It forms a cobweb-like growth on the leaves and on the young twigs a dirty whitish felt, within which are embedded the small brownish spherical receptacles of the asco-spores. It thrives best in nurseries where the blocks of trees are very closely planted, and may be avoided by thinner planting and spraying with potassium sulphide or Bordeaux mixture. 
Rusts, Gymnosporanginm macropus Lk., G. globosum Farl. Plate XI, c, Colortype 2. Two rusts, similar in appearance, occur here on the apple leaves, the former apparently the more abundantly. The apple stages (Rrestelia pirata and $R$. lacerata) are the I or cluster cup stages of the mature forms which occur as "Cedar apples" on cedar trees in late April to June. Infection of the apple leaves takes place in May or June, producing bright orange-colored spots that begin to show prominently in July. The fringed cluster cups [Plate XI, c] appear on the under surface of these the latter part of July and August, and their spores carry the fungus back to the young cedar twigs for new infection. There is great difference in the susceptibility of different varieties of apple to the attack of these fungi. One often sees certain varieties of trees in the orchard and nursery badly infected while others are free. Selection of varieties, therefore, is one way of avoiding the trouble. Wealthy and Fallowater, apparently, rust badly. Cedar trees in the vicinity of the orchard should be cut down. Spraying, as yet, seems to have given poor results. [Rep. I89I, p. I6I ; Bull. I42, p. 2.]

SCAB, Venturia incequalis (Cke.) Aderh. Plate XII, a-b. One of the fungi most widely discussed is the apple scab. This is partly due to its general distribution and its injurious nature, but also to the fact that it was one of the first whose control was attempted by the use of fungicides. It occurs commonly on the fruit and leaves; very rarely on the twigs. On the fruit it produces superficial olive-black "scabby" spots, that often cause the young fruit to become one-sided and stunted. Scabby fruit, also, is apt to wilt in storage and become rotten through infection with other fungi (see pink mold). On the leaves the scab colonies, one-quarter to one-third of an inch in diameter, are shown by a hand lens to consist of superficial fertile threads radiating out from a common center. The only specimens found on twigs [Plate XII, b] showed small pustules not unlike those of the black rot fungus. Apple scab is the parasitic summer stage (Fusicladium dendriticum) of a sac fungus that develops as a saprophyte on the fallen leaves during the fall and winter, maturing its spores in early spring in time for infection of the unfolding leaves. Spraying experiments have shown that this trouble can be controlled by Bordeaux mixture. The first treatment is given on the unfolding leaves 
before the blossoms open, the second just after the petals fall, and the third, if necessary, follows two or three weeks later. Sometimes a winter treatment with copper sulphate is given on the dormant wood, but this is hardly necessary. [Rep. I893, pp. 72, 88; Bu1l. I42, p. 2.]

Sooty Blotch, ? Phyllachora pomigena (Schw.) Sacc. Plate $\mathrm{XI}, \mathrm{b}$. During the past two seasons this has been one of our most serious apple pests. The fungus forms a prostrate growth of matted threads, that in olive-black colonies more or less cover the surface of the fruit. Because of its superficial growth the fungus thrives best under moist conditions, such as the past two seasons have afforded. It attracts most attention on the lighter skin varieties, as the Greening, because of the contrast in color. The injury to the fruit, at first, is chiefly in its appearance, but this is sufficient to greatly affect the market value. Later, ill effects are shown in the keeping qualities, as badly spotted fruit wilts badly, because of the rupture of the cuticle covering the apple, and not infrequently rotting, from other fungi, develops. So far the writer has not found the mycelium on these blotches producing spores, though apples were kept out doors over winter for this purpose. The fungus, however, probably belongs with the sac fungi. It occurs less prominently on the pear. The treatment ordinarily given for apple scab proves beneficial in keeping this trouble in check. To be most effective, the third spraying should be given when the fruit has attained considerable size. [Rep. I897, p. I7I; Bull. I42, p. 2.]

Baldwin Spot. This trouble shows first in the fall as small sunken rotten spots on the surface of the fruit and later as isolated brown spots within the flesh, the tissue in these often collapsing. When first studied it was thought that fungi or bacteria might be responsible, but now it is generally considered a physiological trouble, possibly resulting from too great loss of water at these places. The trouble increases after storage, especially in the development of the internal spots. Very similar spots have been found in the interior of potatoes, which probably result from similar causes and conditions. During the past season Baldwin spot was more prevalent than usual, being common in Baldwins especially. The poor condition of apples, induced by the peculiar growing season, and by the September gale 
which shook most of the fruit from the trees, may possibly explain its greater prevalence.

Fruit Scald. This is a more serious trouble with cold storage apples than with those stored in the ordinary way. It shows as large brownish scalded places at first on the skin, but eventually penetrating deeper and is usually most prominent on fair skin varieties. While the cold no doubt has much to do with developing this trouble, it also seems certain that the condition of the apples as they enter storage is a very important factor. It is a trouble that is under investigation by our government pomologists.

Spray Injury. Injury to the foliage and the fruit often follows spraying with Bordeaux mixture, especially when combined with insecticides. Circular brown spots are produced on the leaves very similar to those caused by the leaf spot fungi and if the injury is sufficient many of these leaves are shed prematurely. The injury to the fruit shows as russeting, and may cause lop-sided growth. Carelessness in preparing the Bordeaux, failing to properly neutralize the copper sulphate with fresh lime, is sometimes responsible for these injuries. In wet seasons, injury sometimes results where proper precautions have been taken. As a rule, the earliest sprayings on the undeveloped leaves do not seem to cause injury so frequently as later sprayings on the fully matured leaves.

Winter Injury. Plates IX, a-b, X, b. As stated in the introduction, many apple trees were severely injured by the sudden zero weather of December 9, I902. This was due to the sudden change following an open fall in which the trees had not properly matured for winter conditions. The winter of I903-4 has also been a very severe one, but the trees were in better shape for it. The injury in 1902 was shown in two ways. First: In the nursery or very young orchard, especially where the trees were cultivated late and thereby taken into winter in an unripe condition, the injury was confined principally to the wood, the bark and the cambium remaining uninjured. This injury became evident only on cutting across the stem, when the wood [Plate X, b] showed a darker color than normal. When these trees were transplanted the following spring, the unfavorable conditions of a dry May and a wet June finished the career of many. When left in the nursery and severely 
pruned back they made a more or less satisfactory growth according to the severity of the injury. This new growth of wood showed as a white ring in striking contrast to the injured dark wood within. See Plate X. If the old wood was severely injured, even if the new wood grew fairly well, there was frequently developed an evident whitish, fungous growth at the pruned surfaces on the injured wood, showing that there was trouble ahead from wood rot. Badly injured trees, too, were very brittle and easily broken off. Second: In orchards, most commonly on trees four to eight years old, the injury often showed as dead areas in the bark, usually at the base of the tree and more frequently on the northerly exposures. Sometimes these sunken areas completely girdled the tree, thereby finishing its career; again they extended a foot or two up one side, being separated by a fissure from the healthy bark. Trees injured severely in this way put out an abundance of healthy foliage early in the season and appeared in normal health until July, when the leaves began to drop. Plate IX, a, shows a young tree in Mr. Gold's orchard at West Cornwall, photographed in July, I902, that was losing its foliage because of a similar injury to the base of the tree. These dead areas resemble cankered spots, and the writer mistook, at first, the injury at West Cornwall for a fungous trouble, since on some of the dead areas the fruiting pustules of a fungus [Plate IX, b] were found. Evidently these were developing as a later and saprophytic growth. The healthy bark with its lenticels, which are sometimes mistaken for fungous growths, is shown in Plate IX, c. Sun scald is also a winter injury of the bark due to warm weather, starting into activity the tissues on southerly exposures of the trunk, followed by a sudden freeze.

ASH, Fraximus sps.

Leaf Speck, Piggotia Fraxini B. \& C. This produces very small black fruiting pustules on the under surface of the leaves of white ash.

Rust, Ecidinm Fraxini Schw. This rust forms its cluster cups on the leaves and their petioles in July and August. Often it produces considerable distortion of the petioles where these spore cups are embedded. It was observed on the white ash, F. Americana. 
ASPARAGUS, Asparagus officinalis.

Anthracnose, Fusarium sp. This trouble is sometimes associated with the rust on asparagus stems. It causes lightcolored areas that become dotted with numerous pink pustules of the spores. The tissue is killed at these places and so where abundant the fungus may cause considerable injury.

Leopard Spot. Apparently this is the result of some fungus, though it has not been found in a fruiting condition. It produces reddish brown spots usually with a distinct border.

Rust, Puccinia Asparagi DC. By far the most serious fungous pest of asparagus, however, is the rust. This shows as dark red or black pustules breaking through the skin on any part of the plant. These small pustules are usually oval in shape, though they may become more elongated, especially on the larger branches. The reddish color indicates the formation of the uredo- or summer spores, while the black color shows the presence of the teleuto- or winter spores. These different spores may even occur in the same pustules; they are most abundant from August to October. The cluster cup stage appears as early as June, but does little damage and so far has not been observed by the writer. During the past season the rust was later than usual in appearing and consequently less destructive. Some growers in Connecticut are now spraying against this trouble, but the work to be effective must be done thoroughly and repeatedly. Resin Bordeaux seems to be the best fungicide for this purpose because of its sticking qualities. Spraying should begin the latter part of July and be continued until the middle of September. Sometimes the dead fields in the fall are burned over to kill off at least some of the spores. According to some growers the Palmetto is more exempt from rust than most of the varieties. [Rep. I896, p. 28I ; Bull. I42, p. 3.]

\section{ASTER, Callistephus hortensis.}

Rust, Coleosporium Sonchi-arvensis (Pers.) Lev. This rust has been found so far only sparingly on cultivated asters. In nature it is very common on wild asters and goldenrods. The bright orange uredo pustules appear in clusters on the under surface of the leaves.

Stem Rot, Fusarium sp? Some of our growers report as 
serious a stem rot or decay at the base of asters. This is probably caused by a Fusarium fungus, though no special study was made of this trouble, which evidently becomes established in the soil.

Yellows. Apparently this is a physiological disease, which may be similar to peach yellows. Affected plants are often spindling with some yellowish or whitish foliage and ustually develop one-sided flowers imperfect in shape and color. Some growers think that the trouble becomes worse on ground used year after year.

\section{AZALEA, Azalea sp.}

Rust, Pucciniastrum Vacciniorum (Lk.) Diet. The uredo stage of this rust was seen in a local nursery doing considerable injury to certain cultivated azaleas, apparently native varieties. The rust showed on the under surface of the leaves as very small thickly crowded orange dots, while the upper surface was somewhat discolored by the injury to the tissues.

\section{BARBERRY, Berberis sps.}

Anthracnose, Gloosporium Berberidis Cke. In midsummer barberry leaves are often found showing at their tip or margin dead areas which in time may involve the entire leaf. These brown "tip burns" are separated from the healthy green tissue by a distinct purplish border. The very small fruiting pustules can sometimes be made out, on the underside near the healthy tissue, by aid of a lens.

Rust, Puccinia graminis Pers. The cluster cup stage of the common black stem rust of cereals occurs on both the wild and cultivated barberry. This appears in May embedded in slightly swollen clusters on the undersides of the leaves. See Oats.

BARLEY, Hordeum sps.

Powdery MrLdew, Erysiphe graminis DC. The conidial stage (Oidium monilioides) of this mildew occurs on the leaves in greyish moldy tufts, causing discoloration of the tissues.

Rusts, Puccinia graminis Pers., P. rubigo-vera (DC.) Wint. These common rusts cause considerable damage to barley raised for green fodder. See Oats.

Smuts, Ustilago muda (Jens.) Kell. \& Sw. Plate XIII, a. 
The loose smut is not uncommon in the spikelets of barley, changing them into dusty olive-black spore masses. The covered smut (U. Hordei (Pers.) Kell. \& Sw.), which has a firmer blacker spore mass, has been seen but once. These troubles may be prevented by the modified hot water treatment of the seed.

BEANS: STRING, Phaseolus vulgaris; LIMA, P. lunatus.

Antmracnose, Colletotrichum Lindemuthianum (Sacc. \& Magn.) Bri. \& Cav. Plate XIII, c. This is a common trouble of beans. It occurs on both the pods and the leaves, producing on the former evident subcircular spots with a distinct reddish purple border. The bacterial trouble described later seems to be more common on the leaves than this, and most of the spots examined on bean leaves have been due to that. Anthracnose often gets started through infested seed; so only sound plump seed should be used. Destroying infected seedlings and the first diseased leaves should prove helpful in checking its appearance. Spraying with Bordeaux should begin when the plants are only a few inches high and be continued at intervals of two or three weeks until the pods are maturing. Burning the rubbish at the end of the season is recommended, since the trouble is probably carried by this in the soil. [Bu11. I42, p. 3.]

Blight, Pseudomonas Plaseoli Smith. Plate XIII, d. This is very common on the leaves of string beans, producing brown dead areas at the tip or margin or large irregular spots within, the leaf often turning yellowish all over and dying. Parts of these diseased areas often have a pellucid or 'water appearance. On the lima bean leaves, one often finds smaller reddish bordered spots distinct from the above and similar in appearance to those of anthracnose; yet even these seem to be of bacterial origin, probably started by insect punctures. See note by Sturgis in Report 1898 , p. 262. The treatment for blight is the same as for anthracnose. [Bull. I42, p. 4.]

- Downy Mildew, Phytophthora Phaseoli Thaxt. Plate XIII, b, Colortype I2. This fungus was first described from specimens found near New Haven by Professor Thaxter in I889. It occurs only on the lima bean and has since been found in a few other eastern states. It occurs most commonly on the pods, covering them more or less completely with a con- 
spicuous white felt of the mycelium and summer spore stage. This distorts and often aborts the pods, rendering them unfit for the market. Less commonly the fungus attacks the flowers and young leaves and stems. It is most prevalent in moist seasons and in the low wet places in the fields. Too close planting of the vines also induces its development. Just how the fungus passes the winter still remains a mystery, as the winter or oospores have never been found, though looked for carefully by the writer and others. Probably the mycelium gains entrance to some of the seeds and it is carried over this way. Wet, low land should not be used and the plants should stand far enough apart to admit plenty of sunshine. Spraying every two or three weeks from the last of June until September is helpful in controlling the trouble. The first sprayings may be made with Bordeaux and the later with Amm. Sol. Cop. Carbonate. The diseased pods should be gathered at each picking. [Reps. I889, p. I67; I890, p. 97; 1893, p. 77; I897, p. I $59 ;$ I 898 , p. 236 ; Bull. I42, p. 4.]

LEAF Blotcin, Isariopsis griseola Sacc. (Cercospora columnare E. \& E.) In one field this was found abundant, producing angular brownish areas of varying size and giving the leaves a sickly yellowish color. With a lens the fruiting stage can be seen, as small black columns with greyish bushy heads, standing out on the under surface of the leaves. It was also found on the old pods.

Leaf Spot, Phyllosticta phaseolina Sacc. This was seen once. It produces large dark spots showing concentric markings.

MoLd, Fusarium sp. If beans are left too long in the field in the fall or if not properly matured when stored, this fungus. develops a vigorous growth of white mycelium over and in the seeds.

Rust, Uromyces appendiculatus (Pers.) Lk. Plate XIII, e. This is very injurious to some varieties, including both dwarf and pole forms of the string beans. The small, roundish, dusty, . reddish black pustules that usually thickly cover either surface of the leaves contain the uredo- and teleuto-spores. These occur occasionally on the pods. The rust is most common in August and September. Avoid planting varieties that rust badly, and burn the rubbish in the fall. [Bull. I42, p. 4.] 
BEET, Beta vulgaris.

Leaf Blight, Cercospora beticola Sacc. Plate XIV, a. This is a very common trouble on beets and chard. The leaves are more or less covered with roundish spots, one-sixteenth to one-quarter inch in diameter, which have a greyish center and a purplish border. Only summer spores are known, placing it with the imperfect fungi.

Scab, Oospora scabies Thaxt. This causes scabby spots on the roots similar to those on potatoes. In an experiment, Sturgis found that "beets, mangels, turnips and ruta-bagas are susceptible to potato scab in a marked degree if planted on soil infested with the fungus causing that disease. None of these root crops, therefore, should occupy land which has recently borne scabby potatoes." [Rep. I896, p. 266.]

BLACKBERRY, Rubus villosus and vars.

Crown Gall, ? Dendrophagus globosus Toum. Reported on this host but not seen by writer. See Raspberry.

Leaf Spot, Septoria Rubi Westd. Plate XIV, b. This is a common trouble on the foliage, producing small, circular spots that eventually have a whitish center with a purple border. The fruiting pustules when present show as minute black dots sunken in the white area. It is caused by one of the imperfect fungi and occurs also on the raspberry and dewberry. It is questionable just how much damage this causes when fairly abundant, but if it proves serious, early spraying with Bordeaux would probably pay. [Bull. I 42, p. 4.]

Orange Rust, Gymmoconia interstitialis (Schl.) Lagerh. Plate XIV, c, Colortype 9. This forms orange colored dusty outbreals thickly covering the under surface of the leaves from May to July. At first these are covered by the epidermis, upon the rupture of which the spores are gradually scattered. Orange rust (Ccoma nitens) is the I stage of the mature form III, or teleutal, which occurs later in very inconspicuous pustules on the same plants. The mycelium is perennial in the underground parts of the host, so that shoots year after year from these will be rusted. The best remedy is to dig up and destroy the infected plants as soon as discovered; it is especially desirable to remove them early in the spring before the spore pustules break open. Certain varieties seem more subject to this trouble than are 
others, and it also occurs on the raspberry and dewberry and on wild plants of all of these. It is well to see that none of the latter flourish in the vicinity of the cultivated plants. [Rep. I889, p. I72; Bull. I42, p. 4.]

BLUE GRASS, Poa pratensis.

Powdery Mildew, Erysiphe graminis DC. The conidial stage of this mildew often occurs on uncut grass in fence rows, etc. It forms a white powdery coating on portions of the leaves.

BOX ELDER, Negundo aceroides.

Leaf Spot, Phyllosticta minima (B. \& C.) Ell. See Maple.

BROME GRASS, Bromus inermis.

Ergot, Claviceps purpurea Tul. Collected once on this and several times on other species of Bromus; sclerotia smaller than on rye, $q . v$.

BROOM CORN, Sorghum vilgare var.

Grain Smut, Sphacelotheca Sorghi (Lk.) Clint. Collected in Experiment Station grounds. See Sorghum.

BUCKWHEAT, Fagopyrum esculentım.

Leaf Blight, Ramularia rufomaculans Pk. Plate XIV, d. Occasionally this becomes abundant and injurious in buckwheat fields, but usually it is found only sparingly. Its fruiting stage forms whitish, mealy growths scattered in patches over the under surface of the leaves. This summer spore stage is the only one known. [Rep. I89o, p. 98.]

Leaf Spot, Ascochyta sp. Another trouble occasionally found on the leaves produces circular, reddish brown spots. These and the fungus causing them are very similar, if not the same as the leaf spot of Rhubarb.

CABBAGE, Brassica oleracea.

Club Root, Plasmodiophora Brassicre Wor. Plate XV, a. This forms gall-like enlargements on the roots. These are morbid growth of plant tissue, the cells of which are filled with the spores, etc., of the slime mold that produces the trouble. 
Eventually the infected tissues rot, through the action of bacteria, and liberate these germs in the soil. Badly infected plants have little root hold in the soil and so are cut off from gathering sufficient plant food. They become spindling and head out poorly, if at all. The trouble becomes established in the soil when garbage is dumped on it or the refuse from the diseased crop is left in the fields. For this reason infected land is not adapted for raising cabbage or the similar cruciferous plants, cauliflower, turnip, etc. The disease even spreads to cruciferous weeds in the fields, as shepherd purse, and pepper grass. Rotation with different crops should be followed. The young plants should never be grown in infected soil. If an infected field is ever used, a fall coating with lime sown broadcast at the rate of eighty bushels per acre, is said to be helpful in keeping the trouble in check. [Bull. I42, p. 5.]

Leaf Molds, Alternaria Brassica (Berk.) Sacc., A. Brassica var. macrospora Sacc. These cause subcircular, blackish spots of varying size on the leaves. The variety seems to be the more common and has very large spores as seen under the microscope. The same fungus occurs on mustard and radish. Occasionally the trouble becomes rather prominent.

Soft Rot, Bacterial. Often the leaves of the heads are more or less destroyed by a wet brown rot, which may become serious.

\section{CARNATION, Dianthus Caryophyllus.}

FAIRY Ring, Heterosporium echinulatum (Berk.) Cke. This forms on the leaves greyish spots, about a quarter of an inch in diameter, having a distinct purplish border. The fruiting stage shown under a lens is an olive black, upright growth of threads. When occurring on the calyx, it often causes this to crack open, which is very objectionable to the growers. Usually the trouble occurs seriously only in neglected houses. [Bull. I 42 , p. 5.]

Grey Mold, Botrytis vulgaris. Sometimes occurs on the blossoms. See Lettuce.

Leaf Spot, Septoria Dianthi Desm. This often occurs with the preceding and the two look very similar. The leaf spot can usually be distinguished by the small black dots, or fruiting receptacles, that are embedded in the center of the spots. Only 
good plants should be selected for cuttings and all dead leaves removed as they appear. Care is needed in watering. It is easier to keep out these troubles by giving the plants the very best treatment than it is to control them after they are thoroughly started.

Rust, Uromyces caryophyllinus (Schrank.) Schrt. Plate $\mathrm{XV}, \mathrm{b}$. Rust is the most troublesome of the fungous pests of carnation. It breaks out in reddish brown dusty pustules on the leaves and stems. Both uredo- and teleuto-spores occur, but the former are more common. There is considerable difference in the susceptibility to rust with the various varieties. Eldorado, Daybreak, Jubilee, and others are said to rust badly. while Prosperity, Portia, etc., are more exempt. The conditions of different greenhouses and the care given by the growers also make differences in the amount of rust. Plants crowded too closely or watered too freely on the foliage and at improper times rust the worst. Many growers remove the rusted leaves, if not too numerous. No doubt very careful attention to this treatment when the plants are first started and little rust is found, would always repay. Spraying experiments have been carried on to some extent. Bordeaux mixture is objectionable to the grower on account of the sediment. Potassium sulphide to be of value should be applied in season, and repeatedly. [Bull. I 42, p. 5.]

Stem Rot, Rhizoctonia sp. This sterile fungus was found in connection with the rot in one greenhouse. As the fungus lives in the soil, it is desirable to keep it from becoming established, since it will attack other plants as well.

Wilt, Fusarium sp. In the Report for I897, pp. I75-81, Dr. Sturgis reports this troublesome to carnations grown in the Experiment Station greenhouse. Perhaps both this and the preceding fungus are responsible for the common stem rot trouble of growers. The soil, if necessary, can be sterilized with steam to rid it of these fungi.

\section{CARROT, Daucus Carota.}

BLIGHT, Bacterial. While visiting a seed farm in the vicinity of Milford in 1902, there was observed a rather serious trouble of this host due to bacteria. The infected plants showed a wet rot, confined chiefly to the outer layers of the stem. These 
had a greenish black color, were watery and easily mashed out of place with handling. To a less extent the leaves showed blackened spots and the inflorescence was somewhat infected. An examination of these injured parts showed plenty of bacteria, which were, no doubt, the cause of the trouble, though no experimental or cultural work was undertaken with them. So far the writer has seen no description by others of this trouble on the carrot.

\section{CATALPA, Catalpa sps.}

Powdery Mildew, Microsphara clevata Burr. In nurseries especially, but occasionally on the shade trees of lawns, this fungus is found coating the leaves on their upper surface with a more or less conspicuous cobweb-like growth. Imbedded in the dirty white mycelium occur the small black receptacles containing the winter or asco-spores. In the nurseries the trouble ought to be easily controlled by spraying with potassium sulphide.

\section{CEDAR, Juniperus Virginiana.}

Cedar Apples, Gymnosporangium macropus Lk., G. globosum Farl. Colortype 2. The teleutal stage of apple rusts occurs on this host. The "cedar apples". are reddish gall-like bodies that in the moist weather of spring send out elongated jellylike horns all over their surface. These contain spores that germinate in position and produce smaller thin-walled spores, that, on the drying of the horns, are carried by the wind to the apple leaves, where their infection produces the cluster cup stage. The two species on the cedar are.distinguished by the longer, more tapering horns of $G$. macropus, which is the more common species. See Apple.

\section{CELERY, Apium graveolens.}

LeAF Blight, Cercospora Apii Fr. The so-called "rust" of growers shows as reddish brown irregular spots on the leaves. If badly infected, these turn yellowish and have a sickly appearance. The fungus can usually be seen by a hand lens as a not very evident upright surface growth. This is one of the most serious troubles of the celery grower. At bleaching time rusty spots of this or the next fungus may appear on the stalks. 
Where the trouble is likely to prove serious, spraying should begin soon after transplanting. Bordeaux is used for the first and usually Amm. Sol. Cop. Carbonate for the later sprayings. Applications should be made about every two weeks up to the time of banking. Sturgis found that dusting sulphur over the plants was also an effective treatment. [Reps. 1892, p. 44; I893, pp. 81, I03; I897, p. I67; Bu1l. I42, p. 5.]

Leaf Spot, Septoria Petroselini var. Apii Br. \& Cav. This is a trouble very similar to the preceding and the preventive treatment is the same. The two may occur together; but the leaf spot is usually distinguished by the small black dots, or fruiting receptacles, in the rusty spots.

CHARD, Beta vulgaris var.

Leaf Blight, Cercospora beticola Sacc. See Beet.

\section{CHERRY, Prunus sps.}

Black Knot, Plorerightia morbosa (Schw.) Sacc. Occurs injuriously on cultivated species and also on the wild species, Prunus serotina and P. Virginiana. See Plum.

Brown Rot, Sclerotinia fructigena (Pers.) Schrt. Occurs * on both Prunus Cerasus and P. Avium. - See Peach.

Leaf Curl, Exoascus Cerasi (Fckl.) Sad. The leaves become badly discolored and somewhat deformed when attacked by this fungus. Those worst infected usually drop off. The trouble, apparently, is not common, but was collected a few times in Igoo by Sturgis.

LeAF Spot, Cylindrosporium Padi Karst. Colortype II. The crowded, small, purplish spots produced on the upper surface of the leaves by this fungus are shown very well by the colortype frontispiece. On the under surface the spores frequently show as small, pinkish, agglutinated masses. Badly infected leaves turn yellowish and drop off. The trouble is one of the most common and serious occurring on the cherry; it also occurs on the wild black cherry, $P$. serotina, and occasionally on cultivated plums. Spraying with Bordeaux mixture, starting early in May, has successfully prevented the disease elsewhere. [Rep. I890, p. I02; I895, p. I88; Bull. I42, p. 6.]

Powdery Mildew, Podosphara oxyacanthe (DC) DeBy. Plate XV, c. This is most injurious to young trees. The 
under surface of the leaves, and to some extent the upper, becomes covered with the white mycelium of the fungus. In the fall, the winter spore stage is conspicuous, through the numerous small black perithecia (Plate XV, c) scattered among the fungous threads. The trouble can readily be controlled in the nurseries where it is injurious, by spraying either with Bordeaux mixture or potassium sulphide, if taken in time. [Bull. I42, p. 6.]

CHESTNUT, Castanea satiz'a.

Anthracnose, Marsonia ochroleuca (B. \& C.). Humph. Colortype 5. This forms conspicuous spots with brownish centers and purplish borders, on the leaves. It is most injurious to young nursery trees, but probably could be prevented by proper spraying.

\section{CHRYSANTHEMUM, Chrysanthemum Sinense.}

Anthracnose, Cylindrosporium Chrysanthemi Ell. \& Dearn. Greenhouse chrysanthemums sometimes suffer from this trouble. It produces large, brownish or blackish spots or blotches, sometimes covering the entire leaf.

Powdery Mildew, Oidium Chrysanthemi Rabh. This is a very common trouble in greenhouses, the leaves becoming covered with a mealy white growth. Apparently it is only the conidial stage of one of the Erysipheæ, but the winter stage is never produced. Ada Prass, Colonel Appleton, Omega, Merula and Julinda apparently mildew worse than Major Bonnaffon, Glory of Pacific, George W. Childs, or Ivory. The treatment for this should be the same as for mildew of rose, $q . v$.

Rust, Puccinia Chrysanthemi Roze. Plate XV, d. Only the uredo-stage of this rust seems to occur in this country on the chrysanthemum. This is a recent trouble, though one of the worst of this host. The dusty outbreaks of the reddish brown spores are about the size of a pin-head. These occur more or less abundantly on the under surface of the leaves. Attention should be given to the removal of infected leaves as soon as seen. Queen, Black Hawk, Ada Prass, Timothy Eaton, seem to rust worse than Miss Pullman, Major Bonnaffon, V. H. Hallock. 
CLEMATIS, Clematis Virginiana.

LeAF Spot, Cylindrosporiun Clematidis Ell. \& Ev.

CLOVER, RED, Trifolium pratense.

Black Dot, Phyllachora Trifolii (Pers.) Fckl. Colortype 6. The under surfaces of the leaves are usually rather thickly covered by the small black pustules of this fungus. It also occurs on white clover ( $T$. repens) and crimson clover ( $T$. incarnatum). It is not uncommon in clover fields.

Black Mold, Macrosporium sarcinceforme Cav. This is also troublesome in some clover fields. It produces on the leaves reddish circular spots that often show faint concentric rings of development. The fruiting stage is very inconspicuous on these spots.

Leaf Spot, Pseudopeziza Trifolii (Bernh.) Fckl. So far this fungus has not been found very common on the leaves, where it produces irregular reddish brown spots, in the center of which may sometimes be seen the small fruiting disc.

Rust, Uromyces Trifolii (A. \& S.) Wint. Plate XVI, a. the æcidial or cluster cup stage was collected by Thaxter in June on white clover. Apparently this is not so common as the uredo- and teleuto-stages, which are found in July and August very commonly on red and white clover. They appear chiefly on the under surface of the leaves as reddish, dusty pustules. Perhaps this is the most abundant and injurious of these clover fungi; it is not uncommon to find two or more of them on the same leaves. [Reps. I889, p. I74; I890, p. 98.]

\section{COLUMBINE, Aquile gia sp.}

Leaf Spot, Ascochyta sp. The large purplish blotches or diseased areas often seen on the leaves of cultivated columbines seem to be caused by a species of Ascochyta, one of the imperfect fungi.

Powdery Mildew, Erysiphe Polygoni DC. Occasionally this is found forming a whitish mycelial growth, with plenty of the perithecia showing as small black specks, scattered over the surface of the leaves. 
CORN, Zea Mays.

Blight, Bacillus Zea Burr. This usually occurs on the inner surface of the leaf sheaths, where it produces very evident dark purplish discoloration showing slightly through the sheath. Apparently it is not a serious trouble in Connecticut.

Leaf Blight, Helminthosporium turcicum Pass. (H. inconspicunm El1. \& Ev.). Colortype I3. Last year this proved a very serious trouble to corn, many fields looking in August or September as if struck by an early frost. The very unfavorable season for maturing the corn was largely responsible for this unusual attack. Elongated areas or even entire leaves were killed, turning a brownish color and showing the fungus as a very inconspicuous surface growth. Conspicuous growths of other saprophytic molds, however, often appeared on these dead areas. Sometimes the dead spots were small, but usually, because of the venation, they developed into elongated areas. Not all fields were equally affected and it was difficult to always explain this. Possibly the maturity of the plants, or the character of the seed from which they came, was a partial explanation. Thaxter noted this as a serious trouble in Connecticut in 1889. [Rep. I889, p. I7I.]

Rust, Puccinia Sorghi Schw. Apparently this possesses no cluster cup stage. Both the uredo- and teleuto-spores develop as reddish, dusty outbreaks on either surface of the leaves, and can ustaally be distinguished by their color. While not an uncommon fyungus in the corn fields, it does not often prove to be very serious.

Smut, Ustilago Zea (Beckm.) Ung. Plate XVI, b. The conspicuous dusty smut balls of this fungus are familiar to every one. They break out on any part of the host and vary greatly in size and shape according to their situation. These smutty masses are composed entirely of spores. The trouble is most serious in sweet corn. Fresh manure applied to the land is likely to increase the amount of smut in corn, since the spores germinate in this and give rise, yeast-fashion, to numerous secondary germs that have the power of infecting the corn. This is practically the only cereal smut that can not be prevented by seed treatment, as infection takes place through any very young tissue. Some gather the smut balls to keep the trouble from spreading, but it is questionable just how much 
good this does. This smut is not poisonous to stock, as is supposed by some. [Rep. I889, p. I7I ; Bull. I42, p. 6.]

\section{COSMIOS, Cosmos bipinnatus.}

Leaf Spot, Scptoria sp. Occasionally brown circular spots are produced more or less abundantly in the leaves by a Septoria fungus, whose fruiting bodies show as the usual little black dots in the tissues.

\section{COSMOS, Cosmus bipinnatus.}

Stem Spot, Phlyctea sp. Halsted, of New Jersey, gives this as the cause of the large purplish blotches that appear on the stems, especially at the lower nodes. It may eventually produce a more or less serious rot of the stems.

CRAB APPLE (Bechtel's), Pirus Ionensis var.

Rust, Gymnosporangium macropus Lk. This occurs in its æcidial stage, $I$, on the branches, as well as on the leaves, but it does not seem to carry over the winter in the branches, as an examination last spring of those infected the year before failed to show any signs of a new development of the fungus. See Apple.

CROWFOOT, Ranunculus sp.

Powdery Mildew, Erysiphe Polygoni DC. Only the conidial stage was found forming a mealy whitish growth over the leaves.

\section{CUCUMBER, Cucumis sativus.}

Anthracnose, Colletotrichum Lagenarium (Pass.) Ell. \& Hals. See Watermelon.

Downy Mildew, Plasmopara Cubensis (B. \& C.) Humph. This fungus does not produce so conspicuous spots on the leaves of this host as it does on the musk melon; neither is the injury so severe. The fruiting stage, however, shows more conspicuously and with a lens the scattered growth of upright fertile threads bearing the large dark purple spores is easily made out. Spraying gives beneficial results with this host. Bordeaux should be used as soon as the vines begin to run 
and the treatments should be given often enough to keep the foliage well covered with the sediment. The cucumbers may be picked before each of the later sprayings, otherwise no attention need be given to keep the spray off the fruit. See Musk Melon. [Rep. I890, p. 97.]

Powdery Mildew, Erysiphe cichoracearum DC. Conidial stage only occurs; on the leaves.

Scab, Cladosporium cucumerinum Ell. \& Arth. On leaves and fruit. See Musk Melon.

Wilt, Bacillus tracheiphilus Sm. See Squash.

\section{CURRANT, Ribes rubrum.}

Anthracnose, Gloosporium Ribis (Lib.) Mont \& Desm. This is the most serious trouble of the currant. It causes numerous purplish or reddish brown spots, about the size of a pin head, on the upper surface of the leaves. Where abundant, the intervening tissue is also killed and the leaf sheds prematurely. On the under surface of these spots the spores show in small pinkish globules. The trouble is often so serious that the bushes are completely defoliated by August, thus cutting short their season of usefulness. Spraying experiments, elsewhere, have controlled this disease. The first treatment is given before the leaves appear; the second as they are unfolding; others follow at intervals of about two weeks until the fruit begins to turn. [Bull. I42, p. 7.]

Leaf Spot,? Septoria Ribis Desm. This forms larger and fewer spots than the last and the spores ooze out on the upper surface. Apparently it is not common. The spots and spores are not quite like those this fungus produces on the gooseberry, $q . v$.

Red Knot, Nectria Ribis (Tode) Rab. Plate XVI, c. This was found on currants badly infested with the San José scale, which was chiefly responsible for the poor condition of the bushes. It is a question whether the fungus does not occur more commonly as a saprophyte than a parasite. It can be told by the bright red fruiting bodies that break out in roundish clusters on the stems. These are often accompanied by a conidial stage (Tubercularia vulgaris), which forms small roundish pink cushions producing the summer spores. It will do no harm to cut out all diseased branches. 
DAHLIA, Dahlia variabilis.

Powdery MILdew, Erysiphe cichoracearum DC. Conidial stage only formed.

DANDELION, Taraxacum officinale.

Powdery Mildew, Sphaerotheca Castagnei Lev. Found sometimes on plants raised for greens.

DEWBERRY, Rubus Canadensis.

Leaf Spot, Septoria Rubi Westd. See Blackberry.

Orange Rust, Gymnoconia interstitialis (Schl.) Lagerh. See Blackberry.

\section{D0GW00D, Cornus sps.}

Leaf Spot, Septoria cornicola Desm. This fungus produces numerous brownish or purplish circular spots, usually less than one-quarter of an inch in diameter, on the leaves. It was found doing considerable injury to both Cornus sanguinea and $C$. paniculata in nursery rows.

\section{EGG PLANT, Solanum Melongena.}

Fruit Mold, Botrytis sp. This is often responsible for the rotting of the fruit. Its spore stage shows as a dense greyish moldy growth covering the rotten area.

Fruit Rot and Leaf Spot, Phyllosticta hortorum Speg. This was a serious trouble last year of egg plants, especially on the fruit. It causes round brownish spots on the leaves and the fruit gradually rots a reddish brown color, the spore pustules showing as black dots. The spores produced in the leaves are often septate and possibly larger than those on the fruit. A Phlyctena spore stage also often occurs in the same pustules on the fruit with the Phyllosticta. This makes the systematic position of the fungus uncertain, though Halsted determines it as given above. The rotten fruit should be picked and destroyed.

LeAF Mold, Alternaria Solani (E. \& M.) J. \& G. This forms spots on the leaves very similar to the above fungus. See Potato. 
WILT. Last year the egg plants were often attacked by a fungus that caused wilting, yellowing and eventually the death of the leaves, especially the lower ones. This seemed to be the result of a Fusarium that invaded the fibro-vascular bundles of the stem and, by clogging the vessels, cut off the water supply of these leaves.

\section{ELIM, Ulmus Americana.}

- Leaf Spot, Gnomonia ulmea (Schw.) Thm. Elm leaves are very commonly attacked by this fungus, its fruiting stage showing on the upper surface as small black pimples, often somewhat clustered in circles. The spores mature in the old dead leaves the following spring.

White Fungus, Sporotrichum globuliferum Speg. Plate XVI, d. This is the fungus that was used some years ago by the Kansas and Illinois Experiment Stations in experiments to infect chinch bugs generally in the fields. In the summer and fall of 1902 , it was found in Connecticut on the elm-leaf beetles, and as the next year the beetles were greatly reduced in numbers it no doubt had considerable infuence in checking their ravages. The remains of the larvae were frequently found under the loose bark of the trees, embedded in a lixuriant white growth of the fungus (see Plate). Under a hand lens this shows the spores crowded into the numerous minute spore balls so characteristic of the fungus.

\section{ENDIVE, Cichorium Endivia.}

LEAF Spot. A serious leaf spot trouble, apparently produced by a fungus but not in a fruiting condition, was observed in 1902 in the vicinity of New Haven. The leaves were so abundantly covered with the circular brown spots as to render them useless for the market.

Rust, Puccinia Endivice Pass. Apparently this rust has not been reported before in this country, though it is a common parasite of endive in Italy. It was probably introduced in New Haven from that country, for the only place it was found was in a large endive field owned by an Italian market gardener. As endive should have perfect leaves for bleaching, the abundant dusty pustules produced by the rust spoiled many plants or at least rendered them second class. Only the uredo-spores were found, even late in the fall. 
GERANIUM, Pelargonium sp.

Grey Mold, Botrytis vulgaris Fr. This common mold occurs in leaky or too moist greenhouses. Water dropping on the plants from the roof often gives the fungus its chance for infection. Brown dead spots are produced on the leaves and under moist conditions these develop the grey, moldy growth of the fruiting stage.

Leaf Spot, Ascochyta sp. Produces large circular or irregular spots on the leaves; not very common.

Stem and Leaf Rot, Bacterial. Complaint is sometimes made of geraniums rotting off at their base or the leaves decaying or spotting. The trouble seems to be caused by bacteria and no doubt is often induced by too moist conditions. Affected parts or badly diseased plants should be destroyed.

\section{GOLDEN GLOW, Rudbeckia laciniata.}

Powdery Mildew, Erysiphe cichoracearum DC. Common, but not very injurious, and occurring only in the conidial stage.

Stem Rot. The writer's attention has been called to a stem rot trouble of golden glow that has appeared year after year in the same bunch. Each year the rot attacks some of the stems at their base, finally killing them by rotting the tissues and choking up the water ducts. The trouble is carried over in the soil by small black sclerotia, or compacted tubers of fungous cells, that are formed on the rotting stems. The trouble is probably caused by a Botrytis fungus.

\section{GOOSEBERRY, Ribes sps.}

Anthracnose, Gloosporium Ribis (Lib.) Mont. \& Desm. Occurs occasionally on this host. See Currant.

Leaf Spot, Septoria Ribis Desm. Brownish or purplish spots, often having a whitish center, are formed on the leaves. The fruiting bodies, as minute black dots, may sometimes be seen in these. Apparently this is not a common trouble.

Powdery Mildew, Spharotheca mors-uv'e (Schw.) B. \& C. While this has never been collected by the Station botanists, it has occurred in the state, as shown by reference to it in one of the old Reports of the Agricultural Society, where it was named as a serious trouble varying in different seasons. It forms a 
dirty white felt of mycelium on the young branches and leaves and often on the fruit. Imbedded in this are the small reddish black perithecia, containing the asco- or winter spores. Spraying with potassium sulphide, beginning as soon as the buds burst and repeating every two weeks until the end of June, is said to hold this trouble in check.

\section{GRAPE, Vitis sps.}

Anthracnose, Sphaceloma ampelinum DeBy. The bird's eye rot occurs on the leaves, stems and fruit. On the latter it forms circular rotten spots with distinct, bright colored borders, hence the common name. This generally yields to treatment by spraying more readily than the next trouble. Diseased wood should be removed. [Reps. I889, p. I74; I890, p. I02; I893, p. 98.]

Black Rot, Guignardia Bidwellii (El1.) Viala \& Rav. Plate XVII, a. This is the most common and injurious trouble of the grape. On the leaves it produces conspicuous, circular, reddish brown spots. In the small black dots imbedded in these are produced one of the summer spore stages (Phyllosticta Labrusce Thm.) of the fungus. This stage also occurs on the leaves of the Virginia creeper and the Boston ivy, which are related plants. The grapes, on rotting, first have a brown color, but eventually dry up into wrinkled black mummies that adhere for some time to the vine. In these, a summer spore stage, similar to that on the leaves, is first produced, but other stages are also formed, the asco-spore form appearing the next spring. Black rot is a very difficult trouble to control, especially in wet seasons, but persistent spraying year after year reduces the trouble to a minimum. Spraying should begin before the blossoming period, about the last of May; the second application follows after the plants blossom, and others at intervals of ten to fourteen days. Bordeaux is used until the middle of July, and then Amm. Sol. Cop. Carbonate or Soda Bordeaux until the middle of August. The treatment should be thorough for a couple of years until the disease is under control, when the number of sprayings can be reduced from six or seven to three. [Reps. I889, p. I74; I890, p. I00; I893, p. 96; Bull. I $42, \mathrm{p} .8$.] 
Downy Mildew, Plasmopara riticola (B. \& C.) Berl. \& De Toni. Plate XVII, b. This fungus occurs on grapes grown under glass, in the vineyards, and even more commonly on wild species. The thick, white felt that is produced on the under

- surface of the leaves, occasionally on the stems and fruit, bears the thin-walled summer spores; the thick-walled winter spores are rarely formed within the tissues. The treatment given for black rot should prevent this trouble also. When the vines are treated for this alone, perhaps the sprayings need not be so numerous. For grapes grown under glass, Sturgis found the fumes of sulphur safer to use. [Rep. 1893, pp. 77, 97; Bull. I42, p. 8:]

Grey Mold, Botrytis sp. Ripe fruit of greenhouse grapes frequently rots by reason of a common Botrytis mold. . Attention should be paid to the moisture conditions in these houses. Spraying the bunches with potassium sulphide or heating sulphur, probably would prove helpful. The rotting grapes should be removed as soon as they appear.

Powdery M.lLdew, Uncinula necator (Schw.) Burr. This mildew forms a cobweb-like growth on the upper surface of the leaves or occasionally destroys the fruit. In the fall the perithecia are easily seen as very minute reddish or black balls scattered over the surface of the infected leaves. The treatment for black rot should also prevent this. Where this alone is troublesome, the later sprayings may be made with potassium sulphide, if desired. Probably a very late spraying in the fall would prove useful in checking the trotible the next year. The Virginia creeper is also a host for the fungus. [Rep. I895, p. $185 ;$ Bull. I42, p. 8.]

Winter Injury. A very curions trouble was seen the past summer on grapes grown under glass in New Haven. Apparently it was a result of the sudden freeze of December 9, I902, since the greenhouse, contrary to the usual custom, was not heated that winter and the injury was greatest on the west or coldest side of the house. The trouble first showed during the summer in morbid, gall-like growths of plant tissue, that were formed ustually at or toward the base of the vines. These excrescences were more irregular and not so dark colored as black rot. By early winter this morbid tissue was dead and somewhat pulverized by insect larvae. A similar trouble has 
been figured in one of the New York Experiment Station's bulletins on grapes grown outdoors; and has also been described in Europe. It has usually been ascribed to cold weather. As the wood on some of the vines described here also showed winter cracks, this is probably the explanation of the trouble.

\section{GROUND CHERRY, Physalis pubescens.}

White Smut, Entyloma Physalidis (Kalchb. \& Cke.) Wint. The spores of the white smuts are permanently embedded in the tissues, and of light color, so they do not have the black, dusty appearance of the ordinary smuts. This smut of the strawberry tomato, or ground cherry, forms whitish or reddish angular spots on the leaves and is sometimes so abundant as to cause serious injury to the foliage. The character of the host, however, makes it of little economic importance.

HAWTHORN, Cratcegis sps.

Leaf Spot, Entomosporium Thïmenii (Cke.) Sacc. This produces small angular reddish or purplish brown spots on the leaves of the English hawthorn, Crategus oxyacantha, which is sometimes grown in yards.

Rusts, Gymnosporangium macropus Lk., G. clavipes C. \& P. Ecidial stages occur on leaves of cultivated redhaws.

\section{HAZEL, Corylus sp.}

Black Knot, Cryptosporella anomala (Pk.) Sacc. Plate XVII, c. This fungus sometimes becomes very injurious to the ornamental cut leaf hazel. In one nursery it proved so destructive that the owner intended giving up growing this variety. The black knot infects the branches, breaking out between the bark as oval bodies about one-quarter of an inch in length, in the surface of which are embedded the fruiting pustules.

HICKORY, Cary'a alba.

Anthracnose, Glcosporium Caryce Ell. \& Dearn. This forms dark purple blotches on the leaves. 
H.LLYH.OCK, Althea rosea.

Leaf Blight, Cercospora althcina Sacc. The numerous, small, angular spots produced on the leaves by this fungus are reddish brown, often with a lighter center.

Leaf Spot, Ascochyta parasitica Fautr. This sometimes occurs on spots associated with a rust pustule.

Rust, Puccinia Malvacearum Mont. Plate XVII, d. Rust is the most common trouble of hollyhocks and the one most frequently sent to the Station for determination. The fungus shows as roundish cushions, of a light or dark red color, on both leaves and stem. Only teleuto-spores are known and these germinate in position so that the pustules are often covered with a whitish growth due to this germination. Some think the trouble is partially controlled by spraying, but this to prove of benefit should begin before the appearance of the rust pustules. Possibly the trouble might be checked the next year, if in the fall the plants were all cut off below the ground and all of the rubbish destroyed by fire. [Rep. I895, p. I88.]

\section{HONEYSUCKLE, Lonicera sp.}

Powdery Mildew, Microsphara Lonicerce (DC.) Wint. Observed occasionally on Tartarian honeysuckles in old gardens.

\section{HORSECHESTNUT, Esculus Hippocastanum.}

Leaf Spot, Phyllosticta Pavice Desm. A very serious leaf trouble of the cultivated European horsechestnut is caused by this fungus. The large dark red blotches often reach from the margin to the midrib and resemble sunburn. On the upper surface the minute black dots of the fruiting stage are often visible.

\section{HORSERADISH, Cochlearia Armoracia.}

Leaf Blight, Ramularia Armoracice Fckl. This is the fungus ordinarily reported on horseradish, but it does not seem so common here as the next two. The spots are smaller and paler and the leaf tissue often falls out, giving a shothole effect.

LeAF Mold, Macrosporium herculeum E. \& M. It is questionable if this is distinct from $M$. Brassice var. macrospora, which is reported here on cabbage and other cruciferous plants. 
This can usually be told from the other leaf troubles of this host by the brown spots, starting as black dots, forming concentric rings of development. The spots are about one-quarter of an inch in diameter.

Leaf Spot, Cercospora Armoracia Sacc. Plate XVII, e. The fruiting stage often shows as an inconspicuous upright growth on the surface of the subcircular brown spots.

INDIAN CURRANT, Symphoricarpus vulgaris.

Powdery Mildew, Microsphara Symphoricarpi Howe. In nurseries this proves a common trouble, covering the upper surface of the leaves usually with a dense white growth of the summer spore stage, and producing an abundance of the perithecia on the upper surface or, more scattered, on the under side of the leaves.

IRIS, Iris sps.

Leaf Blight, Hetcrosporium gracile (Wallr.) Sacc. This is a very serious trouble of the Iris, especially of Iris Germanica. The prominent elliptical spots appear scattered over the leaves, which often turn yellowish and die at the tips.

Rоoтsтоск Rот, Bacteria. Plate XIX, a. In one of the nurseries, last season, this trouble was common on Iris Germanica and I. cristata. Apparently the disease had been greatly aggravated by burying the rootstocks too deeply when transplanted that spring. The wet season, too, was favorable for the development of the trouble, which, according to the manager, was unusually severe. The rootstocks were rotted off by a wet bacterial rot, which sometimes extended up into the base of the outer leaves. Apparently this is the same trouble that has recently been described from Germany [Zeitschr. Pflanzkrankh. 13: I29-44, I903.] Dr. van Hall, who studied the trouble there, found three organisms associated with the rot, of which Bacillus omnivorus apparently was the chief. The writer made no cultural studies.

Rust, Puccinia Iridis (DC.) Wallr. On the wild species of Iris this is a very common rust, but it was found only once on a cultivated species. It produces the ordinary dusty reddish pustules, thickly covering the leaves. So far only the uredostage (Uredo Iridis DC.) has been found here. 
IVY, BOSTON, Ampelopsis tricuspidata.

Leaf Spot, Phyllosticta Labrusce Thm. This is apparently the same as the leaf spot form of black rot of grapes.

\section{KCELREUTERIA, Kolreuteria paniculata.}

Red Knot, Nectria cimabarina (Tode) Fr. Colortype 3. This occurred in a nursery doing serious injury to this Japanese tree. On the sunken, cankered areas reaching clear into the wood, there was found an abundance of the small, spherical, bright red perithecia of the fungus. There was some question, however, whether winter injury did not form the starting point of the trouble.

\section{LAVATERA, Lavatera sp.}

Rust, Puccinia Malvacearum Mont. See Hollyhock.

\section{LETTUCE, Lactuca sativa.}

Downy Mirdew, Bremia Lactucre Regel. Lettuce, both in and out of doors, is sometimes bothered by this fungus. It produces brownish dead areas which usually show on the under side whitish tufts of the fertile threads of the fungus. As it is a trouble that thrives best in moist places, care in watering greenhouse plants is helpful in controlling it. [Bull. I42, p. 9:]

Grey Mold, Botrytis vulgaris Fr. This causes a rotting or spotting of the leaves, upon the dead portion of which the fruiting stage develops as an erect greyish mold. It is common in moist greenhouses and is apparently the same Botrytis that develops on a great variety of plants under moist conditions. The stem rot of onions, the grey mold of grapes and the fruit mold of egg plants are possibly caused by different species.

LEAF Spot, Septoria consimilis Ell. \& Mart. This can be identified by the fruiting stage, which shows as very small black dots in the spots or dead areas it produces on the leaves. Like the other troubles, care in watering indoor lettuce and the removal of diseased leaves as soon as they appear, will help to keep it in check. It will pay the greenhouse grower never to allow any wilted or dead leaves to remain either on the plants or on the soil. 
IILAC, Syringa vulgaris.

Powdery Mrldew, Microsphcera alni (Wallr.) Wint. Every one has noticed this on the upper surface of lilac leaves. Both spore stages are produced abundantly.

\section{LILY OF THE VALLEY, Convallaria majalis.}

LeAF Blotch. During the summer and fall the leaves of this plant commonly become discolored with purplish blotches, which often run together into large areas. So far no fungus has been found in a fruiting condition on these leaves, but the trouble appears to be of fungous origin.

\section{LILY, WHITE DAY, Funkia subcordata.}

Anthracnose, ? Colletotrichum sp. Produces subcircular brown spots with purplish borders.

\section{LINDEN, Tilia sp.}

Black Mold, Fumago ziagans. The linden trees of a park in Bridgeport were found coated on their upper surface with this fungus, which gave them a sooty appearance.

MAHONIA, Mahonia Japonica.

LeAf Spot, Phyllosticta Japonica Thm.

\section{IIAPLE, Acer sps.}

Anthracnose, Gloosporium saccharini E. \& E. Irregular dead areas, often of considerable size, are produced by this fungus, giving the appearance of sunburn.

Black Spot, Rhytisma acerinum (Pers.) Fr. On Acer dasycarpum. This forms black, slightly elevated "finger prints," about $1 / 2$ inch wide, on the upper surface of the leaves. The lower surface is often concave and not so dark colored. The sac fungus producing these does not mature its spores until some time after the leaves have fallen from the trees.

Leaf Spot, Phyllosticta minima (B. \& C.) Ell. (P. acericola) On Acer dasycarpum, $A$. pseudoplatanus var. Causes reddish or brownish circular spots about $1 / 4$ inch in diameter. 
MARIGOLD, Tagetes sp.

Grey Mold, Botrytis vulgaris Fr. On blossoms. See Lettuce.

MATRIMONY VINE, Lycium vulgare.

Powdery Mildew, Erysiphece undet. Conidia only.

MIGNONETTE, Reseda odorata.

Leaf Blight, Cercospora Reseda Fckl. Not infrequently this fungus produces small whitish spots on the leaves.

Stem Rot, Rhizoctonia sp. In one greenhouse this was found doing some damage to the plants. The stems were rotted off at the base, the leaves turning yellowish. Where the leaves came in contact with the moist ground, they also started to rot.

MUSK MELON, Cucumis Melo.

Anthracnose, Colletotrichum Lagenarium (Pass.) Ell. \& Hals. See Watermelon.

Downy Mildew (Bligirt), Plasmopara Cubensis (B. \& C.) Humph. Plate XVIII, a-b. This trouble has been prominent at least during the past three years, though last year it was not nearly so serious as the year before. As it is a trouble that comes and goes, this may indicate that it is on the wane again. The disease first shows during the latter part of July or early August, when large, brownish, angular spots appear on the leaves. If the season is favorable, the leaves become thickly covered with these, the intervening green tissue dies and the leaf dries up on its stalk. In a very few days the trouble may spread so rapidly that it kills practically all of the leaves. This often occurs before any of the fruit matures, and what little does ripen lacks flavor. In moist weather, by looking closely at the under surface of the leaves with a magnifier, the fruiting threads can be seen at the juncture of the green and dead tissue, as a scanty, dark purple, upright growth. The color is due to the very large purplish summer spores which are borne on the ends of these fertile threads. The winter, or oospores, have never been found, though the writer has searched for them at all seasons of the year. It is not known how the fungus passes the winter in this state. Possibly it does not 
winter so far north, or possibly it is carried over on greenhouse cucumbers. Any curcubit is likely to be attacked by it, but so far it has been observed here only on the common and English cucumbers, on musk melons and rarely on watermelons. During seasons when the trouble develops very seriously, it is questionable if spraying yields any very striking results with musk melons, though it does give good results with cucumbers. During ordinary seasons, however, this, and most of the other troubles of the musk melon, can be held in check by thorough and repeated sprayings with Bordeaux. The first application should be made as soon as the vines begin to run. [Rep. I899, p. 277 ; Bull. I42, p. Io.]

Leaf Mold, Alternaria Brassice var. nigrescens Pegl. (Macrosporinm cucumerinum Ell. \& Ev.) This fungus also produces brownish spots on the leaves that can scarcely be distinguished by the naked eye from those of the preceding fungus. It occurs also on the watermelon. While not an uncommon trouble, it is not usually so serious as the downy mildew. The treatment is the same. [Reps. I895, p. I86; I896, p. 267 ; I898, p. 233 ; I899, p. 272 ; Bull. I42, p. Io.]

ScAB, Cladosporium cucumerinum Ell. \& Arth. (Scolecotrichum melophthorum Pr. \& De1., Cladosporium cucumeris Frank.) Plate XIX, b. This has been reported several times in this country on cucumbers, and in Europe on both cucumbers and musk melons. Last season it was found in this state, on both hosts, but doing most injury to melons. It appeared about the first of August, producing sunken areas on both stems and fruit. The mycelium produces these by collapsing the tissues and then forms on the outside a dense olive growth of a summer spore stage-the only one known. Apparently, the trouble thrives only in very moist weather.

Wilt, Bacterial, Bacillus tracheiphilus Sm. Occasionally occurs, doing damage; see Squash. Bacteria also produce a leaf spot trouble, but probably this is only another form of the wilt disease. [Rep. I898, p. 225.]

Wilt, Fungus, Neocosmospora rasinfecta (Atk.) Sm. In appearance this is the same as the preceding, but the Fusarium stage of the Neocosmospora fungus clogs up the water ducts of the stem and produces the wilt. Apparently it is not as common as the bacterial wilt. [Rep. I898, p. 228.] 
Spray Injury. Bordeaux mixture sometimes slightly injures the foliage. In these cases the leaves turn yellowish at the margin and may die prematurely if severely injured. Occasionally the fruit shows some distortion or the scar of the blossom end becomes greatly exaggerated.

Sun Burn. Sturgis described a similar trouble which he called leaf burn, and ascribed to a sudden disturbance of the equilibrium between water absorption and evaporation. "When cool, cloudy weather alternates with hot sunshine, it is frequently noticed that the large leaves near the center of the hills turn yellow at their margin. Later, these yellowed margins become brown and dry and finally the whole leaf is diseased." [Rep. I898, p. 228.]

MUSTARD, Brassica sp.

Leaf Mold, Alternaria Brassica (Berk.) Sacc. See Cabbage.

\section{OAK, Quercus sp.}

Powdery Mildew, Microsphara quercina (Schw.) Burr. The cultivated English oak, Quercus robur, frequently has this mildew on its leaves.

OAT GRASS, Arrenatherum avenaceum.

Smut, Ustilago perennans Rostr. The smut destroys the grain, but the fungus is not of econonic importance since the host is rarely grown here.

OATS, Arena satira.

Black Stem Rust, Puccinia graminis Pers. Plate XIX, c. This rust produces elongated outbreaks on the stems and leaf sheaths. These are at first the reddish, uredo-stage, but later the black, teleuto-stage. The stems are weakened by the action of the fungus and badly rusted grain is apt to lodge. The barberry is the host for the æcidial stage, but apparently the fungus often skips this step in its life cycle. Black rust also occurs here on red top and timothy. This rust very commonly occurs with crown rust, and the injury they cause to the crop of oats is sometimes considerable. Very little can be done to lessen these troubles. [Rep. I889, p. I74.] 
Crown Rust, Puccinia coronata Cda. Plate XIX, d. This is common on the leaves, producing first the small, dusty, red uredo-stage, and later the blackish teleuto-stage firmly imbedded in the tissues. These outbreaks are not nearly so elongated or prominent as in the preceding. It is called crown rust because the teleuto-spores have curious, horn-like projections.

Smut, Ustilago Avence (Pers.) Jens. Plate XIX, e. This forms the common, dusty, blackish masses that completely destroy the grain. The covered smut, Ustilago levis, less completely destroys the grain, often being confined to the inner basal parts; neither is it as common here. Both of these smuts can be prevented by seed treatment with formalin or hot water. [Bull. I42, p. IO.]

\section{ONION, Allium Cepa.}

Black Mold, Macrosporium Porri Ell. Apparently this does more or less damage to onions. It is found on "blighted" onions and probably is partially responsible for the trouble. Thaxter describes and figures this in the Report for I889, p. I6I. The fungus probably belongs under the genus Alternaria rather than Macrosporium, if these two genera are distinct.

Black Spot, Vermicularia circinans Berk. Plate XX, a. It is on the stored onions that this trouble becomes prominent. Black blotches, made up of the small black fruiting pustules, appear on the outer dry coats of the onion and gradually work through a few beneath. While not causing a rot, this trouble seriously affects the appearance of the onion, especially the white varieties, and thus lessens their market value. So far the only means of lessening it is the best care in drying and storing the crop. Some have advocated the use of air-slaked lime scattered over the onions, but no definite experiment has been undertaken to show the valtue of this. [Rep. I889, p. I63; Bull. I42, p. II.]

Downy Mildew, Peronospora Schleideni Ung. Thaxter found this fungus causing serious injury to the onions at Wethersfield in I889. It has not been seen by the writer, though it probably still causes trouble occasionally. Usually the whitish growth of the mildew is not very prominent and may be obscured by the presence of the black mold fungi. Through the action of the mycelium, whitish or yellowish spots are produced in the tissues and the injury may become so severe that 
a blighting of the vines results. The fungus occurs in the fields as early as July. Spraying experiments conducted in Vermont showed that the trouble could be partially controlled in this way.

Rot, Bacterial. Stored onions are sometimes destroyed by a soft rot due to bacteria. Sometimes the whole onion rots or only certain lavers may go. If the outer ones are rotting, they give a slippery feeling upon pressure with the hand. Maggots often accompany or follow this trouble.

Smut, Urocystis Cepulce Frost. This produces black, dusty pustules on the leaves and bulbs. It may be found early in May on the seedlings or late in the fall on the mature bulbs. The former are often killed outright and the stand seriously affected. The smut may become established in the soil and then it becomes more and more difficult to raise onions on this land. Considerable land valuable for onion culture has become unavailable for this purpose. It has been found that the sets do not smut, to any great extent, and that seed onions germinated in free soil and later transplanted to the infected soil also remain nearly free from smut and that the transplanting increases their size. Preliminary experiments by Thaxter and later work by Stewart, of New York, and Selby, of Ohio, show that the treatment of infected soil with certain chemicals will also lessen the amount of smut. One of the most feasible treatments seems to be the use per acre of roo $1 \mathrm{bs}$. of sulphur, thoroughly mixed with $50 \mathrm{lbs}$. of air-slaked lime, which is drilled into the rows with the seed. Another remedy is sprinkling formalin over the seed before covering. Ground lime, drilled into the soil at the rate of 75 to 125 bushels per acre, has also been used. [Reps. I889, p. I29; I890, p. I03; I893, p. 99; I895, p. I76; Bull. I42, p. II.]

Stem Rot, Botrytis sp. Plate XX, b-c. In Europe there is a Botrytis bulb rot of onions and hyacinths that is possibly the same as that described here. It is known there in its perfect stage as Sclerotinia bulborum. This trouble has occasionally occurred in Connecticut before, but apparently never so seriously as during the past two years. There is a possibility that it is not specifically different from the common Botrytis trouble of our greenhouse plants. The same trouble has been reported before by Halsted, of New Jersey, and during the past two years has occurred also in Massachusetts and, perhaps, elsewhere. Only 
the Southport White Globe seems to have suffered very severely from the rot. This variety is largely grown in Connecticut along the Sound from Green's Farms to Guilford. The onion growers of Green's Farms and Southport have suffered especially. In I902 their loss was estimated at least $\$ 50,000$, and in I903 the crop did not nearly pay expenses. Some growers stopped sending their onions to market, since the returns per barrel paid little more than the freight. One grower near Branford was able to market only about 400 bushels out of I,200 harvested, but these brought him very high prices.

The stem rot does not appear until after the onions are stored in the fall. Crops that were supposed to be in a fair shape when stored have rapidly disappeared with the trouble in October and later. The onions are sorted and the good ones sent to the market, but apparently these rot very seriously in transit. The trouble is called stem rot, because it begins at the stem end of the onion, which becomes soft to pressure at this place due to the rotting of the inner layers. The rot does not seem to usually spread from onion to onion, since the outer, drier layers are generally the last to rot. Plate XX, b, shows the top view of a rotting onion, while a cross section of the same onion is shown in Plate XX, c, where it is seen that only a few of the inner layers have rotted. Upon the exterior, drier layers, there often develops a dense growth of the olive-grey fertile threads of the summer stage. With these are sometimes found the small black sclerotia, or resting condition of the mycelium, that carry the fungus over the winter and apparently in the spring develop the Botrytis stage. A Sclerotina or ascostage has not been seen here. According to the writer's observations, this fungus in its Botrytis stage spreads as a parâsite on the green leaves and on the blossoms in the fields as early in the season as July. It causes yellowish spots on the leaves and blasts the flowers. Wet weather is especially favorable for its development and this accounts for the unusual injury during the past two seasons. Wet weather, when the onions are drying in the field, undoubtedly is very favorable for the development of the mycelium into the bulbs from the drying stems; however, it is only after their storage that the real stem rot begins. Probably a moist fall after the storage also aggravates the trouble. 
So far no remedies have been tried to prevent the trouble. Unusual care in curing and storing the crop apparently does not stop it. The character of the land, whether new or old in onion culture, seems to have had little influence. The very general prevalence of the disease points to the wet seasons as the chief 'factor for its development, and if a dry season should now follow, the chances are that the trouble would lessen very greatly. Attention should be called to the old rotting onions as a means of carrying the fungus over the winter by means of the black sclerotia. These onions should not be used as a fertilizer on the land. The fact that the fungus occurs in summer as an active parasite on the plants indicates that possibly spraying, by keeping the plants free from it during the growing season, may lessen the chances of the bulbs rotting late. If onions are sprayed, the first treatment should be given very early in July. Resin Bordeaux will probably prove the best fungicide to use, since the ordinary Bordeaux may not adhere readily to the plants. The sprayings should be repeated at least three times. This treatment is recommended only as a possible remedy. [Bull. I.42, p. II.]

Yellow Leg oR BLACK MoLd, Macrosporium parasiticum Thm. This trouble is caused by a close relative of the fungus described under Black Mold. Thaxter found it often associated with the Downy Mildew, but he considered it a true parasite. It was found in 1902 by the writer, doing considerable damage to seed onions in the vicinity of Milford. Conspicuous yellowish or whitish areas are produced on the leaves and these. become coated with a luxuriant black growth of the fruiting mold. Spraying ought to prevent this trouble.

\section{ORCHARD GRASS, Dactylis glomerata.}

ERgot, Claviceps sp. The sclerotia are smaller than those of the rye ergot.

\section{PARSLEY, Petroselinum sativum.}

Leaf Spot, Septoria Petroselini Desm. Under the action of this fungus the leaves, or parts of them, turn whitish and become speckled with the minute black spore receptacles imbedded in the tissues. More rarely the fungus produces distinct circular whitish spots in the green tissues. A variety of this fungus occurs on celery. 
PARSNIP, Pastinaca sativa.

Leaf Blght, Cercospora Apii var. Pastinace Farl. This is only a variety of the common leaf blight of celery. It has not been found doing any considerable injury to the parsnip.

\section{PEA, Pisum sativum.}

Leaf Spot, Ascochyta Pisi Lib. While this is a very common trouble with peas it is only occasionally that it causes severe injury. Roundish or angular spots are produced on both the leaves and pods. These are about one-quarter of an inch or less in diameter and usually have a distinct narrow purplish border. [Rep. I899, p. 280.]

Powdery Mildew, Erysiphe Polygoni DC. The powdery mildew is likely to be found on the peas late in the season after they have passed their prime. Sometimes, however, it comes earlier and causes more severe damage. The leaves, stems and fruit become coated with a more or less prominent whitish powdery coating of the mycelium and summer spores; later, the small, blackish perithecia of the asco-spores are produced. Spraying with potassium sulphide should control the trouble.

\section{PEACH, Prunus Persica.}

BaCterial Spot. During the past season, leaves of peach were received from an orchard in Pomfret that were covered with small, reddish brown, angular spots less than one-eighth of an inch in diameter. An examination of the diseased tissues under the microscope showed an abundance of bacteria, which were apparently the cause of the trouble. The spots were very similar to those produced on the leaves by the scab fungus or by spraying injury, and the tissues showed a tendency to fall out, giving a shot-hole effect. As 1903 was a season very favorable for the development of bacterial troubles, in normal seasons this bacterial spot may not prove serious.

Brown Rot, Sclerotinia fructigena (Pers.) Schrt. Plate XXI, b. The fruit is the part of the host most severely injured by this fungus. About the time of ripening it may begin to decay, and if the weather is moist, the brown rot spreads rapidly. The ordinary rot of the peaches bought in the market is caused by this fungus. The brown rotten areas rapidly involve the 
entire peach, and the summer fruiting stage usually shows in the small, dusty, closely packed pustules breaking out on the surface. The disease is not confined to the fruit, but the young twigs and sometimes the leaves are killed. In some cases the mycelium apparently passes down into the branches from the diseased fruit. In wet springs the fungus also sometimes blasts the blossoms. Brown rot is one of our most injurious fungous foes, since in wet years thousands of baskets of peaches are destroyed by it. Usually it is most troublesome with the early varieties. Plums and cherries are also seriously affected by it, while apples, quinces and pears are less subject to this rot. The fungus passes the winter in the diseased branches, and also in the mummied, rotted fruit; the mycelium in these giving rise to new summer spores in the spring. Norton, of the Maryland Experiment Station, has recently found the mature stage of the fungus developing from the mummied fruit buried in the ground. This consists of a narrow pedicle expanding above the ground into a saucer-shaped receptacle that contains the winter or asco-spores. This then is another means of carrying the fungus from one season to another. So far, this stage has not been found in Connecticut.

It is evident that all rotten fruit should be destroyed by fire, and that all nummies should be carefully removed from the trees and the ground each season after the harvest time. During the ripening period, all rotten fruit should be gathered promptly, in order to check the spreading of the trouble. Where fruit sets very abundantly, the common practice of thinning also serves to keep down the trouble later. A good many spraying experiments to prevent brown rot have been recorded, some of which evidently have proved successful; but it is a difficult disease to combat in this way, both because of the rapidity with which it spreads in moist weather, and because of the injury that is likely to result to the foliage from the use of fungicides. Where spraying is to be tried, perhaps the best treatment would be a winter spraying with Bordeaux, given as for leaf curl, followed by two or three sprayings about picking time with potassium sulphide or copper acetate. [Reps. I889, p. I7I ; I893, p. 95 ; I894, p. I38; I898, p. 261 ; I900, p. 232 ; Bull. I42, p. I2.]

Crown Gall, Dendrophagus globosus Toum. See Plum. 
Crown OR FoOT Rot. This trouble is confined to the region of the tree near the juncture of the stock and scion, usually just below the ground. The most peculiar character is the ease with which the trees are broken off at this place. By pushing them from side to side by hand, they will often crack off sharply and sometimes they are even broken off by the winter winds. The trouble is not usually found in the nursery, but it has been seen in young orchards only set out one or two years. It is most conspicuous, however, in the older orchards. The trunk or roots become enlarged at the crown, so that it is sometimes called "club root." Upon breaking off the trees the woody growth is seen to be abnormal here, having become spongy and brittle and thus allowing easy fracture. On this account it is known also as "spongy root." The cortex is abnormally developed and appears diseased. The trees usually show the trouble some years before dying. They cease to grow; the foliage gradually becomes scantier, and often has an unhealthy appearance. The trouble is not uncommon in the peach orchards of the state, and was first described by Sturgis in the Report of the Pomological Society for I9or, p. 235. The owner of one orchard of about thirty acres, examined by the writer, stated that he had removed one year about 400 trees and since then a few trees had been taken out each year. It is a question whether the trouble is contagious, since young trees set out in the place of those removed do not seem to be especially troubled. The cause of the disease is not surely known. Most probably it is due to a fungus developing in the bark and wood, producing these abnormal and diseased conditions of the tissues. Sections of the cortex have shown the presence of nycelium in the diseased tissues, but it is possible that this may have come in late as a saprophyte. The other possible explanation is that the morbid conditions result from too great moisture in summer, followed by injury from severe cold in winter. Most growers remove the trees as soon as found since they never amount to much.

Dead Limb Fungus, Cytospora Persicce Schw. This fungus, apparently, is never the cause of disease, but it is frequently present on the dead limbs as a saprophyte. Sometimes a dead tree is entirely covered with its outbrealks. These show as small white pustules. 
Leaf Blight, Cercosporella Persica Sacc. The name frosty mildew describes more aptly the appearance of the fungus. It produces yellowish or reddish areas on the leaves, showing the fruiting condition on the under surface usually as a conspicuous white growth. Thaxter, in the Report for I889, p. I73, records the defoliation of orchard trees at Deep River by this fungus. The writer has observed it only once, where it was doing a little damage to nursery trees.

Leaf Curl, Exoascus deformans (Berk.) Fckl. Colortype 7. Leaf curl is one of the earliest appearing diseases of the peach, showing soon after the leaves come out. It kills the entire leaf, or the greater part of it, usually from the tip downward. The leaf turns yellowish or reddish brown, and becomes more or less irregularly curled or wrinkled. Often a whitish bloom is seen on the diseased area. The worst infected leaves drop off, so serious defoliation may often take place. The trouble may be prevented largely by a single spraying with Bordeaux mixture just before the buds begin to swell in the spring. In very wet seasons a second application, with the half strength mixture, should be applied just after the petals fall. The winter treatment with the lime, sulphur and salt for the scale is said to also check this trouble somewhat. [Bull. I42, p. I2.]

Powdery Mildew, Sphaerotheca pannosa (Wallr.) Lev. In nurseries where the trees are crowded closely together, this fungus is found sometimes causing trouble. Occasionally it is also found on trees in the orchard. The young leaves and the twigs become covered with an evident white felt of the mycelium and summer spore stage, but the winter stage has not been observed. Planting the trees less closely would no doubt be helpful in preventing the trouble or spraying with potassium sulphide should control it.

ScAB, Cladosporium carpophilum Thm. Plate XXI, a, c-d. This fungus occurs on the fruit, leaves and twigs. It forms the black, circular, superficial spots so commonly seen on the fruit in the market. Very frequently these scabby spots pretty thoroughly cover one half the surface, that which faced upwards on the tree. When abundantly attacking the young fruit, it may cause it to develop one-sided, or to crack open when mature, thus exposing it to decay by the brown rot fungus. On the 
leaves, the fungus produces a reddish brown spotting of the tissue, which later may drop out, giving a shot-hole effect. On the young twigs it also produces conspicuous reddish brown spots often with a purplish border. The mycelium lives over the winter on the infected twigs and produces the summer spores in the spring. The advantage of a winter or early spring treatment on the dormant tree is readily seen. Several Connecticut orchardists report less scab in their orchards after spraying with the lime, sulphur and salt mixture for the San José scale. The treatment for leaf curl should also be of benefit for this trouble. Winter treatment, however, will not wholly stop it. Taking into consideration the few peaches harvested last year, the scab was more injurious than usual. [Reps. I894, p. I38; I896, p. 269; I898, p. 26I; I900, p. 232; Bu1l. I42, p. I2.]

Spray Injury. The experiments of Sturgis, Rep. I900, p. 2I9, showed conclusively that there was danger in the use of fungicides on the mature foliage, at least in Connecticut. Bordeaux mixture, which is the fungicide commonly used, will produce a leaf-spotting and shot-hole effect very like that of the scab fungus. The worst injured leaves fall off, so it is possible to completely defoliate the tree. The writer found that there was even danger in the use of the half strength solution. Potassium sulphide, apparently, is the safest fungicide to use on the mature leaves.

Winter Injury. Plate $\mathrm{X}$, a. The sudden freeze in December, I902, killed the fruit buds very generally and also injured the wood slightly. This darkening of the wood often showed in spots in a cross section of the branch and became more evident toward the ends of the twigs, sometimes ending in a dead twig. The growth of new wood made the next year was good, though not so great where the injury was very manifest. The winter of I903-4 was very much more injurious. While the trees went into the winter in better condition than the previous year, the continued and severely cold weather made its influence felt in a number of orchards. The injury to the fruit buds, apparently, was not so great as the year before. The chief injury was to the wood of the trees; this showed in the blackening or darkening of the wood clear down to the snow line. The few inches of the trunk next the ground, protected 
by the snow, appeared uninjured. As yet, the bark does not show the effect of this injury, and no cases of its girdling was observed, as with apples the previous year. Most orchards escaped this injury, while others in the same locality but lower down, were very severely injured. Many trees will no doubt have to be cut out; others may pull through with a severe pruning. What future troubles may result to trees severely injured, if left standing, is not known.

Yellores. This is now considered a physiological trouble, due to certain enzyms or ferments acting on the tissues and disarranging their normal functions. It is a contagious trouble. No doubt many sickly peach trees present symptoms that may be mistaken for yellows by some. The general characters of the disease are as follows: A premature ripening of the fruit, which becomes streaked with red and is of very poor quality; a premature development of the winter buds, giving rise to excessive branching on the new shoots; the development of adventitious buds into elongated sickly water sprouts; finally, a scantier and sickly yellowish development of the foliage. The usual method followed with this trouble is to grub out the trees as soon as discovered, and plant new ones in their places. [Rep. I893, p. 92 ; Bull. I42, p. I 37.]

\section{PEAR, Pirus communis.}

Bitter Rot, Glomerella rufomaculans (Berk.) Sp. \& von. Schr. Occasionally found on this host but not very injurious. See Apple.

Black Mold, Fumago vagans Pers. This fungus lives in the honey dew secreted by lice, and, while often forming a conspicuous coating on the leaves, it is hardly to be feared in itself. Last year the seasonal conditions were unusually favorable for the propagation of the pear psylla and the green apple louse, and these insects did serious damage to their hosts. Early in June, developing in the honey dew of these insects, there appeared on the pear and apple leaves and twigs a conspicuous coating of the black mold, which remained prominent during the season. Some growers mistook this for the cause of the injury, which really resulted from the attack of the lice.

Black Rot, Spharopsis Malorum Pk. Occasionally occurs on twigs, fruit and leaves. See Apple. 
Brown Rot, Sclerotinia fructigena (Pers.) Schrt. Not a very serious trouble on this host. See Peach.

Fire Blight, Bacillus amylovorus (Burr.) De Toni. This bacterial disease is the most serious enemy of the pear. It was with this that bacteria were first proved to be the agents of disease in plants. Insects visiting the blossoms accidentally carry the germs to the nectar, where by multiplication they gradually work down into the young twigs and cause their death in late spring or early summer. Blighted twigs, a foot or two in length, with the blackened, dead leaves still adhering, occur commonly. Cankered areas also occur in the bark of the older branches or the main trunk. Sometimes sticky exudations of the bacteria may be found on these diseased places, and are thus exposed to distribution by insects. Some growers believe that blight occurs more commonly on cultivated trees than those left in sod. The only treatment is thorough pruning. This should be done in winter, when the germs are less likely to be distributed, and care should be taken to cut off the limbs below the disease. The occasional dipping of the pruning knife into corrosive sublimate, to kill adhering germs, is also advocated. Cankered areas may be scraped and painted. Blight occurs also on the quince, apple and rarely on the plum. [Rep. I894, p. II3; Bull. I42, p. I3.]

LEAF Blight, Entomosporium maculatum Lev. Sometimes this causes serious injury to the leaves and fruit. See Quince.

Leaf Spot, Septoria piricola Desm. So far, this has been found only sparingly here. The leaves become more or less covered with small, greyish, subcircular or angular spots with purplish borders. It may be prevented effectually by the usual treatment for pear scab. [Bull. I42, p. I3.]

Pinis Mold, Cephalothecium roseum Cda. Occasionally causes rot in ripe stored pears. See Apple.

Rust, Gymnosporangium globosum Farl. Thaxter reported the rcidial stage of this rust [Rep. I89o, p. 98] on Japanese varieties, where it was doing considerable damage. See Apple.

Scab, Venturia pirina (Lib.) Aderh. Like apple scab, the parasitic summer stage (Fusicladium pirinum) of this fungus is now known to be connected with a saprophytic asco-spore stage that develops on fallen leaves. Pear scab is closely related to apple scab and very similar in appearance, and the treatment 
for its prevention is practically the same. See Apple. [Reps. I889, p. I73; I893, p. 73, 90; I894, p. I35; Bull, I42, p. I3.]

Sooty Blotch, ? Phyllachora pomigena (Schw.) Sacc. This is not nearly so troublesome on the pear as on the apple, $q$. $v$.

\section{PEONY, Pconia sps.}

Scab, Cladosporium Paonice Pass. This trouble forms very conspicuous blotches, often over an inch in diameter, on the leaves. Usually these start at the border and extend inward. They are purplish on the upper surface and reddish brown beneath. It was found once doing damage in a nursery.

\section{PEPPERS, Capsicum annuum.}

Anthracnose, Colletotrichum nigrum Ell. \& Hals. In the Report for 1899, p. 282, Sturgis states that he found this fungus destroying 25 per cent. of the fruit in certain fields. It develops light brown, rotten areas on the fruit, which greatly enlarge and ruin the fruit. The fruiting stage shows on these rotten spots as numerous minute black pustules. Spraying experiments, conducted by Halsted, of New Jersey, did not prevent the disease very successfully. The rotten fruit, as soon as it appears, should be picked and carried away.

Anthracnose, Glcosporium piperatum Ell. \& Ev. The writer has found this sparingly in the fields. It produces a rot of the fruit like the above, but the fruiting stage shows as minute pinkish globules.

Black Mold, Macrosporium commune Rabh. On the rotten areas of the fruit, one sometimes finds this fungus developing a luxuriant olive-black moldy growth. Apparently, it is only a saprophyte.

Grey Mold, Botrytis sp. The grey mold that affects a great variety of plants also produces rot on the peppers, and develops a dense, erect growth of the olive-grey fruiting threads on them in moist weather.

\section{PHLOX, Phlox sps.}

LeAF Blight, Septoria sp. Forms large, irregular, whitish areas in which are thickly embedded the small black spore receptacles. 
Leaf Spot, Cercospora omphacodes Ell. \& Holw. Forms small whitish spots with purplish borders.

Powdery Mildew, Erysiphe cichoracearum DC. Plate XXIV, a. This is a common trouble with phlox, the mycelium thickly coating the stem and leaves. Both spore stages occur. The trouble could probably be kept in check by spraying.

\section{PINK, SWEET WILLIAM, Dianthus barbatus.}

Stem Rot, Rhizoctonia sp. See Platycodon.

\section{PLATYCODON, Platycodon grandiflorum.}

Stem Rot, Rhizoctonia sp. The stems gradually rot at the ground, and the plants wilt and often die as the result. The fungus lives in the soil and appears year after year, killing some of the stems. The trouble may spread to neighboring plants, as it occurs on Sweet William, mignonette, carnations, etc.

\section{PLUM, Prunus sps.}

Black Knot, Plowrightia morbosa (Schw.) Sacc.. Plate XXIV, c. The black, gall-like excrescences that occur on the limbs are familiar to every one. Ordinarily, they form an elongated irregular enlargement two or three times the thickness of the small branch. The surface is very uneven with minute elevations, indicating the spore cavities. The knots sometimes attain considerable size or produce distortion in the large branches. By the thorough pruning of affected branches, the trouble can be held in check. In the nursery this can be supplemented with spraying. The mycelium penetrates deeply into the wood and causes dark streaks; in pruning, all this should be removed. Where large branches are removed, it is best to paint over the cut surfaces. In some cases entire trees need to be cut down. The Japanese varieties now seem to knot as badly as any of the others. Wild and cultivated plums and wild cherries are subject to the same trouble. While always present, it seems to have developed more vigorously than usual during the past two years. [Reps. 1889, p. I76; 1893, p. 94; Bull. I42, p. 6.]

Brown Rot, Sclerotinia fructigena (Pers.) Schrt. A serious trouble of this host. See Peach. [Rep. I889, p. I76.] 
Crown Gall, Dendrophagus blobosus Toum. Plate XXIV, b. So far this has been found here chiefly in nurseries. The galls are usually on the lower part of the stem near the ground, or on the roots. They are morbid outgrowths of the tissues, usually subspherical in shape and about an inch or two in diameter. Sometimes they practically encircle the crown, girdling the tree. Professor Toumey made a study of this trouble on the almond in Arizona and ascribed it to a new species of slime mold. Nursery stock showing any signs of these galls should be rejected. The same trouble is found here in nurseries on the peach, and the same or similar troubles occur on raspberry and apple. [Bull. I42, p. I4.]

Fire Blight, Bacillus amylovorus (Burr.) DeToni. In the Report for I894, p. II7, Sturgis described a bacterial trouble of plums found doing damage in an orchard at Hartford. It was not known at that time whether the trouble was the same as pear blight, but later study by Jones, of Vermont, seems to show the identity of the two.

Leaf Curl, Exoascus mirabilis Atk. Sturgis records this as doing. damage in an orchard in New London in 1895. The trouble is somewhat similar to peach curl, except the young branch, as 'well as the leaves, becomes distorted into an irregularly thickened body. The injury to the leaves usually extends from the base up. The same treatment given for peach curl should be used for this.

LeAF Spot, Cylindrosporium Padi Karst. This does not occur so commonly on the plum as on the cherry, $q$. $v$.

Plum Pocket, Exoascus Pruni Fckl. So far this has not been recorded from this state, but is included here in the hope that some one will send in specimens. It is caused by one of the curl fungi, which attacks the young plums, forming elongated, inflated bodies.

Powdery Mildew, Podosphara oxyacantha (DC.) DeBy. So far this mildew has been found only in its conidial form, producing whitish growth on the leaves. Apparently it is not common.

ScAB, Cladosporium carpophilum Thm. This has been found here only on wild plums, but no doubt it occurs occasionally on the cultivated sorts. See Peach.

Shot-hole. Spraying and certain fungi may produce shot- 
hole troubles in the foliage of plums, but in most of the cases examined these seemed to have had other agents; at least, the trees were not sprayed and no signs of a fungous agent were found. Insects are probably responsible in some cases, and it is barely possible that, as in the case of the peach, bacteria cause the trouble. Some botanists have attributed it at times to weather conditions. The plum seems to resent any injury to the foliage by dropping out the injured tissue.

\section{POPLAR, Populus sps.}

Anthracnose, Marsonia Castagnei (Desm. \& Mont.) Sacc. The white poplar, Populus alba, is attacked by this fungus. It produces reddish brown, subcircular spots on the upper surface of the leaves; the spots may become so numerous that they merge into one another. The spores ooze out through very small rifts in these spots.

Canker. Nurserymen complain of a trouble of the Carolina poplar that is apparently of fungous origin and produces cankered places in the bark and wood, especially at the base of the young branches.

Rust, Melampsora populina (Jacq.) Lev. This is a common trouble occurring on the leaves of a number of the poplars. The uredo-spores break out as dusty, reddish pustules, but the teleutospores are permanently embedded in the tissues and mature often after the leaves fall to the ground.

\section{POTATO, Solamm tuberosum.}

Anthracnose, V'ermicularia sp. After potato vines die, especially if blighted, this common saprophytic fungtus almost always appears on the stems, showing its fruiting stage in numerous, minute black tufts.

Blight or Downy Mildew, Phytophthora infestans DeBy. Plates XXII, d, XXIII, a-b. Any dead potato vine is likely to be called blighted by the general observer. This trouble, however, does not appear, usually, until about the middle of July or later. Wet weather, of several days duration, any time from the first part of July till the middle of August is very likely to bring it into prominence, whole green fields suddenly turning brown, the vines dying in a few days. A careful examination of these fields, however, would show its presence, in 
an inconspicuous way, some time before this. At first, prominent black spots appear at the tips or margins of the leaves. Careful examination on the under side shows a slight whitish growth at the juncture of the green and diseased tissue. This is the summer spore stage of the fungus, and it is by the quick germination of the spores, in drops of moisture, that the disease rapidly spreads. The black spots soon envelop the whole leaflet, the leaves die, and soon there remain only the upright stems bearing the inconspicuous dried up foliage. The fungus occasionally appears on the green stems, but usually these die only as the result of the death of the leaves. The writer has rarely found the fungus on the tubers, but it apparently passes the winter in them, since the mature or oospore stage has never been surely found. The rotting of the tubers may or may not follow the blighting of the vines. This rotting, apparently, is due to other agents; namely, bacteria and the Fusarium fungus, q. v.

By thoroughly spraying the vines with Bordeaux mixture, the blight can be largely prevented, or so delayed that the yield of tubers is greatly increased over that of unsprayed fields. The writer has this subject under investigation to determine, if year after year, spraying potato fields in Connecticut is a paying operation. The results of two years work indicate that it is profitable when the work is done thoroughly and on time. In one case the sprayed rows gave twice the yield of those unsprayed; in another case the yield was a third greater; in a third case, where the vines were very imperfectly sprayed, the increase, if any, was lost through rotting. The first spraying should be given before the first appearance of the trouble, about the 7 th to the $55^{\text {th }}$ of July, according to the season; the second and the third should follow as the sediment wears off the leaves. If rightly placed, three sprayings will ordinarily suffice, but the vines should be well protected by the sediment until about the first of September. It is very important that the vines be thoroughly covered with the spray when the blight weather comes on and it is usualiy best to immediately follow this weather with another spraying. The best apparatus for spraying is a two-wheeled cart or light wagon that will straddle two rows, allowing the horse to walk between, and the common barrel spray pump mounted in it, having two leads of 
sixteen foot hose provided with double nozzles. One man drives and pumps, and two men follow behind the cart, each spraying three or four rows. The foliage should be well drenched with the mixture, using two or three barrels per acre. In the writer's experience, geared power sprayers are not satisfactory, since with these the foliage can not be properly covered with the spray. [Reps. I889, p. I73, I76; I890, p. I02; I892, p. 39; I893, p. 73, I00; Bull. I42, p. I5.]

Dry Rot, Fusarium oxysporum Sch1. (F. Solani (Mart.) Sacc.) Plate XXII, b. Smith and Swingle, of the United States Department of Agriculture, have lately shown this fungus to be responsible for a wilt of vines, and for end rot and the bundle blackening of the tubers. During the past season, many vines wilted in this state before the middle of July. Possibly this was caused by the fungus described here. After the downy mildew killed the vines, there was general complaint of rotting tubers, and the dry rot fungus, unquestionably, was partially responsible for this. The rot did not do much damage until after the vines were blighted, for very few of the potatoes dug immediately after the vines blighted were rotted, while in adjacent rows, dug two weeks later, very many were rotten. There was a great difference in the amount of rot in different fields, and even in different parts of the same field. During the past winter, the market potatoes have shown an unusual amount of end rot and the bundle blackening. Sometimes, these potatoes appear perfectly sound on the outside. Usually the end rot begins at the stem end and gradually rots the tuber, often showing the fungus as a whitish mold on the outside. The potato shown in Plate XXII, b, was one taken from the field and placed for a day or two in a moist chamber to develop the growth of the mold on the outside, so it shows this more prominently. Care in selecting seed potatoes free from this trouble and spraying thoroughly for the blight are, perhaps, the best methods for lessening the trouble. Season, in some way, seems to be an important factor in determining the amount of rot, since in I902 there was little of this trouble, while in 1903 it was very common, yet, both years the vines blighted. Apparently, wet weather, after the vines blight, develops the trouble most vigorously.

EArly Blight, Alternaria Solani (E. \& M.) J. \& Gr. This trouble produces distinct, subcircular, brown spots about one- 
fourth of an inch in diameter on the leaves. The spots often show faint concentric rings of development. Paris green may burn spots on the foliage so similar to these that the two injuries are not easily distinguished. So far as observed by the writer, this trouble has not proved very serious in this state. It usually appears early in the year, and is most common in moist seasons. The tomato and egg plant are also hosts for it.

Rosette, Corticium vagum var. Solani Burt. So far the writer has not found this doing serious damage in Connecticut, though it has been very injurious in several other states. The trouble appears early in the season, dwarfing the vines or causing the foliage to become crowded into rosette clusters. Badly infected vines may be killed outright. It is caused by the sterile mycelium (called Rhizoctonia) of this fungus, producing cankered or dead areas on the stems near the ground. The plants sometimes send out new roots above these girdled places; but the effect in any case is to produce a crop of small potatoes. Selection of good seed tubers followed with treatment in formalin will prevent the disease if the potatoes are planted in uninfected soil.

Scab, Oospora scabies Thaxt. Plate XXII, c. Professor Thaxter, while botanist of this Station, first found the cause of the scabby or superficially corroded condition of potatoes so common everywhere. This is due to a fungus, which on freshly dug potatoes sometimes shows as a slight whitish mold on the scabby places. It is known that this fungus becomes established in the soil and the use of manure was shown by Sturgis to greatly increase the number of scabby tubers. Seed treatment with corrosive sublimate or formalin (see page 295 of this report for directions) will prevent the scab if the treated potatoes are planted on uninfected land. Beets, turnips, etc., are also subject to scab. [Reps. I877, p. 68; I886, p. 79; I890, p. 8I ; I891, p. I53; I893, p. I02; I894, p. II8; I895, p. I66; I896, p. 246; Bu1l. I03, p. 3 ; I42, p. I 5.]

Wet Rot, Bacterial. Plate XXII, a. During the past season this trouble, together with the dry rot fungus, caused serious rotting of the tubers. The bacterial rot can be told from the dry end rot by the slimy rotten condition of the tissues and the very strong odor. Sometimes the same tuber has both agents at work. The season early in I903 was very unfavorable for potatoes. This was due to the very dry May, followed by 
a very wet June. In some fields, as a result of these conditions, a bacterial rot of the young stems developed, starting usually below the ground and coming possibly from the decayed tubers. It produced a black and often soft rot of the tissues of the stem and caused the wilting, yellowing or death of the parts above. This trouble was found worse in one field that had been planted to potatoes immediately after plowing under green rye. The stand obtained in this field was very irregular, and in the fall the tubers were found badly rotted from the bacterial wet rot. Very probably the bacterial troubles of the vines early in the season and of the tubers later were caused by the same organism, though no experiments were undertaken to prove this.

Paris Green Burn. Potato foliage is very often burned by the use of too much Paris green or by its use without lime to neutralize its caustic effects. The injury may occur as distinct roundish spots, or it may show as a general searing of the margins, which die and dry up.

Tip Burn. Dry warm weather of midsummer may cause many of the leaves to die at their margins, which become dry and rolled up, because the leaves are not able to check or replace sufficiently the water lost through transpiration. It is a trouble, however, that is more common and injurious in the drier states of the Mississippi valley.

PRIMROSE, Primula sp.

Grey Mold, Botrytis vulgaris Fr. See Lettuce.

\section{PRIVET, Ligustrum Japonicum.}

Winter Injury. The freeze of December 9, I902, seriously injured the California privet by killing the branches. Very few plants were killed outright, so that with vigorous pruning the injured spots in the hedges were gradually obliterated during the growing season.

\section{PUNCPIN, Cucurbita sps.}

Powdery Mildew, Erysiphe cichoracearum DC. The conidial stage of this fungus occurs as a scanty whitish growth, in patches on the upper surface of the leaves. Apparently, it does little injury. No doubt, most of the troubles recorded here under squash also occur on pumpkins but were not observed. 


\section{QUINCE, Pirus Cydonia.}

Black Rot, Sphcropsis Malorum Pk. This often causes serious rotting of the fruit as it nears maturity, usually starting at the exposed blossom end. See Apple. [Reps. I892, p. 43; I893, p. 78; Bull. I42, p. I5.]

Brown Rot, Sclerotinia fructigena (Pers.) Schrt. This is another fungus that produces rot in the ripening fruit, though it is not nearly so injurious to this host as to the peach, $q . v$.

FIre Blight, Bacillus amylovorous (Burr.) DeToni. Blight is very common on the quince. The leaves adhering to the dead twigs have a decided reddish brown color, quite different from the blackened leaves produced on the pear, $q$. $v$.

Leaf Blight, Entomosporium maculatum Lev. So far the writer has observed this trouble only on the leaves and the fruit. It is one of the most common and serious troubles of this host. On the leaves it produces small, circular, brownish spots, often showing the fruiting body as a black dot in the center. When the leaves are badly infested, complete defoliation may result before the end of the season. On the fruit, the fungus produces a black spotting, and, especially with pears, may cause it to grow one-sided or crack open. Thaxter was one of the first to successfully prevent this trouble by spraying. Bordeaux mixture should be applied, first just before the blossoms open, again after they fall and a third and fourth time at intervals of about two or three weeks, according to the weather. [Reps. I889, p. I73; I890, p. 99; I89I, p. I50; I892, p. 42; I893, p. 89, 9I; Bull. I42, p. I3, I5.]

LeAf Spot, Hendersonia Cydonice Cke. \& Ell. Occasionally this fungús occurs in spots on the leaves. Sometimes it may cause these, but often it merely develops on spots produced by the black rot fungus. [Rep. I893, p. 8I.]

Rusts, Gymnosporanginm globosum Farl., G. nidus-avis Thaxt., G. clavipes Clke. \& Pk. The æcidial or cluster-cup stages of these rusts were reported by Thaxter and Sturgis on the leaves and fruit of quince. Sometimes they cause serious injury to this host. See Apple. [Reps. I89I, p. I6I; I894, p. I37.]

ScAB, Fusicladium sp. In the Report for 1893, p. 79, Sturgis records the occurrence of a destructive fungus, similar to apple scab, on the leaves of quinces at Tolland. The fungus was not specifically determined and has not been reported since. 
RADISH, Raphanus sativus.

Downy Mildew, Peronospora parasitica (Pers.) Tul. See Turnip.

Leaf Mold, Alternaria Brassica var. macrospora Sacc. This forms numerous, small, blackish spots on the leaves and the diseased tissue sometimes drops out. The smallest spots look like insect punctures. See Cabbage.

White Rust, Albugo candidus (Pers.) Ktze. The small, white blisters are formed on the under side of the leaves. Upon rupture of the covering epidermis the spores are gradually shed out as a dusty powder. While this fungus belongs with the downy mildews, its gross and microscopic characters are quite different, except with the winter spores. It probably occurs on a number of the other cultivated cruciferous plants. On wild pepper grass and shepherd's purse, the stems are often considerably distorted by its presence.

\section{RASPBERRY, Rubus sps.}

Anthracnose, Gleosporium Venetum Speg. Rarely this forms minute white spots on the leaves, but on the stems it occurs very commonly. Here it produces oval to circular white spots, often merging into one another, with purplish borders. It occurs most conspicuously on the new canes; on the old canes which carry it over the winter, the spots often become sunken and less prominently colored. So far only summer spores have been found. At pruning time the diseased canes should be cut out as thoroughly as possible; and after the disease has started on the new canes the worst of these might be taken out. In the spring before the buds swell, the canes should be sprayed with Bordeaux mixture; if repeated after the leaves develop, care should be taken to get it on the young canes chiefly. [Reps. I889, p. I72; 1893, p. 98; I899, p. 274; Bull. I42, p. I6.]

Cane Blight, Spharella rubina Pk. Plate XXIV, e. This blight is not uncommon and causes considerable injury in the writer's opinion. Apparently, it is most troublesome on the red varieties. In its early stage the trouble might be mistaken for a bacterial disease, so it is called blight. It first shows on the young canes early in July, usually at the lower nodes from which the leaves have fallen. It spreads downward from the 
base of the leaf, or its scar, as an elongated purple blotch, which shows very superficial injury to the bark. Rarely these blotches start away from the node. The blotches gradually appear at the higher nodes and slowly grow in size, sometimes completely surrounding the stem. In the fall the diseased stems turn whitish all over, and during the following winter the asco-spore receptacles appear as small black specks, thickly scattered over this whitened bark. The spores are matured by May and ready for the infection of the young canes. So far no summer spore stage has been found. The foliage of the infected canes is usually streaked with yellow and crinkled. The treatment described for anthracnose will apply here. [Bull. I42, p. I6.]

Crown Gall,? Dendrophagus globosus Toum. Plate $\mathrm{XXIV}, \mathrm{d}$. It is uncertain, as yet, whether this is exactly the same as crown gall of plum or not. The raspberry often has distinct knots very similar to those of the plum and peach, but usually they extend in more or less merged excrescences along the stem for some distance. Care should be used not to get stock from a plantation containing the disease; and certainly no plant showing it should be set out. Affected canes, when discovered, should be removed. See Plum. [Bull. I42, p. I6.] - Leaf Spot, Septoria Rubi West. Common on leaves; occurs on wild species, as Rubus odoratus, etc. See Blackberry.

Orange Rust, Gymnoconia interstitialis (Schl.) Lagerh. Common on leaves of cultivated and wild species. See Blackberry.

Wilt, Leptosphceria Coniothyrium (Fckl.) Sacc. The summer stage (Coniothyrium Fuckelii) has been described by Stewart, of New York, as responsible for a serious cane blight of raspberries in that state. The fungus causes dead areas in the bark and wood, sometimes completely girdling the bark, so that the parts above wilt and finally die. The fungus is sometimes associated with the blight fungus and their fruiting pustules are not easily distinguished, except when the former have shed out the spores in a dusty brown coating. On old stems this summer spore stage is often associated with an asco-spore stage (Leptosphceria), which is believed to be merely another stage of the same fungus. Both stages have been found here, but as yet serious injury has not been traced directly to the parasitic one. There has, however, been called to the writer's 
attention a trouble of blackcaps that may be caused by it. The fruiting canes, about the time the fruit should begin to turn, suffer from a serious wilt that dries up the berries. Spraying experiments conducted by Stewart gave no beneficial results.

Yelloz's. Another trouble described by Stewart is the yellows, which, apparently, is not uncommon in this state. The foliage becomes crinkled and mottled with yellowish streaks, and the fruiting canes often die before the fruit matures. This seems to be a physiological trouble, possibly similar to the yellows of peach. Spraying, with Stewart, gave no benefit. The writer has found it worst on soil poor in nitrogen.

RED BUD, Cercis Canadensis.

Leaf Spot, Cercospora cercidicola Ell. This is not uncommon in nurseries. The leaves develop conspicuous reddish brown or purplish, circular spots, one-quarter to three-quarters of an inch in diameter.

RED TOP, Agrostis alba var. vulgaris.

Black Stem Rust, Puccinia graminis Pers. Not uncommon. See Oats.

Suut, Ustilago striceformis (West.) Niessl. The smut is found most commonly from May to July. It occurs on the leaves, forming dusty outbreaks of the spores in elongated lines. These often involve the whole blade, and the plants are more or less stunted in their growth. After the spores fall out, the foliage becomes more or less shredded. The fungus also occurs here on timothy.

\section{RHUBARB, Rheum Rhaponticum.}

Leaf Spot, Ascochyta Rhei Ell. \& Ev. Pie-plant leaves not uncommonly have brownish spots of varying size and shape. Very often these show no sign of the fruiting stage of a fungus. In some cases, however, this fungus has been found.

\section{ROSE, Rosa sp.}

Leaf Blotch, Actinonema Rose (Lib.) Fr. Plate XXV, c. Greenhouse growers report this trouble more serious on the hybrid tea roses, La France, Liberty, Meteor, than on the hybrid 
perpetual. One or several purplish spots appear on the leaflets. These sometimes attain half an inch in diameter. With a lens, the mycelium can be seen radiating out from the center on the upper surface of the spots. When badly infected, the leaves turn yellowish and drop off. The disease also occurs on the hardy outdoor roses. Some of the greenhouse men recommend the sulphur and oil paint on the heating pipes for this trouble. Spraying with potassium sulphide may also prove helpful. [Rep. 1893, p. 86; Bull. I42, p. I7.]

LeAf Spot, Cercospora rosicola Pass. This is not nearly so common or injurious as the preceding. The spots are smaller, less than one-eighth of an inch usually, and often have a lighter center with a purplish border.

Powdery Mildews, Spharotheca Humuli (DC.) Burr., S. pannosa (Wallr.) Lev. Plate XXV, a. The former mildew is the common one seen in greenhouses. It forms a scattered, mealy, or cobweb-like growth over the surface of the leaves, causing them to become more or less crinkled. If badly infected, they may fall off. Only the conidial stage occurs. Tea roses are most likely to suffer; among those most seriously affected are Saffrano, Bon Silene, Bride, Bridesmaid, Niphetos, Pierpont Morgan, Goldengate. Greenhouse men try to avoid drafts and use care in watering to keep down this trouble. Sulphur is very commonly sprinkled on the leaves, and when the fires are started, sulphur and oil mixture is painted on the pipes. The second mildew given above has been collected but once, on an outdoor rambler rose. A thick felt of whitish mycelium develops on the branches and more sparingly on the leaves. The winter stage occurs imbedded in this. [Bull. $\mathrm{x}_{42}$, p. I7.]

Rust, Phragmidium subcorticium (Schrank) Wint. All three stages occur on this host, most frequently on the leaves. Sturgis notes injury to cultivated plants. [Report I893, p. 86.]

RUTA-BAGA, Brassica campestris.

Powdery Mildew, Erysiphe Polygoni DC. Conidial stage only. See Turnip.

RYE, Secale cereale.

Black Stem Rust, Puccinia graminis Pers.' Common on the stems. See Oats. 
Ergot, Claviceps purpurea Tul. Plate XXV, b. This is commonly found in volunteer rye. The conspicuous sclerotia, or compacted masses of sterile mycelium, show as purplish horns extending from the floral parts of the spike. It is from these, after they have fallen to the ground and become buried, that the asco-spore stage develops the next year. Ergot is poisonous, and where abundant in grain, if eaten by cattle, may cause serious trouble. A number of other grasses have smaller sclerotia developing in their flower parts, probably, in most cases, a species different from this.

Orange Leaf Rust, Puccinia rubigo-vera (DC.) Wint. This is common on the leaves, forming spore pustules similar to those of the crown rust of oats, though the spores are very different. [Rep. I890, p. 98.]

Smut, Urocystis occulta (Wallr.) Rabh. Thaxter reported this smut not uncommon, but not very injurious. The writer has found it once in very limited quantity. The black, dusty spore masses break out in lines, rather completely covering the inner surface of the leaf sheaths.

SALSIFY, Tragopogon porrifolius.

Powdery Mildew, ? Erysiphe cichoracearum DC. Occasionally this forms an inconspicuous growth of the conidial stage on the leaves.

White Rust, Albugo Tragopogonis (Pers.) Gray. In one market garden near New Haven this was found doing some damage. The summer spores occur as white blisters on the leaves and on the rupture of the covering epidermis become scattered.

SNAPDRAGON, Antirrhinum majus.

Anthracnose, Colletotrichum Antirrhini Stew. In one instance this was found seriously injuring Snapdragons grown outdoors. The leaves and stems become rather abundantly covered with whitish spots, usually oval in shape and marked with a distinct purple border. Generally these are about onefourth of an inch in diameter, but by merging, may form an extended area. Very small black dots in the center show the fruiting stage of this imperfect fungus. In the fall, all of the parts above ground should be cut off and the rubbish burned. 
SOAPWORT, Saponaria officinalis.

LeAF Mold, Macrosporium Saponarice Pk. The fungus causes whitish or greyish leaf spots, a quarter of an inch or less in diameter. The fungus probably, belongs under Alternaria rather than under Macrosporium.

SORGHUM, Sorghum vulgare.

Grain Smú, Sphacelotheca Sorghi (Lk.) Clint. Usually each grain of the entire panicle is changed into a slightly elongated smutted body. The same smut occurs on broom corn, but neither of these hosts are grown commercially in this state. The trouble can be prevented by either the hot water or formalin treatment of the seed.

Red Spot, Colletotrichum lineola Cda. The leaves become streaked with elongated bright red spots which run together. The fruiting stage shows on these as black pustules.

\section{SPINACH, Spinacia oleracea.}

Anthracnose, Colletotrichum Spinacice E11. \& Hals. Possibly this may occur more abundantly, but so far only a few specimens have been found. It forms greyish elliptical to circular spots, a quarter of an inch in diameter, on the leaves.

SPIREA, Spirca Ulmaria.

LeAF Spot, Septoria Ulmarice Oud. Rather injurious to the foliage.

\section{SQUASH, Cucurbita sps.}

Anthracnose, Colletotrichum Lagenarium (Pass.) E11. \& Hals. On ripe or stored squashes this is not uncommon, and, possibly, it may also cause injury earlier in the season. The depressed, rotten areas may attain considerable size, and usually show the pinkish fruiting pustules. The fungus often opens the way for a general rot by other fungi and bacteria. See Watermelon.

Black Mold, Rhizopus nigricans Ehr. Plate XXVI, b. This is a common mold on rotting fruit and vegetables. It occurs, sometimes with the next fungus, on the fading flowers of the summer squash, and in some cases is responsible for a rot of the fruit. See Sweet Potato. 
Metallic Mold, Choanephora cucurbitarum (B. \& R.) Thaxt. Plate XXVI, c. Very often the black mold described above occurs with this on the faded flowers, but the former can be told with a lens by its shorter threads, bearing firmer, spherical spore heads. This latter fungus is also easily distinguished by the metallic luster of the threads and the more loosely compacted heads. It, no doubt, often blasts the blossoms and may rot the young fruit also.

Powdery Mildew, Erysiphe cichoracearum DC. Conidia only. See Pumplin.

Wilt, Bacillus tracheiphilus Sm. Plate XXVI, a. In this disease, bacteria clog the ducts of the stem or leaf petioles, so that the water supply is largely cut off from the parts beyond, and these wilt and eventually die. Cutting across the stems, one can often squeeze out these organisms in a slight, viscid, milky exudation. Apparently, insects distribute these germs and perhaps produce the disease through punctures in the leaves or by eating holes in them. Very often, diseased leaves are found where the trouble has run down the petiole and in some cases extended into the stem. The tissues of the leaf are more likely to show a diseased condition than are the vascular bundles in the stem. Spraying does not seem to lessen this trouble. The wilted vines should be removed and care taken to keep down the insects. Summer and Hubbard squash, also musk melons and cucumbers, are subjected to this wilt, which last year was more common than usual.

\section{STRAWBERRY, Fragaria sps.}

FRUIT Rot, Botrytis vulgaris Fr. When the writer first came to the Station in July, 1902, he found some strawberries that had recently been sent in for examination, because they were rotting badly on the vines. The common grey mold was abundant on these and has since been seen occasionally in the field. Last year some growers complained of a rot trouble of the ripening fruit, which was probably caused by this fungus. Apparently, the crop often suffers during wet weather at harvest time from this rot. When it is likely to prove serious, the 
writer should judge that it could be minimized by carefully gathering the rotten fruit at each picking.

Leaf Blotch, Ascochyta Fragarice Sacc. This is not so comroon, and consequently not so injurious as the next trouble, though occasionally it is found doing considerable damage. The two are very similar in appearance, but with this one the purplish blotches are larger, often merged, producing a general browning of the margins of the leaves.

Leaf Spot, Spharella Fragarice (Tu1.) Sacc. Plate XXV, d. The spots on the leaflets are usually distinct, circular, and possess a prominent purple border and a whitish center. The imperfect or summer stage is parasitic, while the winter or ascospore stage develops on the old dead leaves. The destruction of these leaves is therefore helpful in keeping the trouble in check. Some growers mulch the beds with salt hay and then burn them over in the spring, thus destroying the old leaves. Others advocate the very frequent renewal of the beds, as the trouble becomes worst in old beds. Spraying with Bordeaux has also been found useful. One treatment is given before blossoming, another after most of the petals fall, and a third and perhaps fourth after the picking season.

Frosty Spots. Last fall some of the growers near New Haven complained of a new leaf trouble that resembled mildew. An examination of the leaves, however, showed that the whitish spots were not due to any fungus but resulted from the flaking away of the cuticle. Later, the whitish appearance gave place to dead brown' spots. Evidently, the trouble was a physiological one that had resulted in the flaking up of the cuticle and the collapse of the epidermal cells. This was, apparently, not due to frost, since it appeared chiefly before the first frosts. It was worst on plants set out between rows of early potatoes, and probably this treatment, with the unusually moist season, prevented the proper transpiration of water, which produced the injury through rupture of the cells.

\section{SUNFLOWER, Helianthus anmus.}

Leaf Spot, Septoria Helianthi Ell. \& Kell. Produces subcircular or irregular brownish spots from which the tissue sometimes drops out. 
Rust, Puccinia Helianthi Schw. The uredo- and teleutospores break out on either side of the leaves, but more abundantly below, in numerous reddish dusty pustules, about the size of a pencil point.

\section{SWEET POTAT0, Ipomca Batatas.}

Black Mold, Rhizopus nigricans Ehrb. This produces a soft rot of the roots. The grocer and the housewife very often find it difficult to keep potatoes because of its attacks. Where the skin is broken, the fungus develops its fruiting stage as a dense growth of blackish threads, ending in the small spore capsules.

SWEET VERNAL GRASS, Anthoranthum odoratum.

Smut, Tilletia Anthoxanthi Blytt. This changes the seed into an inconspicuous smutted body. The smutted spikes are about like the healthy in appearance, so the fungus is easily overlooked. The only time it has been collected in the United States was by the writer near New Haven in July, I902.

\section{SYCAMORE, Platanus occidentalis.}

Anthracnose, Gloosporium nervisequum (Fckl.) Sacc. The leaves with this trouble develop brown, dead areas of varying shape and size, often running along the ribs. The disease may become so serious that defoliation takes place. The young branches, also, are said to be attacked. It is one of the worst troibles of the sycamore in this state.

TEOSINTE, Euchlana luxurians.

Smut, Ustilago Zea (Beckm.) Ung. See Corn.

\section{TIMOTHY, Phleum pratense.}

ERgor, Claviceps sp. Small slender sclerotia are occasionally found in the spikes.

Smut, Ustilago striceformis (West.) Niessl. On leaves. See Red Top. 
TOADFLAX, Linaria vulgaris.

White Smut, Entyloma Linarice Schrt. The fungus produces small, whitish, circular areas on the leaves and stem in which the spores are permanently embedded.

\section{TOBACC0, Nicotiana Tabacum.}

Frost Fungus, Botryosporium pulchrum Cda. (Botrytis longibrachiata). According to Sturgis, this fungus sometimes produces a stem rot in the tobacco while hanging in the barns during the later stages of curing. He says: "Stems affected with this disease are covered with pure white patches having the appearance of a long pile velvet. These patches spread rapidly, encroaching upon the veins of the leaf and destroying the tissue and in the end inducing a more or less widespread decay, especially in the neighborhood of the midrib and veins. It is not unusual upon entering a barn, even during the process of curing, to find the floor partially covered with the refuse of the previous year's crop, the latter often looking as though a fall of snow had whitened it, so densely is it covered with the mycelium and spores of this fungus. The slightest current of air serves to separate the spores from their attachment and carry them through the barn, some finding lodgment upon and at once infecting the curing stems and leaves." This fungus is common in greenhouses upon decaying stems, especially tobacco stems, left on the moist earth. Under certain conditions it may act as a parasite. See Vinca. [Reps. I891, p. I84; I893, p. 84.]

SEed Bed Rot (Fungus). The young tobacco plants sometimes dampen off in the seed bed apparently through the action of some fungus. This trouble has not been thoroughly studied yet. Care in the kind of soil used and in the regulation of temperature and moisture in the beds, should help to check a trouble of this kind.

Pole Burn (Fungi and Bacteria). Sturgis also made a special study of this trouble, which sometimes seriously affects tobacco while drying in the barns, especially when the weather is moist and warm and the barns can not be ventilated properly. $\mathrm{He}$ says of it: "At first the disease is limited to the neighborhood 
of the veins and midrib of the leaf where moisture is superabundant, but its spread is very rapid, the small blackened areas increase in size, become confluent and sometimes within thirtysix, or at most forty-eight hours, not only is the whole leaf affected but the entire contents of the curing barn may be rendered quite worthless as tobacco. Examination shows that the leaves have changed from greenish yellow to a dark brown or almost black color, that the fine texture has disappeared, and that instead of being tough and elastic, the whole leaf is wet and soggy, and tears almost with a touch, falling of its own weight from the stalk." Sturgis found this rotting was due to various bacteria and fungi. Regarding prevention, he states: "We have seen that whatever is the primary cause of pole burn, its ill effects can be in a large measure, if not entirely, prevented by a proper regulation of moisture and temperature." [Reps. I89I, p. I68; I899, p. 265.]

Calico or Mosaic Disease. This is a trouble met in the growing fields of tobacco. The affected plants are usually somewhat stunted in growth, and the leaves have a pale greenish or later a peculiar yellow mottling, due to changes in the chlorophyll of the tissues. Usually these yellow streaks or areas follow the bundles and are separated by the normal green tissue. The trouble eventually renders the plants of little commercial value. Most growers pull up the diseased plants as they find them in the field, for their presence in the cured crop would only detract from its value. The trouble is considered a physiological one, rather than due to fungi or bacteria, and in nature approaches the yellows of peach. Certain unfavorable conditions in setting the plants or of the soil or moisture conditions are said to produce the trouble. As yet, however, too little is known of all the circumstances that contribute to this trouble and how to avoid it. [Reps. I898, p. 242; I899, p. 252.]

Rust. The cause of the irregular, usually small, spots appearing on the leaves in the field and called "rust" by the growers, is not known. Possibly it is also a physiological trouble. [Rep. I899, p. 255.]

Spot. The writer has found in tobacco grown under cloth. circular, brown spots, about one-quarter of an inch in diameter, on the leaves. These were not uncommon in one field and had 
the appearance of the spot produced by the Alternaria fungus on potato, etc. They showed the usual faint concentric rings of development, but no signs of any fungus were discovered. This is probably the same thing described by Sturgis, Rep. I 898 , p. 254, on tobacco grown in the open. He assigned no cause. Its presence, in moderate amount, is not generally regarded as a damage to the crop.

TOMATO, Lycopersicum esculentum.

Anthracnose, Colletotrichum phomoides (Sacc.) Chest. Plate XXVIII, b. This was found in a few fields on the ripening fruit, producing conspicuous sunken areas, in the center of which numerous closely clustered spore pustules occurred. Evidently it is a trouble that some seasons may produce serious injury at the ripening period.

Blight, Bacillus Solanacearum Sm. Plate XXVII, a-c. The southern tomato blight was found, apparently for the first time, in the vicinity of New Haven last season. While noticed in several fields, it was only in the field of Mr. Andrew Ure, described here, that it was found especially injurious. A general view of the affected part of this field is shown in Plate XXVII. It was peculiar in that four rows straight through the field were very badly infected, many of the plants dying; the bordering rows were less seriously affected, while the remainder of the field away from these was practically free from the disease. So far as could be learned, there was no difference in the field or the treatment that could have produced this. The only way the writer could explain it was that possibly a certain block of the plants in one of the seed beds had contracted the disease and had been set out together in the field. Mariy of the plants had been killed before they showed any considerable growth in the field. Others less seriously infected were somewhat smaller than the healthy plants and showed diseased leaves here and there. The leaves on any part of the plant were affected, sometimes first turning yellow, but usually soon dying outright. Very often the leaflets and most of the petiole were brown and dead, while the lower part of the petiole for an inch or two was still alive and green. Cut- 
ting across the green stems or petioles, the trouble showed as diseased brownish spots, or as a complete ring in the bundles, which are situated between the pith and the bark. In severe cases there was also a lesion of the tissues in this vicinity. See Plate XXVII, c. In very advanced stages the base of the stems showed a general soft rot. Sometimes the leaves showed dead areas around the bundles and examination of the ducts showed these choked with bacteria. It was not determined if this was caused by the same bacterial agents that produced disease in the potatoes this same year; there is a possibility that it was. The potato bug and other insects probably carry this disease after it gets started in a field. It should be noted in this case, however, that the disease, apparently, did not spread through the field, neither were the potato bugs, etc., numerous last year.

Downy Mildew, Phytophthora infestans DeBy. Thaxter collected this fungus on the tomato where it was doing damage; but apparently, its occurrence on this host is comparatively rare. See Potato. [Reps. I890, p. 95 ; I893, p. 103.]

FRUIt Mold, Macrosporium Tomato Cke. Very commonly, this forms a dense, olive-black, moldy growth on the point rot of the fruit and formerly was thought to be the cause of this trouble, but now it is considered only a saprophyte. See Point Rot.

Leaf Mold, Alternaria Solani (E. \& M.) J. \& G. Occurs not uncommonly on the leaves, occasionally doing damage. Often it is associated with the next trouble and may be mistaken for it. See Early Blight of Potato.

Leaf Spot, Septoria Lycopersici Speg. This is one of the most serious troubles of the tomato and has come into prominence during recent years. The leaves, stem and, rarely, the green fruit, may be attacked. The trouble is most injurious to the leaves, which become thickly covered with small, angular spots, usually having a greyish center and a deeper colored border. Apparently, it rarely matures on the small black specks it may produce on the fruit. Very probably it passes the winter through the summer spores formed in the fruiting receptacles on the stems, since no winter spore stage has been associated as yet with it. The trouble may be prevented largely by spraying with Bordeaux. The first spraying should be given a couple of weeks after transplanting, and two or three 
additional sprayings should follow each other at intervals of about three weeks. [Bu11. I42, p. I8.]

$\mathrm{SCAB}$, Cladosporium fulvum Cke. This fungus forms dense olive-brown growths in areas of varying size, on the under surface of the leaves, and often produces discoloration of the tissues on the upper surface. It is a trouble that occurs both in the field and greenhouse and sometimes does considerable injury. Spraying with Bordeaux, if taken in time, will prevent it. In the greenhouse care should be used in sprinkling water on the foliage, and the vines should not be planted too closely. [Reps. I889, p. I73; I89o, p. 95 ; I893, p. I02; Bulls. III, p. I5; II 5, P. I6.]

Sleeping Disease or Wilt, Fusarium Lycopersici Sacc. In the Experiment Station greenhouse, for several years past, this trouble has appeared with increasing severity. As the seed has been selected each year from these plants, possibly this explains in part the severity of the trouble. It does not usually show until the plants have attained full size and are beginning to blossom abundantly. At first, a lower leaf or two will wilt, turn yellow and finally die. Gradually, the disease works up, successive leaves dying and drying up on the vine. At the time the plants come into bearing, the trouble usually shows prominently. Cutting across the green stem or petioles at the base of the plant, the disease first shows a discoloration in the vicinity of the bundles. Very often three diseased spots show in these cross sections. If the fibro-vascular bundles are examined in cross section under the microscope, they are found to be more or less filled with the mycelium of the fungus. This choking up of the vessels, with their later diseased condition, prevents the proper amount of moisture being carried up the plants, which in time suffer severely because of this. As the leaves die, the fungus may work to the surface from the vicinity of the petiole, producing dead areas on the stem which eventually show abundance of the whitish mycelium. The spores are formed abundantly on this, and it then assumes a pinkish color from their presence. Eventually, the whole plant dies and dries up, the stem becoming more or less completely covered with the pinkish, moldy growth. Very often this pink mold may show on the ripe fruit, especially at the base, develop- 
ing out on it from the petiole. The disease is unquestionably carried in the soil and possibly also by the mycelium developing up the petioles into the seed. In cutting across green fruit, one occasionally finds that the disease has penetrated partially into it, and in this way may finally reach up into the seed. Where the trouble is established in a greenhouse, sterilization of the soil and treatment of the seed with hot water will apparently stop the trouble, if done thoroughly. Perhaps it would be best merely to sterilize the soil and get seed from an uninfected source.

Point Rot. Plate XXVIII, a. Apparently, the point rots of the greenhouse and the field are the same trouble. It usually first shows on the green fruit as a sunken, brown, rotted spot at the blossom end. This gradually enlarges, and later often becomes more or less covered with mold, especially the black mold. As yet, the cause of point rot is not surely known-it may be a. bacterial trouble or it may be a physiological one. Selby, of Ohio, states that sub-irrigation in the-greenhouse will largely prevent it. Spraying has not given very encouraging results.

TULIP TREE, Liriodendron Tulipifera.

Powdery Mildew, Erysiphe Liriodendri Schw. Forms a rather inconspicuous cobweb-like growth on the leaves. The asco-spore stage is not produced very abundantly.

\section{TURNIP, Brassica sps.}

Club Root, Plasmodiophora Brassicce Wor. See Cabbage.

Downy Mildew, Peronospora parasitica (Pers.) Tul. Plate XXVIII, c. The fungus forms whitish tufts of the summer spore stage in patches on the lower surface of the leaves and produces discoloration of the tissues above. It occurs rather commonly in the fall in turnip (Brassica Rapa) fields and has also been found on the radish.

Powdery Mildew, Erysiphe Polygoni DC. The conidial stage only occurs on the upper surface of the leaves (Brassica campestris), producing the usual whitish powdery growth. 
Scab, Oospora scabies Thaxt. Observed by Sturgis on roots of both Brassica campestris and B. Rapa. See Potato. [Reps. I894, p. I26; I896, p. 266.]

\section{VINCA, Vinca major.}

Frost Fungus, Botryosporium pulchrum Cda. Ordinarily this fungus occurs as a saprophyte on dead stems lying on the moist ground, but on the Vinca it acted as a parasite. However, the varigated vinca plants were in pots placed temporarily under the greenhouse benches, where the water dropped down from above, so the conditions were favorable for the fungus, but not for the plants. The plants became so abundantly infested with the fungus that they were all killed. The luxuriant, white growth resembles somewhat the very heavy hoar frost that sometimes covers sticks on the ground. Examining it carefully with a hand lens, the erect threads, about one-quarter of an inch high, are seen to be provided with diverging side branches upon which are clustered the spores, the whole having a feathery aspect. See Tobacco.

VIOLET, Viola odorata.

Anthracnose, Colletotrichum Viole-tricoloris Sm. Occurs occasionally on the leaves.

Leaf Blight, Cercospora Viole Sacc. Apparently occurs only occasionally, the spot disease being the common trouble.

Leaf Spot, Phyllosticta Viole Desm. Another occasional trouble. [Rep. I89I, p. I66.] These three leaf fungi are very similar in appearance, producing whitish or greyish spots.

Root Rot, Thielavia basicola Zopf. Reported by Thaxter in Rep. I89I, p. I66.

Spot Dịsease, Alternaria Viola Gall. \& Dor. PlateXXVIII, d. This seems to be the chief trouble with greenhouse violets in this state. The white spots are circular, usually about oneeighth of an inch in diameter. They seem to start as black specks; and on the stem this blackening is most pronounced. It is only rarely that the writer has found the Alternaria producing spores on these spots, which seems strange since the disease often spreads rapidly in the beds. The trouble is likely 
to get started in the houses in the fall before heat is turned on, especially if the grower is trying to cut down his coal bill. The character of the house, as to moisture, soil, etc., probably also plays a prominent part in the trouble. The disease is very often worst where violets have been grown for some time. Growers generally pick off the diseased leaves as soon as they appear; in bad cases, however, this often means very severe pruning. Possibly the thorough removal of all diseased leaves when the plants are set out, followed with a treatment with Bordeaux mixture, might prove helpful in preventing the trouble. After the disease is thoroughly started, perhaps little can be expected from spraying. [Bull. I42, p. I8.]

VIRGINIA CREEPER, Ampelopsis quinquefolia.

Leaf Spot, Phyllosticta Labruscre Thm. On the leaves only. See Grape.

Powdery Mildew, Uncinula necator (Schw.) Burr. See Grape.

\section{WALNUT, Juglans nigra.}

Anthracnose, Marsonia Juglandis (Lib.) Sacc. Produces subcircular, usually dark reddish brown, spots or blotches on the leaves.

\section{WATERCRESS, Nasturtium officinale.}

Leaf Spot, Cercospora Nasturtii Pass. Produces roundish light colored spots on the foliage, thus rendering it inferior for decorative purposes.

WATERMELON, Citrullus vulgaris.

Anthracnose, Colletotrichum Lagenarium (Pass.) Ell. \& Hals. Plate XXVIII, e. This fungus occurs on both the fruit and the leaves. On the former it produces sunken, rotted areas, at first small, but increasing in size and number, usually until the melon is worthless. On these areas, the spores ooze out in viscid, pinkish masses; sometimes they may germinate in position, giving rise to a superficial growth of white mycelium, as 
shown in the plate. Either green or ripe fruit may be attacked. On the leaves, the fungus causes dead brown areas, upon which the exudation of spores may not be very conspicuous. This same fungus occurs on cucumbers, musk melons and squash. In the fall, the old vines and rotted fruit should be gathered from the field and burned, as they help to carry the trouble in the soil. Spraying with Bordeaux should begin when the vines start to run, and these should be kept covered during the season. [Bull. I42, p. 7.]

Downy Mrldew, Plasmopara Cubensis (B. \& C.) Humph. So far as observed, this has not proved serious on this host. The fruiting threads are produced so meagerly on the under surface, that usually they can not be detected by a hand lens. See Musk Melon.

Leaf Mold, Alternaria Brassica var. nigrescens Pegl. See Musk Melon. 


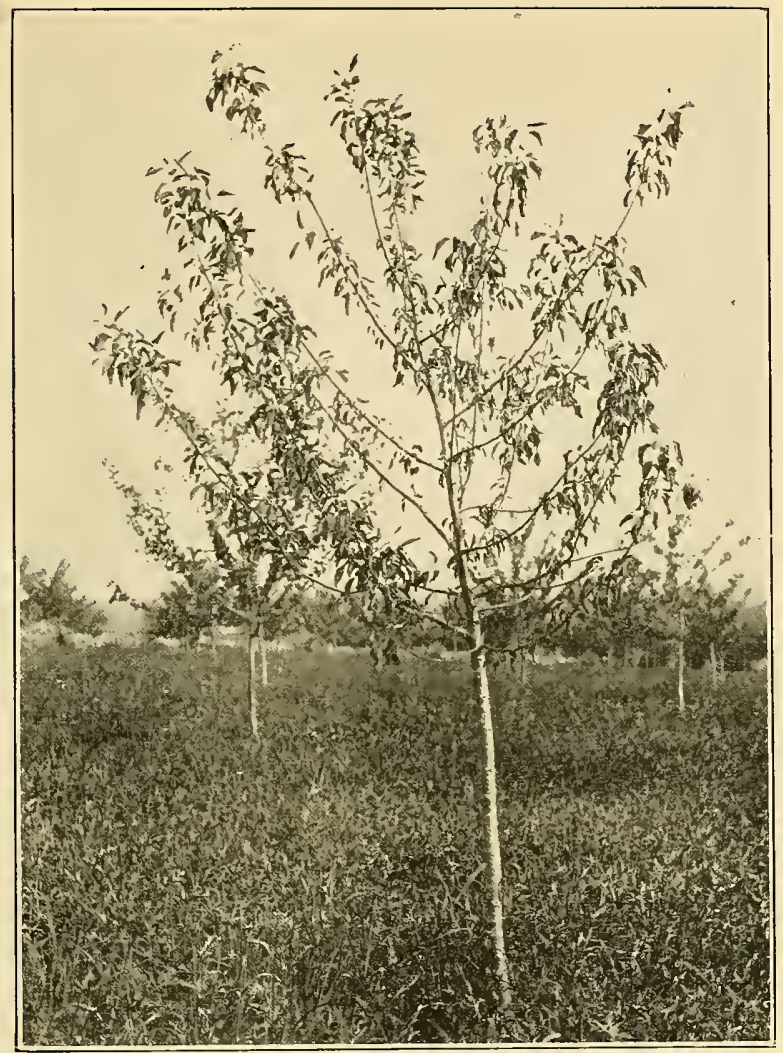

a. Young tree with injured bark at base dropping its leaves in July, p. 303.

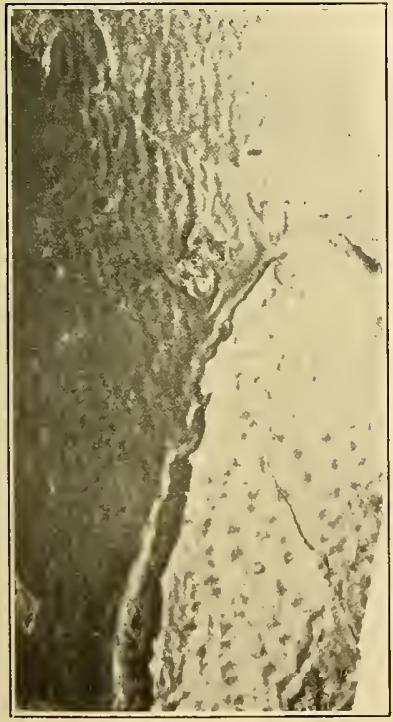

b. Injured bark studded with fungous growth. $\times 2$.

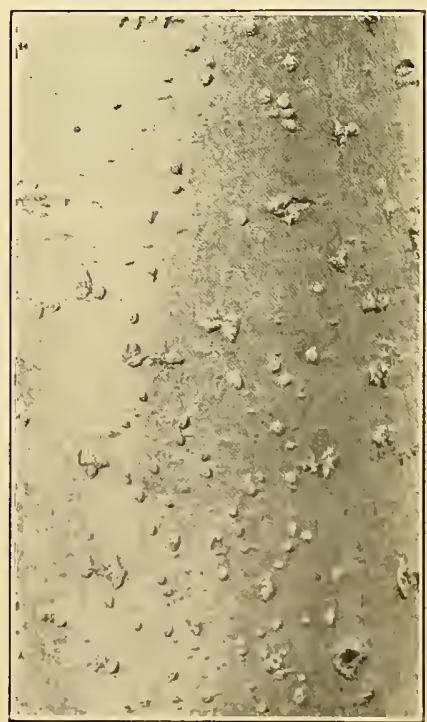

c. Healthy bark showing lenticels. 

PLATE $X$.

a. Peach, p. 34I.

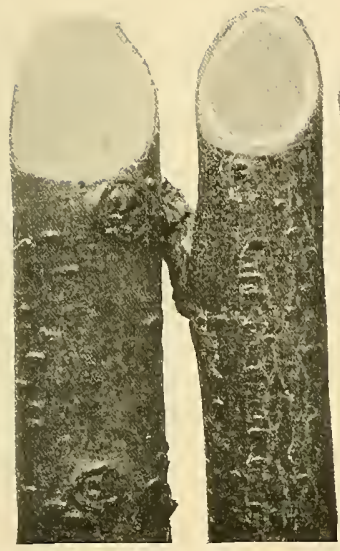

Healthy.

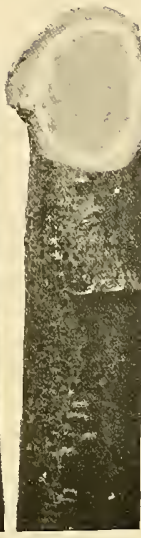

Injured.

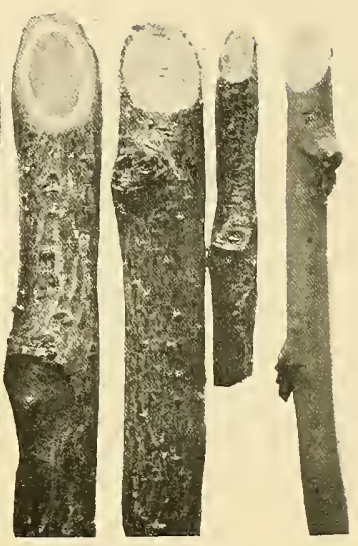

Healthy. b. Apple, p. 303 .

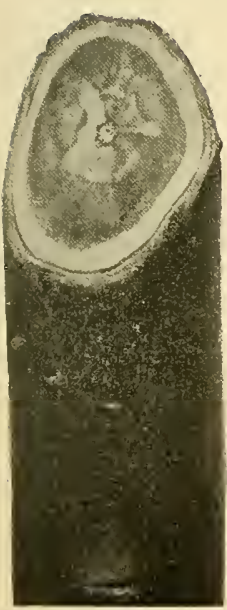

Injured.

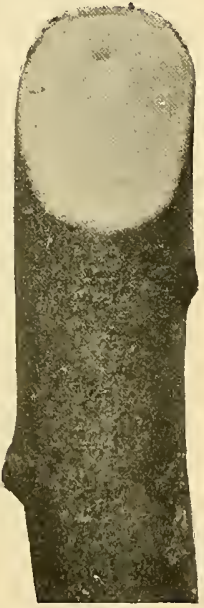

Healthy. c. Plum, p. 345 .

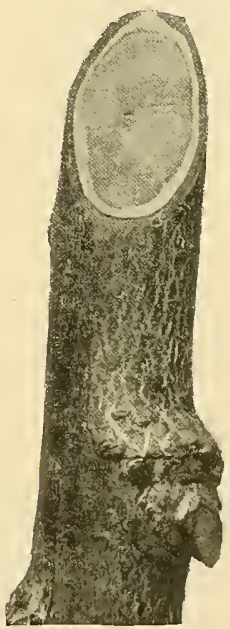

Injured.

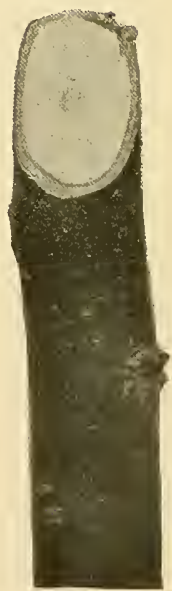

Ilealthy.

WINTER INJURY TO WOOD OF FRUIT TREES. 

PLATE XI.

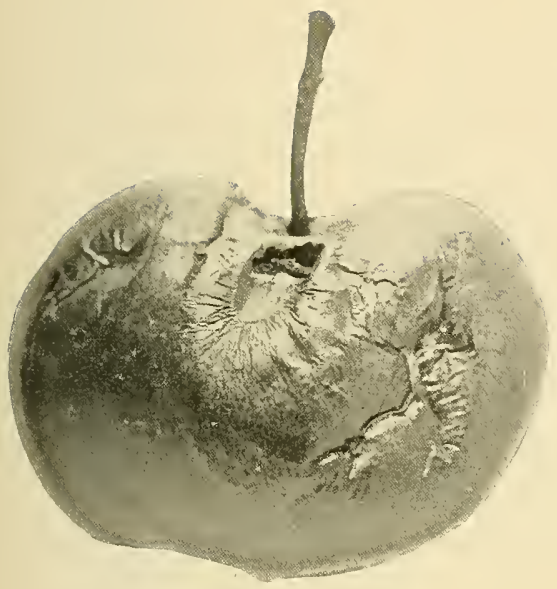

a. Black Rot, p. 298.

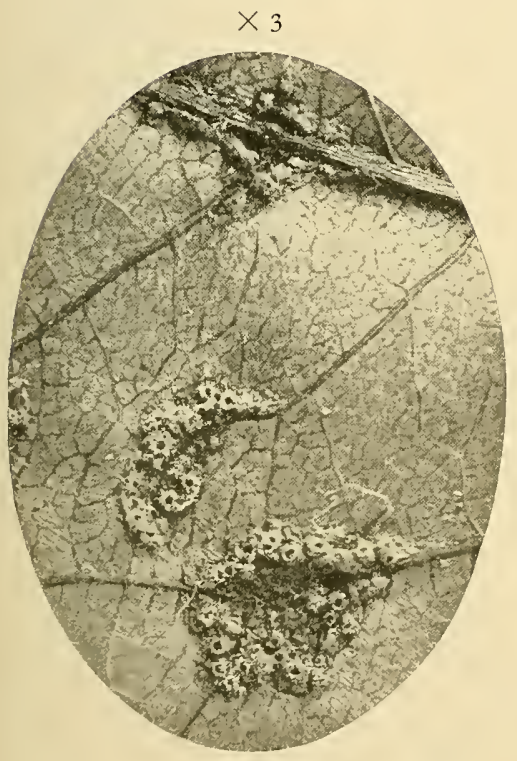

c. Cluster Cup of Rust, p. 3or.

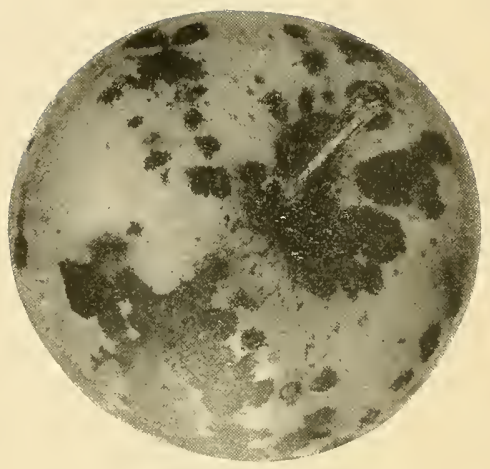

b. Sooty Blotch, p. 302

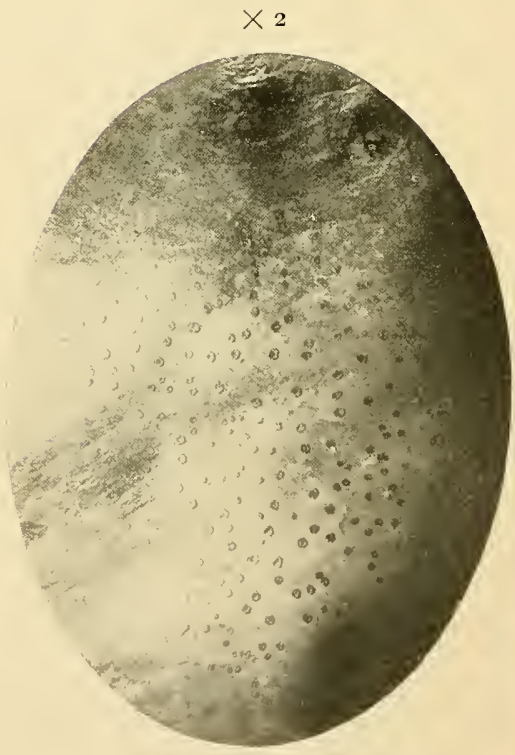

d. Fly Speck, p. 299.

FUNGI OF THE APPLE. 


Barley.

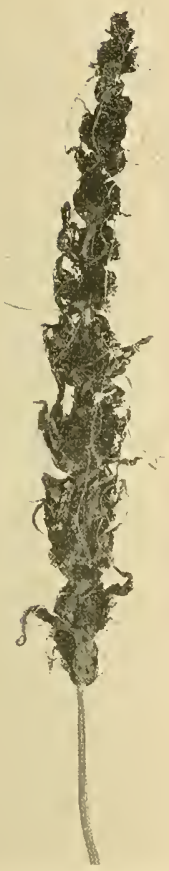

a. Smut, p. 306 .

$\div 1 / 2$

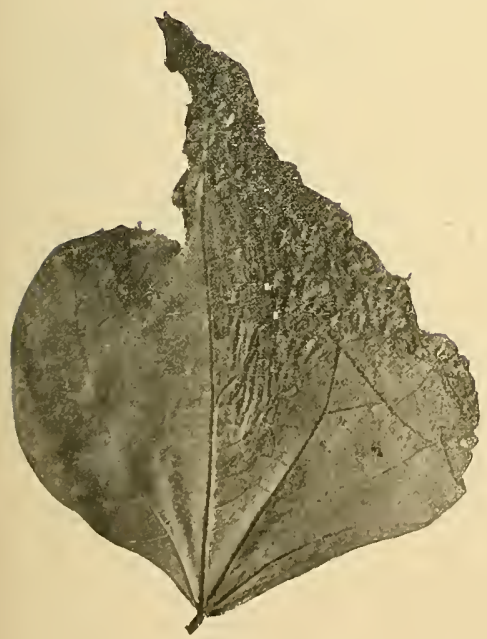

d. Blight, 1). 307.
Bean
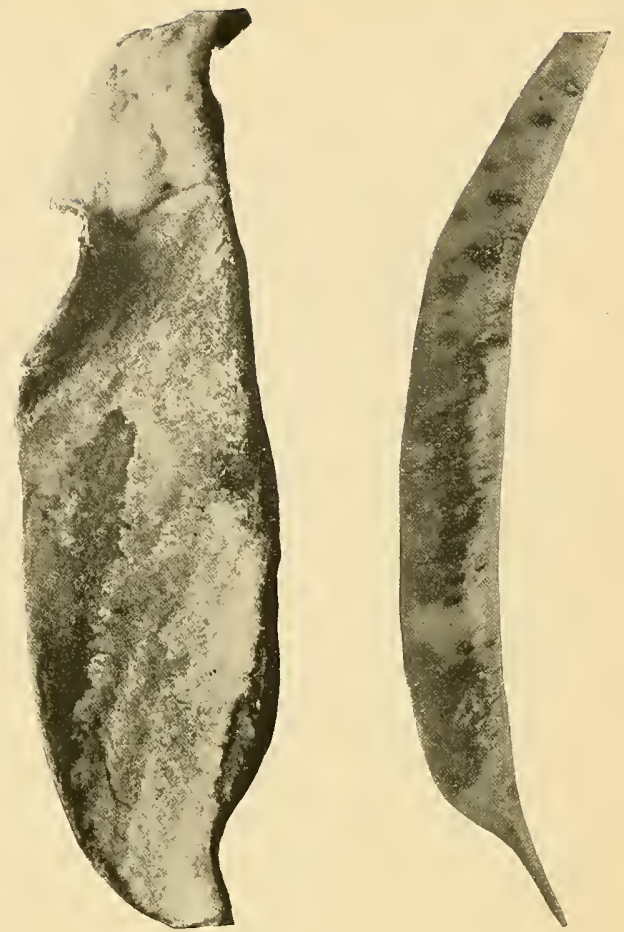

b. Downy Mildew, p. 307. c. Anthracnose, p. 307.

Bean.

$\times 2$.

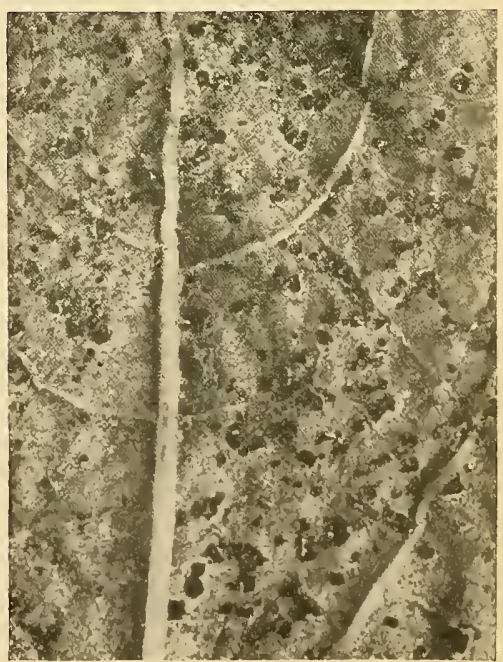

c. Rust, p. 308 .

FUNGI OF BARLEY AND BEAN. 

PLATE XIV.

Blackberry.

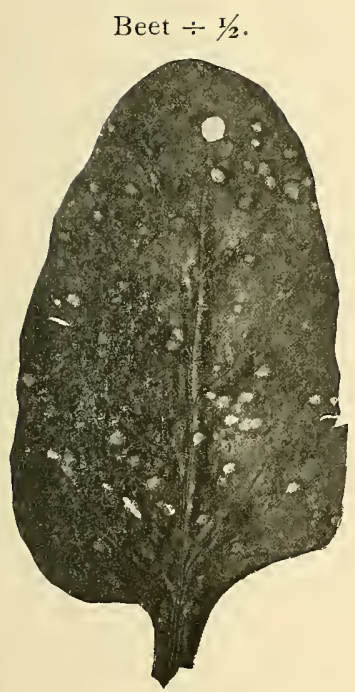

a. Leaf Spot, p. 309 .

Blackberry.

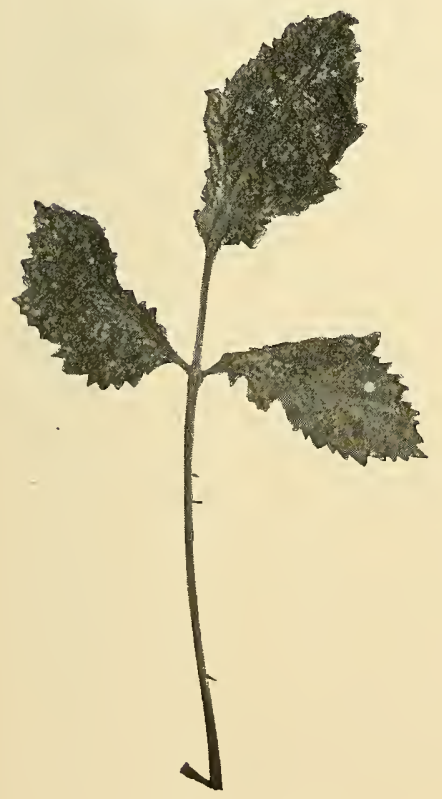

c. Rust, p. 309 .

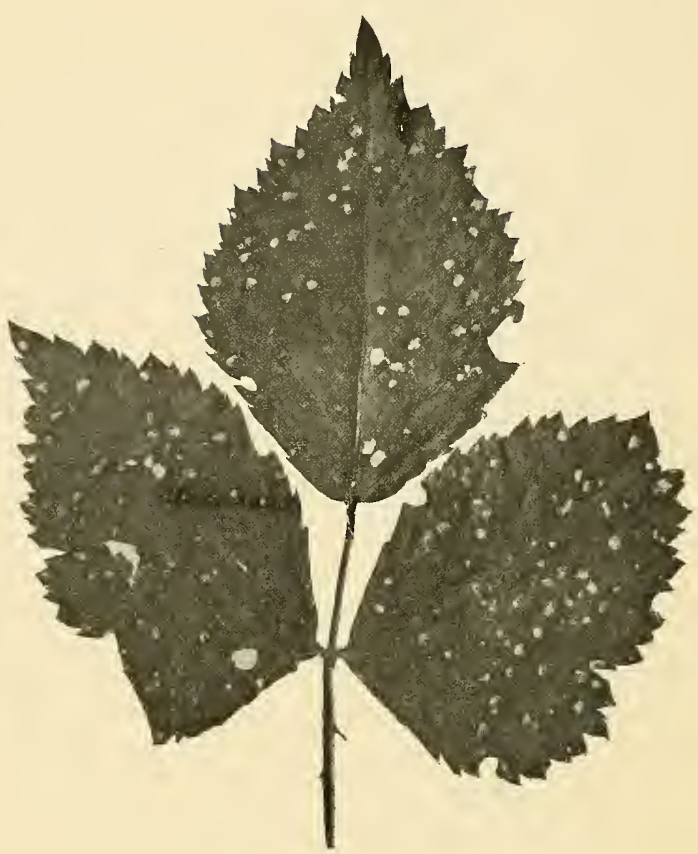

b. Leaf Spot, p. 309 .

Buckwheat.

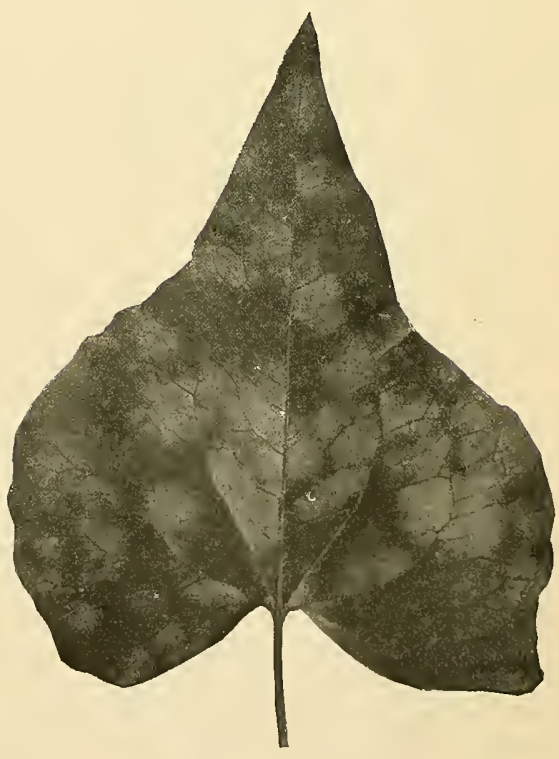

d. Leaf Blight, p. 3 ro.

FUNGI OF BEET, BLACKBERRY, BUCKWHEAT. 



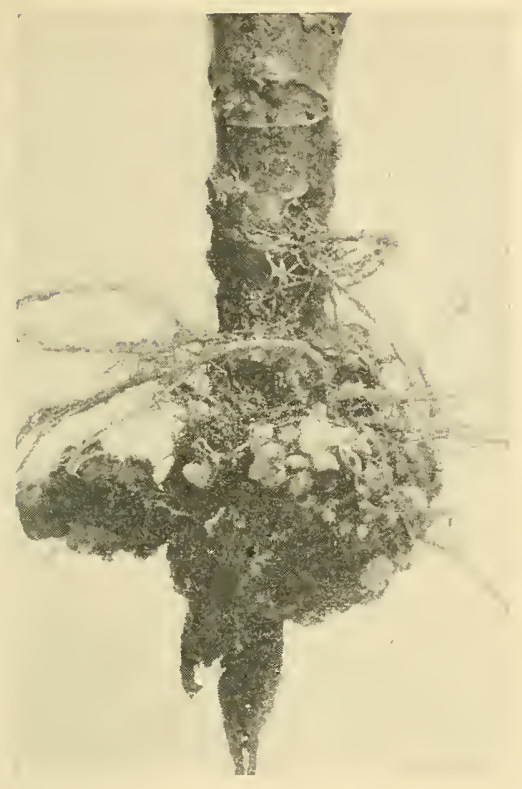

a. Club Root, p. 3 Io.

Cherry $\times 2$.

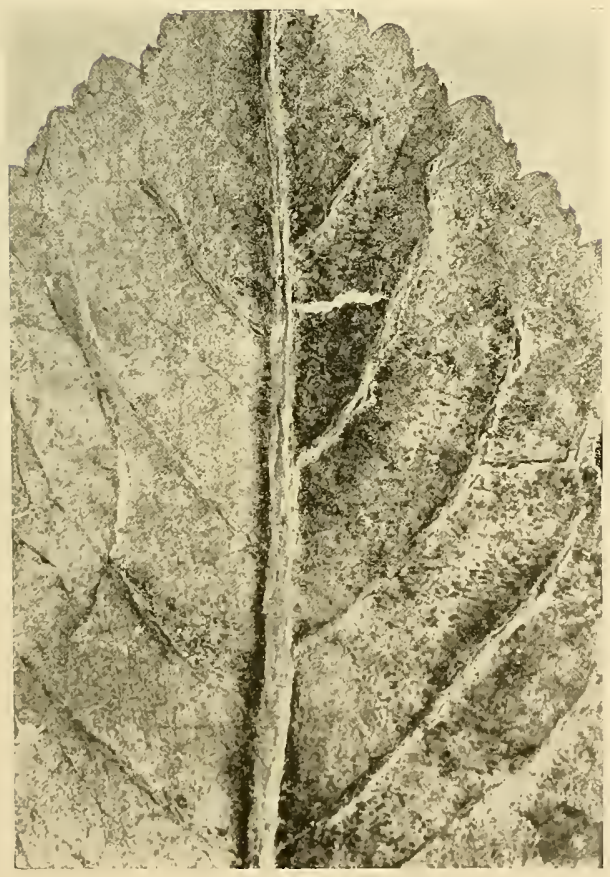

c. Powder Mildew, p. 314 .

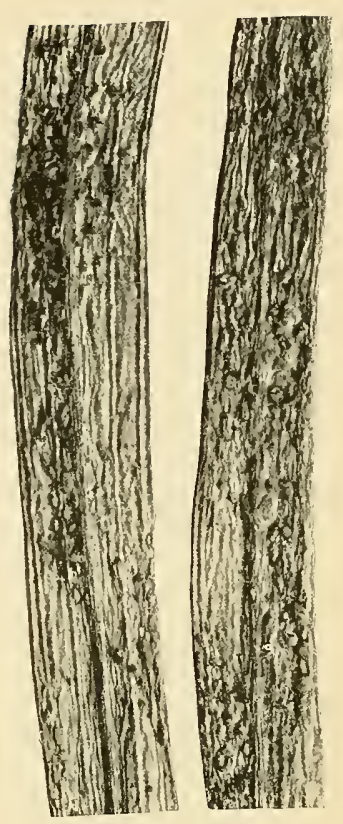

b. Rust, p. 3ז2.

Chrysanthemum $\times 2$.

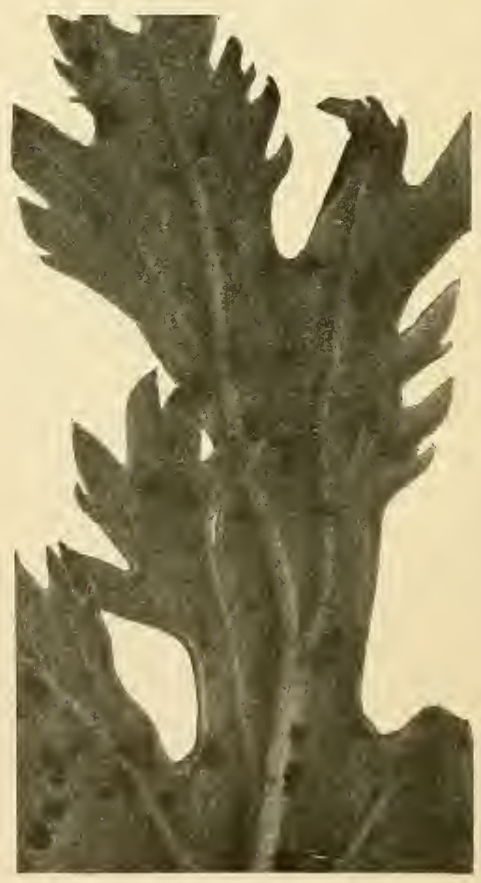

d. Rust, P. 3I5. 

Corn. $\div 1 / 2$.

Clover.

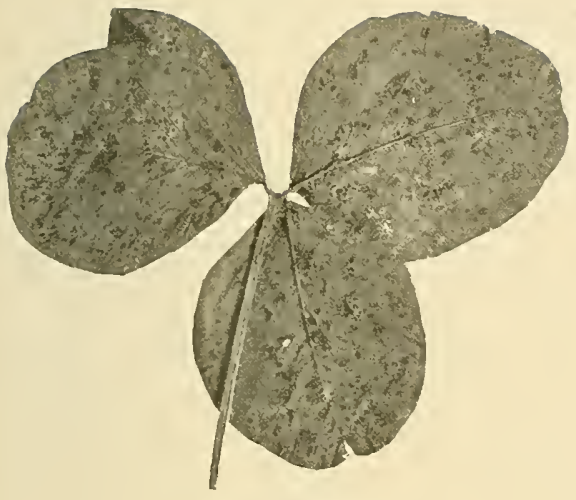

a. Rust, p. 3I6.

Currant. $\times 3$.

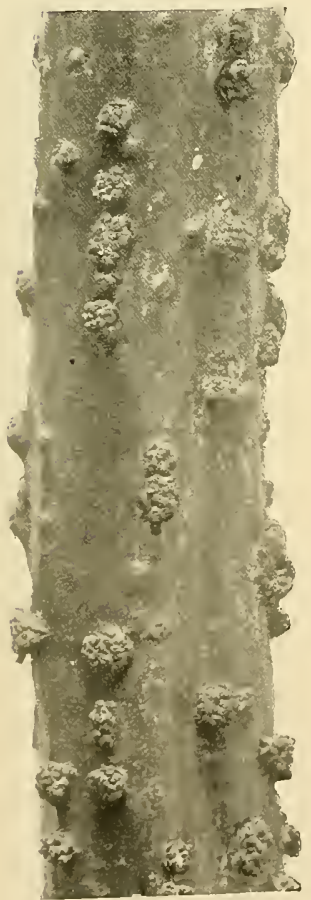

c. Red Knot, p. 319 .

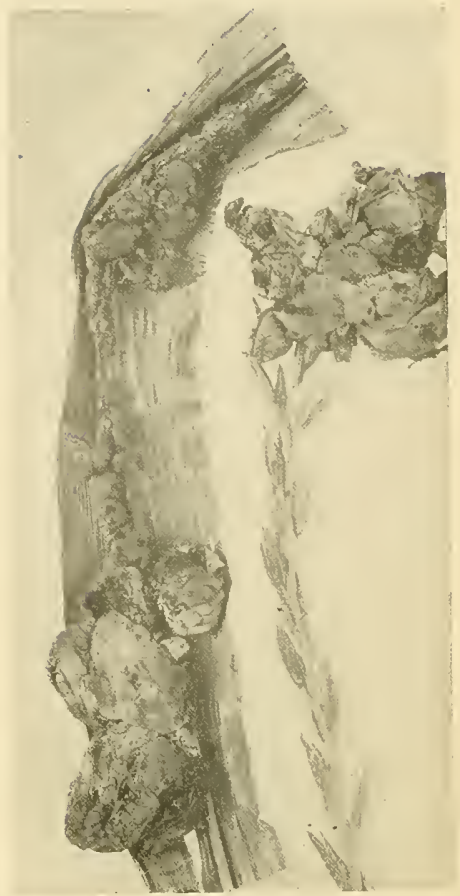

b. Snut, p, 3i 7 .

Elm Bark. $\times 2$.

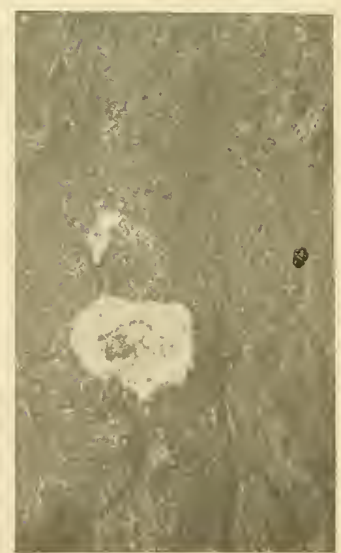

d. White Fungus on Elm-Leaf beetle, p. 32 I.

FUNGI OF CLOVER, CORN, CURRANT, ELM BEETLE. 

Grape.

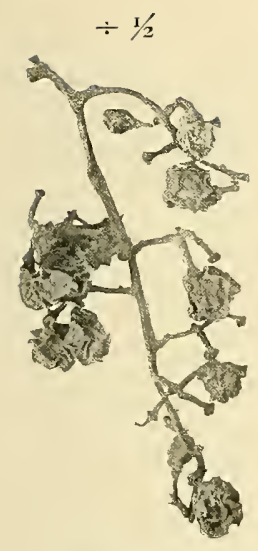

a. Black Rot, p. 323 .

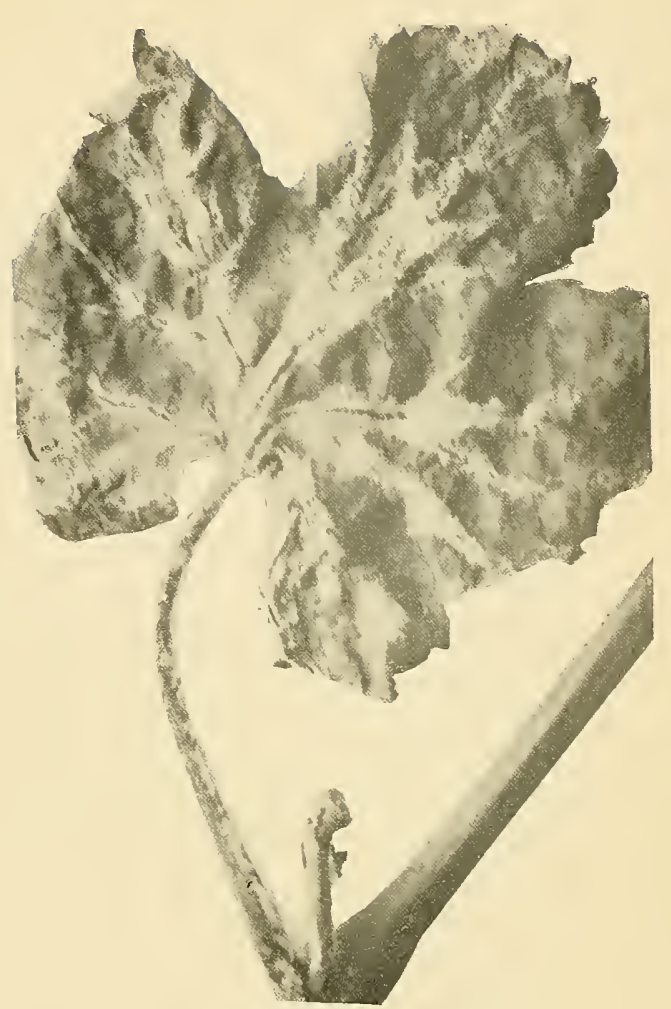

Hazel $\times 2$

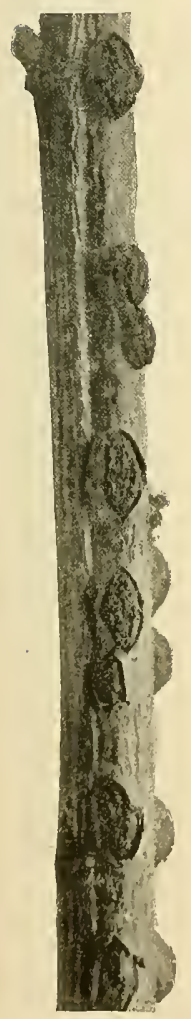

b. Downy Mildew, p. 324 .

Hollyhock $\times 2$.

Horseradish.
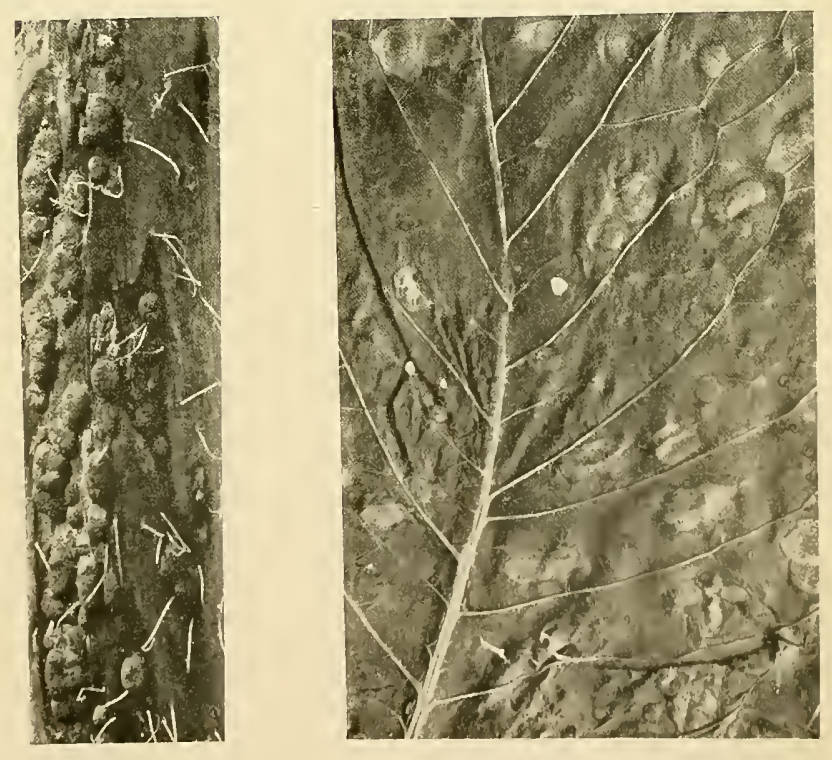

c. Black Knot, p. 325 . d. Rust, p. 326.

e. Leaf Spot, p. 327 .

FUNGI OF GRAPE, HAZEL, HOLLYHOCK, HORSERADISH. 



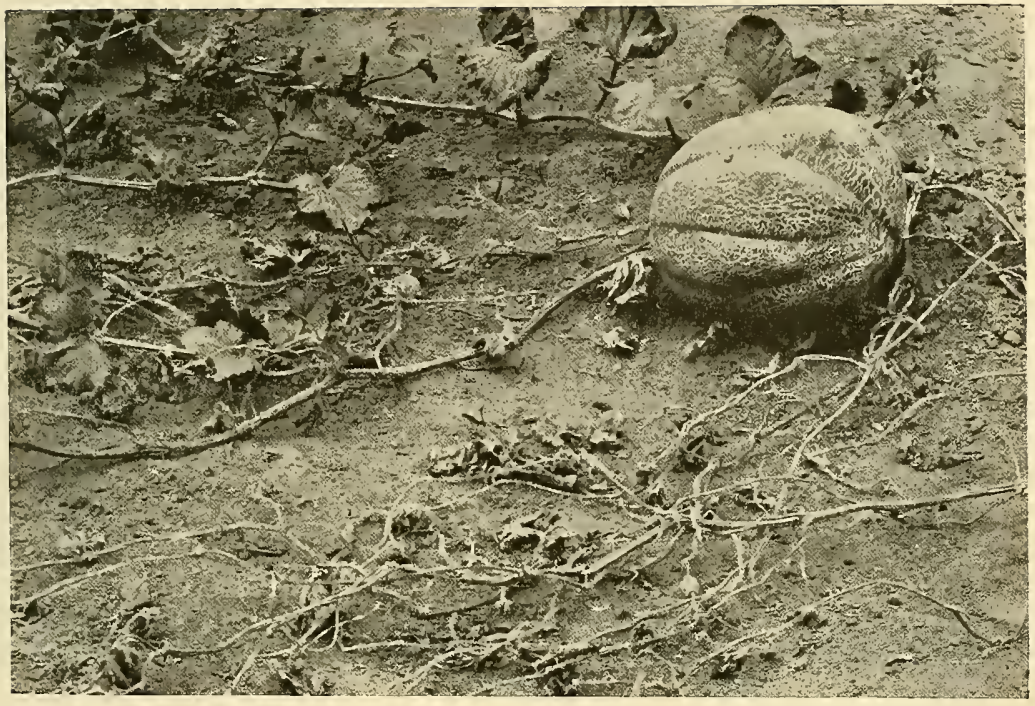

a. Blighted vine in the field.

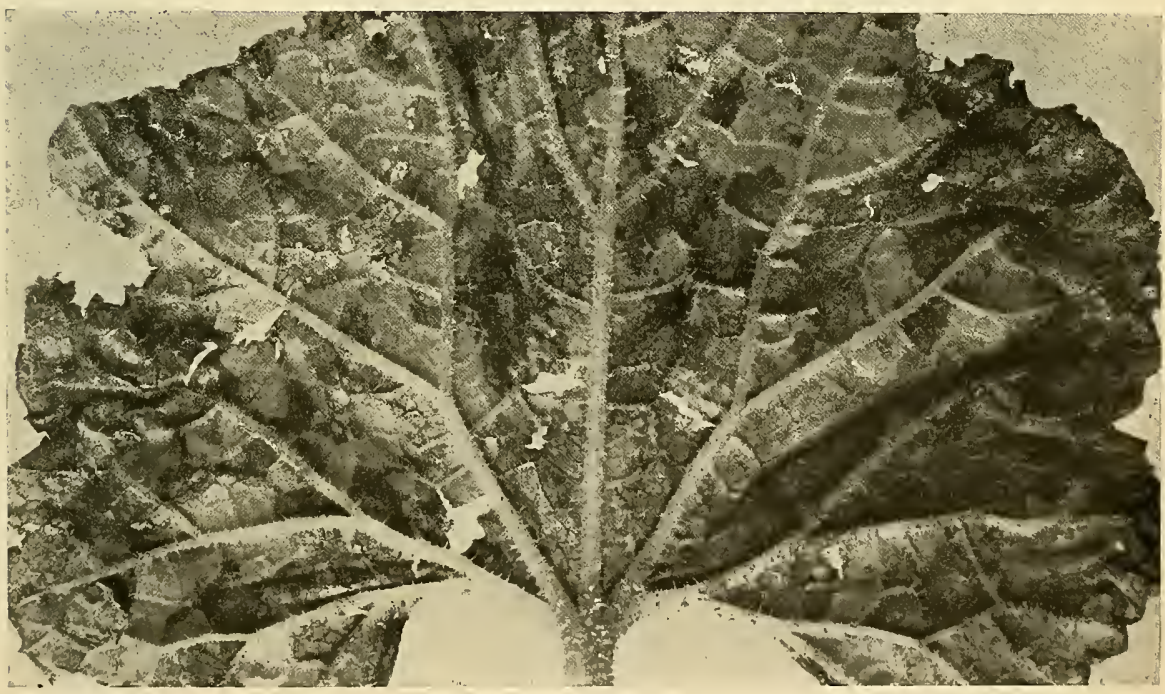

b. Under surface of leaf showing dead areas.

BLIGHT OR DOWNY MILDEW OF MUSKMELON, p. 330. 

PLATE XIX.

Iris.

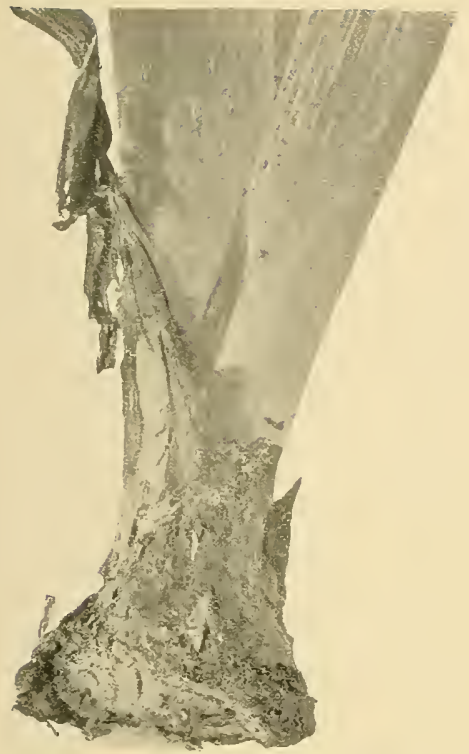

a. Rootstock Rot, p. 327.
Musk Melon.

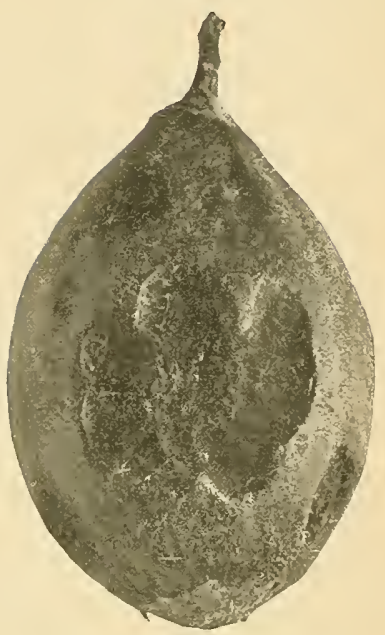

b. Scab, p. 331 .

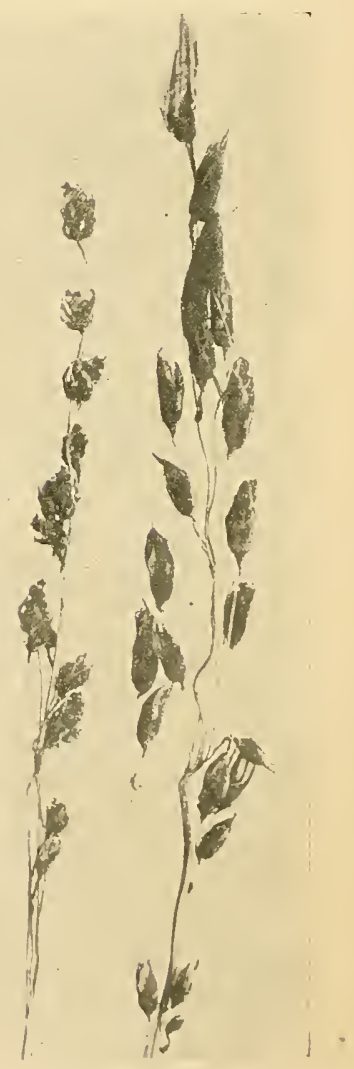

c. Simul, p. 333 .

c. Black Rust, p. ${ }^{3} 32$.

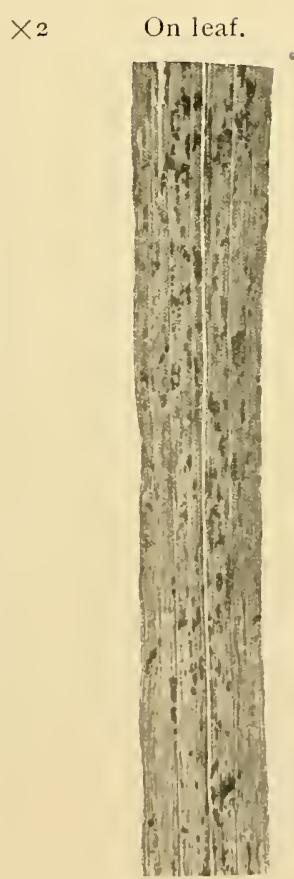

d. Crown Rust, p. 333.

FUNGI OF IRIS, MELON, OATS. 

PLATE XX.

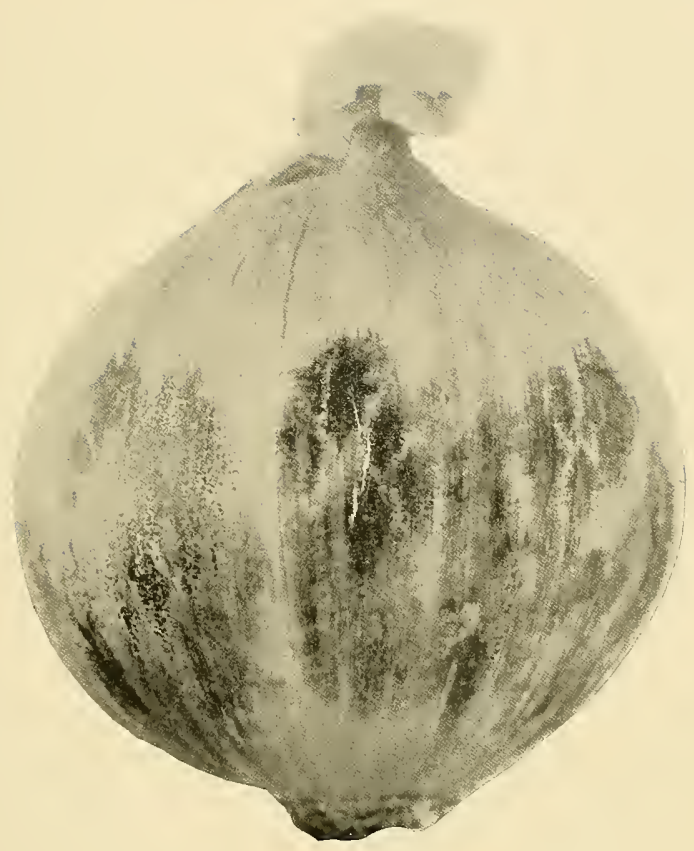

a. Black Spot, p. 333.

Stem Rot, p. 334.

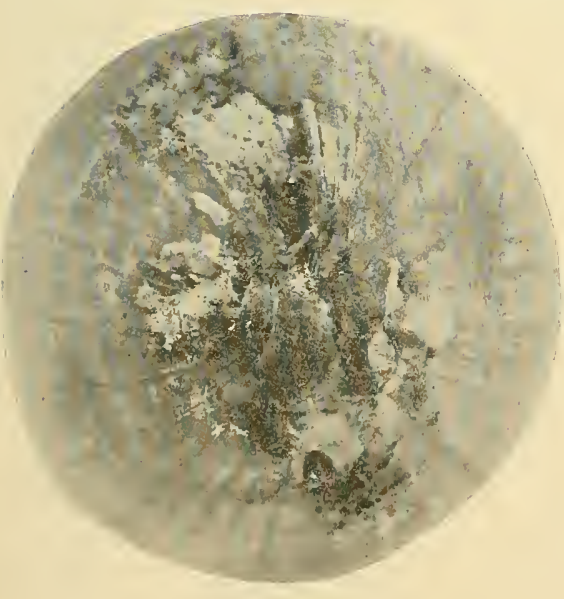

b. End view.

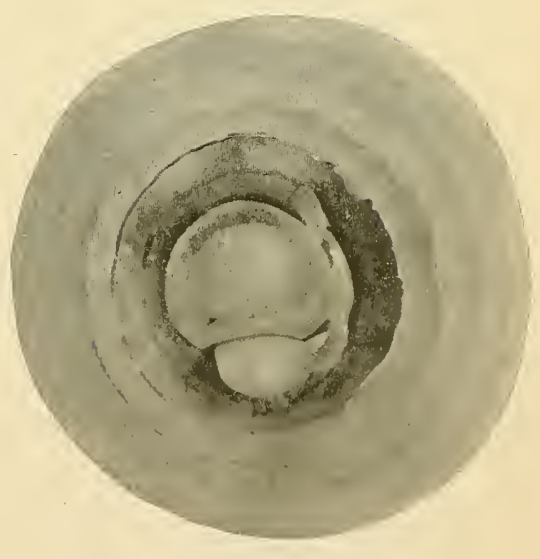

c. Cross-section.

FUNGI OF ONION. 

PLATE XXI.

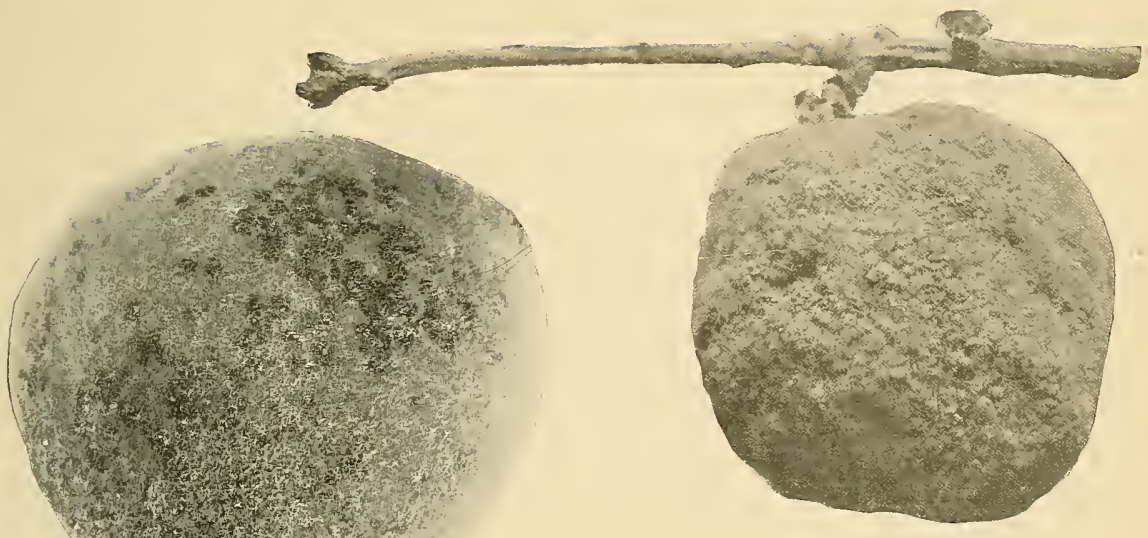

b. Brown Rot, p. 337 .

a. On fruit.

Scab, p. 340.
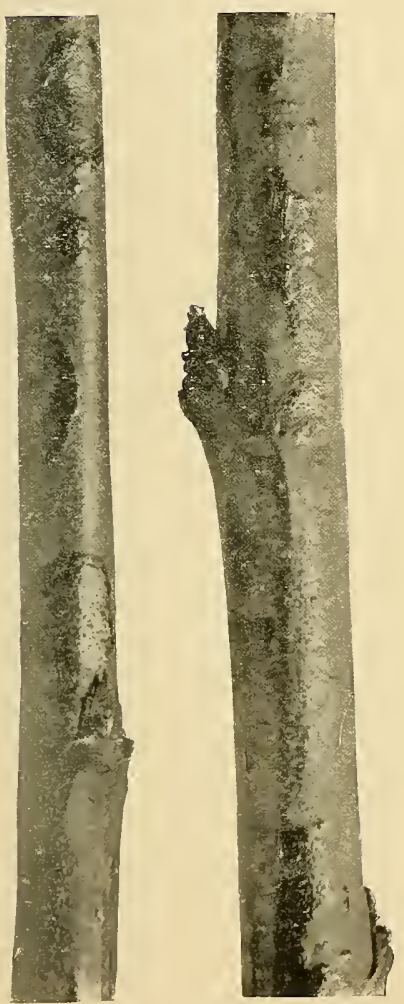

c. ()n lwigs. $\times 2$.

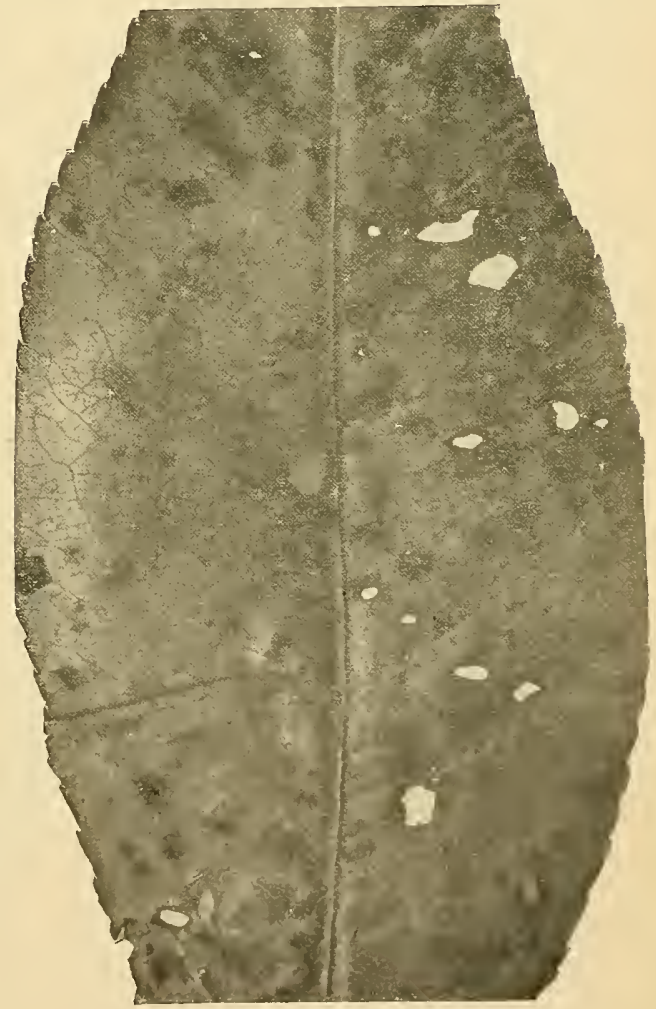

d. On leaf, $\times 2$. 

PLATE XXII.

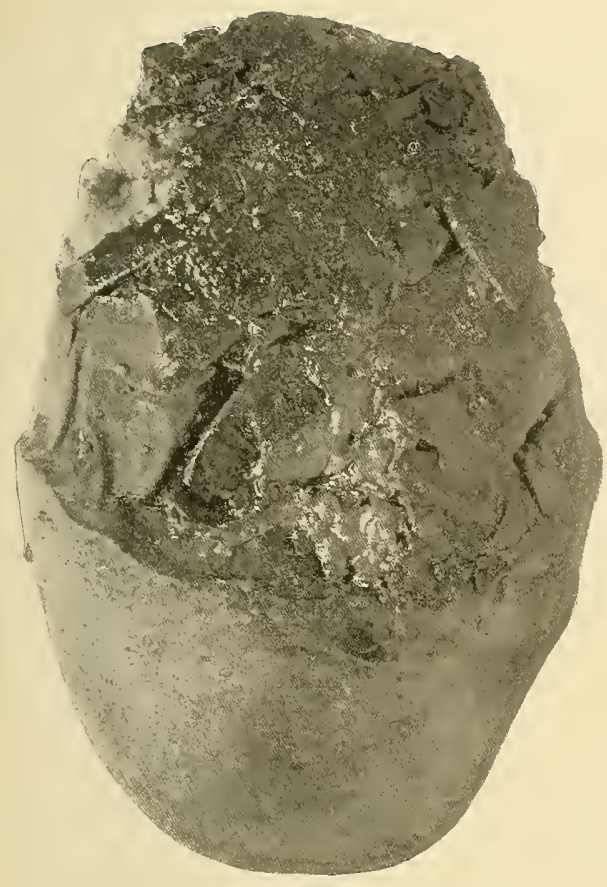

a. Bacterial Rot, p. 350 .

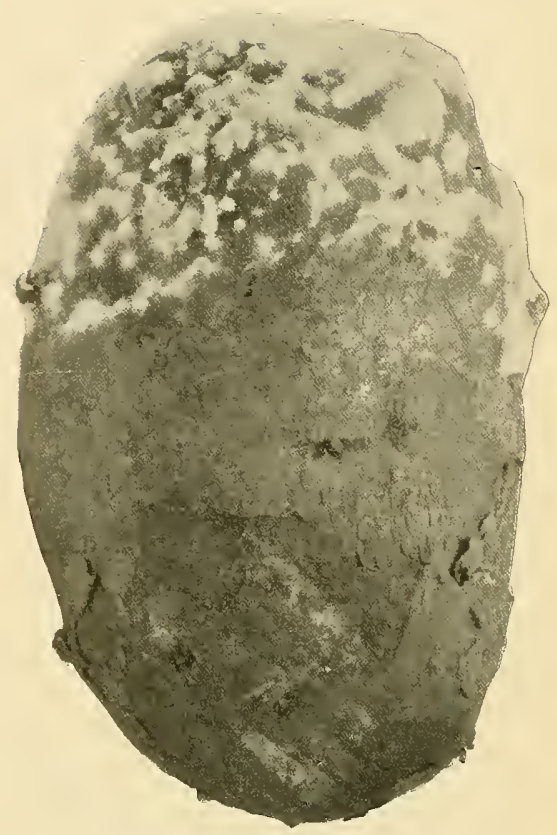

b. Dry End Rot, p. 349 .

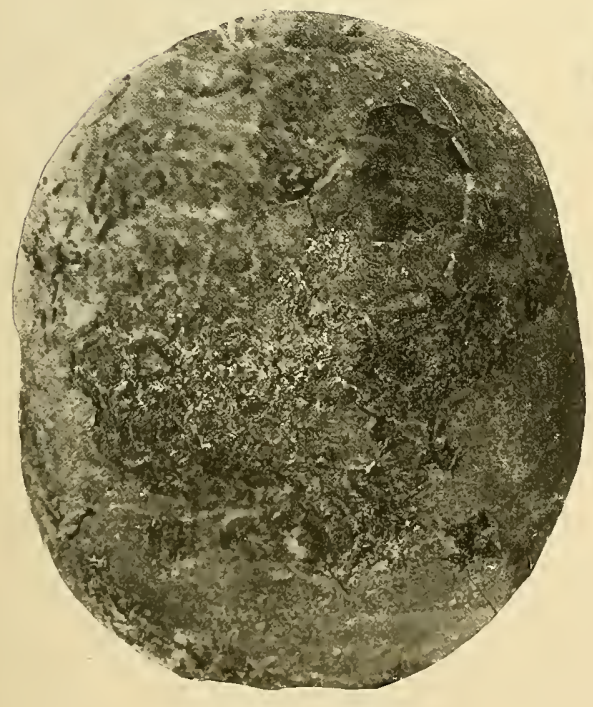

c. Scal, 1). 350 .

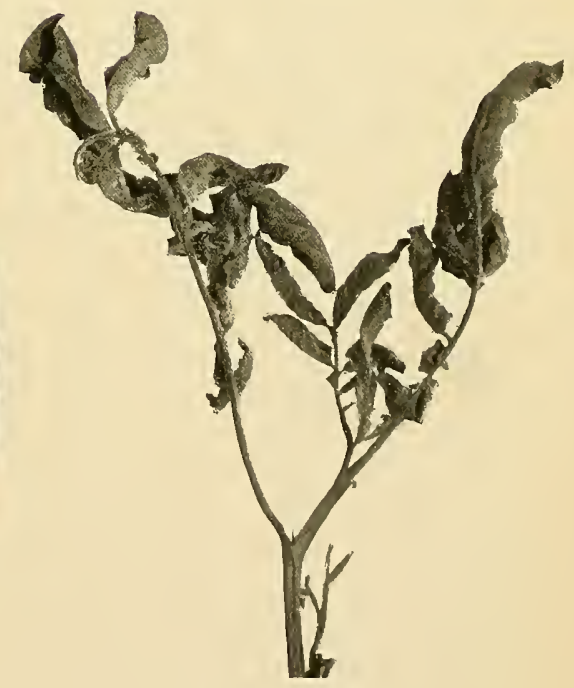

d. Blight, p. 347. 


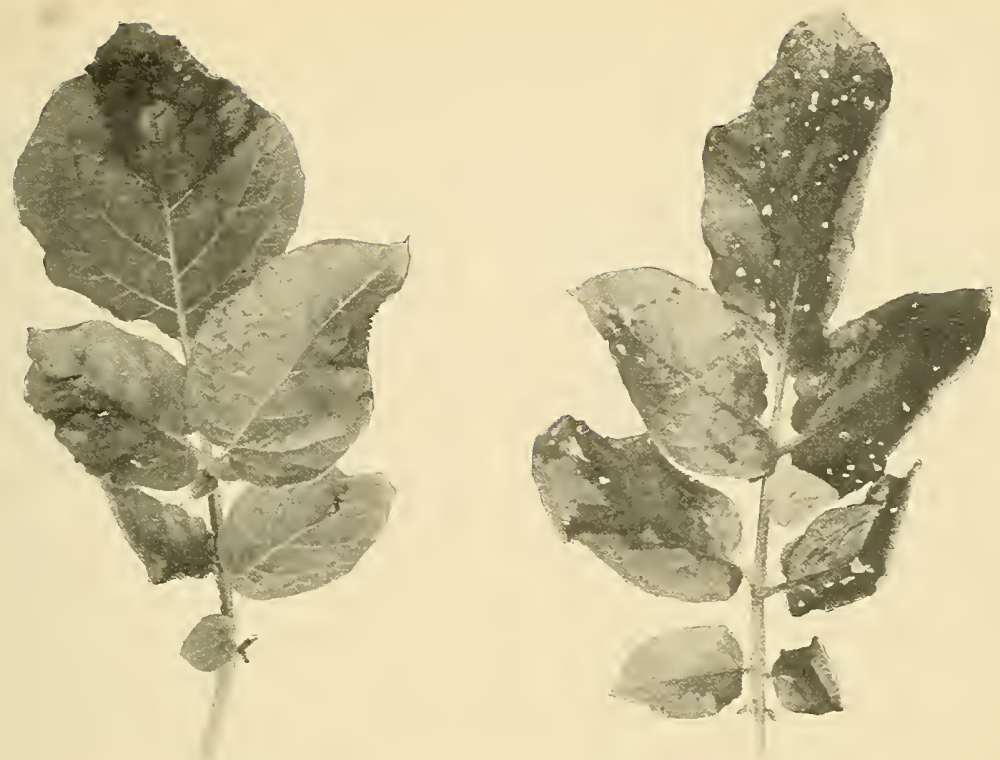

a. Green leaves showing early stage of blight. p. 347 .

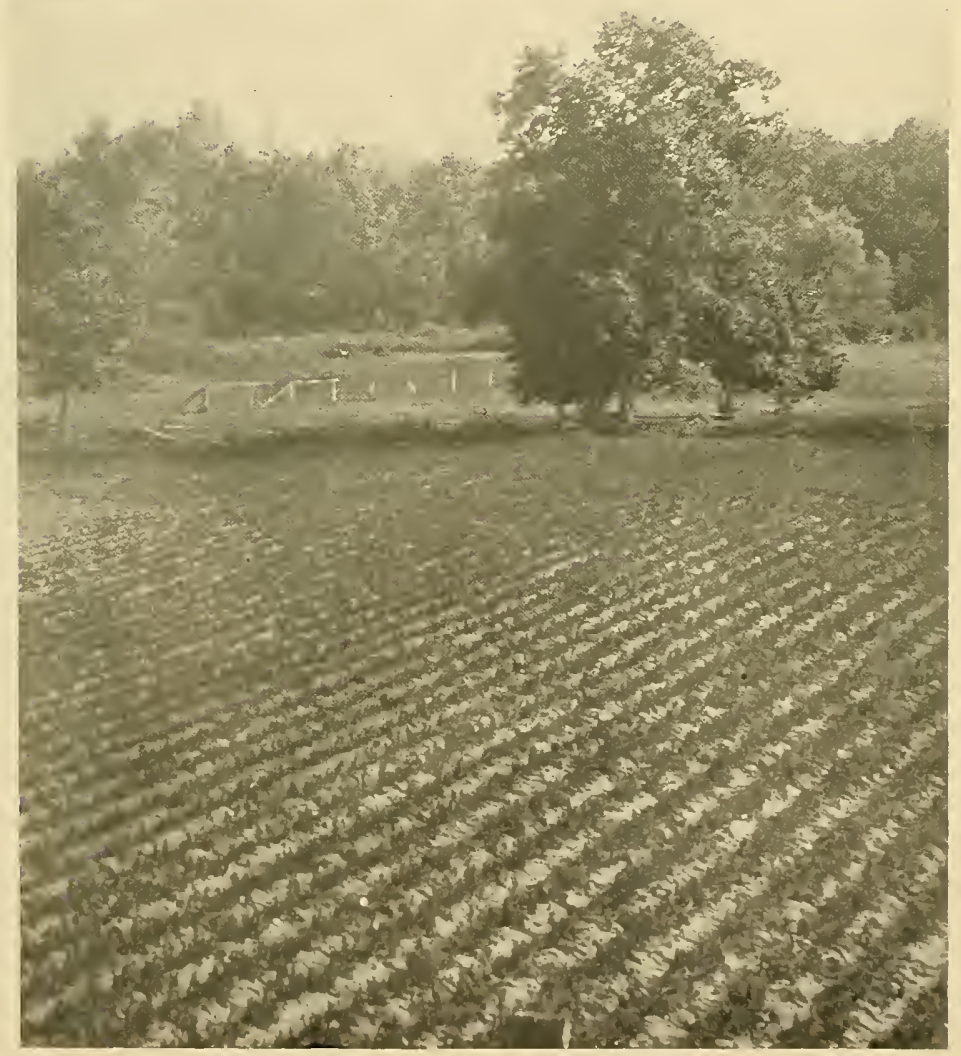

b. Todd's blighted field, photographed July 28 , I902; less than a week before, this field was perfectly green. 



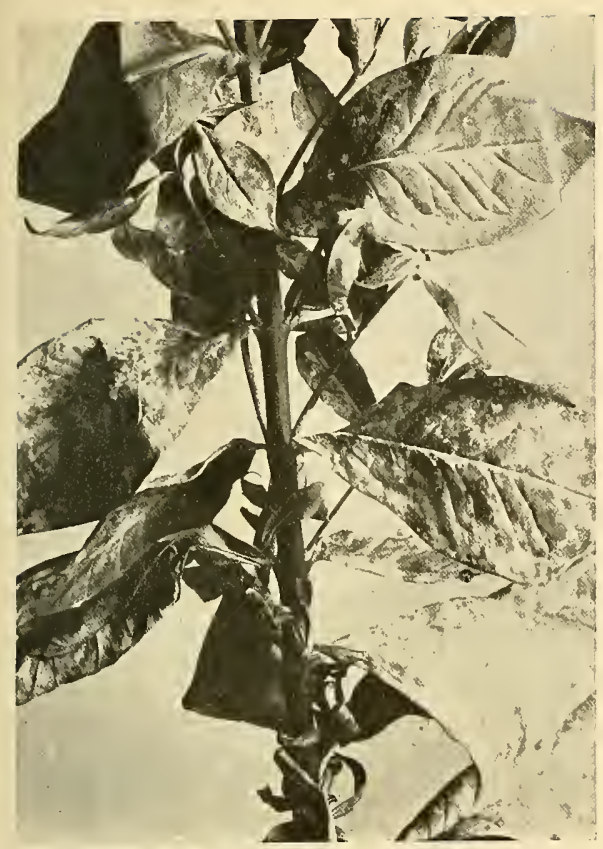

a. Powdery Mildew, p. 345.
Raspberry.

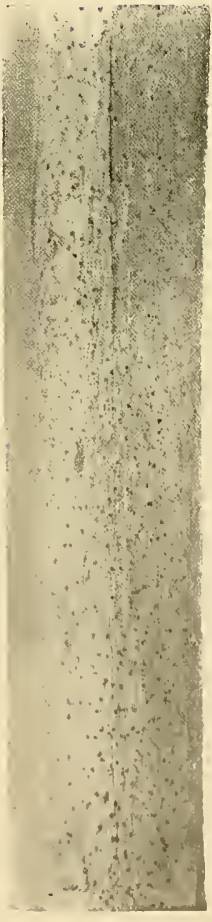

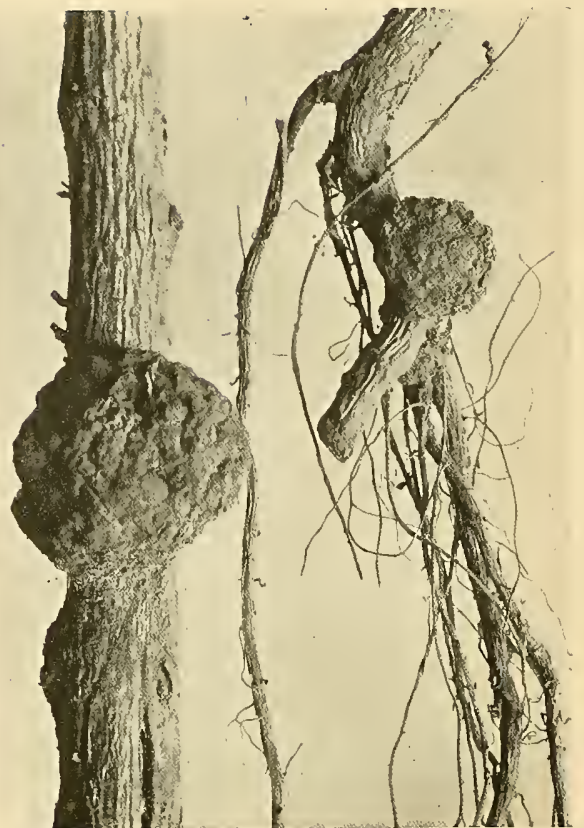

b. Crown Gall, p. 346 .
Plum.

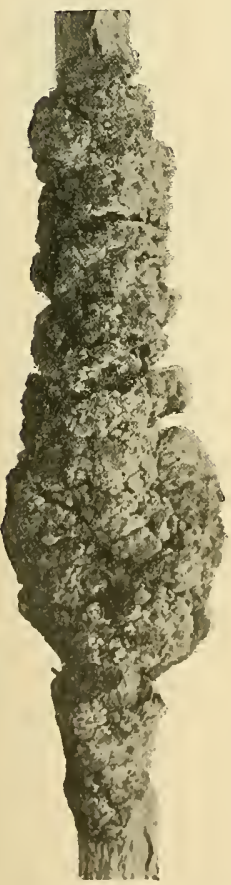

c. Black Knot, p. $3+5$.

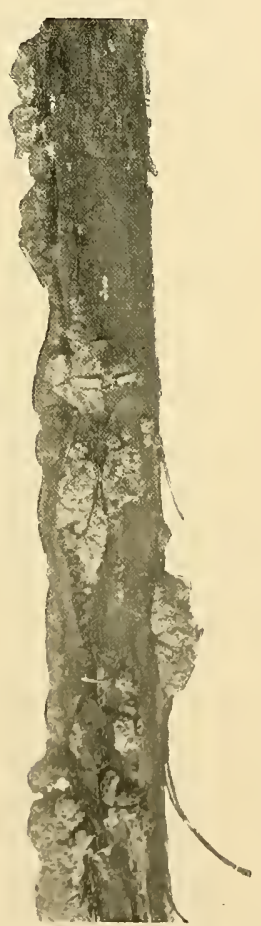

d. Crown Gall, p. 354. $\times 2$

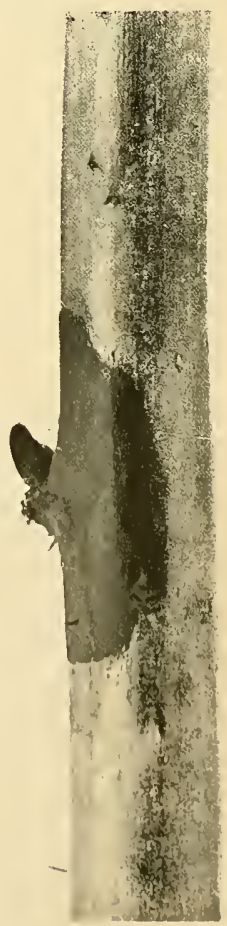



PLATE XXV.

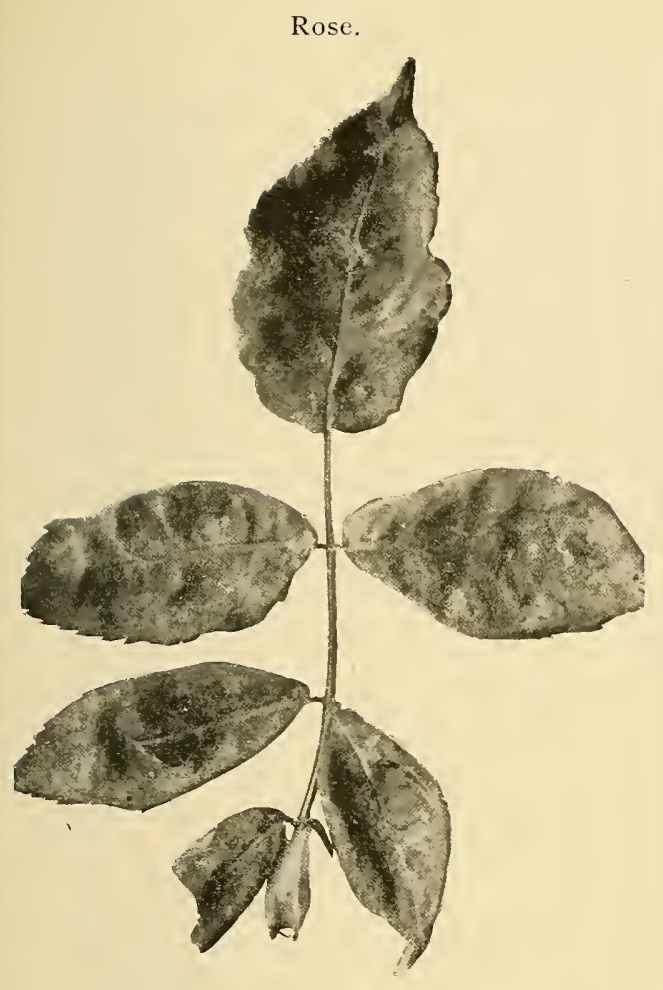

a. Powdery Mildew, p. 356 .
Rye.

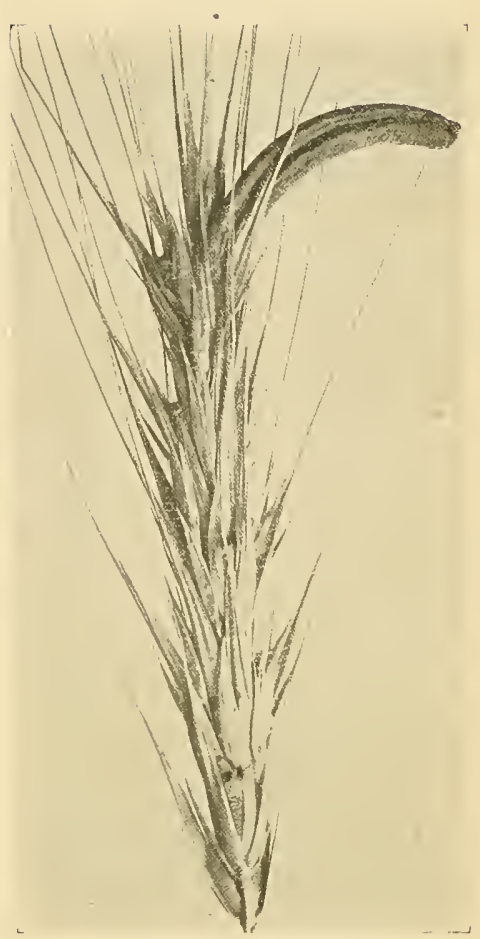

b. Ergot, p. 357 .

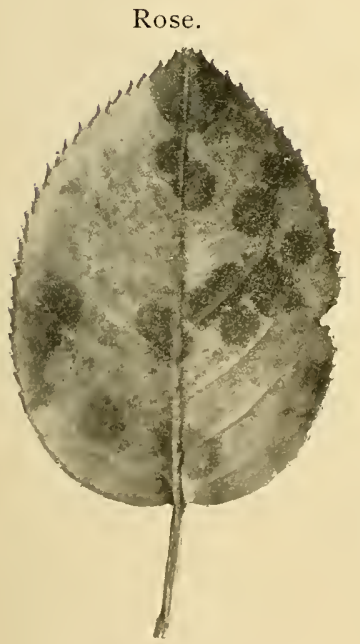

c. Leaf Blotch, p. 355 .
Strawberry.

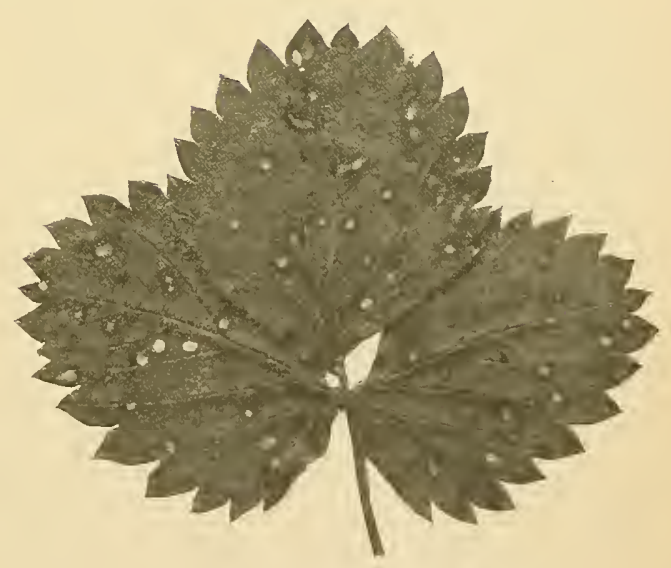

d. Leaf Spot, p. 360 .

FUNGI OF ROSE, RYE, STRAWBERRY. 

PLATE XXVI.

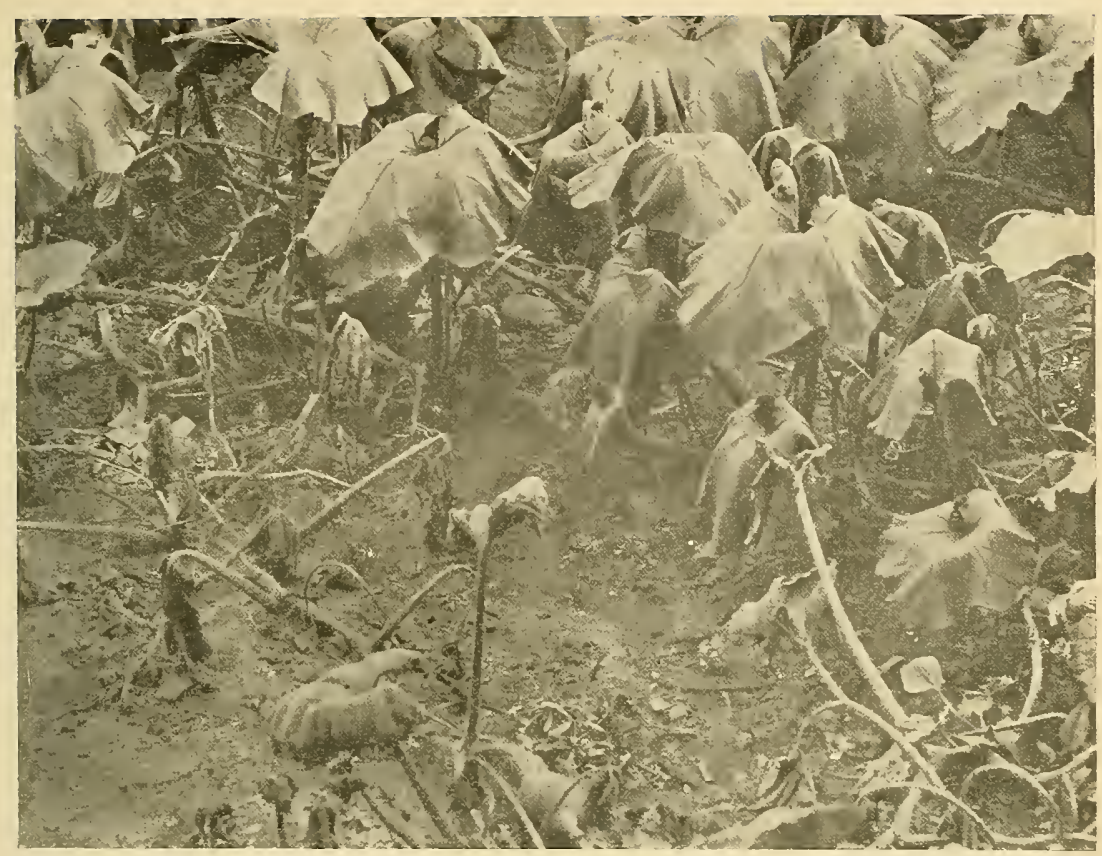

a. Bacterial Wilt, p. 359 .

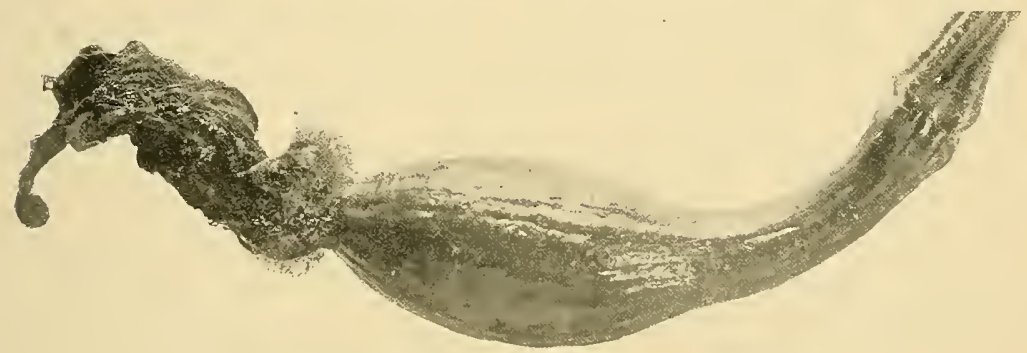

b. Black Mold at base of blossom, p. $35 \mathrm{~s}$.

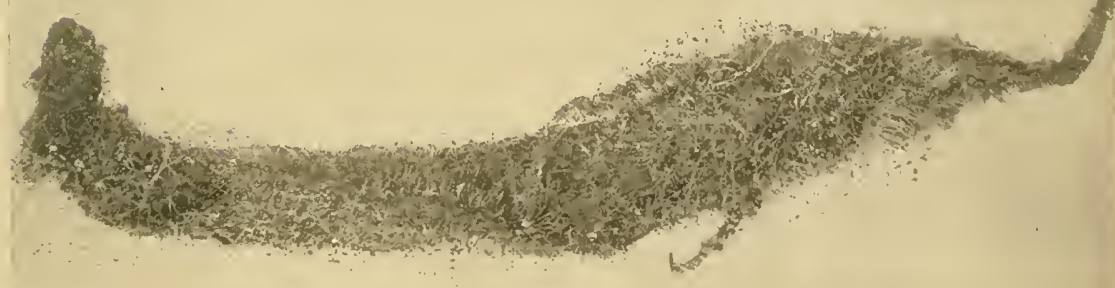

c. Metallic Mold on blossom, p. 359. $\times 2$.

FUNGI OF SQUASH. 

PLATE XXVII.

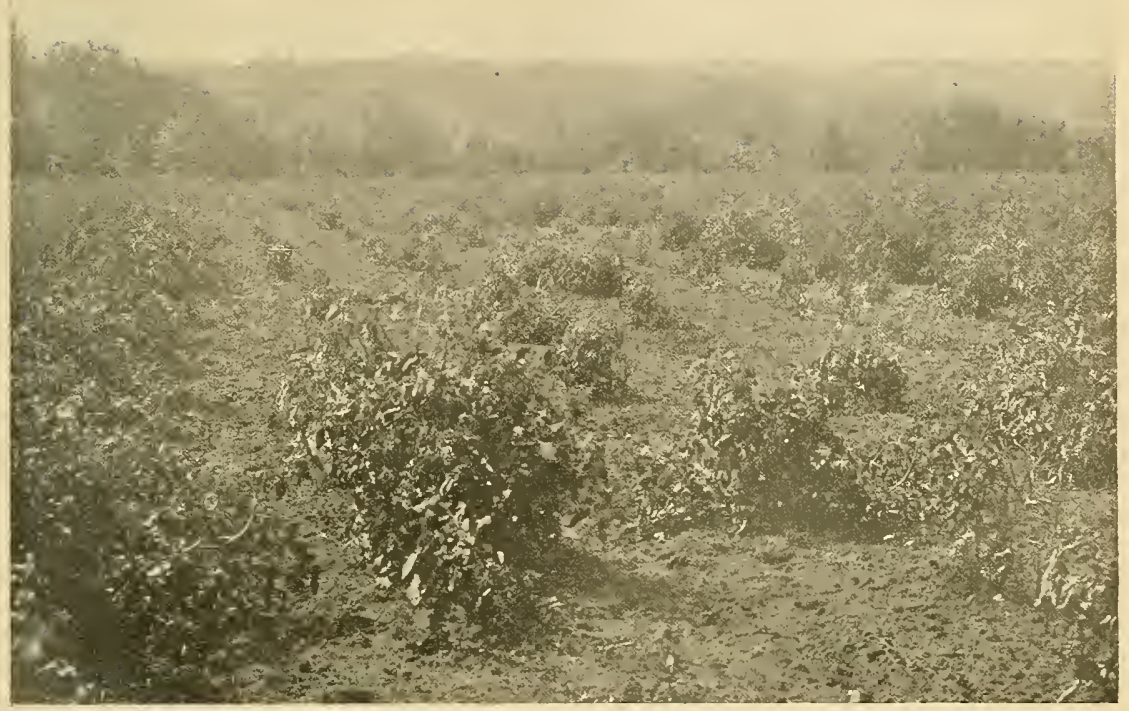

a. Showing area in A. Ure's tomato field where blight killed many plants.

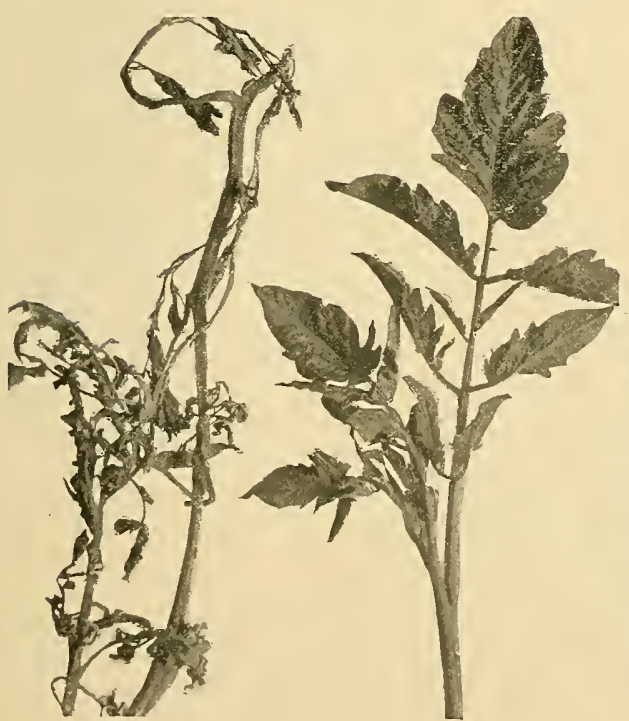

Blighted.

b. Tomato leaves.
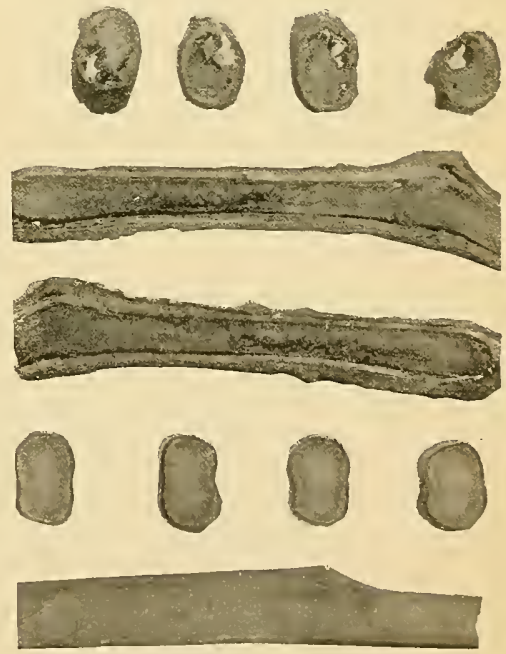

c. Cross and longitudinal sections of tomato stems. Upper three rows blighted; lower two rows healthy stems. 



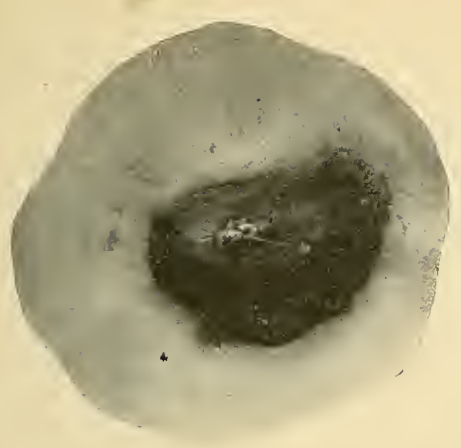

a. Point-Rot, P. 367-

Turnip, $\times 2$

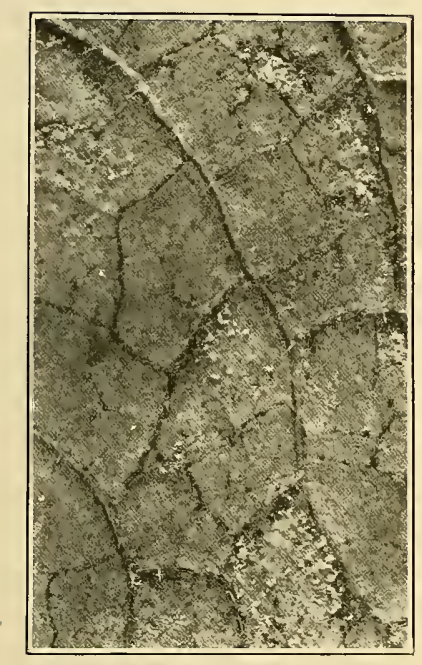

c. Downy Mildew, p. 367 .
Tomato.

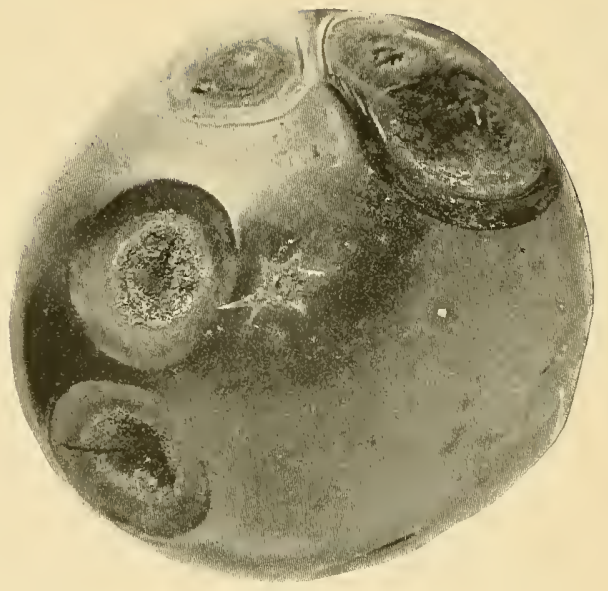

b. Anthracnose, p. 364 .
Violet.

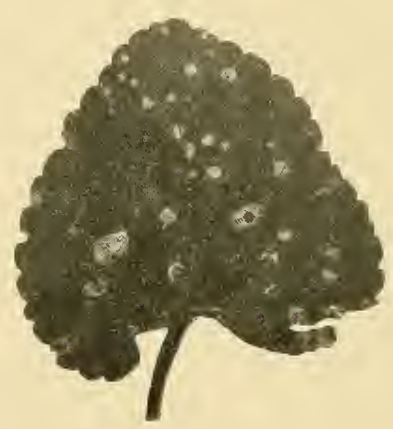

d. Spot Discase, p. 368.

Young Watermelon.

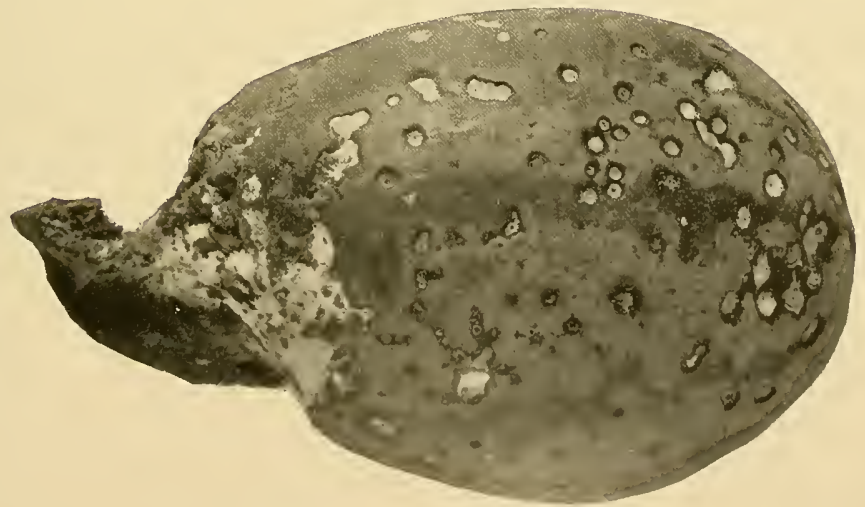

c. Anthracnose, p. 360.

FUNGI OF TOMATO, TURNIP, VIOLET, WATERMELON. 


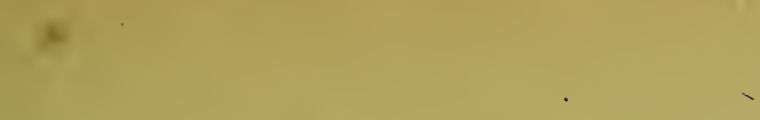

.

, 



\title{
Itate of Connecticut
}

\author{
REPORT \\ of
}

The Connecticut Agricultural

Experiment Station

FOR THE YEAR 1904

PART IV.

REPORT OF THE STATION BOTANIST 



\section{CONNECTICUT}

\section{AGRICULTURAL EXPERIMENT STATION}

\section{REPORT OF THE BOTANIST}

G. P. CLINTON, Sc. D.

I. Notes on Fungous Diseases, etc., for I904.

II. Downy Mildew, or Blight, Peronoplasmopora Cubensis (B. \& C.) Clint., of Musk Melons and Cucumbers.

III. Downy Mildew, or Blight, Phytophthora infestans (Mont.) DeBy., of Potato. 



\section{REPORT OF THE BOTANIST.}

NOTES ON FUNGOUS DISEASES, ETC., FOR I904.

In the last Annual Report, I903, pp. 279-370, the writer gave short notes on all of the fungous and bacterial diseases and physiological troubles which had been observed up to that time on the cultivated plants of Connecticut. In the present article are given notes on those that were prominent the past year and those that were much less conspicuous than during the two previous seasons, together with brief descriptions of the few troubles found in the state for the first time and additional information gained concerning old ones. The half-tone illustrations are natural size unless otherwise stated. On the whole, I904 was not conspicuous for serious outbreaks of fungous troubles, especially when compared with the two previous years. This was largely due to the warmer, drier season.

ALFALFA, Medicago sativa.

Leaf Spot, Psendopeziza Medicaginis (Lib.) Sacc. Plate XVIII, a. Recently further attention has been called to the cultivation of alfalfa in this state for dairy purposes. While undoubtedly a valuable plant in many regions, most efforts to raise it here have been unsuccessful thus far. In the Report for 1903, p. 297, attention was called to the leaf spot disease of this plant. During the past season this disease considerably damaged a small plot of alfalfa grown on the Experiment Station grounds. Plate XVIII, a, shows the general appearance of the purplish spots it produces on the leaves, which, as they become badly infected, turn yellowish and die prematurely.

\section{APPLE, Pirus Malus.}

Powdery Mil.dew, Podosphaera leucotricha (Ell. \& Ev.) Salm. Plate XVIII, b. As noted in the Report for I903, p. 300 , this fungus does most damage to nursery stock, occurring commonly on the twigs. It is worse on some varieties than on others and was found especially abundant on Rome Beauty in one nursery the past season. The illustration shows the minnte 
perithecia crowded together in dark patches on the dirty white mycelium that enveloped the twigs of that variety.

Rust, Gymnosporanginm macropus Lk. Plate XVIII, c. Apple rust was not as prominent as usual the past year. Certain varieties are known to be very susceptible to attack. (See Report I903, р. 301.) This was shown very plainly last spring in the Experiment Station disease garden in the case of Bechtel's Flowering Crab. A ripe "cedar ball" of the above rust was attached to the top of a young tree during moist weather in May. In June the spermagonial stage was very prominent on the upper side of many of the leaves to which had been carried the germinating sporidia from this cedar ball. The illustration shows the clusters of spermagonia on a leaf which developed about forty separate points of infection. On another leaf over one hundred distinct spermagonial clusters were counted, while on some of the leaves the whole surface was covered, so that there was no separation into distinct colonies. In July the aecidial stage became prominent on the under surface of these leaves.

Scab, Venturia incqualis (Cke.) Aderh. This fungus was not unusually prominent the past season. Attention was called in the last Report, p. 301 , to a case where the parasitic stage, Fusicladium dendriticum, was found on the twigs of a single nursery tree. Last fall it was found again in another nursery on the twigs of the Fall Pippin and the leaves of this variety were unusually scabby. No sign of the asco-spore stage has yet been observed on the twigs.

Winter Injury. Mention was made in the Report for 1903 of the injury done by the two unusual winters of 1902-3 and 1903-4. During the past summer further observations have shown a number of young orchards that suffered severely from winter injury. Its effect on young orchard and-nursery trees was usually shown by the killing or severe injury of the wood. If snow was on the ground this injury only extended down to the snow line. Externally the trees looked all right, as the bark and cambium were not injured, so that new wood was formed during the summer, but this annual ring of growth was often very slight. A cross section of the stem showed this as a white growth just beneath the bark and around the blackened injured wood of the preceding seasons. Some trees were killed outright or so severely injured that they died during the sum- 
mer. When the injury did not extend entirely down to the stock, badly damaged trees were cut off and a new trunk started from a bud on the uninjured part of the scion. Such trees, if properly cultivated, made very satisfactory growth during the summer. Where the injury was not so severe, thorough pruning proved helpful.

In bearing orchards the injury usually showed itself in the bark and not in the wood. Usually the bark was injured only at the base of the trunk by a girdled, dead area extending from the ground up, often only on one side. Sometimes isolated dead areas could be found further up on the trunk or on the branches. The younger trees suffered more severely and often in the summer shed many of their leaves, and if the trunk was completely girdled finally died. When the bark becomes loosened on these dead areas it should be scraped off and the wood painted over to prevent rot. For orchard sites high, exposed hillsides are preferable, other things being equal, to sheltered lowlands, where, in our experience, winter injury most commonly occurs. Late cultivation and excessive fertilization, too, are apt to send the trees into winter with their wood in an unripened condition and thus more susceptible to injury. Some of the nurseries of the state suffered severely from winter injury to stock left outdoors. To prevent future trouble from this source one firm the past summer built a large storage house where all of the stock offered for sale in the spring can be wintered out of reach of the cold. See Peach.

\section{ASPARAGUS, Asparagus officinalis.}

Rust, Puccinia Asparagi DC. Plate XIX, a-c. This fungus has been mentioned before as doing damage in this state, having been reported first in 1896 . So far, however, the aecidial stage (see Report 1903, p. 305) has not been reported. This was observed the past season in a certain bed in Westville. The bright orange spores of this stage are produced in minute, toothed cups, embedded ustrally in elliptical clusters on the stems. (See Plate XIX, b.) Compared with the red and black rust stages of this fungus, this stage is infrequent and harmless (except as it serves as the source of infection for these other stages) and appears only in the spring and early summer. In most of the 
plants examined it was confined to the lower twelve inches of the stem. In this particular field the asparagus had been gathered by snapping off the tender tips, thereby often leaving stubs several inches long. It was on these old stubs that most of the aecidia were found. This method of removal hence served as a means of increasing the rust in the field, for if the asparagus had been cut off close to the ground the rust would have developed only on a few of the old plants. The reason why the aecidial stage ustrally appears on the base of the plants is apparently because infection takes place from the black rust stage carried over winter in fragnents of the old stems in the ground and the bases of the stems are the most favorably situated portion of the plant for infection.

As the aecidial stage was just appearing in this field and as there were few old plants, the field having been severely cropped, it was decided to see if the subsequent injurious stages of the rust could be kept out of the field by thorough removal of stubs and stems showing the aecidial stage, since the bed was somewhat isolated. The aecidial stage was first observed June I4, but many of the aecidial cups were unopened and the weather was not favorable for the spread of the rust from the mature ones. June I 5 to $I 7$ the writer went carefully over the field, about a quarter of an acre, and removed all of the parts showing rust. The field was gone over twice at this time, as it was discovered that on the first search not all of the rust was found. In all 858 rusted stubs (chiefly) and stems were removed. There was no sign whatever of either the red or black rust stage at this time. On June 27 the field was again examined and 38 stems and stubs were removed. Of these, however, I I showed the red rust (uredo) stage, though not abundantly. (See Plate XIX, c.) These were chiefly on the lower parts of the plants and were just beginning to split open to shed their spores. They were also mostly confined to plants showing the aecidial stage. The field was examined a third time on July I I and I92 stems were removed. As many of these were large plants, further removal was impossible without injury to the bed. Then, too, the uredo stage had become quite common at this date and a few teleuto sori (black rust) were also present. Lest than half the stems removed showed the aecidial stage. It is quite probable that not all of the plants showing the uredo stage were cut at 
this time, as in large plants the scattered outbreaks were easily overlooked. Angust 4 the field was examined again and the uredo stage was found rather common through it. About September 23 the field was mowed and the tops raked together,not very carefully,-and burned. The field was not examined until after this was done, so the relative amount of rust present at this time was not determined. It is easily seen from what has been stated that this removal of the aecidial stage did not prevent the uredo stage at least from becoming fairly abundant in the field. What effect this removal, coupled with the burning of the canes in the fall, will have, remains to be seen another year. That the very careful removal and burning of all of the tops and litter in the fall for several years helps to decrease the rust, if the patch is isolated, has been shown, apparently, in a small bed at the Experiment Station. In 1896 Dr. Sturgis first observed the rust in this bed. Beginning about I897, and for at least four years, the tops and litter from this bed were removed and burned. The rust has gradually become less, until last season none whatever was found in it.

Rust Parasite, Darluca Filum (Biv.) Cast. Plate XIX, d. This fungus is parasitic on the rust fungus, and so is beneficial in checking the latter. It was very abundant in the field described above. Unquestionably it prevented many of the aecidial cips from maturing their spores. The fruiting receptacles of this fungus appear in the illustration as minute black dots covering the area infested by the rust. The same fungus also is common here on the uredo and teleuto stages of the asparagus rust. In one field observed the past year that had been killed, apparently, by the rust, this parasite was much more conspicuous than the rust itself. Probably in this case the fungus was parasitic on the hidden mycelium of the rust and largely prevented its spore formation, so that the parasite, rather than the rust, appeared to be doing the harm. It is barely possible, however, that to some degree the parasite was really intruding on the host without the aid of the rust and so was responsible for part of the injury. This same parasite occurs on a number of other rust species in this state; for example, carnation rust and blue-grass rust. 
BEANS (IIMA), Phaseolus lunatus.

Bacterial Spot. Plate XX, a. The cotyledons of the lima bean at the time the seedlings appear above ground often show purplish discolored areas that develop into sunken spots, as is shown in the illustration. Microscopical examination of these in their young state generally reveals bacteria present before the fungi which later often fruit at these places; while without positive evidence, these cankered areas seem to be one of the sources of infection of the bacterial disease which later in the season often appears on the leaves as reddish bordered spots (Report 1903, p. 307) and does considerable injury.

\section{CABBAGE, Brassica oleracea.}

Downy Mrldew, Peronospora parasitica (Pers.) Tul. 'This fungus has been reported before on other cruciferous plants, but was observed for the first time last spring on young cabbage plants grown in a hot-bed. The trouble did not continue after the plants were set in the field, and, no doubt, was induced by too moist and crowded condition of the plants in the bed.

CHERRY, Prumus avium.

Brown Rot, Sclerotinia fructigena (Pers.) Schröt. Plate $\mathrm{XX}, \mathrm{b}$. A specimen of Governor Wood cherry in the Experiment Station grounds seems to be especially subject to this rot year after year. In 1904 the disease showed very early on the perfectly green fruit. An examination indicated that the curculio or other puncturing insects had considerable to do with spreading it, as often the infected fruit showed signs of a sting and the trouble was almost as bad while the fruit was green as it was later when the fruit was ripe and more easily infected. Some of the blossoms were also infected, but no diseased twigs were found, though careful search was not made for them. The tree had been sprayed during the winter with lime and sulphur, which still covered it rather thoroughly, but this apparently had no influence in keeping down the rot, as one might suppose it would if it started first from spores produced on the twigs. A careful search has been made for three years for the Sclerotinia stage cn the old cherry pits lying on the ground, but this has never been found. Very few mummies remain hanging on the 
tree at the beginning of spring, though their pedicles more often remain attached. The illustration shows that the disease often kills these pedicles, sometimes producing spores on their upper end. It was thought that possibly the fungus was perpetuated by its mycelium passing down the diseased pedicles into the fruiting spurs and then up into the flowers in which it was found in the spring. Examination of the fruiting spurs in the winter showed that often those having the old pedicles attached were dead, while cross sections of others revealed reddish discoloration of the tissues. Rough microscopic sections of these showed that often many of the parenchyma cells of the bark and pith were dead or severely injured, but there was no evident indication of mycelium, and when diseased or dead spurs were placed in a moist chamber or diseased tissue from them was inserted in Petrie dishes of agar agar no development whatsoever of the Monilia fungus took place. On the other hand, when the mummied fruit and diseased pedicles were placed in the moist chamber the production of the Monilia spores was abundant. These observations, then, indicate that the fungus does not travel down the diseased pedicles and from these infest the fruit spurs, but that the infection each spring comes, as ordinarily supposed, either from the mummied fruit (and pedicles) or infected branches, in which the Monilia spores are again produced in early spring during moist weather, and from these carry the disease first to the blossoms and from them to the young fruit, their infection of the latter being largely aided by puncturing insects. The influence of a puncture on the fruit was shown with green cherries, kept in a moist chamber in the laboratory, in which the spores of the fungus were inserted through a needle puncture. These cherries started to rot immediately at the punctured places, while others with spores placed on them without puncture and checks with no spores placed on them, though rotting later, usually started at some other point than where the spores were placed, probably from some injured place in the skin where spores had previously lodged.

\section{CORN, Zea Mays.}

Leaf Blight, Helminthosporium turcicum Pass. This fungus, which was so injurious in I903, did practically no damage the past season, thus showing that it is to be feared only in very moist seasons when the corn naturally does poorly. 
CUCUMBER, Cucumis satious.

Downy Mildew, Plasmopara Cubensis (B. \& C.) Humph. Not injurious this season. See Musk Melon.

\section{DEWBERRY, Rubus Canadensis.}

Orange Rust Parasite, Tuberculina persicina (Ditm.) Sacc. Plate XXI, a. This fungus, especially in the west, is a common parasite of various rusts. Here, on the orange rust, it does not form the dusty purplish spores of the Hyphomycetous stage so conspicuously as it does later the subspherical sterile purplish sclerotia (See illustration.). There is little doubt that if these were properly developed they would reveal the existence of an asco-spore stage as yet unknown. It is questionable whether the fungus is of any practical use here in keeping the orange rust in check.

\section{EGG PLANT, Solanum Melongena.}

WILt, Fusarium sp. Plate XXI, b. The cause of this trouble has not been determined definitely, though it is probably a Fusarium fungus. It was present again the past year in some of the fields of this plant. Infected plants showed a dwarfed, yellowish appearance, and produced little and inferior fruit. Late in the season an examination of the badly diseased plants showed that the stem and roots under ground were badly rotted, as shown in the illustration. As was expected, spraying produced no favorable results with this trouble. There is no question that the disease begins in the very young plants, probably always in the seed bed, though it may not show plainly at this time, and starts from infected soil or diseased seed. Care, therefore, when possible, should be used to select the very best seed from undiseased plants and to use fresh soil in the seed beds.

\section{FIG, Ficus Carica.}

Smutty Mold, Sterigmatocystis Ficuum (Reich.) P. Henn. Plate XXI, c. This smutty mold has been unusually common the past season in the market figs. The spores of the fungus partially fill the interior of the figs with a black smutty mass so much like the true smuts that the fungus was originally 
described as one of these. It belongs, however, under the Hyphomycetes, or imperfect fungi. The same or a similar fungus also occurs in dates, but has not yet been reported in this state, though probably not uncommon in the markets.

\section{GRAPE, Vitis sps.}

Powdery Mildew, Uncinula necator (Schw.) Burr. Plate XXII, a-c. The powdery mildew of grapes was unusually abundant last fall, becoming especially prominent on the fruiting stems and the berries. It did not seem to cause unusual injury, however, except where it occurred on the thin-skinned varieties, especially the white varieties, in which the berries were more or less wilted, besides being somewhat disfigured by the presence of the fungus. The illustrations show the minute black perithecia, or spore, receptacles, very abundantly scattered or clustered in the superficial whitish mycelium that covers various parts of the host. Suggestions for treatment were given in the Report for 1903, p. 324 .

\section{MULBERRY, Morus sp.}

Bacterial Disease, Bacillus Cubonianus Macch. (Bacterium Mori Boy. \& Lamb.) Plate XXIII, a-b. This disease was found in the state for the first time in one of the nurseries, where it was causing more or less injury to the young trees. Upon the leaves the disease shows as small reddish brown spots, when moist often semi-pellucid, that penetrate through the tissues to both surfaces. These are often more prominent and numerous than is shown in the illustration. The chief injury in this nursery, however, was to the twigs. Many of the branches and even whole young trees had a stunted, yellowish appearance. Usually the cause could be traced somewhere on the stem to an evident canker, like those shown in the illustration, which more or less completely girdled the stem. As these diseased areas in the bark become older, the growth of the tissues often tends to cut them off from further development, so that they show merely as a rough or corky superficial spot in the bark. When the disease penetrates to the cambium, however, the disease usually spreads internally between the bark 
and wood, doing considerable injury to each; see cut end of the largest branch in the illustration. This diseased condition, then, may not show exteriorly except through the yellowish, sickly growth. Sometimes the trouble becomes so bad that the young stem can be easily snapped off at the diseased place. This disease was first described from Italy and France and has been observed by the writer in Illinois on both cultivated and wild species of the mulberry. Probably the best treatment is to thorouglily prune out the disease in winter time, as is done for pear blight.

\section{MUSK MELON, Cucumis Melo.}

Bacterial Rot. Plate XXIII, c. A bacterial rot of the fruit was not uncommon in some of the musk melon patches the past summer. It seems to have been caused by the same organism that produces the wilt of the vines, or at least this may have been its starting point. The fruit developes a soft internal rot, without external evidence in the youngest stages, but eventually it spreads to the exterior, especially on the side next the ground. Some melons were found in which the bacteria were limited to the bundles in the peduncle and to those in the interior of the fruit, the surrounding tissues being healthy as yet, thus suggesting its relationship to the bacterial wilt, which was also found in these fields. Vines that were thoroughly sprayed several times during the season developed the rot in the fruit as badly as those not sprayed.

Downy Mildew (Blight), Plasmopara Cubensis (B. \& C.) Humph. This trouble, which has been so common and injurious during several seasons past, was very uncommon the past year, so far as the writer observed doing 110 damage whatever. In I903 its diminishing injury and later appearance was reported by the writer and the prediction made that it was on the wane. In 1904 for the first time in several years a fair crop of musk melons was obtained. This was largely due to the drier, warmer summer, which, besides keeping this fungus in clieck, was responsible for a vigorous growth of vines so necessary for the production of fruit in this crop. (See special article on this blight in the present Report.) 
ONION, Allium Cepa.

Stel Rot, Botrytis sp. Plate XXIV, a-b. The stem rot trouble of the Southport White Globe onions (see Report, I903, p. 334), which was so bad the two previous years, did no damage in 1904. As was suggested in the last Report, this trouble is largely induced by unusually wet seasons, especially during July and August. These months, in 1904, being considerably drier than those of the two previous years, were thus unfavorable for the development of the fungus. No signs of it whatever was found on plants in the field and no especial complaint of the rotting of the stored onions was made by the growers. Where planted, this variety did fairly well last season, except for the injury of the onion maggot, which was unusually common on all onions. Many growers, however, were so disheartened by the losses of the previous seasons that the acreage devoted to this variety was very much smaller than usual. So far, the writer has been unable to find any Sclerotinia stage connected with this fungus. The selerotia which often develop in the rotting tubers and carry the fungus over the winter apparently develop only the Botrytis stage, which causes the injury in the field and store house. Plate XXIV, b, shows an old onion, gathered outdoors in the spring, with several of these black sclerotial bodies.

Not being able to predict the character of the season as to its moisture, experiments to determine the value of spraying in preventing stem rot in White Globe onions were undertaken the past year on the farm of W. H. Burr at Green's Farms. As it turned out, there was no stem rot, so no information regarding the value of this treatment for the rot was gained, yet some points of value regarding spraying onions were obtained. Four or five treatments were planned, but on account of sickness only three were made, on June 24th, July 5th, and August 3d. Different plots of the onions were sprayed once, twice, three times and not at all. Onions are planted so closely together in the fields that no apparatus drawn by a horse can be used. In this experiment knapsack sprayers were used: These, however, are so cumbersome that they meet with little favor where any considerable spraying is to be done. The small barrel pump, mounted on wheels somewhat higher than usual, to bring the bottom of the barrel nearly clear of the tops of the onions, 110 doubt would be the best apparatus where any considerable 
spraying is to be done. One man can then pump and pull the barrel and another spray several rows of onions as they go along. The first treatment need not be made before the first week in July, since the plants are rather small before this time, and there is little danger of fungus troubles until then. It is very difficult to make Bordeaux mixture adhere to onions because there is very little surface, but chiefly because of the very smooth, glaucous character of this surface. This makes it almost necessary to use resin Bordeaux to secure fair results. Soap added to the ordinary Bordeaux proved of little value. Even with resin Bordeaux the glaucous character of the tops prevents the spray from adhering any length of time if there is rainy weather. This being the case, at least four or five sprayings will be necessary to secure moderate protection against any serious fungous trouble. With all these difficulties and objections it is not likely that spraying onions against fungous trouble, unless very serious, will come into very general use. The onions sprayed in this experiment were stored separately, but very little difference was noticed in their keeping qualities, and no true stem rot developed.

\section{PEACH, Prumus Persica.}

Brown Rot, Sclerotinia fructigena (Pers.) Schröt. Plate XXIV, c-d. Because of the light crop for two years the brown rot of peach was not especially prominent. Search last spring brought to light, for the first time in this state, the presence of the Sclerotinia, or asco-spore stage (see illustrations) on the old mummies partly buried in the ground. While these were not very common, they were found on both peach and plum mummies, and are no doubt more common when more of the rotten fruit is left on the ground. They serve as another means of infecting the young blossoms in the spring and thereby spreading the trouble to the fruit.

Frosty Spots. In August there were sent to the Experiment Station from Cannon Station diseased leaves of peach which showed in their first stage a purplish discoloration of the under surface and later a silver grey color as if mildewed. Sections of the diseased leaves, however, showed no fungus present, but did show that the epidermal cells and later the spongy parenchyma cells beneath had turned purplish, finally lost their contents and collapsed. The injury, apparently, was a physiologi- 
cal trouble caused by some unusual disturbance of natural conditions. Possibly it was due to insufficient water supply brought about through winter injury to the roots. Lack of water as a cause was suggested by the trouble showing first in the vicinity of the bundles, through which the water is brought, and by its occurrence on the under surface of the leaf where the stomates are, which regulate the transpiration of the water. A very similar trouble was noted in the Report for 1903 , p. 360 , on strawberry leaves.

Winter Injury. Many peach orchards were severely hurt by the winter of 1903-4. In most cases the wood was injured, usually down to the snow line, as shown by the darker color, without damage to the bark and cambium. Many trees had been similarly injured the year before, and so formed very little new wood the past season. Occasionally the trunks of older trees were split toward their base with prominent longitudinal cracks. In one orchard the injury was confined chiefly to the roots of certain trees. In the spring these trees put out a scanty, yellowish, sickly foliage. Examination showed the trunks generally healthy, but the roots injured or dead. The innermost vertical roots were always least injured, as they were more protected than the outer more horizontal roots. Apparently only those trees had suffered where the snow had blown off the most exposed places in the orchard, which was on a hill side. Many growers in the spring severely trimmed their trees and dug out those very badly injured. Undoubtedly the peach can stand severe winter injury to its wood and still make a slight growth of new wood the next year. Just what the ultimate value of these trees will be, however, is a point not yet settled. So far as observed by the writer, trees that were injured did better when severely pruned than when not pruned. See apple, also Report, I903, p. 34I.

\section{PEAR, Pirus communis.}

SCAB, Venturia pirina (Lib.) Aderh. Plate XXV, a-c. This disease was not especially bad the past season, but is mentioned because the scab stage was found on the twigs of certain trees; see illustration. The occurrence of the fungus on the twigs is more common with pear than with apple scab. In the cases examined, the bark was more or less corroded or pustular at the infected places. Usually the outbreaks, especially in a fruit- 
ing condition, were found only on the one and two-year-old twigs. On the older twigs apparently the diseased bark gradually sloughed off and was replaced by a healthy growth. There was some indication that the mycelinum passed from last year's to this year's twigs, since on the latter the outbreaks often appeared first and most abundantly at their basal end. Undoubtedly, however, new infections often and possibly always take place by reinfection of the young twigs from spores produced on the older. In the winter time the scab areas may show plenty of the spore-bearing mycelium, but no spores, which begin to form early in the spring. Certain varieties are known to scab much worse than others, and in these cases it is probably largely because the fungus readily becomes established on the twigs. This being the case, spraying the dormant wood in the spring should have some effect in retarding and lessening the trouble. Observations made on certain trees sprayed last winter with lime and sulphur showed them freer the following summer from scab than usual, probably for this reason.

\section{PLUM, Prunus sps.}

Brown Rot, Sclerotinia fructigena (Pers.) Schröt. The Sclerotinia stage was found for the first time in this state on the mummied fruit half buried in the ground. See peach.

\section{POTATO, Solanum tuberosum.}

Bacterial Disease, (?) Bacillus Solanaceamum Sm. Plate XXVII, a-b. The bacterial disease of potato stems mentioned in the Report of 1903 , p. 35I, was found again this season. This trouble appears early in June. Usually a plant here and there in the field is injured, but the disease does not seem to spread as the season advances. Diseased plants can usually be identified by their yellowish foliage and often dwarfed growth. Very badly diseased plants can be pulled easily from the soil, the underground stem being rotted (Plate XXVII, a) and few roots or tubers are developed. Sometimes these stems look as if attacked by borers, the pith within being rotted and hollowed out for some distance. Above the rotted part cross sections of the green, apparently healthy, stem usually show the bundles darkened and diseased when the rest of the tissues are healthy; see Plate XXVII, b. In these bundles there is found an abun- 
dance of bacteria. The Rhizoctonia fungus sometimes girdles places on the underground stem (see Plate XXVI, b) and may easily be confused with this trouble. The disease is apparently the southern tomato blight, described on tomatoes and potatoes in last year's report. Whether this trouble subsequently developes as the common soft rot of the tubers is a question not settled in the writer's mind. If so, it then becomes a serious disease in this state.

Downy Mildew (Blight), Phytophthora infestans (Mont.) DeBy. This trouble was very late in appearing and did no damage to the foliage of early varieties and but little to the late. The tubers, especially of the late varieties, however, rotted very badly. (See special article in this Report on the potato blight.)

Rhizoctonia (Rosette), Corticium vagum var. Solani Burt. Plate XXVI, a-c. Last spring the small black sclerotia of the sterile Rhizoctonia stage of this fungus were very common on tubers used for seed; Plate XXVI, a. Again this spring, I905, the seed tubers were abundantly covered with these sclerotia. Such tubers if used for seed will yield a crop similarly infected, just as do scabby tubers, as was shown last season in a small experiment with infected and free tubers. So far as appearance goes, these sclerotia do very little harm since they are rather obscure and often resemble dirt. They become evident when one attempts to wash the tuber, as they do not wash off and the water brings out more strongly the contrast between their black color and that of the skin. An examination of the fields early in June showed the fungus present, the Corticium, or fruiting stage (Plate XXVI, c) being found then for the first time in this state. The mycelium, developed from the sclerotia, certainly grows out on the young stems and roots. Sometimes it produces diseased or girdled areas, as shown in Plate XXVI, b. When the mycelium reaches the stem just at the surface of the ground, it developes for a short distance a more abundant but still rather inconspicuous greyish mealy growth. This is the fruiting or Corticium stage and no injury is done to the stem here, as the fungus does not penetrate the tissues, but loosely covers the stem with a coating that gradually wears off as the spores are matured, and eventually disappears. Several fields were examined which showed from 15 to 20 per cent. of the plants having the Corticium stage on some of their stalks. 
Apparently the plants did not suffer so severely from the fungus as some writers claim they do elsewhere. However, the relative injury caused here by this fungus is a subject that needs further attention, since with the parts attacked occurring under ground the injury and cause can easily escape notice. See Report, 1903, p. 350, for further description and treatment.

In the writer's opinion there is no doubt that the Corticium stage is the same fungus described by Prillieux and Delacroix of France [Soc. Myc. 7:220] in I89I, as Hypochmus Solani. They did not recognize its relation to the Rhizoctonia stage, Rhizoctonia Solani Kühn, which has been known in Europe for some time.

Scab, Oospora scabies Thaxt. Considerable complaint was made of the damage caused by this fungus, which was unusually prevalent in 1904. See Report, I903, p. 350, for treatment.

\section{PRIVET, Ligustrum Japonicum.}

Winter Injury. Plate XXVII, c. The California privet hedges were generally injured by the severe winter of 1903-4. In most cases the stems were killed down to about a foot from the ground. This injury apparently extended down to the snow line, which completely protected the parts below, since young hedges less than a foot high were not injured at all. There was some question among owners of these hedges as to what treatment should be given them. The best treatment, apparently, is to wait until the new growth begins to start in the spring and then trim back evenly to the uninjured portion. Plate XXVII, c, shows an injured hedge on the Experiment Station ground after the new growth had made a fair start and illustrates the trimming necessary in this case to remove the injured stems. As the roots of the hedges were rarely injured, the plants, when properly trimmed, made so vigorous a growth that often by midsummer all indication of injury had been obliterated.

\section{RADISH, Raphanus sativuls.}

Root Rot, Rhizoctonia sp. Plate XXVIII, a, shows specimens, received from Elmwood, of greenhouse radishes that were severely injured by a dampening off and root rot trouble. This was caused by the sterile mycelium of a Rhizoctonia fungus which undoubtedly becomes established in the soil, and when 
this is kept damp injures the underground parts of various plants. It is quite probable, for instance, that the stem rot of rhubarb, mentioned later, and possibly even the Rhizoctonia of the potato, is caused by this same fungus. In the Experiment Station greenhouse certain specimens of the cigar plant have been injured recently by a similar agent. In previous years other greenhouse plants have been attacked. Last spring young radishes in the New Haven market not infrequently had conspicuous, but shallow, injured spots on them which apparently had also been caused by the Rhizoctonia fungus. See Report I903, p. 345 .

RASPBERRY, Rubus sps.

WiLt, Leptosphaeria Coniothyrium (Fckl.) Sacc. For three years a small patch of berries at North Haven has been injured by a wilt of the fruiting stems, which wither and die just as the berries begin to mature. The trouble has increased in severity, killing out most of the Palmers on which it started and finally appearing on the Kansas variety, several rows removed. The trouble apparently is caused by the above fungus girdling the stems or producing dead areas on them. Last May the parasitic pycnidial stage and the saprophytic asco-spore stage were both found on the stems. The former was especially abundant on the tips of the pruned stems. Probably this trouble is not uncommon in the state, though not often reported. See Report I903, p. 355 .

Winter Injury. Complaint was made by one grower that part of his raspberries had leaved out in the spring, but afterward had sickened and died. Examination of specimens received showed no sign of a fungus. The injured plants were on an exposed hill, where the winter's winds swept the ground bare of snow. Apparently the roots were severely injured or killed during the winter, while the stems were not, so they were able to leaf out but not to develop any further. The injury in some respects resembles the wilt disease.

\section{RHUBARB, Rheum Rhaponticum.}

Stem Rot, Rhizoctonia sp. Plate XXVIII, b, shows the base of leaf petioles with dark sunken cankers apparently caused by the sterile mycelium of the Rhizoctonia fungus which was 
present at these places. These specimens were sent from Southington, and a similar trouble was found on plants in New Haven. In the latter case the petioles sometimes rotted at the base and the leaves turned yellowish, wilted and finally died.

\section{SWEET WILLIAII, Diantlus barbatus.}

Rust, Puccinia Arenariae (Schum.) Schröt. Plate XXVIII, c. This rust was found for the first time in the state this year in some seedling plants grown in a yard in Westville. Only certain kinds of the seedlings were infected and the trouble apparently did not spread to the others in the same bed. This fungus, like the hollyhock rust, possesses only the teleuto spores which may germinate $i n$ situ as soon as formed and thus spread the disease.

\section{TOBACC0, Nicotiana Tabacum.}

CANKer (Black Spot*). This and the following are two warehouse troubles of tobacco not mentioned in our last Report. They appear in the leaves after these have been packed in cases for fermentation. Canker is apparently a fungus trouble in which dark colored patches are produced that often extend down through the leaves of several overlapping hands. The injured tissues are dark colored, become brittle and easily fall to pieces. Microscopic examination reveals the presence of abundant but isolated purplish black spores, apparently those of Sterigmatocy'stis niger. It is not known just what conditions favor the development of this trouble, whose presence is not known until the cases are opened for examination. Probably too much moisture favors its development, especially if care has not been used in selecting and packing the tobacco.

Must is a fungus or bacterial trouble also developed in the packed tobacco and is named from its musty odor. Examination of specimens sent the writer from East Hartford showed the presence of a slight whitish growth, especially along the midribs. Numerous bacteria and also some molds were found in these growths. Cultures from a specimen placed in a damp chamber produced a reddish brown mold. Sometimes the dealers renovate musty tobacco by washing the leaves with rum.

* Loezv, O. Physiological Studies of Connecticut Leaf Tobacco. U.S. Dept. Agr. Rept. $65: 48$. 
Alfalfa.

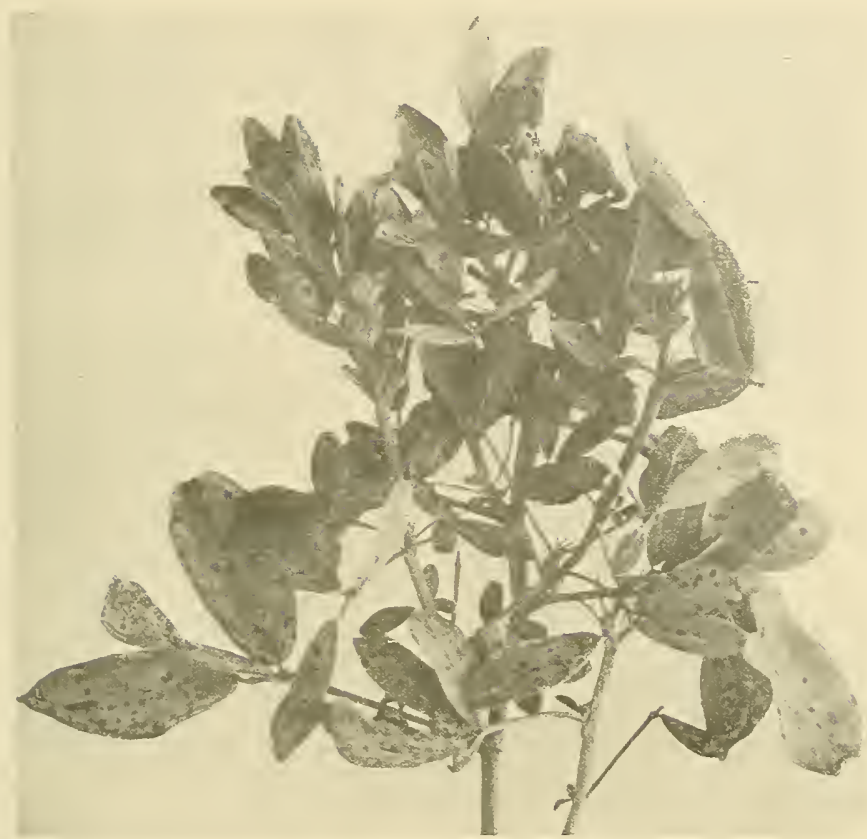

a. Leaf Spot, p. $31 \mathrm{I}$.

Apple.

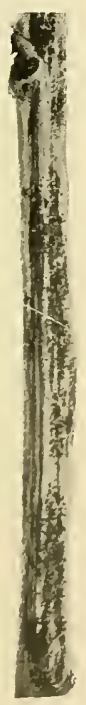

b. Powdery Mildew, p. 3 II.

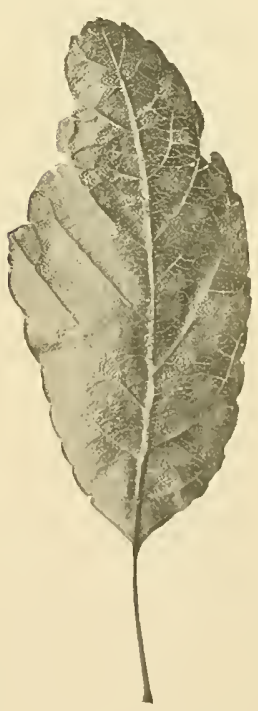

c. Rust, p. 312 . 

PLATE XIX.

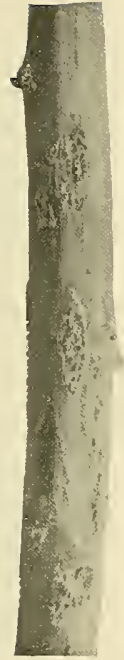

a. I Rust.

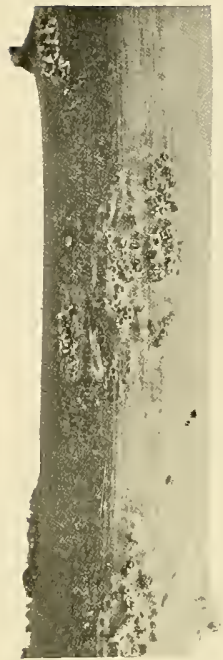

b. I Rust. $\times 2$.

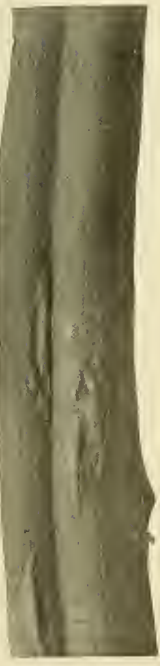

c. II Rust. $\times 2$.

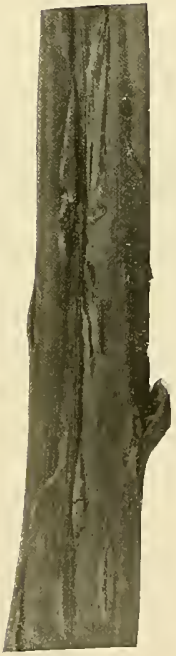

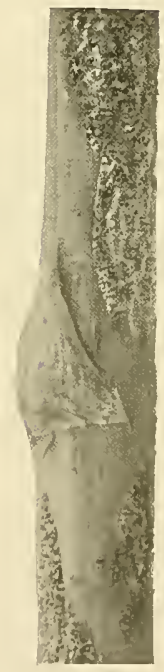

d. Rust Parasite. $\times 2$.

FUNGI OF ASPARAGUS, pP. 313-I5. 

Lima Bean.
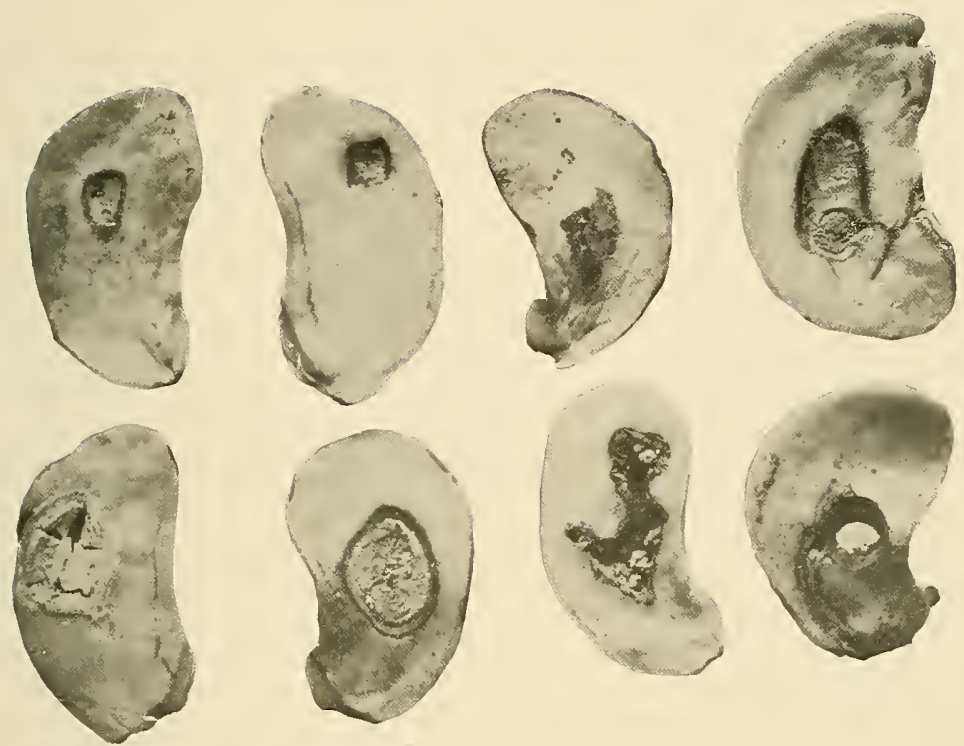

a. Bacterial Spot of cotyledons, P. 316.

Cherry.
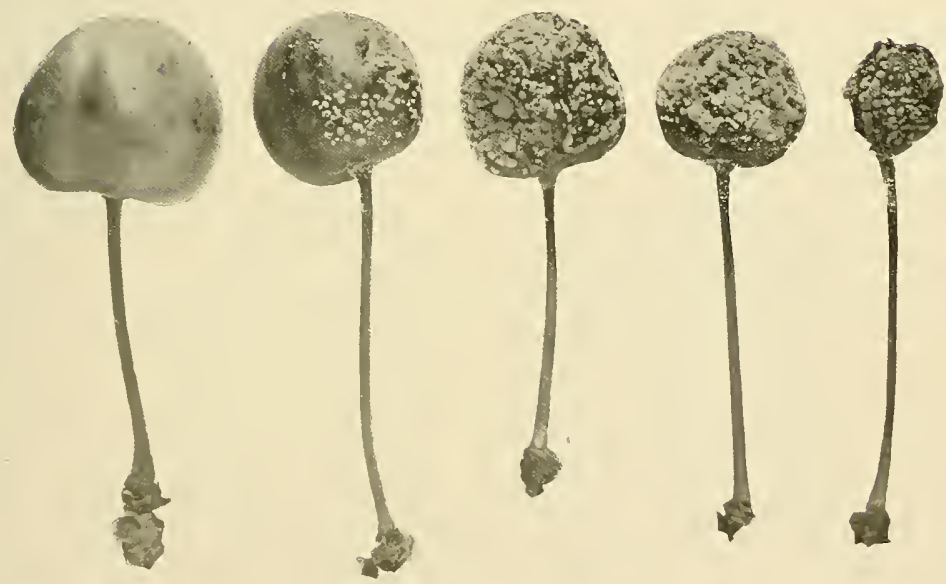

b. Brown Rot of fruit, p. 316 .

DISEASES OF LIMA BEAN AND CHERRY. 

PLATE XXI.

Dewberry.

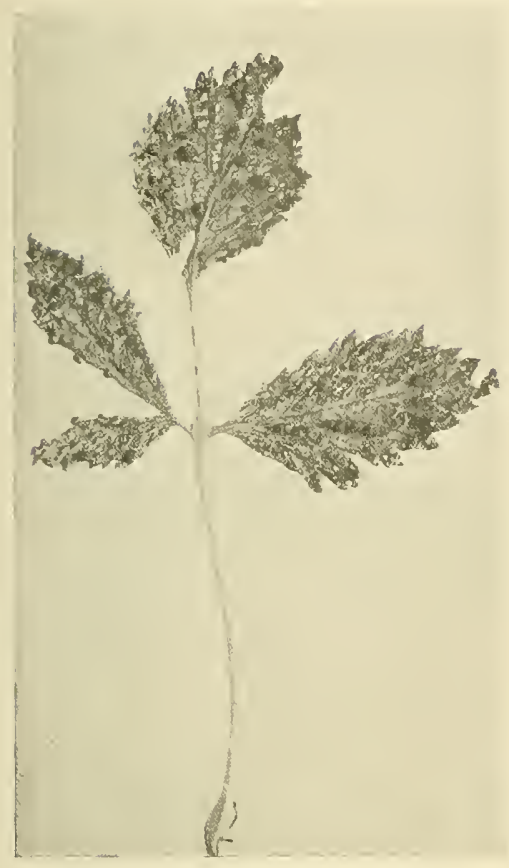

a. Orange Rust Parasite, p. 3I8.
Egg Plant.

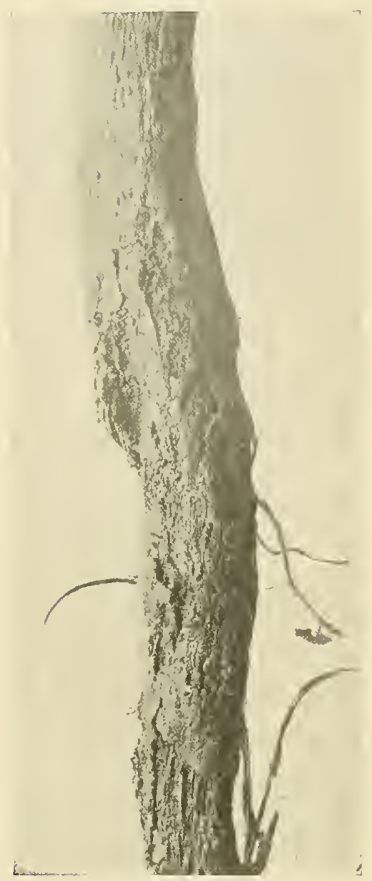

b. Wilt, p. 3 I 8 .

Fig.

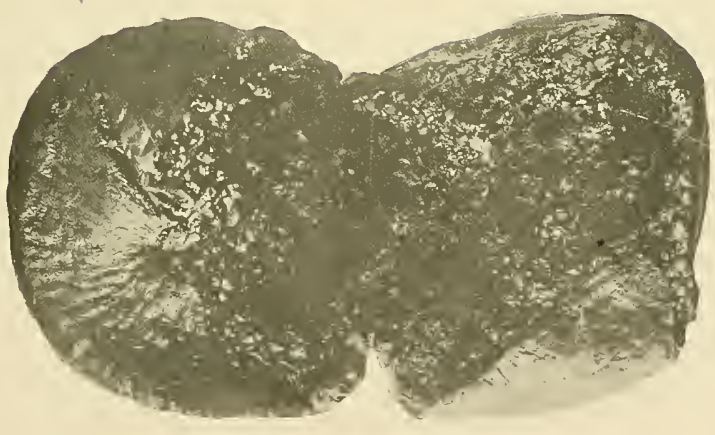

c. Smutty Mold, p. 318.

FUNGI OF DEWBERRY, EGG PLANT, FIG. 



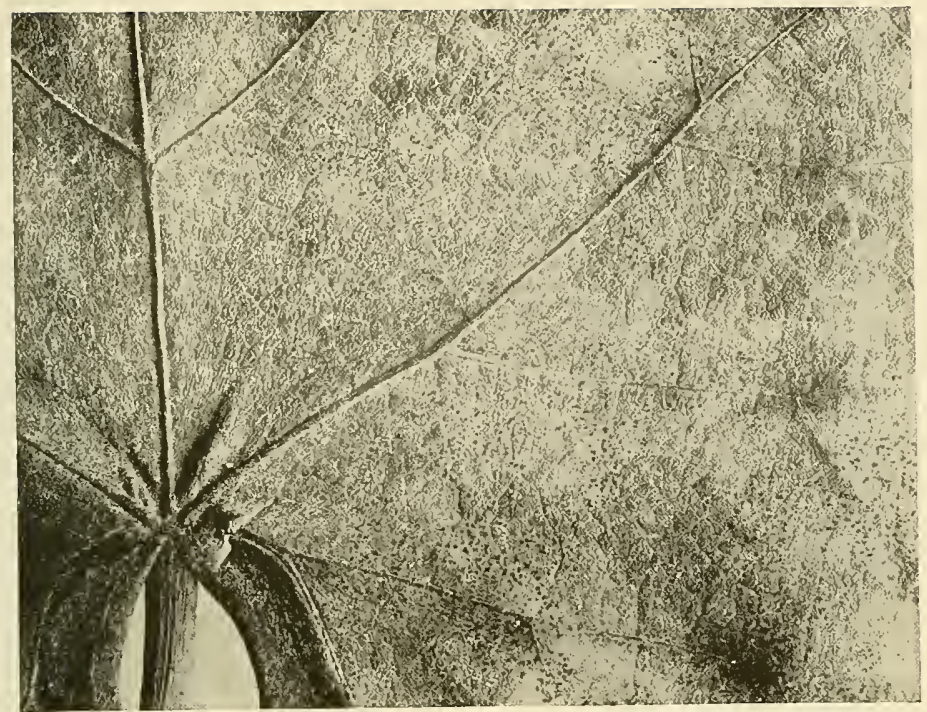

a. Showing white mycelium and minute black perithecia on leaf. $\times 2$.

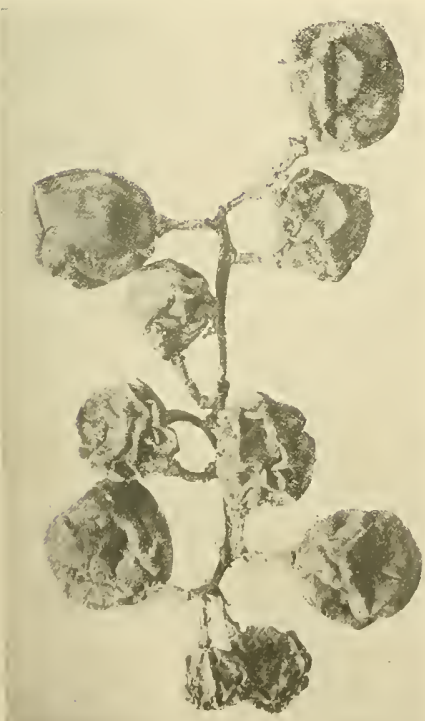

b. On the fruit.

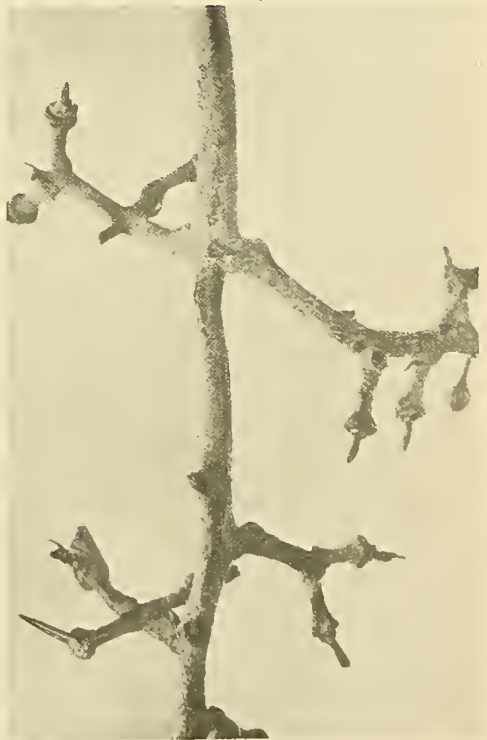

c. On the fruiting stem. 

Mulberry, p. 319.

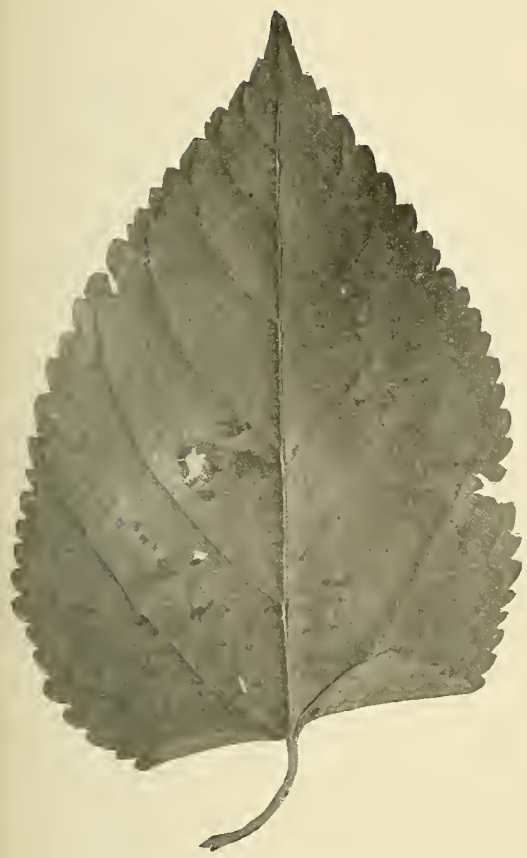

a. Bacterial disease on leaf,

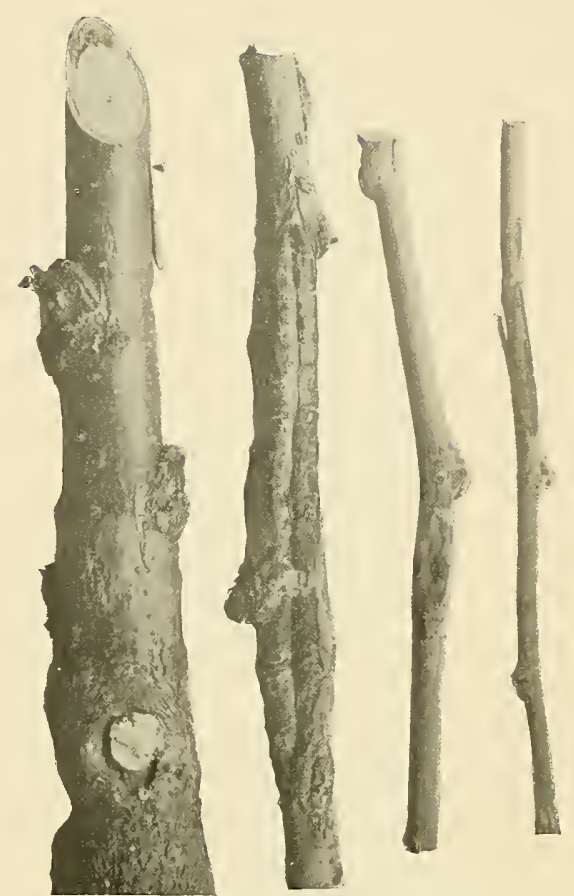

b. Bacterial disease on stems.

Musk Melon.

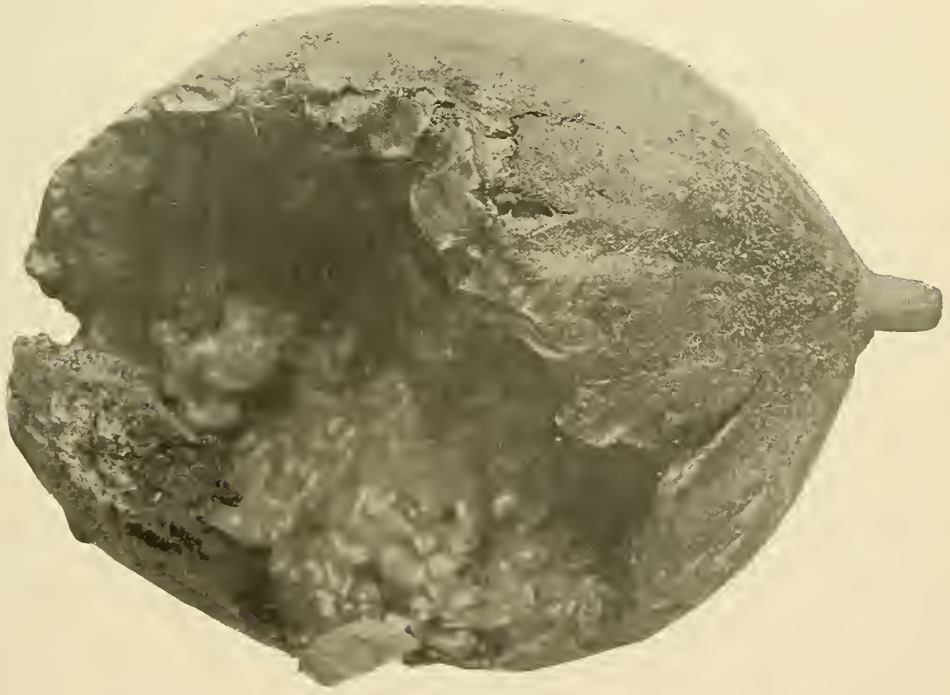

c. Bacterial Rot of fruit, p. 320.

BACTERIAL DISEASES OF MULBERRY AND MUSK MELON. 

Stem Rot of Onion, p. $32 \mathrm{I}$.

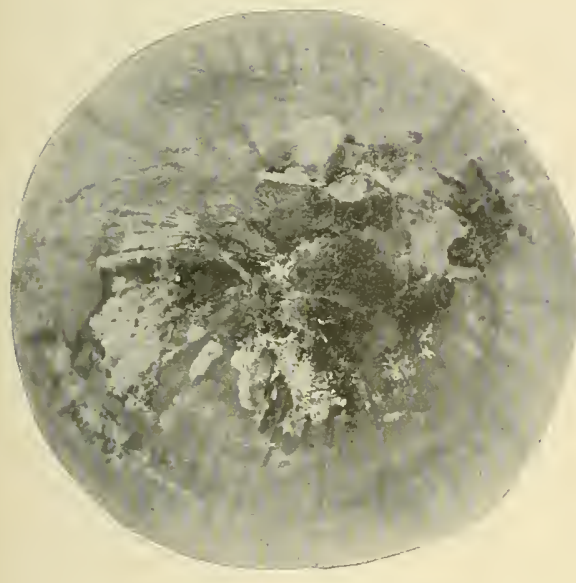

a. End view of rotting bulb.

Peach, p. 322 .
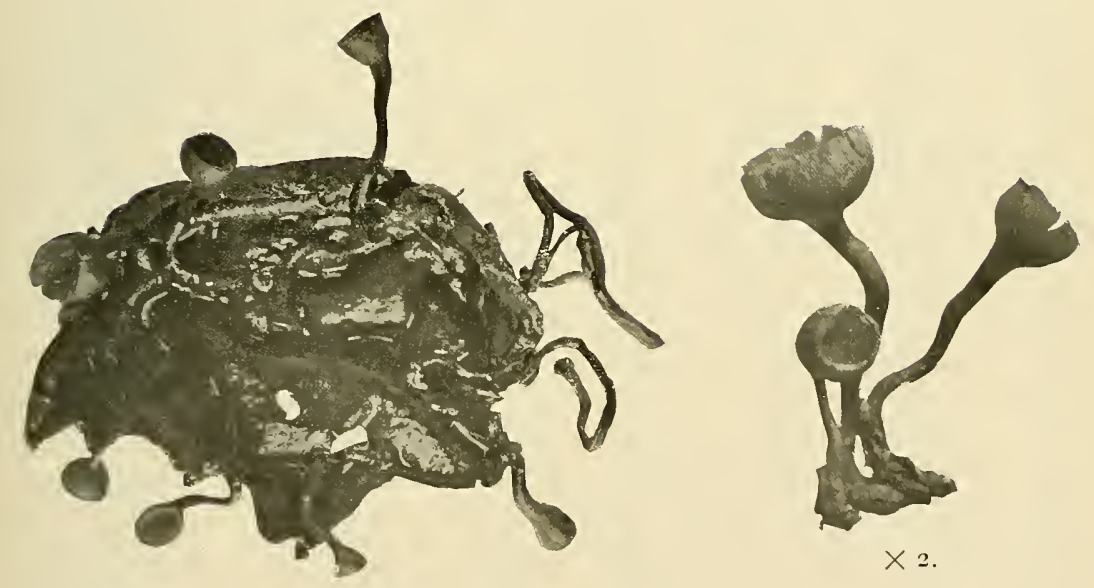

c. - d. Sclerotinia stage of Brown Rot appearing on mummied fruit.

FUNGI OF ONION, PEACH. 



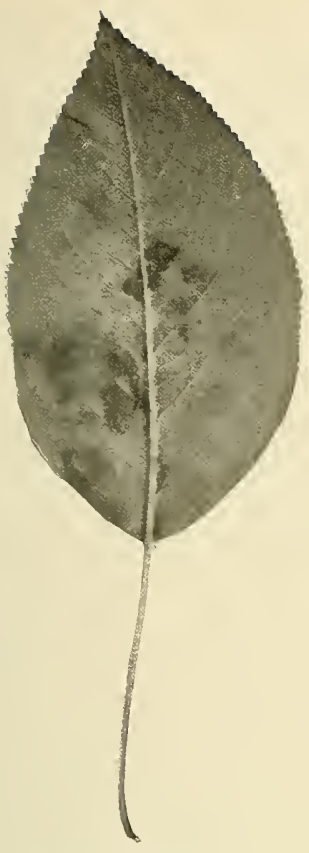

a. On the leaf.

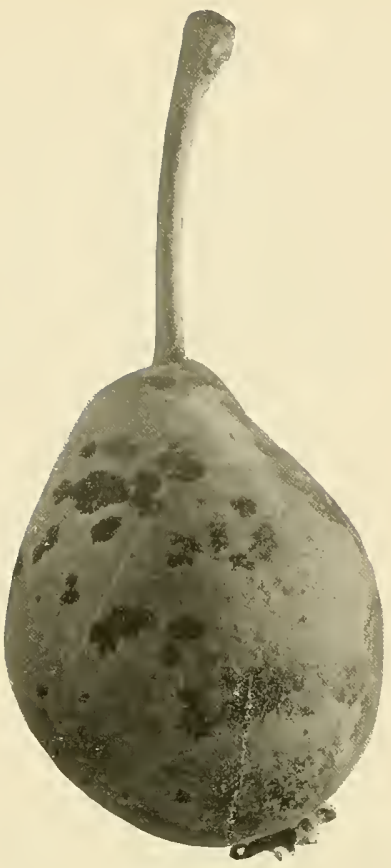

b. On the fruit.
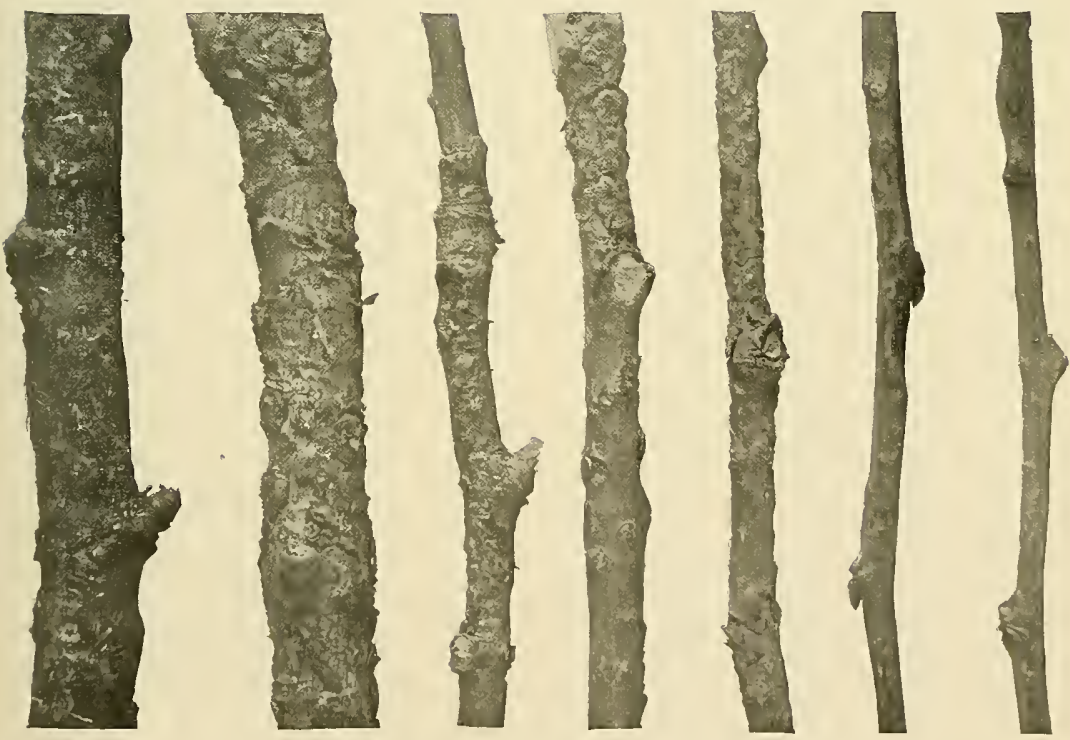

c. On the twigs producing cankered places in bark. 

PLATE XXVI.

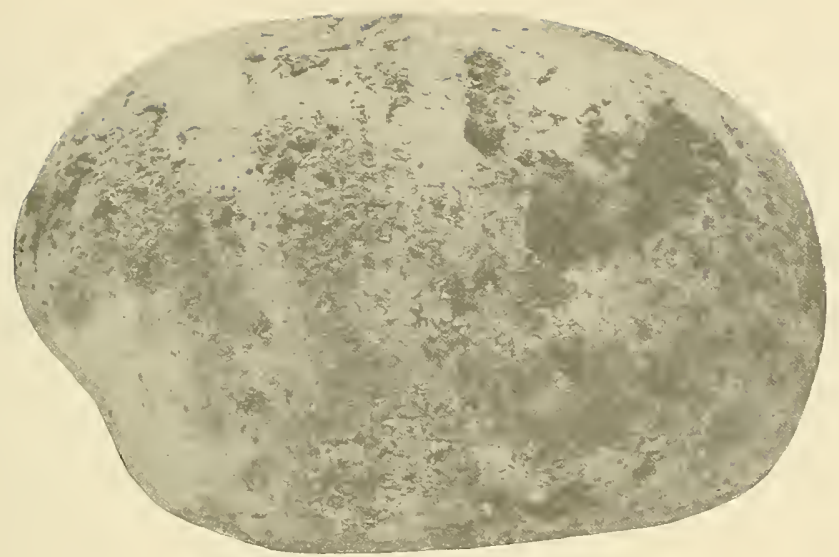

a. Rhizoctonia sclerotia on tuber.

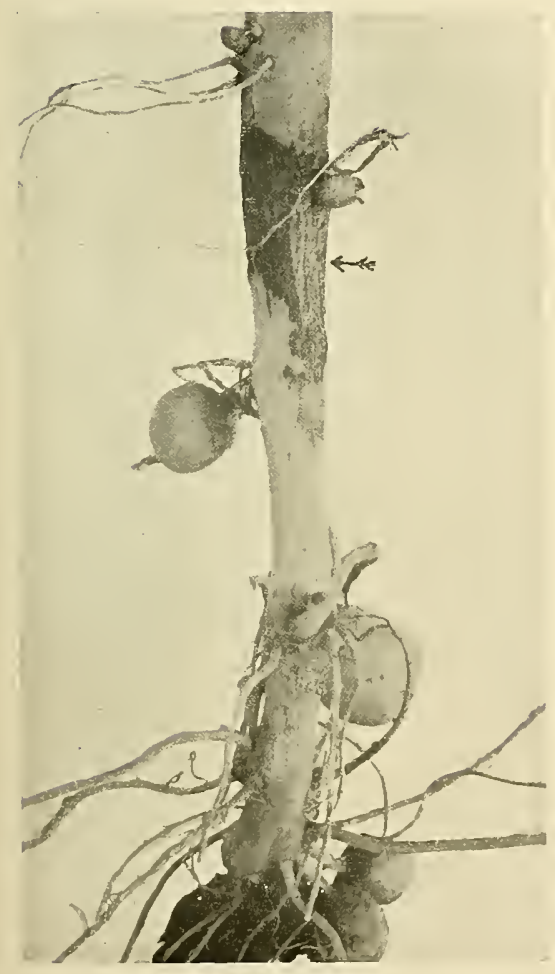

b. Cankered area on underground stem.

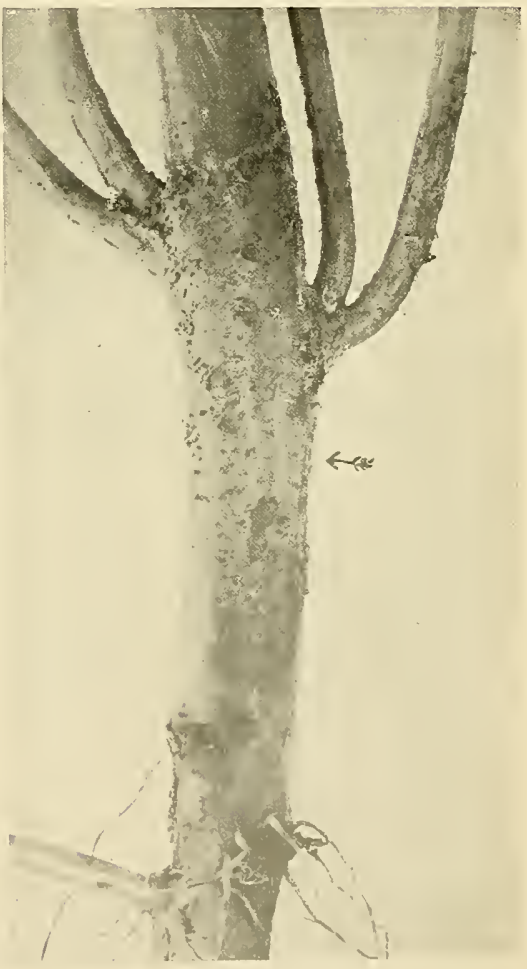

c. Corticium stage on stem just above ground. 

Bacterial disease of Potato, p. 324.

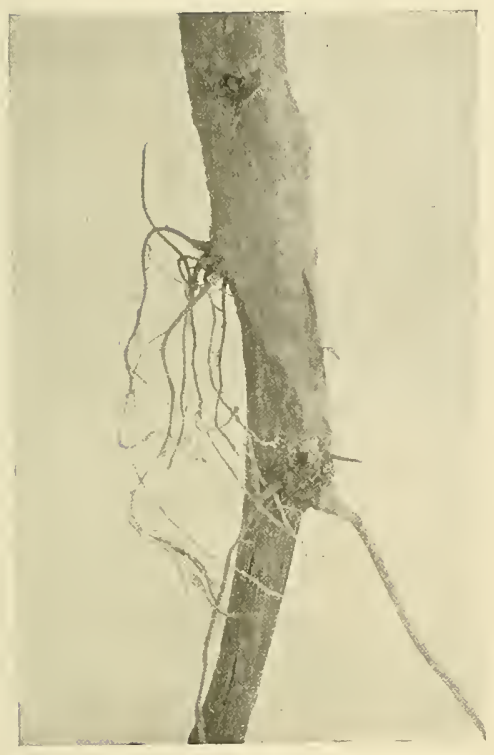

a. Diseased root.
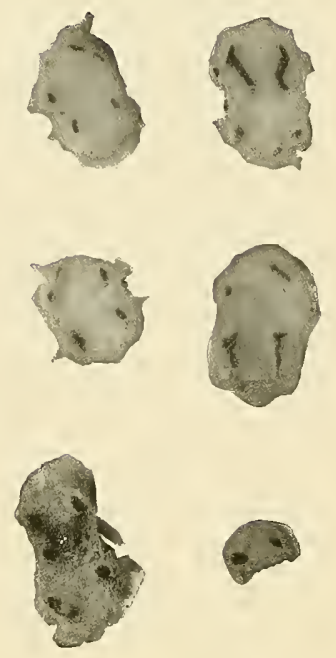

b. Cross section stem.

Privet.

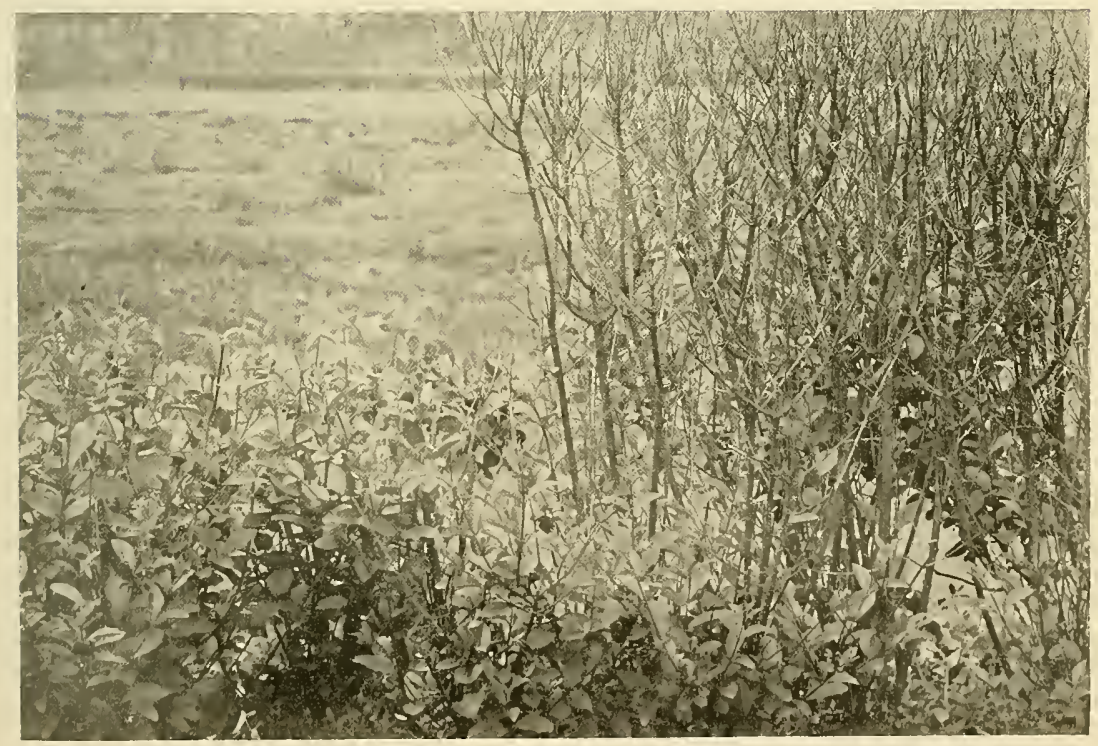

c. Winter injury of California privet hedge, p. 326 . 



\section{Radish.}

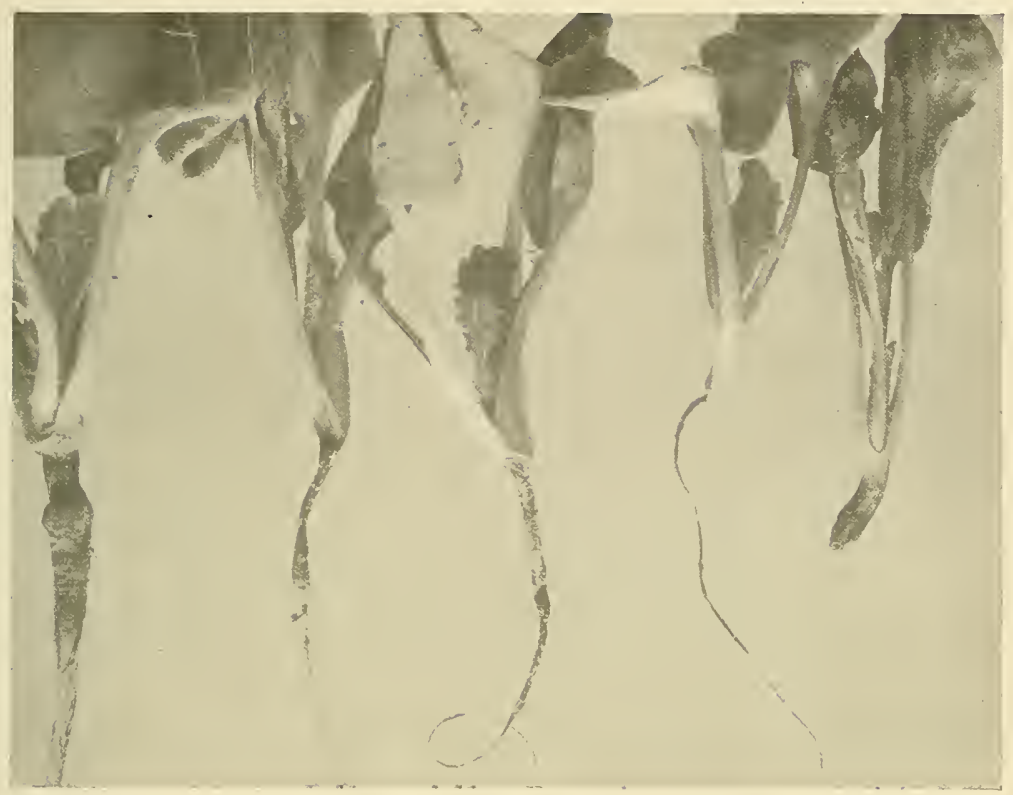

a. Rhizoctonia injury to roots, p. 326.

Sweet William.

Rhubarb.
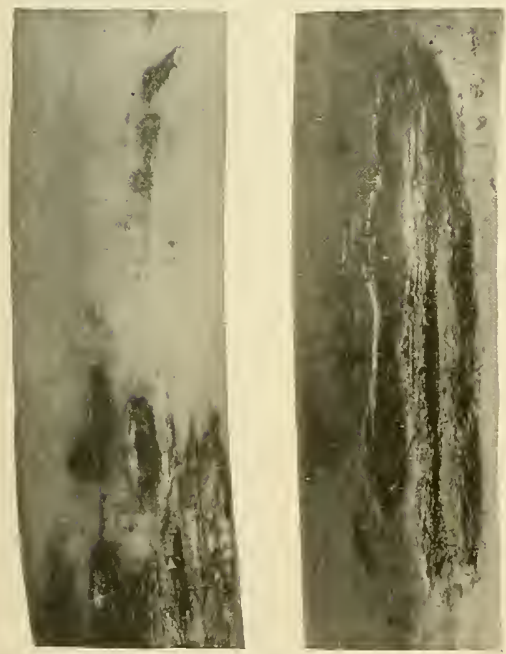

b. Rhizoctonia injury, p. 327.

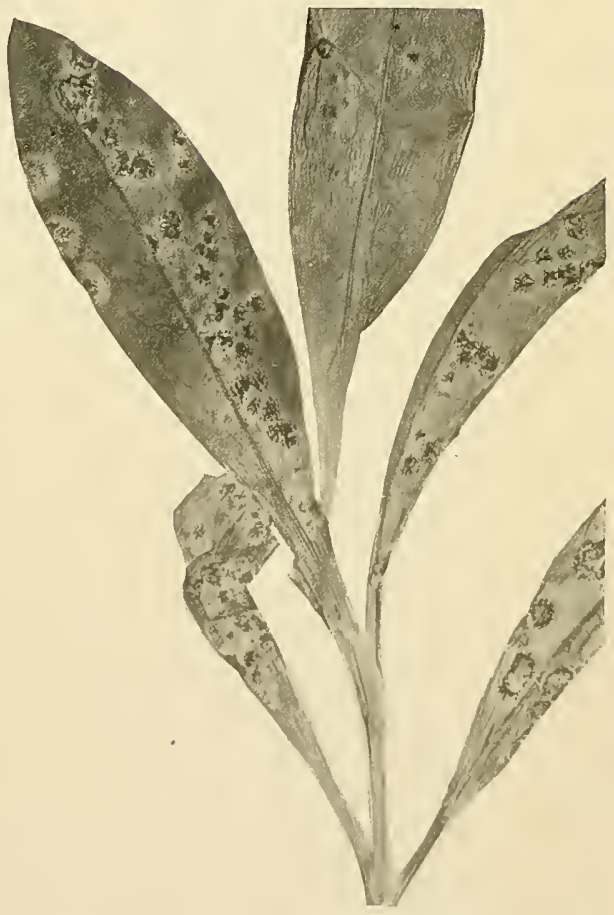

c. Rust, p. 325 . 

DOWNY MILDEW, OR BLIGHT, Peronoplasmopara Cubensis (B. \& C.) Clint., OF MUSK MELONS AND CUCUMBERS.

HISTORICAL AND SYSTEMATIC CONSIDERATION.

Early Record. The downy mildew, or blight, of cucumbers, musk melons, and other cucurbits was first described in 1868 by Berkeley of England from specimens collected by Wright on a cucurbitaceous plant in Cuba. He named it Peronospora Cubensis B. \& C. The description given was very meagre and the species was not regarded of special economic importance. Nothing more was heard of it until I889, when Halsted (13) noted in the Botanical Gazette that a serious Peronospora trouble had been found on greenhouse cucumbers in New Jersey. He did not specifically identify the fungus. The same year Farlow (IO), having seen Halsted's specimens, reported the fungus as Peronospora Cubensis B. C. and also stated that he had received specimens on cucumbers and another cucurbitaceous plant, collected the previous year in Japan, sent to him by Miyabe, who had recently examined the Berkeley and Curtis type specimens at Kew and found them to be the same. Late in this year Halsted (I4) reported that the fungus had been injurious on cucurbits grown outdoors in New Jersey, giving as hosts squash, pumpkin and cucumbers; and Galloway (II) reported it as a serious pest of cucumbers in Florida and Texas. Humphrey (28) reported the fungus injurious to cucumbers and squashes in Massachusetts in I890; and Thaxter (6I) found it the same year on cucumbers at South Manchester in this state.

Recent Record. Since first found by Halsted this fungus has been reported nearly every year by some one in the United States though not discovered elsewhere until recently. The fungus, however, has not been so common here in some years as in others, and seens to have periods of vigorous development for a year or two, then gradually disappearing from conspicuous view. Apparently in 1896 and I897, it was more serious than usual, especially on cucumbers, as it attracted especial investigation in these years from Stewart (53) of the New York and Selby (44) of the Ohio Experiment Station. Again, 
beginning about I90I, and reaching its climax in 1902, it was specially destructive in New England on musk melons and cucumbers. In 1903 the fungus was not especially prominent in this state, while in 1904 it was scarcely to be found.

In I899 Massee (36) stated that the fungus had recently been introduced in England, on Cucurbita pepo and Cucumis sativus, from Japan. This seems to have been its first appearance, or at least discovery, in any European country, though recently it has attracted considerable attention in Russia and the Mediterranean region. Rostowzew (40) gives an account of its injury (in 1902) to cucumbers in the province of Twer, Russia, and the next year, as reported by Linhart (35) from Hungary and by Hecke (24) from Austria, certain cucumber and melon fields of Austro-Hungary were seriously injured. Saccardo (42) and others also reported it injurious in 1903 to cucurbits in Italy.

Hennings (26) stated in 1902 that the fungus was collected in Brazil in 1900. Zimmermann (65) also in 1902 described the fungus as a new variety from Java, and a year later listed it from Dutch East Africa.

Hosts and Distribution. All of the hosts upon which this downy mildew has been found belong to the cucurbit family, and nearly all of the reports of its occurrence have been on the cultivated species. Selby has reported it in Ohio on Sicyos angulata and Echinocystis lobata, two wild species common in the United States, but he notes that it escaped to these from a cultivated field near by. Others have looked for the fungus on these hosts, but have not found it, so it seems probable that they are not original hosts in the United States. Apparently the fungus is not a native of this country, but introduced, probably, from the West Indies, first in the southeastern states. Cuba may have been its original home, or it may have had independent origin in several places. The following distribution is taken chiefly from the literature of the fungus, together with the hosts and name of the person reporting:

Cucurbitaceae: Cuba, type (Berkeley), Japan (Farlow); Citrullus vulgaris, water melon, Conn. (Halsted), N. J. (Halsted), Ohio (Selby), Hungary (Linhart); Cucumis Anguria, gherkin gourd, Fla. (Swingle), Tex. (Swingle); Cucumis Melo, musk melon, Conn. (Sturgis), Ill. (Clinton), Mass. 
(Stone), N. H. (Lamson), N. J. (Halsted), N. Y. (Stewart), Ohio (Selby), R. I. (Stene), Hungary (Linhart), Italy (Saccardo); Cucumis sativus, cucumber, Conn. (Thaxter), DC. (Galloway), Fla. (Galloway), Ill. (Burrill), Ky. (Garman), Mass. (Humphrey), Md. (Swingle), Mich. (Orton), N. H. (Lamson), N. Y. (Stewart), Ohio (Selby), Penn. (Orton), R. I. (Stene), S. Car. (Orton), Tex. (Galloway), West Virg. (Orton), Austria (Hecke), Brazil (Hennings), Dutch East Africa (Zimmermann), England (Massee), Hungary (Linhart), Japan (Farlow), Russia (Rostowzew) ; Cucumis sations var. Anglicus, English cucumber, Conn. (Clinton); Cucurbita sps., squash, Mass. (Humphrey), N. J. (Halsted), Ohio (Selby); Cucurbita moschata, winter crook-neck squash, N. Y. (Stewart); Cucurbita pepo, pumpkin, etc., N. J. (Halsted), Ohio (Selby), England (Massee), Java (Zimmermann); Echinocystis lobata, wild cucumber, Ohio (Selby); Sicyos angulatus, star cucumber, Ohio (Selby). Besides these hosts Selby of the Ohio Experiment Station in I899 planted in a disease garden a large number of cucurbits to determine if the fungus would develop on them. It spread from the usual hosts upon the following not reported above: Cucumis odoratissimus, Cucumis erinaceus, Cucurbita Melopepo, Cucurbita verrucosa(?), Lagenaria vulgaris, Coccinia Indica, Bryonopsis laciniosa erythrocarpa, Mukia scabrella, Momordica balsamia, Momordica Charantia, Melothria scabra, Trichosanthes colubrina.

Systematic Position. Berkeley's original description of this fungus is so vague that it is only upon the authority of Miyabe, who has examined the specimens, that we are sure of its identity with the specimens since collected. Berkeley placed it under the genus Peronospora, calling it Peronospora Cubensis B. \& C. Both Halsted and Tanaka (see Farlow IO) observed the germination of the spores, which was by zoospores. Humphrey also reported germination by zoospores, and as this type of germination is not characteristic of Peronospora, whose spores germinate through germ tubes, but of the genus Plasmopara, he renamed the fungus Plasmopara Cubensis (B. \& C.) Humph., but at the same time called attention to the fact that it possessed characters common to both genera. A number of botanists have since made a more or less thorough 
study of the fungus and have placed it under one or the other of these genera, sometimes indicating doubt as to its real position.

Waite, for instance, in the Journal of Mycology in I892, called attention to its resemblance to his new species, Peronospora celtidis and said: "The conidiophores of $P$. celtidis while of the type of Peronospora may be regarded as a step toward Plasmopara. . . . Mr. W. F. Swingle has pointed out to me that Peronospora cubensis B. \& C. resembles P. celtidis quite closely and is its nearest ally and that these two species form a group by themselves, differing considerably from either Peronospora or Plasmopara. Both have long very dark conidia, pointed at each end and germinate by zoospores, with conidiophores of the so-called dichotomous type and strongly hygroscopic. For the present the form on Celtis is thought to be best placed in the genus Peronospora." Swingle, in an article on American Peronosporaceae in the same number of the Journal, places these two species under Peronospora in a doubtful section. A step further than this was taken by Berlese (4) in I90I, when he created a new subgenus, Peronoplasmopara Berl., of the genus Plasmopara, especially for these two species.

Zimmerman $\left(6_{5}\right)$, in 1902 , described a new variety of the fungus from Java, collected on leaves of Cucurbita pepo, calling it Peronospora cubensis var. atra. This author labored under the impression that the spores of $P$. Cubensis were hyaline, as has been stated by some authors, while those of his specimens were a dark grey, and so he made the variety on this difference. He also stated that their germination in water was by germ tubes. Unless the germination is always through germ tubes there seems to be no reason for considering the Java specimens distinct from those reported elsewhere.

Recently Rostowzew (40), a Russian botanist, has studied the fungus more in detail than any of the preceding investigators and has decided, like many of them, that it does not agree exactly either with Peronospora or Plasmopara, but has intermediate characters. So he has created a new genus, Pseudoperonospora, for it. While this author contrasts and compares the type of this genus with Peronospora and Plasmopara, he makes the mistake of not giving a brief scientific 
description of his new genus, so that one is left somewhat in doubt as to just what its chief characters are. He does state, however, as have others, that its type species agrees with Peronospora in the character of the branching of the conidiophores and with Plasmopara in the conidia having an apical papilla and generally germinating by zoospores. Rostowzew also described the Russian form as a new variety, calling it Psendoperonospora Cubensis var. Tweriensis Rostow. He had American specimens with which to compare his and found the following supposed differences: Ist, The Russian variety formed a more luxuriant, felt-like, growth on the leaves; 2d, the conidiophores were usually 2 or 3 or even 3 to 7 at a stomate while the American specimens had I or 2 ; and $3 \mathrm{~d}$, the. conidia averaged slightly larger.

These points, if fairly constant, would without doubt entitle the Russian specimens to distinct varietal rank. Upon look: ing over American material, however, the writer finds that there is considerable variation, and it seems quite probable that Rostowzew's specimens from here did not show this. For instance, on the water melon there is usually no evident growth of the fungus; on the musk melon it often becomes evident especially at the juncture of diseased and healthy tissue; while on the cucumber, upon which host the Russian variety occurred, one often finds a very evident tinted growth on the under side of the leaves, especially when the weather conditions have been favorable for its development. Again, while the conidiophores are usually $\mathrm{I}$ or 2 at a stoma in American specimens, the writer has frequently found 3 or 4 in some specimens, and Stewart (53) of New York says, "the number of sporophores which proceed from a single stoma is small, usually one or two; but it is not uncommon to find as many as five and even larger numbers are occasionally seen." Finally, the writer has measured spores from the musk melon that averaged as large, or larger, than the average and the large measurements given by Rostowzew for his variety. It seems from these comparisons that the Russian form is not distinct, especially since the other European specimens have not been so considered.

Along with others the writer has had difficulty in placing this species generically, but after a careful consideration of 
the subject is in favor of a distinct genus for it. The only objection to this is that possibly a critical study of all of the species of Peronospora and Plasmopara, especially as to their germination, might show that these genera grade into each other through so many forms that an intermediate genus would only magnify the difficulties of generic distinctions. Berlese's subgenus, Peronoplasmopara, because of priority of publication and also because it was given definite descriptive characters, seems to merit precedence over Rostowzew's rather indefinite Pseudoperonospora. Elevating Peronoplasmopara to generic rank, the distinctive characters of these three genera, in the writer's opinion, are as follows:

Peronospora Cda. Conidiophores chiefly of the dichotomous or modified dichotomous type of branching; with branches spreading mainly at acute angles, the ultimate spore-bearing tips being separate and sub-acute. Conidia hyaline or tinted, small to large, epapillate and germinating by germ threads. Haustoria usually conspicuous, branched and filiform, more rarely abbreviated and simple.

Peronoplasmopara Berl. Conidiophores of the dichotomous or modified dichotomous type of branching; with branches spreading mainly at acute angles, the ultimate spore-bearing tips being separate and sub-obtuse. Conidia chiefly large, tinted (violet chiefly), with a conspicuous papilla of dehiscence and germination typically by zoospores. Haustoria small and usually simple. Types: Peronoplasmopara Cubensis (B. \& C.) Clint., Peronoplasmopara Celtidis (Waite) Clint.

Plasmopara Schröt. Conidiophores chiefly of the monopodial type of branching, with the successive shorter side branches (and their sub-branches) given off chiefly at right angles to the main branch, and with the ultimate, spore-bearing tips truncate and often somewhat clustered at the swollen ends. Conidia chiefly small, hyaline, papillate, and germinating by zoospores. Haustoria small, chiefly ovoid.

Specific Description. Since this species has been described rather meagerly and imperfectly, we give the following description, based on an examination of abundant material, and include references to synonymy and exsiccati: 
Peronoplasmopara Cubensis (B. \& C.) Clint. n. comb.

Peronospora Cubensis B. \& C., Journ. Linn. Soc. Bot. Io: 363. I868.

Plasmopara Cubensis Humph., Ann. Rept. Mass. Agr. Exp. Stat. 8: 212. I891.

Plasmopara [Peronoplasmopara] Cubensis Berl., Riv. Pat. Veg. 9: I23. I901.

Peronospora cubensis var. atra Zimm., Centr. Bak. Par. Infekt. 8: I48. I902.

Pseudoperonospora Cubensis Rostow., Flora 92: 422. 1903.

Pseudoperonospora Cubensis var. Tweriensis Rostow., Flora 92: 422. 1903.

Exsiccati: Peronospora Cubensis B. \& C., on Cucumis sativus, Séym. \& Earle Econ. Fungi 4I, Ell. \& Ev. N. A. F. 2426 a, on Cucurbita sp. (squash), Ell. \& Ev. N. A. F. 2426 b; Plasmopara Cubensis (B. \& C.) Humph., on Cucumis sativus, Syd. Phyc. et Prot. II9, Barth. Fungi Col. 1840, on Cucumis Melo, D. Sacc. Myc. Ital. 1276. ?[K. Pósch Fungi Par. Exs. Plant. Cult. Hungariae.]

At first forming yellowish, rather indefinite discoloration of the leaves, but often finally producing definite reddish brown (sometimes purplish beneath) dead areas of varying size scattered over the leaves. Outbreaks of fungus chiefly hypophyllous, often invisible or evident only at margin of the spots, but sometimes forming a conspicuous purplish growth. Conidiophores chiefly I or 2 , occasionally 3 or 4 , rarely more, from a stoma, I8o to $400 \mu$ in length by $5-9 \mu$ in width, often with a slightly swollen base, $2-5$ (chiefly $2-4$ ) dichotomously (sometimes imperfectly) branched from upper third of length, with ultimate spore-bearing tips tapering, slightly curved, blunt, and $5^{-20} \mu$ long by about $2 \mu$ wide. Conidia olive brown to grayish purple, chiefly ovoid to ellipsoidal, with evident papilla of dehiscence and sometimes with remains of pedicel of attachment, $2 \mathrm{I}-39 \mu$ by $\mathrm{I} 4-23 \mu$, though chiefly $23-30 \mu$ by $\mathrm{I} 6-20 \mu$. ?[Oospores spherical, yellowish, warty papillate, $30-43 \mu$, maturing only after leaves decay in the ground, according to Rostowzew.]

Hosts and Distr.: on various Cucurbitacex, especially on cultivated species, reported from United States, Cuba (type), Brazil, England, Russia, Austro-Hungary, Italy, Japan, Java, Dutch East Africa. 


\section{Life Histori.}

Iycclium. The mycelium consists of hyaline, somewhat irregular, branched threads, about $5.5-5.7 \mu$ in dianeter, that push their way between the cells of the leaf. These mycelial threads are found more abundantly on the lower side in the spongy parenchyna than in the palisade, or closely packed, cells of the upper leaf tissues. The cellulose walls are moderately thin and septa are rarely found. Protoplasmic contents at first fill the threads, but later they may become empty, especially in the old dead tissues. The threads reach the surface of the leares usually on the under side, pushing their way through the stomates or more rarely boring directly through the epidermis. Here they give rise to the conidiophores, apparently developing one to several at the same time, or subsequently, according to weather conditions. When the tissues have become severely injured or killed, the production of conidiophores gradually ceases and new ones are then formed, chiefly at the margins of the enlarging injured areas.

The mycelium penetrates the cells of the interior of the leaf only by short orate haustoria. These were first described and figured by Humphrey (28). It is rather difficult to make them out, since they are often obscured by the cell contents. Rostowzew found that they lacked the cellulose wall of the mycelium and that often they developed finger-like processes from their swollen tips. The object of the haustoria, of course, is to take food from the plant cells for the growth of the fungus.

Conidiophores. The conidiophores are the spore-bearing branches of the fungus, and from one to rarely five or six derelop from a single stoma. When produced abundantly they make an evident growth on the exterior of the leaf. They are simple for about the lower two-thirds of their length and dichotomously branched at the upper third. This branching is not alwars exactly dichotomous, for sometimes one branch is larger and tends to continue as the main stem. The branches separate usually at acute angles and may be similarly sub-divided sereral times, usually two to four times. The main stem of the conidiophere is 5.5 to $9.5 \mu$ wide, with the base often slightly swollen just above the stomate, and then it is sometimes eren I I $\mu$ wide here. The stem and branches very gradually narrow upward so that the ultimate, conidia-bearing tips are about $2 \mu$ 
or less in width. These tips or final branches vary from 5.5 to $I 4 \mu$ (rarely longer) in length and are usually slightly curved and taper somewhat to a bluntish apex. A single spore is borne on the end of each branch, which readily drops off when mature, especially if the conidiophore is placed in water. According to Rostowzew, the ultinate branches end in temporary sterigmatal tips that lack cellulose and dissolve in water, thus freeing the spores. The walls of the conidiophores certainly contain cellulose, as shown by color reaction with chloroiodide of zinc, and sometimes the extreme tips fail to color and often after the spores fall off are blunt. These points may indicate the fugacious sterigmata of Rostowzew, but if so these organs are not very completely differentiated. The conidiophores vary greatly in length, probably depending on weather conditions at time of their formation or possibly on the number produced from the same stoma. The extreme lengths observed were $140 \mu$ and $4 \mathrm{IO} \mu$ with the average lengths about half way between these. The branching of the short conidiophore often begins lower down than the upper third, while that of the longer form may begin above this point. When young the conidiophore is filled with a uniform protoplasmic content, but as the spores are formed this gradually disappears from the base upward and is all gone when spore production ceases. With this disappearance of the protoplasm a septum or so is rarely formed in the conidiophore.

Summer Spores, or conidiospores, or temporary sporangia, as they are variously called, are formed, as stated above, on the tips of the ultimate branches of the conidiophores. When small these are hyaline, but they very soon assume a greyish or olive purplish color. When looked at with a hand lens they may even appear purple black. Some authors have incorrectly described them as hyaline, and of course as seen under the high powers of the microscope they are much lighter in color than when seen with a hand lens, but even then they always appear strongly tinted. They vary in shape usually from ellipsoidal to ovate, but occasionally are even subspherical. Specimens examined by the writer from the musk melon averaged longer and proportionately narrower than those from the cucumber. The measurements varied from $2 I-39 \mu$ in length and $\mathrm{I} 4-23 \mu$ in width, while the average sizes were about $23-30 \mu$ 
by $16-20 \mu$. The spores have a uniform, rather thin wall, except at their apex, where there is an evident hyaline papilla of dehiscence, while at the base there is more or less evidence of the point of attachment. Except at these two points the cell wall gives the cellulose reaction when tested with chloroiodide of zinc.

Germination of Spores. The germination of the spores through zoospores has been mentioned by a number of writers, but no one has figured or carefully described this method. When placed in a drop of water in a Van Tiegham cell the spores sometimes started to germinate inside of two to four hours if they were in good condition. Many of the attempts to germinate the spores failed altogether, probably because in ordinary dry weather the spores very soon lose their power of germination. Generally they were successful where fresh spores, developing in a moist atmosphere, were used. In all cases the germination was by means of zoospores. Occasionally a faint division of the protoplasmic contents into areas (see Plate XXXI, 5) could be seen before the zoospores were discharged, but it was difficult to distinguish anything like separate zoospores even when apparently completely differentiated. The zoospores suddenly begin to escape from the spores through a pore formed by the dissolution of the papilla of dehiscence. Usually they were completely differentiated and escaped one at a time, swimming off immediately after their release; more rarely they escaped into a bunch just outside of the spore, from which they very soon isolated themselves and swam away. The pore by which they escape is too small to admit their unhindered passage, though they quickly push their way through, their plastic body admitting the necessary contraction for this. Plate XXXI, 6 shows the dumbbell shape assumed by a zoospore when half way through the opening. Rarely one of the zoospores fails entirely to escape and may finally germinate inside the spore, Plate XXXI, 7.

The zoospores very soon after escape lose the plasticity of the body wall and assume their permanent shape. This is somewhat turtle-like; that is, oval in dorsal view (that usually seen), but with side view more elongated, showing the dorsal aspect convex and the ventral often slightly concave. Two elongated cilia are attached to the ventral surface. These are 
too fine to be detected without staining, but one is carried forward and the other extends to the rear. The protoplasmic contents of the zoospores are rather uniform, but often with granules of a more highly refractive index and with a prominent vacuole toward the forward end. The zoospores swim forward with a swift, gliding motion, often at the same time revolving more slowly around their elongated axis. At first they are very active, rarely remaining at rest long enough for one to measure them accurately, but their length is about I 2 to $I 8 \mu$. After an hour or two, or perhaps sometimes even considerably longer, they become more sluggish in their movements and gradually come permanently to rest. The cilia disappear and the zoospore assumes a spherical shape, about IO-I $3 \mu$ in diameter (Plate XXXI, I4). Some zoospores, instead of rounding up entirely, assume an amoeboidal appearance, but with scarcely any perceptible movement, and eventually go to pieces without further development (Plate XXXI, I5). Usually most of the rounded, resting zoospores soon begin to develop germ tubes, into which pass their contents. This germ tube is the infection thread by which the fungus gains entrance to its host. In water it becomes a simple (rarely branched) regular or irregular thread, eventually several times the length of the resting zoospore from which it issues (Plate XXXI, I6). After attaining some length it gradually becomes empty of contents at its base.

None of the spores observed by the writer germinated directly through germ tubes, but always through zoospores. Their germination, however, was tried only in water. Possibly had some nutrient solution been used, the germination would have been by germ tubes, as the potato blight spores, which ordinarily in water germinate through zoospores, in nutrient solutions will produce germ threads instead. Zimmermann (65), however, describes and figures the germination of his var. atra with germ threads, and Rostowzew (40) with his variety Tweriensis states that the germination is either by germ threads or zoospores. The germ threads proceed from the spores, usually from some other point than the papilla of dehiscence. Both these authors note the papilla of dehiscence, and as this is characteristic of germination by zoospores this may be considered the typical method. 
Infection of Host. In moist summer weather the melon and cucumber leaves are often covered with small drops of water. During a cloudy day these may remain on them all day. This moisture offers a means for the germination of the spores produced on these leaves or carried there, and thus an infection of the tissues. The germ tubes of the resting zoospores, or of the spores when these germinate by germ threads, bore directly through the epidermis or push their way between the guard cells of the stomate into the interior of the leaf. (See Plate XXXI, I7-20.) Infection can take place through either the upper or lower surfaces of the leaves. Spores produced on the cucumber can infect leaves of the musk melon, as shown by an experiment by the writer, and no doubt the reverse is true. Once inside the leaf the infection thread develops the mycelium and from this soon arise the conidiophores to the exterior.

The extent of infection depends largely on weather conditions. If moist for some time after the fungus gains entrance to its host, this is favorable for the development of numerous conidiophores and spores and for the germination of the latter. During ordinary dry weather the conidiophores are not produced very abundantly and the spores soon lose their power to germinate. The effect of moisture on the production of conidiophores and spores was well illustrated in the infection experiments carried on in the laboratory. Usually two or three days after placing the spores in water on the leaves small discolored spots could be seen at these places, showing successful infection. If the plants were then left exposed to the ordinary dry air of the room, very few or no conidiophores were developed, though the diseased spot often slowly developed in the leaf. But if the leaves were sprayed with water and the moist plants covered with a bell jar to preserve a moist atmosphere, there resulted an evident increase of conidiophores, often by the next day. The following are short descriptions of two of these indoor infection experiments.

Experiment I $769-70$. September 20 placed spores from cucumber in drop of water on upper side (I769) of each cotyledon of five seedling cucumbers and on lower side (I770) of four seedlings; seedlings in crocks under bell jars. September 22, two cotyledons of I770 plainly, and one faintly showing small sunken and discolored spots; bell jars removed. 
September 23, eight of the ten cotyledons of 1769 and five of the eight of I 770 showing discolored spots; replaced bell jar over those of I770 after spraying the seedlings with water. September 29, conidiophores and conidia on one cotyledon of I770 but none on I769. This experiment was in the laboratory room, which was not adapted for the plants.

Experiment $177 \mathrm{I}-72$. September 26, used cucumber seedlings having two cotyledons and one leaf each; on the upper surface (I77I) of one of the cotyledons and the leaf of each of seven seedlings placed spores from cucumbers in drop of water and on the upper surface (I772) of both cotyledons and the leaf of seven other seedlings placed small fragment of cucumber leaf containing spores; sprayed plants with water and left in greenhouse, as day was cloudy and moisture from leaves did not evaporate. September 29, only one or two leaves of I 772 showed slight discoloration. October I, six cotyledons and two leaves of I77I showed slight yellowish discoloration where spores were placed; I772 showed several cotyledons with discolorations. October I5, I77 I showed six of the seven cotyledons and five of the seven leaves infected, infected areas dead, but no luxuriant growth of conidiophores, as atmosphere of greenhouse was dry; I772 showed every cotyledon and five of the seven leaves infected; the cotyledons were almost dead at this time and the dead areas on the leaves were more prominent than in I77I. Conidia and conidiophores, however, were not abundant, so sprayed I772 with water and placed under bell jar over night and the next morning there was an abundance of new conidiophores developed at the margin of the dead areas.

Winter Spores. The spores that have been described so far are thin-walled, temporary bodies that cannot survive over winter and are never produced saprophytically. The hosts, too, are annuals, and for this reason the mycelium cannot be perpetuated from year to year in perennial parts, as is the mycelium of the potato mildew (blight) in the tubers. Both these mildews, however, belong to the family Peronosporaceae and it is characteristic of this family to produce, besides the summer spores, large, thick-walled resting spores, or winter spores, that are formed within the infected tissues and often liberated only on their decay. Through the germination of those spores the next season their hosts are infected anew. These winter, or 
oospores, have been looked for on the melon, cucumber, etc., by a number of botanists, but have never been reported, except by Rostowzew (40). He claims to have found half-matured oospores in cucumber leaves infected with this mildew, and he gives a figure and description of them. He states that apparently they do not mature until the leaves have rotted in the ground, and so are largely saprophytic in their development. There is some question if what this writer saw really had any connection with this fungus, as often other fungi develop quite early in the dead spots of the leaves killed by the mildew. It is not impossible that the oospores develop only as a saprophyte rather than as a parasite, as is usual with this stage. There is need, however, of more evidence to show the nature and identity of the immature spores Rostowzew describes before they can be accepted or rejected as being connected with this mildew. The writer has made a special effort to discover oospores of the fungus on its recognized hosts in this state. All parts of the hosts, under all conditions of infection and decay and at different times of the year, have been examined, but nothing was found that suggested that the fungus develops such a stage either as a parasite or a saprophyte. So far there has been obtained no evidence that the fungus, in the United States, carries itself over the winter in this way. That such a stage may develop under certain conditions* or in certain regions or on certain hosts is entirely possible. Rostowzew seems to have had some further evidence of this stage, or some other stage, developing in old leaves in the ground, since he obtained earth from the infected region in Russia and using this on beds planted with cucumbers, finally developed the disease, while a check bed having none of this infected soil on it did not.

Before seeing the experiments of Rostowzew, the writer thought that possibly the fungus might be carried in the soil containing the remains of diseased plants, and conducted a couple of experiments to determine this. In the first experiments, in the fall of 1902 , dead leaves from infected vines were mixed with new earth in crocks and planted with cucumbers; also old soil in which diseased plants had grown was placed in

* It is barely possible that the oospores are produced only on the union of distinct or sexual mycelial strains that do not commonly occur together. 
crocks and planted with cucumbers. These were kept in the greenhouse and the plants did not grow very luxuriantly, but though they lived two months no signs of the mildew appeared. In the second case musk melons were planted in a greenhouse bed in the winter, and after they were up, soil gathered the middle of February from ground that had badly diseased melons in it the fall before was placed around the plants, which were also sprayed with water drained through this soil. Other plants had the disintegrated remains of infected leaves placed on the soil and were sprayed with water drained through the leaves. No mildew showed on these plants two weeks after this treatment, but further observation was prevented by sickness. These experiments, while not necessarily contradicting Rostowzew's results, unfortunately do not confirm them.

If, then, the fungus in Connecticut is not carried over the winter by summer spores or mycelium, and if, as it appears, the oospores also are not developed here, how does it manage to be perpetuated? Two possible ways have been suggested, both of which may be of service. First, it is quite possible that the fungus in some places is carried over winter by cucumbers, etc., raised in greenhouses and later in hot-beds, finally spreading to the outdoor plants in the summer. A good many early reports of this fungus were of its occurrence upon greenhouse cucumbers, so that its occurrence there is not uncommon. The writer has found it on the English and market cucumbers in greenhouses late in the fall, and one year found the first observed infection of the summer on melons started originally in a greenhouse where cucumbers were usually grown in the winter. Second, the fungus may carry over winter in the south on hosts that grow outdoors the year around. Hume (27) states that this is true in Florida. The fungus in this case would have to advance northward with the season, and its appearance, no doubt, would be greatly influenced by the character of the weather each year. This would account for the variableness with which it appears and disappears. Selby, of Ohio, who has been especially interested in the study of this trouble, strongly supports this theory.

Effect of Season. As stated before, the downy mildew develops most vigorously when there is a very moist and cold season, especially during July and August. The cold is per- 
haps not so favorable for the development of the fungus, but when the seasons are unusually moist they are apt to be cool as a consequence. Periods of foggy or damp, cloudy weather, with perhaps not much rain, offer better opportunities for the development of the disease than violent rain storms followed by clear weather. Aside from any injury from the fungus, a cold, wet season, in itself, is just the opposite of what musk melons need in this state for their best development. For instance, the failure of musk melons in 1903 was as much due to the unfavorable season for growth as it was to injury by fungi. The cold, damp weather retarded the growth of the vines so that they were very late in coming into bearing, and this, coupled with fungous attacks, made the crop a failure. The development of the cucumber is not influenced so much as the musk melon by weather conditions.

Injury to Hosts. The mildew is one of the most injurious pests of the cucurbits. Ordinarily the cucumber and musk melon have suffered most, though the squash and watermelon have been reported as seriously injured. Halsted ( $\mathrm{x} 7$ ) reported that Sturgis found watermelons in this state severely injured, but Sturgis made no statement of such injury in the Reports of the Station. The writer has found the fungus only a few times on this host, and then doing no serious injury. These specimens showed a few dead areas on the leaves, but no external evidence of the fungus, whose presence was established only by microscopic examination. On the cucumber the fungus developed much more aggressively. There was a greenish yellow spotting of the leaves on their upper surface, while beneath usually could be seen a growth of the conidiophores, whose purple black spores became quite conspicuous under a hand lens. Later the leaves often became more conspicuously spotted or withered away, new growth ceased to take place and the plants finally died. With the musk melon the trouble seemed to be most severe, as the yellowish spots soon changed into dead reddish brown areas, with the resultant death of the intervening tissues and withering of the leaves. With weather favorable for the spread of the disease, the vines very quickly succumbed. The growth of the fungus on the under side of the leaves of the musk melon was not usually so evident as on the cucumber and became most pronounced at the border of the 
dead areas. Even when the vines were not killed outright they rarely matured their fruit, or if some of the melons ripened they always lacked the requisite flavor. (See Plates XXIX, XXX.)

Financial Loss. It is difficult to estimate the financial loss caused by any disease. In this state the injury, due chiefly to this fungus, and partially to other fungi and unfavorable weather for growth, was so great during the years I90I, I902, I903 that the area devoted to musk melons was gradually cut down until it reached almost a zero limit in 1904, which year proving a fairly favorable season, no doubt the acreage will gradually go back to the maximum. In I9OI, and especially in I902, the fungus practically destroyed the melon fields in a few days.

The loss from injury to cucumbers in this state, while possibly equalling that of the melons, was not so evident. These plants often lag along under the disease and give a partial crop, especially the early plantings, and the flavor of the fruit is not an important question. Late cucumbers grown for pickles, however, suffer worse than the early, since the disease is often at its height when these are just starting, and the vines are usually killed before any fruit is obtained. Raising pickling cucumbers for the factories is not an important industry in this state, and so the loss here has been very much less than on Long Island and in Ohio.

Confusion with other Diseases. There are a number of other diseases of the cucurbits that have been in part responsible for the injury of these hosts. It is not always possible for one not well acquainted with these to distinguish them from the downy mildew. With this the most distinguishing macroscopic character is the growth of the fungus on the under surface of the spots, especially at the margins, the purplish black spores on the conidiophores becoming quite evident when a hand lens is used. The distinguishing characters of the other troubles as determined by the naked eye or a hand lens are as follows:

Scab, Cladosporium cucumerinum, occurs on the leaves, stems and fruit, producing sunken areas on the latter two, and the dead spots become covered with a more or less evident olive, moldy fungous growth.

Leaf Spot, Altemaria Brassicae var. nigrescens, usually forms roundish, dead, reddish brown spots on the leaves; these spots often show faint concentric rings of development, but no evi- 
dent fungous growth. This sometimes becomes a serious trouble, considerably resembling the downy mildew in its ultimate effect and appearance.

Anthracnose, Colletotrichum Lagenarium, is a common and widespread trouble present more or less each season. It is most conspicuous on the ripening fruit, but this is often attacked while quite green, showing sunken, rotten areas that are usually covered with pinkish, often sticky, exudations of spores. The minute spore exudations on the leaves are easily washed off by rain, and the reddish brown spots are very similar to those of the leaf spot, but angular and often more extended.

Bacterial Wilt, Bacillus tracheiphilus Sm., often wilts down the whole vine without any spotting of the leaves, which merely dry up on their petioles. Sometimes, however, there appear distinct, often semi-pellucid, areas in the leaves. In the former case the bacteria merely clog the water ducts and cut off the supply of water from the leaves, which then wither and die, while in the latter case the bacteria also cause disease of the leaf tissues. A soft bacterial rot of the fruit, apparently, is sometimes connected with this trouble.

\section{Prevention.}

Cucumber. So destructive has the downy mildew proved to cucumbers grown in the eastern United States that a number of experiment stations have made experiments to determine if it could be controlled. Practically all of the experimental work has been done by spraying with Bordeaux mixture, the chief points of interest being to determine if the disease could be controlled, when and how often it was necessary to spray, and if spraying could be done on a paying basis.

Halsted (20) of New Jersey was the first to report spraying experiments against this trouble, conducted in 1895 . He wrote in part as follows: "Spraying with Bordeaux gave very favorable results in the cucumber belts so treated. Two fungi peculiar to the cucumber, namely, the mildew (Plasmopara Cubensis B. \& C.) and anthracnose (Colletotrichum Lagenarium Pass.), were sufficiently abundant to do serious injury. . . By August 20 the combined attack of fungi and insects resulted in the destruction of most of the vines in all of the belts 
except in the two sprayed with Bordeaux. . . . As a result the Bordeaux vines were green and vigorous for over a month after those in the adjoining belts were dead. The yield of fruits was considerably increased and the percentage of fruitrot greatly diminished."

The next year Stewart (53) of New York carried on experiments on Long Island to prevent this trouble on late or pickling cucumbers, which were being severely injured in that region. He says in his report of these experiments: "The downy mildew first appeared on the unsprayed plants August 7, and by August 2I it had injured the foliage to such an extent that scarcely any cucumbers were produced after this date. The thirty-two rows of plants which had been sprayed were in perfect health and vigor on August 2I, and after this date produced two hundred and sixty dollars worth of cucumbers, which represents approximately the benefit resulting from spraying." In 1897 and in I 898 Stewart and Sirrine carried on other successful spraying experiments, both with early and late cucumbers. These experiments were conducted on a large scale and gave satisfactory financial results.

Selby (44) of Ohio, in 1897 , also conducted successful spraying experiments on late or pickling cucumbers. He makes the following statement: "For Wayne County, Ohio, this fungus disease has caused in 1897 a loss of about $662 / 3$ per cent. of the crop. Computed at an average of about 2 Io bushels per acre, and one-third large pickles, this loss at factory prices reaches almost $\$ 45,000$ for the single season in Wayne County. . . . These two diseases (mildew and anthracnose) may be very largely, if not entirely, suppressed by spraying about seven times with Bordeaux mixture, making the first application as the plants begin to vine and keeping the leaves covered with the fungicide thereafter, until about September ro. The cost for these sprayings need not exceed \$IO per acre, and may be reduced to $\$ 7.50 . "$

Since these earlier and most extensive experiments several other investigators have reported more or less successful experiments. With those conducted by the writer, chiefly against the mildew on the musk melon, one row of cucumbers was also sprayed, and the results obtained in this case were sufficient to show that ordinarily the mildew, anthracnose, leaf spot and scab 
could be controlled on this host by spraying a sufficient number of times with Bordeaux, and that when these troubles were bad such treatment was a paying venture. The bacterial wilt, however, seemed to be as bad on the sprayed as on the unsprayed vines.

The consensus of opinion, then, seems to be favorable for spraying cucumbers, especially late cucumbers raised for pickling, when suffering from mildew, anthracnose, etc. Of course, in the years when these fungous troubles are not injurious spraying would not pay for itself. Bordeaux mixture (four pounds copper sulphate, four pounds lime and forty to forty-five gallons water) is the best fungicide for this purpose. The spraying should begin about July 5 to I 5 , according to the season, but the first application should always precede rather than follow the first appearance of the disease. From five to seven sprayings are necessary to keep the foliage well covered with the fungicide until the first part of September. Where an acre or less of cucumbers are grown the small barrel pump mounted on two wheels and dragged by hand is a very convenient outfit. The vines can be trained about every fifty feet so that a path of sufficient width for the cart can be kept open. From this the vines on each side can be sprayed by using a twenty-foot hose, one man pumping and pulling the cart and another spraying the vines. Where more than an acre of cucumbers are grown it is advisable to leave roadways (perhaps planted with some early maturing crop), and from these the vines can be sprayed from a barrel pump carried in a light wagon. Before each spraying the ripe cucumbers should be picked, otherwise no attention need be paid about the spray getting on the fruit.

Musk melons: experiments elsewhere. The spraying experiments against this trouble on the musk melon are not nearly so favorable as those on the cucumber. In fact, when the mildew is severe it is doubtful if any good results, and even taken year in and year out very little will be gained if the failures are counted in. This does not mean that good does not result sometimes from spraying, as regards moderate attacks and especially with anthracnose, leaf spot or scab, which are more easily controlled, but in general the results do not warrant the extra cost and trouble of spraying. 
Selby (46) of Ohio was one of the first to report spraying experiments, made in 1898 , against the mildew on musk melons. His experiments were not so extensive with the musk melon as with the cucumber, and while favorable results were reported in one case, he states: "On the whole, we cannot conclude that the use of Bordeaux mixture for the fungus parasites of the musk melon has proven a decided success."

Lamson (33) reports that spraying experiments in I9or made on garden musk melons after the mildew appeared gave little, if any, good results, while in I9O2 (34) treatments started earlier and repeated five times kept the musk melons alive two or three weeks later than those not sprayed.

Stone and Smith, in the I 5 th Ann. Rept. of Mass., write as follows: "The subject of spraying as a preventive for this trouble has received considerable attention from this division for several years. During the past season [1902] experiments were made in coöperation with a local grower along the lines which previous experience had suggested. The details of this work will be reserved for a bulletin; but it may be said here that, even where plants were thoroughly sprayed with Bordeaux mixture, commencing early in July when the first leaves developed, no effect could be seen upon the development of the mildew, sprayed and unsprayed plots and fields were alike a complete failure."

Bennett (I) of Storrs Station, this state, reports spraying experiments in I903, as follows: "Three plots of musk melons were planted, two of which were sprayed, the third being left unsprayed. Owing to the cold season none of the melons matured fruits. The result of the spraying was practically the same with the melons as with the cucumbers. Traces of blight could be seen on the sprayed foliage, but they were not sufficiently abundant to do any harm. The unsprayed plants succumbed to the disease even before the cucumbers did."

Musk melons: experiments in Connecticut. During the three seasons 1902, I903, 1904, the writer conducted a number of experiments to determine how efficient and practical spraying was in preventing the downy mildew and other fungous troubles of the musk melon. Each year presented weather conditions somewhat different, varying from exceedingly favorable to unfavorable for the development of the mildew. From the 
results of these experiments, coupled with the experience of others, we have come to the conclusion that spraying musk melons with Bordeaux as a yearly practice will give no better average financial results than where no spraying is practiced. There are probably seasons when spraying would pay, if these could be foretold, but again there are seasons when it will be money thrown away. The results of these experiments are as follows :

In 1902 the mildew, which evidently had been very injurious to musk melons the year before, was first found in New Haven in a private garden about the middle of July. From then on to the first of August it appeared on practically all of the cucumbers and musk melons raised in this vicinity. With the musk melons the injury was sudden and severe, so that all of the vines were dead before any fruit ripened thoroughly. This was a cold, wet year, especially in July, which was unusually cold and foggy:

I. July ig the writer examined three small patches of musk melons in the garden of Mr. Sperry, New Haven, and found the first outbreak of the mildew observed this year. The plants of the oldest patch had been started in the greenhouses, to mature them earlier, and these showed the disease rather badly, while the two younger patches were not yet visibly infected. Upon the advice of the writer, the gardener sprayed these younger vines a few days later. August 2 visited the garden again and found this spraying had not prevented the appearance of the disease on these melons, which were now in about the condition of the older melons when first seen. Numerous rains, however, had washed off all the spray. The vines soon died, with no melons matured.

2. M. W. Frisbie \& Son, of Southington, on July 28 , sprayed part of their commercial field at the writer's suggestion. At this time no mildew was seen in the field, though some bacterial wilt was present. When examined again, August 8, a few leaves showed the presence of the mildew. It was intended by the writer that other sprayings should be given, but wet weather prevented at the proper time, and then the owners were afraid the spray might injure the appearance of the fruit. No good resulted from this single treatment and the crop was a failure.

3. August 4 the writer sprayed a row of melons in each of two fields on the farm of Mr. Nesbit in Hamden. At this time 
the mildew was just beginning to appear scattered through the fields, though a week previous the anthracnose and bacterial wilt had been noticed in spots. August 9 examined the field and found the mildew spreading rapidly, with little difference between sprayed and unsprayed plants. August I 3 one of these fields was pulled up, as both sprayed and unsprayed plants were beyond recovery. Sprayed the second field again on this date, but expected little or no good to result, as plants were severely injured. This field also was soon pulled up, as no melons were expected from either sprayed or unsprayed plants.

4. August 5, a little mildew was first seen on a few melons grown on the Experiment Station grounds, and on August 7 a part of these were very thoroughly sprayed with Bordeaux mixture. A few vines were sprayed above and then turned over and sprayed on their under surface. On August 20 the vines were sprayed thoroughly again. The mildew carried off the unsprayed vines finally. Those thoroughly sprayed on both surfaces did not develop the mildew much further, but they failed to make sufficient new growth to mature their fruit. Plate XXX, b, shows the condition of sprayed and unsprayed vines on August 30 .

5. August 23, sprayed the greater part of a small patch of musk melons in the garden of Mr. Hartley at Centreville. The blight had rather severely injured these, but the spraying was made to see if its advance could be checked and the melons recover by new growth. September 2, examined the patch again, but as no beneficial results of the spraying could be seen no further treatments were given. No melons matured.

It will be noticed that most of these experiments were started after the appearance of the mildew on the vines. This was because the writer did not take up his work at the Station until July and so did not know what to expect from this trouble. It was thought desirable, however, to make these tardy treatments to see if the disease could be checked and a partial crop obtained. The experiments show that this certainly cannot be done when the disease is at all serious and the season unfavorable for the growth of the vines. However, it is quite certain that very few or no melons would have been obtained even had the spraying been started early and applied thoroughly through the season, as the following reports from Connecticut growers for this year show: 
6. Mr. J. C. Eddy of Simsbury sprayed melons five times, twice in the greenhouse before transplanting. These vines were somewhat better than those not sprayed, but still "blighted" and producęd no marketable fruit.

7. Mr. J. S. Eddy of Unionville thoroughly sprayed his melons, but they did not amount to anything. When examined by the writer on August 26 no mildew was found, but there was a small amount of leaf spot. The cold, damp season, apparently, was chiefly responsible for their feeble growth, which the owner described as "hide bound." The crop was a failure.

8. Mr. C. B. Meeker of Westport sprayed his melons six or seven times, beginning as soon as the vines started to run. $\mathrm{He}$ got no results from his spraying.

9. Mr. E. M. Ives of Meriden sprayed a few melons in his garden. He sprayed both sides of the leaves, turning the vines over to reach the under surface. He reports a few melons for his trouble.

In 1903 the growing season was also wet and somewhat cool, but not so bad as the previous one. The mildew was very much later in its appearance, being first found in the vicinity of New Haven September I4. On the whole it did no more damage to musk melons than did anthracnose, leaf spot, scab or wilt, all of which were found during the season, sometimes several occurring together in the same field. Taken altogether, these various fungus pests perhaps did not do as much injury to the melons as the cold, wet growing season did in preventing favorable growth of the vines. Little or no fruit was gathered from any of the fields and gardens.

Io. A spraying experiment this year was made at the Experiment Station grounds on musk melons especially planted for this purpose and carefully watched during the whole season. A row each of Early Gem, Jenny Lind and Hackensack (also one of cucumbers) was planted and divided into five equal plats. These, except the fifth, or check plat, were all sprayed five times, as follows: July I4, July 28, August 8, August 26, September Io. The season was late, so that the first spraying was made on the plants when quite small and with no sign of any fungous disease on them. Bordeaux mixture was used on all four plats for the first three treatments, after which plat I received two treatments with resin Bordeaux, plat 2 two treat- 
ments with soda Bordeaux, plat 3 two treatments with potassium sulphide, and plat 4 two treatments with fresno (ammo. sol. cop. carb.). These other fungicides, except resin Bordeaux, were used in the last two sprayings to avoid any sediment on the fruit when ripe, as some growers seem to be afraid to spray after the melons begin to ripen.

The conclusions drawn from this experiment are as follows: (a) The sprayed plats, especially the Bordeaux plat I, gave the best results in freedom of the foliage from fungi and in size and vigor of plants and number of young melons started. The unsprayed plat 5 was the poorest in these respects and developed considerable anthracnose and scab, and possibly a little mildew at the very end of the season. (b) The spraying did no good in preventing the bacterial wilt, as a few plants were killed in all of the plats and the fruit suffered some from a soft rot, possibly caused by the same organism. Some of the earlier sprayings did some slight injury to the leaves, shown by their turning yellow at the margins and slowly dying. (d) Resin Bordeaux adheres better than Bordeaux, but is more expensive and difficult to make, and so will not generally be used. If any spraying is to be done, everything considered, Bordeaux mixture is the most desirable fungicide, even for the late sprayings, as little spray reaches the melons if the ripe ones are picked before spraying, and no injury or harm can come from any little sediment that may remain when the fruit is picked subsequently. (e) The spraying in this experiment did not pay for itself, since practically no marketable melons were obtained. The failure of melons on the sprayed vines was chiefly due to the cold, wet season, which prevented vigorous growth of foliage.

In 1904 the season was warm and fairly dry during July and August, so that it was favorable for the growth of the vines, and also unfavorable for the development of fungous troubles. No mildew was found by the writer anywhere, except a little on some garden cucumbers on September Io. So this fungus did no damage whatever this season; neither were the other fungous diseases troublesome, so far as observed, except the wilt, which did less damage than usual. For the first time in several years, due chiefly to the warmer, drier growing season, a fair crop of musk melons was generally obtained throughout 
the state, though this was shortened somewhat by a killing frost on September 2 I.

II. A spraying experiment this year was conducted on the farm of Andrew Ure of Highwood to determine whether spraying with Bordeaux mixture was a desirable and profitable treatment to advocate to market gardeners for their melons. A patch of about a quarter of an acre was planted by Mr. Ure for this purpose and two-thirds of this was thoroughly sprayed four times. These treatments were made July 6, July 2I, August 4 and August I8, and as the season was not very wet the vines were fairly well coated with the spray during the entire season.

The results may be summarized as follows: (a) No mildew appeared on either sprayed or unsprayed plants. A little leaf spot was finally observed on some of the unsprayed plants, but there was not enough to do any damage. The bacterial wilt injured and killed a few vines and there was considerable injury from a soft bacterial rot of the fruit about the time of its maturity, probably also caused by the wilt organism. (See Plate XXIII, c.) As shown last season and in this experiment, spraying was of little or no benefit in preventing the wilt. (b) The first spraying was really made on all of the vines, except two rows, but as it looked as if the treatment had caused some yellowing of the foliage, over one-third of the patch was left unsprayed thereafter. No evident or permanent injury resulted from spraying, however. At the end of the season the sprayed vines looked fully as vigorous, if not a little more so, than those which were not sprayed. The spraying, then, was of little or no benefit to the foliage and vines. (c) A fair crop of melons was gathered from both sprayed and unsprayed vines. No effort was made to determine the exact number from each, as it was evident that if any difference existed (and it would have been small) it would scarcely be due to the spraying.

CONCLUSIONS FROM EXPERIMENTS. Summing up the results of these three seasons' experiments, we conclude: FirstWhen the downy mildew is very severe, as in rg02, spraying musk melons is useless. Second-When the seasons are cold and damp but fungi not unusually destructive, spraying may show some benefit to the foliage, but the unfavorable influence of the weather will not be overcome by this treatment. Third-Warm, fairly dry seasons (moisture well distributed) are necessary for the best development of musk melons in Connecticut and such seasons are not likely to bring serious attacks 
of fungi, so that spraying in these seasons is of little or no advantage. Fourth-Everything considered, spraying musk melons scarcely merits recommendation in this state. These statements do not apply to the cucumber, which host without doubt is often benefited by thorough spraying.

\section{LiteRATURE.}

The following references include all the more important articles and even notes which the writer has found in literature relating to this mildew. As a natural consequence of the fungus being found, until recently, chiefly in this country, and because of its severe injury to cultivated plants, the literature is largely from our Experiment Station workers.

I. Bennett, E. R. Bordeaux Spraying for Melon Blight. Storrs Agr. Exp. Stat. Bull. 30: 17. I904.

Reports favorable results from spraying seven times with Bordeaux mixture, especially with the yield and foliage of the cucumbers, while with musk melons the foliage was improved.

2. Berkeley and Curtis. Peronospora Cubensis B. \& C. Journ. Linn. Soc. Bot. Io: 363 . I868.

Describe this new species collected on cucurbitaceous host by Wright in Cuba.

3. Berlese, A. N. and De Toni, J. B. Peronospora cubensis Berk. et Curt. Sacc. Syll. Fung. 7:261. I888.

Give Berkeley's description of this fungus.

4. Berlese, A. N. Plasmopara cubensis (B. et C.). Riv. Pat. Veg. 9: I23-6. I90I. [Illustr.]

Gives botanical description, hosts, distribution and general discussion of this fungus, for which he creates a new sub-genus, Peronoplasmopara.

5. Cazzani, E. Sulla comparsa della Peronospora cubensis Berk. et Curt. in Italia. Centr. Bakt. Par. Infekt. I2: 744. I904. [Reprint from Atti Inst. Bot. Pavia 9: I4. I903-4.]

Reports this on melon leaves from Pavia and Rimini, Italy, in 1903 .

6. Clinton, G. P. Report on Fungous Diseases of ig03. Conn. Pom. Soc., Ann. Vol. 6:23. 1904 .

States that downy mildew appeared later and did less damage in Conn. in 1903 than it did the previous year.

7. Clinton, G. P. Downy Mildew (Blight) Plasmopara Cubensis (B. \& C.) Humph. Conn. Agr. Exp. Stat. Rept. I903: 318-19, 330-31, 370. 1904. [Illustr.]

Gives a short account of the fungus, with its hosts and the injury done in Conn.

8. Cooke, M. C. Cucumber and Melon Rot Mould. Journ. Roy. Hort. Soc. $27: 823$. 1903. 
Gives short note on this fungus with suggestions for its prevention.

9. Eckardt, C. H. Ueber die wichtigsten in neuerer Zeit aufgetretenen Krankheiten der Gurken. Prakt. Blät Pflanzenb. Pflanzensch. 2: [Review by Pósch, Centr. Bakt. Par. Infek. I3: 787. I904.]

Notes injury in Austria from this trouble, and suggests spraying.

Io. Farlow, W. G. Notes on Fungi I. Bot. Gaz. I4: 189-90. I889.

Gives a general account of Peronospora Cubensis received from Japan, and identifies specimens from Halsted of New Jersey, the latter being the first collection in the United States.

II. Galloway, B. T. New Localities for Peronospora Cubensis B. \& C. Journ. Myc. 5:216. 1889 .

Reports this from Fla. and Texas, on cucumbers, which suffer severely from the fungus.

12. Garman, H. Cucumber Mildew. Ky. Agr. Exp. Stat. Bull. 9I: 50-I. I90I.

Notes this fungus especially destructive to cucumbers in Kentucky in 1897 and 1898 ; finds conidia larger than described by Berkeley.

13. Halsted, B. D. Peronospora upon cucumbers. Bot. Gaz. I4: 152-3. I889.

Notes appearance of an unidentified Peronospora (see Farlow) on greenhouse cucumbers in May, I889, at New Brunswick, N. J. This is the first collection of the mildew in the United States.

14. Halsted, B. D. Some Notes upon Economic Peronosporeae for I899 in New Jersey. Journ. Myc. 5:20I-2. I889.

Reports this later very abundant and injurious outdoors upon squash, pumpkin and cucumbers.

15. Halsted, B. D. 'Notes upon Peronosporae for i89o. Bot. Gaz. I $5: 322$. I 890 .

Notes the absence of cucumber mildew this year in N. J.

I6. Halsted, B. D. Notes upon Peronosporeae for I89I. Bot. Gaz. I6 : 339. I89I.

Notes prevalence of Peronospora Cubensis B. \& C. in I89I; lists from N. J., Dist. Col., and Conn. (on watermelon).

17. Halsted, B. D. Peronospora Cubensis B. \& C. (Cucumber Mildew). N. J. Agr. Exp. Stat. Rept. I2 : 248. 1892.

Notes prevalence of this fungus in $189 \mathrm{I}$ in N. J. and elsewhere; states Sturgis found it in Conn. on watermelon.

I8. Halsted, B. D. Fungous Diseases of the Muskmelon. N. J. Agr. Exp. Stat. Rept. 14:352-3. I894. [Illustr.]

Briefly describes damage done by downy mildew.

19. Halsted, B. D. The Downy Mildew (Plasmopara Cubensis B. \& C.). N. J. Agr. Exp. Stat. Rept. I5: 348, 350, 359. 1895.

Lists on cucumbers, musk melons and squash from N. J.

20. Halsted, B. D. Bordeaux with Cucumbers. N. J. Agr. Exp. Stat. Rept. I6: 327. I896. 
Notes favorable results from spraying against downy mildew, etc., since the sprayed plants lived one month longer than those not sprayed.

2I. Halsted, B. D. Experiments with Cucumbers. N. J. Agr. Exp. Stat. Rept. I7:340-44. 1897 .

Sprayed plants with Bordeaux, soda Bordeaux, potash Bordeaux, but results of little importance in determining value in preventing downy mildew, as this was not present.

22. Halsted, B. D. Experiments with Cucumbers. N. J. Agr. Exp. Stat. Rept. 18 : 319-22. 1898 .

Reports Bordeaux and potash Bordeatux as useful in preventing the downy mildew.

23. Halsted, B. D. The Blight of Cucumbers. N. J. Agr. Exp. Stat. Rept. $22: 437,440.1902$.

Notes that this was common in N. J. in I90I, and destroyed most of the musk melons; a plot of cucumbers was kept in full leaf and vigor by spraying with soda Bordeaux.

24. Hecke, L. Ueber das Auftreten von Plasmopara cubensis in Österreich. Ann. Myc. 2: 355-8. I904.

Reports the mildew from Vienna, Austria, on cucumbers; gives historical and botanical account of fungus.

25. Hecke, L. Ueber das Auftreten von Plasmopara cubensis in Österreich. Zeit. Landw. Ver. Oester. I904. [Review, Bot. Centr. 95 : 640-41. 1904.]

Notes presence in Austria on cucumbers; gives distribution, history, etc.

26. Hennings, P. Fungi S. Patlenses I. Hedw. 4I : 104. 1902.

Lists Peronospora cubensis B. et C. on Cucumis sativus from Sao Paulo, S. Amer., collected in Igoo.

27. Hume, H. H. Downy Mildew of the Cucumber. Ann. Rept. Fla. Agr. Exp. Stat. I2-I3: 30. 1900.

Reports this serious in Fla. on cucumber; states that it lives there throughout the year; gives short botanical and historical account of fungus, and reports successful spraying experiments by a grower.

28. Humphrey, J. E. The Cucumber Mildew.-Plasmopara Cubensis (B. \& C.) Humph. Ann. Rept. Mass. Agr. Exp. Stat. I89o: 210-2. I89I. [Illustr.]

Notes injury in Mass. to cucumbers and squash by Peronospora Cubensis B. \& C., which he here places under the genus Plasmopara; notes structure and germination of fungus.

29. Humphrey, J. E. The Downy Mildew.-Plasmopara Cubensis (B. \& C.) Humph. Dept. Veg. Path. Mass. St. Exp. Stat. 1902: I8-I9.

Notes its injury to cucumbers grown in greenhouse.

30. Jaczewski, A. de. Note sur le Peronospora cubensis B. et C. Rev. Myc. 22: 45-7. I900. [Illustr.] 
Reports Plasmopara australis on Schizopepo bryoniaefolius collected in Manchuria in 1876 [not $P$. Cubcnsis as reported by Hecke]; calls attention to differences between these two mildews, and gives scientific description of $P$. Cubensis, but makes mistake in calling conidia hyaline.

3I. Jaczewski, A. de. Plasmopara Cubensis. Bull. Torr. Bot. Club $29: 649 . \quad 1902$.

Notes presence of this fungus in Russia.

32. Kornauth, K. Ueber in Jahre 1903 beobachtete Pflanzenkrankheiten. Zeitschr Landw. Vers. Oester. I904: I59. [Review, Centr. Bakt. Par. Infek. I3: 46r.]

Notes presence of Peronospora Cubensis on cucurbitaceous plant in Vienna greenhouse.

33. Lamson, H. H. Downy Mildew of the Cucumber and Musk Melon. N. Hamp. Agr. Exp. Stat. Bul1. 87 : I29. Ig0I.

Notes this fungus injurious to cucumbers and musk melons in N. Hamp.; spraying experiments, begun after appearance of the disease, did no good.

34. Lamson, H. H. Fungous Diseases and Spraying. N. Hamp. Agr. Exp. Stat. Bull. IOI : 63, 64. I903.

Reports favorable results from spraying cucumbers and musk melons with Bordeaux beginning about the middle of July; applied five times at intervals of about io days.

35. Linhart. Die Peronospora-recte Pseudoperonospora Krankheit der Melon und Gurken in Ungarn. Zeits. Pflanzenk. I4: I43-45. 1904.

Reports severe outbreak of downy mildew on cucumbers, musk and watermelons in Hungary in 1903.

36. Massee, G. Cucumber and Melon Mildew. A Text Book of Plant Diseases: 80 . I899.

Notes its recent introduction into England, on Cucurbita pepo and Cucumis sativa, from Japan.

37. Orton, W. A. Plant Diseases in the United States in I901. Yearbook U. S. Dept. Agr. I9or : 670. 1902.

Notes downy mildew did damage to musk melons in Long Island, N. Y., Mass., Conn., N. J.

38. Orton, W. A. Plant Diseases in the United States in 1902. Yearbook U. S. Dept. Agr. 1902 : 717. 1903.

Reports downy mildew injurious to cucumbers and musk melons in southern New England.

39. Orton, W. A. Plant Diseases in 1903. Year Book U. S. Dept. Agr. I903 : 553. I904.

Reports downy mildew causing large loss of cucumbers in Florida and S. Car.; also destructive in West Virg., Penn., N. Y. and Mich.; occurred in Ohio, Mass., Conn., R. I.

40. Rostowzew, S. J. Beiträge zur Kenntnis der Peronosporeen. Flora $92:$ 405-30. I903. [Illustr.]

Describes a new var., Tweriensis, of the downy mildew, from the province T'ver, Russia; places this and the species under a new genus, Pseudoperonospora; gives detailed botanical account 
of the mildew; describes immature oospores; gives experiments with infected soil, etc.

4I. Saccardo, D. Plasmopara Cubensis (B. \& C.) Humphrey. Myc. Ital. 1276 .

Issues specimens from Italy and states conidia are $22-25$ by $15^{-1}, \mu$ hyaline, finally olive brown, and not violet, as reported by Humphrey.

42. Saccardo, P. A. Notae mycologicae. Ann. Myc. 2: I4. 1904.

Notes mildew was found on Cucumis Melo at Selva (Treviso), Italy, in I903.

43. Selby, A. D. Downy Mildew of Cucumbers. Ohio Agr. Exp. Stat. Bull. 73:234. I897.

Notes prevalence in Ohio on cucumbers in greenhouses and also outdoors.

44. Selby, A. D. Cucumber Diseases. Ohio Agr. Exp. Stat. Bull. 89:99-116. I897.

Notes very injurious effect of downy mildew on late or pickling cucumbers in Ohio, especially in I897; gives botanical account of fungus; records successful spraying experiments with Bordeaux.

45. Selby, A. D. Studies of the Diseases of Cucurbits and Tomatoes. Ohio Agr. Exp. Stat. Bull. I I : I40-4I. 1899.

Refers to work done by Ohio Station in study and prevention of downy mildew of cucumbers, etc.

46. Selby, A. D. Further Studies of Cucumber, Melon and Tomato Diseases, with Experiments. Ohio Agr. Exp. Stat. Bull. 105:2192I, 223-29, 230-1. I899.

Gives notes on downy mildew; also list of hosts upon which it spread in the disease garden; gives successful spraying experiments with Bordeaux on cucumbers, and chiefly unsuccessful ones on musk melon.

47. Selby, A. D. Additional Host Plants of Plasmopara cubensis. Bot. Gaz. $27: 67-8$. $\quad$ I899.

Grew a large number of cucurbits in a disease garden on most of which the mildew spread from the ordinary hosts. (See hosts elsewhere in this article.)

48. Selby, A. D. Certain troublesome Diseases of Tomatoes and Cucurbits. Reprint Journ. Columbus Hort. Soc. I I : I.

Notes downy mildew becoming conmon in Ohio, especially in greenhouses.

49. Selby, A. D. A Condensed Handbook of the Diseases of the Cultivated Plants in Ohio. Ohio Agr. Exp. Stat. Bull. 121 : 29, 33, 38, 5I, 54, 58. I900.

Gives short notes on downy mildew under the following hosts: cucumber, gourd, musk melon, pumpkin, squash and watermelon.

50. Selby, A. D. Calendar for Treatment of Plant Diseases and Insect Pests. Ohio Agr. Exp. Stat. Bull. I47 : 50, 51. I904.

Recommends for downy mildew of cucumber and musk melon at least four sprayings with Bordeaux, at intervals of eight to ten days, beginning about the time the vines start to run. 
5I. Sirrine, F. A. and Stewart, F. C. Spraying Cucumbers in the Season of I898. N. Y. Agr. Exp. Stat. Bull. I 56:376-96. 1898.

Give very favorable results of several spraying experiments with Bordeaux made on a large scale with pickling cucumbers; recommend first treatment July I5 to August I, repeating every eight to ten days until frost; give cost of spraying, yields and profits in their experiments.

52. Stene, A. E. When to Spray. R. I. Agr. Exp. Stat. Bull. I00: I27. I904.

Notes downy mildew difficult to control, recommends Bordeaux beginning middle of July and repeating every ten to twelve days during season of vines.

53. Stewart, F. C. The Downy Mildew of the Cucumber; what it is and how to prevent it. N. Y. Agr. Exp. Stat. Bull. I19: 155-82. I897. [Illustr.]

Gives general and botanical account of this fungus, which was serious in New York in 1896; reports very successful spraying experiments with Bordeaux on late cucumbers; recommends spraying the young plants and repeating every eight to ten days till frost.

54. Stewart, F. C. Further Experiments on Spraying Cucumbers. N. Y. Agr. Exp. Stat. Bull. I38:636-44. 1897.

Gives favorable results from spraying early cucumbers with Bordeaux ( $\mathrm{I}$ to 8 formula) to prevent downy mildew in 1897 ; notes impractical results of trying to prevent mildew by shading with corn; reports new host, Cucumis moschata.

55. Stone, G. E. and Smith, R. E. Cucumber Mildew (Plasmopara Cubensis B. \& C.). Mass. Agr. Exp. Stat. Rept. 13: 72-3. I90I.

Note appearance on greenhouse cucumbers in Mass.

56. Stone, G. E. and Smith, R. E. Melon Failures. Mass. Agr. Exp. Stat. Rept. 14:62-6. I902.

Report downy mildew with Alternaria and Colletotrichum, the cause of unusual failure of musk melons; also bad on cucumbers; spraying not entirely effective with musk melon, but advocated.

57. Stone, G. E. and Smith, R. E. Report of the Botanists. Mass. Agr. Exp. Stat. Rept. I5 : 28, 29-32, 37-8. 1903.

Give general notes on prevalence of downy mildew on cucumber and musk melon in Mass.; note growth of plants under tents; think mildew can be kept off from plants grown in greenhouse by proper watering; report little gain from spraying musk melons.

58. Stone, G. E. Cucumbers under Glass. Mass. Agr. Exp. Stat. Bull. $87: 36-7$. I903. [Illustr.]

Gives general account of the downy mildew and preventive measures.

59. Sturgis. W. C. Downy Mildew on Melons. Conn. Agr. Exp. Stat. Rept. 1899: 277-78. 1900.

Gives account of damage done at Meriden, Conn., on musk melons and advocates starting plants under glass to get an earlier start and escape in part this trouble. 
6o. Swingle, W. T. Some Peronosporaceae in the Herbarium of the Division of Vegetable Pathology. Journ. Myc. 7: 125. 1892.

Lists Peronospora cubensis B. \& C., under doubtful section of this genus, on Cucumis anguria from Texas and Florida, and on Cucumis satious from Texas and Maryland.

6I. Thaxter, R. Peronospora on Cucumbers. Conn. Agr. Exp. Stat. Rept. I890: 97. I89I.

Notes appearance of this fungus, for first time in Connecticut, at South Manchester.

62. Tubeuf and Smith. Peronospora (Plasmopara) cubensis. Diseases of Plants: I34. I897.

Merely list as an injurious species.

63. Waite, M. B. Description of two New Species of Peronospora. Journ. Myc. 7 : I06. I892.

Notes the resemblance of his Peronospora Celtidis, $n$. sp., on Celtis occidentalis to Peronospora Cubensis B. \& C.

64. Weed, C. The Cucumber Mildew. Fungi and Fungicides: I60. I894.

Gives short account of the fungus.

65. Zimmermann, A. Ueber einige an tropischen Kulturpflanzen beobachtete Pilze II. Centr. Bakt. Par. Infek. 8: I48. I902. [Illustr.]

Describes Peronospora cubensis var. atra, $n$. var., from Buitenzorg, Java, or Cucurbita pepo.

66. Zimmermann, A. Untersuchungen über tropische Pflanzenkrankheiten. Ber. über Land- und Forstwirtschaft in Deutsch- Ostafrika 2: II-36. [Review, Centr. Bak. Par. Infekt. I2: 3I6. I904.]

Lists Peronospora cubensis var. atra on cucumber leaves from Dutch East Afrika.

\section{Explanation of Plate XXXI.}

Detailed drawings of Peronoplasmopara Cubensis. Magnified about 600 diameters, except $\mathrm{I}$, which is only magnified about 350 diameters.

I. A single conidiophore emerging from a stomate of a leaf.

2. Base of a conidiophore and lobes of the mycelium from which other conidiophores develop in favorable weather.

3. Top of a conidiophore, showing an immature (a) and a mature (b) spore still attached.

4-9. Spores (temporary) that were produced on the conidiophores. 4. Contents emptied out through pore of dehiscence. 5. Spore about to germinate, showing areas in the protoplasm. 6. Showing last of about a dozen zoospores escaping from the spore. 7. A zoospore that failed to escape from the spore. 
8. Cross section of an empty spore. 9. Empty spore, showing the pore through which the zoospores escaped.

IO-I2. Motile stage of the zoospores; IO, showing the separation of zoospores into individuals.

13. An unusually large zóospore making an unsuccessful attempt to divide.

I4. Zoospores after coming to rest and before their germination.

I5. Zoospores (in an amoeboid condition) that never germinated and finally died.

I6. Different stages of the germination, in water, of the resting zoospores.

I7-20. Infection of the host through germinating zoospores resting on the epidermis. I7. A zoospore settled down over a stomate. I8. The same zoospore two hours later, with its germ tube apparently entering the leaf between the guard cells of the stomate. I9-20. A resting zoospore (a) on leaf near a stomate; (b) its final position after starting to germinate two hours later; 20 , its condition twenty-four hours later, apparently trying to bore into leaf through the epidermis. 
PLATE XXIX.

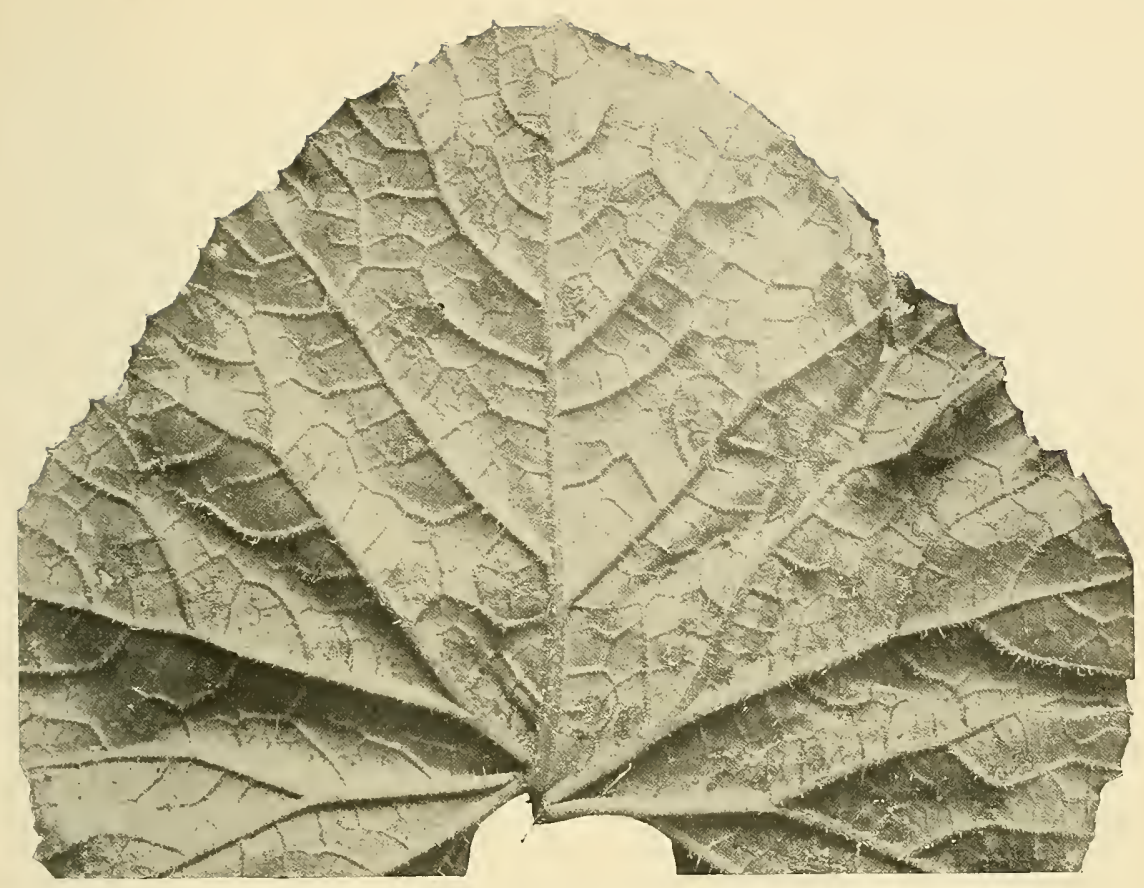

a. Under surface of leat showing early stage of blight.

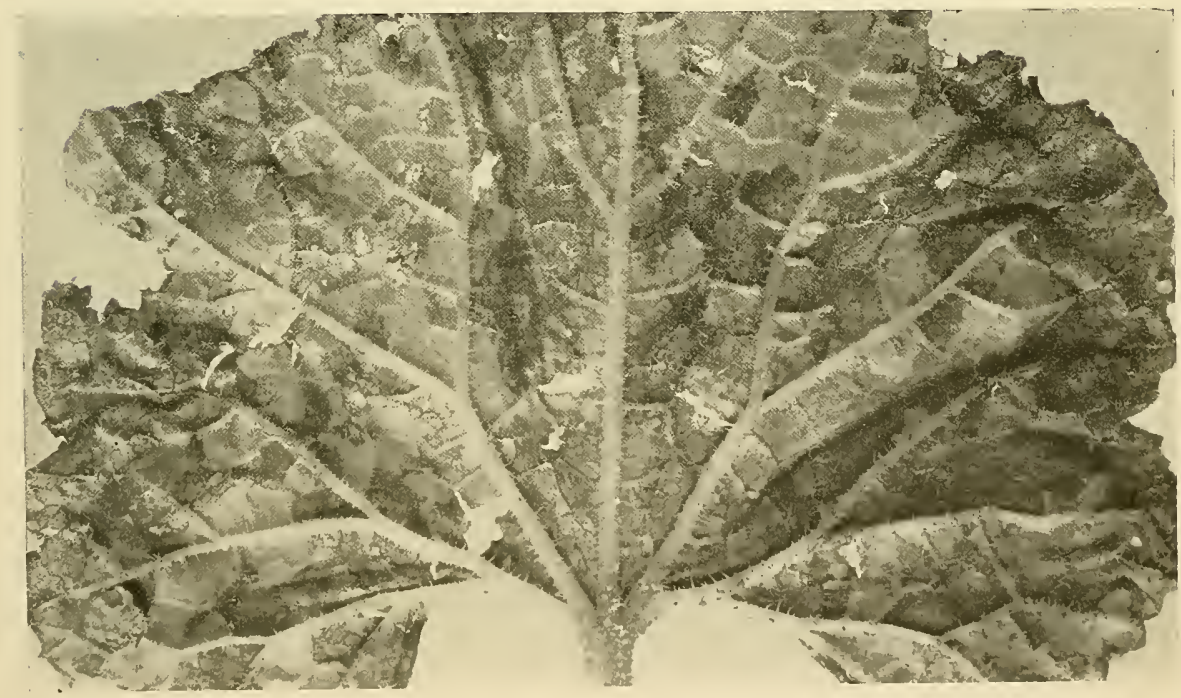

b. Under surface of leaf showing later stage of blight.

BLIGHT, OR DOWNY MILDEW, OF MUSK MELON, Peronoplasmopara Cubinsis, p. 3H. 

PLATE XXX.

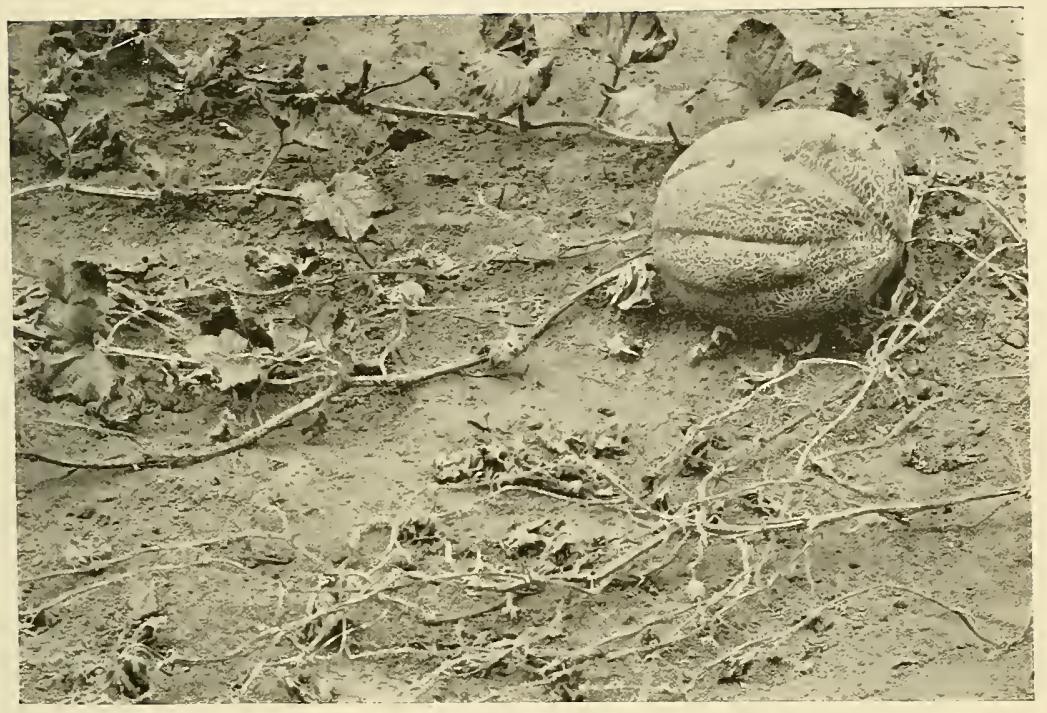

a. Blighted vine in the field, p. 344.

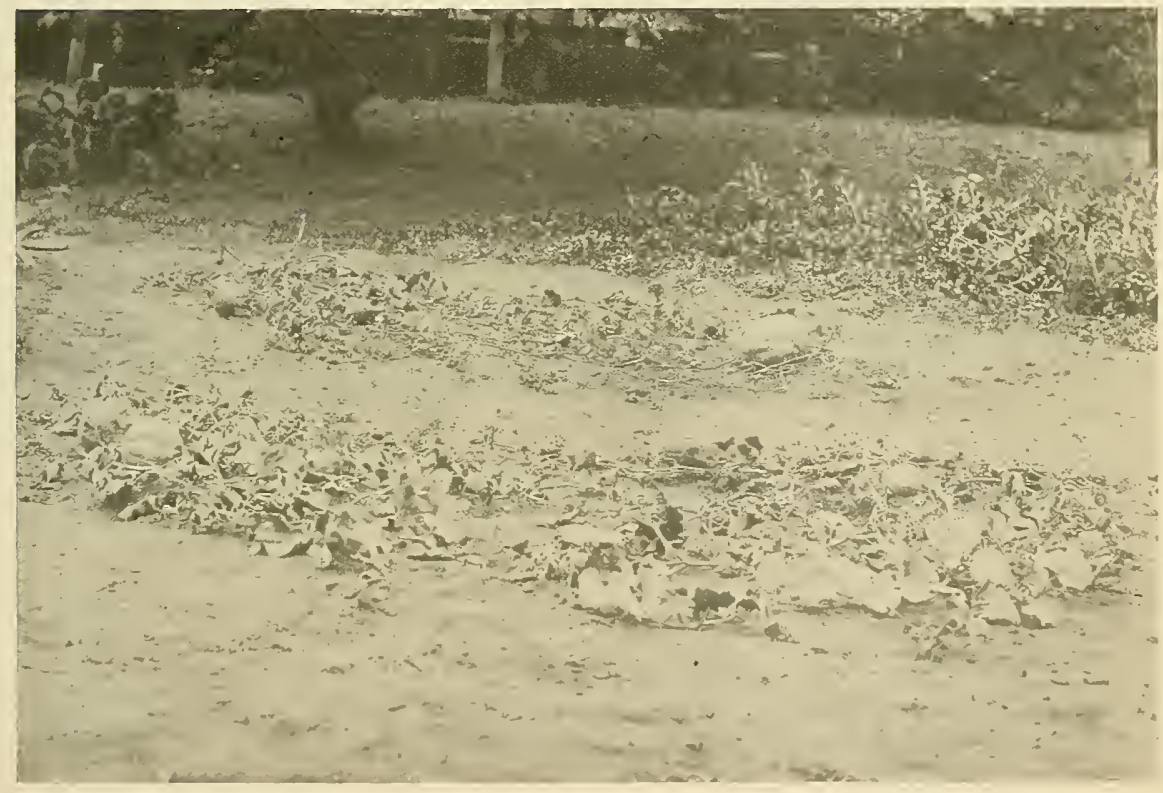

b. Vines in foreground sprayed; those in rear not sprayed, p. $35 \mathrm{I}$.

BLIGHT OR DOWNY MILDEW OF MUSK MELON. 

PLATE XXXI.

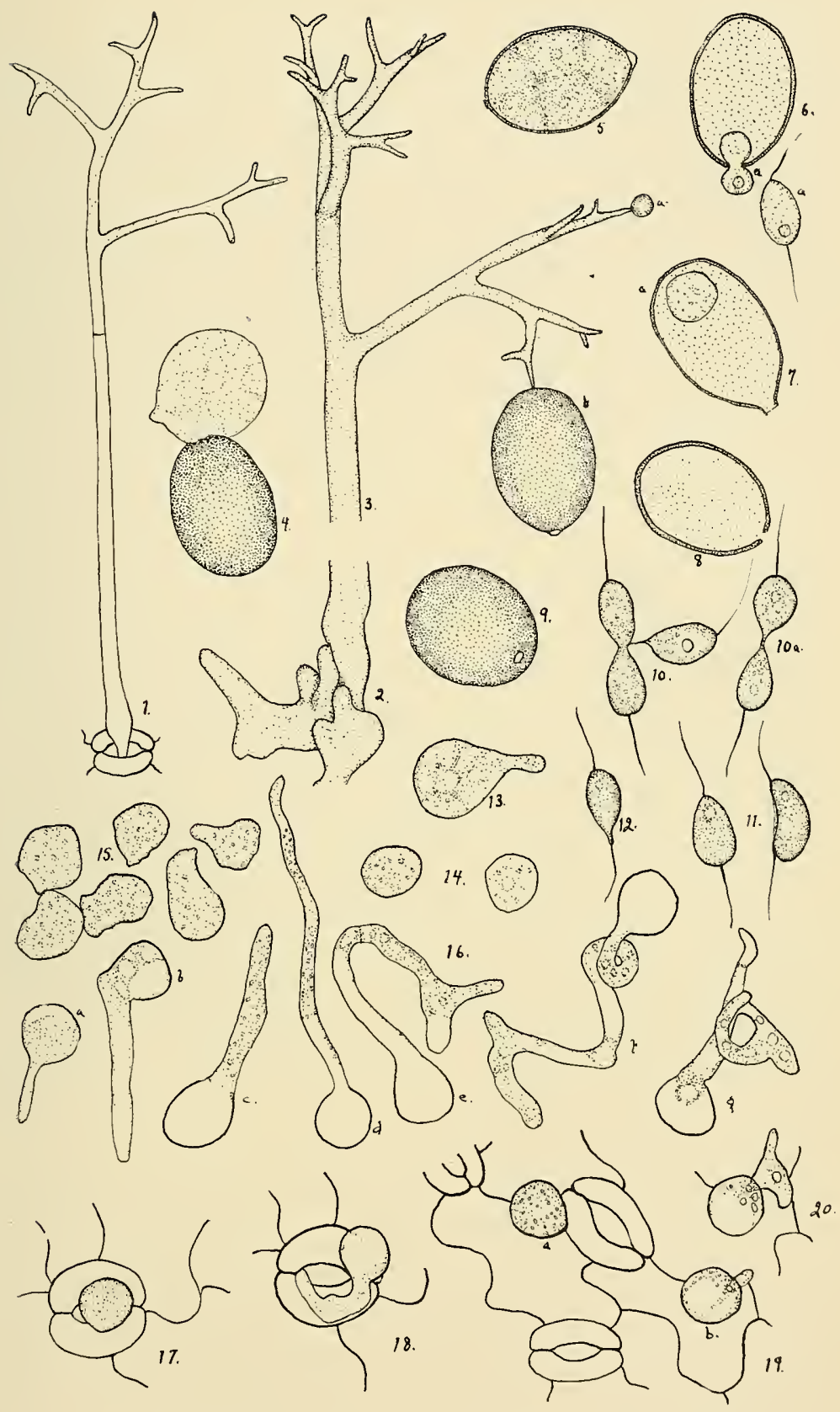

DETAILED DRAWINGS OF Peronoplasmopara Cubensis. 

DOWNY MILDEW, OR BLIGHT, Phytophthora infestans (Mont.) DeBy., OF POTATOES.

Aim of Investigations. In 1902 the writer began a series of spraying experiments with potatoes having two objects in view, namely, first, to determine just how injurious the blight fungus, Phytophthora infestans, is in this state year after year, and second, to determine the most effective and practical method of spraying to prevent it. No especial originality is claimed for these experiments, since the object was to apply chiefly what the general results of others had determined and see how these were adapted to the conditions that exist here. We report in this paper the results and suggestions that have been gained so far.

No idea was had at the start of a special study of the fungus that is responsible for blight, as it has had the attention of many European botanists. There are a number of points in its life history, however, that the writer has been forced to believe are not known, or at least have not been positively settled. A complete knowledge of the fungus must have considerable bearing in determining the very best ways for controlling the disease. Consequently, during the past year, efforts have been made to gain all possible information concerning the fungus itself. This second phase of the subject is not dealt with especially in this paper, as it is still under consideration, but as a general knowledge of the blight fungus is necessary to an intelligent understanding of the methods employed in combating it, we give briefly what we understand from our own observations and those of others to be the main facts in its life history.

\section{Life History of Fungus.}

Infected Tubers. To the ordinary observer blight begins in his field when it shows with the sudden or gradual death of the vines in the middle of July or later. Its first development, though hidden, really began when infected tubers in that or some other field were planted in the spring. In other words, the blight fungus is carried over the winter in the tubers from a previous diseased crop. Furthermore, so far as we now know, the fungus is perpetuated only by the infected tubers, 
and not through diseased tubers that have rotted outdoors, or by the old rotted vines, or through infection of the land, or on some other host of the fungus. However, there is a possibility that one or more of these other means may also serve to perpetuate the fungus, but as yet proof is lacking. A good deal of study has been made on this phase of the subject, but it needs still more.

The appearance of the disease as ordinarily shown at time of storage on potatoes is a reddish brown rot that develops only slowly, if at all, when the tubers become dried out and are kept in a cool, dry place. This discoloration shows at the surface, often extending inward from the skin to the bundles or further, and the surface may also become slightly sunken or pitted. (See Plate XXXIII, b.-c.) In the fields, and while still damp in storage, the rotting is often very rapid. This is largely due to the presence of bacteria or the Fusarium fungus that develop independently or as a consequence of the blight and are apparently more active agents of decay. Very often tubers are found having an end rot, usually the stem end, that affects the whole tuber as it progresses forward. Not infrequently the freshly diseased, or innermost, tissues have the same reddish brown color found in blighted tubers, and probably the fungus is sometimes present, but usually this end rot seems to be caused by the Fusarium fungus which breaks out in white fruiting pustules on the surface. This also becomes a slow dry rot in storage after the tubers have dried out. The bacterial trouble is usually shown in the field by a slimy, sticky, ill-smelling rot that, if first started by the blight fungus, soon outstrips it as the agent of decay and no doubt often starts independently of this fungus. In storage it gradually dries out and works slower and is often found in connection with the Fusarium or other fungi.

The blight fungus persists in the infected tubers by means of its mycelium, or its vegetative stage. This consists of microscopic threads that have pushed their way slowly between the cells of the tuber, occasionally sending short, thick-walled branches inside the cells to obtain nourishment for growth. This stage has directly to do with rotting the tubers and blighting the vines, but not with spreading the disease. During the storage of the tubers it apparently exists in a dormant, or at least not very active, condition. 
When infected tubers are planted in the spring the mycelium may push out on the undiseased cut surface of the tuber from the diseased tissue and there form the temporary spore, or reproductive stage, the same that it develops in July or August on the leaves. This spore development is likely to continue only for a short time, as the blight fungus is easily crowded out by other fungi and it does not form this stage at all on rotten tissues. Some of the spores produced here may be carried accidentally by insects or washed by the rains to the young buds of the sprouting tuber and on germination infect these with the disease. Or probably the mycelium as often grows directly from the diseased tissue into the healthy tissue of the developing buds and secures infection in this way. It is quite probable that comparatively few plants in the field become infected through the diseased tubers; at least we can say positively from experiments that diseased tubers do not necessarily produce infected plants. In an experiment by the writer where badly rotted blight tubers were planted in a greenhouse, the tubers either failed entirely to produce plants or else developed plants in which the disease never appeared, though the fungus grew out on the cut surface in its spore stage. So far the writer has not observed in the fields stems developed from infected buds, but the few seen in the greenhouse remained dwarfed and of a reddish brown color at the surface, as if the fungus was superficial in the tissues. These infected stems do not produce spores except under proper conditions of moisture. This fact, together with their scarcity, possibly explains why the disease is so slow in getting started in a field, rarely ever appearing before the middle of July, and often much later. Once the spores begin to be produced above ground, however, with proper weather conditions they spread the disease through the field and, no doubt, to other fields. Just how far and how often the fungus is carried by these spores from one field to another are points that need further investigation. Also the whole subject of the very early development of the disease requires more observations and experiments.

Blighted Vines. This temporary spore stage may be described very briefly as follows: The fungus once started in a leaf, through infection from a germinating spore, develops its mycelium between leaf cells, killing the tissues as it goes, 
and also sends out to the exterior through the stomates, or openings in the epidermis, erect branched fertile threads that form the temporary spores. The spores mature very quickly and can germinate immediately if they fall in a drop of water. Many of the spores perish, however, as they cannot live long in dry air. The germination usually consists in the formation and liberation of several motile animal-like bodies called zoospores that swim around in the water for a short time and then come to rest. They then send out a germ thread that grows into the leaf tissues and develops the mycelium from which arise the spore-bearing threads as before. This process of spore formation, germination, infection and development of mycelium can be kept up indefinitely, or at least as long as weather conditions are favorable and there are green potato leaves left. The wind, rain and insects serve in spreading the spores. Moist, cloudy weather of several days' duration is best adapted for the growth and spread of the fungus, since the fruiting threads are then formed most abundantly; then conditions are also favorable for the germination of the spores and infection of the leaves and the diseased area in the leaf develops rapidly. In dry weather the blackened, diseased tissues of the leaf dry up, but the fungus makes very little further advance, while very few new fertile threads are developed on the exterior. The blackened, diseased spots usually start at the margin of the leaves and develop inward, and on the under side the spore threads, especially in moist weather, can be seen as a faint whitish growth just in advance of the discoloration. (See Plate XXXII, a.) The character of the weather during July and August determines largely how much injury the fungus will do to the vines. If after the disease has spread somewhat through the fields there comes a period of blight weather, the vines may all be gone in a week; or if the weather is less favorable for its development the disease may lag along slowly: Some seasons it does not appear until the very end.

Rotten Tubers. It has been stated by some writers that the blight fungus, through its mycelium, passed down the stems into the tubers. We have seen no evidence that this is so, and doubt if it ever (perhaps rarely) occurs. With the Fusarium and the bacterial rots of the tubers this may be true, since the disease in these cases often starts in the stem end of the tubers. 
Infection of the blighted tubers takes place through the spores that fall on the ground from the infected leaves above. If these are washed down to the tubers, infection takes place on their germination by the germ threads boring directly into the tissues and there developing the mycelium. So far as observed by the writer, the fungus is not apt to send out fruiting threads on the surface of these tubers while in the ground and spread the disease this way. Such fruiting threads, however, have been seen in potatoes freshly dug and kept in a moist atmosphere, and probably are formed somewhat in the ground. The amount of moisture in the soil while these spores fall on the ground and the nearness of the tubers to the surface are two factors in determining the extent of the infection. Severity of blight in the foliage does not necessarily mean a corresponding severity of rot in the tubers. At least in July, I902, there was a sudden and severe blighting of the vines, many fields being entirely dead a week after the appearance of the trouble, and yet there was comparatively little complaint of rot that year. On the other hand, in 1904 the blight made its appearance very late in the fields, doing comparatively little injury to the foliage; but this year the tubers rotted badly from the blight. The rot in the tubers does not usually start until the vines are dead. As mentioned before, all the rots of the tubers are not due to the blight fungus. In 1903, for instance, the tubers rotted rather badly, but this was caused chiefly by the bacterial rot and the Fusarium fungus.

Winter Spores. The spores of the blight fungus are temporary and cannot carry the fungus over the winter, but, as previously stated, this is accomplished by the mycelium in the infected tubers. Many of the fungi in the group to which the blight fungus belongs, however, develop thick-walled oospores (winter or resting spores), and these serve as a means of perpetuating such fungi. These spores have been looked for in connection with the potato fungus, but their existence has never positively been proven, though some investigators have thought that they found them. The writer has made a special search for them, and while some suspicious things have been seen, no positive evidence of their existence has been gained, though artificial cultures of the fungus have been grown on various media in test tubes and search has been made in the potato 
leaves and tubers in all stages of infection and decay. From these investigations we are inclined to the belief that if such spores are formed in this locality they develop only in the rotted tissues, tubers most likely in the very last stages of their complete decay; that is, in the late spring in the tubers left in the fields, and later in the summer, after rotting to pieces, in the infected seed tubers. Blighted tubers in this condition not infrequently contain spores of this nature that look suspicious, but as yet no positive proof of their connection has been obtained, and as a number of unrelated saprophytic fungi develop in the rotted tubers they could easily belong to some of these. It has occurred to the writer, also, that possibly these oospores are formed only on the union of two strains of mycelia (which may rarely occur together), as has recently been shown for a somewhat related group of fungi. In any case, whether this fungus possesses such spores or not, further study along this phase of the subject is needed.

\section{Spraying Experiments.}

Previous Experiments. Both the former botanists of this Station made a few spraying experiments that may be briefly mentioned here. Professor Thaxter, in I889, when blight was unusually severe, made one of the very first spraying experiments against this trouble that has been reported. He sprayed three times with Bordeaux mixture, on July 18 , July 25 and August 3, and got a decided difference in the foliage between those sprayed and those unsprayed. On August 3 the sprayed vines retained 50 to 60 per cent. of their foliage, while the unsprayed were entirely dead, and on August to the sprayed vines still retained 25 per cent. of their foliage. Unfortunately (Thaxter thought possibly due to error in harvesting) the treatment gave no increase in yield. In 1890 Thaxter reported a successful treatment by Mr. N. S. Platt, made after the blight appeared in the field; in this case the yield was reported considerably increased. Dr. Sturgis also conducted spraying experiments in 1892 and in 1893 , but both these years there was little, if any, blight in the sprayed fields, so that his experiments were chiefly of value in showing what effect spraying has in years when blight is not troublesome. He reported consider- 
able benefit resulting from the treatment the first year, but not the second, which was a very dry year.

Recent Experiments. The following experiments have been made personally by the writer in order that he might learn of the disadvantages as well as the advantages of spraying. They have been conducted on all scales from a small garden plot to a five-acre field. The various types of spraying apparatus have been tried to determine their merits and demerits. The number of sprayings in each case has been reduced to the minimum, because it was felt that a maximum number of treatments did not meet with favor among growers generally. Most of the treatments, however, were made very thorough, for upon this thoroughness and the proper time of application largely depends the success of spraying. Bordeaux mixture (four pounds lime, four pounds copper sulphate, and forty to fifty gallons water) was used in all cases, with the addition, when needed, of Paris green for the potato beetle. The check plants were also usually sprayed once or twice with Paris green. In making the Bordeaux, the lime was slaked in a small amount of water and then strained into a barrel about half filled with water. The copper sulphate (kept in stock solution of one pound to one gallon of water) was poured into another barrel, about half filled with water. The half-barrel of copper sulphate solution was then poured into the half-barrel of the lime water, stirring the mixture as this was done.

No direction was assumed of the sprayed fields as to their culture, fertilization, etc., and these conditions varied considerably in the different experiments. In testing the yields it was desired to determine how much more or less the sprayed plats gave over those unsprayed in number and weight of tubers and the amount of rot in each. These tests were always made from the same measured lengths of the sprayed and unsprayed rows, practically side by side, and from at least two places in the field. This was to eliminate, as far as possible, any other influence beside the spraying that might affect the yields.

\section{Spraying Experiments in 1902.}

General Notes. This year the blight appeared suddenly in July and a number of the fields were ruined by it before the end of the month. (See Plate XXXII, b.) The weather during 
July and August was of the kind especially fitted to develop blight, being cold, rainy and foggy, often several days occurring together with little or no sunshine. By the middle of August there were few green potato fields in the state. For example, on August 26, while riding on the train from Unionville to New Haven, there were counted about sixty potato fields, and in all of these the vines were entirely dead, excepting three or four, where the vines were still partially green. Except for the blight, the fields of late potatoes should have lived until killed by the frost, which this year, according to the weather bureau at New Haven, did not occur until October Io and October 22. Little rot developed in the tubers, the injury being thus largely confined to this very premature death of the vines.

Exp. I, in Ogden field with late potatoes. This field, of about half an acre, was elevated, stony and the soil naturally rather poor, but it was well dressed with artificial fertilizers and the culture was fair. The potato vines did not cover the ground so densely as they often do in richer, moist soil, so it was easier to protect this field against blight than one of rank growth. The first spraying, July 30 , was made just after a small amount of blight appeared in the field. This application was somewhat tardy, about ten days, but it made less difference in this field than it would have made in one of luxuriant vegetation. The second and third treatments were made on August 5 and August 23, and on the latter date there was evident difference between the sprayed and unsprayed parts in the injury from blight. On September 2 the unsprayed plants were nearly all dead, while the sprayed plants were mostly alive, being the only green field in the vicinity. At the time of digging, September 25, forty-two of the two hundred and twenty sprayed plants reported in Table I were still partially green. Plate XXXVI, a-b, shows the condition of sprayed and unsprayed plants on September I6. The spraying was done with an ordinary barrel pump carried on a light spring wagon. One man drove and pumped and one man sprayed about six rows, using a twenty-five-foot hose with a single nozzle. The wagon reach was about six inches too narrow for straddling two rows perfectly, so the vines were run over somewhat. This caused little permanent injury, much less than is ordinarily supposed, but by planting the rows at the right distance or by using a cart 
having the right gauge this trouble can be largely avoided. The results of the spraying are given in detail in Table $I$. This shows that the sprayed plat gave an increase of Ios per cent. in weight of tubers over the unsprayed plat and the increased yield was evident not only in the number of marketable tubers, but also in their larger size. Neither sprayed or unsprayed potatoes rotted at all. This experiment gave the best results of any tried during the three years.

Table I -Late Potatoes. Ogden Field, igo2.

\begin{tabular}{|c|c|c|c|c|c|c|c|c|c|c|c|}
\hline \multirow[b]{2}{*}{ Treatment. } & \multirow[b]{2}{*}{ Dug. } & \multirow{2}{*}{ 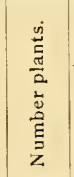 } & \multicolumn{2}{|c|}{$\begin{array}{l}\text { Large to me- } \\
\text { dium tubers. }\end{array}$} & \multicolumn{2}{|c|}{$\begin{array}{l}\text { Medium to } \\
\text { small tubers. }\end{array}$} & \multicolumn{2}{|c|}{$\begin{array}{c}\text { Total } \\
\text { marketable. }\end{array}$} & \multicolumn{2}{|c|}{$\begin{array}{l}\text { Very small } \\
\text { tubers. }\end{array}$} & \multirow{2}{*}{ 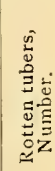 } \\
\hline & & & $\frac{\stackrel{\breve{d}}{\Xi}}{\stackrel{\Xi}{z}}$ & 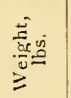 & 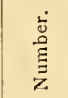 & 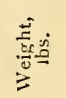 & 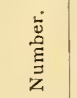 & 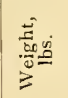 & 苟 & 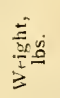 & \\
\hline $\begin{array}{l}\text { Sprayed July } 30, \\
\text { August } 5, \\
\text { August } 23 .\end{array}$ & \multirow{2}{*}{$\begin{array}{c}\text { Sept } 25, \\
\text { equal } \\
\text { length } \\
\text { in each } \\
\text { plat. }\end{array}$} & $220^{*}$ & 512 & 237 & $87 I$ & I 57 & 1383 & 384 & 296 & $14 \frac{1}{3}$ & 2 \\
\hline Unsprayed. & & $197^{*}$ & 264 & $106 \frac{8}{4}$ & 479 & $78 \frac{8}{4}$ & 743 & $185 \frac{1}{2}$ & 248 & I 2 & 5 \\
\hline
\end{tabular}

* Planted rather unevenly by planter, but possibly part of plants in unsprayed rows destroyed by blight.

E.xp. 2, in Nesbit field after blight staried. These potatoes were on rather rich lowland and the vines were very luxuriant, entirely covering the ground. When first sprayed, the mildew was well scattered through the field (not consipcuous, except in a few scattered patches, where the plants were plainly injured), and all the conditions were favorable to rapid advance of the blight with the proper weather. The experiment was undertaken to determine if in a field of this character spraying would be of any value when tardily applied. The first treatment was made August 4 on a small part of the potatoes on either side of a roadway, spraying in as far as could be reached with the twenty-five-foot hośe. Favorable blight weather followed the spraying, and when examined again on August $\mathrm{I} 3$ those sprayed on one side of the roadway were little or no better than those unsprayed, as both were badly blighted. The potatoes on the other side of the roadway were apparently of a later planting and were still green, though severely injured by the blight, and 
these were given a second treatment. These two sprayings, however, failed to check the progress of the blight, and when finally examined on September I5 the only difference seen between the sprayed and unsprayed parts was an occasional partially green plant in the sprayed plat. The rest of the field was entirely dead. As no influence on the yield was expected from these results, this was not determined. We conclude from this experiment that it is useless to begin spraying in a field with luxuriant foliage after the blight has become well established and the season is favorable for its development.

\section{Spraying Experiments in 1903.}

General Notes. This season was also wet, though not so cold or damp as the preceding. The blight appeared considerably later; the very first found by the writer was on August 8. From this time on it spread through the fields, gradually killing the leaves until August 24 to 3I, when in a period of weather favorable to blight all of the fields where it had a foothold were quickly ruined. The possible yield was not cut down so much as the year before by premature death of the vines, but the rot in the tubers was much more serious. These did not begin to rot, with the late varieties at least, until the plants were killed by the blight; yet from an examination of the tubers the writer could not find the blight fungus as the agent of the rot. Most of the tubers examined began to decay at the stem end and the rot seemed to be caused by bacteria and the Fusarium fungus. The largest tubers suffered the most. By killing the green vines the blight fungus probably (indirectly) was responsible for starting these troubles.

Most of the spraying this year was made or started with geared spraying carts in order to test the efficiency of this kind of an apparatus. (See Plate XXXV.) Spraying by hand requires more time and men than these machines, where the horse, at the same time he is pulling the apparatus through the field, is pumping (by means of gearing attached to the wheels) the Bordeaux from stationary nozzles that project over the potato rows. Only one man is needed, and he drives, seated on the cart. Two machines were used that seemed to be as well fitted for the work as any. Our experience with these machines, and our observation and information concerning others, leads us to conclude 
that such machines are not to be recommended for applying Bordeaux mixture against potato blight. There is need, however, of some cheap machine that will do the spraying more rapidly and cheaply, and yet about as thoroughly as can be done by hand. One of the machines tried had single nozzles for covering four rows, while the other had double nozzles. Neither machine could place sufficient spray, well distributed, on the vines, even by going over the potatoes two and three times, at the same spraying. Usually the Bordeaux showed as a streak of blue on the tops of the full-grown vines. The use of stationary nozzles, even with two to a row and a level and evenly planted field for spraying, occasionally caused parts of a row to be missed. The slower the geared machine is driven the less the power, and yet it is desirable to go slow in order to place more spray on the vines. Even at their best, these machines used only about a barrel of the spray to an acre and a half, whereas two or three barrels per acre is needed to thoroughly protect the mature vines.

The apparatus shown in Plate XXXIV, b, is a type often used. In this case the stationary nozzles are attached to the end of an ordinary cart carrying a barrel pump, and the pumping is done by hand. This, too, has some of the objections of the geared machines. By very slow driving, however, more spray can be placed on the vines, but because of the stationary nozzles it will not be done very thoroughly or evenly. In this particular apparatus better work would have been done if the pump had been stronger. It was not powerful enough to readily supply the eight nozzles used.

By far the most satisfactory type of spraying outfit for thoroughness of work is that shown in Plate XXXIV, a. This is merely a two-wheeled cart, of sufficient reach to straddle two rows of the potatoes, which carries an ordinary barrel pump and a man to pump and drive. Two men follow the cart, each using a twenty-five-foot hose with a single nozzle, and they each spray three rows without moving from the row, in which they travel backward. The man drives the length of the hose and the men spray their rows up to the cart, which then moves on again. In this way the ground can be gone over fairly quickly and the spraying can be done as thoroughly as desired. Two nozzles to a hose seem to be little better than one and waste 
more of the material. Where only two men are available for the work, only one need be used for spraying. Each hose should be fitted with a cock at the nozzle and a holder for inserting a short pole for directing the spray. The chief objections against this method of spraying are that it requires an extra man or two, and its slowness; but, taken altogether, it is the best way known to the writer for spraying any considerable area thoroughly.

Exp. 3, in Farnham field with late potatoes. This level field, of about six acres, has a rich but slightly sandy soil. The cultivation and fertilization were good. The first blight was found in the field August 8, or after the first two sprayings had been made. These treatments were made with the geared power sprayer, but this worked so unsatisfactorily that six rows (plat A, see Table II) next the four unsprayed rows were sprayed on August 8 and August 24 by hand, as shown in Plate XXXIV, a. On August 24 the blight had made such progress in the main part of the field sprayed by the geared machine that part of this was sprayed more thoroughly by hand, but this was too late to materially check the advance of the blight. On this date the thoroughly sprayed six rows, plat A, were in fair condition, while the unsprayed rows were two-thirds gone with the blight. On September 3 the unsprayed rows were entirely dead; the imperfectly sprayed main field, plat B, was about as badly gone; while the more thoroughly sprayed plat A was still green, having only about half the foliage destroyed. (See Plate XXXVII.) The yield, as tested on September 4, gave the more perfectly sprayed plat A 59 per cent. greater yield by weight than the unsprayed rows next to it, while the imperfectly sprayed plat B, which was tested quite removed from the check unsprayed rows, gave 42 per cent. greater yield. At this date little rot had developed in the field. As the vines in plat A were still partially green at this time, a second test of this and the check rows was made on September 25, after all the vines were dead. This test was made in rows side by side with the first. It showed that while plat A had made some increase in weight and number of marketable tubers during this interval, this was completely offset by the rot that had developed. The unsprayed rows, however, being entirely dead, had made no increase and had suffered more severely through rot. So on the second digging the sprayed plat A showed 9I per cent. increase in weight over the 
unsprayed. This experiment indicates that the rot starts soon after the death of the vines, usually in a week or so, as was shown in the digging of the main field.

Table II.-Láte Potatoes, Farnham Field, 1903.

\begin{tabular}{|c|c|c|c|c|c|c|c|c|c|c|c|c|}
\hline \multirow[b]{2}{*}{ Treatment. } & \multirow[b]{2}{*}{$\begin{array}{c}\text { Dug } \\
\text { (200 feet). }\end{array}$} & \multirow{2}{*}{ 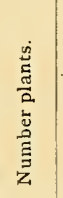 } & \multicolumn{2}{|c|}{$\begin{array}{l}\text { Large to } \\
\text { medium } \\
\text { tubers. }\end{array}$} & \multicolumn{2}{|c|}{$\begin{array}{l}\text { Medium to } \\
\text { small tubers. }\end{array}$} & \multicolumn{2}{|c|}{$\begin{array}{c}\text { Total } \\
\text { marketable. }\end{array}$} & \multicolumn{2}{|c|}{$\begin{array}{l}\text { Very small } \\
\text { tubers. }\end{array}$} & \multicolumn{2}{|c|}{$\begin{array}{l}\text { Rotten } \\
\text { tubers. }\end{array}$} \\
\hline & & & 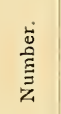 & 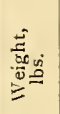 & 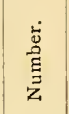 & 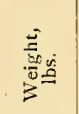 & 离 & 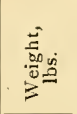 & 䓌 & 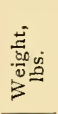 & 崖 & 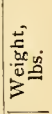 \\
\hline $\begin{array}{l}\text { (A) Sprayed: } \\
\text { July Io, Aug. I, } \\
\text { Aug. 8, Aug. 24. }\end{array}$ & $\begin{array}{lr}\text { Sept. } & 4 \\
\text { Sept. } & 25\end{array}$ & $\begin{array}{l}129 \\
\text { II }\end{array}$ & $\begin{array}{r}\text { I } 5 \text { I } \\
53\end{array}$ & $\begin{array}{l}72 \\
27 \frac{1}{2}\end{array}$ & $\begin{array}{l}563 \\
65 \mathrm{I}\end{array}$ & $\begin{array}{l}\text { I } 15 \\
150 \frac{1}{2}\end{array}$ & $\begin{array}{l}714 \\
704\end{array}$ & $\begin{array}{l}187 \\
178\end{array}$ & $\begin{array}{l}\mathrm{I} 25 \\
\mathrm{I} 72\end{array}$ & $\begin{array}{l}7 \\
8 \frac{8}{4}\end{array}$ & $\begin{array}{r}0 \\
50\end{array}$ & I4 \\
\hline Unsprayed, or & Sept. 4 & I 26 & 29 & I3 & 618 & $104 \frac{1}{2}$ & 647 & $\operatorname{II} 7 \frac{1}{2}$ & I 23 & $6 \frac{1}{2}$ & 5 & \\
\hline Check. & Sept. 25 & I27 & I I & 6 & 369 & 82 & 380 & 93 & I 43 & 9 & IO4 & 25 \\
\hline $\begin{array}{l}\text { (B) Imperfect- } \\
\text { ly sprayed: July } \\
\text { Io, Aug. I, Aug. } \\
24 \text {. }\end{array}$ & Sept. & 130 & 140 & 67 & 444 & 100 & 574 & $x 67$ & 62 & 4 & 4 & \\
\hline
\end{tabular}

Exp. 4, in Farnham field with late variety planted very late. This was in the same field reported in experiment 3 , but the potatoes were not planted until about the middle of June. The experiment was to determine if such late planting on land used earlier in the season for other crops was feasible if the potatoes were sprayed to ward off the blight, which might otherwise carry them off before the tubers were of marketable size. Unfortunately only two treatments were made. Doubtless three would have given better results, especially if the first had been made a little earlier. At the time of the first spraying, August 8 , a little blight was found on these plants, but it was not nearly so abundant as in the unsprayed part of the earlier planted potatoes. On August 24, at the time of the second spraying, the fungus was common in the check rows of the unsprayed late-planted potatoes, but still was not nearly so abundant as in the unsprayed early planted potatoes. This confirms DeBary's statement that blight generally seems to develop most prominently in a field when the vines are in their prime of development. On September 3 the unsprayed rows were very nearly gone with 
the blight, while the sprayed rows still retained half of their foliage. The sprayed plat was dug September 25, when the yield was found to be a little greater and the rot a little less than in the unsprayed plat of the early planted portions of the field. It was not possible to compare it with its proper check, since this had been dug by accident a few days before, but the man in charge said that these unsprayed rows had yielded very poorly. It would seem from this experiment, then, that where it is very desirable to use a field for another crop until the middle of June, a moderate yield of potatoes can be secured from it afterward if these are thoroughly sprayed three times to ward off the blight.

Exp. 5, in Ogden field with early and late potatoes. This field contained about one acre and a half of rather level and medium rich land. The day before planting the potatoes the green rye on the field was plowed under. Dry weather followed, so that the potatoes were a long time coming up, and a very uneven stand was made, as many of the plants never came up or were rotted off below the ground by a bacterial rot. Without much question, the humus of the decaying rye had much to do with this stem rot and the severe rot of the tubers that developed later. The field was very poorly cultivated and became very weedy. All of these conditions were against the potatoes. The vines were sprayed three times (July 5, August II, September I), twice with the geared spraying machines and once with the stationary nozzle outfit shown on Plate XXXIV, b. It was impossible with either of these appliances to properly cover the foliage, even by going over the field two and three times each spraying. Consequently the spraying was done very imperfectly. August II, at the time of the second spraying, blight was first noticed in the field, being most abundant on the unsprayed early potatoes. September I the blight was quite prevalent in the field and with but slight difference in favor of the sprayed parts. When dug on September 2I all of the vines had been dead for some time. The rot, which developed very badly, was largely a soft bacterial rot. A field nearby suffered very little from rot. The sprayed plat of the late variety, which constituted most of the field, gave 20 per cent. less yield by weight than did its unsprayed plat. This was the only experiment during the three years in which a smaller yield was got from a sprayed than from an unsprayed 
plat, but even here the yield was originally greater in the sprayed plat, but lost through more severe rotting of the tubers. The early variety, however, gave an increase of 100 per cent. for the sprayed over the unsprayed vines. Because of the imperfect spraying and the development of severe rot, probably due to plowing under the green rye, the experiment was not very satisfactory. See Table III. for details.

Table III.-Late and Early Potatoes, Ogden Field, Igo3.

\begin{tabular}{|c|c|c|c|c|c|c|c|c|c|c|c|c|}
\hline \multirow[b]{2}{*}{ Treatment. } & \multirow{2}{*}{$\begin{array}{l}\text { Dug. } \\
\text { (roo fert.) }\end{array}$} & \multirow{2}{*}{ 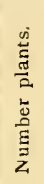 } & \multicolumn{2}{|c|}{$\begin{array}{l}\text { Large to } \\
\text { medium. } \\
\text { tubers. }\end{array}$} & \multicolumn{2}{|c|}{$\begin{array}{l}\text { Medium to } \\
\text { small } \\
\text { tubers. }\end{array}$} & \multicolumn{2}{|c|}{$\begin{array}{c}\text { Total } \\
\text { marketable. }\end{array}$} & \multicolumn{2}{|c|}{$\begin{array}{l}\text { Very small } \\
\text { tubers. }\end{array}$} & \multicolumn{2}{|c|}{$\begin{array}{l}\text { Rotten } \\
\text { tubers. }\end{array}$} \\
\hline & & & $\begin{array}{l}\text { 㟧 } \\
\text { है } \\
\text { है }\end{array}$ & 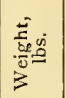 & 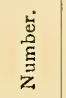 & 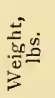 & 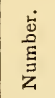 & 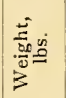 & 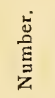 & 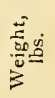 & 岕 & مُ \\
\hline $\begin{array}{l}\text { A. Late variety. } \\
\text { Imperfectly } \\
\text { sprayed: } \\
\text { July I5, Aug. I I, } \\
\text { Sept. I. } \\
\text { Unsprayed: }\end{array}$ & $\begin{array}{l}\text { Sept. 2I } \\
\text { Sept. 2I }\end{array}$ & $\begin{array}{l}64 \\
64\end{array}$ & $\begin{array}{l}6 \\
2\end{array}$ & $\begin{array}{l}3 \\
\mathrm{I}\end{array}$ & $\begin{array}{r}92 \\
131\end{array}$ & $\begin{array}{l}17 \\
23\end{array}$ & $\begin{array}{r}9^{8} \\
\mathbf{1} 33\end{array}$ & $\begin{array}{l}20 \\
24\end{array}$ & $\begin{array}{r}96 \\
\text { r } 88\end{array}$ & $\begin{array}{l}4 \\
9\end{array}$ & $\begin{array}{r}165 \\
81\end{array}$ & $\begin{array}{l}22 \\
\text { II } 1 / 2\end{array}$ \\
\hline $\begin{array}{l}\text { B. Early variety. } \\
\text { Imperfectly } \\
\text { sprayed: } \\
\text { July I5, Aug. II, } \\
\text { Sept. I. } \\
\text { Unsprayed: }\end{array}$ & $\begin{array}{l}\text { Sept. 2I } \\
\text { Sept. 2I }\end{array}$ & $\begin{array}{l}60 \\
55\end{array}$ & $\begin{array}{l}2 \\
0\end{array}$ & $\begin{array}{l}\text { I } 1 / 2 \\
0\end{array}$ & $\begin{array}{r}223 \\
92\end{array}$ & $\begin{array}{l}35 \\
18\end{array}$ & $\begin{array}{r}225 \\
92\end{array}$ & $\begin{array}{l}361 / 2 \\
18\end{array}$ & $\begin{array}{r}126 \\
73\end{array}$ & $\begin{array}{l}6 \\
4\end{array}$ & $\begin{array}{l}74 \\
39\end{array}$ & $\begin{array}{r}\text { I0 } \\
6\end{array}$ \\
\hline
\end{tabular}

Spraying Experiments in 1904.

General Notes. This year was drier and warmer than either of the two preceding years and did not develop special blight weather during July or August. The very first blight seen was on August 3, but September found most of the late potato fields still green, and it was during the moist weather of this month that most of the injury to the foliage was done. Coming so late in the season, however, this injury would have been insignificant, and a large crop would have been harvested, but for the fact that this late blighting served to supply the spores that during the moist weather of September and October started a very serious and widespread rot of the tubers. Unlike the pre- 
ceding year, this rot could be directly traced in its beginning to the blight fungus. The rot started at any place on the tubers, attacking small as well as large ones when severe, and showed the characteristic sunken areas with reddish brown discoloration of the superficial tissues beneath. There is little doubt, however, that after the blight fungus started the trouble, bacteria were often responsible for extending it, even outstripping the blight fungus in their progress and injury.

Exp. 6, in Farnham field with early potatoes and early spraying. This was a level, rather low field of rich but slightly sandy soil, and was well fertilized and thoroughly cultivated during the season. The aim of the experiment was to determine if spraying would prove profitable in a field of early potatoes that were to be dug and sold, at least in part, as soon as they were of marketable size. As the earliest potatoes are often dug for the market about the time that the blight appears, it was not expected that benefit would result so much from preventing blight as it would from better protection against potato bugs and flea beetles, and from the stimulation that Bordeaux mixture seems to give potatoes even when free from fungus attack. Blight was so late in appearing that it was not found in this field even on the unsprayed vines. The gain from spraying, therefore, resulted entirely from better protection of the foliage from insect attack and from the stimulative action of the Bordeaux mixture. The spraying was made with the barrel pump mounted in a cart and was done very thoroughly. The first treatment was given June I7, and the second, on July 7 , was made on only part of the field next the unsprayed rows. The difference in appearance of foliage between the sprayed and unsprayed plats on July 7 was marked. In the plats sprayed with Bordeaux mixture one pound of Paris green per barrel was used, and as the foliage was thoroughly covered and the sediment adhered through the season, this protected the vines completely from the potato beetles. The check rows also had been sprayed twice with Paris green only (by the owner), with a geared spraying machine. The spraying by this method was imperfectly done and there was nothing to keep the poison from washing off by rains, so these vines suffered severely from attack by the bugs, and as no lime was used with the Paris green this also burned the foliage considerably. The 
first digging was made on July 20 , as soon as the tubers were ready for market. Despite the injury from the bugs and Paris green burn, the unsprayed plat at this digging yielded about as well as either the plat sprayed once, which gave only 3 per cent. greater yield by weight, or the plat sprayed twice, which gave 5 per cent. greater yield. As the sprayed plants at this time were still in their prime and the unsprayed plants nearly dead, a second test was made August 5, after all the plants were about gone. The test showed an increase of 8 per cent. in those sprayed once and of $\mathrm{r} 7$ per cent. of those sprayed twice over the unsprayed plat. There was no loss from rot. This experiment indicates that, where early potatoes are dug as soon as marketable, spraying with Bordeaux mixture does not pay, but when these potatoes are left until the vines are entirely dead the spraying will be of greater value, especially if early blight has been injurious or the late blight appears before the end of their season. There is no doubt that Paris green used in Bordeaux is more effective in repelling attack of the potato beetle and even the flea beetle than when used alone, and there is then absolutely no danger of burning the foliage. It is the extra cost of applying the Bordeaux mixture, especially if labor is an important factor, that largely offsets its benefits in spraying early potatoes, unless these are severely injured by preventable fungus attack. For details of experiment, see Table IV.

Table IV. Early Potatoes, in Farnham Field, igo4.

\begin{tabular}{|c|c|c|c|c|c|c|c|c|c|c|c|}
\hline \multirow{2}{*}{ Treatment. } & \multirow{2}{*}{$\begin{array}{c}\text { Dug. } \\
(200 \text { ft. })\end{array}$} & \multirow{2}{*}{ 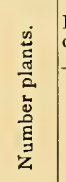 } & \multicolumn{2}{|c|}{$\begin{array}{l}\text { Large to me- } \\
\text { dium tubers. }\end{array}$} & \multicolumn{2}{|c|}{$\begin{array}{c}\text { Medium to } \\
\text { small tubers. }\end{array}$} & \multicolumn{2}{|c|}{$\begin{array}{c}\text { Total } \\
\text { marketable. }\end{array}$} & \multicolumn{2}{|c|}{$\begin{array}{l}\text { Very small } \\
\text { tubers. }\end{array}$} & \multirow{2}{*}{ 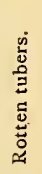 } \\
\hline & & & 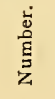 & 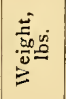 & 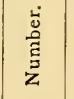 & 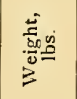 & 总 & 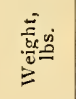 & 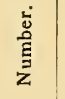 & 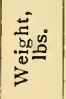 & \\
\hline Sprayed once, June I7. & $\begin{array}{l}\text { July } 20 \\
\text { Aug. } 5\end{array}$ & I46 & $\begin{array}{r}4 \\
22\end{array}$ & $\begin{array}{r}3 \\
13\end{array}$ & $\begin{array}{l}1007 \\
1022\end{array}$ & $2071 / 2$ & $\begin{array}{l}\text { IOI I } \\
\text { IO44 }\end{array}$ & $\begin{array}{l}2001 / 2 \\
219\end{array}$ & $\begin{array}{l}3 \text { I9 } \\
356\end{array}$ & $\begin{array}{l}121 / 2 \\
15\end{array}$ & $\begin{array}{l}0 \\
2\end{array}$ \\
\hline $\begin{array}{l}\text { Sprayed twice, June } \\
\text { I } 7, \text { July } 7 .\end{array}$ & $\begin{array}{l}\text { July } 20 \\
\text { Aug. } 5\end{array}$ & $\begin{array}{r}148 \\
--\end{array}$ & $\begin{array}{r}4 \\
34\end{array}$ & $\begin{array}{l}21 / 2 \\
20\end{array}$ & $\begin{array}{ll}\text { I I I } 4 \\
\text { IO34 }\end{array}$ & $\begin{array}{l}210 \\
2241 / 2\end{array}$ & $\begin{array}{l}\text { II } 18 \\
\text { I068 }\end{array}$ & $\begin{array}{l}2121 / 2 \\
2441 / 2\end{array}$ & $\begin{array}{l}294 \\
400 \tilde{0}\end{array}$ & $\begin{array}{l}\text { I3 } \\
\text { I6 }\end{array}$ & $\begin{array}{l}0 \\
2\end{array}$ \\
\hline Unsprayed. & $\begin{array}{l}\text { July } 20 \\
\text { Aug. } 5\end{array}$ & $\begin{array}{r}148 \\
---\end{array}$ & $\begin{array}{l}17 \\
20\end{array}$ & $\begin{array}{l}\text { I I } 1 / 2 \\
\text { I } 2\end{array}$ & $\begin{array}{l}915 \\
99^{8}\end{array}$ & $\begin{array}{l}184 \\
196\end{array}$ & $\begin{array}{r}932 \\
1018\end{array}$ & $\begin{array}{l}\text { I95 } 1 / 2 \\
208^{2}\end{array}$ & $\begin{array}{l}387 \\
334\end{array}$ & $\begin{array}{l}15 \\
15\end{array}$ & \\
\hline
\end{tabular}


Exp. 7, in Farnham field with late potatoes. This was an acre field of about the same character as the preceding, except the cultivation given the potatoes was very poor. As a result the field became very weedy, which somewhat hindered spraying, and the tubers were formed so close to the ground that they were easily reached by the spores of the blight fungus and so suffered severely from rot. All the potatoes except three check rows were sprayed four times, using the barrel pump mounted on a cart, namely, on July 7, July 20, August 5 and August 20. As the potatoes were planted very late, the first spraying was made when they were only eight to ten inches high. The vines were severely attacked by potato bugs, especially the check rows, though these were sprayed twice by a geared machine with Paris green only. On August 5, or at the time of the third spraying, no blight was found in the field. The writer was not present at the fourth spraying, but when examined again on September 8 the unsprayed vines were all dead, though the stems were still green, having apparently been injured chiefly by the potato bugs. The sprayed vines were still green, but now showed many blighted leaves scattered through the field. The fungicide at this time was almost all off the foliage and the wet September weather that followed rapidly developed the blight, so that at the end of the next ten days the vines were mostly dead. The effect of this delayed appearance of the blight was to develop a serious rot of the tubers, especially in the sprayed plat, for the vines in the unsprayed plat had largely died before the appearance of the blight. If the potatoes had been properly cultivated, and especially if the tubers had been buried deeper under the soil by some system of ridge culture, it does not seem likely that the rot would have developed nearly so badly. The potatoes were not dug for the test until October 4, when it was found the rot had become very serious, especially in the center of the field, which was slightly lower and probably more moist. The rot apparently had developed recently, as the lower end of the field when dug a week or ten days before revealed little rot. The test showed that while the sprayed plat developed much more rot (half the tubers were rotted) than the unsprayed plat, it still gave a yield of sound tubers 73 per cent. greater in weight. For details, see Table V. 
Table V. Late Potatoes planted late, in Farnham Field, I904.

\begin{tabular}{|c|c|c|c|c|c|c|c|c|c|c|c|c|}
\hline \multirow[b]{2}{*}{ Treatment. } & \multirow[b]{2}{*}{$\begin{array}{c}\text { Dug. } \\
(200 \text { ft. })\end{array}$} & \multirow[b]{2}{*}{$\begin{array}{l}\text { Number } \\
\text { plants. }\end{array}$} & \multicolumn{2}{|c|}{$\begin{array}{l}\text { Large to } \\
\text { medium } \\
\text { tubers. }\end{array}$} & \multicolumn{2}{|c|}{$\begin{array}{l}\text { Medium to } \\
\text { small } \\
\text { tubers. }\end{array}$} & \multicolumn{2}{|c|}{$\begin{array}{c}\text { Total } \\
\text { marketable. }\end{array}$} & \multicolumn{2}{|c|}{$\begin{array}{c}\text { Very } \\
\text { small } \\
\text { tubers. }\end{array}$} & \multicolumn{2}{|c|}{$\begin{array}{l}\text { Rotten } \\
\text { tubers. }\end{array}$} \\
\hline & & & 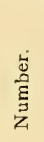 & 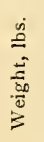 & $\begin{array}{l}\text { 岀 } \\
\text { हี } \\
\text { z }\end{array}$ & 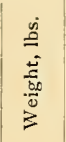 & 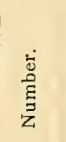 & 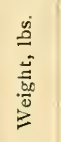 & 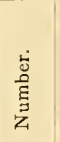 & 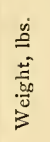 & 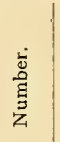 & 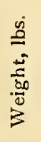 \\
\hline $\begin{array}{l}\text { Sprayed, July } \\
7 \text {, July 2o, } \\
\text { Aug. 5, Aug. } \\
20 .\end{array}$ & Oct. 4 & $\begin{array}{c}\text { Not } \\
\text { Recorded }\end{array}$ & 5 & 4 & 367 & $681 / 2$ & 372 & $72 \frac{1}{2}$ & I90 & $7 \frac{1}{2}$ & 370 & 82 \\
\hline Unsprayed. & Oct. 4 & & 3 & 2 & 265 & 40 & 268 & 42 & $44 I$ & I4 & 44 & 4 \\
\hline
\end{tabular}

Exp. 8, in Clinton garden with early and late potatoes. This garden is in an isolated spot, well shut off by trees and hills from any other garden or field, and has been in use only two years. Whether this accounts for it or not, it is a fact that during these two years blight has been slower in appearing here and less injurious than in almost any place observed by the writer. The location is rather low, and moist at one end, and the soil is derived largely from red rock, but with plenty of humus. These potatoes were sprayed with one of the compressed air knapsack sprayers, which work fairly well when comparatively small patches are to be sprayed. The blight did little damage to the early potatoes and developed in the late abundantly only

Table VI. Late and Early Potatoes, in Clinton Garden, 1904.

\begin{tabular}{|c|c|c|c|c|c|c|c|c|c|c|c|c|}
\hline \multirow{2}{*}{ Treatment. } & \multirow{2}{*}{$\begin{array}{l}\text { Dug. } \\
\text { (50 ft.) }\end{array}$} & \multirow{2}{*}{ 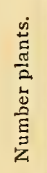 } & \multicolumn{2}{|c|}{$\begin{array}{l}\text { Large to } \\
\text { medium } \\
\text { tubers. }\end{array}$} & \multicolumn{2}{|c|}{$\begin{array}{c}\text { Medium } \\
\text { small } \\
\text { tubers. }\end{array}$} & \multicolumn{2}{|c|}{$\begin{array}{c}\text { Total } \\
\text { marketable. }\end{array}$} & \multicolumn{2}{|c|}{$\begin{array}{l}\text { Very small } \\
\text { tubers. }\end{array}$} & \multicolumn{2}{|c|}{$\begin{array}{l}\text { Rotten } \\
\text { tubers. }\end{array}$} \\
\hline & & & 离 & 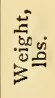 & 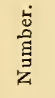 & 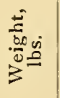 & 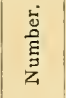 & 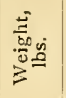 & 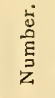 & 营 & 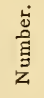 & 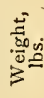 \\
\hline $\begin{array}{l}\text { A. Early Potatoes. } \\
\text { Sprayed June 23, } \\
\text { July 2.... } \\
\text { Unsprayed }\end{array}$ & $\begin{array}{l} \\
\text { Oct. } 6 \\
\text { Oct. } 6\end{array}$ & $\begin{array}{l}33 \\
33\end{array}$ & $\begin{array}{l}4 \\
0\end{array}$ & $\begin{array}{l}2 \frac{1}{2} \\
0\end{array}$ & $\begin{array}{l}\text { I } 84 \\
\text { I } 50\end{array}$ & $\begin{array}{l}38_{\frac{1}{2}} \\
29\end{array}$ & $\begin{array}{l}192 \\
150\end{array}$ & $\begin{array}{l}4 \mathrm{I} \\
29\end{array}$ & $\begin{array}{l}30 \\
53\end{array}$ & $\begin{array}{l}1 \frac{1}{4} \\
2 \frac{1}{4}\end{array}$ & $\begin{array}{r}3 \\
17\end{array}$ & $3^{\frac{3}{4}}$ \\
\hline $\begin{array}{l}\text { B. Late Potatoes. } \\
\text { Sprayed July 2, } \\
\text { Juily 27-... } \\
\text { Unsprayed }\end{array}$ & $\begin{array}{l}\text { Oct. } 6 \\
\text { Oct. } 6\end{array}$ & $\begin{array}{l}32 \\
36\end{array}$ & $\begin{array}{l}\text { II } \\
\text { II }\end{array}$ & $\begin{array}{l}8 \\
8\end{array}$ & $\begin{array}{l}161 \\
163\end{array}$ & $\begin{array}{l}47 \\
42\end{array}$ & $\begin{array}{l}\text { I } 72 \\
\text { I } 74\end{array}$ & $\begin{array}{l}55 \\
50\end{array}$ & $\begin{array}{l}27 \\
27\end{array}$ & $\begin{array}{l}\mathrm{I} \frac{1}{4} \\
\mathrm{I} \frac{1}{3}\end{array}$ & $\begin{array}{l}7 \\
6\end{array}$ & $\begin{array}{r}2 \frac{1}{2} \\
\frac{8}{4}\end{array}$ \\
\hline
\end{tabular}


at the very end of the season. These latter should have had one or two more sprayings. There was very little rot, probably because the tubers were well covered by earth through ridge culture; the patch was a decided contrast, in this respect, with the Farnham field, Exp. 7, which was dug a few days before. The early potatoes gave an increase of $4 \mathrm{I}$ per cent., but the late only io per cent. over their unsprayed rows.

\section{Summary and Conclusions.}

The blight fungus, Phytophthora infestans, while by far the worst fungous pest of the potato in Connecticut, is often held responsible for any serious injury to the vines or rot of the tubers. The Rhizoctonia fungus, the early leaf blight, the Fusarium fungus, the bacterial stem rot, the wet bacterial rot of tubers and the well known scab are all parasitic agents at work in our potato fields and cause more or less injury. Considerable burning of the leaves is also done by the careless use of Paris green. In dry seasons, due to uncontrolled loss of moisture, tip burn of the leaves may develop.

During the three seasons I902, 1903, I904, which were years more moist than the average, the potatoes in this state suffered rather severely from blight, the crops being cut down at least 25 per cent. In I902 the sudden and early blighting of the vines prevented a large yield, but there was little rot; in 1903 the yield was affected somewhat by the blighting of the vines, but was decreased chiefly by bacterial and Fusarium rots of the tubers that were apparently started by the premature death of the vines; while in 1904 blight was so late in developing that it did little injury to the vines, but did develop a serious rot of the tubers that carried off a large percentage of the crop.

Early potatoes suffer very much less from blight, especially in limiting the life of the vines, than the late varieties. This is because the blight often appears only toward the end of their season and sometimes not until they are entirely gone. It might be advocated, then, that early potatoes should largely supplant the late varieties. The yield from the late varieties, however, aside from serious injury from blight, is considerably greater, and because of this, and probably for other reasons, the late varieties generally seem to be much more in favor with 
growers. Early potatoes, too, are not exempt from serious troubles.

There is no doubt that the character of the season is the dominant factor in determining how little or how much damage will be caused by blight. Rainy weather in July and August starts the fungus in the fields, and if there then comes a continuous period of rainy, cloudy or foggy weather the foliage will soon be destroyed. Wet weather in August or September following the blighting of the vines determines largely the amount of rot that develops in the tubers.

Besides the weather conditions, the moisture capacity of each field or portion of a field no doubt determines largely in a wet season the amount of rot that develops. This moisture in the soil is determined largely by elevation, drainage, mechanical character of the soil and its humus content. Other conditions being equal, well-drained, light, sandy soils apparently develop the least rot. As manure adds to the humus of the soil and is a carrier of certain troubles, as scab, etc., artificial fertilizers, rather than manure, should be used on the land the year it is planted with potatoes.

As the blight fungus, so far as known, carries over the winter only in the seed potatoes, the first step in lessening the disease should be with the selection of seed as free as possible from this and any other fungus disease, as scab, Rhizoctonia, etc. The selection of even perfect seed will not secure freedom from blight, as this trouble is often carried from one field to another after its general appearance; but it possibly may defer the time of its attack and lessen the injury.

Thorough cultivation tends to conserve the moisture of the soil in a dry season (when there is little danger of rot) and in a wet season it helps to keep the ground from becoming wet and soggy. Ridging the rows as late as possible in July holds up the vines from the ground and thus aids in a quicker evaporation of moisture from the foliage and ground, and in so doing aids in retarding the spread of the blight. It also covers the tubers deeper in the soil and so protects them better from the blight spores that fall from the leaves. Where spraying is practiced it also makes this operation easier. The objection to ridging is that in a dry season it may cause the plants to suffer for lack of moisture. 
The results of spraying with Bordeaux mixture vary with different seasons, but depend largely on the thoroughness of the treatments and their application at the proper time. It is much easier to secure an increased yield of potatoes from spraying than it is to prevent rot in these afterward. This increased yield varies from almost nothing to sometimes over roo per cent., and the rot of the tubers is usually less in the sprayed than in the unsprayed fields. An average gain of 15 to 20 per cent. should be had in order to pay for the extra cost and trouble of spraying; any gain above that is profit.

When late potatoes are to be sprayed for blight, the writer advocates three or four thorough applications, the first to be made July 5 to 15 , according to the weather, and the final one the last of August or first of September. Paris green, if needed, can be used in the Bordeaux, half a pound to the barrel. Two to three barrels of the mixture should be used per acre at each spraying. Aim to have the vines thoroughly protected with the fungicide when the blight weather appears.

Geared spraying machines are rather unsatisfactory for spraying Bordeaux mixture, since they cover the vines very imperfectly with the spray. If used, the vines should be gone over two or three times each spraying. The barrel pump mounted on a cart that can straddle two rows of potatoes, and one man to drive and pump and one or two men to follow on foot, each with a twenty-five-foot hose, treating three or four rows, is the most thorough way of spraying a field. (See Plate XXXIV, a.)

When there is danger from rot the potatoes should be dug only in bright weather, after the dew is off the vines, and they should be spread out to dry off and be gathered up before evening. When the vines are blighting it is difficult to dig the potatoes without the spores coming in contact with the tubers, so some advocate leaving the potatoes in the ground at least ten days or two weeks after the death of the vines. Potatoes should be dried as thoroughly as possible before storage and should finally be stored in a dry, cool place. A little dry airslaked lime dusted over them no doubt aids somewhat in their drying out. 

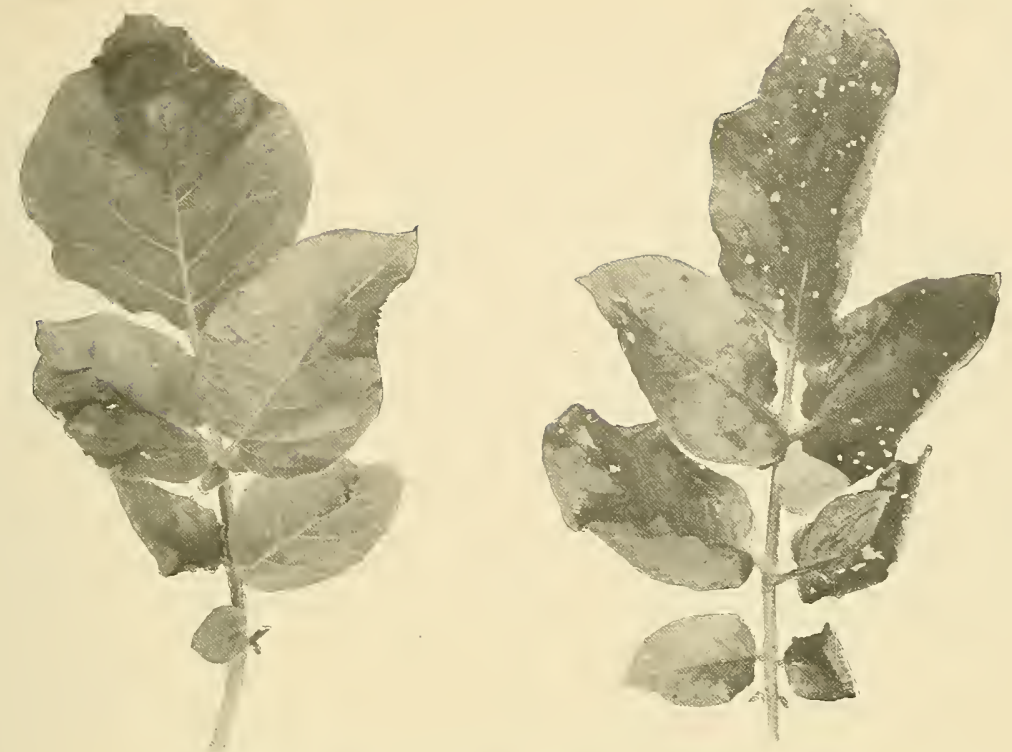

a. Green leaves showing early stage of blight, p. 356.

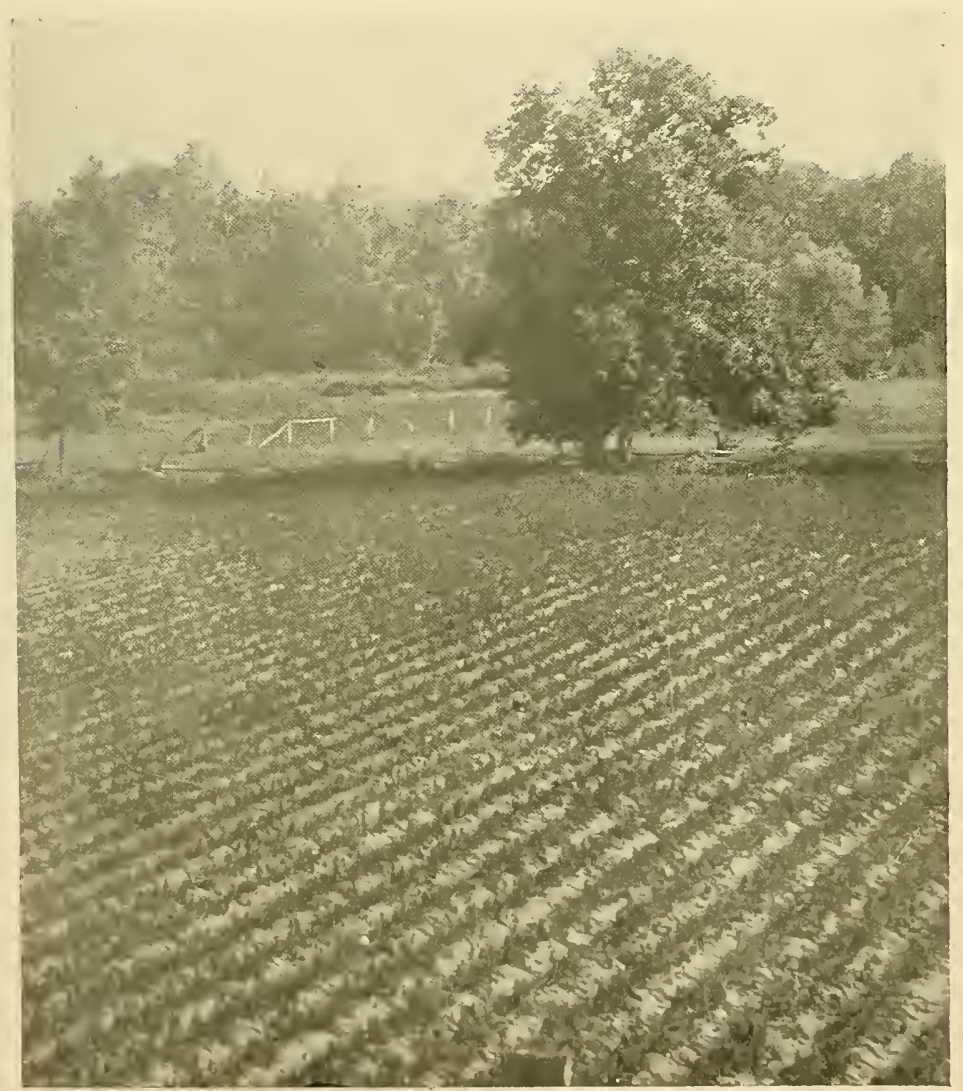

b. Blighted field which less than week before photographed was perfectly green, p. 300 . 


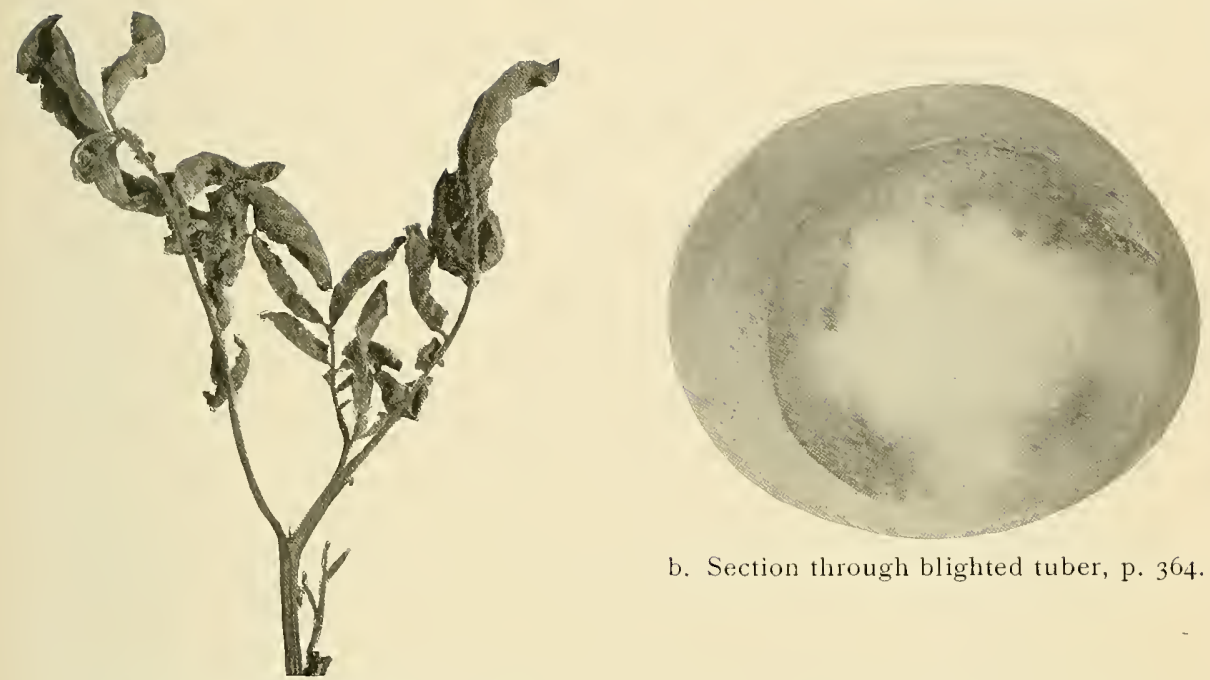

b. Section through blighted tuber, p. 364 .

a. Late stage of blighted leaves, p. 366.

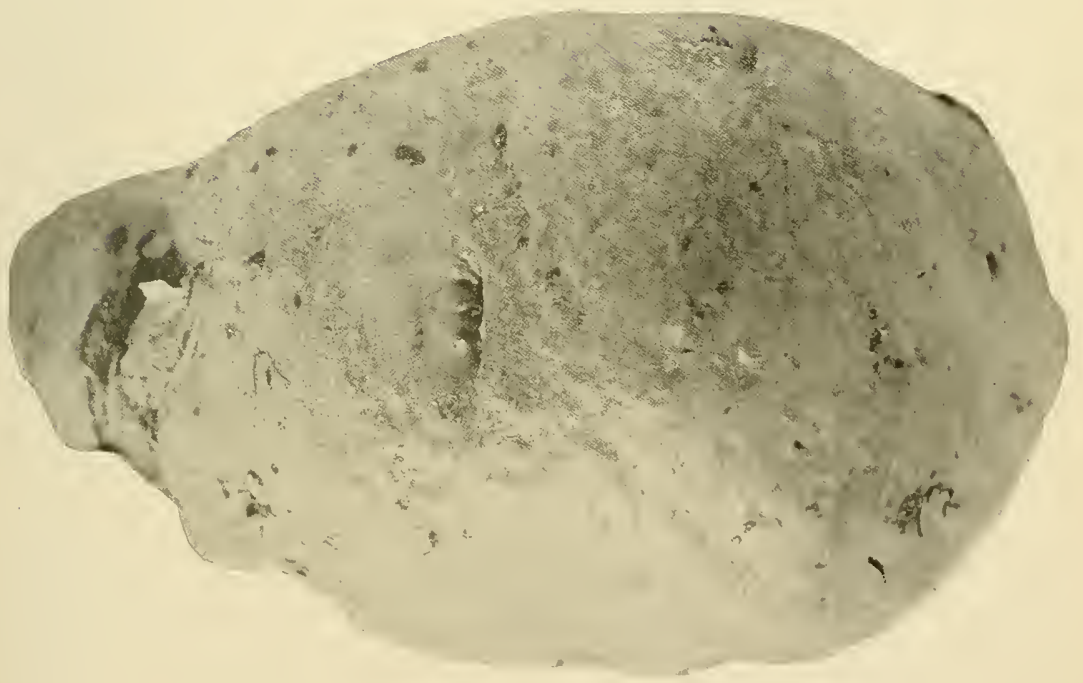

c. Blighted tuber, pitted and discolored reddish brown.

BLIGHT OF POTATO, Phytophthora infestans. 

PLATE XXXIV.

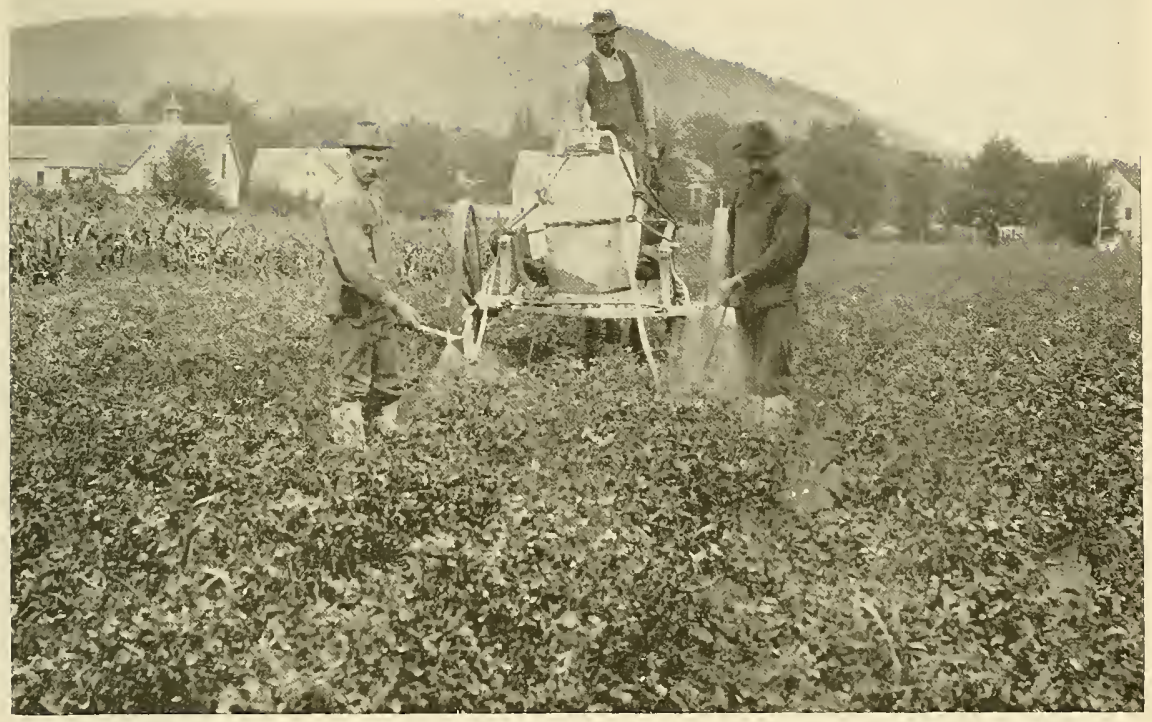

a. Best method for spraying potatoes, because the work can be done thoroughly, p. 373 .

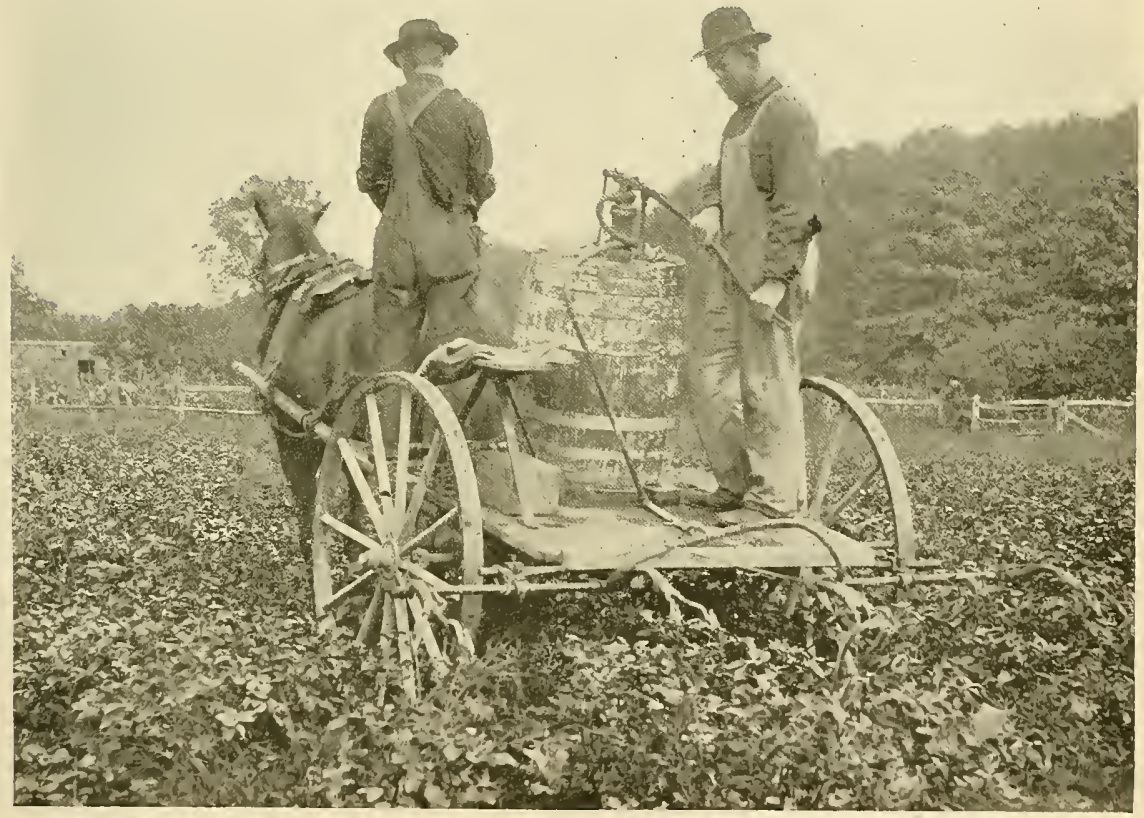

b. Less satisfactory, because of stationary nozzles; pump, also, was not powerful enough to use the eight nozzles, p. 373. 

PLATE XXXV.

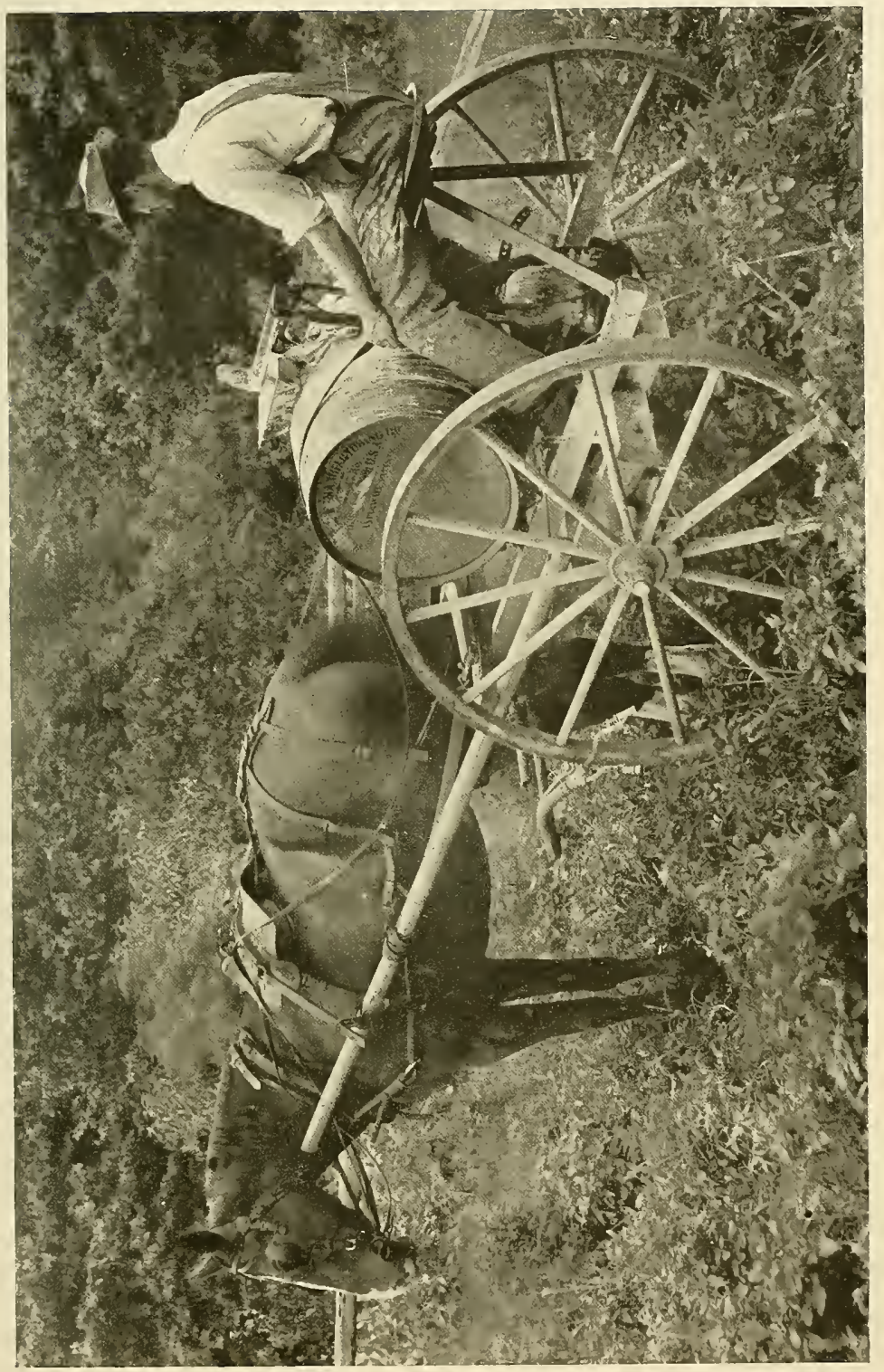

م 



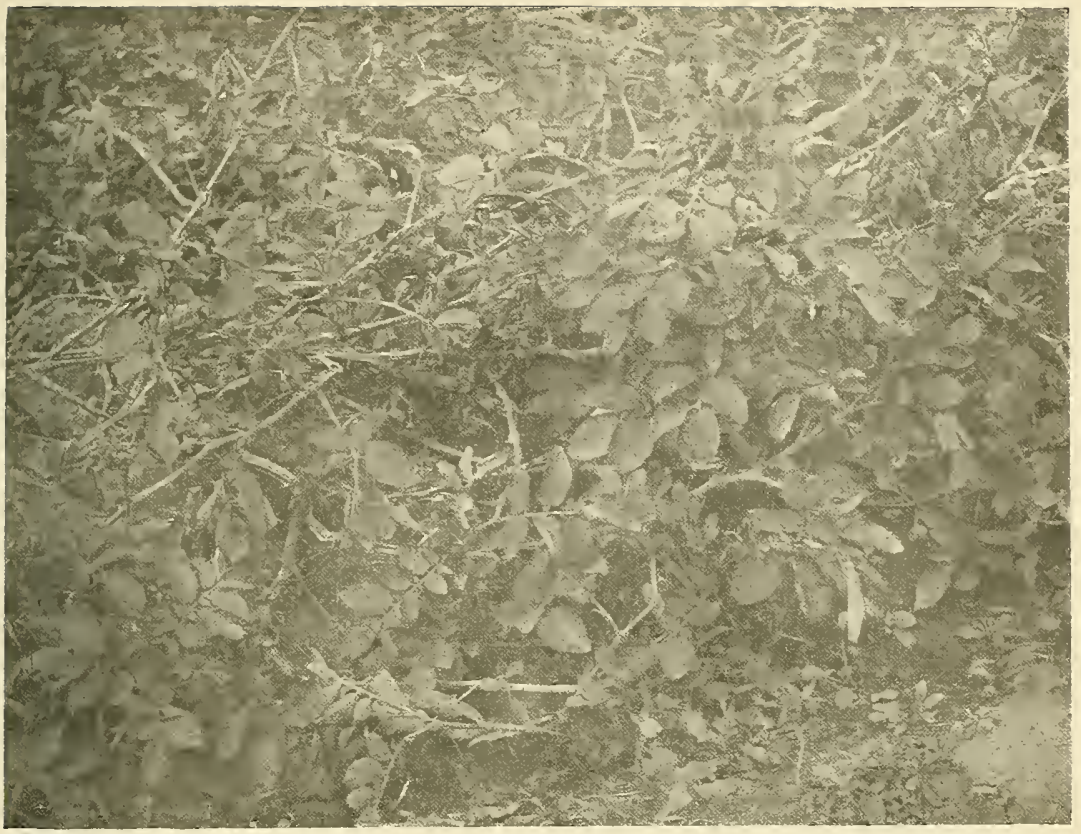

a. Sprayed plant in Ogden's field; photographed Sept. I6, IgO2, p. 370.

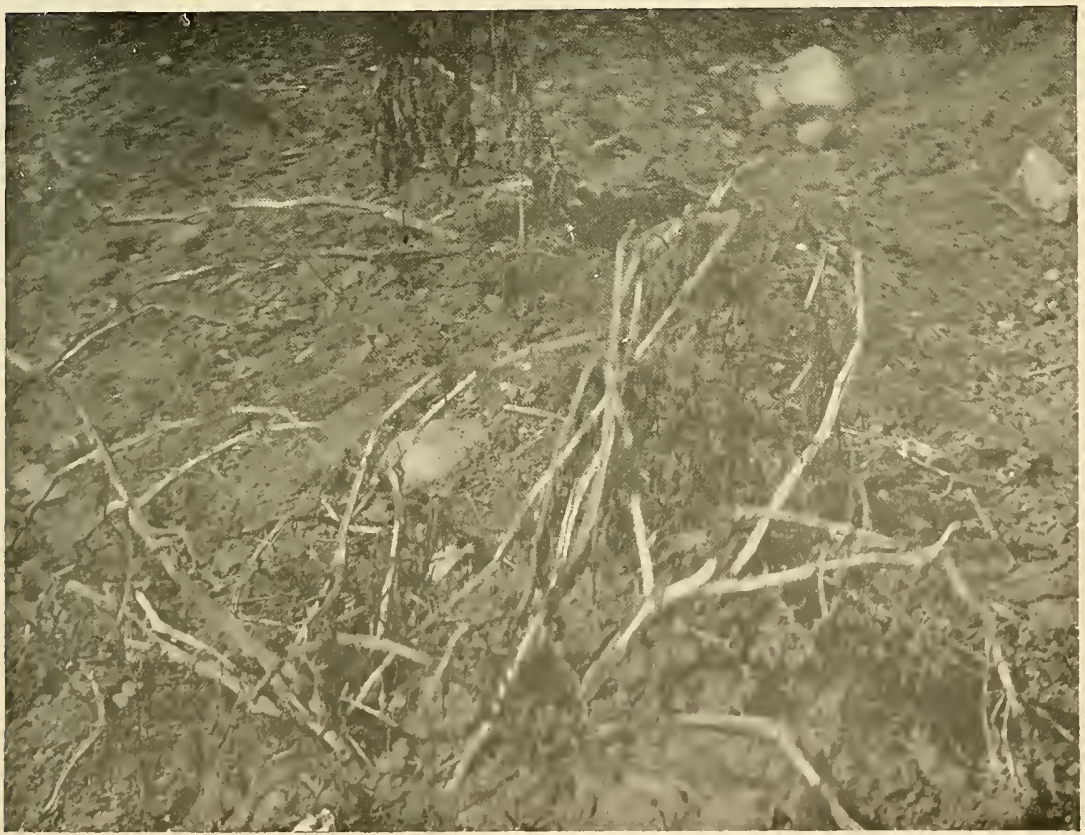

b. Check or unsprayed plant in Ogden's field: photographed same date, p. 370.

SPRAYING FOR POTATO BLIGHT, Phytophthora infistans. 

PLATE XXXVII.

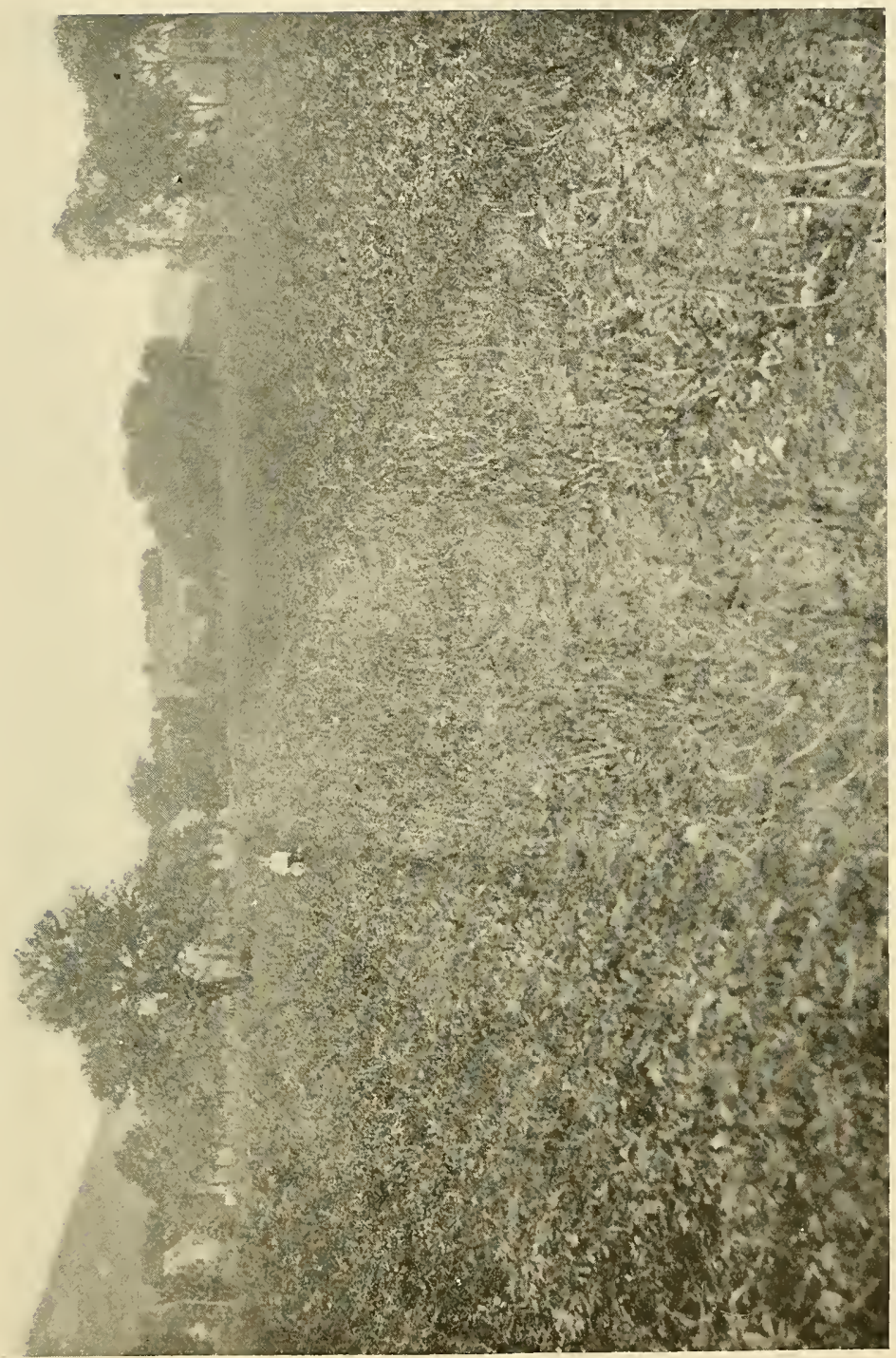

D 





\section{Itate of Connecticut}

REPORT

. OF

The Connecticut Agricultural Experiment Station

FOR THE YEAR 1905

PART V

REPORT OF THE STATION BOTANIST 



\section{CONNECTICUT}

\section{AGRICULTURAL EXPERIMENT}

\section{STATION}

\section{REP0RT OF THE BOTANIST}

G. P. CLINTON, Sc. D.

I. Notes on Fungous Diseases, etc., for 1905.

II. Downy Mildew, Phytophthora Phaseoli Thaxt., of Lima Beans.

III. Downy Mildew, or Blight, Phytophthora infestans (Mont.) DeBy., of Potatoes. II. 



\section{REPORT OF THE BOTANIST.}

\section{NOTES ON FUNGOUS DISEASES, ETC., FOR I905.}

Fungous diseases during the year I905, on the whole, were less troublesome to cultivated plants in Connecticut than for several years past. This was due to the comparatively dry growing season up to the first part of August. From this time on, however, the weather was sufficiently moist to develop a few troublesome diseases, belonging chiefly to the downy mildew group. The more important of these were as follows:

Brown rot of peach, Sclerotinia fructigena, probably took off a third of the crop and was much worse than usual, being one of the most serious fungous outbreaks of the year. The injury was induced by the rainy weather coming on just about harvest time. The loss from rot was felt most seriously in the Wallingford district. Plums, also, were injured but less noticeably.

The downy mildew of grapes, Plasmopara viticola, was more abundant than usual this year but no especial complaints were received concerning it.

Muskmelons, though not now so generally planted because of injury from fungous enemies, were largely a failure, partly because of the attacks of the leaf mold, Alternaria Brassicae var. nigrescens, and of the downy mildew, Peronoplasmopara Cubensis. The latter fungus was also injurious to the cucumber, though the injury was not so great as in I9OI and I902.

The downy mildew of lima beans, Phytophthora Phaseoli, was more destructive than it has been since I897. The oospores of the fungus were found for the first time, though the writer and others had previously looked for them very carefully. The fungus is discussed in detail in a special article later in this report. The rust of string beans, Uromyces appendiculatus, also seemed to be more prevalent than usual.

The downy mildew, or blight, of potatoes did not appear until after the middle of August. By that time the combined injuries of potato bugs, flea beetles, dry weather, and early 
blight (this last being more prominent than usual) had killed the potatoes in many fields, so that these, missing the blight on the foliage, did not suffer subsequently from rot of the tubers. Those fields, however, that were still green when the blight did appear were gradually killed by it and the tubers often rotted considerably. Thus, while there was considerable complaint of rotten potatoes, this injury was not as great as in I904, and the blight injury to the foliage was still less conspicuous.

Point-rot of tomato did some damage to the fruit-more than has been noticed for several seasons. It was not determined whether this trouble was due to bacteria or fungi, but superficial observations seemed to indicate both as primary agents of the disease.

\section{New Diseases.}

The following troubles were not necessarily especially injurious in 1905 but are briefly described here because they have not been mentioned before (see Reports of Botanist for years 1903 and 1904) as occurring in Connecticut.

\section{APPLE, Pirus Malus.}

Fruit Speck, Fungus undet. Plate XIII, a. In February, I905, Mr. E. M. Ives of Meriden gave to the writer for examination specimens of apples showing superficial small spots or specks scattered over the skin. This trouble, while observed by Mr. Ives at harvest time, did not develop conspicuously until some time after storage. The same trouble has been observed by the writer the present winter on apples in the New Haven markets and also on specimens of the Tallman variety at the mid-winter exhibition of the Connecticut Pomological Society. These areas of brownish dead tissue usually varied from the size of a pin head to a quarter of an inch in diameter and extended but slightly into the flesh. The diseased spots in some cases were even more thickly placed than on the Tallman Sweet in the illustration given here. Frequently one could see at the center of the specks small ruptures, as if made by insect-puncture, or possibly the trouble started at the lenticels and these were of that nature. Cultures in test tubes were made at different times by taking diseased tissue beneath 
the epidermis with a sterilized knife and these all developed a fungous growth but in some cases mixed with bacteria. As the fungus was apparently the same in all the cultures, presumably it was the primary cause of the trouble, but it cannot be a very aggressive parasite since the spots remained so small and developed so slowly even on the stored fruit. Nevertheless it is a serious pest for certain varieties in that it greatly mars their appearance and possibly later opens the way for more extended and deep-seated rotting. According to Mr. Ives, Tallman Sweet was the variety most seriously affected, Northern Spy suffered less, while Baldwin was injured but little. From this it would appear that the more tender or earlier maturing winter varieties were more susceptible of attack. Mr. Ives also informs the writer that these apple trees were sprayed in 1905 and the disease did not trouble the crop of that year. No reference in literature has been seen that relates to this trouble, which apparently is a common one.

BEAN, LIMA, Phaseolus lunatus.

Pod ANd Leaf Blight, Phoma subcircinata E \& E. Plate XIII, b. Halsted in I892 briefly mentioned in the rath Ann. Rep. of N. J. Agr. Exp. Stat., p. 287, under the name of Phyllosticta sp., a fungus collected on the pods and leaves of Lima beans. In I893 Ellis also described, in the Proc. Phil. Acad. Nat. Sci., a new fungus on the pods of Lima beans, calling it Phoma subcircinata E. \& E. In a more detailed description in Bull. I5I of the N. J. Agr. Exp. Stat., p. 24-5, Halsted identifies Ellis' fungus as the one to which he had previously referred. The past year the writer found a fungus, apparently the same as described and illustrated by Halsted, on the leaves of Lima beans in the vicinity of New Haven. It was not observed on the pods but may have escaped notice because it was not especially looked for there. While attacking leaves here and there on the plants, the injury was not especially conspicuous in the field. The fungus produced large subcircular, or more irregular, brown, often bordered, spots that gave evidence of their development through faint, elevated, concentric rings of growth. The spore receptacles showed as numerous small black specks immersed in the tissues. In time the dead tissues cracked more or less and wore away, leaving 
holes in the leaves. Our specimens do not agree exactly with those issued by Ellis (N. A. F. No. 2840) on the pods, since their spores average larger, $5^{-1} 2 \mu$ by $2.5-3.5 \mu$, and are occasionally septate. This might be considered by some sufficient to place the fungus under the genus Ascochyta, and Saccardo has described a species, $A$. Phaseolorum, with spores Io by $3^{\mu}$, that possibly may be the same as this.

\section{BUTTERNUT, Juglans cinerea.}

White Mold, Microstroma Juglandis (Berang.) Sacc. This is not an uncommon parasite of butternut leaves, forming white moldy growths more or less thickly on their under sides. Presumably it is not a serious pest. Dr. Britton collected specimens on wild butternuts the past summer at New Canaan.

\section{CATALPA, JAPANESE, Catalpa Kempferi.}

LeAf Spot, Macrosporium Catalpae E. \& M. Plate XIV, a. This trouble was conspicuous during the past summer on a Japanese catalpa at the Experiment Station. Reddish brown, bordered spots, 5 to $10 \mathrm{~mm}$. in diameter, are formed more or less abundantly on the leaves. The tissues of these spots are dead and often crack apart, sometimes falling out. When the trouble is serious the trees are partially defoliated. It has been observed on different species of catalpa in various parts of the United States and has been discussed most extendedly in the Ann. Rep. U. S. Dept. Agr. for 1887, pp. 364-5. Experiments are reported there in which spores of this fungus, and also of another found with it, failed to produce these spots when sown on catalpa leaves. From what the writer saw of the disease he has been led to believe that possibly the Macrosporium (Alternaria) develops on the leaves as a consequence and not as the cause of these dead spots. The fungus belongs to a genus whose species are more often saprophytic than parasitic and are apt to occur on dead tissues. The spores were found only sparingly on the dead spots and sometimes did not seem to be present. No other fungus, however, was observed on these, and so if they were not caused by the Macrosporium they probably were not the result of injury by any other fungus. Further study of the trouble is needed to definitely determine its cause. 
CELERIAC, Apium graveolens var. rapaceum.

Leaf Spot, Septoria Petroselini var. Apii Br. \& Cav. Plate XIV, b. Celeriac is merely a variety of celery having a swollen base. It is not largely grown in Connecticut, but specimens raised for the New Haven market were found to be injured by the leaf trouble which so frequently occurs here on celery (see Report of this Station for IgO3, p. 314).

\section{DANDELION, Taraxacum officinale.}

Rust, Puccinia Taraxaci Plow. This rust, so common on dandelions as weeds, was also observed on dandelions cultivated by a Highwood market gardener; but it was not causing serious injury. The spores form dusty reddish brown outbreaks, about the size of a small pin-head, scattered more or less thickly over either surface of the leaves.

\section{MAPLE, SUGAR, Acer saccharum.}

Leaf Scorch. Plate XV, a. During the past summer and fall maple leaves similar in appearance to that shown in the illustration were sent to the Experiment Station from different parts of the state with inquiry as to the cause of the trouble. Similar specimens and requests have been received in years past. The leaves die at the margins, forming irregular brown patches extending inward a greater or less distance. Sometimes isolated spots are formed wholly surrounded by healthy tissue. In time there often appears a more or less conspicuous blackish growth of saprophytic fungi on the dead tissues. The appearance of affected leaves moreover is very similar to that produced by a true fungous parasite of the maple, namely Glcosporium saccharinum. In no case, however, was this fungus found on the leaves sent in for examination. The trouble is undoubtedly a physiological one, such as has been described by Stone of Massachusetts and Stewart of New York as occurring in those states. For some reason (due probably to drought or winter injury to the roots) the leaves under certain weather conditions are not able to replace the water in their tissues from the roots as rapidly as it is lost through transpiration, and the death of the tissues from the margin inward results. According to Stone the trouble may be produced by unusually favorable 
conditions for the transpiration of water, such as high winds on clear warm days, when the available water supply of the roots is small. Most observers report the trouble as appearing suddenly. A somewhat similar injury to elm leaves, apparently due to the same causes, has also been reported frequently in the state.

NECTARINE, Prunus Persica var. necturina.

Brown Rot, Sclerotinia fructigena (Pers.) Schröt. The nectarine is only occasionally grown in the state, but these few trees seem to suffer considerably from fungous attacks as well as from winter injury. Specimens of the mummied fruit collected in January showed abundance of the Monilia stage of the brown rot fungous. While this is very common on other species of Prunus in the state, it has not been reported before for this host though apparently not uncommon on it.

$\mathrm{SCAB}$, Cladosporium carpophilum Thm. Plate XV, b. In September specimens of nectarines were received from Thompson, Conn., that were badly injured by the scab fungus which is so common in Connecticut on the peach. As the nectarine is a smooth fruit, the injury more nearly resembles that produced by scab on plums than that on the peach. The skin becomes more or less thickly covered with the circular, brownish scab colonies which occasionally merge together. The fungus incites the formation of a corky growth of tissues and causes more or less cracking in these. The badly infected fruit is said to drop prematurely or else mature imperfectly. As in the plum, the injury to the tissues is more conspicuous than the fungus, while on the peach it is the olive fungous growth that forms the conspicuous spots, the hairy covering no doubt protecting the fruit somewhat and at the same time permitting a more vigorous external growth of the parasite. An examination of the twigs seemed to indicate that the fungus carried over the winter on these as it does on the peach. The preventive measures are the same as those for peach scab (see Report 1903, p. 340).

\section{OKRA, Hibiscus esculentus.}

WILT, Neocosmospora vasinfecta (Atk.) Sm. Plate XVI, a-b. This fungus is very injurious to cotton in the south and was first clescribed by Atkinson (Bull. Ala. Agr. Exp. Stat., 4I : 
19-24) in 1892. He mentions in this bulletin, p. 25, that okra, which is botanically related to cotton, is sometimes attacked. Smith (Bull. U. S. Dep. Agr., Div. Path., I7: 3I) and Orton (Ibid, Bull. 27: 6) both mention okra as having a wilt disease which they consider the same as that of cotton though their identity has not been absolutely proved. Okra is a salad plant occasionally grown in private gardens in this state. Some plants in the Experiment Station grounds the past year showed unmistakable signs of the disease in August and September. The year before some cotton had been grown in the garden a short distance from where the okra was situated. If the disease occurred on this, however, it escaped notice. There are a number of these wilt troubles of cultivated plants that have been described as distinct, such as wilts of cotton, cucurbits, potato, tomato, flax, etc. Several of these occur in this state and the tomato trouble has been especially bad in the Experiment Station greenhouse for years. As they are all caused by Fusarium soil fungi (of which the mature stage has been observed only in one or two cases) and these act much the same on all of the hosts, there may be some question whether they are really caused by different species or merely strains of the same semi-parasitic soil fungus.

The diseased okra plants when first seen by the writer in September looked as if they had been partially killed by the frost; see Plate XVI, a. The trouble showed first on the lower leaves, gradually affecting those above in succession. They became yellowish in irregular streaks from the margin inward and eventually brown and dead. In time the whole leaf is killed and it is usually dehisced at the customary place on the node; see Plate XVI, a. Thus a badly diseased plant may gradually drop all of its mature leaves and finally begin to die at the tip of the stem. The character of the disease is shown on cutting transverse or longitudinal sections of the stem. The woody layer.which occupies a prominent band between the central pith and the outside bark appears in these cases plainly diseased, having a dark brown color; see Plate XVI, b. This discoloration of the wood even shows when the outside of the stem appears normally green and healthy. Microscopic sections demonstrate that the diseased condition is caused by the presence of the Fusarium stage of the fungus which develops 
vigorously in the vascular bundles, more or less completely filling the water-carrying ducts and causing disease of their walls and the surrounding tissues. The fungus even penetrates eventually into the bundles of the leaf petioles. Thus the water supply of the leaf is gradually cut off and the blade finally dies.

These wilt fungi apparently develop to a certain extent on decaying rubbish in the ground and thus become more troublesome from year to year if the land is used consecutively or continuously for plants liable to infection. In some cases, as unquestionably with the tomato wilt, the seeds from diseased plants may carry the trouble and serve as a means of infection. The continued use of the same soil in hot beds favors the establishment of the fungus there, when it becomes a means of infecting the young plants of tomatoes and egg plants. Egg plants, especially when transplanted to apparently uninfected fields, often suffer seriously, even though they showed no sign of the disease in the young plants transferred from the hot-bed. All these points must be taken into consideration in combatting wilt troubles. Spraying, because of the infection of the plants through the underground parts, is of little use. Apparently soil treatment with chemicals will usually be of little practical value though based on good theoretical grounds. Orton was successful, with cotton, in rearing plants that were wilt proof through selection of wilt resistant individuals in the infected fields.

\section{ONION, Allium Cepa.}

Brittle, Fusarium? Plate XVII, a. Early in June, I905, the writer, with Dr. Britton, examined an onion field owned by Mr. Burton W. Bishop of Guilford to determine the cause of a disease which is a serious menace to the onion industry in that region. According to Mr. Bishop, at least one hundred acres of desirable onion land in the vicinity of Guilford are not available for growing onions because of this trouble. It usually starts in some section of a field and spreads in area from year to year, as the onions are generally grown continuously on the same land. In Mr. Bishop's field the disease had appeared the year before near a stone fence and this year was occupying a considerably larger area. In a neighbor's field the trouble apparently started from a spot on which a manure pile had 
recently stood. A report from Mr. Bishop after the onion season was over showed that the disease did not progress much later in the season, thus indicating that it is chiefly injurious to the young plants. At the time of the visit the onions in the main part of the field examined were several inches high and well beyond the dampening off stage. In the infected areas they averaged much smaller and the stand was very poor. Mr. Bishop stated that the weeds in these infected areas usually made a poor growth, but this was not evident, at this time, to the writer.

One of the most general characteristics of the disease is the brittleness of the onion leaves, from which character the disease takes its name. Another very evident character is the peculiar curling of the leaves of some of the plants. In exaggerated cases these leaves had developed spiral coils of two to three turns, as is shown in the illustration. Frequently the leaves are unevenly thickened or constricted and show somewhat indefinite yellowish spots. The general appearance of the plants suggested that possibly the disease resulted from insect injury of some kind, but neither Dr. Britton nor the writer could find any evidence to support this theory. Neither was there any evidence of a fungus attack on the parts above ground. Usually the roots appeared normal when the plants were pulled up and later examination in the laboratory showed no sign of any external fungus at work on them. However, when the plants were taken very carefully from the ground without breaking off the smaller roots, examples were found in which some of the roots, especially toward the extremities, showed slight irregular swellings, and these roots were more brittle than normally but otherwise appeared perfectly healthy.

Microscopical sections of these roots, even in places not. enlarged, showed the presence of an internal mycelium of some fungus. The mycelial threads were most evident in the intercellular spaces around the parenchymatous cells and not infrequently sent conspicuous irregular branches into these, causing plasmolysis of their protoplasmic contents, but, so far as observed at this stage, no evident injury to the cell walls. Apparently the presence of the fungus caused an unusual local multiplication of the parenchyma cells, resulting in the irregular swellings of the roots. No sign of the mycelium was found in 
the tissues above ground even when their malformation was conspicuous. Probably this injury resulted in some way from the stimulating or irritating action of the mycelium in the roots. Whether later in the season the fungus penetrated into the leaf tissues or caused further disease of the roots was not determined. Specimens of the infected onions left exposed for a few days in a moist chamber developed growths of several, apparently saprophytic, fungi, but no special growth showed on the enlarged roots. The most conspicuous of these external fungous growths was that of a species of Fusarium.

Soil from an infected field was brought to the Experiment Station greenhouse and placed in two boxes and a third box was filled with the soil used in the greenhouse. Onion seed was planted in each of these, but in one of the boxes of Guilford soil a heavy coating of a mixture of lime and sulphur was scattered over the seed in the rows before covering. The young plants in the untreated Guilford soil dampened off considerably more than in either of the other two boxes, but none of the plants in any of the boxes developed the peculiar malformation or brittleness observed on the diseased onions in the fields. The plants were kept under observation several months. Those grown in the treated soil made the least growth, as undoubtedly too much lime and sulphur was used for their best development; those in the untreated Guilford soil had a poorer stand but made a slightly better growth; while those in the greenhouse soil made by far the best growth. This might indicate that the Guilford soil was somewhat deficient in plant food, but Mr. Bishop states that it had been liberally fertilized.

Everything considered, the trouble seems to be caused by some soil fungus, possibly a Fusarium, as the mycelium observed in the roots could easily belong to such a fungus and it is known that this genus furnishes several soil fungi. Its development in the onion fields seems to be due to the practice of growing onions continuously on the same land and using manure as a fertilizer. Probably the disease would cease to be troublesome if a proper rotation of crops on the land was followed, such as corn, onions, rye and clover, using stable manure only the year the land was in corn and commercial fertilizers at other times, especially when in onions. Possibly when infected land is used the trouble could be lessened by isolating 
the infected part by a ditch from the remainder of the field and by the use of chemicals, such as sulphur and lime, in the drills in the infected area.

\section{PLUM, Prunus sp.}

Bacterial Black Spot, Pseudomonas Pruni Sm. Plate XVII, b. In the summer of 1904 Mr. F. L. Perry of Bridgeport brought to the Station green plums showing a disease, apparently of bacterial origin, but which was not definitely determined at that time. The past summer similarly diseased plums were received from Rhode Island, and at our request Mr. Perry sent specimens from Bridgeport. This trouble, apparently, occurs only on the Jananese plums, but may attack any of the varieties of these, according to growers. The green plums show conspicuous black-purple spots which are often slightly sunken. These spots vary in size up to half an inch in diameter. There are not many on a single plum and these are usually isolated. The diseased tissue does not extend much below the skin, so the injury is quite superficial. Usually only a few plums scattered over the tree show the trouble, but occurring on the green fruit one is apt to fear that later it will develop into a very serious pest. This does not happen, as the trouble becomes less conspicuous and vigorous on the ripening fruit and fails to spread further. Specimens of the nearly grown but green fruit when placed in a moist chamber in the laboratory did not show any further progress of the disease though kept for some time under observation. Cultures made from diseased tissue from the interior uniformly gave growths of a yellow motile organism, thus showing bacteria to be the cause.

So far as found by the writer, this disease has been described only by Erwin F. Smith in short notes (Science, 17: 456-7, I903, Ibid., 21: 502, I905) from his extended studies of the disease, which he found on Japanese plums in Michigan. Dr. Smith states that the disease also occurs on the leaves forming numerous small water-soaked spots which finally may end in shot holes. The writer has not had the opportunity to examine infected trees to see whether the disease affected the leaves here, but the correspondents have not complained of injury to these. In the Report of this Station for I903, page 337 , the writer called attention to a bacterial spot of peach 
leaves about which nothing at that time had been written. The general appearance of these leaves seems to be similar to that described by Smith for the diseased plum leaves. No cultures were attempted from the peach leaves, so it is impossible to state definitely whether their disease was caused by the same organism as the plum disease. Smith discovered in his investigations with the plum spot that the bacteria gained entrance into the leaves and fruit through the stomates and for some time confined their development to the substomatic cavities. He also found that the disease was chiefly of meristematic tissue, which accounts for its failure to progress with the maturity of the leaves and fruit. While the disease in its present condition is not very serious, one can not assume that it will remain so since it may spread to other varieties and become more virulent. Though of bacterial origin, it is quite different from the bacterial blight that has been found occasionally on the plum and commonly on the pear, etc., in this state.

\section{RASPBERRY, Rubus sp.}

Grey Mold, Botrytis patula Sacc. \& Berl. This fungus was collected at the Frisbie farm, Southington, in July, I902, on the fruiting canes. These were dying prematurely, apparently from the attack of some fungus. While this fungus was by far the most conspicuous one found in the stems, it may not have been the primary cause of the injury, as the cane wilt fungus, Leptosphaeria Coniothyrium, was also present. The Botrytis formed a greyish growth which broke out in small sori on the epidermis, but these were often so closely placed that they formed a conspicuous felt-like mat, resembling considerably that of a vigorous downy mildew. The spores are large and look more like those of the Peronosporeae than they do those of Botrytis. The fungus is certainly not a typical Botrytis and possibly does not belong to that genus, but further study with fresh material would be necessary to determine its exact relationship, as it is difficult to say from the old material how the spores are borne. This species was described in 1885 by Saccardo and Berlese from specimens sent by Ellis from New Jersey. In the Syll. Fung. 4, p. 25, the host is given as Salix (?) which is apparently a mistake, ${ }^{*}$ as specimens collected by Ellis

* In the host index, volume I3 of the Syll. Fung., both Salix sp. and Rubus strigosus are given as hosts. 
at Vineland, N. J., June 28, I884, and which the writer has examined, through the kindness of Dr. Underwood, from the N. Y. Bot. Gard., are labeled "on living red raspberry canes." Apparently the fungus has been very rarely collected.

\section{SPINACH, Spinacia oleracea.}

LeAf MoLD, Heterosporium variabile Cke. Plate XVIII, a. Halsted, of New Jersey, who has issued a bulletin on the fungi which attack spinach, does not give this fungus in his list, though he does mention other molds that appear on the old leaves. It was described originally by Cooke, of England, in Grevillea, 5, p. I23, in 1877 , and the host was given as "languishing leaves of Spinacia." The specimens collected by the writer were on leaves of spinach obtained in the New Haven market in January. Usually only the outer two or three leaves of each head were attacked by the fungus. These leaves showed subcircular dead spots, about a quarter of an inch or less in diameter, which were more or less densely covered above and also usually below with a conspicuous olive-black moldy growth. When the spots were thickly placed the intervening tissue was a sickly yellowish color and the leaf worthless. Even when the spots were not so abundant the market value of the spinach was lessened because of its appearance. The fungus may or may not be a true parasite, as the writer has often seen spinach leaves in the fields with spots on them but with no sign of fungous growth. That it is not a very vigorous parasite was shown by its presence being limited largely to the older leaves. A species of Alternaria which produces a general appearance very similar to this fungus has also been observed on the older leaves of spinach in the market.

\section{SQUASH, Cucurbita Pepo.}

Downy Mildew, Peronoplasmopara Cubensis (B. \& C.) Clint. The squash is a host not before reported for this fungus in Connecticut. The appearance of the infected leaves was so different from that of the usual hosts that the writer did not recognize the trouble at the time of collecting it but mistook it for a bacterial leaf spot. The leaves were thickly covered with 
small angular brown spots which were more conspicuous on the upper than on the lower side and much smaller than those ordinarily seen on the musk melons and cucumbers. There was no evident growth of the fungus and the microscopic examination revealed the presence of only a few conidiophores. The spores, apparently, averaged smaller than on some of the other hosts.

\section{STRAWBERRY, Fragaria sp.}

Leaf Scorch. About the last of June, 1905, Dr. Britton and the writer visited Mansfield Bros.' farm at West Hartford to determine the cause of an unusual trouble of their strawberry plants. Many of these were drying up and dying. The older plants suffered more than the younger and the older leaves before the newer leaves on the same plant. The leaves turned purplish and then gradually dried up and died. No sign of insect or fungous work was visible on them and an examination of the roots and crowns gave no indication of any special pest as the cause of the injury. The plants suffered most where the imatted row method of culture was used. As the early summer had been unusually dry, the writer finally came to the conclusion that this was largely responsible for the trouble, though this injury did not show prominently until the very dry weather was past. Possibly the trouble was aggravated by winter injury of the roots and the method of culture, which was not so well adapted to dry weather.

Powdery Mildew, Sphaerotheca Humuli (D. C.) Burr. Plate XVIII, b. This mildew had not been collected in the state until last June, when Dr. Britton found, at Poquonock, a few infected plants in a field near a manure pile. It is a trouble, however, that is rarely reported injurious to the strawberries. The leaves become covered on either surface, but showing most conspicuously on the upper, with a mealy white growth of the fungus. This is the conidial or summer stage and the winter spore stage is rarely formed on this host.

\section{TOBACC0, Nicotiana Tabacum.}

Dampening off, ? Sclerotinia sp. Plate XIX, a-b. Several seed-bed troubles of tobacco have been described by Selby in a recent bulletin, No. $\mathbf{1}_{56}$, of the Ohio Experiment Station, but 
apparently the one mentioned here is different from any described by him. In appearance, Plate XIX, b, the injured plants were very similar to those figured by Selby for a bed-rot injury caused by a Rhizoctonia fungus, but examination of the specimens received here did not reveal the presence of this fungus. The disease showed on the young plants at the base of the stem as a conspicuous dead area or a complete girdle. Often the injury was so severe as to cause the death of the plant. When placed in a moist chamber the infected plants produced a growth of a sterile white fungus at the injured part. Plate XIX, a, shows cultures of this fungus growing on potato agar. These cultures never produced any spores but instead formed the numerous small sclerotia similar to some of those described by Smith for the Sclerotinia drop fungus of lettuce, which is also a soil fungus.

Mr. W. E. Frost of Bridgewater, who sent the diseased tobacco plants, wrote in part as follows: "Is there anything that can be done to stop the rotting of tobacco plants in the seed beds? Where they rotted last year they are doing so this year. Can anything be done so that it will not appear in the same beds another year? Would it be safe to set plants from beds where there is some rot if the plants appear all right when taken up?" Fungous troubles in seed beds are chiefly due to two conditions: first, keeping the plants too moist by improper watering, insufficient ventilation or crowding the plants too closely together; second, fertilizing with manure or using the same soil in the beds year after year, thereby establishing in these special injurious soil fungi. When the trouble is of the second sort, as in the present case, the soil should be changed or new beds made and where feasible only artificial fertilizers should be used. Applications of lime and sulphur to infected soil possibly in some cases may prove of benefit. In answer to the last question asked by Mr. Frost, it may be stated that the writer set out some of the least diseased plants received and these did not develop the trouble any further and did fairly well during the whole season. There are some diseases, however, contracted in the seed beds, as the wilt of egg plants, where the infected individuals do poorly the whole season. 
DOWNY MILDEW, Phytophthora Phaseoli Thaxt., OF LIMA BEANS.

In the Botanical Gazette (I8) and the Annual Report of this Station (19) for I889, Professor Thaxter, then botanist of the Station, recorded the discovery of the Lima bean mildew, which he found doing damage in Connecticut. Besides giving a general and scientific description of the fungus, Thaxter described and illustrated in detail the parasitic, or summer stage, but he was not successful in discovering the oospores, or winter stage. His successor, Dr. Sturgis, also in the Botanical Gazette (16) and the Reports of the Station ( 15, I7) added to our knowledge of the fungus by describing its methods of infection, especially that accomplished by the aid of insects, and recorded successful spraying experiments. $\mathrm{He}$, too, failed to find the oospores, though special search was made for them. The writer adds, in this paper, his contribution to the knowledge of the fungus in a description of the missing oospores and of artificial cultural experiments. Practically all that is known of the mildew, except its limited distribution, has resulted from the work of the botanists of this Station. It is fitting, therefore, that a detailed account of the fungus, its injury and methods of prevention, be given in this place.

\section{PARASITIC, OR SUMMER STAGE.}

Relationships. The Lima bean mildew belongs to the small genus, Phytophthora, which is especially characterized among the downy mildews by the nodular swellings on the conidiophores (spore-bearing threads) that mark the position of the successively developed spores. The genus includes serious parasitic pests, the most conspicuous of which is the downy mildew, or blight, of potato. This is the only other species that occurs in Connecticut. Another species, found in the East Indies, has tobacco for its host, and a fourth is injurious to seedlings of beech, Coniferae, etc. One or two other species have been described recently. Apparently the mildew of Lima beans is most closely related botanically to the species that occurs on tobacco.

Distribution. Thaxter first found the Lima bean mildew in September of 1889 at Hamden, Conn., near New Haven, where 
it had been injurious at least two years before his discovery. In the Report for I890 (20) he writes: "This mildew (Phytophthora Phaseoli) described and figured in last year's report, has been again destructive this year and has made its appearance in a number of new localities in the neighborhood of New Haven. So far as ascertained it extends from New Haven to Hartford and west to South Norwalk, but has not yet been discovered outside of Connecticut." So far as recorded, Sturgis' work and observations on the fungus were in the vicinity of New Haven (East Haven, Westville, etc.). The writer's experience, too, has been limited to this vicinity, though complaint of it has been received from Green's Farms. Probably the fungus has appeared in Connecticut (in a more or less conspicuous way) each year since its discovery. Thaxter collected specimens in 1889 and 1890 . Sturgis records it as being injurious "for some years" in I893 but failed to find it that year in localities where it had always been abundant; he also records it for the years 1897 and $I 898$ and states it was prevalent for two or three years previous. Rorer collected specimens in I90I and the writer made collections in 1902, 1903 and 1905.

Outside of Connecticut the fungus was first reported in New Jersey by Halsted (4) in 1897 , and he has found it several times since in the same state. It was also reported about this time by Speschnew (I3) from Tiflis, Russia, and has been found by other Russian botanists. Smith (12) states it was injurious in 1903 in Delaware. So far as the writer has learned, these are the only published records of distribution. Thinking that possibly it had been noticed but not reported in other of our eastern states, where the chances for its introduction and development seemed favorable, information on this point was asked of the Division of Vegetable Pathology and Physiology of the U.S. Department of Agriculture and of the Experiment Station botanists of fourteen states, chiefly those bordering on the Atlantic coast. Letters received from these showed that the mildew had not been observed in any other states than those mentioned except in two cases. Mr. Stewart, of the Geneva Station, N. Y., reports the receipt of specimens from Long Island once each in 1904 and 1905, and Mr. Woods, of the Division of Vegetable Pathology and Physiology at Washington, states that the fungus was very injurious in Frederick county, Maryland, in 1905 . 
Injury to host. So far as reported, only the Lima bean, Phaseolus lunatus, is subject to the attacks of this mildew. The writer has seen it on both the pole and dwarf varieties, though rarely on the latter. The dwarf varieties are not usually grown on a commercial scale in Connecticut and probably do not present so favorable conditions, as regards moisture, for the spread of the fungus, though Sturgis has reported a case where they were severely injured. The pods are the parts of the host most subject to attack, but the fungus also occurs to a limited extent on the young leaves, vines and flowers.

The growth of the fungus on the pods, Plate XXII, a-b, is often very conspicuous, forming a dense pure white felt of the conidiophores in irregular patches, or sometimes spreading over the entire surface, on one or both sides. Both Thaxter and Sturgis have noted that the mildew often at first is present only on one side of a pod, and the latter states that this is usually the side furthest from the vine and least protected by the leaves. The injury to the pod generally shows but little beyond the area covered by the fungus, though the green of the healthy tissue may be separated from the diseased by a more or less distinct purplish border. As a pod becomes more and more severely injured it wilts and gradually dies, shriveling up in the irregular form shown in the illustration. The fungus eventually penetrates into the interior of the pod, causing the tissues to become sunken, and the mycelium may enter the seeds. Many pods are attacked so vigorously in their infancy that they are killed outright and others are injured so they never mature. The injury to the large pods varies with the abundance of the fungus, but even when not preventing maturity of the seeds it may still affect their market value by injuring their appearance. The mildew opens the way for further injury to the pods and seeds by other fungi, so that quickly following its prime development there appear such fungi as Fusarium, Alternaria, Cladosporium, etc. The growths of these eventually discolor the pure white of the mildew.

The attack of the fungus on the flowers is not usually very conspicuous, though it is through insect visitation to these, as shown by Sturgis, that the infection of the young pods often takes place. So, too, the leaves, petioles and vines are generally not much injured and apparently are infected only 
in their young state. The infected leaves often show an irregular injury of the tissues with more or less of a purplish discoloration, especially on the veins, and there is no very evident growth of the fungus showing on them. See Plate XXI, b.

Financial loss. In this state a few Lima beans are usually grown by each farmer for home consumption and most gardeners grow the pole varieties in quantities for the market. They are probably raised most extensively around New Haven, though each large city has more or less grown in its vicinity. The largest grower in the state, A. N. Farnham of Westville, often plants twelve or more acres and sometimes most of these are in a single large field. The financial loss due to injury by the mildew comes chiefly on the market gardeners and is greatest in those localities where the beans are grown extensively. Thaxter's statement, based on his observations at Hamden, that the mildew "bids fair to become the most serious obstacle yet encountered in the cultivation of this vegetable," especially in the Atlantic seaboard states, was not exaggerated. Sturgis wrote that "during the summer of 1897 the conditions were such that in many places the effects of the fungus have been most disastrous." In 1898 , in a number of counts in a certain field, he found that the percentage of pods attacked by the mildew varied from $3^{6}$ to 53 per cent. of the total number produced during the season. The writer's observations on the disease began in I902, when the fungus did considerable damage, especially in the lower, more moist places in the fields. During the next two years there was comparatively little injury, but in 1905 the loss caused by it was the greatest since I 897 . In one of the largest fields in the state, the grower estimated that the yield was cut down about one-third by this pest.

Halsted (4) states that the mildew was so serious in New Jersey in 1897 that "few or no pods were picked from some of the fields." $\mathrm{He}$ also reports numerous complaints of it in that state in 1902 . Smith (12) records the mildew as injurious in Delaware in 1903 ; and Woods in a letter to the writer states that, in Frederick county, Maryland, in I905, "it is said to have destroyed from 25 to 90 per cent. of the crop."

Relation to weather. The prevalence of most parasitic fungi is largely influenced by the character of the weather, particularly in regard to moisture. This is especially true of the 
downy mildews. An abundance of rainy or cloudy weather at certain periods of the year determine whether or not these troubles will be injurious. July, August, and to a less degree September, are the months in which unusual moisture develops the downy mildew of the Lima bean, just as it does the downy mildew, or blight, of the potato. So far as yet ascertained, the middle of July is the earliest that the Lima bean mildew has been found in this state and frequently it does not appear until the middle of August. After its appearance it can be found more or less abundant, according to the weather, up to the time the vines die. Halsted (6) notes the fungus as late as October 24 on green pods, after the leaves had been killed by frost, and the past year the writer collected it in several fields on October 4 under the same conditions. Sturgis reports, however, that in 1897 "for some reason not wholly clear, perhaps because of lessened insect activity, the mildew ceased spreading about September Ioth."

From the published data it seems quite certain that trouble from the mildew may generally be expected in very moist years. Halsted (5), writing on this point, says: "The year 1897 had its counterpart in that of 1889 . During the past ten years there have been in the Eastern States two Julys noted for their excess of rainfall (I889 and I897). . . . In connection with what has been said above concerning the influence of copious rainfall upon the unusual development of the potato rot, it is in order to report that another member of the genus Phytophthora [the Lima bean mildew] has been complained of bitterly during the season of 1897 . . . Particulàr emphasis is placed upon the date of the discovery [1889] and the fact that it was very abundant at the time it was taken, because that was the year in which the three months of July, August and September gave a total rainfall of 27.33 inches for New Jersey and presumably as wet in Connecticut; which is 9.54 inches more than the average of those three months for the past ten years." Besides in I889 and I897, the mildew was unusually abundant in 1902, which year was characterized by cold damp weather in July and August, and again in 1905, which though dry previous to the middle of August was rather moist the remainder of the month and during the first part of September. 
The middle Atlantic seaboard states apparently offer the best conditions for the development of the fungus, and as it has spread into most of these, there may be expected increasing trouble from the pest in their market garden districts in years with very moist weather during July or August. Not many Lima beans are grown in New England north of Connecticut. In the drier middle and western states less injury may be expected should the fungus become introduced, except possibly in localities affected, as to moisture, by the Great Lakes.

Methods of distribution. The means by which the fungus spreads over the vines after it once gets started in a field and presumably by which it is carried to some extent from one field to another, have been discussed somewhat in detail by Sturgis. $\mathrm{He}$ found that both insects and wind were important agents in its distribution. Rains also aid greatly by washing the spores from the infected parts over the same plant.

Concerning insects as agents of distribution, we quote from Sturgis (I5) as follows:

"The occurrence of the mildew on the pods at a very early stage of their growth, led to the supposition that insects were responsible in a measure for the spread of the fungus. Examination of the flowers served to confirm this supposition, and a few words regarding the structure of the bean flower will explain how infection takes place. The conspicuous portions of the bean flower consist of an upright petal known as the standard; two narrower petals, distinct, projecting forward below the standard and known as the wings; and two petals in the form of a closed, spirally coiled tube occupying a position between the standard and the wings, and called the keel. (Fig. $8,^{1}$ ) At the base of the keel is the ovary or young pod surrounded by the stamens and prolonged upwards into the style. The long stamens and style are completely enclosed in and protected by the keel. Under such conditions crossfertilization would seem to be impossible, especially as the pollen is shed abundantly from the anthers which are borne upon the stamens in close proximity to the upper portion of the style, and neither the stigma nor the anthers appear beyond the end of the tube in which they are enclosed. But the wings form a convenient resting place for visiting bees in search of nectar, and in case a bee lights upon them his weight deflects them and at the same time draws the keel down and backward, thus causing the stigma and the hairy portion of the style covered with pollen to protrude from the mouth of the tube. (Figs. $8,{ }^{2},{ }^{3}$ ) As the insect plunges his head into the flower, the stigma and pollen-laden style come into contact with his abdomen and cross-fertilization is assured by subsequent visits to other flowers. But fungous infection is 
assured with hardly less certainty, provided the bee has previously had contact with the spores of the fungus. In that case we should expect to find the first attack of the fungus at the two points where the bee, in his search for nectar, touched the more moist and delicate tissues of the flower; viz. on the style and at the base of the ovary or pod. A large number of flowers was examined and this supposition was

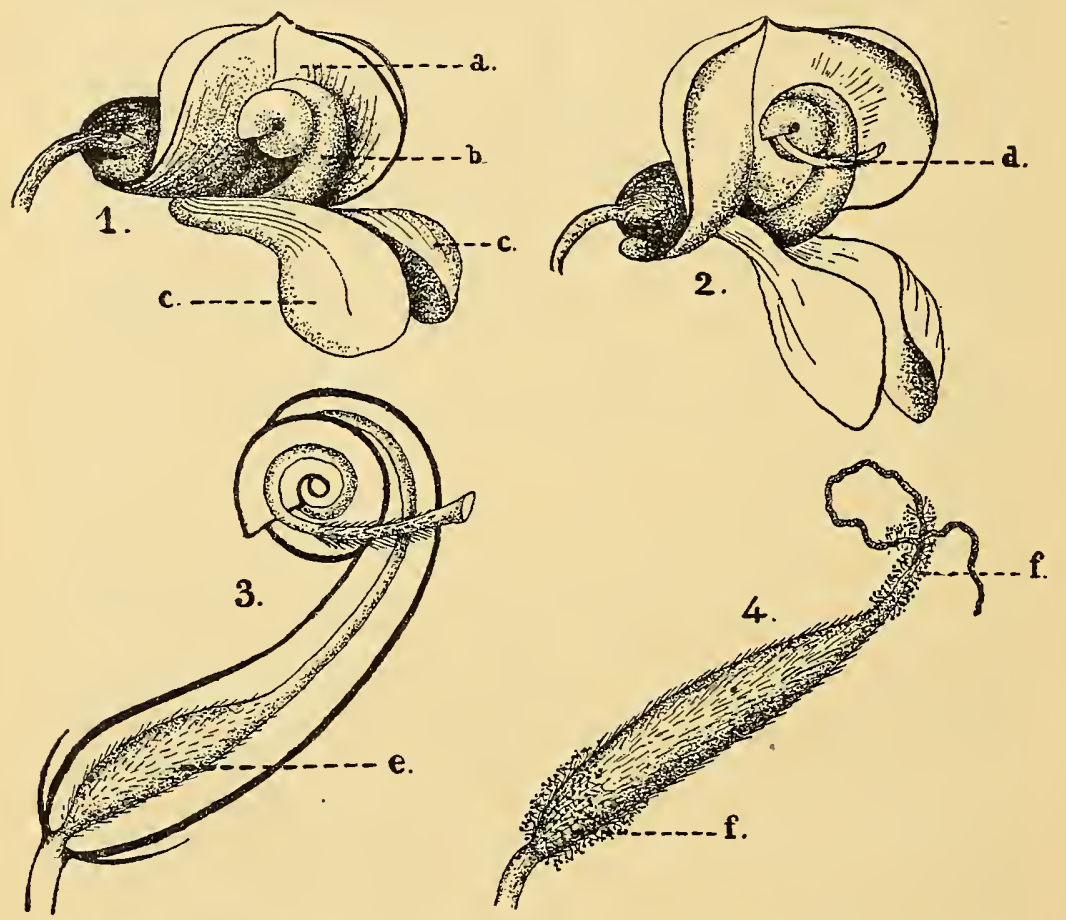

Fig. 8. Showing details of bean blossom with reference to infection with mildew by bees. I. Parts of blossom: a. standard, b. keel, c. wings. 2. Showing how the weight of a bee alighting on the wings causes protrusion of style, d. 3. An enlarged keel in cross-section, showing enclosed pistil with young ovary or pod at its base, e. 4. Pistil showing growths of mildew (f.) at base and apex of the young pod resulting from spore inoculation by bee visitation during blossoming period. ( $\mathrm{I}-2$ after Gray; $3-4$ after Sturgis.)

strikingly confirmed. The mildew was found in many of the flowers, and in every case it occurred on the spots above mentioned and nowhere else. (Fig. $8,{ }^{4}$ ) It seems certain, therefore, that the spread of this mildew is largely due to the agency of insects, particularly of bees, and this view is further confirmed by the fact that in the case of young pods the mildew almost always appears first at the base or tip and very rarely in the middle." 
The influence of wind on the distribution of the fungus in a field is shown by the following account, also quoted from Sturgis :

"The Lima beans on the Station grounds are on high land composed of a light sandy soil, and have never been affected with mildew. The rows run east and west. Directly south of them at a distance of about one hundred feet, but separated from them by a pile of lumber and a few trees, are two rows of bush Limas running north and south. On August I4th, when the mildew had been abundant in the neighborhood for a month or more, the Station vines were examined and found to be entirely free from the fungus. A few mildewed pods were brought from a distance, and the spores from one of them were rubbed and dusted on the surface of a sound and nearly ripe pod at the east end of each row of the pole Limas. Within a few days the mildew made its appearance on the infected pods, and from this point of vantage, the prevailing winds at the time being from the northeast and north, it swept down both rows and in two weeks the whole patch was completely mildewed. The spores had also been carried over a distance of one hundred feet to the bush Limas, and the mildew, beginning at the north end of the rows, that is, at the point nearest to the pole beans, spread rapidly down the rows. It

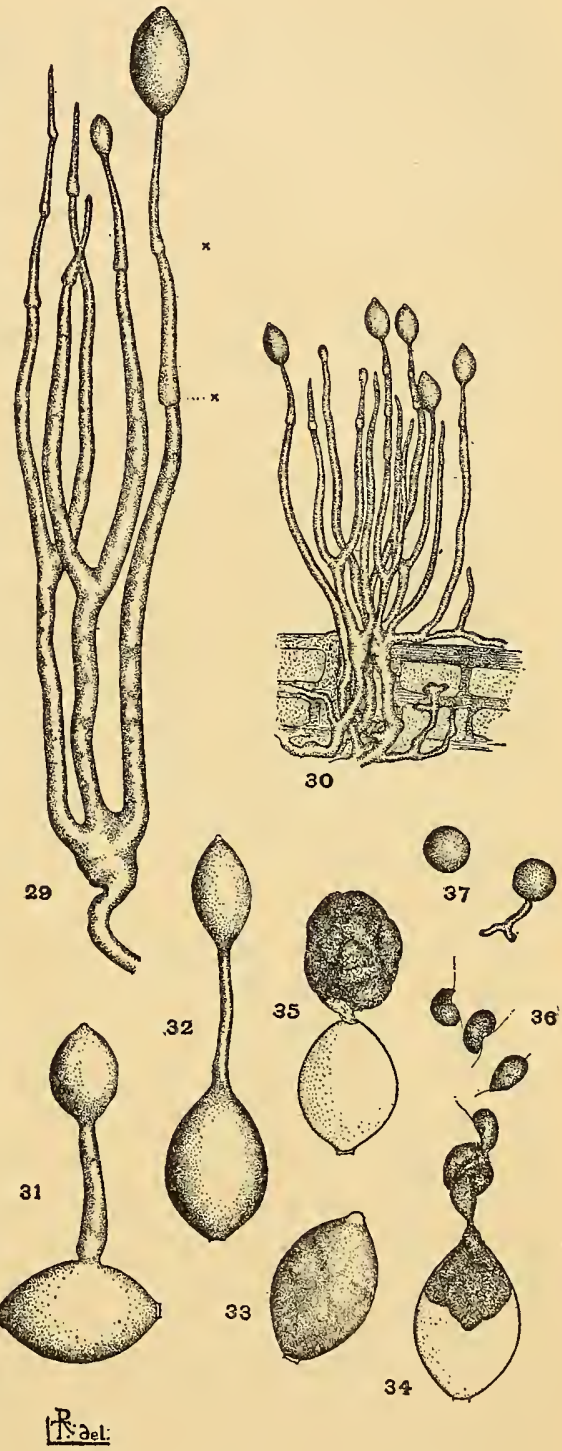

FIG. 9. Details of conidial stage. (After Thaxter.) 
is evident then, that spores placed upon the surface of a sound Lima bean pod were enabled to start the disease, which thereupon spread with great rapidity in the direction of the prevailing wind."

Microscopic structure. Having considered the more general character of the fungus and its environmental factors, let us proceed to a study of its minute structure as revealed by the microscope. For a preliminary account we can do no better than to give Thaxter's (I9) description:

"Examination of a section of the diseased tissue shows it to be penetrated by the irregular branching hyphæ of the fungus [mycelium] which run between the cells and, collecting in the air spaces beneath the breathing pores, push out through them into the air (Fig. $9,^{30}$ ) in such numbers that the latter are completely obliterated. These hyphæ (Fig. $9,{ }^{29}$ ), just at their point of exit from the breathing pores, are usually slightly swollen and give rise to one or more branches [conidiophores] which grow almost vertically into the air, and, taken together, produce the white woolly appearance already mentioned as characteristic of the disease. These vertical branches may themselves be once dichotomously branched, that is give rise to two branches, forming a more or less symmetrical fork; while at their tips they swell out into the large, terminal, oval conidial spores represented in the figure. A peculiarity of the genus Phytophthora consists in the fact that after a spore has been produced at the apex of a hypha, the hypha continues to grow at the point where the spore is attached, pushing it to one side if it has not already fallen off, and soon swelling into another spore. This may be repeated several times, the points where spores have been previously formed being marked by successive vesicular swellings (Fig. $\left.9,{ }^{29} \mathrm{x}\right) . "$

The mycelium is similar to that usually formed by the downy mildews. Its hyaline threads, Plate XX, $I-6$, are more or less branched, are occasionally somewhat irregular in shape and have a comparatively thin cell wall which on staining with chloroiodide of zinc shows the presence of cellulose. They are chiefly $5-7 \mu$ or occasionally even $9 \mu$ in diameter. The contents at first completely fill the threads and consist of a very homogeneous protoplasm, or this may also contain numerous oil globules of varying size. As the threads advance in their growth they often become empty in their older parts and also rarely develop septa with the recession of the protoplasm. The writer has not studied the special haustorial branches that push directly into the cells in search for food, and Thaxter simply states that the mycelial hyphae rarely penetrate the cells of the host by irregular haustoria. 
The conidiophores of this mildew are much longer than those produced by the potato mildew. In the figures shown here from Thaxter, Fig. 9, ${ }^{29}, 30$, the young conidiophores have not reached their full length. In fact they usually become so long and lax that they form an interwoven mat rather than erect distinct threads. They also differ from the conidiophores of the potato mildew (which give off two to several simple branches along the apical third of their length) in that they are simple or more rarely dichotomously branched, usually near their base. Some conidiophores were found having over a dozen swollen nodes, thus indicating the formation of as many spores, but usually they have less than half a dozen, which may be scattered or grouped toward the terminal end. Occasionally it is difficult to detect any nodal swellings on a thread. From these statements it is seen that the conidiophores are not so differentiated into spore-bearing organs as in the potato mildew. For this reason it is hard to tell whether the white matted growth that covers the exterior of the pods is composed entirely of conidiophores or partly of mycelium from which the conidiophores develop. The latter, however, are often found growing directly from the stomates in clusters which sometimes contain a dozen individuals but more frequently about half that many. Thaxter does not give the length of the conidiophores and it is difficult in the old matted growths to separate out single ones for measurements. Specimens were measured that varied from 300 to $475 \mu$ but these were probably not extreme lengths. In an examination of artificial cultures, one fruiting thread that was traced measured over I $200 \mu$ in length. The diameter of the conidiophores is usually about 5 or $6 \mu$, rarely $8.5 \mu$, at their lower end, and they taper to about 2.5 or $3 \mu$ at the apical extremity. The swollen nodes generally vary from 4 to $6 \mu$ in width. At first the conidiophores are filled with protoplasm, but as spore production proceeds their contents are limited to the distal end and finally they may become entirely empty. Their walls are thicker than those of the mycelial threads and give a stronger reaction in the test for cellulose, as do also the spore walls. Very rarely septa are seen in the empty conidiophores.

The conidia, or spores, of the Lima bean mildew, Fig. 9, ${ }^{\mathbf{2 9}, \mathbf{3 3},}$ are similar to those of the potato mildew, but larger. The 
spores of the latter vary from I 7 to $35 \mu$ in length by II to $20 \mu$ in width, while those of the Lima bean mildew are chiefly 28 to $42 \mu$ in length by $I 7$ to $27 \mu$ in width, and Thaxter records some even $50 \mu$ in length. They are hyaline, elliptical to chiefly ovoid in shape or rarely even broadly ovoid to subspherical. The papilla of dehiscence is very evident at their apical end, and when shed from the conidiophores the basal end is usually marked by a short hyphal plug showing the point of detachment. Protoplasmic contents fill the spores usually without special differentiation, though sometimes at germination faint areolations appear.

Germination of spores. The spores do not germinate readily unless perfectly fresh. The germination of such spores placed in a drop of water in a Van Tiegham cell takes place in a few hours and can be easily watched under the microscope. Thaxter's excellent description of their germination is as follows :

"The germination takes place in two ways. In the one case a single hypha of germination is produced, which may enter the host plant directly or give rise to another, or secondary spore like itself (Fig. $9,{ }^{31},{ }^{32}$ ) which germinates in its turn like the ordinary conidia. In the second case, which is by far the most common, the content of the spore becomes very faintly lobular, as shown in Fig. $9,^{33}$ and suddenly and rapidly begins to make its exit, through the ruptured apex of the spore, Fig. $9,{ }^{34}$ in the form of a continuous chain of spindle-shaped bodies, consisting of naked protoplasm; the orifice alternately expanding and contracting as each body is, as it were, squeezed out by the pressure from within. In some cases the whole content of the spore makes its exit thus, the chain winding itself into a round or oval mass above the apex of the conidium as in Fig. $9,{ }^{35}$. Usually, however, the chain breaks in the course of its discharge and almost instantly a rapid motion begins, at the point of separation, which draws the spindle-shaped bodies successively apart. The motion is due to a slender thread or cilium, drawn out by the pulling apart of the narrow zone connecting two adjacent bodies, and the rapid vibration of this thread gives rise to the motion just mentioned. The spindle-shaped bodies, as soon as they are free, move irregularly for a moment, changing their shape the while, till they become contracted, the two extremities being drawn together on one side towards a small clear spot, usually present in bodies of this nature, so that in one view the outline is slightly crescent or bean-shaped (Fig. $9,{ }^{38}$ ). After or during this change of shape the motion of the cilia becomes very rapid, and the bodies, which are known as zoöspores, dart away in the surrounding water. After swarming for a certain time, usually about half an hour, the zoöspores come to rest, assume a 
spherical shape, swell considerably, become surrounded by a thin cell wall and very soon begin to germinate (Fig. $9{ }^{37}$ ) by giving rise to a hypha which makes its way into the tissues of the host plant, thus infecting it with the disease. The whole process, owing to the minute size of the zoöspores which are less than $\frac{{ }_{10}^{3}, 000}{00}$ of an inch in diameter, may take place upon the moist surface of a leaf or other portion of the host plant, the thinnest pellicle of water being sufficiently deep for them to swim in. The usual number of zoöspores formed from spores of average size is about fifteen, so that each spore may give rise to fifteen distinct points of infection."

Perpetuation of the fungus. The zoospores just described are very short lived, lasting so far as known but a few hours. The conidial spores, too, are of a temporary nature, retaining their power of germination but a comparatively short time even under favorable conditions and in dry weather perishing in a few days or even hours. The conidiophores and mycelium are more persistent, but as the Lima bean is an annual it is impossible for the mycelium to live over the winter (except in the seeds) as a dormant parasite. It may be thought, possibly, that the mycelium survives in the rubbish of the diseased beans and in the spring as a saprophyte gives rise to the conidial spores. This, however, is contrary to the known habits of the downy mildews and against all evidence that the writer can find after a careful examination of this species. Invariably the Lima bean mildew suffers in development by the decay of the infected pods and is at a decided disadvantage in competition with bacteria and saprophytic fungi that follow in its wake. So far as observed, it then gradually ceases to form conidial spores and fails entirely to spread further, at least in this spore stage. If the mycelium does develop as a saprophyte, which we doubt, it would most likely produce an entirely different kind of spores-the oospores.

Sturgis made some observations and experiments to determine if the mildew survived the winter in the refuse of a mildewed crop by means of "resting spores, a perennial mycelium or any other form." In his search through such material that had been kept out doors over winter he failed to find "any trace of a vegetative or reproductive body which could be even remotely associated with the Phytophthora causing the mildew." Seeds taken from this refuse and planted all rotted but one. which produced a perfectly healthy plant. The refuse was used 
as a mulch on ground at the Experiment Station and planted with Lima beans, but the beans came up through the mulch without apparent infection and remained free from the mildew until near the close of the season, when some did appear. In judging of the results of this experiment one must remember that Sturgis found no sign of oospores in the refuse he used and presumably they did not occur in it abundantly if at all. The writer, however, has found them recently under similar conditions though mostly in poor shape due to attack of other fungi on them before they were matured. It must be taken into account, too, that the mildew did appear on these beans toward the end of the season, but possibly it was brought in by insects, though the Experiment Station grounds are far from any other place where Lima beans are commonly grown and the mildew has rarely appeared on beans planted there. Sturgis evidently considered the experiment largely a failure because "diseased plants" were not produced from diseased seed and because the mildew did not appear out of season and in abundance from primary infections.

In a preceding paragraph it was stated that as the Lima bean was an annual plant it was impossible for the parasitic mycelium to be carried over from one year to another by it except in the seeds. We believe this is sometimes done and in the report of the Station for 1903, p. 308, expressed the belief that it was the ordinary way the fungus perpetuated itself. From our examinations of the past year we now know positively that the mycelium does often penetrate from the pods into the seeds. If the pod is badly diseased the seeds are destroyed, or at least injured so they will not germinate, by this and other fungi that follow it. There are, however, probably all gradations between seeds destroyed and those in which the mildew barely gains entrance. Experiments made by the writer go to show that diseased seeds that germinate do not produce "diseased plants"; that is, the mycelium does not pass from the seed into the young plant and produce a conspicuously injured plant from which the fungus is eventually spread by conidial spores to other plants. There is reason, however, for believing that the dormant mycelium may be carried over the winter in the seeds (just as is the potato mildew in the tubers) and that on the living tissue of the 
seed when planted it may form a few of its conidial spores (as can the potato mildew on the cut surface of the seed tuber) or that possibly in some cases a delayed production of the oospores takes place in the cotyledons. In either case the writer believes that the primary infection of the plants takes place by the germination of the conidial spores or the oospores into zoospores and these latter infect the parts of the plant brought into contact with them in the moist earth. That the mycelium is sometimes present in apparently sound seed is shown by the following case, in which nearly matured seeds were taken from diseased pods in the fall and placed in a damp chamber on moist cotton. These seeds were taken away from the diseased part of the pods and to the naked eye showed no sign of disease or evidence of the mildew. Yet in less than a week some of them were developing abundance of oospores in their tissues and some few had a slight conidial development on the outside. The only point not determined was how long the mycelium would have lived had the seeds been dried out; or in other words, if it could have passed the winter in them and then have gone through the same development when they were planted in the ground in the spring.

Mention has been made several times of oospores. Such spores are of an entirely different character from the temporary conidial spores. They are thick-walled and are usually produced by the mycelium within the tissues of the host. They do not, as a rule, germinate when formed but are for the purpose of carrying the fungus over the unfavorable winter period and on germinating the next season produce the primary infections of their hosts. Oospores are characteristic of the downy mildews, but until discovered recently by the writer were not known for the Lima bean mildew. Let us now pass to a consideration of this stage of the fungus.

OOSPORES, OR WINTER STAGE.

Where and when found. Although Thaxter, Sturgis and the writer made especial search for the oospores they escaped notice until September, 1905, at which time the mildew was unusually abundant in the region of New Haven. There may be two reasons why the oospores were not found before; namely, either they did not occur commonly or they were 
not looked for at the proper place and time. The latter reason more likely explains the failures to find them. Judging from the experience of the past year, the oospores should be looked for toward the end of the season and in the seeds of the pods badly infected with the mildew. Sturgis searched especially for them in the pods and the decaying rubbish. The writer also looked for them chiefly in these places and in fact actually collected pods in 1902 which a recent examination shows had immature oospores in the seeds that escaped detection. Not all of the seeds from infected pods contain oospores and there is no sure way of determining whether they are present or not except by microscopical examination. Often after the mycelium of the downy mildew penetrates from the pods into the seeds, the mycelia of other fungi, especially that of Fusarium, develop so abundantly as to seriously interfere with the further growth of the Phytophthora. Frequently, too, the mycelia of these other fungi form the more conspicuous growth both outside and inside of the seeds. Plate XXI, a, shows in the lower row several dried seeds, containing oospores, that were taken from badly mildewed pods. So far the oospores have been found in the seed coats and cotyledons of the seeds and to a limited extent in the tissues of the pods, but not in the leaves or the stems.

If the oospores generally occur only in those seasons when the mildew is unusually abundant, it has occurred to the writer that this might be explained on the supposition that there exist two mycelial strains of the fungus, possibly sexual in nature, and that the production of oospores can only result when these strains occur together on the same pods. Naturally a season very favorable for the spread of the fungus would multiply the chances of these occurring together. This idea of distinct mycelial strains is discussed further in this report in the following article dealing with the potato downy mildew, where are given the writer's reasons for believing that such strains may exist among the downy mildews, as has recently been demonstrated for the related family of the Mucoraceae.

Description of oogonia, etc. The downy mildews, or the Peronosporeae as they are called scientifically, have a characteristic oosporic stage which has been observed for many of the species and is supposed to exist for all. One of the chief 
functions of these spores is to carry the fungus over the unfavorable winter period. The oospores differ essentially in structure from the temporary conidial spores in that, as resting spores, they have thick walls, and are formed singly inside - a special envelope called the oogonium, and further differ from them in origin in that they are the result of the conjugation of differentiated sexual branches of the mycelium developing usually within the tissues of the host. The male cell of the mycelium is known as the antheridium and after its contents are emptied into the special female cell, the oosphere (immature oospore), it often withers away.

The characters of the oogonia, oospores and antheridia of the Lima bean mildew, as found by the writer, are as follows: Oogonia (Plate XX, 22-25) inter- or intracellular in seed coats or cotyledons of seeds, occasionally in tissues of pods and more rarely imbedded in mycelium on surface of seeds and pods, with rather thin scarcely folded walls loosely enclosing oospore, at first hyaline or slightly tinted but finally reddish brown, subspherical, chiefly $23-38 \mu$ in diameter. Oospores (Plate XX, 22-25) spherical or sometimes subspherical, with apparently smooth and moderately thick walls $(2.5-4 \mu$, chiefly $3^{\mu}$ in thickness), hyaline or light yellowish, I8-26 $\mu$, chiefly $19.5-22.5 \mu$ in diameter. Antheridia (Plate XX, 8, 9, 12-17b) temporary, hyaline, variable, sometimes irregular but chiefly ovoid to ovate, usually applied to oogonia near their place of attachment to the mycelium, chiefly $8.5-\mathrm{II} .5 \mu$ in width by $\mathrm{I}_{4}-\mathrm{I}_{7} \mu$ in length.

Development of oogonia, etc. It is not easy to make out exactly the stages of development of the oogonia even from living material. This is because the mycelium forms a matted growth within the tissues, often obscuring details. The very general notes given here were obtained partly by teasing into fine bits pieces of the seeds known to contain oospores and examining this material under the microscope and partly from microscopic examination of cultures of the fungus grown on artificial media in test-tubes, though some fixed and stained sections were also prepared for examination. No attempt was made to study the cytological phenomena. Apparently when the oospores are to be formed the mycelium becomes more abundant and is often crowded into matted growths of threads 
which are more variable and irregular in shape than normally. The mature oospores, therefore, are likely to occur more thickly in certain places rather than to be scattered uniformly in the tissues or cultures. So far as could be determined the antheridia and oogonia are developed on distinct mycelial threads. . It was not possible to trace these threads far, as the mycelium by the tearing apart is more or less torn, but also it becomes less distinct on the differentiation of these organs, through loss of contents. These fertile threads possibly ultimately have origin on a common mycelium, but more probably they represent distinct mycelial strains mixed together whose combined presence is necessary for the production of oospores. The writer is inclined to the latter view, but was unable to determine any very distinctive characters by which an antheridial developing mycelium can be told from that bearing oogonia, if such really exist. Very often the mycelial threads had swollen places in them (Plate XX, 4) as if these might be tentative antheridia but which because of the absence of oogonial contact had run out again into threads, perhaps developing similar swelling further on. It seemed to be true, however, that the antheridia are not usually entirely differentiated on the thread until after contact with the oogonium. Likewise there were not found many isolated young swollen cells that represented the early stages of the oogonia. From this one would expect that, if there be distinct strains, their mycelia would not show, when grown separately, any development of antheridia or oogonian but would both form conidiophores. This would agree with DeBary's statement that, "In all known Peronosporeae and Saprolegnieae the antheridia are not formed until after the extremity of the branch which supports them, and from which they are afterward separated by a septum, has attached itself to the oogonium and this attachment takes places in the early stage of both organs."

In a preceding paragraph the mature antheridia were described. They are formed as a swollen cell (Plate XX, I2b) at the end of a mycelial thread or a short mycelial branch as circumstances determine, so that there are no characteristic antheridial threads. A basal septum (Plate XX, I4b) soon separates. the swollen end of the mycelial thread into a distinct terminal cell, the walls of which remain thin. Usually the contents of the 
antheridia did not seem to be so sharply marked off from the cell wall as those of the oogonia, often appearing empty because of this lack of contrast. This was probably because oil drops are not so prominent a constituent as in the oogonia. Often after the antheridia are cut off the threads bearing them are empty of contents and difficult to trace any distance. Some of the antheridia showed, when isolated from the oogonium, a prominent protuberance (Plate XX, 8) but nothing was seen like a distinct fertilization tube which penetrated into the oogonium and through which the contents were emptied into it, as has been described for some species.

The oogonium also starts as a swelling (Plate XX, IOC) at the end of a mycelial thread or a short branch or in some cases is intercalary. It gradually enlarges and assumes a subspherical shape. It is thin-walled, filled with protoplasm and oil drops, and after emptying the thread from which it originates of the contents is separated from this by a septum (Plate XX, I3c). Usually before the oogonium has reached large size a young antheridial branch has reached it and the antheridium is formed at the base of the oogonium, that is, where it is joined to the mycelial thread. Soon after the application of the antheridium the oogonium reaches full size and a further step in its development appears in the transfer of its principal contents into a central denser mass, the ooplasm (Plate XX, I5, 16), which a less conspicuous marginal periplasm surrounds. This central ooplasmic body is soon further marked off by the formation of a thin limiting wall and is then known as the oosphere (Plate XX, I9). Though not observed, presumably by this time the antheridial contents have passed into the oosphere by means of a fertilization tube. From now on the contents of the oosphere show changes of development the character and sequence of which were not definitely made out. At the same time the wall of the oogonium becomes slightly thicker and eventually has a reddish brown tint. The periplasm does not seem to be prominent but probably assists in the formation of the wall of the oospore. This gradually thickens until 2.5 or $3^{\mu}$ thick (Plate XX, 22) and is uniform, smooth hyaline or slightly yellowish tinted and consists of a single evident layer, but outside of this the periplasm apparently forms an amorphous envelope which probably serves as a protection 
against absorption of water out of season. A large oil drop often occupies the center of the mature oospore and this is surrounded by a dense uniform layer of protoplasm. The oogonial wall permanently invests the mature oospore (Plate $\mathrm{XX}, 23,24)$ as a loose envelope, but all signs of the antheridium are often obliterated by this time.

Germination of oospores. The germination of the oospores was tried several times, but they have failed to germinate up to the first of April of the year following their development. The germination of spores in pure cultures left out-doors during the greater part of the winter will be tried later, since they too failed to germinate as early as April.

Artificial cultures. This is the first time the downy mildew of Lima beans has been reported as grown in artificial cultures, and apparently the first report of the production of oospores of any mildew in cultures of this character. The writer has grown the downy mildew of the potato in artificial cultures during the past two years and even previous to this two French botanists had published accounts of its growth under similar conditions. The downy mildew of tobacco is said to have been grown in the same way. Apparently these three fungi, all belonging to the genus Phytophthora, are the only species of the Peronosporeae that have been grown in this manner.

The vigorous development of the Lima bean mildew in the fall of 1905 suggested that perhaps it could be grown on various media under control in the laboratory, as had been done with

- the potato mildew. As certain precautions are necessary to secure growths, a short account of the methods are given. In the first place a culture cannot be obtained by transference of spore material to a test tube from a growth on the pods. This is because of sure contamination with other fungi or bacteria which will stop or seriously interfere with the development of the comparatively slow-growing mildew. Neither can cultures be obtained from the spores by the Petrie dish separation method, because of their slow growth and more natural germination by zoospores instead of by germ tubes. The best method for securing pure cultures is to transfer into the culture tubes pieces of the tissue, or better whole seeds, which contain mycelium of the fungus, taking these from the interior of pods showing the freshest and least contaminated external growth of the 
mildew. Care should be taken in breaking or cutting open the pods and a sterilized knife or forceps are necessary to remove the tissue or seeds from the interior. The first attempts seemed to indicate that cultures could be easily obtained in this way but later experience showed that many of these became impure with age. Other fungi, especial Fusarium, closely follow the development of the mildew, and unless seeds or tissues in a very early stage of infection are selected some mycelium of these or bacteria will also be included and eventually spoil the cultures.

In the test tube cultures the following media were used: (I) Living beans on moist cotton. These cultures were obtained in two ways. (a) Beans were taken with aseptic precautions from diseased pods and placed in the test tubes. As these beans were usually already inoculated with the mycelium penetrating into them from the pod, the subsquent development of the fungus could be determined by examination from time to time. (b) Beans were removed from perfectly healthy pods with the same aseptic care and after placing in the test tubes were inoculated with a culture of the fungus or tissue from a diseased bean. The beans, especially the (a) cultures, usually formed a more or less evident, though not luxuriant, external growth of the conidial stage, but the greatest development was in the production of oospores within the tissues. The beans generally turned reddish brown, indicating enzymal action, and in some cases there was practically no external growth of the conidial stage. Plate XXI, a*, shows a bean artificially infected in which oospores were produced abundantly but on which practically no conidial growth occurred; at $\mathrm{a}^{* *}$ is shown a perfectly healthy bean. Most of the successful cultures were made on these living beans, as there was less interference from bacteria and other fungi when the cultures were impure. (2) Sterilized bean tissues, of which the following combinations were tried; (a) whole beans on moist cotton, (b) a mixture of ground green beans and pods, and (c) a combination of (b) the corn meal. These were fairly good media, but bacteria, yeasts and fungi bothered considerably if they were not inoculated with perfectly pure material. Both the conidial and the oogonial stages are formed. (3) Agar agar, usually made with (a) potato juice water but in some cases (b) with sugar, and peptone and certain salts. The mildew developed poorly 
in most of these trials, but both conidia and oogonia occurred to some extent. (4) Corn meal which was made up with (a) potato juice, (b) peptone, sugar and certain salts, and (c) ground beans and pods. Corn meal is a good medium when once the fungus gets started, and in these trials also both stages occurred. Because of oogonial production the fungus did not penetrate as deeply into the medium as expected.

Cultures of the mildew were kept going from the middle of September to the middle of November. At first there was a more luxuriant growth of the conidial stage than toward the end of the period and finally this stage seemed to so run out that it was practically impossible to continue cultures. At all times it was easier to start cultures from inoculated tissue than from tufts of the fungus transferred by needle from one tube to another. There was required, too, a certain degree of moisture in the culture to insure the best growth. By far the best results were obtained on the living bean cultures. Fungi, bacteria and yeast bothered considerably, especially on the sterilized media. It was very difficult to get cultures that aid not finally develop such impurities, though a number of these were obtained. The growths of the Lima bean mildew were in marked contrast with those obtained of the potato mildew in that the development of the conidiophores was inconspicuous while the reverse is true in nature. No doubt the formation of oospores greatly interferes with the conidial development, and if this latter could have been secured alone, as it was with the potato mildew, a much more luxuriant external growth would have been made. One of the most interesting questions connected with the cultures of these two mildews is why in one case oospores were always produced and never in the other. This question is discussed more fully in the following article on the potato mildew.

PREVENTIVE MEASURES.

From the preceding discussion one can see that there are certain conditions that favor the introduction and spread of the mildew in the Lima bean fields. Some of these factors can be controlled, at least to a certain extent, by the grower. In the following paragraphs are given briefly the means by which he may hope to prevent or lessen the injury inflicted by this parasite. 
Selection of seed. It has been shown how the dormant mycelium and the oospores carry the fungus over from one year to another in the seed. If possible, therefore, the seed should be gathered from a field entirely free from the disease. Where this is impossible a very careful selection should be made from pods that show no sign of the mildew and from these only the best and least shriveled should be used.

Rotation. It will do no good to select disease-free seed if this is planted on land that bore a diseased crop the year before, as the old seed rotting in the soil will probably furnish oospores for infection. Each year the beans should be planted on a different piece of ground, so that three or four years pass before it is again used for this crop. This is a practice not always followed, as one large grower in the state, at least, has planted beans year after year on the same land and his beans are sure to be attacked by the mildew if any are that year.

Destruction of rubbish. Where rotation is faithfully followed each year perhaps little good will be accomplished by destroying the old vines, as the oospores probably will not live in the ground more than a year or two. Where, however, the grower deems it very essential to use the same land the next year for Lima beans, the chances for infection will probably be lessened by gathering and burning in the fall all of the rubbish of the old crop. It should be borne in mind in this work that the pods and seeds are the parts it is most necessary to destroy.

Methods of planting, etc. The Lima beans are usually planted to climb upright poles and these are set in rows to allow cultivation in one direction. They should be set a sufficient distance apart in the rows (say three to three and a half feet) and the rows should be of sufficient width (about four and a half feet) to allow free entrance of the sunshine to dry off the foliage and prevent the enclosed air from being too damp. Neither should more than two or three vines be grown to a pole for the same reason. Low moist spots in the field favor the first infections and the spread of the mildew afterwards, so it is desirable if such exist to plant some other crop on these spots. So, too, considering injury from the mildew only, it is more advantageous to use a high dry field than a lower more moist one.

Spraying. Sturgis is the only investigator who has reported spraying experiments for the prevention of this mildew. His 
first experiments were made in 1893 with a number of fungicides, but as the mildew did not appear in this field even on unsprayed vines no conclusions could be drawn, except that the fungicides did not injury the foliage in any case. In 1897 he made further trials using Bordeaux mixture, ammoniacal solution of copper carbonate, potassium sulphide, and sulphur as the fungicides. The best results were obtained with a row that was sprayed three times with Bordeaux and twice with Amm. Sol. Cop. Car., as this yielded 296 marketable pods against 25 on an adjacent unsprayed row. Sturgis says, "The conclusion to be drawn from this experiment is that even in a season most favorable to the Lima bean mildew, thorough treatments of the vines with the Bordeaux mixture will ensure a crop."

While the writer has conducted no spraying experiments for the prevention of this mildew, he has watched certain fields in the vicinity of New Haven that have been sprayed. From these observations and the results of Sturgis' work the following suggestions are offered: Spraying need not be commenced before the middle of July, or possibly in very wet seasons about the first of this month. Bordeaux mixture is the most satisfactory fungicide and in later sprayings need not be replaced by Ammo. Sol. of Cop. Car. or potassium sulphide if the marketable pods are picked before each spraying. Even if some sediment does still adhere to the pods when picked, this can do no possible injury unless prejudice militates against their sale. The spray should be directed chiefly to the young parts of the vines and should be delivered in a fine mist. It is most important that the spray reach the pods and least important that the foliage be covered. Three or four thorough sprayings with Bordeaux mixture will probably be sufficient for most seasons. Most of the spraying observed by the writer has been partially ineffectual because it was done too early in the season and because the leaves were the parts chiefly protected.

Factors beyond control. Season is the chief factor in determining the amount of injury by the mildew. As stated before, very wet weather from July to September is favorable for the development of the trouble. Of course the weather can not be controlled, but where one has taken the preceding precautions his loss should be much less than one who has not. A 
second factor not under control is insect visitation. As shown by Sturgis, bees may spread the disease in a field and we have reason to believe that they may carry it to a certain extent from one field to another. This being the case, one who makes the preceding precautions to keep the disease out of his field should also isolate it, as far as possible, from other fields, especially from those that are likely to be seriously troubled. Where the fields are very close together not only insects but also the wind may help to carry the disease from one to another.

\section{EXSICCATI.}

Specimens of the Lima bean mildew have been issued in the following exsiccati, all the specimens having been collected in the vicinity of New Haven on Phaseolus lunatus: Seym. \& Earle Eco. Fungi, 9 (Thaxter, Sept. Oct., I889); Ellis \& Ev. N. A. F., 2707 (Thaxter, Sept., I890) ; Bri. \& Car. Fung. Par., 35 I (Rorer, Sept., I90I) ; Ell. Ev. Barth. Fungi Col., I949 (Clinton, Aug. 29, I902).

\section{LITERATURE.}

The following references to the literature of this mildew include all of any importance that the writer has been able to find. Even some of these contain only data taken from Thaxter and Sturgis.

I. Berlese, A. N. Phytophthora Phaseoli Thaxt. Riv. Pat. Veg., 9: 4I-4. I902.

Gives scientific description and general notes on this fungus, which he lists only from New Haven, Conn., drawing his data from Thaxter and Sturgis.

2. Briosi, G. and Cavara, F. Phytophthora Phaseoli Thaxt. Fung. Par. No. 35I. [Illustr.]

Issue specimens from New Haven collected by Rorer and give figures and descriptions taken from Thaxter.

3. Clinton, G. P. Downy Mildew, Phytophthora Phaseoli Thaxt. Ann. Rep. Conn. Agr. Exp. Stat., I903: 307-8. 1904. [I1lustr.]

Gives short general account of the fungus and suggestions for its prevention.

4. Halsted, B. D. Notes upon Mildew of Lima Beans. Ann. Rep. N. J. Agr. Exp. Stat., I897: 297-9. I898. [Illustr.]

Reports this very serious in Bergen Co., N. J., in I897; mildew worst on low land that had Lima beans on it the year before. 
5. Halstead, B. D. The Phytophthora of Lima Beans. Bull. Torr. Bot. Club, 25: 16I-2. 1898. [Illustr.]

Notes this fungus as serious in New Jersey in 1897 , which was a wet season.

6. Halsted, B. D. Late Growth of Bean Mildew-Phytophthora Phaseoli Thaxt. Bull. Torr. Bot. Club, 26: 20. 1899.

Notes late growth of the fungus, Oct. 24, on the green pods after the leaves had been killed by frost.

7. Halsted, B. D. The Downy Mildew of Lima Beans. Bull. N. J. Agr. Exp. Stat., I5I: I8-24. I90I. [I1lustr.]

Gives a general account of this fungus, which has proved a serious trouble of Lima beans in New Jersey in wet seasons.

8. Halsted, B. D. The Mildew of Lima Beans. Ann. Rep. N. J. Agr. Exp. Stat., I902: 399-403. 1903. [Illustr.]

Reports troublesome in New Jersey in 1902 and gives extracts concerning it from Bull. I5I of the New Jersey Station.

9. Jaczewski, A de. Phytophthora Phaseoli. Bull. Torr. Bot. Club, 29: 649. 1902 .

Salmon quotes portions of a letter from above botanist, who notes presence of this fungus in Russia.

I0. Orton, W. A. Phytophthora Phaseoli Thaxt. Yearbook U. S. Dep. Agr., 1903: 554. Ibid., I904: 584.

Lists the fungus as injurious in Connecticut, New Jersey and Delaware in 1903; but in 1904 it is reported only from New Jersey.

II. Saccardo, P. A. Phytophthora Phaseoli Thaxt. Sacc. Syll. Fung., 9: 34I. I89I.

Gives scientific description taken from Thaxter and lists only from New Haven, Conn.

12. Smith, C. O. Mildew of Lima Bean. Bull. Dela. Agr. Exp., 63: 23-4. 1904.

Deals briefly with this fungus and notes its appearance in Delaware from July on in 1903 .

13. Speschnew, N. N. Les parasites vegetaux de la Cakhetie. Arb. Bot. Gart. Tiflis, lief, 2, I897. [Review: Zeitsch. Pflanzenk., II: II3.]

Lists Phytophthora Phaseoli Thaxt. from the Gouvr. Tiflis (Kaukasus).

14. Sturgis, W. C. Mildew of Lima Beanș. Ann. Rept. Conn. Agr. Exp. Stat., I893: 77. I894.

Used several fungicides but as the fungus was not present in the sprayed field their value was not determined.

15. Sturgis, W. C. The Mildew of Lima Beans (Phytophthora Phaseoli Thaxt.). Ann. Rep. Conn. Agr. Exp. Stat., 1897: I59-66. 1898. [Illustr.]

Gives a general account of the fungus and shows how bees spread the fungus to the flowers; gives results of successful spraying experiments with Bordeaux mixture, etc. 
16. Sturgis, W. C. On some aspects of Vegetable Pathology and the Conditions which influence the Dissemination of Plant Diseases. Bot. Gaz., 25: I9I-4. I898. [Illustr.]

Shows how insects and wind are influential in the spread of Phytophthora Phaseoli.

I7. Sturgis, W. C. Mildew of Lima Beans. Ann. Rep. Conn. Agr. Exp. Stat., I898: 236-4I. I899.

Made experiments to determine effect of thin and thick planting an upright and slanting poles on amount of mildew, which was very bad this season; looked especially for means by which it carried over winter in old rubbish but found nothing.

I8. Thaxter, R. A new American Phytophthora. Bot. Gaz., I4: 273-4. I889.

Gives a general and a scientific description of this new species, Phytophthora Phaseoli Thaxt.

I9. Thaxter, R. Mildew of Lima Beans -(Phytophthora Phaseoli Thaxt.). Ann. Rep. Conn. Agr. Exp. Stat., I889: I67-7r. I890. [Illustr.]

Includes a general description of the fungus, an account of its germination, its relation to other species and methods for its prevention.

20. Thaxter, R. Mildew of Lima Beans. Ann. Rep. Conn. Agr. Exp. Stat., I890: 97-8. I89I.

Notes distribution of fungus in Connecticut, especially during this year.

2I. Thaxter, R. Phytophthora Phaseoli Thaxt. Journ. Myc., 7: 279. I893.

Gives scientific description and references to literature of this fungus. 
DOWNY MILDEW, OR BLIGHT, Phytophthora infestans (Mont.) DeBy., OF POTATOES. II.

In the Report of this Station for 1904 the writer gave the first installment of his work with the potato blight. This included a short general account of the life history of the fungus, so far as known, and of spraying experiments looking toward the most practical methods for controlling the disease. The investigations of the past year, reported in this article, have been made chiefly to determine more minutely and accurately points in the life history of the fungus in the hope that when this is definitely and completely known, prevention of its ravages will be an easier task to those who take advantage of this knowledge. The points that need especial elucidation are the way or ways by which the fungus first infects the vines in the summer (that is the primary infections), its history, if any, in the soil, and the means by which it is carried over from year to year. To gain such information the writer made careful observations of the very first appearance of the disease in various fields, examined the plants and tubers in all conditions of health and decay, carried on indoor inoculation experiments and grew the fungus in artificial culture for two years. We are not yet satisfied with what is known of the fungus and hope later to make additional reports concerning it.

\section{Primary Infections.}

Discased plants. What conditions do the very first infections of the year in a given region or field require? We know that the disease has never appeared, or at least has never been recorded, in Connecticut before the first week of July, and sometimes it is not found before the middle of August, and that the more rainy, cloudy and foggy these months are the quicker it gets a start and the more rapidly it spreads. Smith and DeBary also report that the blight is seldom seen in Europe before July or August, though rarely it has been found even in May or June. The common belief, or at least the one advocated by DeBary concerning the advent of the fungus in a field, is that it comes from "diseased plants."

Perhaps DeBary's (2) views can be best shown by the following quotation: "The facts which have been observed estab- 
lish that there are two methods by which the conidia may pass from the tuber to the foliage. First, it is known that the mycelium of the fungus in the tuber, even when in the ground, is able to produce conidiophores bearing conidia directly from the tuber. We can easily see how the conidia thus produced could reach the foliage-they might be carried up either by the growing plant which may have touched them, or by small animals which frequent both situations. Neither of these methods can be easily detected. Moreover, the formation of conidia in the soil cannot be very frequent. There should therefore perhaps be little weight attached to this method. The second method can be easily observed and with great exactness. It consists in the mycelium growing from the tubers in and with the young plants and producing conidia on them in the usual way; and these [diseased plants!] of course extend the fungus to the healthy plants beside them. In I86I I called attention to the fact that tubers containing Phytophthora when they are growing, not unfrequently send out shoots into which the fungus passes from the tubers. The fungus advancing slowly in its growth at last kills the shoots, which for the most part were always in a sickly condition. The same tubers, as is known, may also send out healthy shoots at the same time. I further showed that under special circumstances the fungus in these diseased shoots develops conidia. These were not conjectures, but facts observed in experiments. The observations, however, were not made in the open field, but in the house and laboratory, and had not been confirmed by myself or observed by others in the open field." DeBary tried to demonstrate this second theory by planting tubers he infected through the eyes outdoors along with healthy ones, and observing if, upon the growth of the plants, the disease spread to the leaves of all the plants. In his first trial, although he grew a diseased plant, the fungus never fruited on this and so did not spread the disease. In the second trial the healthy and diseased tubers were planted out early in the garden in a box and several diseased shoots appeared which in time developed a fruiting condition of the fungus, so that before the end of May the blight had spread to many of the leaves of all of the plants. This was long before its appearance elsewhere in the neighborhood. 
The writer, thinking that DeBary's "diseased plants" might offer the best explanation of the first appearance of the blight, made special search for them in different fields after the vines were above ground at various times up to the general appearance of the disease, but was not successful in finding such plants. True, one sometimes finds plants stunted by the bacterial stem rot and also those with cankered areas on the parts below ground caused by the Rhizoctonia fungus, but no sign of any disease like or unlike these containing outbreaks of the blight fungus. For two or three years efforts also have been made in the greenhouse to produce blight diseased plants from tubers known to contain the mycelium of the blight fungus. The badly diseased tubers often failed entirely to grow; others, less diseased, produced plants, sometimes making a poorer growth than usual, but never showing any signs of the blight. Thinking that possibly the greenhouse conditions were not favorable for determining this point, as the atmosphere there was usually rather dry, a more extended experiment was conducted outdoors in the spring of 1905. Through the kindness of some thirty Connecticut potato growers who had suffered from rot of tubers in I904, a few potatoes showing disease were obtained from each. While these growers were requested especially for tubers showing the reddish superficial rot characteristic of blight, the potatoes sent showed the Rhizoctonia, scab, and Fusarium rot troubles as much or more than they did the blight. The tubers were divided into five lots and planted in five rows, as follows: (I) tubers freest from disease, also treated with formalin; (2) same as ( $\mathrm{r}$ ) but not treated; (3) tubers badly scabbed; (4) tubers with abundance of Rhizoctonia; (5) tubers with Fusarium or blight rots, or both. In the last case some of the tubers were badly rotted and the plants in this row came up somewhat slower and less uniformly than in the others, but there were no blight diseased plants seen at any time and the first blight that appeared was on leaves of a plant in the row whose tubers had been selected as freest from disease and then treated with formalin! Neither did the tubers produce any more rot in the fifth row than those in the other rows, while the row of scabby tubers produced a crop badly scabbed and the Rhizoctonia row one with that trouble very prominent. Other experimenters (Smith, DeBary) have also reported cases 
in which perfectly sound plants were grown from blightdiseased tubers.

The only instance in which the writer has seen anything like a blight-diseased plant, as recorded by DeBary, was in the greenhouse, where a healthy tuber, planted in a crock with the top just above the surface of the soil, was inoculated with the blight fungus on one of the young buds, which was then covered with moist cotton and a small bell jar. This bud was finally killed and the reddish brown rot of the blight extended in time down into the tissues of the tuber about a quarter of an inch and spread for some distance beneath the skin, reaching another eye from which eventually was grown a stem several inches long. This stem, see Plate XXIV, b, about thirty or forty days after the inoculation showed a reddish brown discoloration on the exterior from the base to the tip and the conidial spores of the blight fungus were produced sparingly upon it. The interior tissues of the stem, however, seemed to be perfectly healthy and free from the fungus, and so if the disease came from the mycelium in the tuber growing up into the stem, this growth occurred in the external tissues rather than through the bundles, as one might expect. There was a possibility, even in this case, that the disease was inoculated externally by lice carrying spores from the inoculated place on the tuber, since perfectly healthy stems grew out of the sides of this diseased one. So far as the writer can judge from reports in literature and his own experience, DeBary's "diseased plant" method of primary infection does not seem to have sufficient support so far to justify the belief that it is the common method in nature.

Contact of leaves with ground. But if the blight does not generally first spread from a diseased plant, how does it start in a field? There is offered here an explanation which our observations of the past year seem to indicate as the ordinary method of infection. Possibly this idea has been advanced before, since the writer has not carefully examined the literature to determine this point. In support of our observations that the blight does not usually start from diseased plants, let us first quote the following from Smith (6, p. 293): "It is obvious that if the potato disease is annually reproduced by diseased tubers containing perennial mycelium, the disease must invariably begin in the seed tuber and ascend the stem; but it is known 
by experience that in the vast majority of instances this is not the case, but that the disease first invades the leaves." This corresponds with our observations of the past summer; namely, that the disease first appeared on a few leaflets, often on the outermost leaves, of the fully grown, perfectly healthy plants, and these conditions of its appearance preclude the belief that the disease came by the mycelium in the diseased tubers ascending the stems and growing out into the leaves, all without causing any injury or evidence of its presence until finally it produced the characteristic black spots on the isolated leaflets! But Smith does not state definitely how the disease came on the leaflets in these cases. We believe it comes by contact of the leaves with the ground at the critical zet periods of July and August when the germs of the blight are probably first generally available in the soil for infection, and that this is the usual method of primary infections in the fields.

In support of the preceding statement we give the following evidence: The season of 1905 was dry during midsummer, so the blight was backward in its appearance. A number of fields, chiefly in the vicinity of New Haven, were examined from time to time to note the very first signs of blight. Weather favorable for this trouble came on about August 9th to the I6th and the first blighted leaves found anywhere, August IIth, were in an isolated field at Southington that had not been examined before. This field of two or three acres had been in potatoes the year before but was greener and in a better condition than many fields at this time, as the drought and other agents had been very injurious. After a careful search of the field the attempt to find any blighted leaves was about to be given up when two plants near together were found on which a dozen leaflets showed a single blight spot each. Two of these leaflets were still in contact with the moist ground and half of the others showed by the dirt on them that they had recently been in contact with the soil. Of course it is possible that some of these spots may have come from secondary infections, as the fungus was already fruiting on these leaves. There was no sign of a diseased plant in the field so far as observed and certainly none in the vicinity of the outbreak, and an examination of the two plants having the diseased leaflets showed no sign of the fungus on their stems. The later development of the blight in this 
field was not observed. The second place where the blight was found was on August I2th, in the small isolated plat at the Experiment Station, previously mentioned, where the tubers showing different kinds of disease were planted. In this case they were in sod land that had not been in potatoes before. The plat was carefully watched, so that a diseased plant could not have escaped observation. Here, too, no such plant occurred and the blight first appeared on a healthy plant which had about ten leaflets with single blight spots, in fruiting condition, when found. Two of these leaflets were still in contact with the soil and two thirds of them showed dirt on their under surface, indicating recent contact with it. There were no outbreaks anywhere on the stem of this plant or even on the parts below the ground so far as could be observed. The disease afterward gradually appeared throughout the plat. The third case found was in an isolated field of half an acre in Whitneyville, by which the writer often passed and stopped to look for the blight. This was first found August I6th, when after a careful search a plant was discovered with a single leaf showing the blight. While this leaf was then off from the ground, the dirt on its under side again showed recent contact with it. A photograph of this leaf is shown in Plate XXIII, a; only the badly diseased leaflet was producing conidial spores. No sign of the blight was found on any other part of the plant, though looked for carefully. In a second place in the field, but removed from this, another plant was found with several blight spots on the leaves, some of which were still in contact with the ground. Here the blight had spread, in some cases, from the blades onto the pedicles and petioles, but these were always near the blight spots and all of the petioles were perfectly free from the disease at their base. There was again absolutely no sign of the fungus on the stem of the plant. Later the blight gradually spread over the field. Other fields examined up to this time had shown no blight, but by the $22 \mathrm{~d}$ of August it was found appearing generally in a number, so that from this time on the disease was not uncommon in fields still green.

Planting potatoes without rotation. It is not an uncommon practice for farmers in this state to grow potatoes two consecutive years on the same land and there is at least one field in the vicinity of New Haven that has had potatoes on it for several 
years in succession. While the writer has not yet determined from his own observations whether the fungus can carry over the winter in the old tubers in the soil, Massee (3) of England makes the following very definite statement: "I have observed the important fact that, when the diseased potatoes are planted, after the crop has been lifted, the remains of the old seed potatoes when brought to the surface of the ground will produce a crop of the fungus bearing myriads of spores. If such old seed potatoes are kept buried in soil until the following year and then exposed to light, under favorable conditions, fungus fruit is still produced, and continues to grow so long as a scrap of the old potato remains. I have now in the laboratory at Kew Gardens scraps of last year's seed potatoes covered with the fungus, and with the spores thus produced have successfully inoculated the leaves of young potato plants." If Massee's statement is true, then fields used two years in succession should, as a rule, develop the blight earlier and spread it more rapidly than fields not in potatoes before for some time. As the writer knew of three fields which had produced a badly diseased crop the year before and were used again last year for potatoes, these were examined to see if this was so. The one most carefully watched was in Westville and had abundant rotten tubers from the preceding crop left on it. In this case, however, the vines were practically dead before any blight appeared in the neighborhood, so that all that could be determined was that its use a second year did not cause an unusually early appearance of blight in it. The other two fields were at Green's Farms and so could not be watched so closely. When first examined on August I9th they both showed blight more prominently than other fields in the neighborhood. This was especially true of the earlier plant field, in which the blight was very prominent, while another field on the same farm isolated from this, but on land not in potatoes for years, was at this time practically free from blight-only a single blighted leaf being found there. On August 28th at Hamden a fourth field was examined that was said to have had potatoes on it several years in succession, and this showed more blight in it than had been seen in any field up to that time in the vicinity of New Haven. Other fields examined generally showed an earlier or a more vigorous start of the blight if they had been in pota- 
toes the year before. We do not wish to state positively, from these observations, that the blight starts earlier and more vigorously in a field that bore a blight-diseased crop the year before, as such factors as situation of the land, earliness of planting, etc., may need consideration here, but so far as they go they seem to point to this conclusion.

\section{Secondary Infections.}

By secondary infections are meant all those that take place from and after the original infections (the outbreaks on a diseased plant, if such exists, or on leaves infected from contact with the ground), and thus generally spread the disease to the leaves of these plants, to those throughout the field or even to other fields. The means cited here (rain, wind, and insects) have usually been considered agents for the distribution of the blight spores, though few special observations have been published showing them to be such or indicating how far the disease may be carried by them. To determine these points more fully the following observations and experiments were made the past year.

Rain. The testimony of all who have written concerning blight shows that rainy or moist, muggy weather is absolutely essential to the development and spread of blight in the fields. This is especially necessary for this fungus because the spores on germination usually form swimming spores, zoospores, which are the common agents of infection. Not only is moist weather necessary for infection, but dry bright weather following the infection largely stops the spread and even the development of the fungus already within the leaves. The moist blackened tissues then dry up, and though the disease may seem to have suddenly caused great damage, it is not progressing into the healthy green tissues beyond as it would have done had the weather remained moist. Rain not only induces the formation and germination of the spores, but it serves as an agent in distributing them. over the infected plants and also washes them down into the soil to the tubers. It can not of course be of much service in carrying spores from one plant to another unless they overlap, and therefore by itself could only very slowly spread the disease throughout a field if there had been but a single starting point. 
Wind. It is not so easy to prove that wind serves as a means of distribution, but it no doubt acts as a carrying agent of the spores to vines in the same field or to fields situated closely together. The fungus, however, is not especially adapted for dispersal by the wind, since the spores are borne on the under side of the leaves and on the whole are not produced in great abundance. The dry winds of bright weather would be of little value, as it is in such weather that the spores rapidly lose their power of germination and would find least opportunity for germination, even if carried into a field. It does not seem likely, therefore, that wind is a common agent in carrying the spores from one isolated field to another. The case cited in a previous paragraph-the field the second year in potatoes at Green's Farms in which blight developed vigorously and earlyseems to indicate that wind may be a prominent agent of dispersal for short distances, since the prevailing winds were from the direction of the infected field toward an adjoining one, which also soon became infected with the blight.

Insects. Apparently insects are a common agent in the distribution of the spores throughout a field, and the chief means of conveying them from one field to another somewhat remote. In other words, if it were not for insects, the selection of an isolated field which had not been used recently for growing potatoes and which was planted with tubers free from the disease should give a crop exempt from blight. The most comnion insects in the potato fields of Connecticut are the flea beetle and the common potato bug, or Colorado beetle. The latter is well adapted for carrying spores, since the under side of the tarsi of the legs, especially the third tarsus, is provided with a stiff brush of hairs that would easily retain spores temporarily as the insect crawled over an infected leaf. The only insect examined to determine this point did not actually have the spores of the blight fungus on the brushes of hairs, but these did have spores of other fungi, showing they could serve such a purpose. The soft, somewhat moist body of the larvae of the potato beetle, too, possibly aids in distributing the spores. Just how helpful to the fungus the flea beetles are in this work is not known.

To determine whether insects could carry the blight from one isolated field to another, an experiment was conducted last 
year at Mr. Burr's place near Green's Farms. The potatoes were planted in a garden on soil that had not contained potatoes for at least five years. The garden was isolated and well surrounded by trees, etc., and was not situated so that wind would blow from another field toward it. The nearest potatoes were at least an eighth of a mile away and the badly diseased field mentioned before, about half a mile. The seed tubers were obtained from Colorado on the recommendation of Mr. Orton of the Division of Vegetable Pathology of Washington that this was a region of the United States exempt from blight. So far as could be learned, the grower of these potatoes had never been troubled with this disease and Professor Paddock of the Colorado Experiment Station writes that he has never identified the blight in that state. These potatoes were examined the same time, August Igth, that the writer looked through the other fields on Mr. Burr's farm. After a searching examination a couple of leaves showing the blight were found, and Mr. Burr wrote in the fall that eventually these potatoes suffered from the blight about as badly as the others. Without much question the potato bug was the means of introducing spores for the first infection, after which the blight spread from this throughout the plot. Part of the Colorado potatoes were planted on land not recently in potatoes, but very close to the badly blighted field mentioned before, and these on August igth showed considerable blight on the leaves. Both the wind and insects were no doubt the carrying agents here. Some potato seed was also obtained from this Colorado grower and planted in the greenhouse during the winter and the young seedlings set out later on the Experiment Station grounds about five rods from ordinary garden potatoes. These seedlings, too, became infected with the blight, but not until sometime after it appeared on the garden potatoes. The potato bug was again the most probable carrying agent. From this experience, the writer concludes that the grower can not depend upon isolation of a field and absolute freedom of soil and tubers from the fungus to secure a crop free from blight since insects are very likely to carry in the disease, though the more isolated the field the less likelihood of infection. Such conditions, however, will insure a later appearance of the blight in the field, but whether retarding the invasion will prove of any practical value 
will depend upon how long the infection is delayed and the weather conditions thereafter.

\section{Artificial Infections.}

By this is meant indoor infections produced by the writer, chiefly with pure artificial cultures of the blight fungus. To secure infection it is necessary that the cultures be in fresh spore-producing condition and that the inoculated plants be kept moist or in a moist atmosphere, not only during the infection period, but also afterwards if the fungus is expected to appear in its fruiting stage on the surface of the infected parts. The few experiments tried were made to determine how easily infection takes place under different conditions and how soon the conidial stage appears after the spores are applied. Both leaves and tubers were used as subjects for infection.

With the leaves. DeBary showed that the germ tubes of the zoospores of potato blight can enter the leaves either through the stomates or by penetrating directly through the epidermis. The usual method in the latter case is for the germ tube to push its way down between the walls where two cells come together and then grow down into the intercellular spaces of the leaf beneath, but DeBary also observed cases in which the germ tubes bored directly into the epidermal cells themselves. The ability of the fungus to gain entrance in these various ways greatly aids its spread over its hosts. The stomates are more numerous on the under surface of the leaf, but most of the infections probably take place from the upper surface, as the spores are most likely to be carried here from the conidiophores borne on the under surface of leaves above.

In our infection experiments after the spores were placed on the upper surface of the young leaves, usually by the end of three days it could be determined if the inoculation was successful by the slight discoloration of the tissues. By the end of the fourth day this discoloration was more evident and conidiophores were beginning to protude through the stomates, and by the end of the fifth day the diseased spot was well marked and a few mature conidiophores and conidial spores were present. As these spores can germinate immediately, secondary infections could take place within five days after the primary. Perhaps the development of the fungus can be shown 
best by a detailed account of the infection of the plant shown in Plate XXIV, a, which was photographed ten days after the spores were applied. Its history is as follows: Jamuary IIth, placed spores in water on three lower leaves, covered each with a small piece of moist cotton and the plant with a small bell jar. Jamuary I4th ( 3 days), the two lower leaves showed slight discoloration at points where spores were placed. January I6th (5 days), the spots were well marked and conidiophores and spores were formed in small numbers. January 18 th (7 days), about two thirds of the two lower leaves were plainly diseased (yellowish, limp and partly blackened) and the conidiophores were developing over the greater part of this area, but most abundantly on lower surface; two diseased streaks showed on the stem but had few conidiophores on them; petiole of one leaf was covered with conidiophores, but showed little discoloration. Jamuary 2Ist (Io days, see illustration), the two lower leaves were dead and hanging limp; the third leaf showed yellowish discoloration over apical half and was producing conidiophores; the fourth leaf (apparently a secondary inoculation by lice) had a few conidiophores on it, but no injury to its tissues showed as yet; several blackish streaks showed on the stem where the fungus had gained a foothold from the diseased leaves above.

With the tubers. There are a number of different conditions under which inoculation of the living tissues of the tubers may be tried; namely, on the cut surface in a moist atmosphere, on various uninjured parts (eyes, buds, skin) before or after removal of the tuber from the plant, or on these same places after mechanical injury to them. In the experience of the writer the development of the fungus varies greatly under these dissimilar conditions. It grows most luxuriantly, at least externally, on the cut surface of the tuber in a moist atmosphere. Before inoculation it is always desirable to soak the whole tuber in a 2 per cent. formalin bath for half an hour and to use a sterilized knife in cutting it, in order to limit as much as possible the development of other fungi and bacteria which easily crowd out the Phytophthora. Discoloration of the tissues, at least for some time, does not follow the development of the fungus on the cut surface of the tuber; this probably indicates very superficial penetration into the tissues. 
DeBary states that he secured infection of the tubers very readily through the terminal eyes. Presumably the buds were slightly developed in the tubers he used. Our experiments, at least, seemed to indicate that it is very much easier to secure successful inoculation through the very young buds than it is at the eyes of a perfectly dormant tuber in which no bud is yet evident. These experiments, too, go to show that inoculations on the uninjured skin of a dormant tuber are not likely to be successful, while at the same spot if the skin is first injured by a knife puncture the inoculation succeeds. Likewise, in the single experiment tried, the inoculations were not very successful on the uninjured skin of very young tubers still attached to the plant, and scarcely more so when the tissues were injured before inoculation. Possibly some of these results were partly due to the age of the cultures used, but even then there seems to be no doubt that there is greater variability and difficulty in securing infection of the tubers than of the leaves.

Three of these inoculation experiments with the tubers are recorded here: $I$, November $I g t h$, tried to inoculate five dormant tubers, using artificial cultures of the blight. Each tuber was buried in the soil of a crock so that a single lateral, deeply indented eye, showing no sign of bud formation, was exposed above the surface of the soil. These uninjured eyes served as a cavity into which the spores and water were placed, when they were then covered with watch crystals lined with moist paper to retain the moisture. The tubers, however, were so thoroughly seasoned that the water in the eyes was rapidly absorbed and had to be replaced many times during the next few days, though the soil around the tubers was also kept moist. Possibly this dying out influenced the result, for not a single inoculation was effective, and at the end of 32 days the tubers were still perfectly sound at these eyes. 2, December 2Ist, used the same tubers but placed the spores away from the eyes on a small spot where the skin had been injured by a knife. On examination ten days later rots showed at all of the points of puncture. Some of these were the characteristic dry reddish brown rot of the Phytophthora, with or without the conidiophores showing slightly at the punctured point, while in other cases bacteria were also agents of the decay. January gth one of the tubers was half rotted and a short shoot from it had been 
killed by Phytophthora and bacteria, having, apparently, become inoculated externally by lice. February 2Ist, took up all of the tubers and the plants that had developed from them. All of the seed tubers were entirely rotted, showing more or less of the characteristic reddish brown dry rot of the Phytophthora, especially near the outside, but all but one had produced plants and small tubers. None of these new tubers showed any sign of rot; neither were any of the plants diseased. Cross sections of the stems close to the old seed tubers and of the underground shoots running from these to the new tubers in no case showed any sign that the mycelium of the blight fungus had passed or was passing from the diseased tubers into these. 3, February 2Ist, inoculated four young tubers (about one inch in diameter, growing in greenhouse bench) with culture of the blight fungus,- - two with and two without injury to tissues. February 23d the injured spots showed evident but very slight rot, while the uninjured showed doubtful start. March 2oth the injured spots had rotted but little, being only $1 / 4$ of an inch in diameter and extending but slightly into the flesh; while the uninjured spots were only about $1 / 8$ of an inch in diameter and still more superficial. The fungus did not fruit at any of these places and bacteria may have been partially responsible for the rot, though in the case of the check tuber, injured but not inoculated, no rot appeared.

\section{Artificial Cultures.}

So far as known to the writer, the reports of Matruchot and Molliard $(4,5)$ made in 1900 and 1903 are the only ones so far published concerning pure artificial cultures of the blight fungus. The work reported here was begun in the fall of I9O4, before learning of the investigations of these French botanists, and has been carried on now for about two years. Growth of the fungus on various media in test-tubes was undertaken chiefly to see if this would not throw some new light on the life history of the fungus, especially with regard to the missing oospores. The general results obtained agree with those of the French investigators, though the details of methods and media used were not altogether the same.

How obtained. Fure cultures of the blight fungus are not so easily obtained as are those of many fungi, since because of 
their slow growth they are easily crowded out in competition with other fungi, and because the ordinary Petrie dish separation method is not available with their spores, which prefer a fluid medium for germination. Matruchot and Molliard apparently made most of their cultures by exposing the cut surface of an infected tuber in a moist chamber until the fungus ran out on this in its fruiting stage, when material from the growth was transferred by a sterilized needle to test tubes containing various media. Such growths on the tubers are nearly always contaminated and usually only a few of the cultures made from them remain pure. If the tubers are first sterilized on the outside by a bath in formalin and cut with a sterilized knife, better results will be obtained. It is desirable, too, if possible, to use only tubers showing a superficial decay of the Phytophthora rot. On the whole, the writer was most successful in obtaining cultures when the reddish brown diseased tissue from the interior of a tuber next the healthy tissue was removed in small pieces, about a third of an inch in diameter, by a sterilized knife and then inserted on the medium in the test tube. In this case the mycelium from the diseased tissue in time runs out onto the medium and often produces a pure growth of the fungus. Where infected tubers are not available for cultural work, the fungus can be started on the freshly cut surface of a sterilized tuber by suspending over it a leaflet containing a vigorous, fresh outbreak of the blight. The spores falling on the cut surface soon start a growth of the fungus, from which material may be transferred to the test tubes. Here, too, contaminations usually prevail in spite of precautions. Plate XXIII, b, shows a nearly pure growth of the fungus started in this way. One of the most common fungous interlopers is a species of Fusarium and it is often impossible to distinguish between the growths of this and the Phytophthora and they soon become intermingled. Microscopical examination is usually necessary to determine which part of the growth on the cut surface of the potato presents the blight fungus in a pure condition.

Media, appearance, etc. Altogether twenty-five to thirty different cultural media and modifications of the same medium were tried to determine the most satisfactory ones and also to see if the fungus could be induced, under different conditions, to develop any unknown stage. These media fall in four gen- 
eral classes; viz., I. Plugs of living plant tissue, 2. Sterilized plant products, 3. Agar agar media, 4. Earth and manure. The results are discussed briefly in the following paragraphs.

I. The writer found, as did Matruchot and Molliard, that plugs of living tissue taken with antiseptic precautions from the interior of a potato, and to a less extent from the pumpkin, offered a very favorable medium for the growth of the fungus. These plugs were cut from the interior of a sterilized tuber with a knife, which had been sterilized with heat and allowed to cool so as not to sear the tissue, and after slicing off the sides a second time were placed in the test tubes on a sterilized cushion of cotton saturated with water. With proper care these plugs can usually be obtained free from organisms and if the atmosphere of the tube is kept sufficiently moist upon inoculation the mildew forms a very favorable growth. This is more or less luxuriant, apparently, according to the conditions of moisture and the success with which the original infection took place. Sometimes a scanty growth of normal conidiophores producing numerous spores occurs or again a conspicuous pure white felt develops, of which a large part is made up of mycelial threads. Plate XXV, a, shows (b) a rather scanty and (c) a very luxuriant growth of the fungus, (a) being a check or uninoculated tube. On the other hand, similar plugs taken from the sweet potato, apple, and cucumber gave practically no growths.

2. Sterilized corn meal properly mixed with water was the best medium used. The chief difficulty lies in inoculating these tubes, as the top of the corn meal usually dries out in a short time into a hard mass and this may prevent the fungus getting a proper start. On the other hand, the mechanical conditions allow the fungus, when once started, to gradually work down toward the more moist base of the tube. To facilitate inoculations and removal of tufts of the fungus, it is best to have the corn meal in a slant at its upper end. Plate XXV, b, shows a growth of the mildew on corn meal, of the same age as those shown on the potato plugs. In the few trials made, a mixture of ground green Lima bean pods and seeds with corn meal gave very satisfactory growths and probably this medium without the corn meal would do as well. Sterilized potato plugs, however, gave scarcely any growth, and according to Matruchot 
and Molliard this is due to the mechanical interference of the swollen starch grains in preventing the spread of the fungus.

3. Agar agar cultures, with various ingredients added, were tried, but on the whole were less satisfactory than the preceding media. Most of these cultures gave slight growths, while, in all, the fungus was slow in developing. Usually a slight growth of the mycelium penetrated the medium and a more or less conspicuous development of conidiophores and mycelium was formed on the surface. Potato and pumpkin juice agar media were as satisfactory as any tried. Plate XXV, c, shows an old culture on pumpkin juice agar, in which the development was more prominent than usually obtained on agar media.

4. Sterilized manure, earth, mixtures of these and of these with other ingredients were used to a limited extent to see if they would furnish proper media for the development of the fungus. It was thought that if this was the case there might be some ground for believing that the fungus made some such development in nature. In all of these trials the growths made were very slight or there was none at all. The very poor growths noticed were due, in some cases, to the medium added with the fungus on inoculation. So far as could be learned from these cultures there is no reason for believing that the fungus makes any unknown growth in the soil.

Results. These investigations showed that the fungus can be grown in artificial cultures rather readily under favorable conditions. The cultures can be kept alive for some time, especially on a medium, as corn meal, allowing the fungus to spread slowly through it. By occasional re-inoculations the fungus, apparently, can be kept indefinitely in culture. In some cultures and under some conditions, there is a more luxuriant development of the fungus than in others. The most conspicuous growths usually indicate a more vigorous mycelial than conidial development. No sign of an oogonial or other unknown stage appeared in any of the cultures. In one case, however, there was a very slight growth from the pieces of an infected tuber inserted in agar tubes and in this medium some peculiar swollen. bodies were formed whose nature was not definitely determined. They resembled somewhat the immature so-called oospores that Smorawski (7) has figured. A few cross inoculations were tried with cultures obtained from different sources, but nothing 
unusual occurred. These trials were made with the hope that different mycelial strains might be discovered whose growth together would result in the production of oospores. As the different cultures were few in number and were obtained chiefly from the same vicinity, but during two different years, it is not desirable to draw even a negative conclusion from the results.

\section{Perpetuation of the Fungus.}

The known vegetative and reproductive states of downy mildews in general are mycelium, conidial spores, zoospores and oospores. The conidial spores and zoospores are so short lived that these fungi, so far as known, have to depend on the mycelium and oospores to carry them over the unfavorable winter period. In the following paragraphs is discussed how the potato blight is, or possibly may be, perpetuated.

Dormant mycelium in tubers. So far, this is the only way in which it is positively known that the fungus survives the winter. The disease caused by its presence in the tuber does not need to be conspicuous, and in fact the more diseased the tuber the less capable this is of germinating and so, presumably, the less likely it will be of perpetuating the mildew. The fungus may be present in the tuber and yet escape notice, as the rot is sometimes very superficial and slight; in fact DeBary records a case where the fungus grew out on the cut surface of a tuber he was using for an experiment on the supposition that it was entirely free from the fungus. This being true, it is doubtful if much good would result where tubers were selected to avoid diseased ones, though it is not advisable, of course, to use those showing a superficial or even deep-seated reddish brown dry rot. The mycelium in the tubers seems to be much less active in the spring than when the tubers are first dug. Ordinarily in the fall if the cut surface of a diseased tuber is exposed in a damp chamber the fungus will spread more or less over this surface. On the other hand, of the thirty samples obtained from Connecticut growers and tested in this way in the spring, the fungus developed on only two lots, yet most of those tried had the appearance of blight tubers. This decreased activity or vigor of the fungus is apparently due to the drying out of the tissues of the tuber, which induces a hibernating condition of 
the mycelium, and in some instances where the tubers have been stored in unusually dry places no doubt the mycelium does not survive.

Two views are advanced to explain how the mycelium in the infected tubers planted in the spring perpetuates the fungus. First, by growing up from the tuber into the stem, it produces a "diseased plant." This view has been previously discussed in the paper. We believe that the mycelium rarely passes up into the plants in this way, and just as rarely passes down from the plants after infection into the new tubers, as was formerly believed by some investigators. Second, the mycelium forms the conidial stage on the cut surface of the tubers or rarely in tufts through punctures in the skin, and the conidial spores or their zoospores, on being carried to the buds of the tuber or later to older parts, cause infection. The chief objection to this view is that infection in this way probably could only take place during a short time in the spring (the writer's and DeBary's experience indicates that the mycelium forms the conidial spores only on the living and not on the badly diseased tissue of the tubers) whereas the first visible outbreaks, so far as known, do not appear until July or August. Could it be possible that owing to the rapid growth of the young plants these primary infections remain isolated in the tissues and do not develop further until the growth of the host ceases and favorable blight weather appears?

Heterceism. This means that a fungus has different stages of its development on different hosts, as is the case of the wheat rust with two stages on barberry plants and later two more on wheat. DeBary, who first demonstrated this life cycle of the wheat rust, has discussed the possibility of the potato mildew being heterœcious. He concluded that there was no likelihood of this being so, though at one time false rumors stated he had found a different stage on another host. There are absolutely no data in favor of such a supposition for the potato mildew and no evidence of heterœcism has ever been found for any of the downy mildews.

Unknown stages. Various writers, often to support some theory, have suggested possible or probable stages of the potato mildew, not known for other downy mildews, but no real evidence of their existence has yet been produced. For instance, 
Smith (6, p. 292) writes: "It is not unreasonable to imagine that some other condition of the parasite, at present quite unknown to and unsuspected by us, might be brought to light. The fungus may exist in inconceivably fine dust-like particles or in the condition of a mucous fluid." This was an entirely theoretical suggestion, but a Scotchman, A. S. Wilson (8), advocated a more definite unknown stage. His theory was as follows: "Certain bodies were found on the under side of leaves, in all parts of the stem, especially at the nodes, and in the tubers, especially around the eyes. These he originally called sclerotiets (analogous to sclerotia) but later named them granules of mucoplasm. They are translucent, microscopic globular bodies coated with oxalate of lime. His observations caused him to believe that these, on germination, gave rise to the mycelium of the potato mildew and that thus the disease could break out on any part of the host without translocation. As the resting spores are not parasitic but live and germinate in the soil or in any dead matter, it is contact with the mucoplasm exuded from their fresh mycelium which originates the parasitism in the potato. As the tubers are infected, especially at the eyes, with mucoplasm granules, the general elements of the parasite are carried over from one race of potatoes to the following and from one season and country to another, not requiring invasion from without for a new display of the disease.' This is apparently a case where there is too much theory and too little exact observation and no experimentation to back it.

Oospores. These are thick-walled sexual spores often produced by the downy mildews and constitute the common means by which they are carried over from one season to another. Several investigators claim to have found these spores for the downy mildew of potato, but in no case have they produced sufficient evidence to satisfy botanists in general of their reality. Different suggestions have been advanced to account for the absence or rarity of these spores, and these, briefly summarized, are as follows: I. That the oospores have never existed for the potato mildew. 2. That this mildew has lost the power to produce these bodies. 3. That they may occur only in certain regions of the world. 4. That they are produced only in certain hosts, - the potato mildew having been found on a number 
of other plants. 5. That they are formed in the potato more as a saprophyte than as a parasite. 6 . That possibly these spores are formed only on the union of distinct mycelial strains which do not commonly occur together-a suggestion by the author.

The more the writer looks into this matter the more he is inclined to believe that oospores of the potato mildew do exist, especially since he has recently demonstrated their presence for the closely related species occurring on the Lima bean. Therefore, so far as he is concerned, the first two suggestions given above may be dismissed as unsatisfactory. Those persons who suggest special regions where the oospores may be found name Chili, the original home of the potato, as a possible locality or region where the genus Solanum occurs in a wild state. This mildew has been recorded on a number of the Solanaceae, more especially on the genus Solanum, and even on a couple of the Scrophulariaceae family. The writer has not had opportunity to study the blight to any extent outside of Connecticut, and, besides the potato, has collected it only on the tomato. Specimens of the latter, collected both in Connecticut and Porto Rico, did not throw any light on the oospores. The question of hosts and distribution cannot, therefore, be discussed on the basis of personal experience. The fifth and sixth suggestions, however, have had our attention during the past two years and may be discussed further.

Are oospores produced in decaying potato tissues? Worthington Smith, of England, was the most prominent advocate of the existence of oospores and claimed to have found them commonly in that country in the decaying leaves and tubers. The Royal Horticultural Society awarded him a gold medal for his alleged discovery. While his investigations were made twenty to thirty years ago, they have never been substantiated unquestionably. At the same time he was at work, DeBary, of Germany, the most able mycologist of his time, was also undertaking a study of the potato disease at the request of the Royal Agricultural Society of England. He was unable to find any positive evidence of oospores and he criticized Smith's work severely and apparently on good grounds. There is no doubt that Smith did not always record accurate observations, and there is little doubt that in his study of the developing "oospores" 
he dealt with more than one fungus. The chief question is, however, did he have under consideration at any time true oospores of this fungus. Unfortunately the writer can not give a positive opinion on this question, as he has not seen Smith's specimens and has so far been unable to confirm his results. The drawings he gives of the mature spores in his book (6) resemble such spores, but other of his drawings are questionable. But even DeBary (2) does not deny that some of the bodies Smith described might have been oospores, for he says, "The warty bodies are possibly its oospores." In another place in this same article DeBary also says: "Ever since the oospores of a Peronospora were discovered, innumerable searches have been made for those of Phytophthora. I have myself looked for them in the stalks, leaves, flowers, fruit and tubers of the potato. In July of the present year (I875), when the fungus appeared in this district in sad abundance, I obtained a very large amount of material for study and at the same time secured the kindly assistance of two botanists experienced in researches of this kind, Dr. Rostafinski and Dr. Stahl. But again only negative results were arrived at." Since Smith's time, Smorawski and others have claimed to have found the oospores, but these claims always lack positive proof. However, most botanists probably believe with DeBary that they will be found sometime. He said, "That they will be regularly found somewhere or other is assumed, for our knowledge of the habits of numerous allied fungi make this more than probable."

Snith stated that it was an easy matter to obtain the oospores by merely placing a number of diseased leaves overlapping each other in a moist chamber and examining them as they rotted down. The writer has tried his method a number of times but never succeeded in finding spores that were decidedly suspicious. True, one frequently finds various kinds of rounded, usually isolated, bodies in such leaves, some of which are apparently spores of fungi and others merely encysted stages of the lower animals. Even if one were to find the oospores under these conditions, it would be a difficult matter to accurately trace their development because of probable confusion at times with other things. After considerable search in the dying and dead leaves and stems, it finally seemed to the writer that the diseased tubers offered the most likely place for the formation of the 
oospores. Consequently these have been searched in all stages of infection and decay and at various times of the year. While some suspicious bodies have been seen from time to time, no very definite evidence has been gained that the fungus produces oospores even here. If they are formed in the tubers it is only in the decayed parts, as the healthy tissue offers little opportunity for their development and no suspicious signs have been found there. Examination of tubers decayed from a dry reddish brown rot usually shows the presence of the peculiar short haustoria of the blight fungus and these seem to become more prominent and develop thick, swollen walls with the advance of the decay. Often two of these haustoria are seen standing side by side in a cell, and while they indicate a living mycelium, even in advanced stages of rot and disintegration of the tuber, nothing definite concerning any further development of them or the mycelium has been made out. Resting spores with thick walls and somewhat of the type of oospores have been seen, but there was never any evidence that they were formed from the mycelium of the blight fungus. The potato tuber before its final dissolution in the ground is the workshop of many different fungi, as well as of the lower animals, hence the necessity of caution in forming decided opinions of forms found there. These tubers finally, through the work of the animal life, are more or less scattered through the soil, so that if oospores are formed they would secure more or less of a local distribution in the soil, probably about the time the blight appears in the fields.

Mycelial strains. In recent papers Blakeslee* has shown that in a related family, Mucoraceae, certain species possess mycelial strains, apparently of a sexual nature, that produce zygospores only when these grow together. Securing artificial cultures of the two strains, which he calls + and -, of such a species, he was able to produce the zygospores at will merely by inoculating the same cultural tube with both forms. In the study of various downy mildews it has occurred to the writer that possibly similar conditions are true for certain of these fungi, and in our Report for 1904 this was suggested as a possibility for the

\footnotetext{
* Science, 19: 864-6. 1904. Proc. Amer. Acad. Arts Sci., 40: 203-321. 1904 .
} 
potato mildew. Some effort, as stated previously, has been made to secure such strains in pure cultures and prove the theory by cross inoculations, but as yet no evidence has been secured in this way. While no positive proof has been gained for this belief, there are yet certain facts, as given in the next paragraph, that may be considered at least favorable to it.

In the first place the oospores of the Peronosporeae, like the zygospores of the Mucoraceae, are not commonly found in nature. There are species, other than the potato mildew, for which they have never been found; others for which they have been rarely found; some for which they have been found only on certain of their hosts; and finally, some in which they are not uncommon if looked for at the proper time and place. All of these facts are in favor, rather than against, distinct mycelial strains (heterothallic forms) except the last, which might indicate a homothallic form (one which contains both antheridia and oogonia on the same mycelium). Secondly, our culture experiments with the Lima bean and potato mildews, both species of Phytophthora, is in accord with this theory. The potato mildew cultures never produced oospores under any condition, possibly because there was but one strain present, and our cultures of the Lima bean mildew ran to the production of oospores, possibly because the cultures were obtained from material containing both strains. The potato mildew cultures often gave a very evident aerial growth of the mycelium and conidiophores, while this development in cultures of the Lima bean mildew was usually inconspicuous, though in nature its conidial stage is much more prominent than that of the potato mildew. Thirdly, Smith, in a drawing of the development of his supposed oospores of the potato mildew, shows two different mycelia. side by side, one producing oogonia and the other antheridia. DeBary at first criticized this on the ground that the oogonia and antheridia were not on threads in anatomical relation with each other, but later, according to Smith, withdrew this criticism. Smith, of course, may have shown in this drawing something having no connection with the potato mildew, yet in all of the drawings, seen by the writer, of DeBary (I) and others showing the development of oogonia of various mildews, the antheridia and oogonia are always figured on threads having no connection with each other. It is true that only a 
short piece of each thread is shown in these drawings, but it is usually difficult to trace these further. In our study of the Lima bean mildew effort was made to follow these threads as far as possible, and the evidence, so far as obtained, pointed to their independent origin, so that they could easily have been borne on two different mycelia closely interwoven.

Delayed appearance of blight. It is not as yet definitely known why the blight does not appear earlier in the potato fields. The weather in May and sometimes in early June is as favorable for its development as that of July and August, when it does first appear. On the face this would indicate that the germs for infection were not generally available so early in the year, and yet this is the very time when the mycelium* in the seed tubers underground is best situated for producing the conidial stage on them. DeBary possibly explains this delayed appearance in the following statement: "From large experience I consider it probable that Phytophthora grows more easily on a plant at the height of its development than on young stalks and leaves. It would be interesting, but not easy, to establish this clearly by experiment." In the writer's experiments already given it was found possible to easily infect young leaves and stems, but whether the subsequent development of the fungus was more or less vigorous than on old tissues was not a point at issue. Possibly the point previously suggested in this article explains the late appearance; viz., that the mycelium from primary infections on young, rapidly growing tissue remains localized until after vegetative growth of the host ceases and then renews its activity on the appearance of favorable blight weather. If the primary infections, however, usually take place, as the writer believes, by contact of the leaves with the ground, this is best accomplished in the full grown plants. The young plants are rigid and shoot straight up out of the ground, and by the time they have attained any

* According to DeBary's and our experience the mycelium will produce its conidial stage only in the living tissues of the tubers, but Massee, on the other hand, reports this stage in the old diseased tubers even a year after they have rotted; if the fruiting stage found by him was developed by the germination of oospores, this apparent conflict of observations might be explained. 
considerable growth and are likely to lop over on the ground, the wet weather of the spring is largely past. If it were known definitely that oospores were produced, the most feasible explanation would be that these did not germinate until the wet weather of July and August and then their zoospores in the moist earth infected the leaves that were washed down in contact with them by the rains. This would agree perfectly with what the writer has been able to ascertain so far, of the primary infections in the fields.

\section{Literature.}

The botanical and general agricultural literature dealing with the potato mildew is perhaps more extensive than that for any other fungus. There are given here merely a few articles, to which reference has been made in the preceding discussions.

I. DeBary, A. Recherches sur le développement de Quelques Champignons Parasites. Ann. Sci. Nat. Bot. IV, 20: 5-I48. I863. [Illustr.]

Deals in this paper especially with the Peronosporeae and gives considerable information, with illustrations, of the potato mildew.

2. DeBary, A. Researches into the Nature of the Potato Fungus, Phytophthora infestans. Journ. Bot., n. s., 5: I05-26, I49-54. 1876. [Illustr:]

Gives in this excellent paper the life history of the fungus, so far as known, and treats especially of his studies made for the Roy. Agr. Soc. of England and a criticism of Worthington Smith's so-called oospores.

3. Massee, G. Diseases of the Potato. Journ. Roy. Hort. Soc., 29: I39-4I. I904.

Gives short general account of the mildew and makes two recommendations, based on field and laboratory observations, for keeping it in check; namely, collection of the diseased and old seed tubers at harvest time and use of seed tubers showing no sign of disease.

4. Matruchot, L. and Molliard, M. Sur la culture pure du Phytophthora infestans DeBary, agent de la maladie de la pomme de terre. Bull. Soc. Myc. Fr., 16: 209-IO. I900.

Note that they have been able to grow this fungus on living and sterilized media in pure and artificial cultures.

5. Matruchot, L. and Molliard, M. Sur le Phytophthora infestans. Ann. Myc., I: 540-3. I903.

Give further more extended notes on the artificial cultures of this fungus on living and sterilized slices of potato and pumpkin; 
note that the fungus does not discolor the living plugs of potato if grown pure; found no oospores.

6. Smith, W. G. Potato Disease, I, II. . Diseases of Field and Garden Crops: 275-329. I884. [Illustr.]

Makes an extended report on Phytophthora infestans in both its active and passive state; discusses in detail his discovery of oospores.

7. Smorawski, J. Zur Entwicklungsgeschichte der Phytophthora infestans (Montagne) DeBy. Landwirthsch. Jahrb., I9: I-I2. I890. [Illustr.]

Gives a general account of the investigations of others and records observations and experiments of his own; describes and illustrates immature oospores that he connects with this fungus.

8. Wilson, A. S. Potato Disease and Parasitism. Trans. Proc. Bot. Soc. Edinburgh, I9: 656. I89I.

Explains his mucoplasm theory, by which he accounts for the spread of the blight. 
PLATE XIII.

Apple.

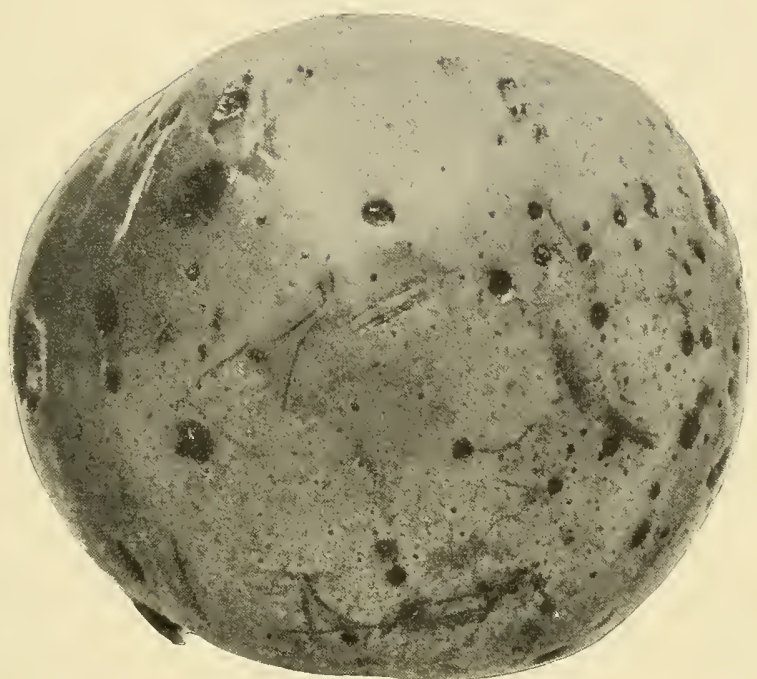

a. Fruit Speck, p. 264.

\section{Lima Bean.}

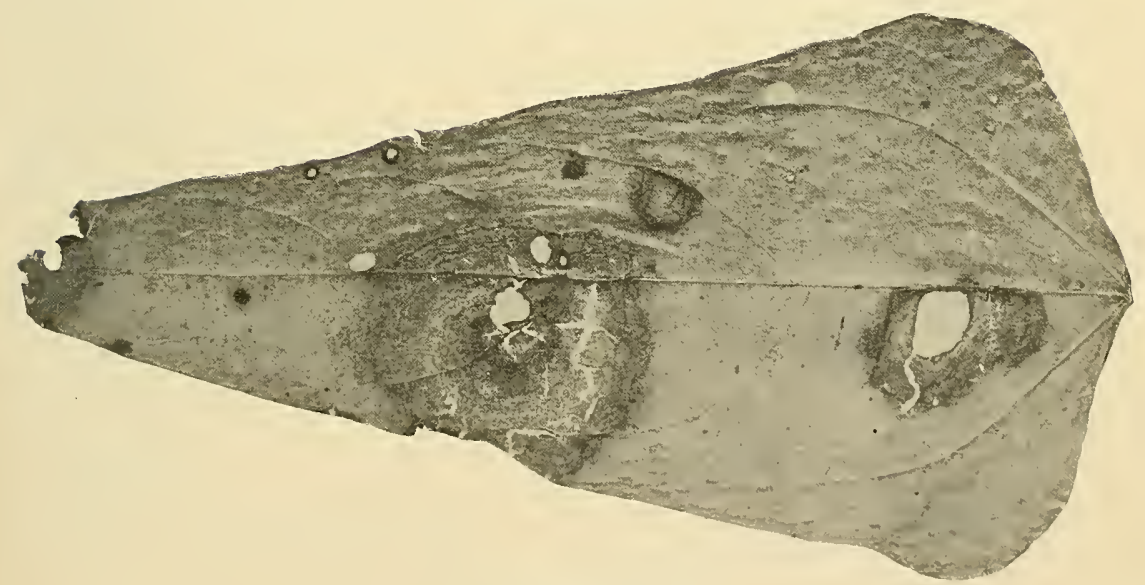

b. Leaf Blight, p. 265 .

FUNGI OF APPLE AND LIMA BEAN. 



\section{Catalpa.}

PLATE XIV.

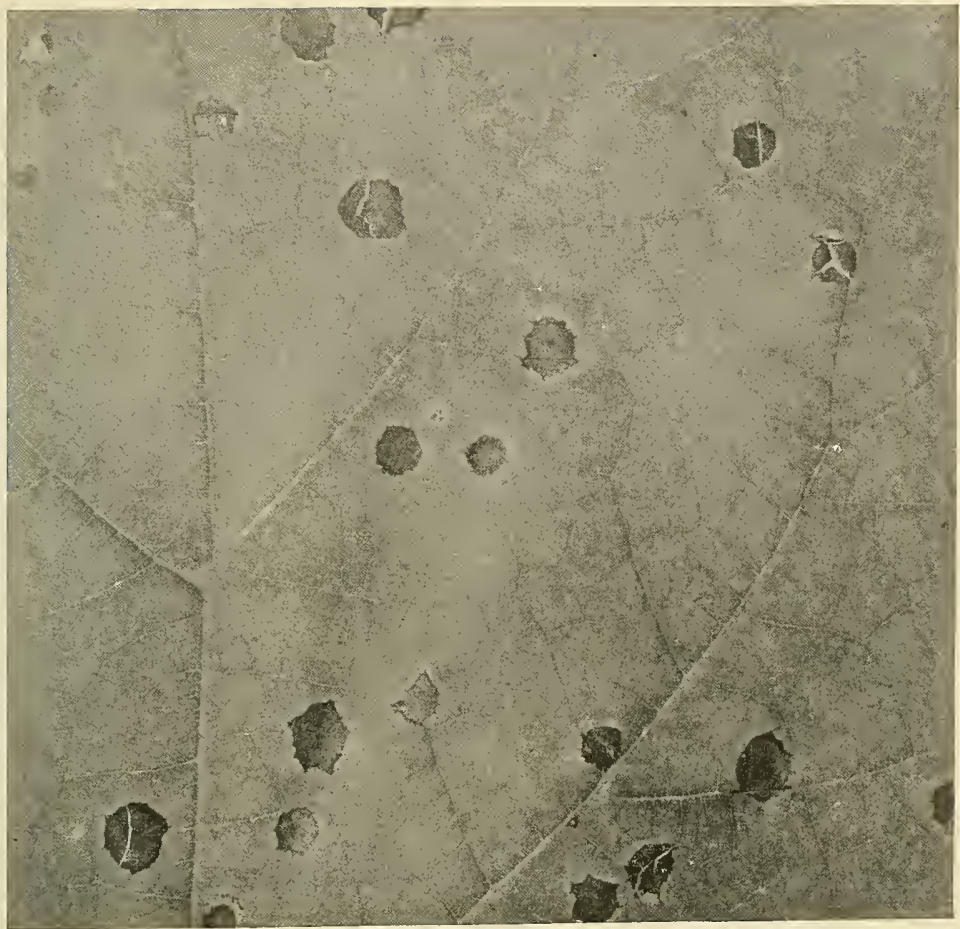

a. Leaf Spot, p. 266.

Celeriac.

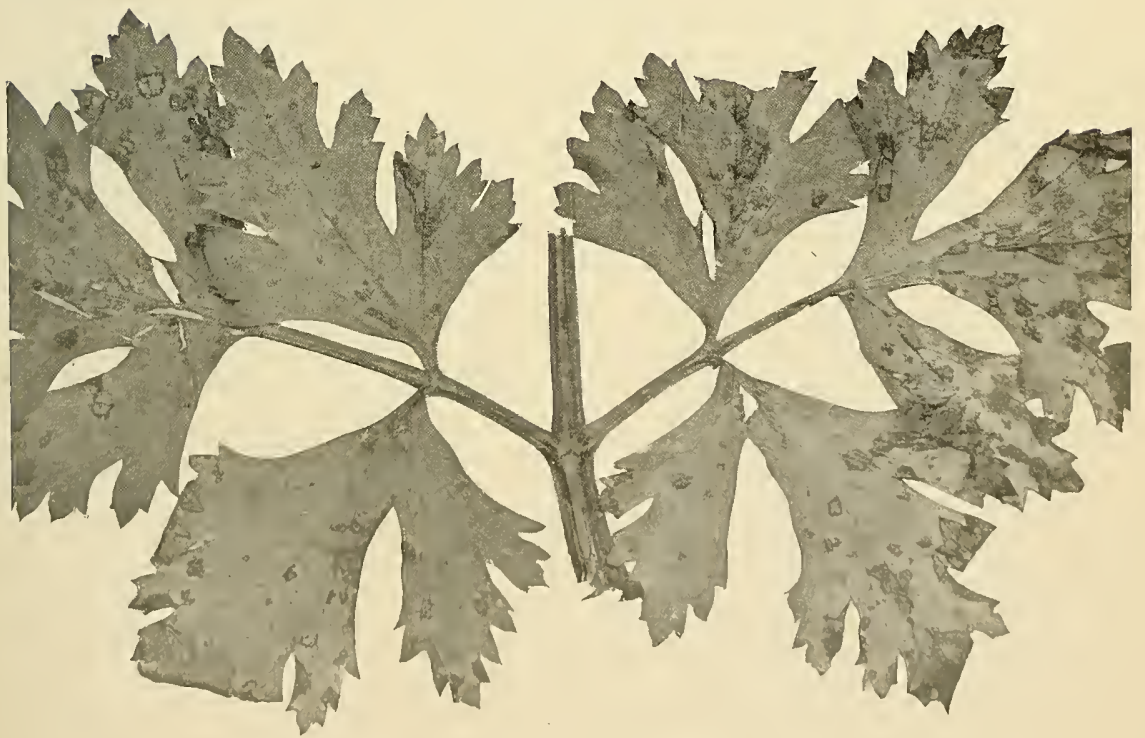

b. Leaf Spot, p. 267.

FUNGI OF CATALPA AND CELERIAC. 



\section{PLATE XV.}

Maple.

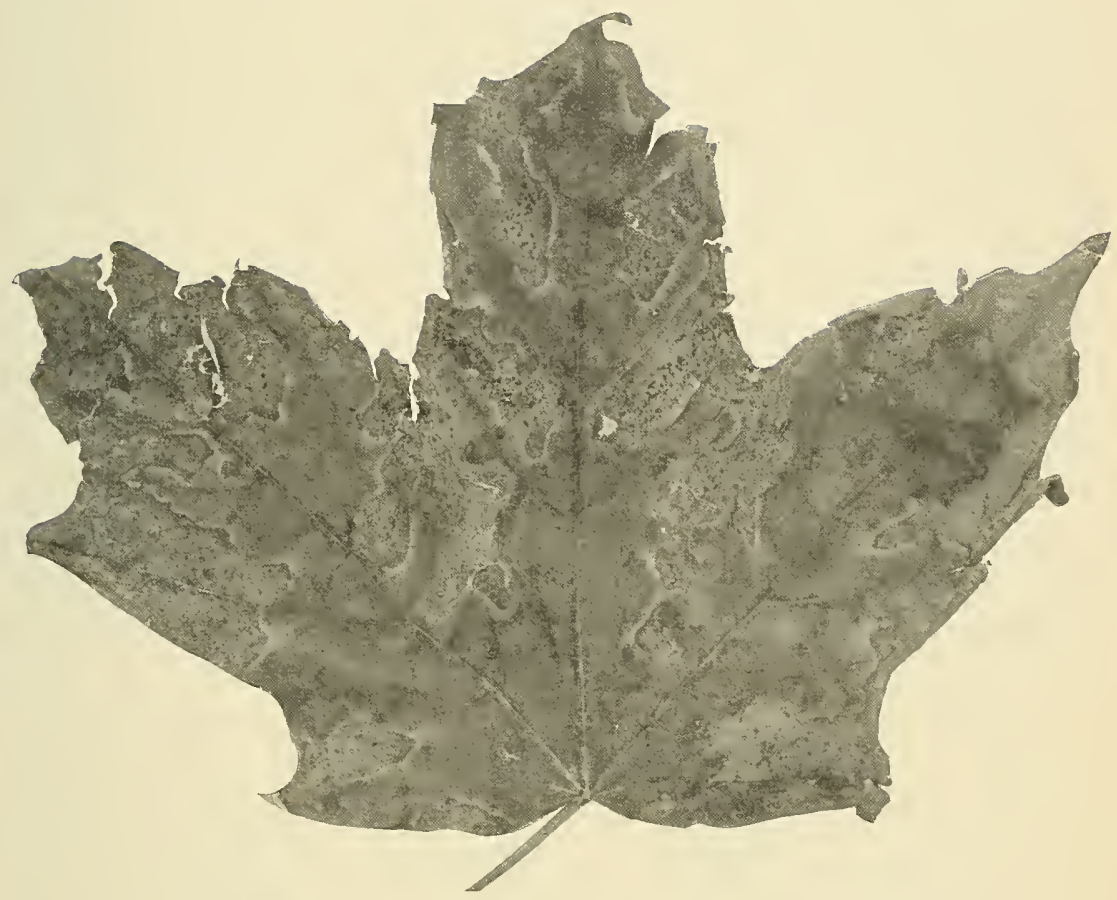

a. Leaf Scorch, a physiological trouble, p. 267.

Nectarine.
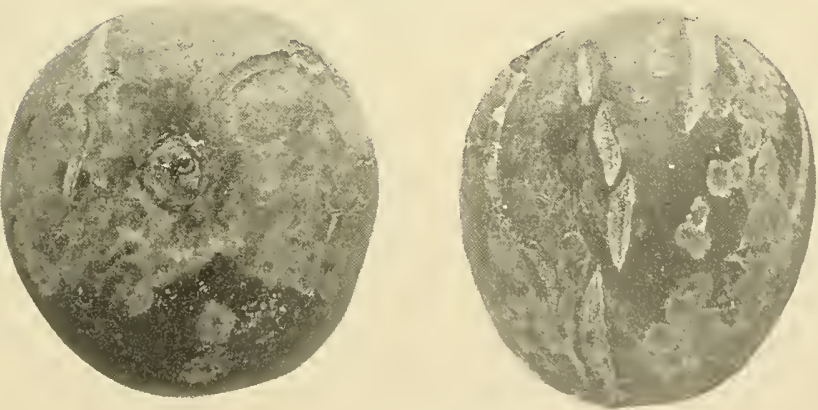

b. Scab, p. 268 .

DISEASES OF MAPLE AND NECTARINE. 



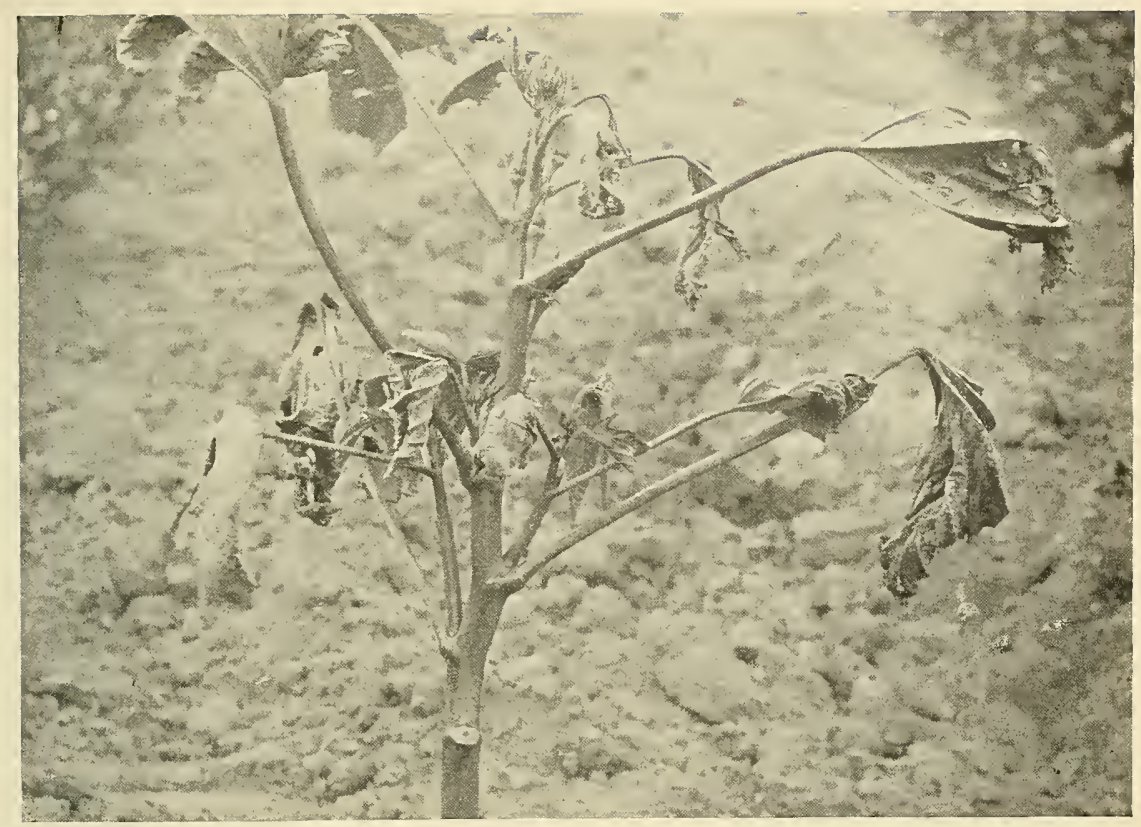

a. Showing upward progress of disease by character of leaves.

Diseased.
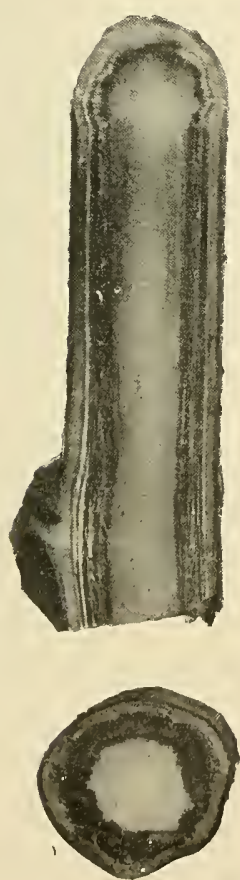
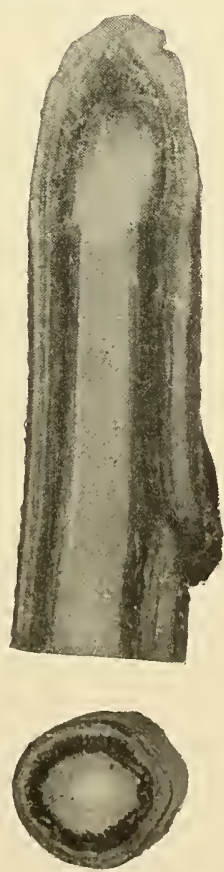

Healthy.
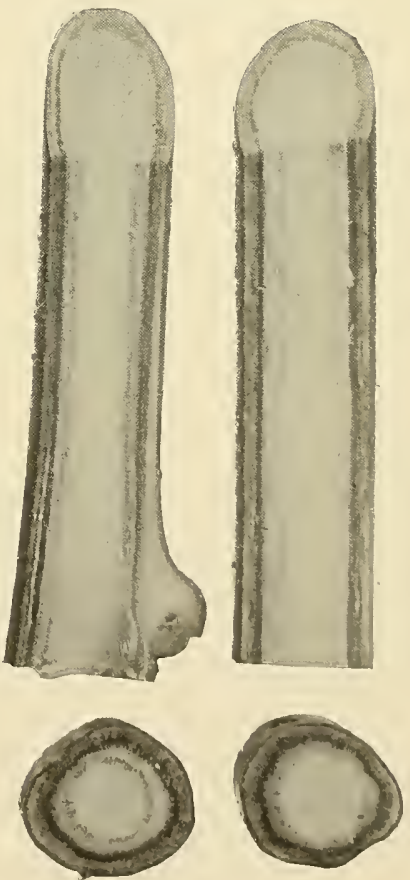

b. Longitudinal and cross sections of stems, showing how tissues are injured. 

PLATE XVII.

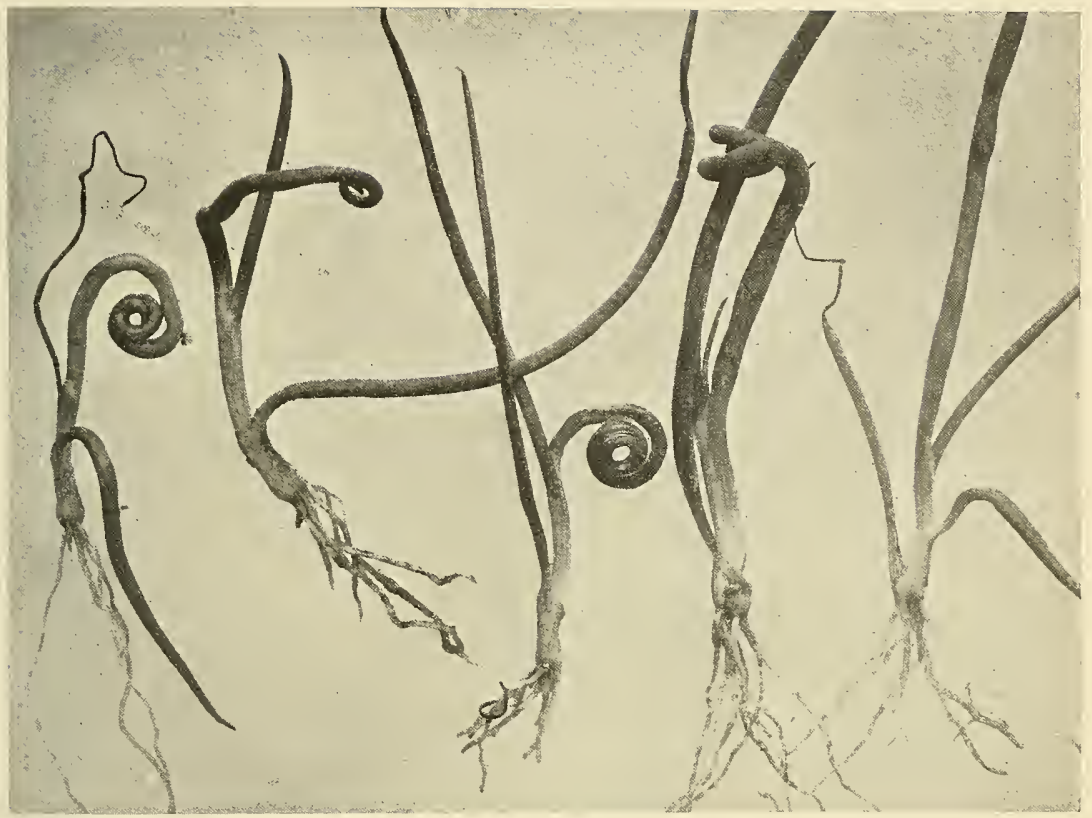

a. Onion Brittle, showing peculiar malformation of leaves, p.270.
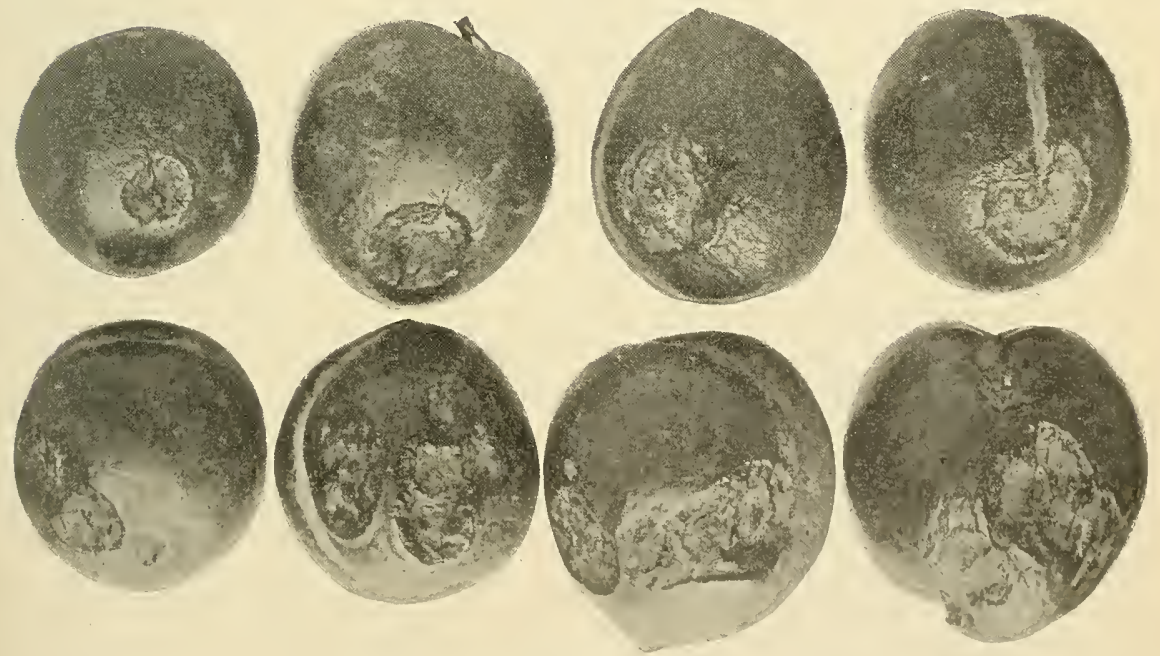

b. Bacterial Black Spot of Plum, p. 273.

DISEASES OF ONION AND JAPANESE PLUM. 

Spinach.

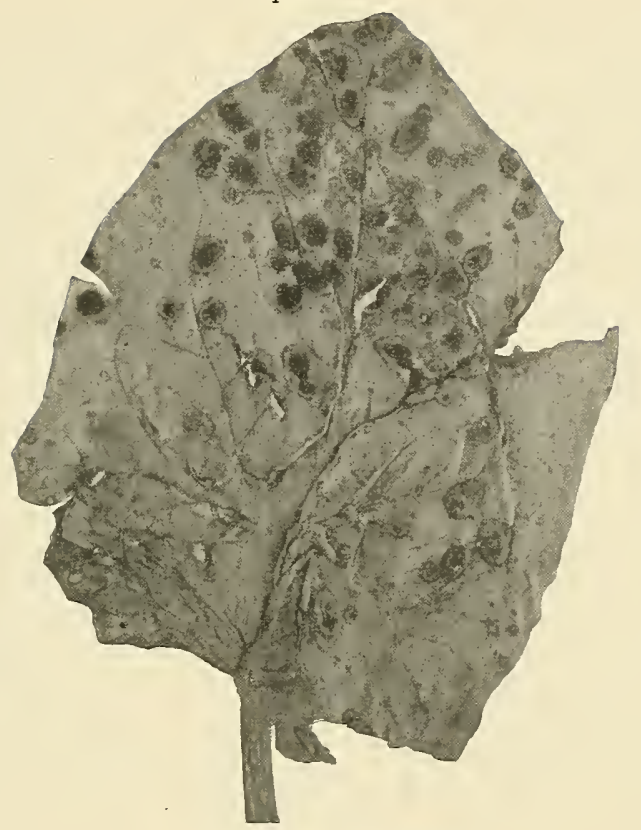

a. Leaf Mold, p. 275 .

Strawberry.

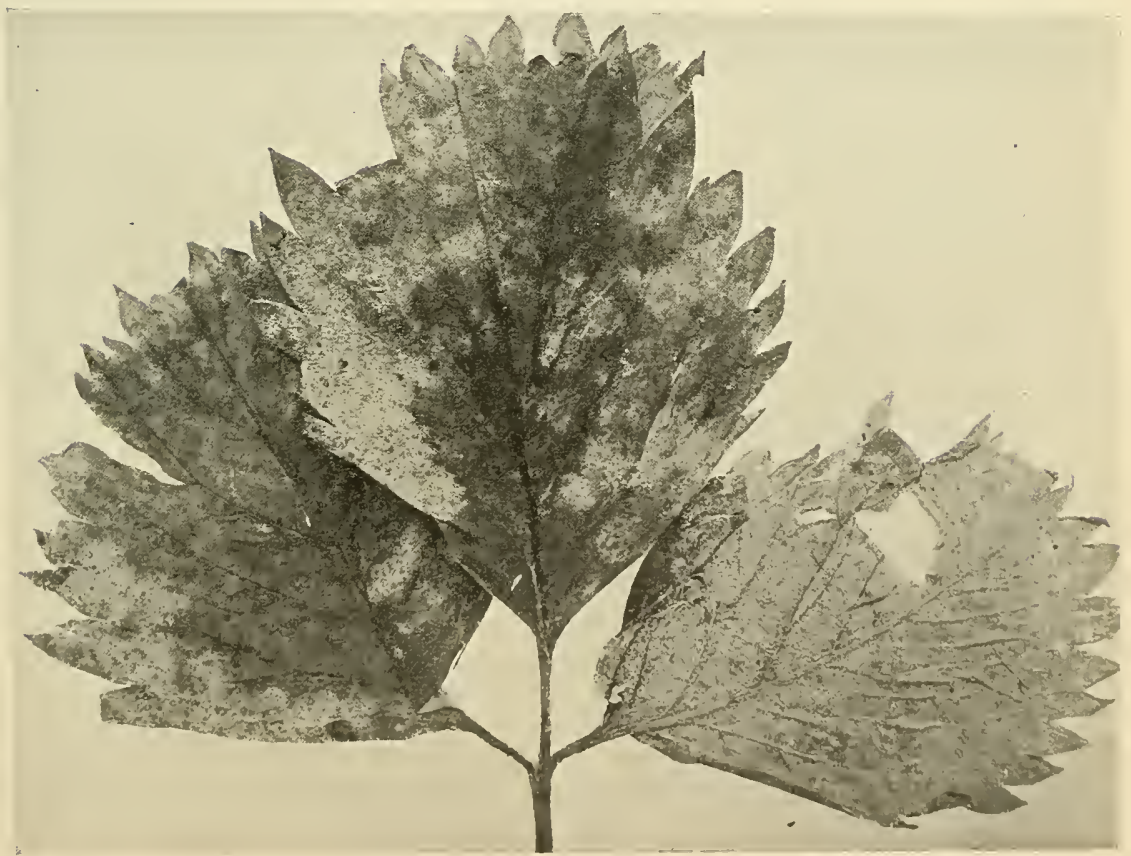

b. Powdery Mildew, p. 276 .

FUNGI OF SPINACH AND STRAWBERRY. 



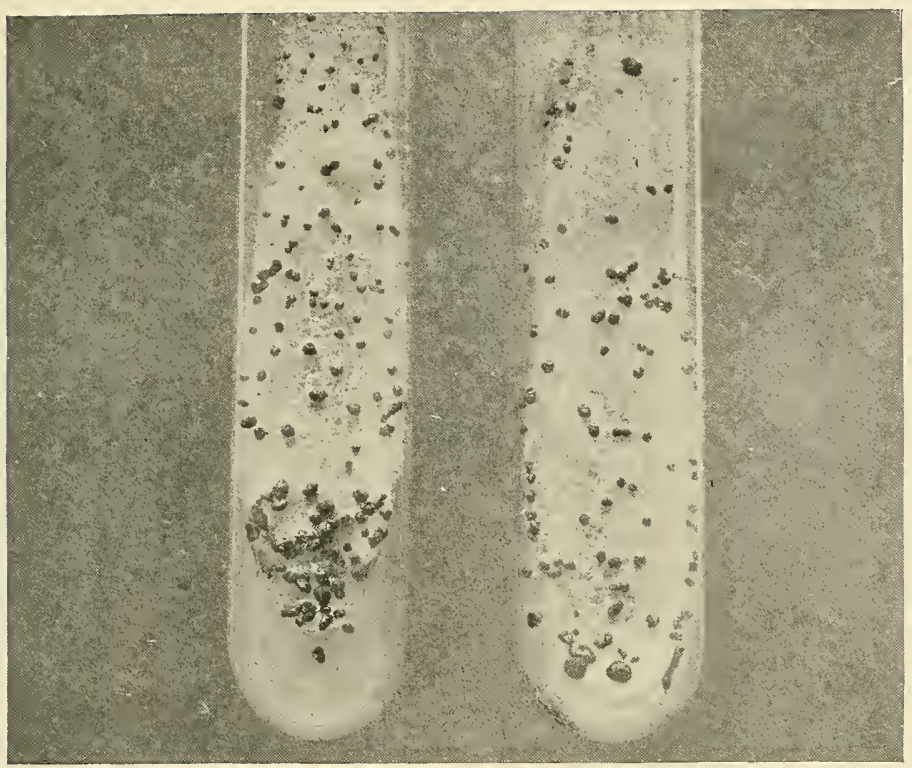

a. Cultures of the fungus on potato agar, showing sclerotia.

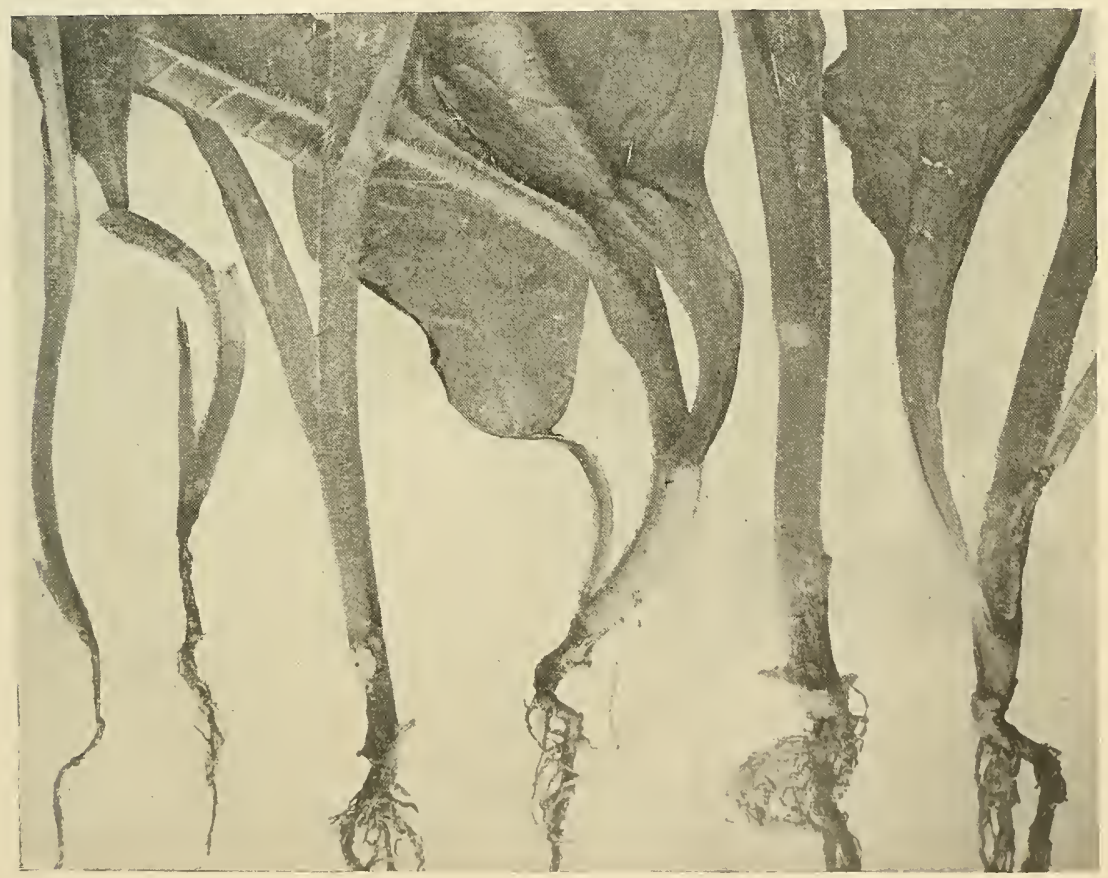

b. Showing how the fungus injures base of stems. 

PLATE XX.

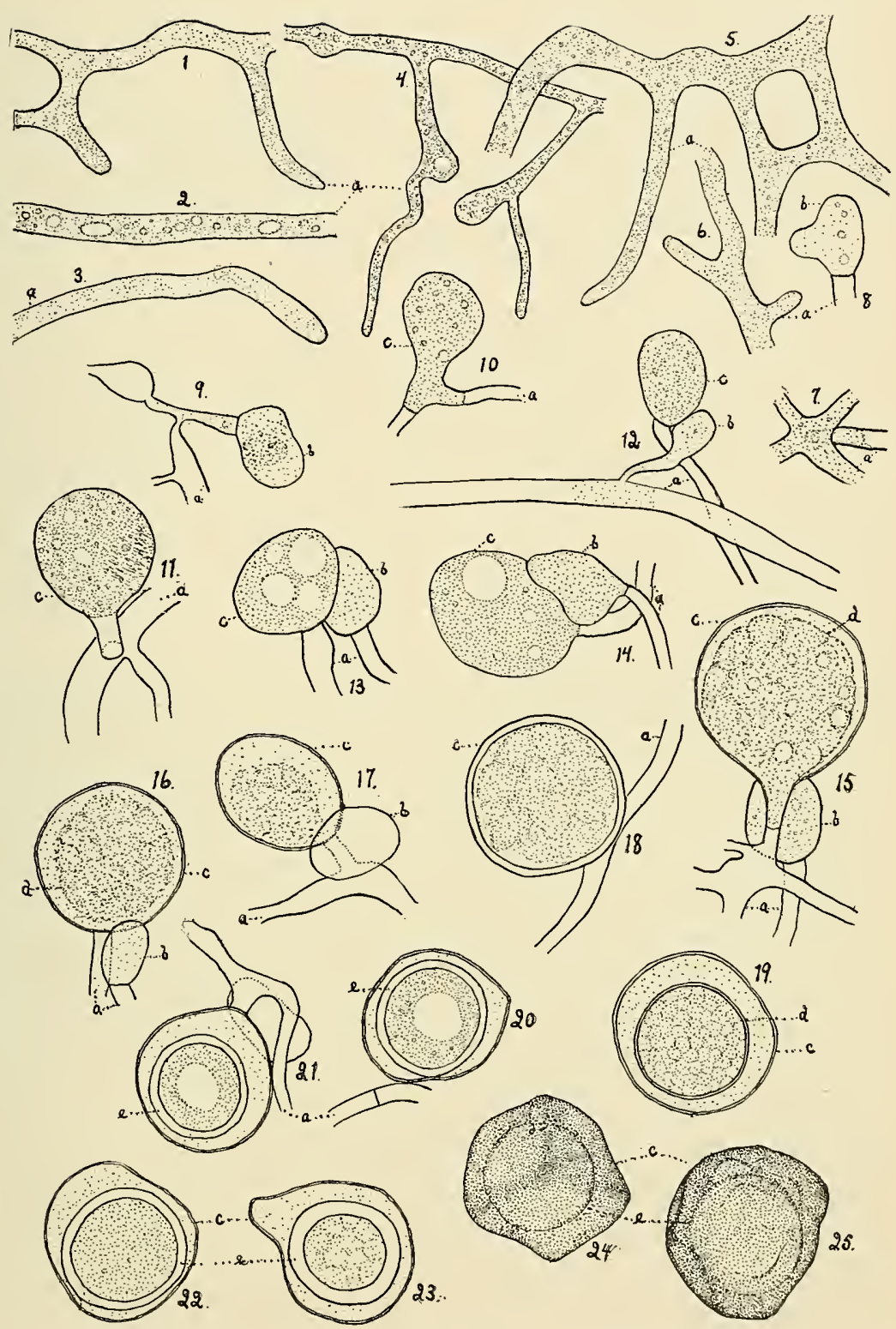

$a$, mycelium; $b$, antheridium; $c$, oogonium; $d$, oosphere; $e$, oospore. Figs. I-7, showing character of mycelium. Figs. 8-2I, antheridia and oogonia and their development. Figs. 22-25, mature oogonia and oospores. Magnified about 600 diameters.

DEVELOPMENT OF MYCELIUM AND OOSPORES OF LIMA BEAN MILDEW, Phytophthora I'laseoli. 

PLATE XXI.
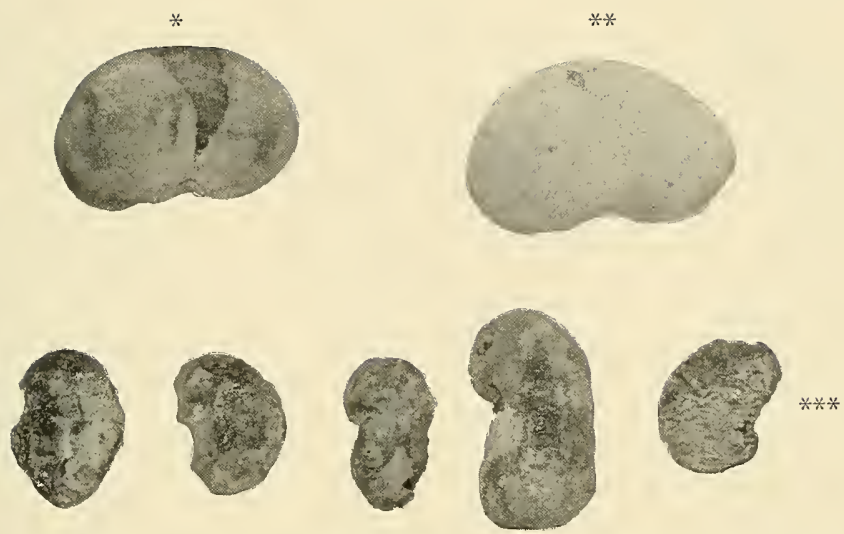

a. Diseased seed containing oospores, except healthy one at **, pp. 292, 297.

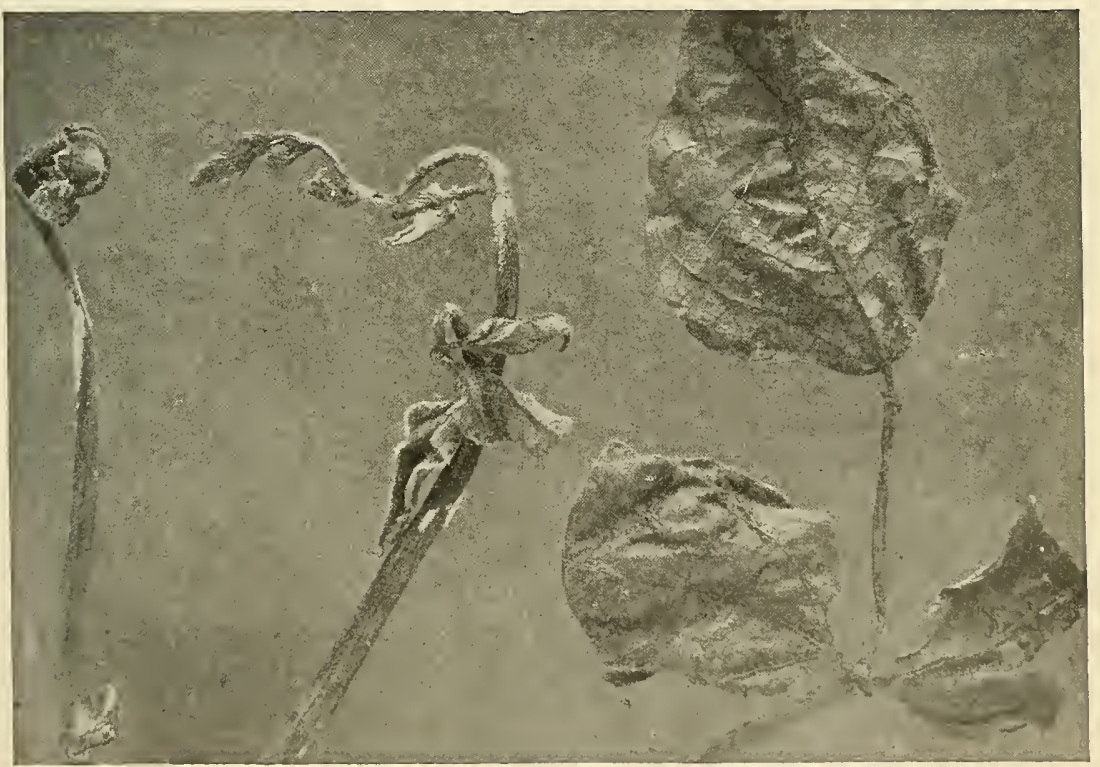

b. Showing injury to young stems and leaf, p. 28I .

DOWNY MILDEW OF LIMA BEAN, Phytophthora Phaseoli. 


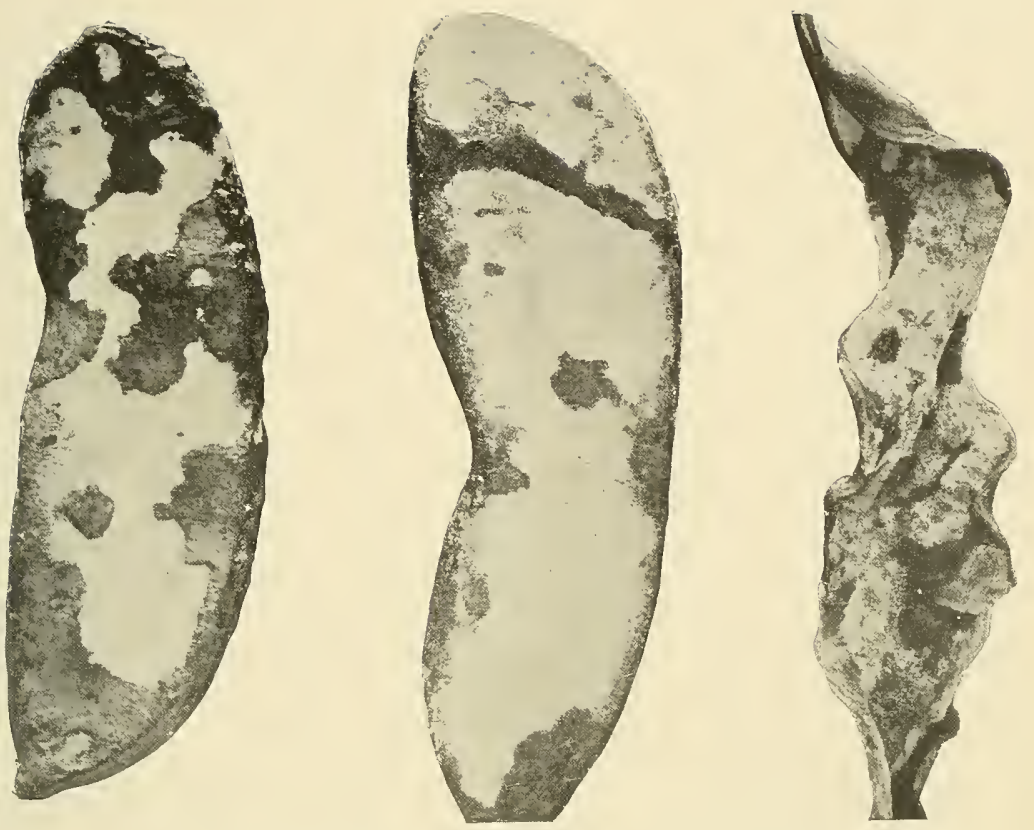

a. Showing mildew in young and old state on pods.

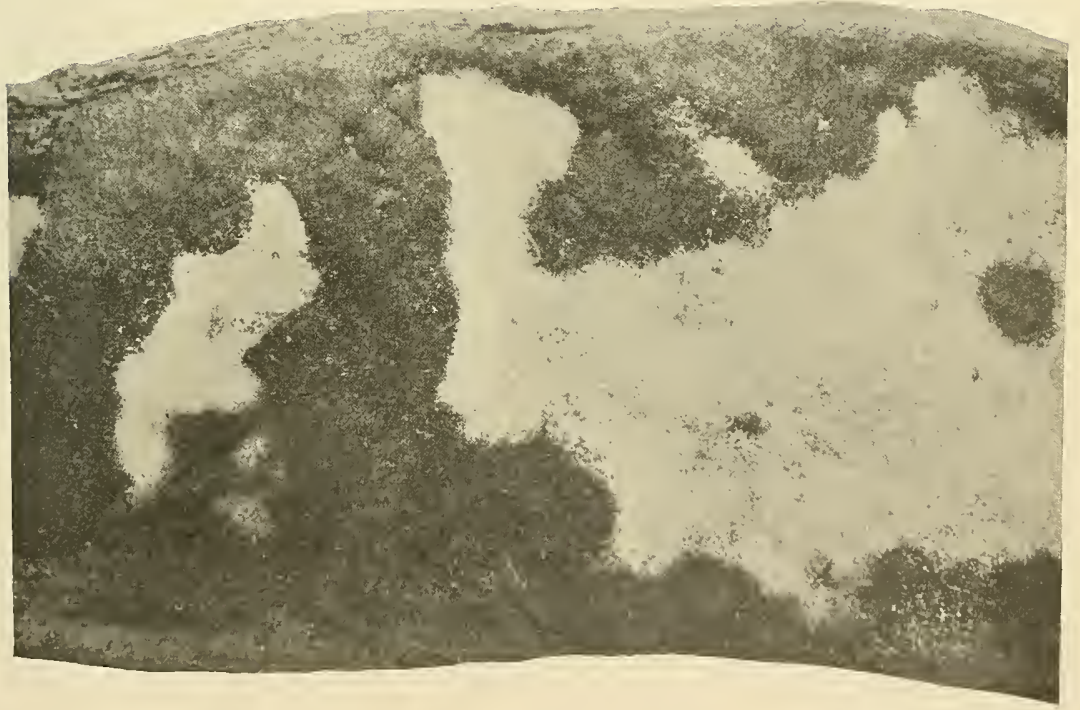

b. Showing portion of infected pod enlarged two diameters. 



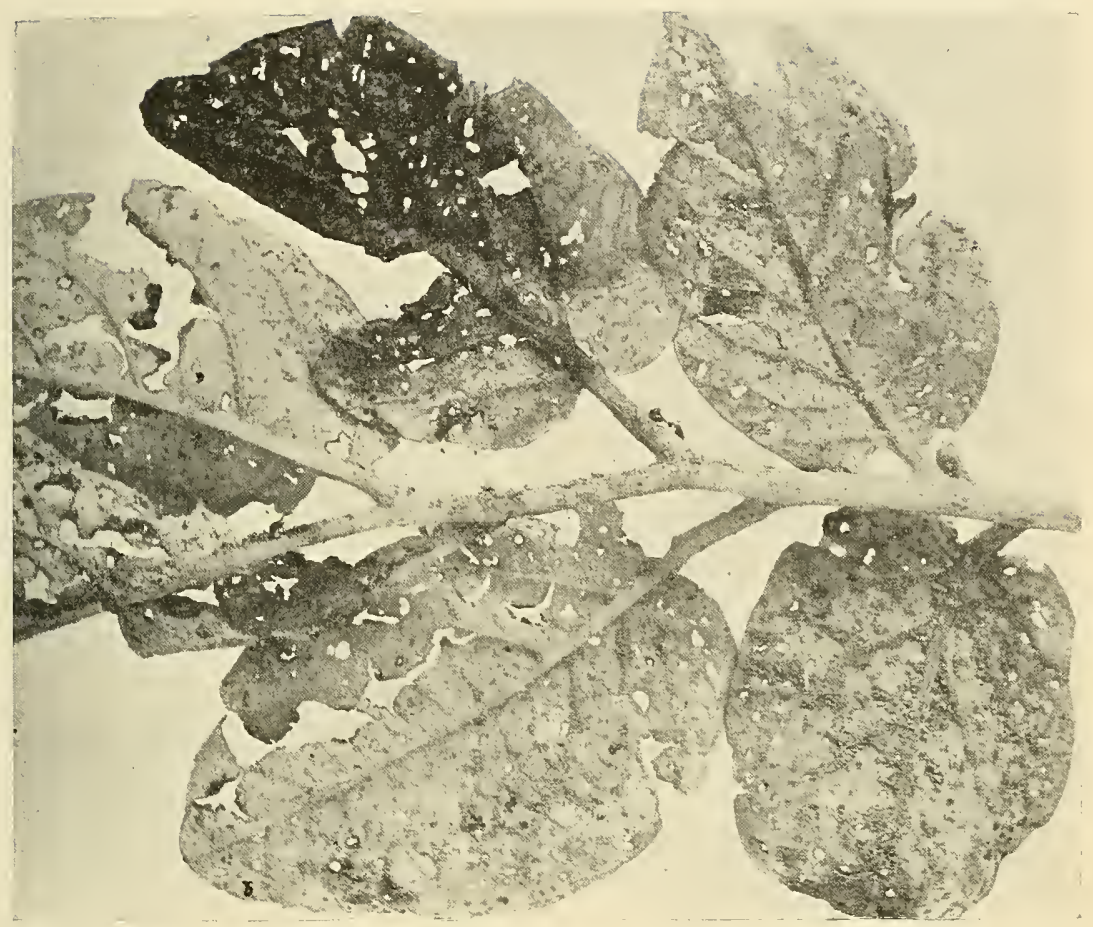

a. Showing primary infection from contact with ground, p. 309 .

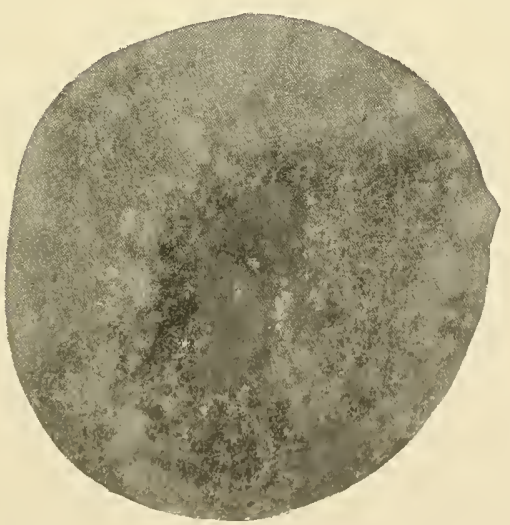

b. Artificial infection of the mildew on cut surface of tuber, p. 3I8. 



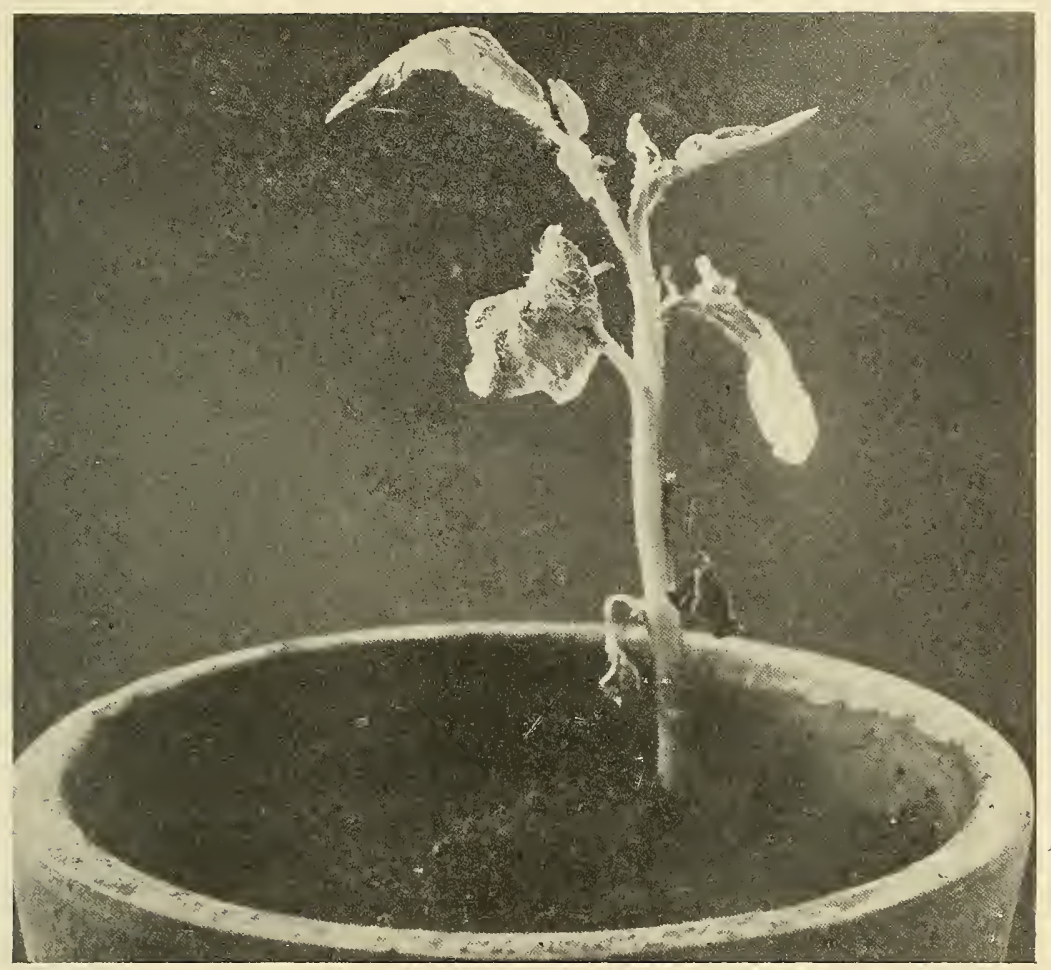

a. Two lower and tip of third leaf killed by fungus, Io days after inoculation, p. 3I5.

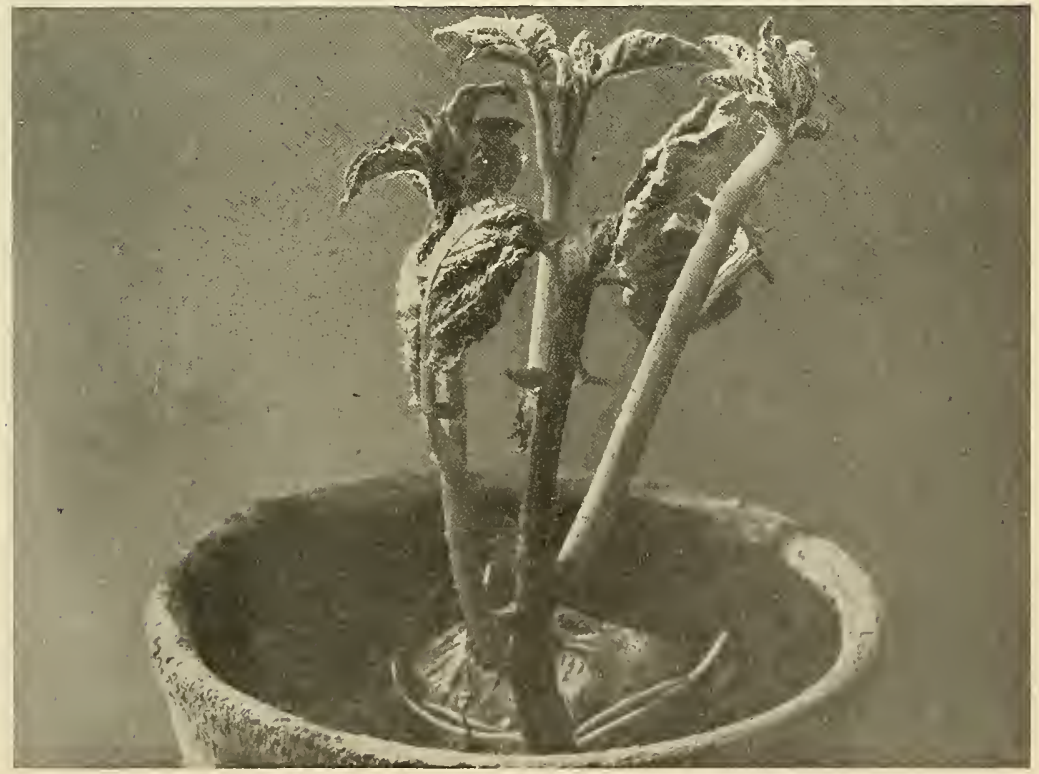

b. Central diseased shoot grown from an inoculated tuber, p. 307. INFECTION EXPERIMENTS WITH Phytophthora infestans. 

PLATE XXV.

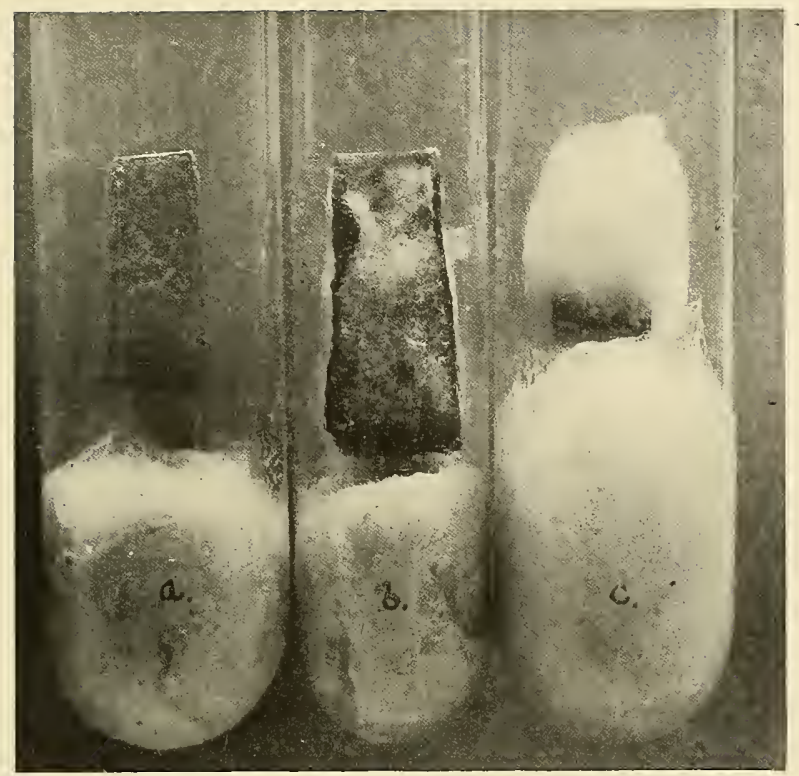

a. On plugs of living potato. a, check.

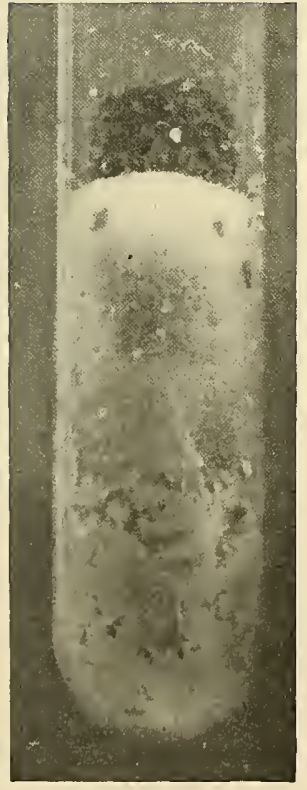

b. On corn meal.

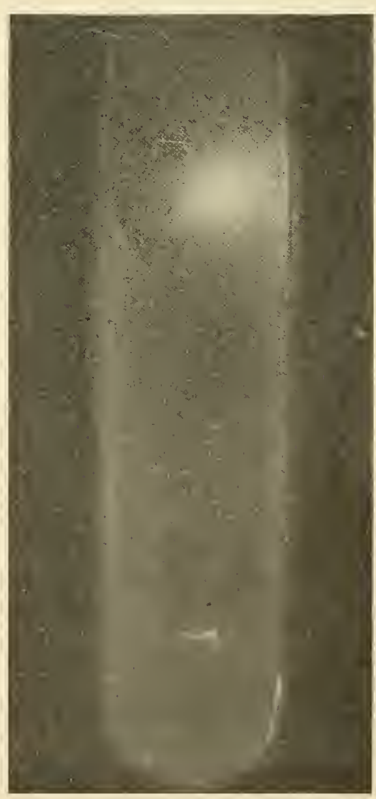

c. On pumpkin agar. 

- 



\section{Itate of Connecticut}

\section{REPORT}

OF

The Connecticut Agricultural Experiment Station

FOR THE YEAR 1906

$$
\text { PART V. }
$$

REPORT OF THE STATION BOTANIST 



\section{CONNECTICUT}

\section{AGRICULTURAL EXPERIMENT STATION}

\section{REPORT OF THE BOTANIST,}

G. P. CLINTON, Sc.D.

I. Notes on Fungous Diseases, etc., for I906, p. 307.

II. Experiments to prevent Onion Brittle, p. 332.

III. Dry Rot Fungus, Meruiius lacrymans (Wulf.) Schum., p. 336.

IV. Root Rot of Tobacco, Thielavia basicola (B. \& Br.) Zopf, p. 342. 



\title{
PART V.
}

\section{REP0RT OF THE BOTANIST FOR I 906.}

\author{
G. P. Clinton, Sc.D.
}

I. NOTES ON FUNGOUS DISEASES, ETC., FOR Igo6.

GENERAL NOTES ON DISEASES PREVIOUSLY REPORTED.

During the year 1906 fungous diseases as a rule were not especially troublesome in Connecticut. In this respect it was like the preceding year, though the distribution of the moisture was somewhat different. In 1905 the drier part of the growing season came before August, and the moister period was during August and September; but in 1906 the moist weather came in June and July, while the latter part of the season was dry. During last June there was a rainfall of 5.14 inches, which was over two inches in excess of the average rainfall of the past 34 years; July also gave a slight excess over the average. This abundance of moisture was favorable for starting certain fungous troubles, but as it came in thunder showers, without especially cloudy or foggy weather, and as August and September were largely free from rains, the fungous troubles on the whole did not become prominent. A peculiarity of the season, however, was the large number of leaf scorch or similar troubles, due to peculiar weather conditions during June and July.

The diseases mentioned in the following paragraphs are old troubles that were unusually serious or that were less injurious than usual. They are, grouped according to their hosts, as follows :

Apple. Sooty blotch, Phyllachora pomigena, was very prominent the past fall on apples all over the state. This is now one of the most serious fungous troubles of the apple in Connecticut. While the fungus was especially conspictious in the small 
orchards, and on the few trees kept by each farmer for home use, it also did more injury than usual in the larger orchards, even when they had been sprayed. One could scarcely find any good specimens of Greenings, in the fall and early winter markets, because of blemishes by this superficial parasite. Black rot or canker, Sphaeropsis Malorum, was also frequently sent to the Experiment Station for identification.

Asparagus. A single grower in Norwalk reported one of his beds seriously injured by the rust, Puccina Asparagi, but the writer did not have opportunity for determining whether or not this trouble was common.

Beans. The downy mildew of the Lima beans, Phytophthora Phaseoli, did some injury, but was probably not quite so injurious as the previous year. A grower in Southport, however, reported a crop practically destroyed by it. The oöspores of this fungus were again found, thus indicating that they are probably not so uncommon as supposed. Anthracnose of string beans, Colletotrichum Lindemuthianum, was more common and injurious than for several years.

Cucumber and muskmelon. On the whole these plants suffered less than usual from fungous attacks. The growers even had a fair crop of muskmelons. More or less injury, however, was done by the downy mildew, Peronoplasmopara Cubensis, and the leaf mold, Alternaria Brassicae var. nigrescens.

Grape. The black rot, Guignardia Bidwellii, and possibly other rots, were considerably more injurious than usual. Spraying failed to satisfactorily control this trouble in some cases.

Onion. There was considerable complaint of poor onions in Igo6. Most of the trouble was due to the character of the season and insects. Fungi were responsible to a less degree in some cases. There seems to be a tendency of onions grown for seed in the onion districts of the state to deteriorate. The cause of this decline, however, is not yet satisfactorily determined, though in some seasons fungous troubles seem to be largely responsible. Onion brittle was more conspicuous this year than last, in the infected fields in the neighborhood of Guilford, since it seems to be a soil trouble that increases in extent each year. A discussion of this disease, including experiments made to control it, is given elsewhere in this report. 
Peach. While last year there was considerable injury from the brown rot, Sclerotinia fructigena, this year the peaches were almost entirely exempt from it. Some little rot appeared at first on the early varieties that are most subject to decay, but the weather as a whole was so fair and dry during the picking season that the crop was conspicuous for its fair size, good quality and freedom from rot.

Pear and quince. There were a few complaints of the bacterial blight, Bacillus amylovorus, on pear, and one grower informed the writer that he had never seen this trouble so injurious to his quince trees as it was this year.

Potato. Tip burn and early blight, Alternaria Solani, were more common than usual. The wet weather of June and July came at a time most favorable for the development of the early blight, while the sudden alternation of bright, hot days with those of abundant rainfall was responsible for most of the tip burn, rather than any long period of dry weather. There were some unusual cases of injury to potato leaves in June that were hard to account for except on this basis. The late blight, Phytophthora infestans, because of the wet weather of June and July appeared this year considerably earlier than the previous year, the first specimens being found on July 23rd, as compared with August IIth, in I905. However, the dry weather of August and September prevented the fungus from causing even the ordinary damage. There was a little injury to the foliage of the early potatoes, where the vines grew rankly, and a little rot showed in their tubers; but the injury was soon checked by the dry weather. Although we had unusual opportunity for learning of injury in late potatoes, there was absolutely no complaint of rot anywhere in the state. Without question the late blight did the least damage in the state this season of any of the five years the writer has had it under observation.

Raspberry. The wilt of raspberry, Leptosphaeria Coniothyrium, which has been complained of in a general way for some years past, was unusually prominent during June and July of the past season, since complaints were received from a number of places scattered over the state of the wilting of the half matured fruit. Further mention of this trouble is made under 
new diseases because of a new discovery, concerning its inoculation by insects, which was brought out in our study of the trouble. Aside from the wilt, this was a very good year for raspberries.

Tobacco. The early spring seems to have been rather unfavorable for tobacco seed beds, since dampening off and root rot troubles were more conspicuous than usual. The weather for curing tobacco in the barns at the end of the season, however, was so unusually favorable that pole burn did no damage whatever, and the tobacco cured much earlier than usual.

\section{NEW DISEASES.}

Each year a certain number of fungi occurring on economic plants are observed that have not been reported previously in this state, or old species are found on new hosts, or some new point is made out in the life history of a fungus. Such data are recorded in the following paragraphs. Some of the fungi briefly mentioned, though of little economic importance at present, may eventually become conspicuous enough for more extended notice later. By recording from time to time these new observations, we aim to have finally a complete survey of all the diseases of cultivated plants of the state. Most of the troubles reported this year are entirely new, special note being made of the exceptions. As usual, we distinguish between those diseases caused by fungi and bacteria, and physiological troubles caused by unfavorable environment (such as heat, moisture, wind, cold, etc.). The common names of the latter class are printed in italics, while those of the former are printed in small caps, followed by the scientific name of the fungus.

\section{APPLE, Pirus Malus.}

Winter Injury and CANker, Sphaeropsis Malorum Pk. Plate XVII, a. We have reported before injuries due to the severe cold of winter, and those caused by the canker fungus, but last spring Dr. Britton called to our attention a peculiar trouble of apple limbs that seemed to be due to a combination of these causes. The specimens were from an apple grower of West Hartford, who first noticed the trouble while pruning his trees. The specimens sent to the Station for examination showed large 
dead sunken areas in the bark, usually starting from dead twigs, and apparently caused by the canker fungus, since it was in fruiting condition on some of the specimens. Some of the smaller of the injuries had been outgrown by the development of a new growth of bark beneath. Another and more peculiar feature of the trouble was the enlargement of the limbs into somewhat fusiform swellings, as shown in the illustration. In some cases several of the swellings followed one another on the same limb. These enlargements generally showed a greater swelling on one side than on the opposite, and often the bark was split down the more swollen side. Cross and longitudinal sections showed that the swellings were apparently the result of severe cold, which had injured the limbs unevenly along the branch, as shown by the blackened wood on the injured portion. The winter injury was most severe on the side of the limb least swollen, and had restricted the growth of the woody layers the following years, while on the swollen side the wood had made a greater growth, as shown by the larger annual rings. The growth of the bark had been affected, too, by the winter injury, but was thickest on these swellings, and as a rule had made a greater growth on the injured side. The longitudinal cracks in the bark apparently had not been caused by winter injury, but by the abnormal and excessive growth of the wood on the more swollen side of the branch. The cracks only extended through the outer bark, as a healthy growth of new bark beneath was healing them over. Here, then, we have a case of winter injury to limbs acting irregularly (possibly due to unequal maturity of wood at the time of the injury) so that as a whole it stimulated the bark to unusual activity at the injured places, the wood on one side of the limb being so injured as to retard growth the following years, while on the other side the injury was so slight as really to act as a stimulus to unusual growth. The cankered areas occurred on the sides most injured, and apparently the canker fungus largely got a start here through the smaller twigs that had been entirely winter killed.

\section{BEANS, Phaseolus vulgaris.}

Leaf Scorch. During the early summer Mr. Andrew Ure of Hamden called the writer's attention to a field of string beans that had been injured suddenly by some cause that rendered 
many of the plants worthless. The injury resembled somewhat the bacterial blight of this host, but an examination of the injured tissues failed to reveal bacteria or any fungus as the probable cause. The leaves in some cases were entirely dead, but in others only a part of the leaves were injured. The irregular area of dead tissue of the leaves partially injured was usually separated from the healthy by a reddish purple border, but there was no water-soaked appearance, as is usually the case with the bacterial trouble. Examination failed to reveal any more probable cause than leaf scorch, due to bright, warm weather suddenly following a very violent rain storm, with high winds, which occurred shortly before the trouble was first noticed. A peculiar feature, however, was that some other bean fields in the neighborhood did not suffer from this trouble. This, while difficult to explain, might have been due to the variety of beans, their age, or unknown differences in the soil conditions.

CARNATION, Dianthus Caryophyllus.

Spot, Alternaria sp. This disease was called to the writer's attention by Mr. Walden of this Station, who collected specimens in the greenhouse of Mr. S. Perry Beers of Greenfield Hill. Mr. Beers had obtained his carnations already rooted from another greenhouse, where this trouble was also present. In a few cases the disease was severe enough to kill the plants outright, but usually the injury was limited to the leaves dying at their tips or to the whole top of the plant dying as the result of a girdled area beneath. Generally the injured places were of a whitish color having a rather inconspicuous black growth of the fruiting stage of the fungus. The only mention of a similar disease of carnation caused by Alternaria that the writer has seen is that made by Mr. Orton in the Yearbook of the U. S. Department of Agriculture for 1905 (p. 6II). Mr. Woods, of the Department of Agriculture, who has made a special study of the fungus, in a recent letter to the writer says :-

"The disease is quite serious on the softer-leaved varieties, such as those of the Lawson type, especially the Lawson and the Enchantress. The disease behaves very much like the other Alternaria diseases, especially the one on the violet, attacking not only the leaves, but the 
stems, and cutting the plants back very seriously in many cases. In fact, I have seen whole houses of carnations practically stripped of their leaves and losing a large part of the top. Plants grown out of doors, exposed to rain and dew, especially in the night, are very subject to the disease and suffer seriously when the plants are moved into the house. It is, of course, then rather difficult to free the plants of the disease without cutting them back very severely and spraying them thoroughly with soap Bordeaux. The proper treatment is to spray the plants from the time they are set in the field until the time they are moved into the house, keeping the young growth well covered with Bordeaux and continuing the treatment after the plants are in the house until they become well established. If the plants are grown in the house all of the year and the leaves are not allowed to remain wet over night, the disease seldom, if ever, does much injury."

\section{CAULIFLOWER, Brassica oleracea.}

Black Rot, Pseudomonas campestris (Pammel) Smith. While the black or brown rot of cabbage, turnips and allied plants is not a rare bacterial trouble, it has never been definitely reported in this state. From occasional complaints received from growers, there is little doubt that, while not reported before, it has been present for some time, doing more or less injury. Last October the writer made his first collection of this disease from some cauliflowers grown on the Experiment Station grounds. The heads were blackened and blasted, much as if injured by frost. There was also complaint of a rot of turnips on a Hamden farm which no doubt was also of this nature, though no specimens were seen. The black rot bacteria usually enter their hosts through injured tissue or the water pores at the margin of the leaves. The bacteria develop abundantly in the fibro-vascular vessels, working from the veinlets into the large veins and ribs, which are turned black as a result of the invasion. Finally they may reach the stem, and cause a more general injury. As a result of the clogging and disease of the bundles, the water supply is gradually cut off from the fleshy tissue, and the leaves turn yellow, wilt, and finally die. In diseased cabbage, the bacteria sometimes work their way directly from the infected leaf through adjacent leaves, causing an internal rotting while the head from the outside may appear sound. When this disease appears in a field, rotation with noncruciferous crops should follow for a few years. The diseased 
plants should be destroyed, and rubbish from the plants should never get into the manure pile. It has lately been shown that the bacteria causing this disease can be carried on the seed and cause infection of the young plants, so care should be used to obtain seed from healthy plants.

\section{CORN, Zea Mays.}

Black Mold, Cladosporium Zeae $\mathrm{Pk}$. This is a fungus that sometimes appears conspicuous on both sweet and field corn, though it is not strictly a parasite, and possibly not directly the cause of any injury. It shows as an olive-black growth on the kernels, usually at the tip of the ears. Apparently it develops on improperly matured or injured kernels, and makes this injury, appear more conspicuous. When the seed corn is not properly dried before storage or is left too long stacked in damp places, the fungus probably extends the injury. While Peck described this fungus as a distinct species, it is quite possible that it is not distinct from the common saprophytic black mold, Cladosporium herbarium (Pers.) Lk. The renewed interest taken by some of our growers in the selection of seed corn is likely to call their attention to the fungus as one of the blemishes of perfect seed ears, especially of the sweet corn.

\section{GRAPE, Vitis sps.}

Bitter Rot, Glomerella rufomaculans (Berk.) Spald \& von Schr. This fungus has previously been found in this state on the apple and pear, but not until the past season on the grape. On the apple it certainly does not do the damage here that it does further south, and possibly its injury to the grape is also inconspicuous. Just how common the grape bitter rot is in the state, however, cannot be stated at present, as usually all the rots of grapes are indiscriminately called the black rot. This season it was found in one place at Westville, where it seemed to be the cause of considerable decay, and a few berries, chiefly rotting from other causes, were also found among specimens sent from New Haven and New London. The spores ooze out in small pinkish masses, and by these the rot can often be told with the naked eye from the more common black rot. 
Blue Mold, Penicillium glancum Lk. A trouble which has not been reported before, but which is common, is that caused by the ordinary blue mold found on cold storage grapes, especially towards the end of their season. The fungus attacks the grapes that are more or less bruised by packing or handling; also where the grapes are overripe it seems to gain entrance at their stem end. Along the cracks in the skin the fruiting stage of the mold shows at first as a whitish, but soon as a dusty, blue-green growth. Of course all such berries are worthless, and the spores from these form the means for a much more general spread of the trouble through the basket. While usually but few grapes are injured, if sold soon after removal from cold storage, after they are out some time the trouble may even spoil the whole basket. Some of the baskets offered for sale last fall had as high as a third of the grapes spoiled in this way. Another quite similar blue mold, (Aspergillus glaucus) may also at times be partly responsible for this decay, as one of the cultures made from the grapes showed that it was present.

Shelling and Rot. One case of serious shelling off of Niagara grapes, about the time of maturity, was reported from New London, and the same variety at the Experiment Station was similarly injured. As in both of these cases the grapes rotted more or less, especially after falling to the ground, it is a question whether or not some fungus might have been partially responsible for the trouble. It is generally conceded, however, that shelling (without rot) is the result of non-parasitic causes. Among the non-parasitic causes the peculiar seasonal conditions of the year, already mentioned elsewhere, which apparently caused an unusual number of physiological troubles, may have been the chief cause of this trouble. The grapes on the ground in time showed the fruiting stage of a species of Macrophoma. This fungus probably occurred on them as a saprophyte; at least Macrophoma flaccida (on the fruit) and Macrophoma rimiseda (on the branches), which agree somewhat closely with the species reported here, are usually considered non-parasitic species. The shelling of Niagara grapes has been mentioned once before, by Sturgis, in the Experiment Station Report for I896, p. 278. Since, through oversight, this 
was not included among the troubles mentioned by the writer in his general report of diseases, made in 1903, and since it was probably a common trouble the past season, the following is quoted from Sturgis' article:-

"Shelling grapes, at least in the case of green varieties, show a peculiar though indistinct mottling of the surface; the skin is abnormally thick, and the whole berry, therefore, feels harder than healthy berries at the same stage of development; a section of a diseased berry shows a narrow brown zone just beneath the skin; the taste of shelling grapes is noticeably insipid as compared with the tart, astringent flavor of the unripe but healthy fruit; finally, the woody tissues of the stem which enter the fruit and, in the case of sound berries, remain attached to the stem when the berry is pulled off, are so far weakened in the case of shelling grapes that the weight of the berry is sufficient to cause them to separate from the stem, and the berries fall to the ground, leaving the ends of the stem perfectly even, 'as if cut with a knife.' This dropping of the fruit from two to three weeks before maturing, is a characteristic symptom of shelling, and may result in very serious loss, a loss emphasized by the fact that the trouble does not confine itself to certain bunches on a vine, leaving others unaffected, but affects portions, generally the end, of every bunch.

After a most exhaustive consideration of all the possible causes of shelling, Lodeman concludes that neither insects nor fungi are to be considered as a primary cause of the trouble; that the condition of the soil, apart from the supply of available plant food, does not exercise any marked influence on the degree of shelling; that meteorological conditions are not primarily responsible for it; and that it is not due to a lack of phosphoric acid. Among the agencies which may increase or favor the diseased condition, Lodeman mentions parasitic fungi, which weaken the function of the leaves; a weakening of the plant due to overbearing; the drawing of nourishment from the fruit by overproduction of wood; an excessive supply of nitrogen, emphasized by too much tillage; long drought or excessive rains following drought; and a poorly developed root system, resulting in a general weakening of the plant. The condition of the food supply as regards potash seems to be the only remaining factor to be considered, and Lodeman is inclined to attribute the primary cause of shelling to a lack of that element. This view is in a measure substantiated by observation and experiment."

0ATS, Avena sativa.

Yellow Leaf. This trouble was first seen at Portland, the second week in June. During June and July it was noticed in almost all the oat fields examined, and so must have considerably reduced the yield. The leaves, especially the lower, became 
a sickly yellow, and many finally died prematurely. In some respects this trouble resembled the bacterial disease that occasionally occurs in the early summer in the oat fields of the West; but the leaves lacked the water-soaked appearance of that disease, and on examination failed to show any bacteria present. The trouble apparently resulted from unfavorable weather conditions, possibly aggravated by some root disease, though the few examinations made of the roots failed to show any suspicious fungus at work there. June and July had many heavy rain storms suddenly followed by bright hot days, and these sudden changes, as in other cases already mentioned, probably caused the injury. The same trouble was seen to a less degree on a number of other grasses, both wild and cultivated.

PEACH, Prunus Persica.

Leaf Fall. Another physiological trouble called to the writer's attention by J. H. Hale, of Glastonbury, at the annual meeting of the Connecticut Pomological Society, was the unusual loss of the peach foliage in his orchard during August and September. Many of the leaves turned yellow, finally dying and dropping off. In some cases there was some shothole injury, but otherwise nothing to indicate that any fungus or insect was the cause of the defoliation. Conversation with a number of other large peach growers brought out the fact that this defoliation was a common trouble this year in the state. Both bearing and young trees were affected, but certain varieties more than others. Alberta and Late Crawford were among the varieties that suffered most. Some of the growers were inclined to believe that fungi or insects were the cause of the trouble. From their descriptions, however, it seems that neither of these agents, if responsible, was at work on the leaves themselves. The San José scale, if very bad on a tree, may cause partial defoliation, but there was no likelihood that it was unusually prominent in the orchards complained of. It is barely possible that such denudation of the trees might follow root injury. There is no fungus trouble in the state, however, that has been known to act exactly in this way. The crown gall and the crown or foot rot are the only root troubles so far known here, and"it does not seem plausible that either 
of these was responsible for so general and unusual a trouble. Among the insects the peach borer is the only one that might be suspected, but if this was responsible, it would undoubtedly have been detected by the growers, and its injury is not quite like that described here. Everything considered, it seems probable that this was also one of the seasonal physiological troubles that were unusually common this year. The wet months of June and July no doubt developed a tender and luxuriant leaf growth on the trees, and the bright, dry months of August and September offered such different conditions (especially if the roots still showed any effects of winter injury from the cold winter of 1903-04) that the evaporation of moisture from the leaves became disproportionate to the amount supplied by the roots, and the defoliation of the older leaves gradually followed as a consequence.

\section{PEONY, Paeonia sp.}

Root Injury or Rot? Plate XVII, b. In September complaint was received from Southington of a root rot of peonies, which had gradually become quite serious. In writing of this trouble, the grower, Mr. H. R. Whitney, said: "When the plants first became established they were very beautiful, but since this disease has come upon them they do not amount to anything, some not even blooming. The first sign noticed is a discoloration of the leaves, turning to a chocolate color, accompanied by wilting, and finally death of the stalk. Sometimes the wilting occurs without any discoloration; the roots seem to rot to pieces at the surface of the ground much after the manner of the rootstock rot of iris (which, by the way, is very prevalent hereabouts, and all our iris beds are seriously affected by it). These peonies were set on a sloping hillside facing the north, and the lowest plants were the first ones affected. The disease has now spread to all. They have always had good care. I am now going to transplant them to higher ground, in fresh soil, and see what this will do."

I am not certain about the cause of this trouble. The specimens sent for examination showed a dry, rather than a wet rot, though possibly this was because they had dried out somewhat. The statement that the iris on his grounds was being 
injured by a bacterial rot might indicate that the same agent was at work on the peony. An examination of the roots, however, did not lead the writer to the conclusion that bacteria were responsible for the injury, though some bacteria were present in the tissues, and cultures made from the diseased parts usually gave mixed growths of bacteria and fungi. Microscopic examination of the diseased tissues showed that there was present the sterile mycelium of some fungus that looked as if it might be the cause of the trouble. The fungus was peculiar because of numerous roundish, dark reddish brown chlamydospore-like bodies that occurred in the threads. Cultures from this tissue seem to indicate that these were possibly threads of a Torula developing under unfavorable conditions. In this case the fungus was apparently only a saprophyte that developed in the tissue after the injury, rather than its cause. A peculiarity of the trouble, at least in the specimens sent for examination, was the sharpness with which the healthy tissue was marked off from the diseased, as shown by the lengthwise section of the root in the illustration given here. This may indicate that the trouble was not the result of bacterial or fungous attack, but possibly a winter injury. Usually the injury was on one side of the root, but in some cases it extended up into the interior, with white healthy tissue on either side. Mention of this trouble has not been found in the literature of plant diseases, though probably it has not entirely escaped observation before. Further study of injured plants is needed to determine definitely the cause.

\section{PINE, Pinus sps.}

Leaf Blight, Hypoderma Desmazierii Duby. This caused the pine needles to die from the tip inward, changing the normal green color to a reddish brown, and in time to a grey brown. On the lighter areas the spore stage of the sac fungus which causes the injury developed as small, longitudinal black lines. The fungus does more or less injury to the large pitch pine trees, Pinus rigida, in this state, but just how much is not known. Undoubtedly it causes in time a premature defoliation of the infested leaves. No complaint has been made in this country of the fungus, though in Europe Tubeuf \& Smith men- 
tion a similar species on white pine as doing considerable injury.

Rust, Peridermium acicolum Und. \& Earle. During the spring, complaint was received of a fungus injuring the leaves of the pitch pine on an estate at South Manchester. As the owner wished to develop the young native trees into a pitch pine grove for landscape effect, she was anxious that no serious injury be done by this fungus. The writer made a special study of the fungus, with the result that some new features of its life history were brought to light. The fungus forms on the leaves fragile, tongue-shaped, whitish receptacles filled with orange-colored spores. By the first of July these had largely disappeared, as the fungus did not spread further on the pine leaves. It was found that this stage was merely the aecial stage of another rust (Coleosporium Solidaginis) that is common on goldenrods and asters. In July, following the disappearance of the rust on the pine leaves, this other rust became very abundant on the leaves of Solidago rugosa in this forest, especially where these plants were close to the infected pines. The writer was also able to produce the rust on an indoor specimen of Solidago rugosa by infecting it with spores taken from the pine leaves, thus conclusively proving their relationship. The rust at South Manchester appeared chiefly on the young trees six to fifteen fect high, whose limbs in many cases reached the ground. Some few large trees with no limbs near the ground were not at all infected. In order to prevent the spread of the trouble, at the suggestion of the writer, the young trees were trimmed of their lower branches, and the goldenrod, especially under the trees, was all cut off. In this way it was hoped to prevent any large amount of reinfection of the pine leaves from the rust on the goldenrod another season. The writer hopes to make a more detailed account of his study of this fungus elsewhere.

Winter Injury? The state forester, Mr. Hawes, recently had called to his attention a trouble of white pine, Pimus Strobus, at Windsor. The injured trees were scattered through the forest, and some were of large size, so that their death meant considerable financial loss. The injury first showed in the death of the leaves on the uppermost branches, but gradu- 
ally progressed downward until the whole tree was dead. An examination of the injured and dead trees by Mr. Britton, the entomologist, showed that while some were infested with a number of borers, these usually confined their attention to the dead or dying parts of the trunk, and were not species liable to directly cause such injury. The writer saw several badly injured trees (but still possessed of a living trunk and some green leaves) which had blown over, and an examination of these showed in every case that the roots were all dead except a few small and apparently new ones near the surface of the ground. This plainly indicated that the injury was primarily one of the roots. At first we were inclined to believe that the roots had been winter killed, but an examination showed that the mycelium of some hymenomycetous fungus was present in the dead roots and to some extent on the surface of the living. This fungus was not determined, as its fruiting stage was not present at the time of the examination, in March. Of course it is possible that the fungus was present merely as a saprophyte. A similar injury in Massachusetts was recently called to the writer's attention by Professor Stone, who after a thorough study has attributed it to winter injury.

\section{RASPBERRY, Rubus sps.}

WILT, Leptosphaeria Coniothyrium (Fckl.) Sacc. Plate XVIII, a. This trouble has been mentioned before in the Reports for 1903 and 1904 , but this year there were more complaints of serious injury from it than any previous year. A more thorough study of the trouble has developed a new point in its life history. Apparently the very wet weather of June offered favorable conditions for the development of the fungus, as it began to be quite conspicuous in its injury in the fruit about the middle of the month. At this time the disease showed on a few of the young canes, which gradually wilted from the top as if they had been injured below in cultivation. Examination of these showed no such injury, but rather a rot at the base or under the ground apparently due to the wilt fungus, though not in a fruiting condition to fully identify it. Cankered areas (as described by Stewart, of the Geneva, N. Y., Station, who 
has made a special study of this trouble) may also occur on various parts of the plant, and by girdling produce a wilt of the parts above. On the fruiting or dead canes the fungus usually appears more generally distributed in its fruiting condition. From minute imbedded receptacles in the bark large numbers of the spores are shed out on the surface as a dark reddish brown coating. On the pruned canes the fungus often gains entrance through the cut ends, killing the tips and producing its fruiting stage on the dead tissues. The most serious injury shows on the green, but nearly full-grown berries, which begin to wither and dry up about the middle of June. This usually occurs so prominently and suddenly as to alarm the grower, who has not previously noticed the trouble, as indicated by the following letter from Mr. W. B. Eastman of Bethel:- "This A. M. I noticed that many of the berries throughout the entire field were dying. I am afraid that the entire crop will be lost should the dying continue."

The writer had previously had this drying up of the berries called to his attention, and had attributed it to the fungus at work in an obscure way at the base of the plants, or in underground parts, as usually there was no evidence of it on these canes above ground. These plants at Mr. Eastman's were bearing for the first time and showed, as a whole, good vigorous canes except for the wilting of the fruit. There was a little of the wilt fungus present on old stems, and a few new ones were dying from it, but in general there did not seem to be any special reason why the fruit of certain canes should wilt and in other cases not. This, with the fact that the wilting or drying up of the berries started on certain ones of a bunch before it did on others, and a single berry might be dried up on one side while perfectly green and healthy on the other side. suggested that possibly the trouble was not due to a wilting caused by the fungus at work at the base of the canes, but rather was a dry rot due to direct infection of the berries by this fungus. This same idea had been suggested some years before to the writer by a grower whose berries had been thus dried up, but our imperfect examination at that time showed nothing to support the belief. This time, however, it was proved to be correct by a microscopic examination of the diseased and 
healthy tissues. In the healthy green tissues no sign of the mycelium of the fungus was found, but in the adjacent diseased tissues it was present more or less prominently. In the berries, for instance, it formed slightly tinted branched threads that worked their way into and between the cells of the fleshy parts of the drupelets, but not into the stony tissue or the embryo. When first infecting the berries, the fungus caused the normal green color to become slightly tinted, as if ripening prematurely; then the tissues gradually turned brown and dried up from the dry rot, which under favorable conditions of moisture advanced through the whole berry, into its receptacle and the calyx, and finally even down into its pedicel, killing the tissues as it advanced. The illustration given in Plate XVIII, a, shows the upper three berries perfectly healthy while those in the lower row are entirely rotted by the fungus except in the center berry, where the fungus had passed down the pedicel only halfway, the lower half being still alive and green, as shown by the lighter color. When going down the pedicels and peduncle, the mycelium penetrates through the parenchyma cells of the bark, kills the young cambium cells, and is also found in the cells of the pith. Just how far down the cells of the stem the mycelium may pass was not noted by later examination of the canes. Certainly it often goes far enough to wilt other berries in the bunch that may have escaped direct inoculation, though in this particular case most of the berries seemed to have been inoculated directly.

While the fungus was not found in fruiting condition on the berries, the search was not continued later than June. Neither did specimens brought into the laboratory and kept for a short time in a moist chamber develop the fruiting stage on the diseased berries, but in one case where a bunch was kept in water for some time, the fungus did finally fruit on the common peduncle. There was no other suspicious fungus in $\mathrm{Mr}$. Eastman's patch, and while this one was not so conmmon in its fruiting condition as seen later in other patches, it was quite common nearby on wild plants along the roadside, whose fruit was suffering from a similar dry rot. There is no doubt in the writer's mind that the infection took place through the flowers and very young fruit, and that the spores were carried by bees 


\section{CONNECTICUT EXPERIMENT STATION REPORT, 1906.}

or other insects that had previously crawled over stems coated with the spores.

This wilt seems to be most severe on the blackcap varieties. Among those complained of are the Parmer, Cumberland and Kansas. To a less extent it has injured the red varieties. As stated above, it was also found on wild black raspberries and a few bunches of wild blackberries were seen that possibly may have been suffering from the same trouble. When once the fungus becomes established in a patch, it is apt to give trouble thereafter, and in some instances it has eventually ruined the patch. The few spraying experiments that have been tried have not been very effective. Possibly if the spraylng was kept up for two or three years, better results might be expected. It is quite difficult to make Bordeaux mixture stick to the new canes, and this may possibly partially explain the failures. Of course a thorough cutting out of the dead and diseased canes soon after the fruiting season and again in early spring is desirable. It might be well, too, to destroy any wild raspberries in the immediate neighborhood.

\section{TOBACC0, Nicotiana Tabacum.}

BED Rot, Corticium vagum var. Solani Burt. A special study of tobacco diseases the past year has brought to light several fungous troubles that have not been reported before in this state. The Rhizoctonia stage of the above fungus, which is so common on potatoes, has recently been reported by Selby in Ohio as the cause of a bed rot of tobacco. He attributed to it a dampening off of the young plants, and cankered areas on the stems of the larger ones. This trouble is so similar to the one mentioned in our last Report and attributed to a Sclerotinia fungus that we afterward questioned whether it might not be the same. Our much wider examination of tobacco beds the past year, however, seems to show that the Sclerotinia fungus is the common dampening off agent in the tobacco seed beds in this state. We did, however, find the Rhizoctonia fungus present in some of the beds, but so far as observed, its injury was slight, and was confined, as with the potato, to the underground parts. This does not mean that it may not be as serious a pest here as in Ohio, but so far we have not been able to prove 
definitely that it was the cause of any serious injury. Since it is so well known as a troublesome soil fungus on various plants, there seems to be no reason why it should not be responsible for some of our tobacco seed bed troubles. That it is the same fungus that occurs on potato was shown where some tobacco plants were left in the beds until about the middle of July, since on these the Corticium or fruiting stage of the fungus formed a white mealy coating at their base just as it does on the potato stems. According to Selby, this fungus is likely to develop most abundantly in an acid soil, so the application of lime to such soils may prove in part a remedial measure. The general treatment for its prevention is the same as that described later under the Stem Rot trouble.

Canker, A Bacterial Disease? Plate XIX, a, b. After tobacco has attained considerable size in the field, say from July on, occasional plants are sometimes found that have the stem girdled underground or a cankered area reaching up a considerable distance on the stem, as shown in the illustrations. In time the bark of the diseased area underground may entirely rot off, and yet the plant above may show the trouble only by a slight dwarfing and a sickly yellowish color of some of the leaves. The canker, when reaching above ground, shows a dark brown sunken area in the bark sharply marked off from its healthy green tissue. This trouble has been known by the growers in this state for a long time, but as it occurs only on an occasional plant, nothing has ever been published concerning it. In our study of the root rot trouble mentioned later, these cankers were noticed, but were believed to be merely an extended injury of the root rot, as in the first specimens examined that fungus was at work on the roots and also somewhat on the underground girdled area. Later experience, however, indicated that this fungus never produces the cankered areas on the stem above ground, at least it was never found there in a fruiting condition. In these places, however, there was a more or less prominent development of bacteria, and while no special study has been made with them, it seems probable that they are the direct agents in extending these cankers. No doubt root rot, stem rot, and even insect injuries, may be the starting point of these cankers. Delacroix of 
France has recently described (Recherches sur Quelques Maladies du Tabac en France) a canker trouble of tobacco stems caused by bacteria that possibly may be the same as this.

Dampening ofF, Pythium sp. Plate XXI, b. This fungus was not found in the regular tobacco beds of the state, though probably it does more or less injury in them, but it occurred on some tobacco seedlings grown in the Experiment Station greenhouse in rich loam. Though quite a different fungus, it dampens off the young plants in much the same way as the stem rot fungus described later, but can generally be told from that trouble by the absence of any white fungous threads creeping over the decayed plants. This fungus (probably Pythium DeBaryanum Hesse) is a common dampening off agent of young plants in greenhouses and hotbeds, especially if the soil has been used for some time and contains an abundance of organic matter and moisture. It can be prevented by the same means employed against the stem rot trouble.

Rоoт Rот, Thielavia basicola (B. \& Br.) Zopf. Plates XXIX and XXXI. This was a trouble that was very pronounced in certain tobacco seed beds and fields in the Connecticut valley the past year. While probably not an entirely new disease here, it certainly has not previously attracted the attention it did this year, and has never before been reported by this Station. The injury occurs on the roots, which are often rotted off the young plants. In this respect it differs entirely from the dampening off troubles that rot the stem above the ground. The disease is discussed in detail in a special article in this report, so no further mention need be made of it here.

Stem Rot, Sclerotinia sp. Plates XX, a-b, XXI, a. This is the fungus mentioned in our last Report as a "Dampening Off" trouble of tobacco, but as the Pythium fungus described above usually goes by that name, and has now been found here, its name is changed to the Stem Rot trouble. So far as observed, this is the common trouble with tobacco seedlings in Connecticut. Its injury is quite similar to that described by Selby for the bed rot caused by the Rhizoctonia fungus, and both have very similar sterile mycelial threads. Artificial cultures of the stem rot fungus, however, give rise to a pure white mycelium which forms numerous small black sclerotial bodies 
that are similar to those of the drop fungus (Sclerotinia Libertiana) of lettuce, and apparently quite distinct from the artificial cultures of the Rhizoctonia fungus. Cultures made from diseased plants obtained from the same place in Bridgewater, Conn., both in 1905 and 1906 , gave the same fungus, which we have called provisionally Sclerotinia sp. In passing, it might be well to note that Delacroix of France has described a Sclerotinia trouble of tobacco which occurs on the mature plants. Our fungus usually appears in spots in the bed, dampening off all the plants for some distance when they are crowded and the moisture is abundant. Its white threads, visible to the naked eye, form a slight cobweb-like coating on the soil and the base of the plants. When the plants are quite young, the stems just above ground are injured by a wet rot, which causes the plants to fall over, and eventually they are entirely destroyed. Plate XX, a, shows a specimen where the base of the stem just above ground was rotted, while the stem above and the roots below were uninjured. Sometimes the plants are so far advanced that the tissues of the stem resist the attack, with the result that only cankered spots are rotted in the bark, as shown in Plate XX, b, and these may heal over without further injury from the fungus. Such plants are sometimes transplanted by accident in the fields, but they do not usually make a satisfactory development, as they are often broken off at these cankered places, which also offer entrance for other agents of decay.

The stem rot, like other seed bed troubles, is likely to develop in beds in which the plants are too crowded, or kept too moist, either by excessive watering or lack of proper ventilation. Care in these respects, therefore, will often prevent or stop the trouble after it is started, but of course wet, cold springs often make proper regulation of the moisture difficult. When the trouble has been bad in beds for a year or two, it is likely to cause more or less injury each season, and it is then desirable to either change the beds or the soil in them. Beds made in low, wet spots, or which contain abundant organic matter, are likely to be most injured by this trouble.

The writer made a couple of experiments with spraying diseased beds with weak formalin (I to I500) to see how this 
would work in keeping down further injury from the fungus. Part of a bed at New Milford which was sprinkled twice apparently did not show any improvement over the rest of the bed. In another bed at Bridgewater, part of which was sprinkled three times in June, after the fungus had caused considerable injury, there was apparently some benefit from the treatment. The writer did not see plants from this bed until after they were pulled up, but the owner and his men said that in the treated part the plants rotted less, cankered spots healed over quicker, and the fungus developed less prominently than in the untreated part of the bed. In certain beds at Hockanum, which had been sprinkled several times for the root rot trouble, the owner thought that the treatment had been a benefit. So far as the root rot was concerned, the writer saw nothing to indicate that the treatment had been helpful, but was inclined to believe that possibly some benefit had been derived from lessening the dampening off of the plants. While we cannot state positively from these experiments and observations that sprinkling the beds with weak formalin is valuable in preventing stem rot and similar troubles, it seems well worth a trial in cases where the beds need to be watered more or less. In such cases we would advise the use of weak formalin (the standard 40 per cent. formalin, diluted with water at the rate of I to I 500 ) entirely in the place of water. Such a strength does not seem to injure the tobacco seedlings, and the exposed fungous threads certainly would not develop in this as they would in ordinary water.

Another method of preventing this trouble, when one does not wish to change his bed, is by sterilizing the soil. This may be done either by steam or formalin. The effect of the formalin treatment is shown in Plate XXI, a. In box I the soil before sowing the seed was thoroughly soaked with a strength of formalin at the rate of $I$ to $I 00$ of water; in box 2 the formalin was half as strong, I to 200; and in box 3 the soil was merely soaked with water. These boxes were covered for a day to keep the fumes of the formalin in the soil, and then they were uncovered, aired, and the soil stirred to allow the escape of the formalin. About a week after treatment they were seeded similarly with tobacco. The boxes were covered 
part of the time with glass, which kept the air saturated with moisture, and as the plants came up very thickly, the conditions were excellent for the development of dampening off troubles, except where the fungus had been entirely killed in the soil. At first the two treated boxes were much better than the untreated, showing no dampening off, though the plants were crowded, while the dampening off soon developed in several spots in the untreated box. Finally, however, one dampening off spot appeared in box 2, (the weaker treatment, which apparently had not been quite strong enough to entirely kill the fungus), and because of the very crowded condition of the plants at this time, rapidly spread through the box, and even in time passed, at one corner between the glass partition and the wooden side, into the box treated with the stronger solution. The illustration shows the condition of the three sets of plants about four weeks after seeding.

This experiment shows that the dampening off fungi evidently can be largely killed in the soil if the formalin is strong enough and the soaking of the soil is thorough. Based on the results of this experiment, two infected beds were treated late last fall at Bridgewater. In these cases formalin was used at the rate of I to IOo of water, and the beds were thoroughly soaked by gradually sprinkling on them a gallon per square foot. The beds were then covered with gunny sacks over night to keep in the fumes. Of course the results of these treatments cannot be determined until later in the season.

\section{TOMATO, Lycopersicum esculentum.}

Black Mold, Fumago vagans Pers. Plate XVIII, b. We have reported this fungus before on pears and apples, following attacks of plant lice, and also on the linden. During the past year it occurred at the Experiment Station on tomatoes and nasturtiums in the greenhouse and on tobacco outdoors, in each case following an attack of the white fly. On these various hosts the microscopic characters of the fungus were not always the same, as the Cladosporium may or may not be associated with an Alternaria stage, or there may be more or less of a Tortula-like growth. For convenience we have called all of the specimens Fumago vagans, since this is the species 
credited with growing in the honey dew of insects. The most striking development of the fungus this year was on tomatoes grown during the winter in the greenhouse. The white fly confined its attack to the underside of the leaves, while the black mold developed only on the upper side, where it formed a conspicuous olive-black growth, as shown in the illustration. From casual observation one would have supposed that the fungus was really an active parasite developing on the tomato, quite similar to the injurious scab fungus, which often appears on the under surface of the leaves. The black mold in reality did not grow as a parasite, but as a saprophyte in the honey dew secreted by the fly. This honey dew evidently drops on the upper surface of the leaves.from the insects on the under surface of the leaves above. This was shown in the case of a tobacco leaf where the leaf had been partly folded on itself, exposing its lower surface above. Here the black mold developed on the exposed lower surface, and on the upper surface except where covered by the fold. It is doubtful if the fungus itself does any injury to the leaf other than shutting off the sunlight, but it does cause an unsightly appearance. There is a possibility, however, that such a fungus, after continued growth on a host in this manner, might become parasitic.

\section{TURNIP, Brassica Rapa.}

White Spot, Cercosporella albo-maculans (E. \& E.) Sacc. This fungus forms subcircular, greyish spots, showing on both surfaces of the leaves, and varying from an eighth to a quarter of an inch in diameter. When abundant on the leaf it causes premature yellowing and death. The disease was observed last September at Kent in a field of turnips, following tobacco, where it was doing some damage. There is some question whether or not this fungus is distinct from Cercospora Bloxami B. \& Br., and in general appearance it also resembles the leaf spot trouble of horseradish caused by a species of Cercospora.

VETCH, RUSSIAN, Vicia villosa.

Leaf Spot, Ascochyta Viciae Lib. Plate XXII, a. As the Russian vetch has recently been highly recommended as a winter cover crop for tobacco fields in this state, any fungus attacking it becomes of some economic importance. In one 
field at Suffield, in October of the past year, some plants of this vetch were observed that were being injured by the above leaf spot fungus. This fungus forms subcircular, greyish spots, with a prominent purplish border. The fruiting receptacles are visible as minute black bodies bedded in the center of the spots, as shown in the illustration. As the leaflets are small only one or two spots generally appear on each, but these are often sufficient to cause their premature death. The fungus has been reported before in this country by Ellis, on the pods of this same host, and also from Canada, on the leaves of a different species of vetch. Saccardo lists Ascochyta Pisi, a common fungus of the pea, on the Russian vetch, and as this fungus is very similar to the species reported here, there may be some question as to their distinctness.

\section{VIOLET, Viola sps.}

Speck Anthracnose, Marsonia Violae (Pass.) Sacc. Plate XXII, b. We have previously reported a number of leaf diseases of greenhouse violets. The above is one that has rarely been reported in the United States. It was sent from Niantic last fall by Miss Angie M. Ryon, who reported considerable injury to various species of native violets which she was cultivating for scientific purposes. The trouble differs chiefly from the other leaf troubles of violets so far reported in the very small size of the reddish spots, which are usually smaller than a pin head. The spots, however, may become very abundant, being scattered or clustered, and cause a yellowing of the intervening tissues and serious injury to the leaves. 


\section{EXPERIMENTS TO PREVENT ONION BRITTLE.}

Nature of injury. In our last Report we described a peculiar disease of onions, called brittle, that was reported by Burton W. Bishop of Guilford as being a serious trouble in that vicinity when once it became established in a field. Our investigations at that time indicated that the trouble was caused by a soil fungus that worked especially in the roots but whose identity was not fully established. The past season we made some successful experiments to prevent this trouble but gained little further information concerning its cause, partly because of its obscurity but chiefly because this side of the investigation was not especially considered. The general character of the disease is briefly given in the following paragraph, but a somewhat fuller account may be found on pages $270-3$ of the Experiment Station Report for I905.

The trouble usually starts in some small section of a field and each year extends out further, so that the land eventually becomes of little value for growing onions. Weeds in the infected area also do poorly. In some respects the trouble resembles an acid soil, and yet this could hardly explain the spreading of the trouble or the benefit that resulted from the use of certain soil fungicides. While apparently caused by a fungus, this is never evident externally on the roots and often it does not seem abundant enough within their tissues to cause so prominent an injury. Though not definitely determined by actual observation, apparently many of the very young seedlings are dampened off or killed outright, since the stand in the infected area is usually very poor and irregular. In fact most of the injury seems to be to the seedlings, though the older plants do not entirely recover from the backset they received. The infected plants are much smaller than the healthy ones near them or those in the part of the field free from the disease, as is shown in Plate XXIII, a. Another peculiarity is the brittleness of the leaves, from which the trouble takes its name. Very often the leaves are quite irregular or have peculiar spiral coils as shown in $b$ of this same plate. The onions may also have a sickly yellowish green color, especially in spots, instead of the normal dark green. 


\section{PREVENTIVE EXPERIMENTS.}

Nature of experiments. Through the courtesy of $\mathrm{Mr}$. Bishop, one end of his field was used in 1906 for experiments in preventing the onion brittle. The disease showed first in this field two years before and when seen by the writer in 1905 had infected an irregular area in one corner about two or three rods each way. In 1906 this infected spot had greatly extended itself, in one direction spreading nearly across the field, though tapering out toward the further end. The character of the infected area is shown in Plate XXIV, a, which slightly exaggerates the injury to the onions in 1906 since some plants did come up on the vacant place, but these were so few and scattered that they were finally plowed up as worthless.

As the trouble is in the soil and injures the plants chiefly while young, the treatments were made with this in view. In the corner of the field where the trouble first showed, the ends of one to seven rows (each 53 feet long and I4 inches apart and so representing about one seven-hundredths of an acre) were used for each treatment. The first set of treatments, made at the time of seeding, April 20, was as follows:

Plot. No. Razus.

Treatment.

I..... $6(\mathrm{I}-6) \ldots .$. Check ; no treatment.

$2 \ldots \ldots 4$ (7-10)... Formalin (I to 240 water) at rate of 525 gals. per acre.

$3 \ldots \ldots$ I (II) .... Limoid at rate of 700 lbs. per acre.

$4 \ldots \ldots 7(\mathrm{I} 2-\mathrm{I} 8) \ldots$ Sulphur and limoid (2 to I) at rate $200 \mathrm{lbs}$. per acre. $5 \ldots . .7(19-25) \ldots$ Complete fertilizer (I sol. bone black, I mur. pot., $21 / 3$ sod. nitr.) at rate of 650 lbs. per acre.

$6 \ldots . . \infty(26-\infty)$.. Check; no treatment.

In each case after the seed was sown the fungicide was sprinkled or scattered over it and the adjacent earth before covering. In this way the rates used were much more effective than if the fungicides were scattered broadcast. The fertilizer was scattered directly over the rows after the seed was covered. This complete fertilizer was used partly to determine if the land was lacking in fertility but chiefly to see if, with quickly available food, the young plants could be forced to a rapid development and so outgrow or escape the injurious action of the fungus which seems to attack the plants most injuriously while quite small. The land, however, had already been well fertilized, since Mr. Bishop used at about the rate of 9 tons 
of salt hay, $1 / 2$ ton fish scrap and 3 tons wood ashes per acre. He used the salt hay, partly composed of sea weed, to get more humus in the soil and because he thought that the salt miglit have some influence in checking the brittle.

On June 9th, after the plants had made considerable growth, a second set of experiments (similar lengths of two rows in each case) was made to determine if the treatments would have any effect in stopping or lessening the trouble after it once showed in the plants. These treatments were with limoid ( 700 lbs. per acre), ground fresh lime (700 lbs. per acre), air slaked lime (700 lbs. per acre), fresh lime slaked in water $(I / 2 \mathrm{lb}$. to 2 gals. water used at rate 1400 gals. per acre), and formalin ( $I$ to 1500 water in two applications at rate each of 1400 gals. per acre). These rows all showed at this time considerable injury from the brittle, especially in the poor stand.

Results of experiments. The onions in the second set of experiments (those treated after the plants showed the disease) in no case at any time showed any very appreciable benefit from the treatments. This indicates that the injury to the onions is caused primarily while they are quite small, or at least that this is the time of infection, and so any treatment to be effective must be made at the time of seeding.

In the first set of treatments, made at the time of seeding, the effect was quite evident soon after the plants appeared above ground. The first examination by the writer, made on June 4, showed that the stand and size of the plants were much better in all of the plots treated with formalin, limoid, sulphur and limoid than in the untreated plots and were practically the same as the plants in the best parts of the uninfected portion of the field. The weeds, too, which had been left for observation, were much more numerous and thrifty in these treated plots than in the untreated. The relative size of the diseased and healthy plants at this time is shown in Plate XXIII, a. The plot on which the complete fertilizer had been placed was not any better than the worst of the infected rows that had not been treated at all. This showed plainly that the trouble was in no way due to an impoverished soil or that the young plants could be stimulated in growth to escape the trouble. Of the check plots, No. I, which was on the very edge of the field, was much better than No. 6 , which made such a poor stand 
that the onions were worthless. Check plot No. I, however, was not as good as any of the treated rows, but was considerably better than the plot with the complete fertilizer.

On July 12 the second examination was made and about the same relative condition of the plots was found. The striking difference between the treated plots (limoid, sulphur and limoid, and formalin) and the untreated plots (complete fertilizer and check plot) is shown in Plate XXIV, b. This photograph shows chiefly the sulphur and limoid and the complete fertilizer plots and it brings out the sharp differentiation in size and number of plants even in their two adjacent rows. A more detailed view of the treated and untreated plants is given in Plate $\mathrm{XXV}$. In $a$ is shown plants in the complete fertilizer plot while in $b$, photographed at the same time and size, is shown a row each in the sulphur and limoid $_{4}, \operatorname{limoid}_{3}$, and formalin plots.

The crop was harvested on Sept. 7 , when the number and weight of the onions in each plot was determined. As a whole the season was very unfavorable for onions, so that the difference in yield due to the treatment, possibly, was not so great as it would have been in a more favorable season. The treated plots gave practically the same yield as the uninfected part of the field. Mr. Bishop considers 400 bushels per acre a good yield for this field during a favorable season, but this year only about half this was obtained. The following table gives the details of the yields in the different plots.

\begin{tabular}{|c|c|c|c|c|c|c|}
\hline \multirow{2}{*}{$\begin{array}{l}\text { Plot. } \\
\text { I. . . }\end{array}$} & Treatment. & \multicolumn{2}{|c|}{$\begin{array}{c}\text { Yield of } \\
\text { Onions. } \\
\text { No. } \quad \text { Lbs. }\end{array}$} & \multicolumn{2}{|c|}{$\begin{array}{l}\text { Average per } \\
\text { row } 53 \mathrm{ft} \text {. } \\
\text { No. Lbs. }\end{array}$} & \multirow{2}{*}{$\begin{array}{c}\text { Av.per } \\
\text { acre. } \\
\text { Bu. } \\
\text { І21 . . }\end{array}$} \\
\hline & Check............... & $920 \ldots$ & $541 / 2 \ldots$ & I $53 \ldots$ & $9 \ldots$ & \\
\hline $2 \ldots$ & Formalin ......... & I $161 \ldots$ & $603 / 4 \ldots$ & $290 \ldots$ & $15 \frac{1}{5} \ldots$ & $205 \ldots$ \\
\hline $3 \ldots$ & Limoid.............. & $268 \ldots$ & $\mathbf{I} 5 \ldots$ & $268 \ldots$ & I $5 \ldots$ & $202 \ldots$ \\
\hline $4 \cdots$ & Sulphur and limoid.... & $2072 \ldots$ & $99^{1 / 2} \ldots$ & $296 \ldots$ & $14 \frac{1}{5}$ & IgI. . \\
\hline $5 \ldots$ & Complete fertilizer (cheo & & $\cdots$ & $35 \ldots$ & $\mathrm{I} / \mathrm{s}$. & I 5 . \\
\hline
\end{tabular}

The complete fertilizer plot, No. 5 , and the check plot, No. 6 , were both practically alike and so poor as to be worthless; so the yield from the single row given here probably represents about an average for these and the worst part of the infected field. It is readily seen from this table that the treatments considerably increased the yield over the best of the untreated rows and as the larger part of the infected area was similar to plot 5 the increase in reality was very considerable. 


\section{DRY ROT FUNGUS,}

\section{Merilius lacrymans (Wulf.) Schum.}

Timber-destroying fungi in general. Both parasitic and saprophytic fungi cause injury to our commercial forest trees, the former doing damage to the living trees, and the latter producing decay of their wood after they have died from various causes. Apparently the financial loss caused by the latter class is much greater than that of the former. Such fungous injuries in this country have been studied extensively by von Schrenk of the United States Department of Agriculture, who has issued several bulletins dealing with special troubles of certain kinds of timber trees and their lumber. Popular articles upon fungous injuries to trees have also been written from time to time by other American botanists. Most of the injuries to trees by fungi are caused by certain species belonging to a group known technically as the Hymenomycetes, of which the toadstools and shelf fungi are familiar examples.

In the present article we discuss an injury, caused by one of these fungi, to the timber after it had been placed in a building. This dry rot, or house fungus, is peculiar in that it is what might be called a domesticated fungus; that is, it rarely, if ever, causes rot of the trees in the forests.* Mention has been made in this country of slight injuries caused by this fungus to the woodwork of cellars, greenhouses, etc., where the moisture had been favorable for its development, and short popular articles concerning the fungus itself have been written by MacBride, Freeman and Atkinson; but the writer has found no extended notice of serious injury caused by it. Mr. A. B. Seymour, in a recent letter, writes that some years ago he examined the rafters of a noted old church in Boston, and found them considerably injured by dry rot, which, however, was then entirely inactive. He also wrote that he was informed

* Appel (Arb. K. Biol. Anst. Land. Forstw. 5: 204-6. I906) recently tried to infect seedlings of fir and pine, grown in pots in the greenhouse, by introducing the mycelium through wounds in the stems; and while he did obtain a growth of Merulius lacrymans this in no way seemed to be parasitic on the trees. 
that the house at Cambridge in which Oliver Wendell Holmes was born was so injured by dry rot that it could not be moved, and so had to be torn down to make way for the Hemenway Gymnasium. In Europe, however, where the literature relating to this fungus is more extensive, serious injury to buildings has been reported a number of times. The specific case described in this article is of injury to North Carolina pine in the basement of a church, and was called to the writer's attention the past summer by ex-Senator William J. Clark of Stony Creek. The writer made several trips to Stony Creek to observe the fungus and its injury, and is indebted to Mr. Clark for information concerning its first appearance, etc.

\section{IN JURY BY DRY ROT FUNGUS TO WOODWORK OF A CHURCH.}

General situation. The trouble was called to our attention about the middle of June, the first examination being made the 29 th of that month. This stone church was comparatively new, and a corner of the basement had recently been partitioned off for a Sunday school room. The entrance to this room and the basement was from a tower vestibule above, that also led into the main auditorium. The steps leading down to the Sunday school room were enclosed in a narrow passageway. It was under these steps, close to the entrance of the Sunday school room, that the trouble was first noticed in an inconspicuous way, some months previous to our visit, through the rotting of a few of the boards. These boards had been replaced, and nothing more was seen of the trouble until after the furnace fire was discontinued in the spring. The walls of the Sunday school room are formed on two sides by the stone foundations of the church, and on the other two sides by a board partition separating it from the remainder of the basement, which is used as a furnace and fuel room. The Sunday school room was plastered to the floor directly on the stone on two sides, and on lath on the other two sides. The baseboard and wainscoting, of North Carolina pine in natural finish, covered the plastering to a height of three or four feet all around the room. The back of the board partitions on the furnace side of the basement was sealed tight by unpainted boards. The steps lead into the Sunday school room at one corner; beneath these is a small 
dark closet opening into this room, and nearby in the wooden partition a pair of swinging doors leading into the furnace room. It was in this corner (see Plate XXVI) under the steps (where the trouble originally showed) and in the closet that the fungus started with renewed vigor in the spring. At the time of our visit, a month or two after the first signs of its renewed attack were noticed, it had spread on one side along the wooden partition, past the swinging doors, for a distance of about fifteen feet; but on the other side of the steps, along the stone wall, only a very short distance. Only one or two small isolated outbreaks were found elsewhere, showing on the furnace room side on a sill that rested on the damp earth. Fortunately the floor of the Sunday school was cement, for no doubt if wooden the fungus would have found a very favorable condition for its development beneath it. The furnace room had no floor, but contained piles of old boards for fuel, and in a number of cases where the boards rested directly on the damp ground. there was a slight development of the fungus.

Conditions favoring development. In Europe there have been cases where this trouble developed in buildings apparently because the wood used in their construction was already infected with the fungus. In the present instance however, this does not appear to have been the case, for apparently the fungus started from infected old boards in or under the steps, and afterwards spread to the new lumber because of the very favorable conditions for its development. While this is called the dry rot fungus, it really requires moisture for its development, which was very thoroughly provided in the present instance. During the winter, while the furnace was going, the fungus gave no evidence of its development, if present between the wainscoting and the plastering. After the ordinary damp spring months came an unusually wet June, with very frequent heavy rain storms. These, together with the situation of the church on a rock close to the Sound, made the moisture very evident in the basement. Then, too, the basement was cool, and so tended to condense moisture from the saturated atmosphere on the woodwork. The leaders on this side of the church did not carry the water away from the foundation, and on the other side there was no eave trough. This made the ground around the basement Sunday school room very wet 
during the frequent rains. The effect of the abundant moisture was shown by the warping of the wainscoting even where there was no sign of the fungus at work. The fact that the plastering extended down to the floor under the wainscoting and that the back was sealed up was also most favorable for the development of the fungus along the wooden partition, since here was an enclosure that prevented its damp atmosphere from readily drying out during the dry weather. Lastly, the slight space between the back of the wainscoting and the plastering furnished a most admirable place for the rapid development of the fungus along the wall.

Character of the fungous growth. The fungus consists of three parts: (a) the mycelium, which penetrates into the tissues of the wood, and causes its decay; (b) sterile mycelial strands that develop on the surface of the boards, on the protected side, and serve as a means for rapidly spreading the fungus from one point to another; and (c) the fruiting stage, formed by a luxuriant development of fertile hyphae into special bodies bearing the spores, or reproductive bodies, on their surface. The mycelium consists of branched microscopic threads that penetrate into the wood between and into the cells, and, according to Hartig, dissolve out the coniferin and cellulose of their walls, which causes the cells to become very fragile. In fact, in time the wood may crack up into little areas as it dries out, and eventually is easily crushed into a fine powder between the fingers. The mycelial strands are usually in the shape of a flat mat, with meshes of irregular size and shape (see Plate XXVII, b). Where the fungus showed prominently on the exterior of the woodwork, these flat strands thickly covered the under side of the boards and even the plastering, as shown in Plate XXVII, a. They have a greyish color, and a growing margin of a whitish, fluffy texture, as shown on the wall in the same illustration. In some cases, especially on the ground, or where the conditions for growth were limited, the sterile mycelium, instead of forming a mat, took the shape of cords or strands, and these often grew for a considerable distance. Such strands, by creeping through obscure or inaccessible places, under the sills, etc., offer a very dangerous means for spreading the fungus to other portions of the building. When the moisture conditions of the room became favor- 
able during the very wet weather of June, the fungus began to show its presence by emerging between the boards of the wainscoting and around the woodwork of the closet and the swinging door, and developing its fruiting stage. This outgrowth was quite conspicuous, and appeared very rapidly (see Plate XXVI). The growth at first was a fluffy mat of the white mycelium, which, after appearing in the cracks, spread out on either side for an inch or two in width and for a much longer distance along the crack. While these immature fruiting mats when fresh were an inch thick, when dried out they became quite thin and leathery. At first they were white, and without folds; but soon they began to turn a reddish brown, due in part to the formation of the colored spores. Where they had a chance to fully mature, their surface became sculptured with irregular folds or corrugations, or sometimes with flat, tooth-like projections, after the usual manner of the fructification of the genus. Plate XXVIII shows at a some of the immature fruiting bodies on a piece of the wainscoting, while at $b$ the mature fruiting bodies are shown.

Damage caused. The rapidity with which the fruiting stage of the fungus developed during the favorable weather of June is shown in Plate XXVI. The growth as shown in $a$ had all been scraped off a week or so before this photograph was taken, while $b$ shows the condition just twelve days after the first photograph was made. The fungus was so prominent at this time, and its injury so great, that the trustees of the church decided to remove all the infected woodwork. Many of the boards of the wainscoting were very badly rotted, while others were so badly infected that it was only a question of time before they would be in the same condition. There was danger, too, of the fungus spreading to the remainder of the woodwork, and even above into the church proper. European writers mention cases where the fungus, starting in a wet basement, has spread up into the second story even when that part of the building was dry. The fungus can do this easily by means of its long sterile strands, which also carry food and moisture for its development. Often this moisture is given off, and wets surrounding objects, as the plastering in the present case in one place well up on the wall. On account of this characteristic, the specific name lacrymans (weeping) has been given to 
the fungus. The actual damage in the present case was perhaps less than one hundred dollars, but there was also the danger of possible future attacks, which might be even more serious, especially if the fungus worked into the main part of the church.

Preventive measures. At the suggestion of the writer, all of the infected woodwork was cut out, and even the plastering and laths were removed where the fungus showed. The lower boards on the sealed side of the furnace room were also taken off to allow a circulation of air between the partitions. All the infected material was destroyed, and the basement was also cleaned of all rubbish. The drainage was carried away from the walls of the church to keep these from becoming damp. On July 2Ist, after the diseased wood had been removed, the writer thoroughly sprayed the ground, plastering, and boards near where the fungus had been at work, using water containing two per cent. of formalin and two per cent. of carbolic acid. This was done in order to kill any scattered spores or superficial mycelial strands that might have escaped notice. That this spray was effective against exposed mycelia was shown by spraying part of a badly infected board. This was then sawed in two, and the sprayed and unsprayed pieces were placed for some time in a moist chamber. The sprayed half never made any growth of the fungus, except a slight development on the cut end of the board from the deeply imbedded fungus threads. On the unsprayed board, however, the fungus developed abundantly.

The partition has not yet been replaced, being left out to see if the fungus will develop any further. At this date (March I5th, I907) it has showed no signs of reappearing. 


\section{ROOT ROT OF TOBACCO, \\ Thiclavia basicola (B. \& Br.) Zopf. \\ GENERAL CONSIDERATION OF THE TROUBLE.}

Discovery of the trouble in Connecticut. During the past season a serious root disease of tobacco has been prevalent in certain seed beds and fields in this state. While probably not an entirely new trouble, it certainly has not heretofore attracted any special attention among tobacco growers. Neither has the fungus [Thielavia basicola (B. \& Br.) Zopf] causing it been previously reported on tobacco by the botanists of this station, though Thaxter in I89I found it causing serious injury to violets. Mr. Shamel, of the United States Department of Agriculture, who is coöperating with this station in a study of the improvement of tobacco by selection and breeding, was the first to report it on this plant in the state. In an interview with Mr. Shamel printed in the Hartford Daily Courant of May 28, 1906, attention was called to the serious injury caused by the root rot in the tobacco beds of the Connecticut valley. It was also stated in this article, apparently from personal observations, that this disease had proved a very serious pest in $\mathrm{Cuba}$, and had spread to an alarming extent all over the tobacco-growing districts of America. Mr. Shamel strongly recommended sprinkling the seedlings, in seed beds showing the trouble, with formalin. In view of this serious report, which was partially copied in a number of papers over the state, and because of its especial interest in the tobacco industry, this station, through its director and botanist, made a careful study of the diseased seed beds and the fields during the remainder of the season. There is given here a complete report of this investigation.*

History elsewhere. The fungus responsible for this trouble was first described from England by Berkeley and Broome in 1850 . They reported it as a probable parasite on the base

* A preliminary report (6) of the investigation was made by the Director and the Botanist in Bulletin of Immediate Information, No. 4, of this Station. 
of the stems of peas and another plant. Zopf, of Germany, in 1876 , however, was the first to give a complete account of the different stages of the fungus. He found it injuring the roots of a species of Senecio, and some years later also on the roots of a number of leguminous plants. Thaxter was the first to report the fungus from America, having found it, as previously stated, on the roots of violets in this state. Peglion was apparently the first to find the fungus injuring tobacco. In 1897 he made a report of injury to the roots of tobacco in the fields of Italy. He thought that the waterclogged condition of the soil was in part responsible for the serious injury done by the fungus. Selby, of the Ohio Experiment Station, was the first to find the fungus on tobacco in the United States, having seen diseased specimens from seed beds as early as 1899 .

Nature of the fungus. There seems to have been doubt in the minds of some of the investigators as to the exact parasitic nature of the fungus. In the first place it belongs in a family of fungi that consists chiefly of saprophytic forms, having a few weak parasites. The other two species that have been placed under the genus Thielavia are both saprophytes, one having been found on dung and the other on dead stems of Carduus. The fact that the fungus occurs on the roots also tends to obscure its true nature and apparently at times to induce a saprophytic existence.

Berkeley (2) said of the fungus: "It is either destructive of the plant on which it grows or is developed on it in consequence of previous disease." Zopf (24) considered it a true parasite producing characteristic injuries to the roots, which he called "Wurzelbräune." Sorauer (I7) concluded that it led a saprophytic as well as a parasitic existence, as he found it developing on certain leafmolds, and he also stated that it might occur in the soil at times without doing injury to the roots of plants grown there. Peglion (9), as we have already stated, thought that unfavorable conditions for root development, a water-clogged condition of the soil, influenced its attack on the field tobacco in Italy. Selby (13) while noting that the fungus caused evident injury in the seed beds, stated that "the field development of the trouble remains open for study with us." Aderhold (I), who made some infection experiments, failed 
to infect Begonia semperflorens, though his cultures originally were obtained from a diseased Begonia, but he did succeed with several other species. He was able in these cases, however, to produce the disease only at the crown of the plants. This seems peculiar since with tobacco it is the rootlets that were found most injured. It is quite probable, however, that if infection experiments were carried on with seedlings that the roots would be readily infected. Aderhold agrees with Sorauer that the fungus becomes an aggressive parasite only under certain favorable conditions. Shamel (I5) evidently considered it a very injurious and aggressive parasite.

In Connecticut some of the growers were inclined to regard the fungus as only an incidental, or at least a secondary, factor in the root rot of the tobacco, especially of that in the fields. After an extended study of the subject the writer has no doubt of the parasitic nature of the fungus under certain conditions and believes that it was directly responsible for the serious injury in the seed beds this year. Whether or not the very conspicuous trouble in certain of the tobacco fields of Suffield was primarily and chiefly due to it is not so easily settled in our mind, though there is no doubt that it was at least partly responsible. In any case the development of the fungus and the consequent injury to its hosts depends largely on certain environmental conditions (nature of soil, moisture, etc.) which will be discussed later.

Hosts and distribution. In order to determine how common this fungus is and how large a number of plants it has for hosts, the writer made a rather careful examination of the literature of the subject and also sent inquiries to a number of men who would be most likely to know of its presence in the various tobacco districts in the United States, Cuba and Porto Rico. As a result of this search no one was found who had observed the fungus (based on microscopic examination) on tobacco plants in Cuba, Porto Rico, Kentucky, North Carolina, South Carolina, West Virginia, Pennsylvania, Tennessee, Florida, Texas or Wisconsin. This does not mean necessarily that the disease does not exist in any of those states but simply that no reliable information is yet at hand for stating positively that it does. So far, then, the fungus has been found on tobacco only in Italy, Ohio and Connecticut, but we have reason to 
believe that it also occurs in Massachusetts and possibly in South Carolina. If it occurs in Cuba, the experiment station there, at least, is entirely ignorant of its presence.

All of the hosts and localities, with the authorities for the same, so far noted, are as follows: Aralia quinquefoiia, Ginseng, Ohio (Selby) ; Begonia rubra, Ohio (Selby); Begonia sp., Germany (Aderhold); Cochlearia Armoracia, horseradish, Kazan, Russia (Sorokin) ; Cyclamen sp., Germany (Sorauer); Lupinus albus, Halle, Germany (Zopf); Lupinus angustifolius, Halle, Germany (Zopf) ; Lupinus luteus, Halle. Germany (Zopf); Lupinus thermis, Halle, Germany (Zopf); Nemophila auriculata, King's Cliffe, England (Berkeley \& Broome); Nicotiana Tabacum, tobacco, Italy (Peglion, Cappelluti-Altomare), Ohio (Selby), Conn. (Shamel, Clinton); Onobrychis Crista-galli, Halle, Germany (Zopf); Pisum sativum, pea, King's Cliffe, England (Berkeley \& Broome), Halle, Germany (Zopf), Gembloux, Belgium (Marchal); Senecio elegans, Berlin, Germany (Zopf) ; Trigonella caerulea, Halle, Germany (Zopf) ; Viola odorata, Conn. (Thaxter).

Besides the above host Aderhold, by means of artificial inoculations, infected Scorsonera hispanica, Daucus Carota, Beta vulgaris and Apium grazeolens slightly and Phaseolus vulgaris more prominently. There is also some indication that the fungus attacks somewhat some of the weeds in the tobacco beds in Connecticut. These references show that the fungus has a wide range of hosts, which are widely scattered among the different families of flowering plants, but that, so far as reported, those of the leguminose family are most generally attacked.

Structure of the fungus. The mycelium or vegetative part of the fungus consists of hyaline, septate, branched threads that penetrate into the tissues of the root eventually causing their death. The mycelial threads are of rather narrow diameter, chiefly 3 or $4^{\prime} \mathrm{r}$ and their branches are usually formed near the apex of a cell, the branch being cut off by a septum at its base, as shown in Fig. I4, a. The mycelium developed externally on the hosts soon becomes slightly tinted and eventually gives rise to three kinds of spores, or reproductive bodies. Zopf (22) in his original article described a fourth kind of spores (stylospores or spermatia in pyenidia), but as 
he did not mention these in his later article, and as others have not described them, it may be that he was mistaken about their being connected with this fungus. The writer, at least, has not seen them, but all of the other kinds were found on the diseased tobacco roots.

The first kind of spores formed are called endospores, Fig. I4, c, because they are formed inside a special thread of the mycelium. This special endospore case is formed terminally on

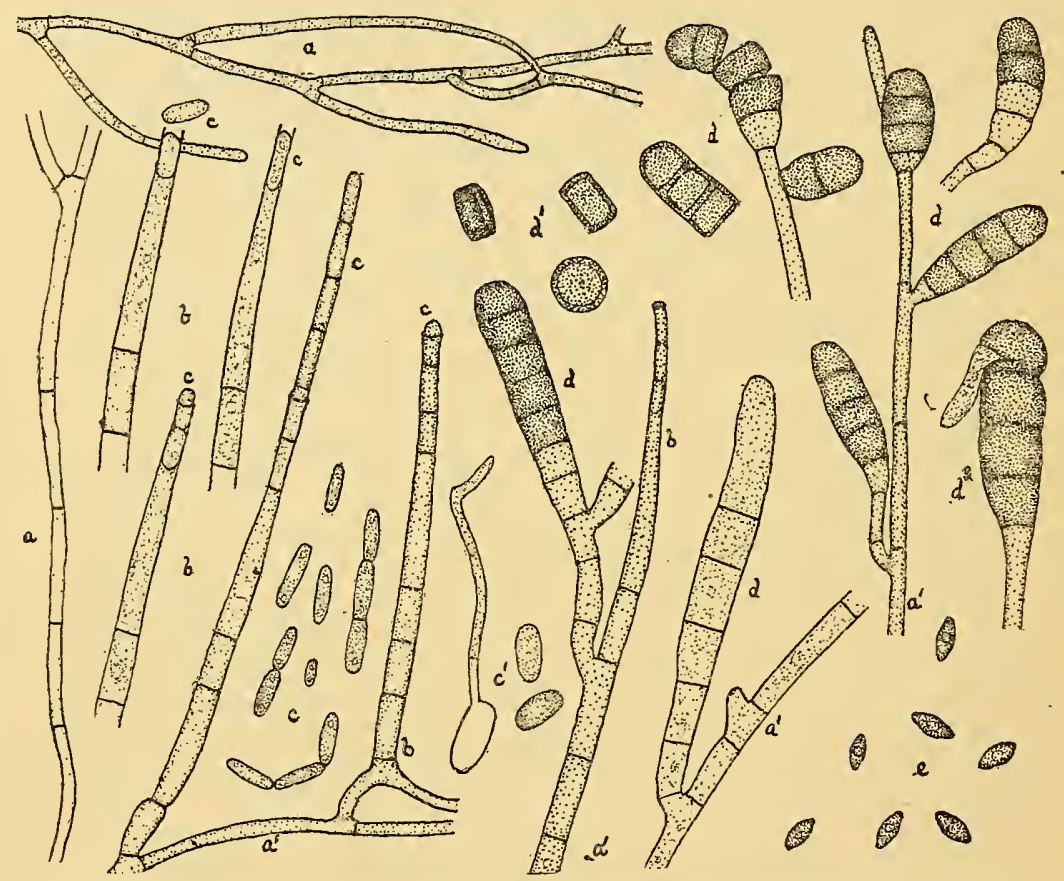

FIG. I4. $a$, mycelium ( $a^{1}$, fertile) ; $b$, endosporous threads; $c$, endospores ( $c^{1}$, germinating); $d$, chlamydospores ( $d^{1}$, fragmenting, $d^{2}$, germinating); $e$, ascospores.

the thread or on terminal, somewhat clustered branches. It has a slightly swollen base, usually with several short basal cells, and a long tapering terminal cell. The endospores are gradually formed in the apex of this terminal cell in a basipetal manner and are pushed out of the ruptured end by the growth of the unfragmented protoplasm of the base. Usually these fertile threads are slightly tinted but have very thin walls, so that it is 
often necessary to use the highest powers of the microscope to determine that the spores originate internally in the thread and not by its direct septation. Often one. can see endospores slightly protruding beyond the case and in old specimens examples are found where the case projects beyond the terminal endospores as shown in Fig. I4. In nutrient cultures very often these endospores remain attached in long strings after being pushed out of the case. The endospores are hyalin, thin walled, oblong to linear, and vary in size from Io to $25 \mu$ in length by 4 or $5 \mu$ in width. They have a conspicuous nuclearlike body in either end. Aderhold does not consider the endospores as sporangial spores but rather as conidia.

The second kind of spores formed are the chlamydospores, Fig. 14, d, which are thicker walled, dark reddish brown bodies. They rarely germinate soon after formation and so are in the nature of resting spores and are adapted for carrying the fungus over periods unfavorable for growth. They are borne on the same mycelium as the endospores, often as side branches at the base of an endospore thread. Some writers have considered them as simple spores adhering in chains, but they are more properly considered as compound spores consisting of one or two, rarely three, sterile basal cells and one to seven fertile cells. The basal cells are hyaline or slightly tinted, while the fertile cells are dark reddish brown, thicker walled and eventually separate into pill-box shaped individual cells. As a whole the compound spores are oblong with the terminal fertile cell rounded and sterile basal cells tapering slightly toward the base. The length of the spores, excluding the sterile base, varies from 20 to $50 \mu$ and their width from 10 to $15 \mu$. While these spores are usually formed on the mycelium externally on the root, they are sometimes produced sparingly inside the cells of the root. In this case they resemble the Torula fungus, hence Berkeley's classification.

The third kind of spores are the ascospores, Fig. I4, e. These are dark colored, single celled, lenticular spores about $12 \mu$ in length by $5 \mu$ in width. They are produced in asci, or hyaline sacs, each ascus containing eight ascospores and in turn these asci are enclosed in a special spherical receptacle called the perithecium. While we have found these ascospores common on the older tobacco roots, especially toward the end of the 
season, they were always shed out on the tissues, which indicated that the asci and perithecia were either very fragile or temporary. So far as our own observations go we could not positively assert their relationship to the other spore forms of the root rot fungus, but from their presence and the observations of others there seems to be no reason for doubting this relationship. Though the fungus develops under ground it is well provided with means for its propagation and dispersal through these various spore forms.

Artificial cultures. Aderhold was apparently the first to make pure cultures of the fungus on various sterilized media. The writer has also obtained cultures from diseased tobacco roots. At first some difficulty was experienced in getting any growth of the fungus, either because the spores did not germinate or because this fungus was easily crowded out by bacteria and other fungi. Finally, however, several isolated colonies (possibly from endospores) appeared in a Petrie dish separation culture of acid potato agar in which spores from a freshly diseased tobacco root had been used. From these, pure cultures in test tubes were easily obtained. The fungus grows very readily on potato agar and soon produces an abundance of its endospores and later of the chlamydospores. It forms a slight aerial growth that at first is greyish but with the production of chlamydospores the cultures finally become quite dark colored. So far the ascosporous stage has not appeared in the cultures; but, as very often such stages do not appear in cultures, this is no real proof that it is not a stage of the fungus as declared by Zopf.

These artificial cultures give very favorable opportunity for studying the fungus in detail and for determining points in its life history not easily made out otherwise. For example, the writer has only occasionally seen the endosporous stage on the roots of tobacco and it might easily be entirely overlooked. In the cultures, however, this stage is the first to appear and produces the endospores in great abundance on the surface of the agar, while the chlamydospores are produced chiefly imbedded in the agar, to which it gives a blackish color in time. The endospores germinate readily in drop cultures of potato agar and manure-water but usually fail entirely to germinate in pure water. The fungus also grows readily on sterilized horse dung. These facts seem to indicate that the endospores 
are aerial spores and would develope abundantly in manure piles, thus greatly facilitating the spread of the fungus. Several writers have spoken of finding a whitish growth (apparently an aerial growth of the endosporous stage) at the crown of infected plants, but so far on tobacco we have seen no such growth but have found chiefly the chlamydospores forming a blackish growth occasionally at the crown but chiefly on the roots or rootlets anywhere under ground. As the fungus is still under investigation further details of its structure and life history will not be given here.

Synonomy and relationships. As has been stated, Berkeley and Broome first described this fungus, placing it under the genus Torula because of the Torula-like character of the chlamydospores, which were the only fruiting stage observed by them. Zopf was the first to recognize the endosporous and the ascosporous stages and because of the latter he placed it in a new genus which he called Thielavia. This same year, 1876 , Sorokin (18), of Russia, found the chlamydospores on the roots of horseradish and, thinking the fungus to be a new species, called it Helminthosporium fragile. Sorauer (16), in I886, apparently, was the first to recognize Sorokin's species to be the same as Berkeley's, for this same year Saccardo (II) ignored their identity by placing Sorokin's species under a different genus, Clasterosporium. The correct name of the fungus and its synonony, so far as now known, is as follows:

Thielavia Basicola (B. \& Br.) Zopf. Sitz. Bot. Ver. Prov. Brandenb. 18: IOI-5. Je. 1876.

Torula basicola B. \& Br. Ann. Mag. Nat. Hist., II, $5: 46$ I. I 850 .

Helminthosporium fragile Sor. Hedw. 15: II3. Au. 1876.

Clasterosporium fragile Sacc. Sacc. Syll. Fung 4: 386. I886.

Winter (2I), Zopf (24) and Saccardo (IO) all placed the genus Thielavia under the family Perisporieae of the Perisporiaceae (the latter also including the family Erysipheae, the powdery mildews); but Fisher (4) did not consider the genus at all related to the powdery mildews, as he placed it in the family Aspergillaceae of the Plectascineae. All the writers, 
however, consider Thielavia nearly related to the genera Penicillium and Aspergillus, or the common blue molds. So far only two other species of Thielavia have been reported and in both of these only the ascosporous stage is described by Saccardo. Thielaviopsis is a possibly related genus, though no ascosporous stage is known, as one of its, conidial stages is very similar to the endosporous stage of Thielavia basicola.

DETAILED CONSIDERATION OF THE TROUBLE IN CONNECTICUT.

In the secd beds.

Difference between dampening off and root rot. For years the tobacco seed beds of Connecticut have been injured more or less by dampening off fungi. These dampening off troubles however, are quite distinct from the root rot disease. With the former, the stems of the young plants are attacked above ground by certain fungi which, when soil and air are very moist, may develop on the surface of the beds and on the base of the plants as delicate, whitish, cobweb-like growths. These filaments of the fungus penetrate into the tissues of the stem and induce a soft rot of the tissues which causes the plants to collapse and a further rot of the leaves takes place, especially if in contact with the ground. Thus vacant spots appear in the beds where all the plants have been rotted out; or, when the trouble is not so bad the stand is thinned by the death of a few individuals. Frequently a plant may be attacked, but, through rapid growth or moisture conditions unfavorable for the development of the fungus, escape injury further than a cankered area on the stem. These dampening off troubles are augmented by very damp and cloudy spring weather, and not infrequently are started by lack of skill or care in watering or ventilating the beds. As the fungi are capable of living in the vegetable mold of the soil, they become established in the beds and cause more or less injury each year.

Characteristics of root rot. The root rot fungus, on the other hand, develops almost entirely underground, attacking the roots and underground part of the stem. The tap root, which is prominent in the young plants, is often rotted off close to the stem or there may be a general rotting of the tap and secondary roots, as shown in Plate XXIX. Not infrequently 
severely injured plants form new secondary roots further up on the stem and under favorable conditions partly or entirely outgrow the trouble. Sometimes the roots are only slightly injured, having the secondary roots rotted off near their ends or there are scattered diseased spots that may be finally outgrown, as the fungus does not develop so readily on the larger and harder roots. All of this injury, except rarely a cankered spot on the base of the stem, is hidden from view until the plants are pulled up. When this is done one is often surprised to find how easily the plants separate from the soil, but an examination shows that there were few or no roots to hold the plants to it.

The grower usually first notices the trouble by the plants failing to make normal growth or coming entirely to a standstill. The leaves may show to his critical eye an unhealthy dark green color which he often describes as "black." In time there is a very uneven stand of the plants in the bed due to some plants being more injured than others. Eventually there may be a sickly yellowing of the older leaves. While some of the plants are killed when quite young and others may be carried off later, still it is very remarkable how many of the plants continue to live even when most of their roots have been rotted off. On a bright day this lack of root system becomes evident through the premature wilting of the plants. Later in the season the beds may show considerable improvement, since the plants have had time to develop new roots and the warmer, drier weather is more favorable for their outgrowing the disease.

Extent of the trouble. In order to determine how general the trouble was in the seed beds of the state, the writer, by visits, personal inquiry and correspondence, attempted to locate as many of the infested beds as possible. Such beds were seen at Simsbury, Granby, Tariffville, Poquonock, Hockanum and Portland. In all, however, the disease was definitely located in the beds of less than twenty growers. Often only one of the beds of the grower was seriously injured. No doubt this does not show the complete distribution of the trouble, as some growers are reticent about giving information concerning such diseases. Others may have suffered but slightly from the trouble and so it would easily escape their notice; still others 
may have suffered in ignorance of its real nature, as some growers at first were inclined to lay the trouble to fertilizer burn. All of these infected beds were in the Connecticut valley, the chief tobacco region of the state. Although similar effort was made to find the trouble in the smaller tobacco region of the Housatonic valley, not a single case was found or even heard of in this region.

Loss caused. The disease at its worst practically ruined the beds, as few of the growers would risk planting from such beds. This meant the loss of time, etc., in taking care of the bed, often the purchase elsewhere of healthy plants and frequently a delay in setting out the fields. One grower estimated that this loss to him was equal to one hundred dollars. In other cases growers, who set from beds that did not show the trouble badly, became scared afterwards because the plants did not start promptly, and they plowed these up and reset with plants from uninfected beds.

Experiments tried. (I) Sprinkling seedlings. Mr. Shamel, in the article in the Hartford Courant, was reported as strongly recommending "that upon the first appearance of the pest the remaining plants in the beds must be sterilized with a solution of formaldehyde," of a strength of I to 2000 of water. $\mathrm{He}$ recommended sprinkling the affected beds once a week with the formalin, thoroughly soaking the plants and the soil. $\mathrm{Mr}$. Shamel based this recommendation on some beds he had sprinkled with formalin where the treated plants afterward seemed to make a better growth than those not sprinkled. In view of this recommendation the writer had treated a part of a bed badly infected with the root rot at Portland. This bed was first treated June IIth with formalin of a strength about I to I500. A very thorough sprinkling was given the plants, using at the rate of a gallon to each six square feet of the bed. Altogether the plants were sprinkled with the formalin five

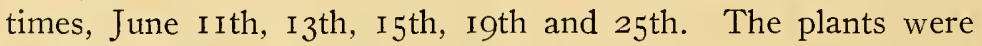
finally examined July Ioth by the writer, and the treated plants did not seem to be any better, more vigorous, or freer from root rot than those side by side that were not treated; neither had the owner noticed at any time any indication of a better growth in the treated part of the bed. 
We also had the opportunity to examine several beds at Hockanum and Simsbury that were sprinkled two to several times under Mr. Shamel's direction, but in no case were we able to find any positive evidence that the sprinkling had been of value in checking the root rot or hastening a healthy. growth of the diseased plants; and two out of the three growers who had tried the experiment reported unfavorably for the treatment. One of the growers, however, thought that the treatment had been of benefit to his beds, but in this case, so far as the writer could determine, this benefit, if any, was not in preventing the root rot, but rather in lessening dampening off of the plants, which is another disease altogether.

From the theoretical side this treatment does not seem to promise much, since the formalin must be used in very weak solution, so as not to injure the foliage or roots when sprinkled on the plants. It is quite possible that this weak formalin might act unfavorably on the very thin-walled endospores of the fungus, but on the thick-walled chlamydospores, which are the common spores on the roots, it is doubtful if such a weak solution would have as injurious an action as it would on the tender root hairs of the tobacco. Then, too, the mycelium of the fungus on the diseased roots is largely within their tissues, and certainly this would not be killed without killing the roots themselves.

Taking all the evidence into consideration, we do not believe that sprinkling beds already showing the disease will be of value in lessening injury from root rot, and we doubt if such treatment will be of any considerable value even if it is begun before the appearance of the rot. Now, in this statement, we do not include the dampening off and stem rot troubles, since in some of the beds having these troubles there did seem to be some benefit derived from the treatment. In these cases, however, the sterile threads of the fungus creep exposed over the surface of the ground and on the plants, and considerable moisture is necessary for their development. If, then, in place of the ordinary water, the weak formalin is used, while it might not kill the fungus threads, it certainly would not be so favorable for their further development. This phase of the subject is discussed under the Stem Rot of Tobacco, page 327 of this report. 
(2) Sterilizing the soil. While the sprinkling method does not appear to the writer to have much value, the use of stronger formalin on the soil, as a disinfectant, before the beds are seeded down did seem to be of value in killing out the root rot fungus, and so exempting the seedlings from its attack. Selby of Ohio has already obtained encouraging results against other soil fungi by such treatment. To test this in a preliminary way, soil from an infected bed was obtained and placed in boxes in the greenhouse. On June 23d, the soil of box I was thoroughly soaked with formalin of a strength of I to IOO of water; the second, with formalin of a strength of $I$ to 200 , and the third, or check, merely soaked with a similar amount of water. After covering for a day to keep in the fumes, the soil was stirred and aired for a week to allow the formalin to escape. The boxes were then seeded with tobacco, and afterward treated alike throughout the test. Root rot did not develop as badly in any of these boxes as it had earlier in the seed bed from which the soil was taken. It did appear in time somewhat prominently in the untreated box. There was also some in the box treated with the weaker strength ( I to 200) of formalin, thus indicating that this treatment was not quite strong enough for practical use. In the box treated I to IOo, while there was a very slight trace of the rot, the treatment practically prevented it. In neither of the treated boxes did the formalin seem to retard germination, or injure the plants afterwards, but instead, these boxes really gave a thicker stand of plants.

From the preceding experiment it seemed probable that thorough treatment of an infected bed with formalin of the strength of $I$ to 100 might prove very useful in preventing the root rot. Consequently part of a badly infected bed at Portland was treated on July Ioth. A thorough soaking was given, using a gallon to every $\mathrm{I} / 2$ square feet. The treated part was covered with sash for a couple of days to hold in the fumes, and then aired for about a week before seeding it and the adjacent untreated strip, which was to constitute the check. The illustration, Plate XXX, a, shows the condition of the treated and untreated plots of this bed on September 5 th. As is seen from this, plants in the treated part were much larger, being large enough for setting out, and there was a thicker and more uniform stand. There was no indication of 
disease to the naked eye. A microscopic examination of the roots showed only traces of the root rot fungus. The untreated plants, on the other hand, revealed some external signs of the trouble, by the dwarfed, darker colored foliage, and an examination of the roots showed the fungus present on all of the plants, in some cases rotting the roots badly. A later examination, on September 24th, still showed the plants in the treated soil superior to those in the untreated; and the owner stated that the difference in weeding the beds had been greatly in favor of the treated part, which indicated that the treatment had been strong enough to kill many of the weed seeds. The only thing that prevents the conclusion that this evident difference between the treated and untreated plants was entirely due to the treatment is the fact that the untreated part of the bed was not soaked down at the time of treatment with an equal amount of water. It is barely possible that the thorough soaking the treated part received was in itself a favorable condition for better plants during the month of July. This month, however, was rather moist, and after seeding the treated and untreated parts were watered alike, apparently as often as needed. Any great amount of water in the soil in the untreated part would have been more favorable for the development of the root rot. Because of this drier condition of the soil, and possibly because of other seasonal conditions, as heat, the root rot was not so bad in this bed as in the spring. Even the dwarfed plants had a better root system, as shown by their not being so easily pulled from the soil. There was no question, however, that the treatment was at least partially responsible for the difference in the condition of the plants.

Based on the above experiment, parts of two other seed beds were treated in the fall to determine the efficiency of this treatment. Another was treated this spring to determine the comparative value of spring and fall treatment. In the fall treatments a very thorongh soaking with formalin, I to I0o, using one gallon to each square foot, was given. It is quite possible that this thorough soaking of the ground in spring, when the soil is naturally moist, will not always allow it to dry out sufficiently for the most favorable growth of the plants, so only $2 / 3$ of a gallon per square foot was used. The results of these experiments cannot be reported until later. 
Besides the sterilization of the soil with formalin, part of a bed in one of the fall treatments was sterilized with steam by means of a steam rake, whose teeth were forced into the soil. Of course the comparative merits of this treatment and the formalin treatment are not yet determined, but in so far as cost and quickness of treatment are concerned, the formalin method without question is far superior. As the result of our various experiments and observations, later in this article, under Preventive Measures, we recommend certain tentative treatments for the prevention of the root rot.

\section{In the fields.}

Effect on the plants. Beside the backset early in the season, which many plants entirely or largely outgrew, there were other cases where the plants made no satisfactory growth the whole season. Examination of the roots showed that the fungus had continued its injurious action here during the season. Such plants usually did not have the normal main and fibrous root system shown in the healthy plant in Plate XXXI, b; but the main roots were more or less rotted off or easily broken when pulled up from the ground, and the development of the fibrous roots and rootlets was very deficient (Plate XXXI, b) or abnormally clustered at the crown. The fungus evidently can work on the young rootlets and the small fibrous roots much easier than on the larger and more woody secondary roots. While it sometimes rotted off the larger roots, it more frequently showed as an encircling banded blackish growth that was apparently doing comparatively little injury. These blackish growths (Plate XXXI, a), in the examination of the washed roots, gave a very good idea of the abundance of the fungus and its probable injury to the plant. So far as was learned, the fungus did not attack any part of the plant above ground, though occasionally plants with black sunken areas were found where the trouble may have had its start from a root rot injury.

Extent of the trouble. In order to determine how general the fungus was in the fields, the writer made a careful examination of forty-six different fields scattered over the state. These were examined chiefly after the tobacco had been cut in the fall. The roots of at least ten plants in different parts of 
each field were pulled up and washed and then examined for the characteristic black spots of the fungus. These tests were verified later by a microscopic examination. Twenty-eight of these fields were in seven different towns in the tobacco region of the Connecticut valley. In all of these fields, except two, the fungus was present, at least to some extent on the roots, thus showing it to be quite general in its distribution in this valley. In two towns in the Housatonic valley eighteen fields were examined, but the fungus was found only in eight of these.

Damage done. In none of the fields in the Housatonic valley was the fungus found in any abundance, and in most of the eight cases only a trace of it was seen on a few of the roots. Neither was there complaint by the growers of any trouble that could at all be attributed to this fungus. So it can be pretty safely stated that in this valley there was no injury this season from the root rot. In at least eleven of the twentyeight fields in the Connecticut valley the fungus was found abundant enough on the plants examined to have caused appreciable injury. In all of these cases conversation with the owners showed that the field as a whole or in spots had not done as well as it should have done. In some cases it was merely a small spot or portion of the field that did not give a normal growth, and an examination of the roots from these places always showed more serious injury by the fungus than in the rest of the field. Serious damage to the fields as a whole, however, was confined chiefly to the region of Suffield, and here the root rot was most abundant. In this town a number of the fields of some of the best tobacco growers did unusually poorly in a year when the crop in general was unusually good. In these fields the tobacco at harvest time was smaller than it should have been and on certain areas made no satisfactory growth through the season and so was practically worthless. The tobacco from these poorest spots often failed to cure down properly in the barns, some leaves still remaining green late in October, when the main bulk of the crop in the same barn was ready to come down. As some of the most seriously injured fields were of considerable size, this short crop meant a serious loss to the growers. According to one 
grower, at least, the quality of this tobacco was not seriously affected.

Secondary factors possibly determining the injury in the fields. Some of the growers, especially with the seed bed trouble, were inclined at first to look upon the injury as a fertilizer burn. There seems to be little ground for this belief as regards the seed beds. Whether or not the presence of more or less of certain of the fertilizers used would stimulate or retard the growth of the fungus is another question not so easily answered. It is not definitely known whether an acid, alkaline or a neutral soil is best adapted to the growth of the fungus, which we know can grow in the soil itself apart from the tobacco root, but it is reasonable to suppose that this factor may have its influence. Neither can we state positively whether or not certain methods of field fertilization (showing in an excess or lack of certain fertilizer constituents this season) had an injurious action on the development of the tobacco aside from, and possibly in the worst fields greater than, the injury that was evidently caused by the root rot fungus. One of the growers whose fields suffered severely was inclined to lay it to the excessive use year after year of potash fertilizers, which gradually accumulated in the soil, and especially to the use of the carbonate of potash. Possibly the use of infected manure may have had a bearing, as this would be favorable for the development of the fungus. No special evidence, however, was obtained along this last line unless it was in the case of one of the seed beds.

A very prominent factor, undoubtedly, is moisture. One grower stated that the worst infected fields in Suffield were those that had been under tents a couple of years previously. If this was generally true, it is possible that the more moist condition of the soil when under the tents gave the fungus a better chance to develop and infect those fields later. A very moist soil seems to be most favorable for the development of the fungus, as the lower or damper spots in the fields usually showed the most trouble. The nature of the subsoil as regards drainage also may have had its bearing, especially early in the summer. The character of the past season no doubt was also an important factor. The cold wet weather of early spring helped along the trouble in the seed beds, particularly when 
they were not properly ventilated. The rainfall* in June and July was considerably above the average, which was no doubt favorable for the growth of the fungus in the fields and may have had its bearing on the fertilizer question.

Future injury? The questions arise, is this trouble likely to occur as seriously in the worst fields another year, and will it grow more injurious in time in the fields where it is at present doing little or no damage? It is not possible to answer these questions definitely, because of the other factors than the mere presence of the fungus in the field that have an influence in determining the injury done. Taking all of these factors into consideration, and the fact that the trouble appeared so suddenly and prominently this year when no doubt the fungus must have been present in the soil, at least inconspicuously, for some time (as it now is in some parts of the Housatonic valley, with no injury to the crop), the writer is inclined to believe that it is not certain that the trouble will appear next year and thereafter with increasing severity. It seems most probable, aside from a certain slight injury each year, that the character of the season will largely determine whether or not serious injury, like that of the present year, takes place. However, it is very desirable for the growers to be well informed regarding the nature of the trouble and to do what is feasible in the way of preventive measures.

Experiments tried in the field. A number of observations were made and a few experiments tried to determine the exact nature of the trouble after plants had been set out in the field, for it was very soon determined that the fungus was present in the tobacco fields even in some cases where the growers had not noticed it in their beds. In these experiments and observations it was aimed to determine three things, namely; (I) Effect of transplanting diseased plants in the fields, (2) Effect of transplanting healthy plants into infected soil, (3) Effect of environment on the development of the disease. We will discuss these points briefly in the following paragraphs.

(I) Effect of transplanting diseased plants in the field. Naturally a grower, when he has a diseased bed, uses only the

* The rainfall at New Haven for June was over 5 inches, giving an excess of considerably over 2 inches when compared with the average for thirty-four years. The excess for July was .68 of an inch. 
best plants from that bed, if he uses them at all. Some growers used plants from diseased beds, and seeing that they did not start promptly, plowed them up. In one case at Portland, a grower used at first the best plants from his diseased bed, and then becoming scared, bought the remainder of his plants. Those used from his own bed in the end made a more satisfactory crop than those he bought, because calico developed badly in the latter. He thought, however, that the plants from the diseased bed did not do quite as well as plants ordinarily did on the land in which they were planted. Another grower at Bushy Hill used plants from his diseased bed, but soon afterward plowed them all up except one row, and reset with plants from a healthy bed. At first the plants in the row that was left did not seem as thrifty as the healthy plants reset later, but at the end of the season they did not appear from a casual examination to be much different, except that they had more calico. In this same field one of the United States Government experts had also set out a row each from healthy and diseased beds. When, through the courtesy of the grower, the writer examined these two rows at the end of the season, the difference between them, if any, was not marked. Likewise some plants from diseased beds set out at Tariffville for the same purpose did not, to the writer, show any marked injury.

The only experiment tried by the writer was on the Experiment Station grounds, with a few plants obtained from diseased beds at Simsbury and Poquonock. These plants were set out in three rows. In the first row the plants were entirely too small for planting, and the roots were very badly injured. Such plants were used because they were the worst that could be obtained. In the second row the plants were in fair shape and almost large enough for planting, but the roots were rotted considerably. In the third row the plants were of fair size and appearance, showing very little rot on the roots, and were such plants as a grower would select as the best from the diseased beds. The plants were set in soil free from the fungus, and on a cloudy day, and were watered at first; but they did not have any special fertilization or cultivation. Unfortunately, soon after they were set out, a heavy rain badly washed the soil over some of the smallest plants in the first row, drowning out a few, so that this may possibly have had some influence on 
their later growth. At the end of the season this test showed the following facts: (a) That very few plants had been killed outright by the root rot. (b) That at first those with badly diseased roots were considerably retarded in growth, since they had to form new roots. (c) That some of the badly diseased plants in the first row made only a very stunted growth during the whole season. Everything considered, those in the second row made a very fair growth, despite the fact that they started with considerable rot on the roots. Those of the third row made the best growth, and were fair plants. (d) The final examination of the roots on October Ist showed that there was then very little evidence of rot on them, even on the most stunted plants, so that evidently the fungus had soon been outgrown; what damage it had caused was that done to the young plants, from which injury apparently in the worst cases they had never recovered. There was no calico on any of the plants. Plate XXXII, b, shows a photograph of a part of these plants taken on October Ist, those in the foreground being in the first row.

From these observations and experiments we may reasonably conclude that because rot appears in a bed it does not necessarily mean that good plants taken from it will produce a poor, or even an inferior, crop. That badly diseased plants will do poorly, especially at first, there seems to be little doubt. That good plants showing some disease, under some conditions will do worse than under others, also seems certain. While we do not advocate the use of plants from diseased beds if others can be obtained, we do think that it is possible under certain conditions of soil, moisture, etc., for the best plants from these beds to do as well as plants taken from a bed not showing the disease. However, the grower in this case must take a risk that they will do as well.

(2) Effect of transplanting perfectly healthy plants in infected soil. As the disease showed in some fields when the plants were obtained from beds supposed to be free from the trouble, there is question whether they became infected in the field. If this were true, the fungus would evidently carry over in these fields from season to season, doing more or less damage as conditions were favorable or unfavorable, since tobacco is grown on the same land year after year. We believe that 
the fungus does become established in the fields in this way. That perfectly healthy plants of the age for setting can become infected when transplanted in infected soil is shown by the following experiment. A grower at Poquonock had a bed that showed the disease prominently, and after the plants were taken from this bed on June $2 \mathrm{~d}$, at our request he set out thirty-nine plants in it, which showed absolutely no sign of the disease on their roots. On July 2oth, see Plate XXXII, a, we examined the roots of a third of these plants, and found more or less root rot on all of them, and in some cases enough to cause considerable injury. The plants were quite variable in size, and not as thrifty as they should have been, but this in part was due to the character of the soil, which was a fine, clay-loam that easily became water-soaked. Later examination showed the disease on the roots of all the plants. I have no doubt that this close, wet soil was favorable for the development of the root rot fungus, since it was the only bed at this place of this character, and the only one in which the root rot appeared.

(3) Effect of environment on development of the disease. We are quite convinced, aside from the presence of the fungus in the soil, that the character of the season (especially the moisture, and possibly unusually cold, wet spring weather) and the character of the soil and subsoil (fineness, liability to become water-soaked, drainage, amount of humus, especially in the shape of manure) have much to do with determining whether or not the fungus does much damage. We have tried growing tobacco in soil from diseased beds and fields in the greenhouse later in the season, but in almost all of these experiments the root rot has not been as bad as it was in the open beds and the fields presumably because the environmental conditions were different. A fine clay soil that easily water-soaks, as in the bed mentioned previously, seems to be one condition favoring the disease, since one of the worst fields seen has a soil similar to this. In another case, the use of a heavy filling of manure beneath the seed bed for artificial heat, coupled with careless watering and ventilating at a critical time, gave what the grower desired, a rapid growth of the plants, but also admirable conditions for the development of the fungus, which soon appeared. To determine the action of fertilizers, a series of tests in duplicate were started late in the fall in crocks in the greenhouse, 
with soil from two diseased fields. So far these tests do not show any marked difference in the amount of rot (which is now present on many of the roots but not doing conspicuous damage), due to using carbonate of potash, high-grade sulphate of potash, slaked lime, acid soil, or no fertilizer at all. There does seem to be more of the fungus in the crocks where manure was used, and in those crocks where the soil was treated with formalin there is no rot at all. The experiment of course is not yet completed, but so far it does not substantiate the complaint made by some growers against injury from artificial fertilizers. The soil was taken from fields of a grower who believed that the excessive use of potash year after year had been responsible for the injury. In these greenhouse tests 450 pounds per acre of carbonate of potash and 600 pounds of high-grade sulphate of potash were used; but as the experiment was not conducted under the same seasonal or field conditions, this might make some difference in the results.

\section{PREVENTIVE MEASURES.}

Danger of infected beds. The common experience of the growers whose seed beds were worst infected was that the trouble had appeared in them last year to a limited extent. This seems to indicate that the fungus, like most other soil fungi, after it has become established in a bed will do more or less injury each year-though no doubt the season and the attention given the bed will influence its development. It seems desirable, therefore, not to use the infected seed beds again for some time when new ones can be conveniently made. Most growers, however, are reluctant to give up their old beds either because of their handy location, the fine condition of the soil or for other reasons. In these cases it will be desirable to use some form of sterilization to eradicate the fungus.

Sterilization of beds. Sterilization of the beds is helpful, not only in preventing or lessening injury by the root rot and dampening off fungi, but it also destroys more or less of the weed seeds and insects. Three methods have been used with more or less success on tobacco and other seed beds: Ist, Burning dry tobacco stalks or other fuel on the beds under a metal cover, which throws the heat down into the soil, has been tried somewhat in this state for destroying weed seeds. It is 
said to be quite helpful in this respect, and it will probably also kill the soil fungi, near the surface of the ground at least. Too hot a fire, however, may burn out the humus of the soil or make plant food less soluble and so do as much harm as good. 2d, Sterilization by steam has been profitably employed against soil fungi and nematodes in greenhouses and hot beds for some time, and is now used in a few cases in this state to kill the weeds in tobacco beds. There is no reason why it should not be as successful in killing the root rot fungus as the other soil fungi. There is on the market a steam rake whose points when forced into a bed carry the steam into the soil from any attached steam boiler. The chief objection to this method of sterilization is the cost of the apparatus and the trouble and time taken in heating the beds. $3 \mathrm{~d}$, Treating the soil with formalin is another method that is coming into use for combating soil fungi. Preliminary tests with this method, as we have already stated, were made the past summer against the root rot fungus in the greenhouse and also in part of one of the badly infected beds, see Plate XXX, a. The results from these tests were so encouraging that we give the following tentative directions for its use:

It is perhaps better to treat the beds in the fall so that they may have a chance to dry out after the thorough soaking they receive. If treated in the spring they should be aired for a week before planting in order to allow the fumes of the formalin to escape and the soil to dry out as much as it will. Whether in fall or spring, the bed should be treated after the tillage is mostly done, for, if cultivated deeply after the treatment, untreated soil containing the fungus may be brought up from below. Commercial fertilizers may be used either before or after the bed is treated, but manure, if used, should be put on before so that it may be sterilized. Use only the strongest formalin, guaranteed 40 per cent. This can be bought in carboys holding about Ioo pounds for Io cents per pound, or a better article in pint bottles at about 40 cents. It is not necessary, however, to get the chemically pure article, but it is necessary to keep the bottles tightly stoppered to avoid loss of strength through evaporation. One pint of this formalin should be added to each twelve and a half gallons of water used, or at the rate of one to one hundred by volume. This 
should be applied immediately to the bed with a sprinkling can so as to evenly and thoroughly wet the soil, using two-thirds to one gallon to each square foot of surface. It may take some time for the soil to soak in the latter quantity, but if applied in partial amount it will soak in while the rest of the bed is being treated. The ground should be covered with the sash or canvas for a couple of days after treatment to help keep in the fumes.

Sprinkling seedlings with formalin. According to our observations and experiments, a very weak strength of formalin (about I to I500) sprinkled several times on the plants in the infected beds did not give very favorable results. So far as the root rot is concerned we do not believe this treatment has much value after the appearance of the disease. As regards the dampening off troubles there was some evidence that this method may have benefited the beds slightly. Possibly if this treatment entirely supplanted the watering throughout the whole season of the beds, it would prove more serviceable, especially against the dampening off fungi.

Treatment of the fields. It is more difficult to advise as to the best treatment of the fields. Of course it is not desirable to use plants from infected beds, if others are available. Care in this respect, as stated before, does not necessarily mean that the trouble will be escaped in the fields. One grower has suggested that it might be well to use formalin in the water (I to I200) when the plants are set out. While it is not likely that this would prove of any great service, it might be worth trial on a small scale, to determine its value. Some form of rotation may be found necessary if the fungus persists in injuring each succeeding crop. One field was seen the past summer, part of which had been in corn the two previous years, and this part, according to the owner, did better than the remainder of the field; an examination of the roots also showed less of the rot there. Where one has reason to suspect that his soil is acid, it might be well to lime part of the field to see if this will prove helpful to the crop. On the other hand, if a grower has been using large amounts of potash (and the growers who used the most were among those whose fields suffered most) it might be well to cut down the amount used on part of his field and carefully compare this part with the remainder of the field 
during the season in order to get data for determining the character of his fertilization another year.

Examination of specimens. During the coming season any grower who suspects he has this trouble in his seed beds or fields is at liberty to send specimens of the plants or the roots to the Experiment Station, at New Haven, for examination. In cases of severe injury or especial interest, inspection of the seed beds or the fields will be made if desired.

\section{LITERATURE.}

The following include all of the references in literature, of any importance, that the writer has found relating to this fungus.

I. Aderhold, R. Impfversuche mit Thielavia basicola Zopf. Arb. Biol. Abt. Land. Fortw. Kaiserl. Gesundh. 4: 463-5. I905. [Review : Centr. Bakt. Par. Infekt. I5: 276-7. 1905.]

Made artificial cultures and inoculation experiments; did not find it a very aggressive parasite in the trials made.

2. Berkeley, M. J. and Broome, C. E. Notices of British Fungi. Ann. Mag. Nat. Hist. II, 5: 46I. I850. pl. II, f. 4.

Describes Torula basicola B. \& Br. as a new species on base of stems of peas and Nemophila auriculata from King's Cliffe, England.

3. Cappelluti-Altomare, G. I semenzai del Tabacco e la Thielavia basicola Zopf. R. Inst. Scafati 1902: 137-47. [Listed: Just Bot. Zahrb. 30: 858. I902.]

Have not seen this reference.

4. Fischer, E. Thielavia Zopf. Engl. \& Prantl Nat. Pflanzenf. ${ }^{1}: 299$. I897.

Describes the genus and gives notes on the single species; places genus under family Aspergillaceae of the Plectascineae.

5. Frank, A. B. Thielavia basicola Zopf. Krankh. Pflanz, 2: 278 I 896.

Gives a short general account of the fungus as taken from Zopf.

6. Jenkins, E. H. and Clinton, G. P. Root-Rot of Tobacco. Bull. Imm. Inform. Conn. Agr. Exp. Stat. 4: I-II. N. Igo6. [Illustr.]

Give a general account of this disease in Connecticut.

7. Marchal, E. In Belgien im Jahre I90I beobachtete pilzparasitãre Krankheiten. Zeitschr. Pflanz. Krankh. I2: 48. Ig02. Ibid, I2: 239. 1902.

Reports Thielavia basicola killing roots of peas grown in water cultures.

8. Orton, W. A. Plant Diseases. Yearbook U. S. Dept. Agr. Igor: 672. 1902. Ibid., 1903: 554. 1904.

Reports Thielavia basicola injurious in tobacco seed beds in I90I and in 1903 in Ohio seed beds. 
9. Peglion, V. Marciume radicale delle piantine di Tabacco, causato dalla Thielavia basicola Zopf. Atti Reale Accad. Lincei V, 6: 52-6. 1897. [Reprint: Centrb. Bak. $3^{2}: 580-3$. 1897.]

Gives literature, botanical description of fungus, and records injury in tobacco fields of Italy, where water-clogged condition of soil favored the development of the fungus.

10. Saccardo, P. A. Thielavia basicola Zopf. Sacc. Syll. Fung. I: 39. I882. Torula basicola. Ibid., 4: 257 . I886.

Describes these as distinct species but notes under former that the latter is a conidial stage of it.

II. Saccardo, P. A. Clasterosporium fragile (Sorok.) Sacc. Sacc. Syll. Fung. 4: 386. 1886 .

Places Sorokin's Helminthosporium fragile under Clasterosporium.

12. Selby, A. D. Diseases caused by Nematodes. Bull. Ohio Agr. Exp. Stat. 73: 228. I897.

Found Thielaria basicola on roots of greenhouse begonias along with nematodes.

I3. Selby, A. D. Root Rot (Black Root). Bull. Ohio Agr. Exp. Stat. 156: 95-7. 1904. [I1lustr.]

Gives a short account of fungus and reports it in Ohio injuring tobacco seedlings.

I4. Selby, A. D. Soil Treatment of Tobacco Plant Beds. Circ. Ohio Agr. Exp. Stat. 59: I-3. O. I906.

Gives suggestions for treatment of root rot based on experiments used with success against the Rhizoctonia fungus.

15. Shamel, A. D. Another Blight strikes tobacco. Hartford Daily Courant. $28 \mathrm{My}$. 1906.

Reports Thielavia basicola as causing serious injury to seedbeds of tobacco in the Connecticut valley; recommends sprinkling diseased plants with weak formalin.

16. Sorauer, P. Thielavia basicola Zopf. Handb. Pflanzenk. 2: 333. I886.

Gives short note on fungus and gives Helminthosporium fragile Sor. as a synonym.

I7. Sorauer, P. Ueber die Wurzelbräune der Cyclamen. Zeitschr. Pflanz. Krankh. 5: 18-20. 1895.

Gives account of injury to roots of Cyclamen by Thielavia basicola.

I8. Sorokin, N. Ueber Helminthosporium fragile sp. n. Hedw. I5: II3. Au. I876. [Illustr.]

Describes the chlamydospores found on horseradish roots in Kazan Bot. Garden as a new species.

19. Thaxter, R. Fungus in Violet Roots. Ann. Rep. Conn. Agr. Exp. Stat. I891: 166-7. I892.

Reports this on violet roots in Connecticut, being first report of the fungus in America. 
20. Tubeuf and Smith. Thielavia basicola Zopf. Diseases of Plants: I82-3. I897.

Give a short general account of the fungus.

21. Winter, G. Thielavia. Rab. Krypt. Fl. $\mathbf{r}^{2}:$ 53. I887. [Illustr.] Gives scientific description of genus and the single species $T$. basicola, with short general account of injury by latter.

22. Zopf, W. Thielavia Zopf. Genus novum Perisporiacearum. Sitz. Bot. Ver. Prov. Brandenb. ı8: I0I-5. I876. [Reprint: Hedw. ı6: II $4-7$. 1877.]

Describes this genus as new, placing Torula basicola B. \& Br. under it as its only species; describes four spore forms.

23. Zopf, W. Thielavia basicola Zopf. Die Pilze: 9I. I890. Have not seen this reference.

24. Zopf, W. Ueber die Wurzelbräune der Lupinen eine neue Pilzkrankheit. Zeitschr. Pflanz. Krankh. i: 72-6. I891. [Illustr.]

Gives extended account of this fungus previously described by him and a list of plants which he found it injuring. 
PLATE XVII.

Apple.
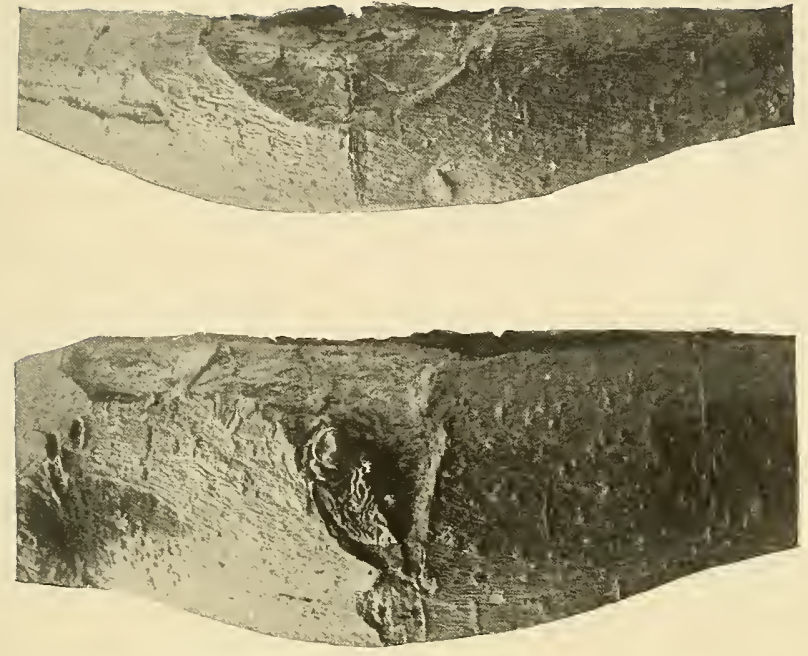

a. Combined Winter and Canker Injury, p. 3 IO.

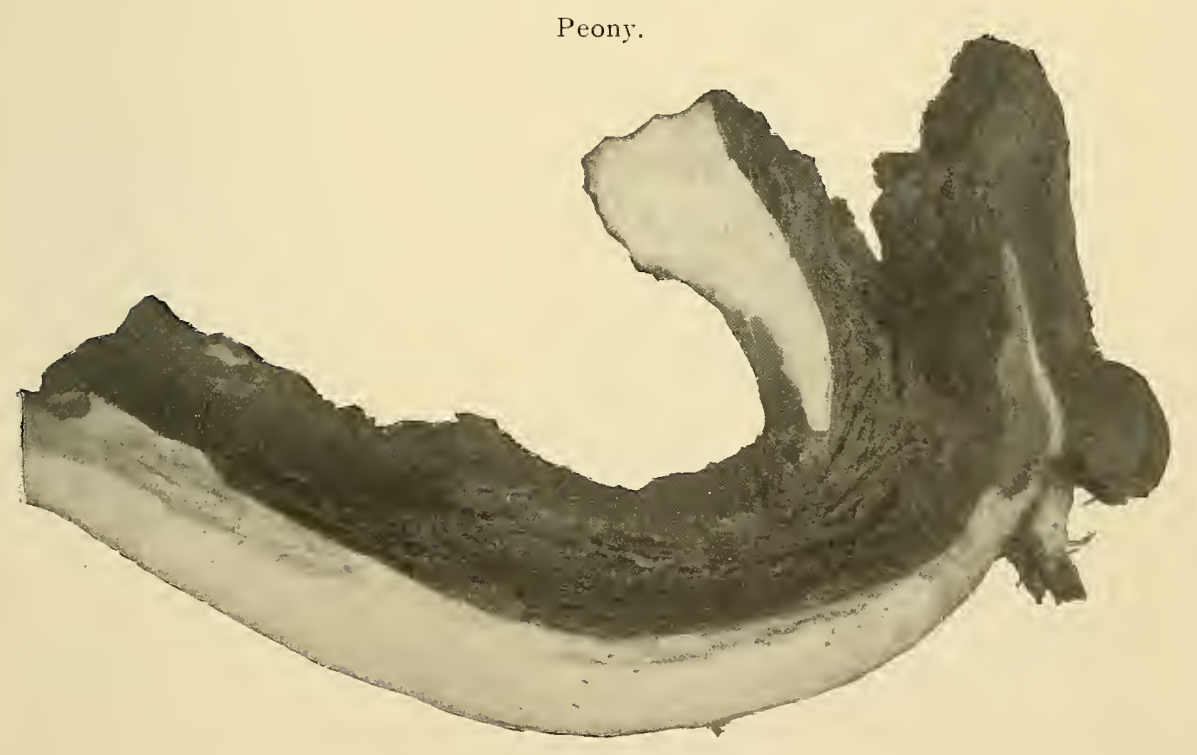

b. Root Injury or Rot, p. 318.

DISEASES OF APPLE AND PEONY. 

Raspberry. $\times 2$.

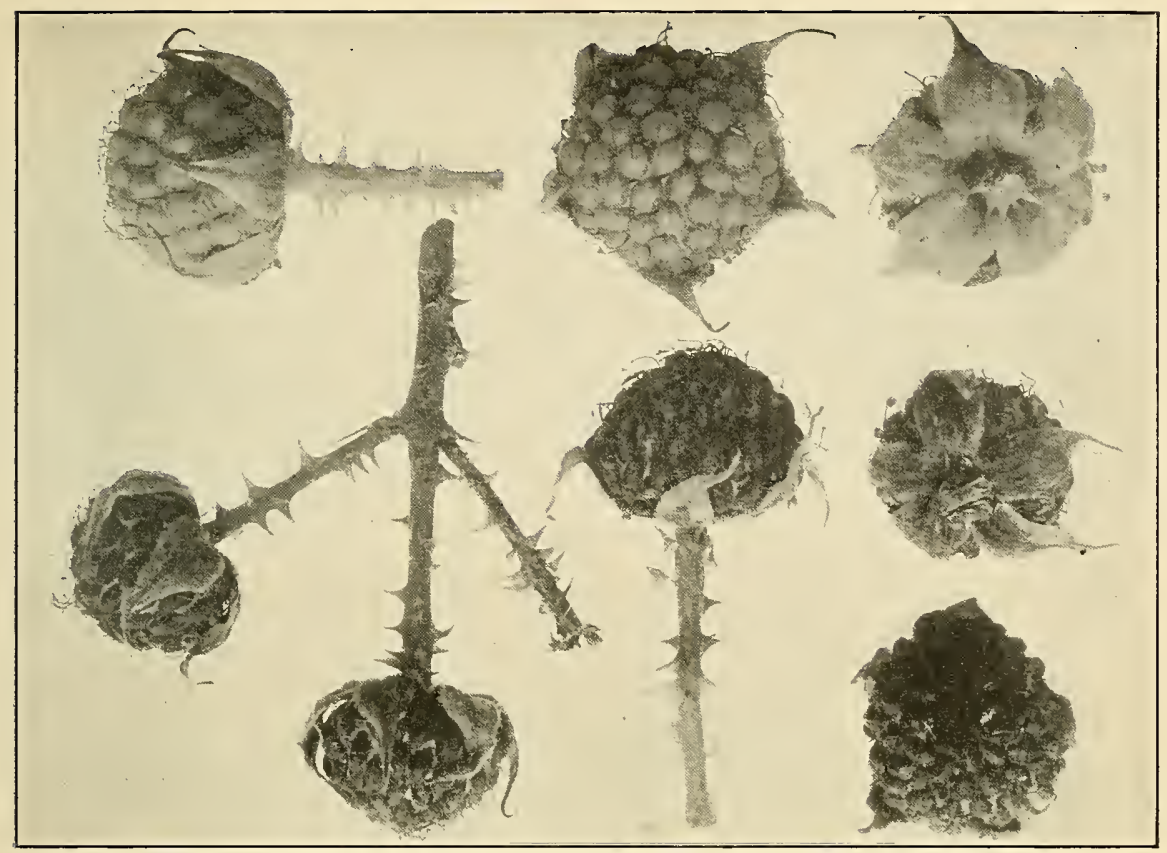

a. Wilt of fruit, showing upper healthy and lower diseased, p. $32 \mathrm{I}$.

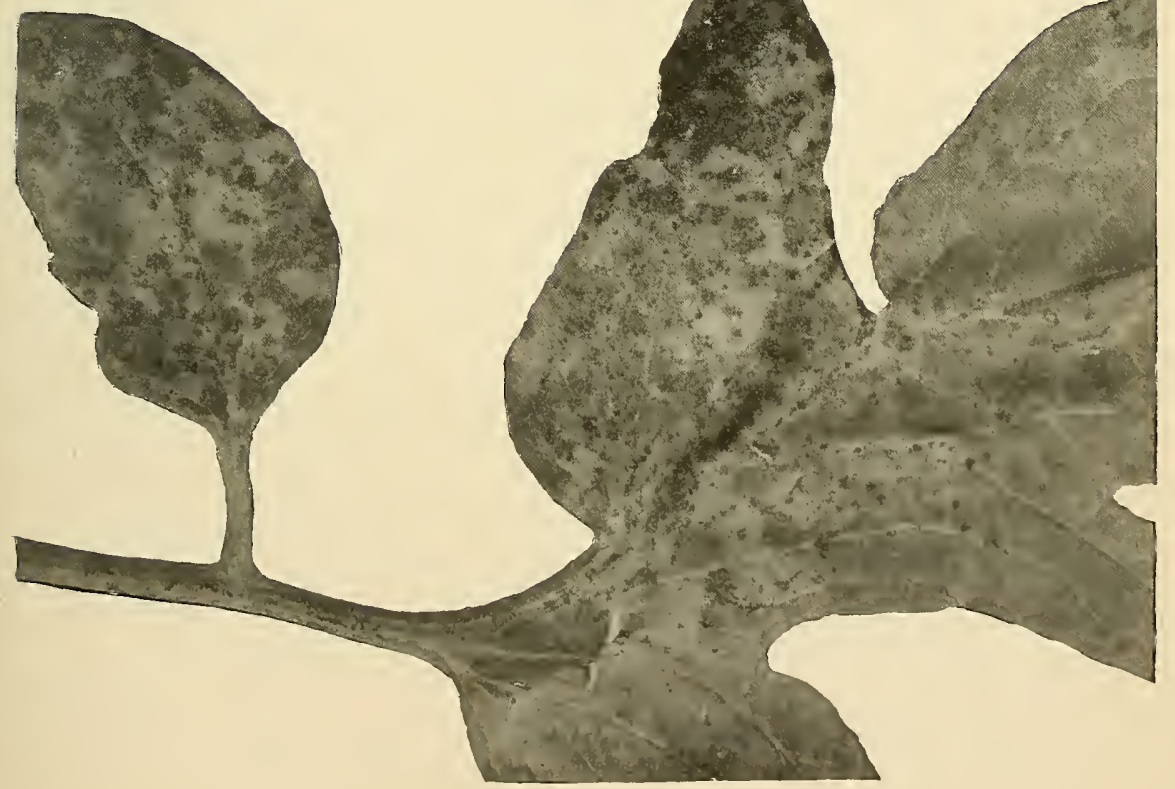

b. Black Mold, p. 329 . 

PLATE XIX.

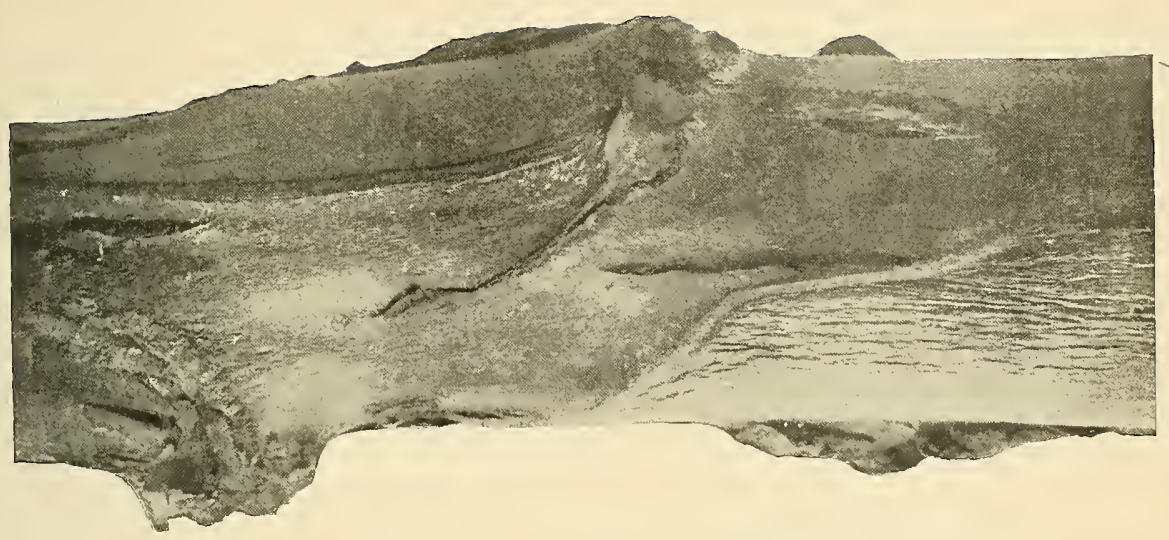

a. Cankered area extending on stem from ground upward.

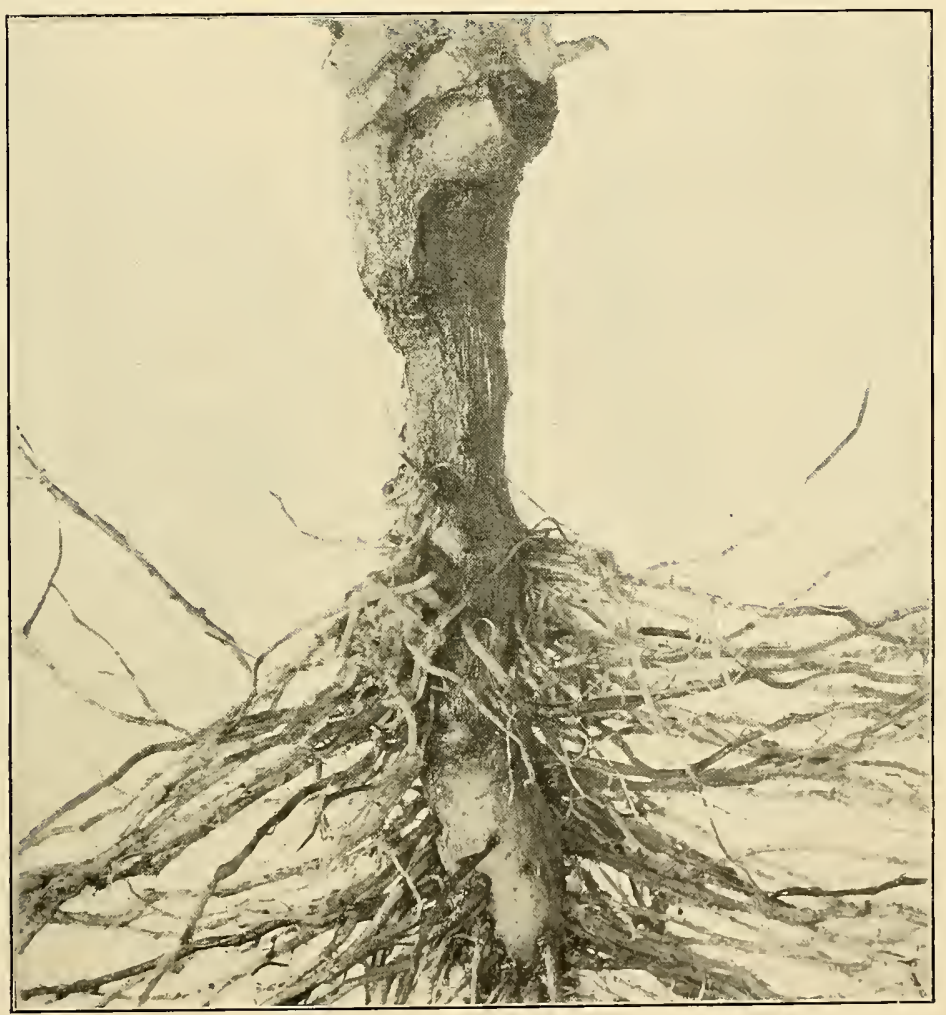

b. Stem girdled under ground.

CANKER DISEASE OF TOBACCO, p. 325. 

PLATE XX.

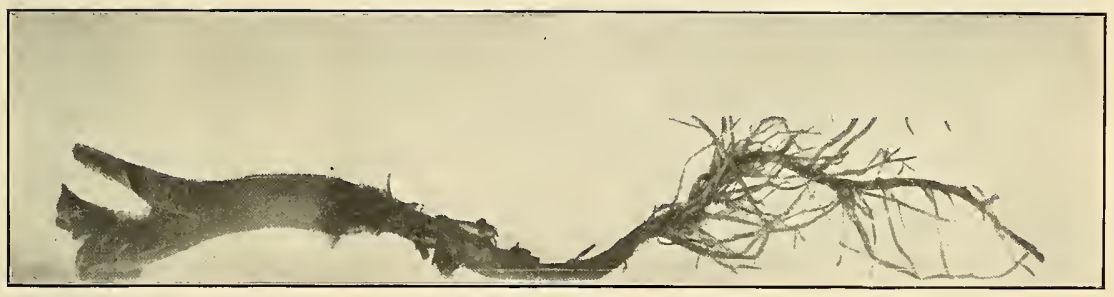

a. Showing rot of stem just above ground.

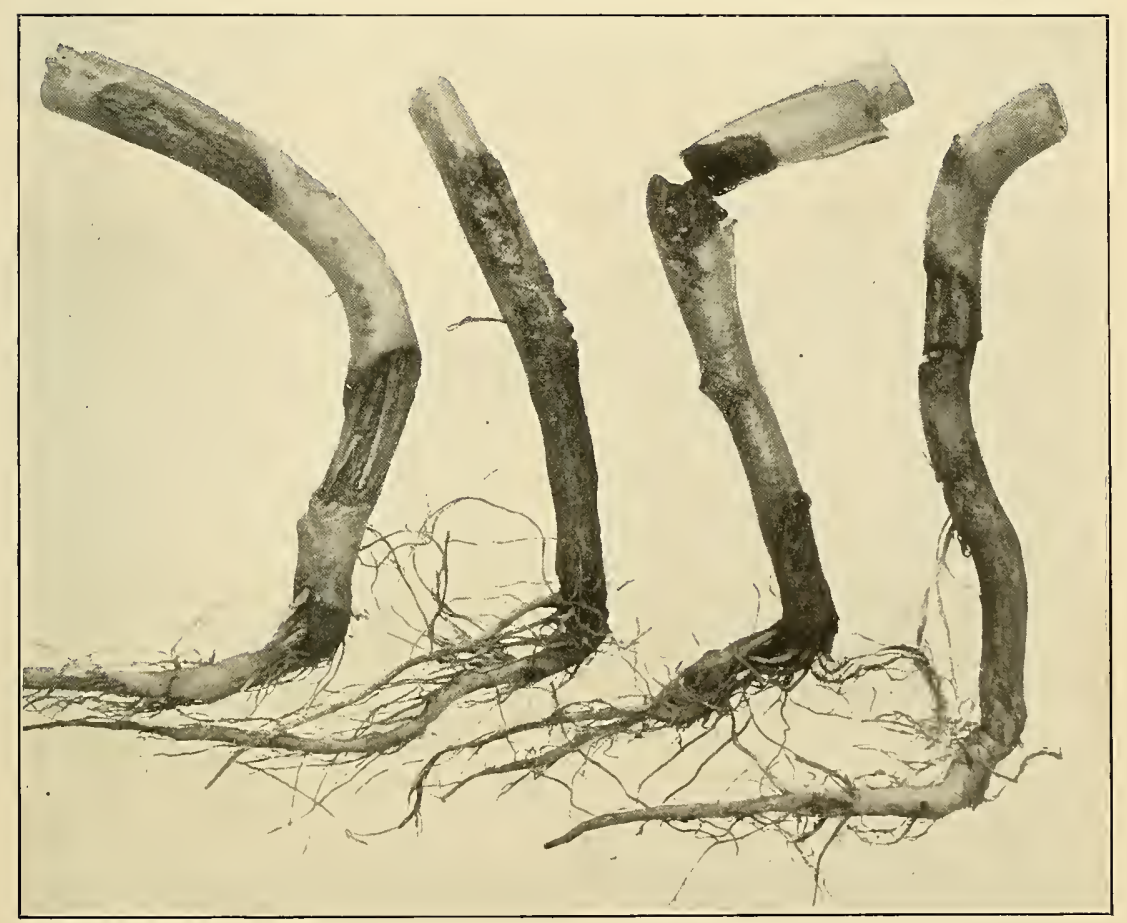

b. Showing cankered spots on older plants.

STEM ROT, Sclerotinia sp., OF TOBACCO, p. 326. 



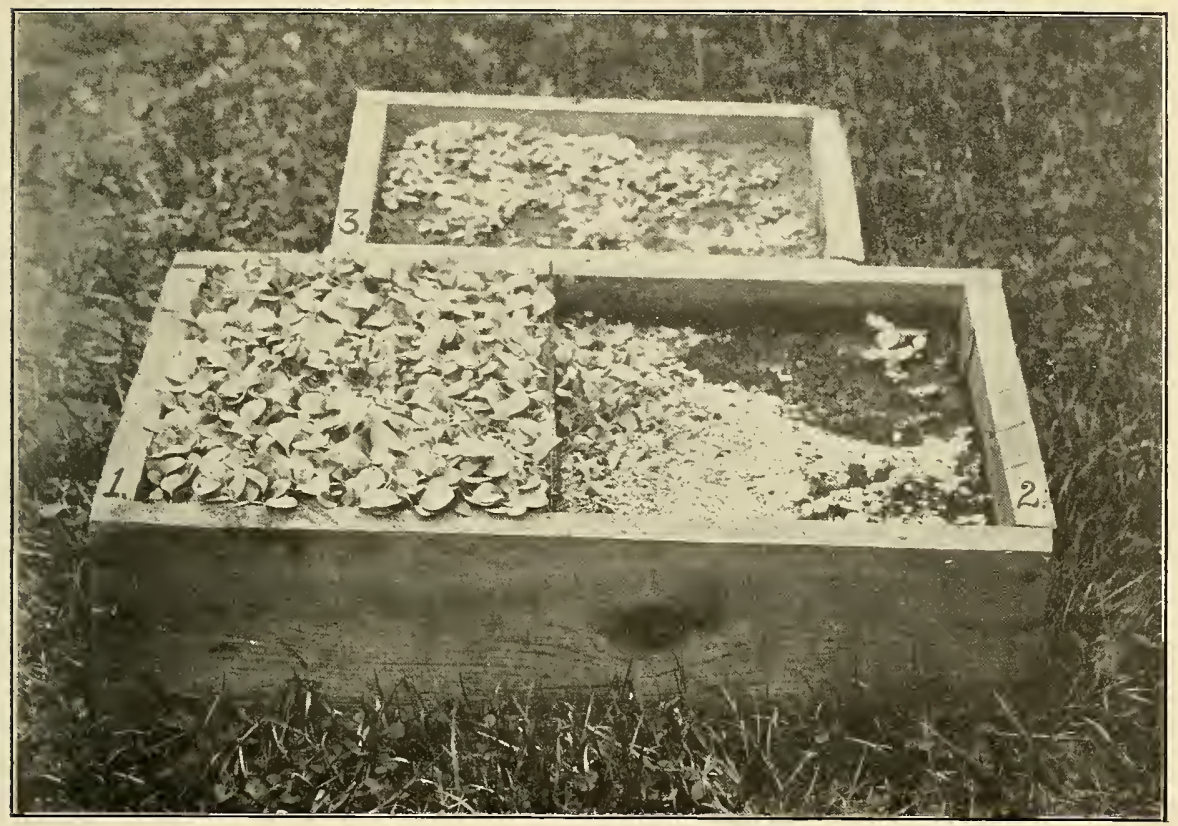

a. Effect of treatment in preventing Stem Rot fungus, p. 328.

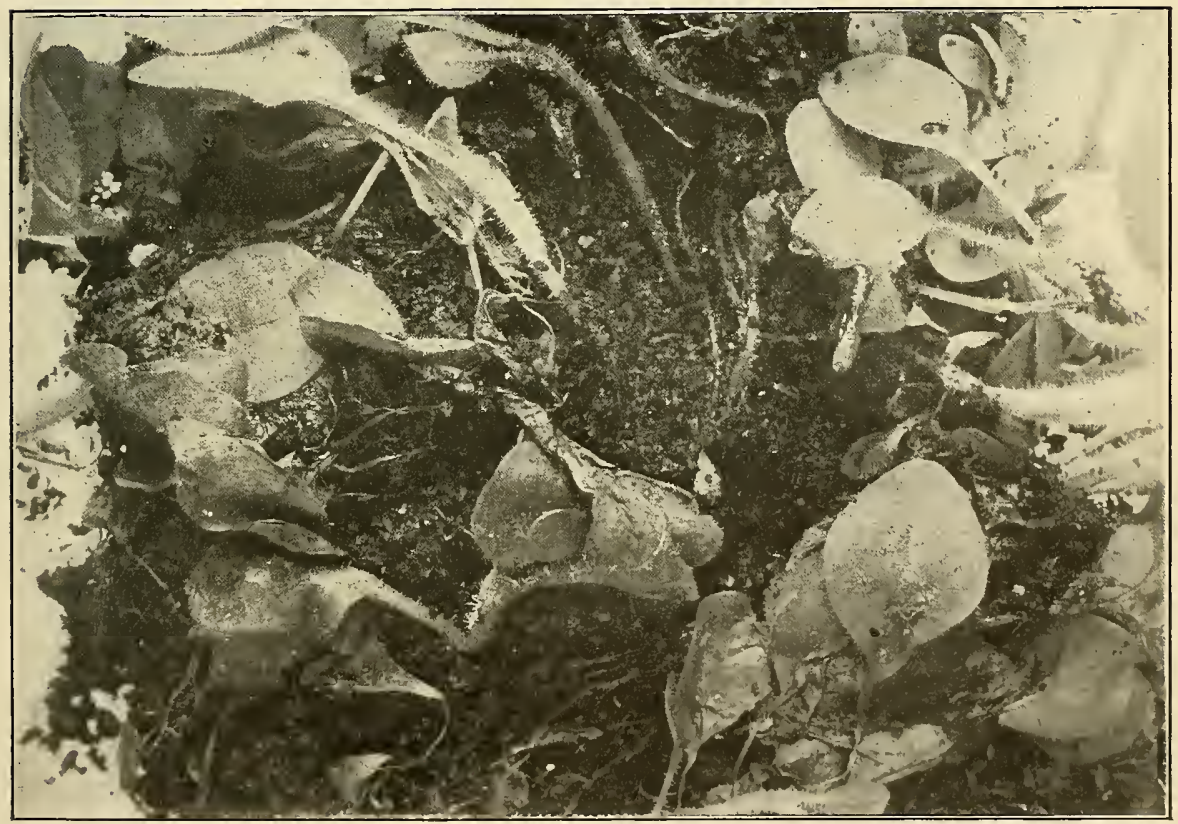

b. Dampening off fungus at work among young plants, p. 326.

FUNGI OF TOBACCO SEEDLINGS. 

PLATE XXII.

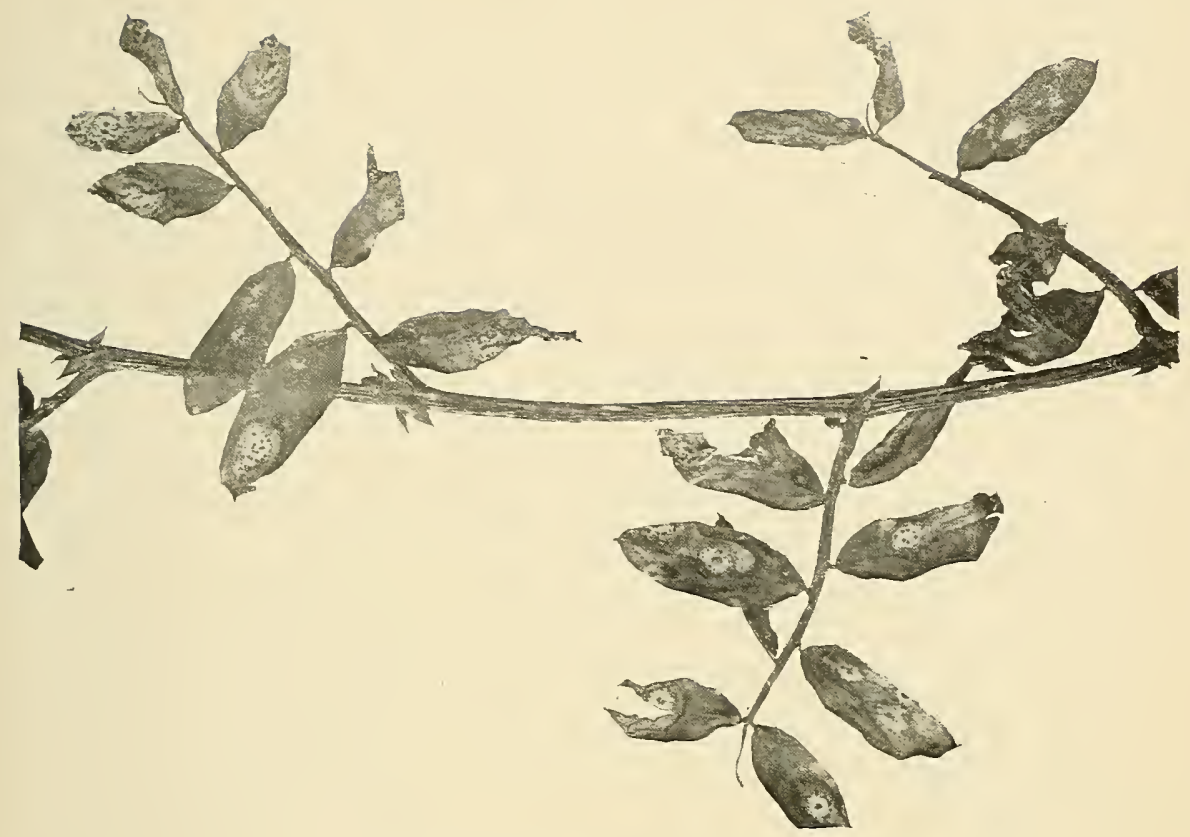

a. Leaf Spot of Russian Vetch, p. 330.

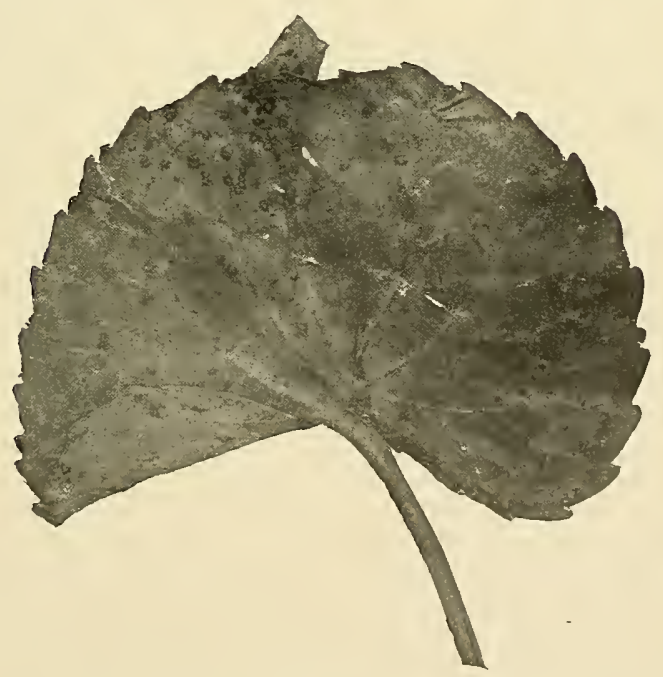

b. Speck Anthracnose of Violet, p. 33I.

FUNGI OF RUSSIAN VETCH AND VIOLET, $\times 2$. 



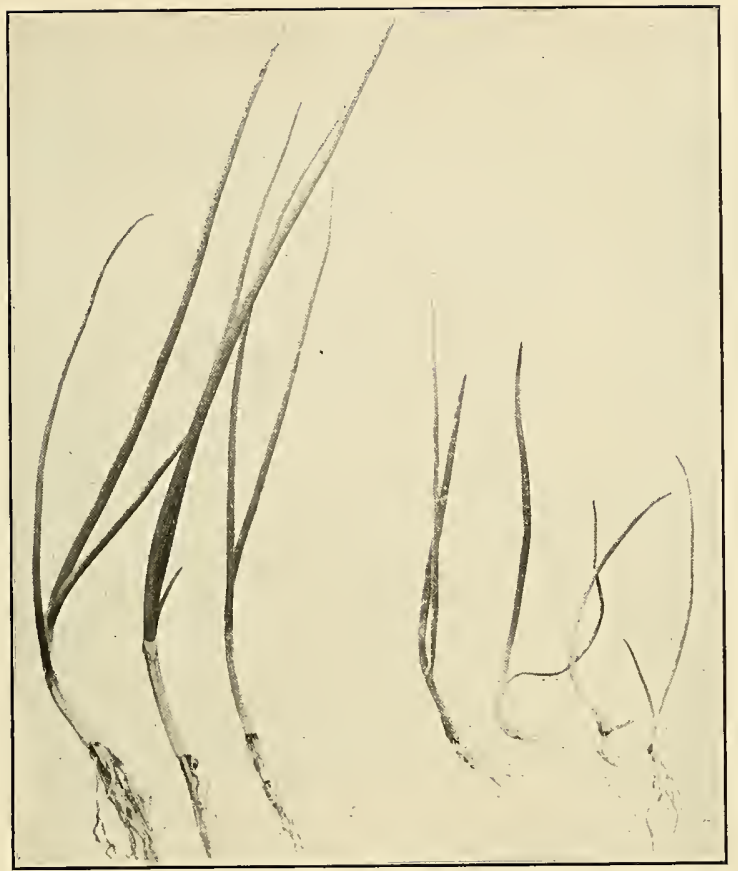

a. Effect of disease on size of seedlings, p. 334 .

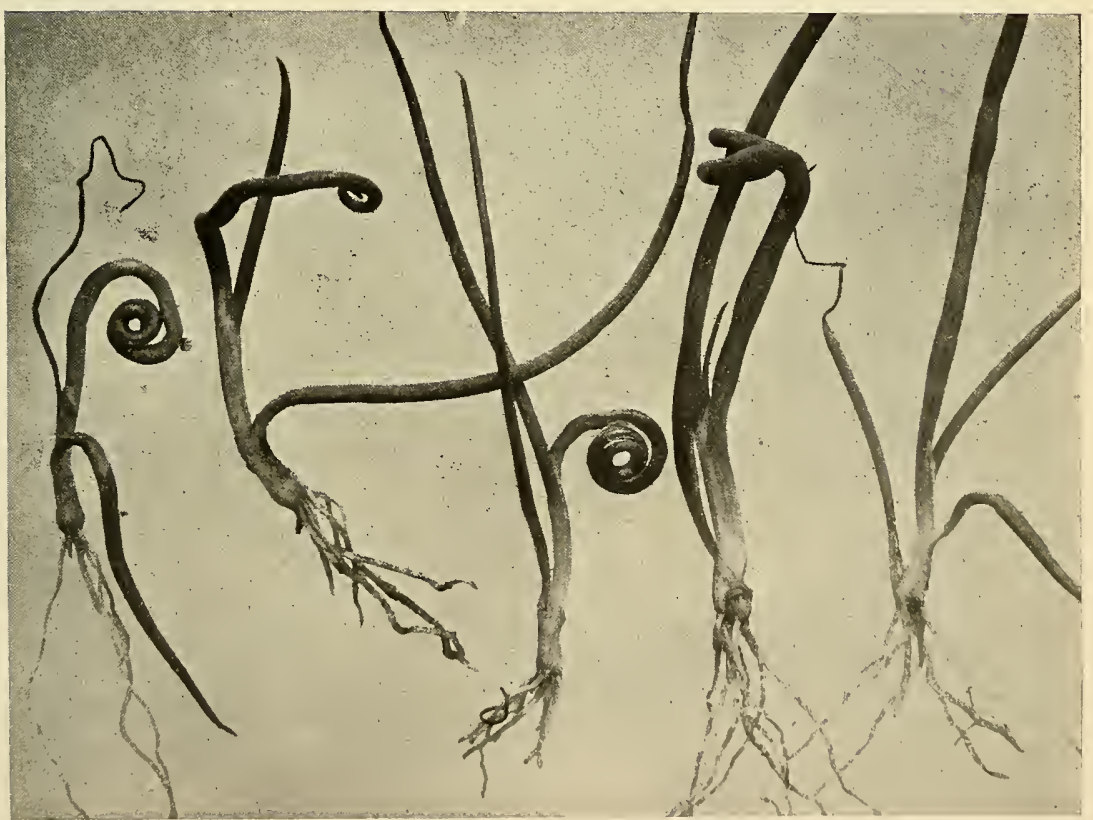

b. Showing peculiar malformations of leares, p. 332 . 



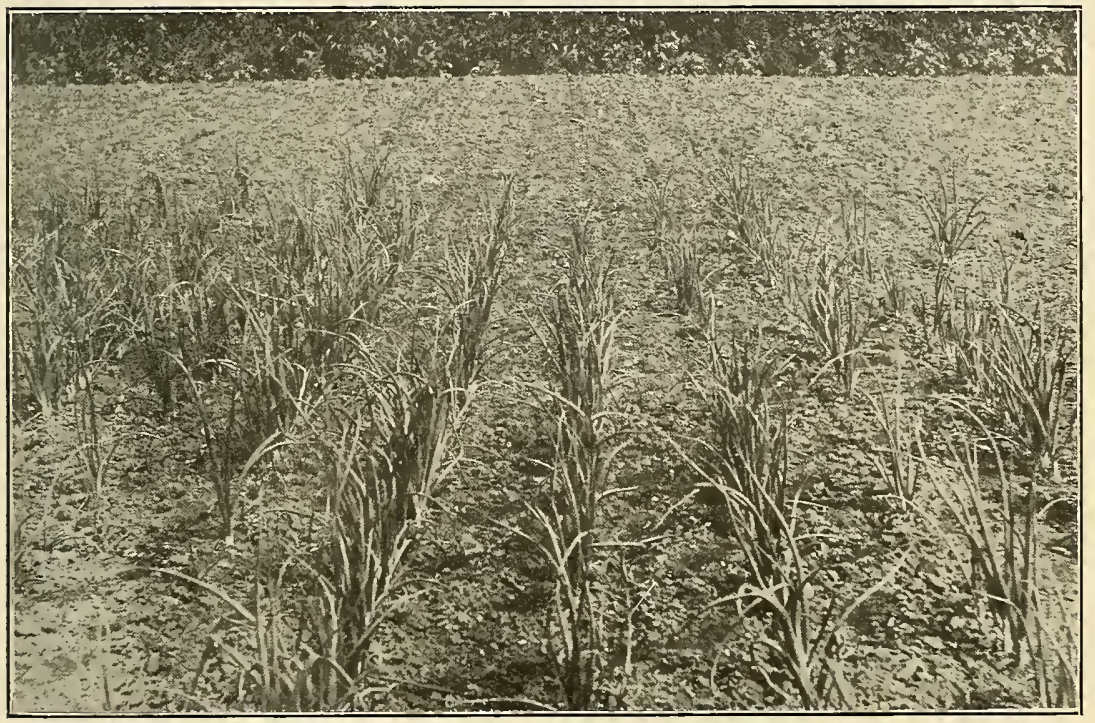

a. Showing how disease spread across end of field, p. 333.

Untreated.

Treated.

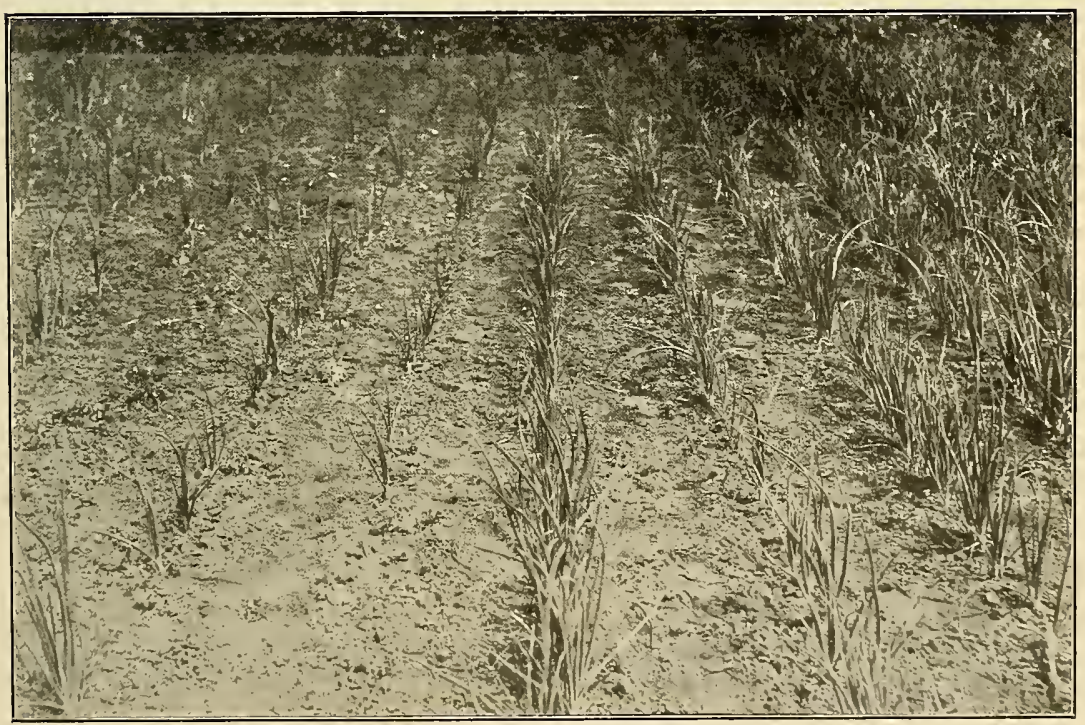

b. Showing effect of treatment, p. 335 . 



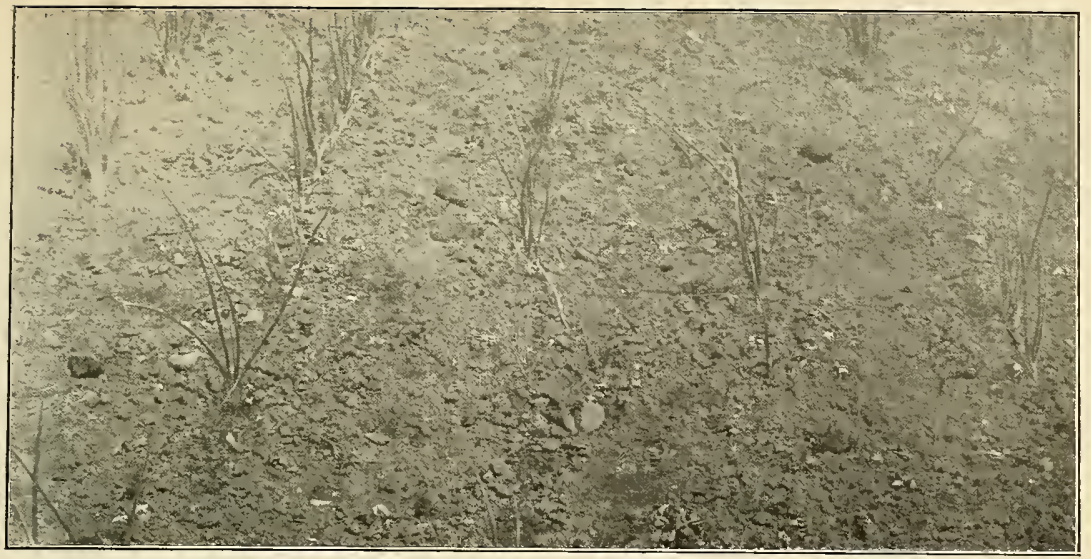

a. Untreated rows that failed to respond to extra fertilization, p. 335 .

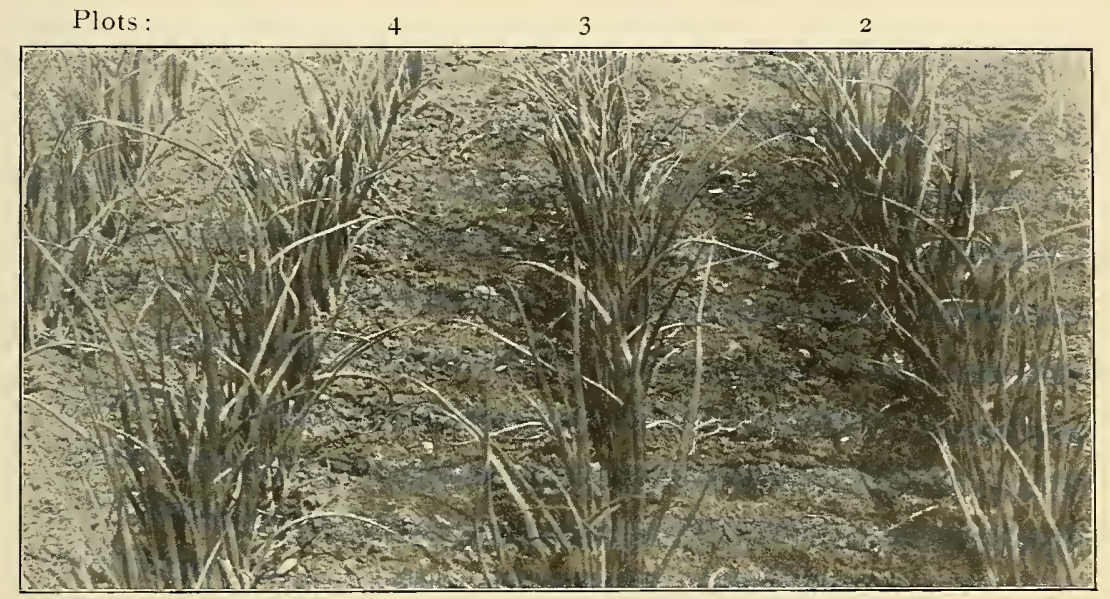

b. Adjacent treated rows photographed at same time and size as $a, \mathrm{p} .335$.

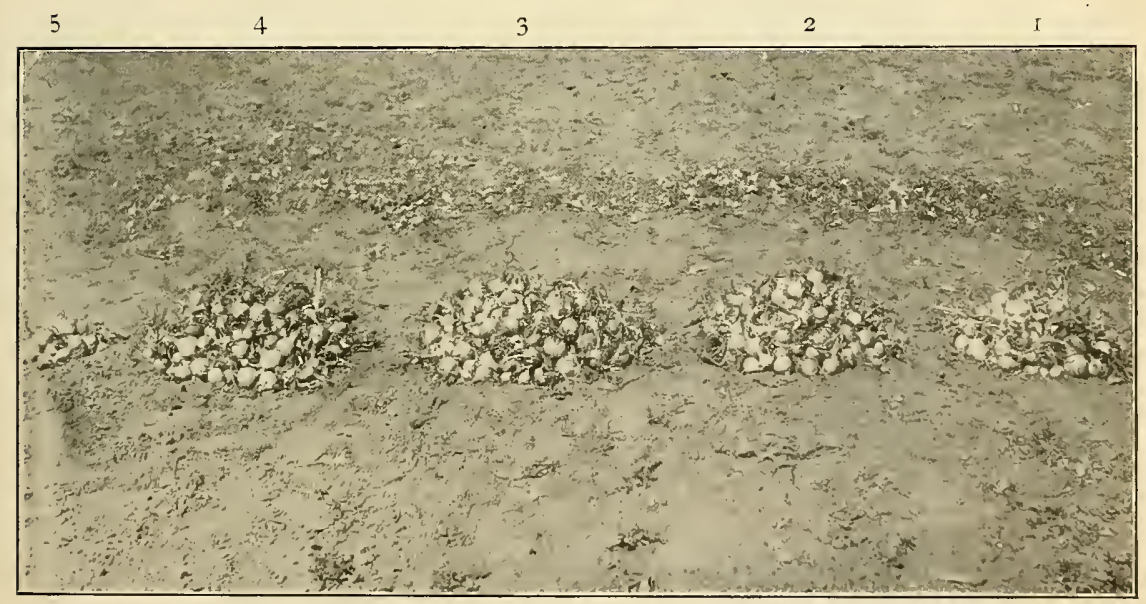

C. Results of treatment on yields from adjacent rows, p. 335 .

ONION BRITTLE, showing untreated and treated rows in detail. 

PLATE XXVI.

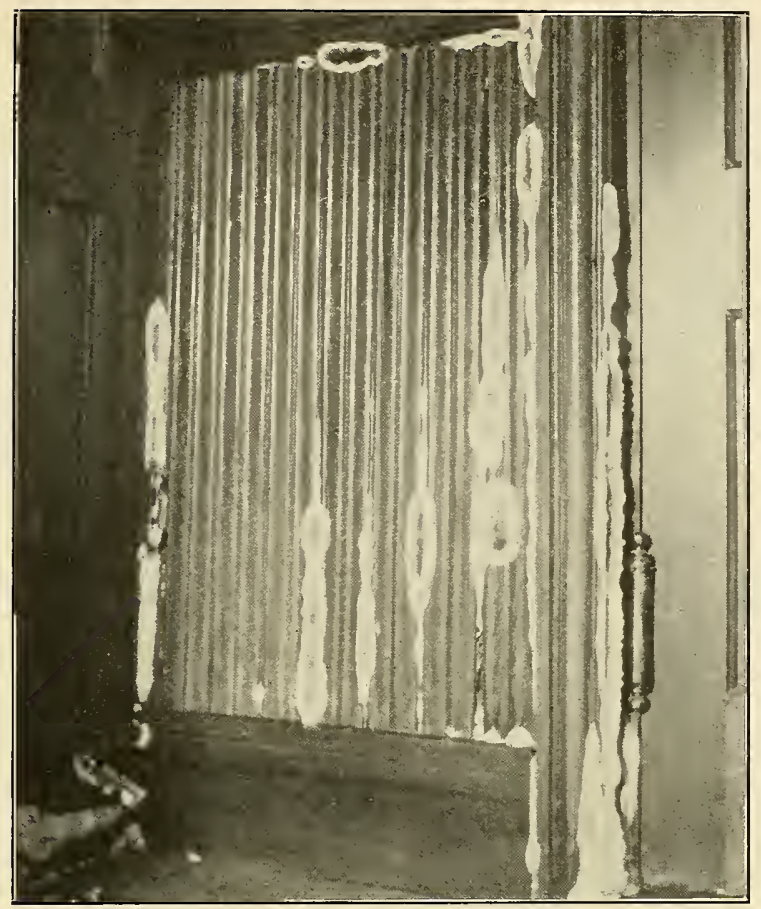

a. After having been scraped off, this new growth was made in less than two weeks.

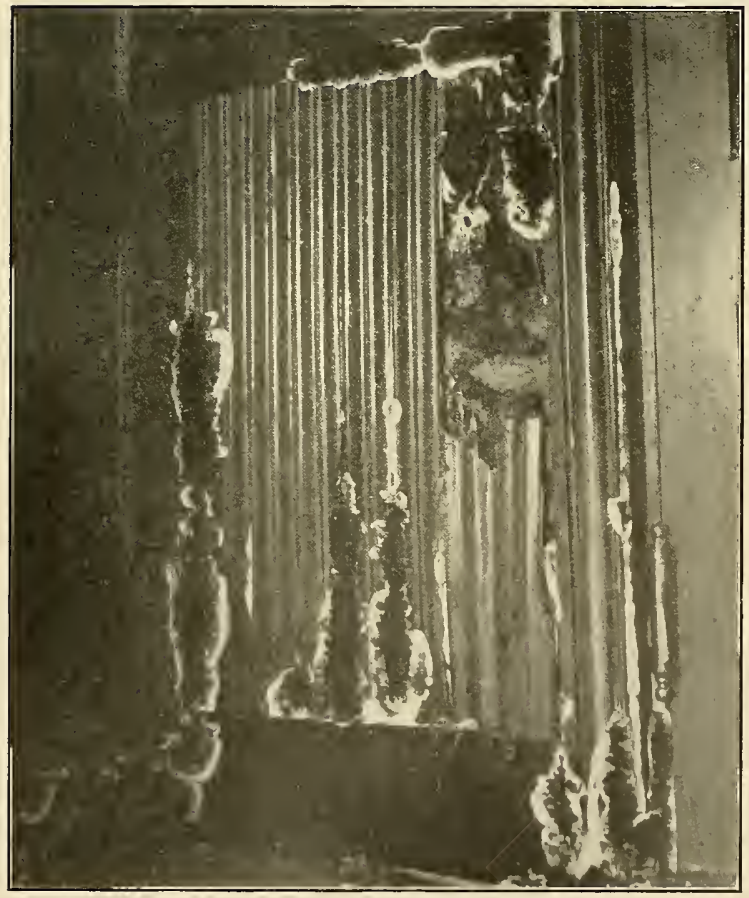

b. Photographéd just I2 days after $a$, p.340.

DRY ROT FUNGUS, Merulius lacrymans. 



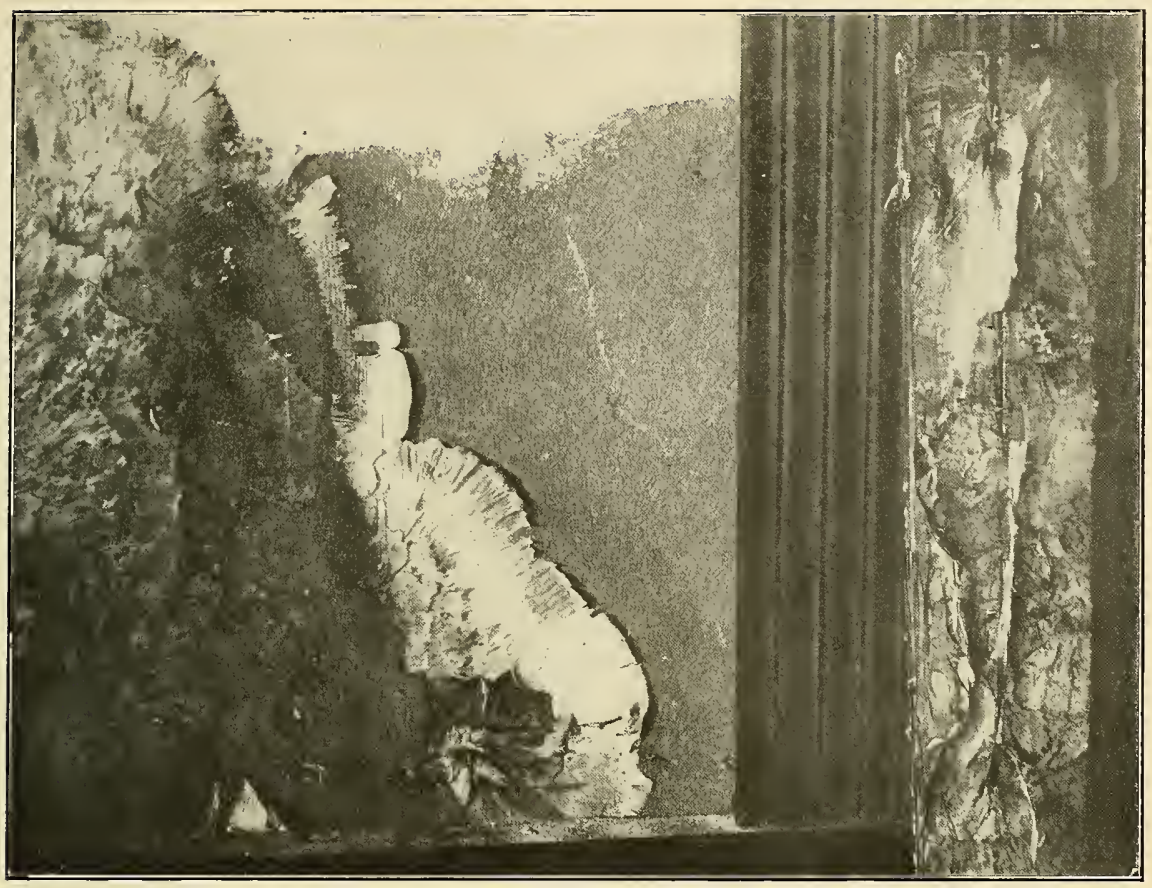

a. Showing growth made on plastering back of the wainscoting, p. 339 .

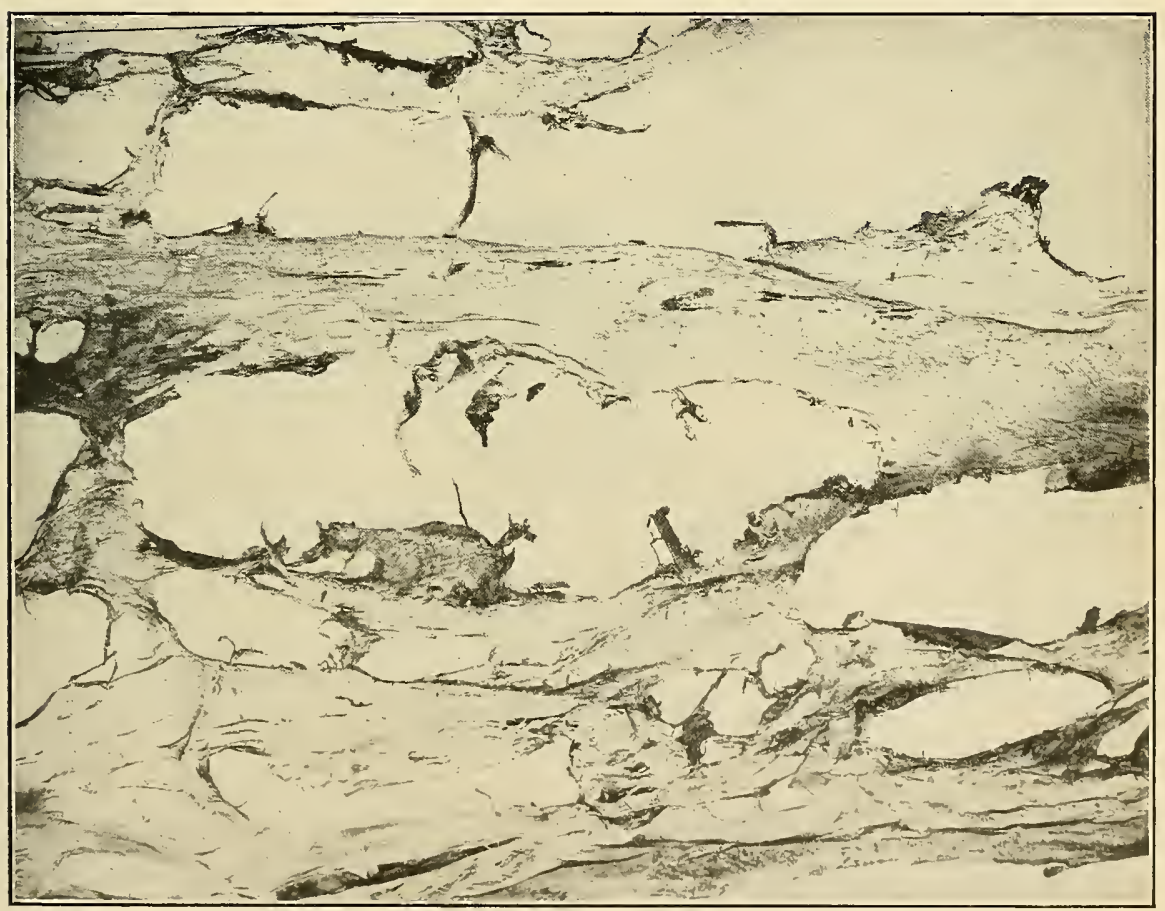

b. Sterile mycelial strands formed on back of the boards, p. 339 . 

PLATE XXYIII.

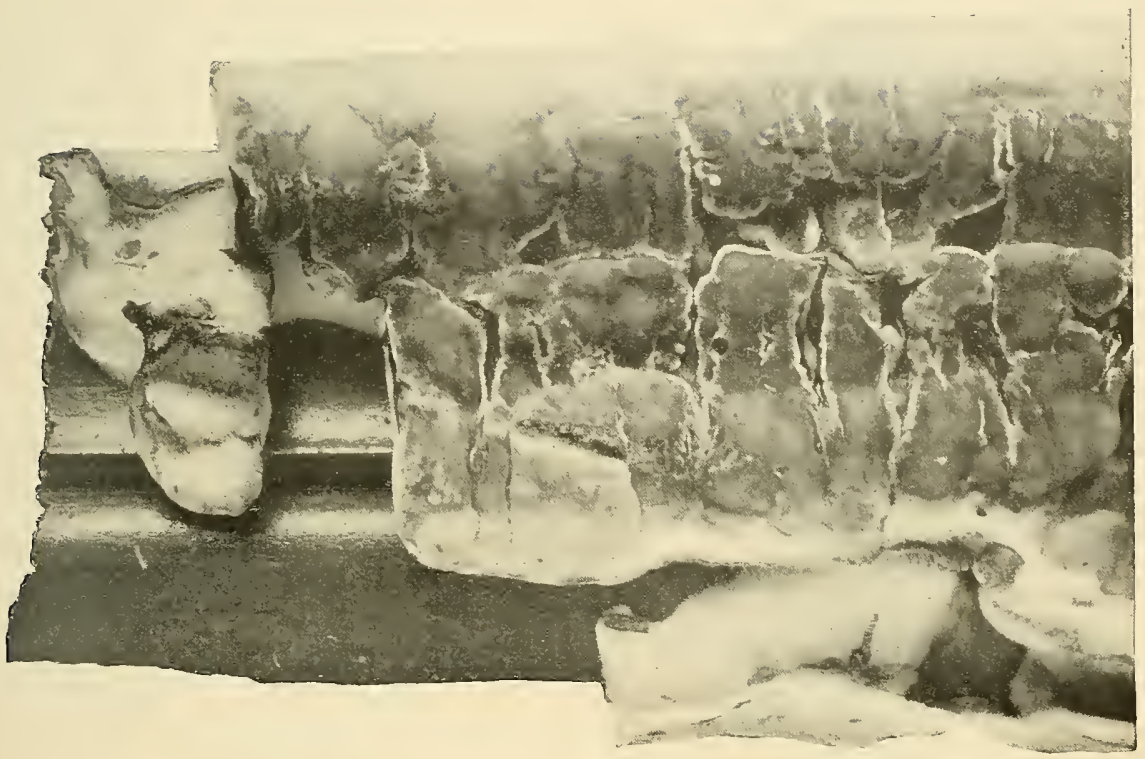

a. Immature fruiting stage, developing on front of board, p. 340 .

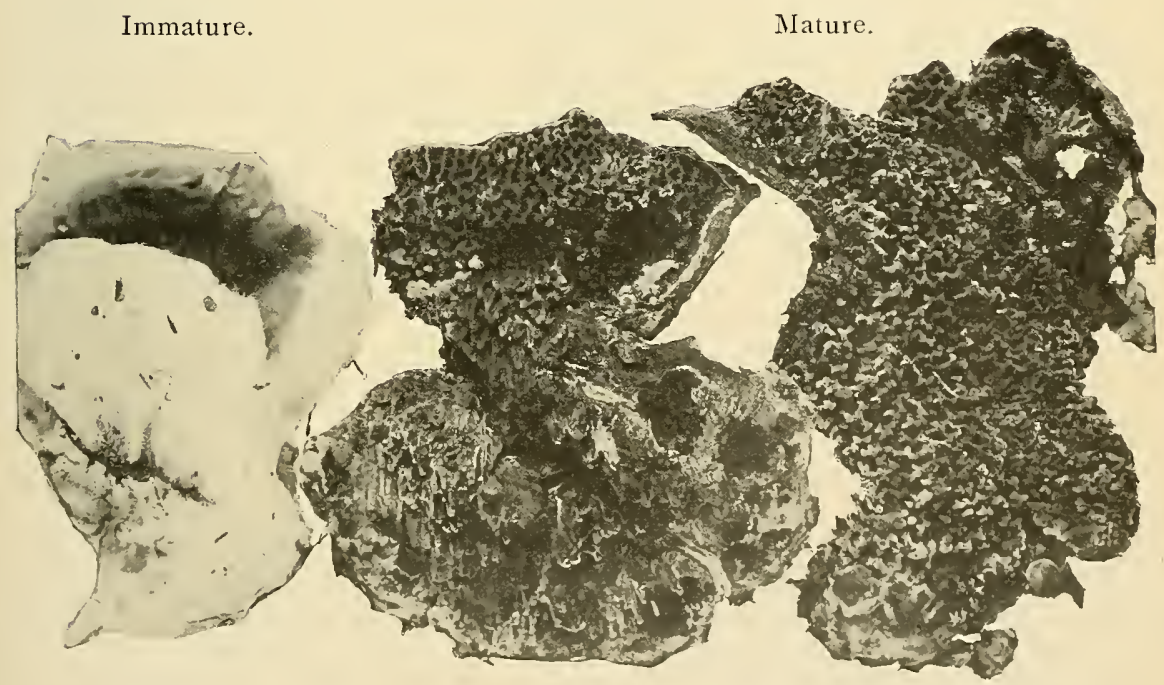

b. Fruiting or spore stage of the fungus, p. $3+0$.

DRY ROT FUNGUS, Merulius lacrymans. 

Heal thy.

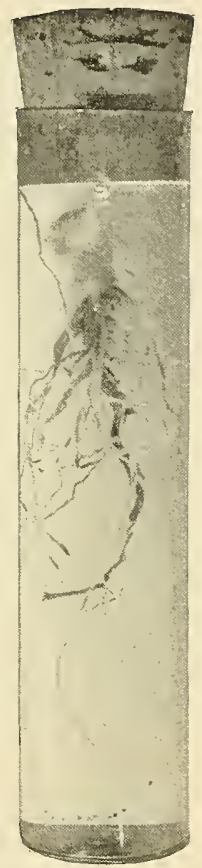

Diseased.

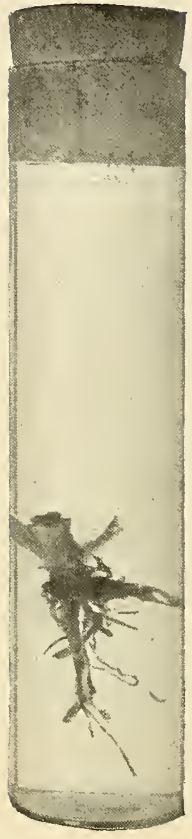

a. Comparative size of healthy and diseased roots of seedlings, p. 350 .

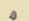

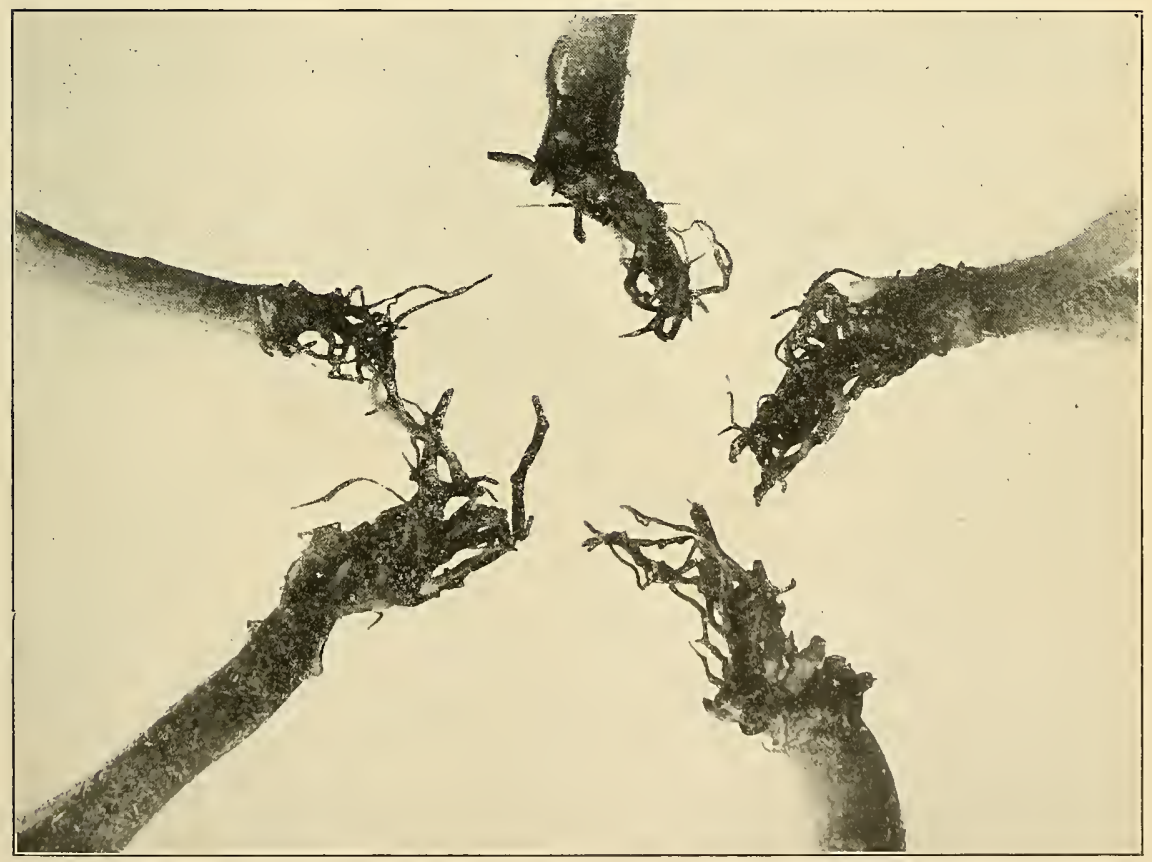

b. Showing badly rotted roots of seedlings. $\times 2$.

ROOT ROT, Thielaria basicola, OF TOBACCO. 



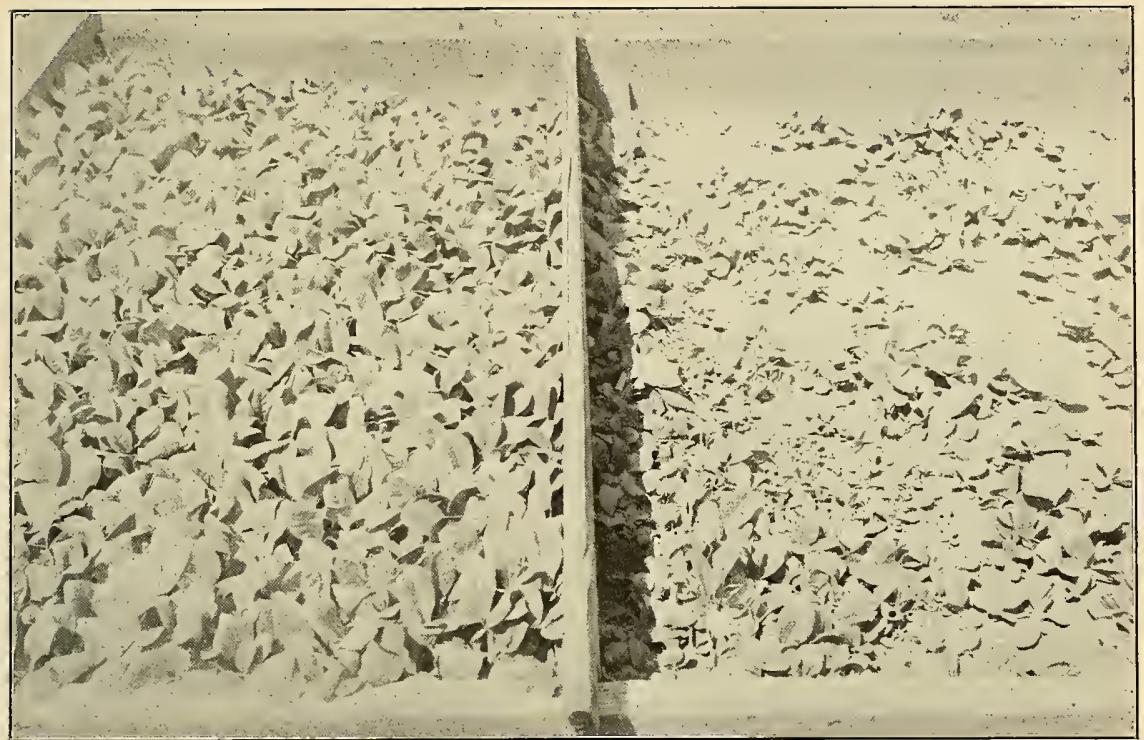

a. Apparent effect of soil treatment with formalin, p. 354 .

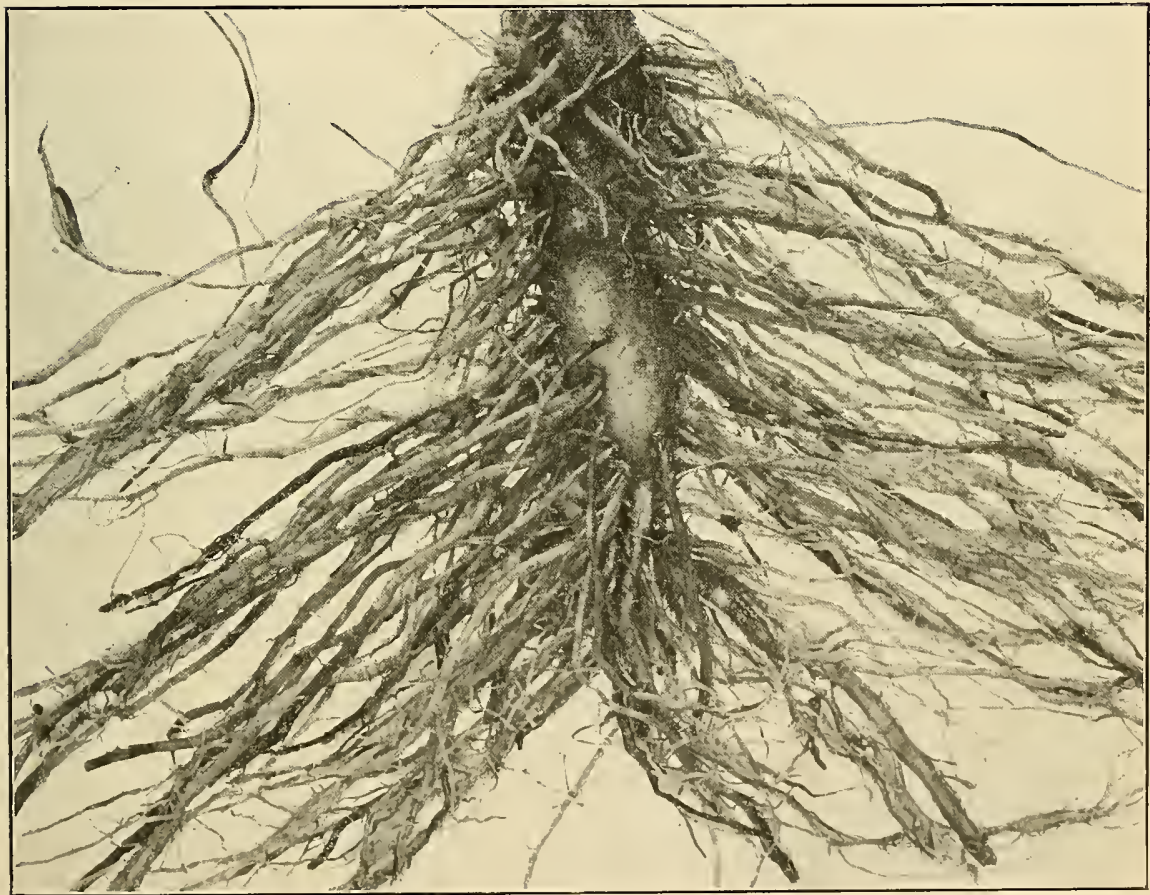

b. Showing rot in the fibrous roots of a field plant, p. 356 . 



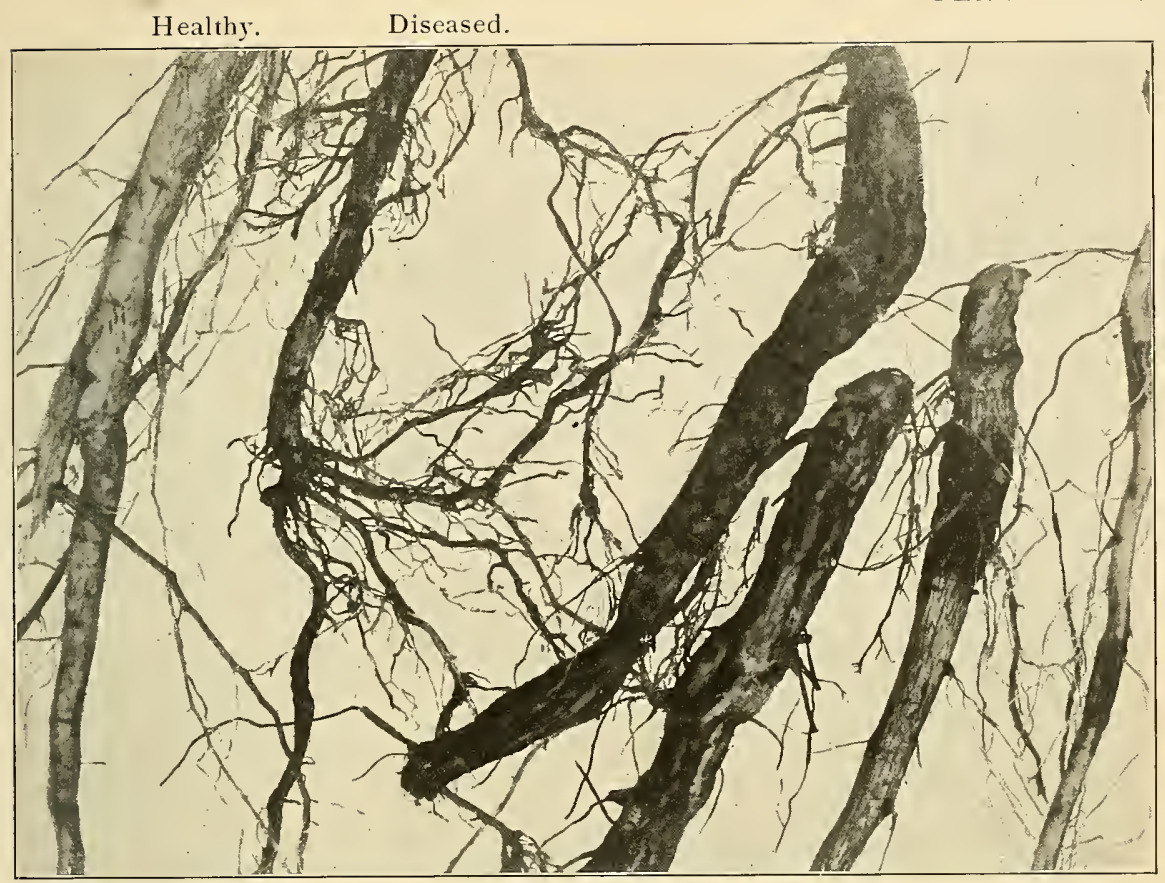

a. Appearance of the fungus on the large roots of field plants, p. 356 .

Healthy. Diseased.

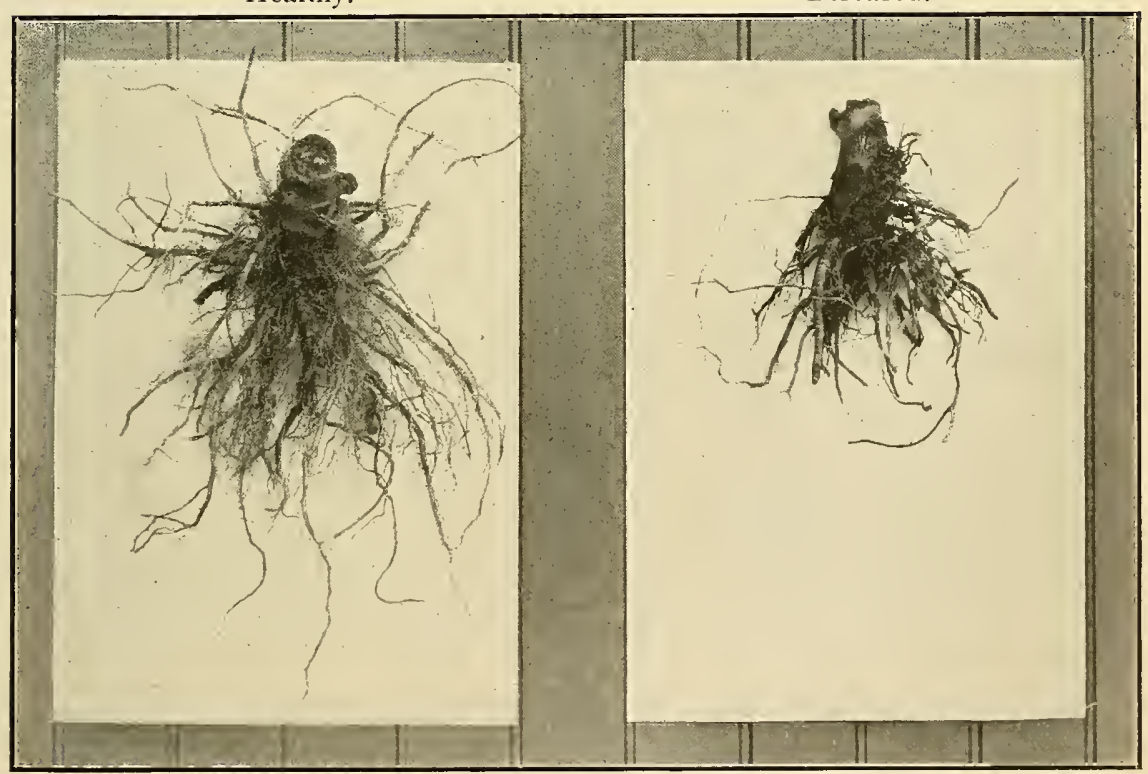

b. Effect of rot on roots of mature field plants, p. 356. 

PLATE XXXII.

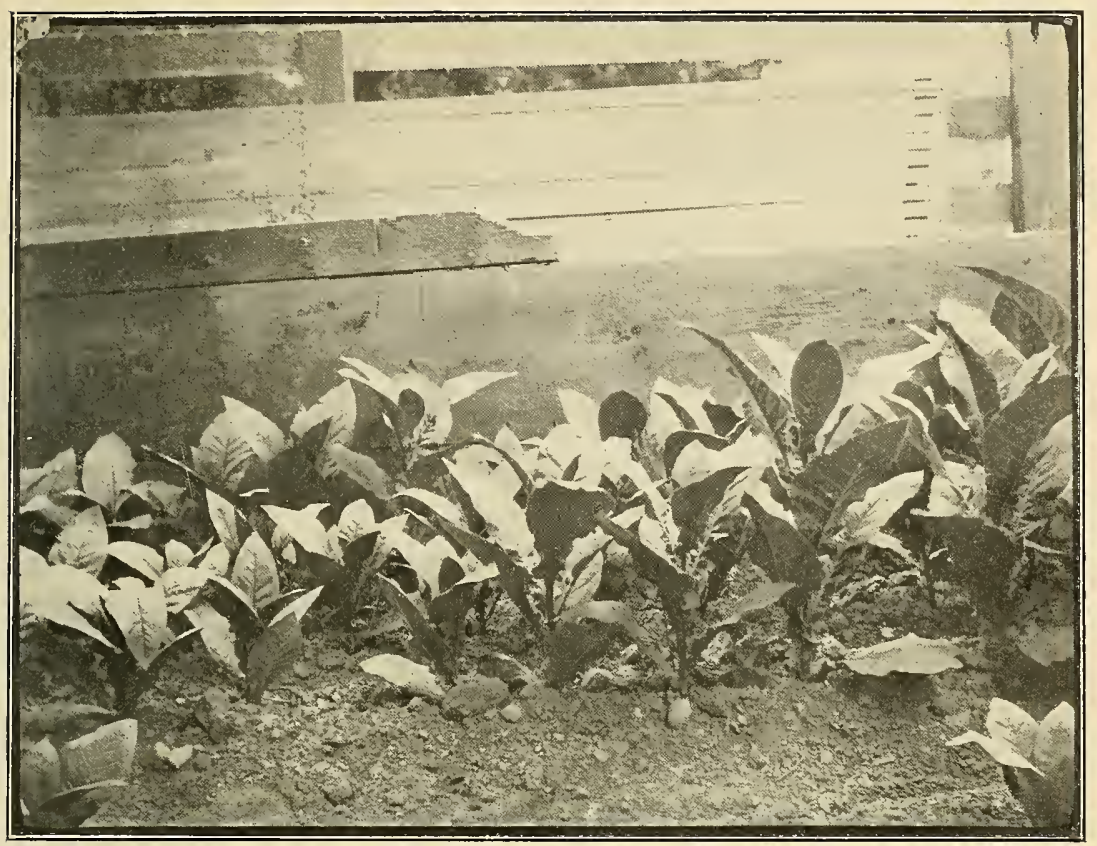

a. Healthy plants that became diseased on transplanting in a diseased bed, p. 362 .

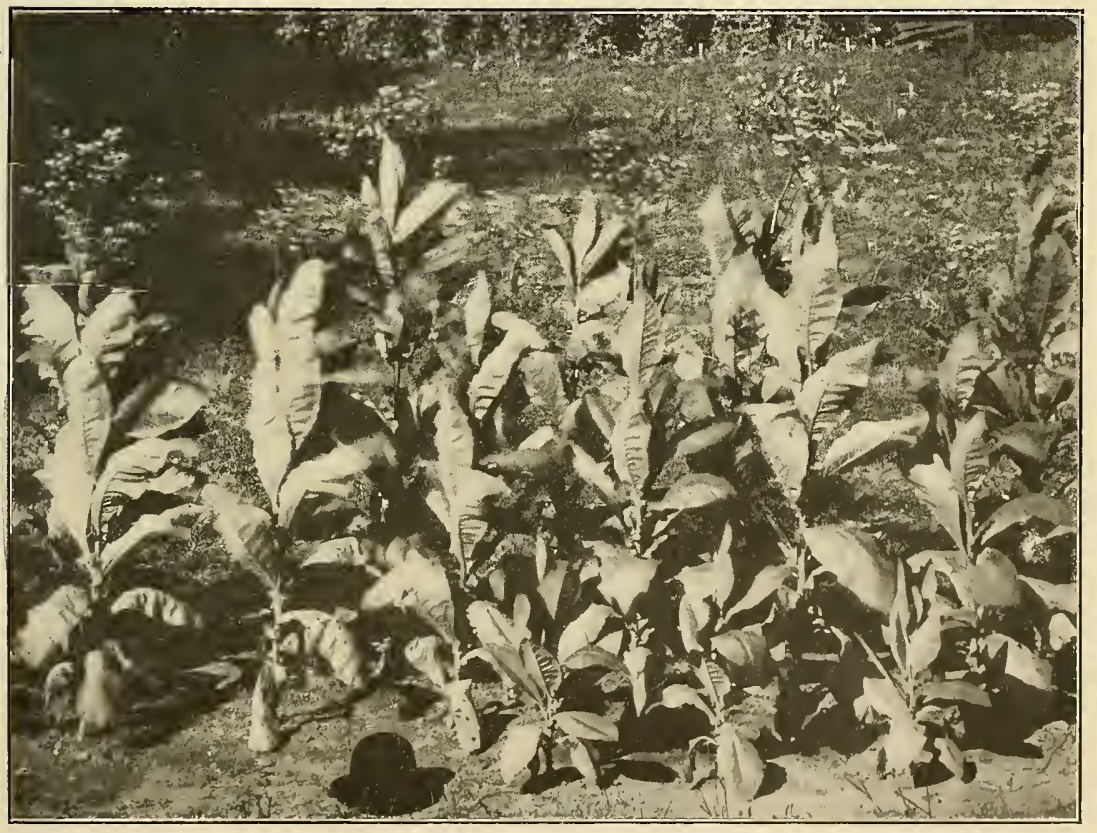

b. Diseased plants transplanted in disease-free soil, p. 361 . 




\section{Etate of Connecticut}

REPORT

OF

\section{The Connecticut Agricultural Experiment Station}

REPORT OF THE STATION BOTANIST, 1907

G. P. CLINTON, SC.D.

BEING PART VI OF THE BIENNIAL REPORT OF 1907-1908 



\section{CONNECTICUT}

\section{AGRICULTURAL EXPERIMENT STATION}

\section{REPORT OF THE BOTANIST}

G. P. CLINTTON, Sc.D.

I. Notes on Fungous Diseases, etc., for 1907, p. 339.

II. Root Rot of Tobacco-II, p. 363.

III. Heteroecious Rusts of Connecticut having a Peridermium for their aecial stage, p. 369 . 



\title{
PART VI.
}

\section{REP0RT OF THE BOTANIST FOR I907}

\author{
G. P. Clinton, Sc.D.
}

I. NOTES ON FUNGOUS DISEASES, ETC., FOR 1907.

GENERAL NOTES ON DISEASES PREVIOUSLY REPORTED.

Weather conditions. Even more so than the previous year, r907 was characterized by comparatively little injury to plants from fungous diseases. This does not mean that it was an excellent year for crops, for, on the contrary, it was an unusually poor one, since the conditions that proved unfavorable for serious attacks by fungi also prevented good plant growth. These unfavorable conditions were chiefly those of the weather. To begin with, there was some winter injury to the fruit buds, especially those of the peach, which, except in restricted localities, were largely killed before spring, so that the peach crop was a practical failure for the state. Some injury, too, was done to the young twigs, but there was no such serious injury to the trees in general, as was experienced during the winter of 1903-04.

The spring was very backward, so that up to the middle of May the work of the market gardeners was about a month behind the usual time. Coupled with the late spring were two unusual frosts on May I Ith and May 2Ist, which did considerable damage to the exposed tender vegetation, and the blossoms developing at that time. Especially there should be mentioned frost injury to the unprotected early tomatoes, to strawberry and grape blossoms, and to the unfolding foliage of the sycamores.

Following this late spring came an unusually dry summer, including most of the months of June, July and August. The total rainfall for these months was only 5.49 inches, as compared with the average of 12.80 inches during the past thirty-four years, as shown by the records of the United States Weather 
Bureau at New Haven. This drought was felt over the entire state, but was especially severe in certain districts, so that the yield of most of the crops was very materially decreased. The drought was not broken in the vicinity of New Haven until August 24th. Fortunately, the fall, both as to its length and the amount of moisture, proved fairly favorable for vegetation, so that crops which were not too severely damaged made good gains during this period. The more important of the previously reported fungous and physiological troubles of the year are briefly discussed under the following heads:

Apple. Little injury was done by either the sooty blotch or apple scab. On the other hand, the fruit speck trouble, first described in our Report for 1905, p. 264, was more conspicuous than usual. We have not been able to study this trouble further, so that the particular fungus responsible for it is still in doubt. Since our first report, we have had complaint of it from Pennsylvania and New Hampshire, and this year it was said to have caused very considerable damage in Maine. The writer was also told that it was a very common and injurious trouble with apples on the Boston market the past season.

Baldwin spot is another trouble that was more prominent than usual. It was seen on the Greening, and some fall varieties, as well as on the Baldwin. The fruit at storage time showed little of the trouble, though it soon began to develop, and continued evident up to the end of the season. The reddish-brown diseased spots often appear entirely within the flesh, but may work outward so as to form a slightly sunken discoloration in the epidermis, as shown in the illustration, Plate XVII, a. On cutting the apple, the tissue of these spots was often torn rather than cut sharply across, indicating a tougher or more spongy texture. Microscopic examination revealed no fungous threads or bacteria present. The cell contents were more or less disorganized, colored reddish-brown and in some cases there was more starch present than in the surrounding healthy tissues. Cultures, attempted both in December and February from isolated spots in the interior, gave absolutely no growth of any kind, thus confirming the results of previous investigators that this is not a parasitic trouble. After these spots reach the surface they may offer entrance for fungi causing true rot, especially that caused by the blue mold. The trou- 
ble seems to be physiological, and possibly bears some relationship to the weather, especially to drought such as was experienced the past season. It was suggested by one grower, whose apples were rather badly affected, that injury by the aphis, when the apples were quite young, might be the starting point of the trouble.

Market Garden Crops. Early in the season some of the cucurbits, especially the cucumber and muskmelon, suffered considerably from the bacterial wilt, but this did not progress, so that where the stand was sufficient the injury was not so great as was expected at first. Onion brittle, or something very similar to it, was more general all over the state than ever before, and some of the crops while quite young were very severely injured. Further study of the trouble did not throw any additional light upon its cause. The onion crop as a whole was fair, since seed onions suffered little, if any, from the blossom blight, and the black spot did little injury to the bulbs of the white varieties.

Tip burn was the only serious trouble of the potato; but this, because of the drought, was so severe that the crop was cut very short in many fields. There was practically no complaint of rotten tubers, and it was only after the most diligent search during the entire season that the blight fungus was finally found on a few green vines at Storrs and at this station about the first of October. In the fall, market potatoes from Maine, however, showed considerable injury from blight, and were seriously objected to by the buyers for a time.

During the drought the tomatoes suffered considerably from the point rot trouble, which was a frequent source of complaint by growers. After the drought it was less evident, which seems to indicate that it was a physiological rather than bacterial or fungous trouble. The Lima bean mildew was not seen during the whole season, though looked for in fields where frequently it is very troublesome.

Ornamental Plants. No very serious or unusual troubles of ornamental plants were found other than those reported under new diseases, except possibly yellows of asters and the leaf spot of the European horse chestnut, which was certainly unusually conspicuous after August. Leaf scorch injuries of shade and forest trees due to the drought were not uncommon. 
Peach. The leaf fall trouble mentioned in our last Report, p. 317, was even more conspicuous than last year. A thorough examination was made of one of the orchards where it showed most prominently, and the trees were found with their wood severely winter injured, while those not suffering were free from winter injury. This winter injury, coupled with the severe drought, was, in our opinion, the cause of the trouble, especially in orchards where the soil could not be thoroughly tilled to conserve the moisture. Yellows is another trouble that showed signs of being greatly on the increase. One prominent grower estimates that fifty per cent. of the trees in the state are now infected with yellows. Mr. Waite, of the United States Department of Agriculture, states that Connecticut is at the northern end of an area reaching along the Middle Atlantic coast in which there is a very severe outbreak of this trouble. Whether or not the outbreak in this state is as severe as some suppose, remains yet to be seen, since the premature development of the buds last fall, taken as one of the signs, may have resulted from the wet fall following the prolonged summer drought.

Tobacco. There was some complaint, especially in the region of Granby, of injury to tobacco beds from the root rot fungus. Tobacco in the field finally did somewhat better than was expected after its injury by the drought, but upon curing, the quality was said to be below the average, and the price obtained was much lower than usual. There was again evident injury in certain fields near Suffield that could not be laid to the weather; and, so far as the writer could determine, did not seem to be entirely the work of the root rot fungus, but was possibly due to unknown soil conditions of a chemical nature.

DISEASES NEW TO THE STATE.

While this year developed few serious fungous outbreaks, at least the usual number of new diseases were found. About one-fourth of these troubles are of physiological rather than of parasitic origin, and such are indicated by italicized common names in the following accounts:

APPLE, Pirus Malus.

Spray Injury. Plate XVII, b. We have mentioned before (Report for 1903, p. 303) the ordinary forms of Bordeaux 
injury, such as spotting of the leaves, and russeting of the fruit. Last December there were sent to the station, by Mr. E. A. Moore of New Britain, Baldwin apples that showed a form of injury which we had not seen before. These apples had been sprayed several times with Bordeaux and lead, the last application being made about the middle of August. When examined, the fruit still showed more or less of the spray in the stem and bloom ends. The injury consisted of small specks, as shown in the illustration, reaching but slightly beneath the epidermis, and clustered chiefly at the bloom and stem ends. Evidently some injurious ingredient of the spray had in time become dissolved and been carried into the tissues, probably through the lenticels or insect punctures, killing the cells with which it came in immediate contact. The damage resulting from this kind of injury is not nearly so serious as the more common forms.

\section{BEAN, LIMA, Phaseolus lunatus.}

Chlorosis. The past summer a trouble of Lima beans was seen on occasional plants that was somewhat similar in appearance to the calico of tobacco. It shows as a yellow mottling of the tissues, the chlorophyll usually retaining its normal color in the vicinity of the larger veins. Attempts to produce the same trouble on healthy plants by touching the leaves with juice from the diseased tissue, as can easily be done.in the case of calico of tobacco, were not successful, thus indicating that the chlorosis is not of an infectious character. Just what conditions produce this trouble is not known, and, since not serious, it is chiefly of interest because of its general resemblance to the chlorosis of variegated plants.

\section{BELIFLOWER, Campanula rapunculoides.}

Rust, Coleosporium Campanulae (Pers.) Lev. Plate XXV. This rust was found in October causing some damage to plants in a New Haven nursery, where it had been noticed by the owner for a few years past. The uredinial or. II stage is the one that does most injury, since this is chiefly influential in spreading the trouble. It shows as dusty orange oxtbreaks about the size of small pinheads scattered or clustered on the under side of the leaves. Sometimes there is a slight discolora- 
tion of the upper surface. The III stage occurs late in the season, as very small, slightly elevated, reddish, waxy areas also on the under side of the leaves. Kellerman has shown that the I stage of this fungus occurs on the needles of the pitch pine, from which it goes to the Campanula. The III stage carries it back to the pine. This fungus is further discussed in the last artiele of this Report.

\section{BITTERSWEET, JAPANESE, Celastrus articulatus.}

Crown Gall, Bacterium tumefaciens Sm. \& Towns. The above is a new host for the crown gall, at least for Connecticut. Dr. Britton found the infected specimens while inspecting a nursery in New Haven. The galls are so similar to those found on the peach and other hosts in this state that there is no reason for believing them different or caused by a different agent. New interest has been aroused concerning the crown gall because of the recent publications of Smith and Townsend (Science 25: 67I-3. Ap. 1907. Centr. Bak. Par. Inf., II, 20: 89-9I. D. I907) of the United States Department of Agriculture, who seem to have proved that crown gall on its various hosts is caused by the bacterial organism named above instead of by a slime mold, as claimed by Toumey, the first extended investigator of the trouble. They were able to produce galls on peaches and a variety of other plants by inoculation with pure cultures of this bacterium obtained originally from galls on cultivated marguerite.

\section{BLACKBERRY, Rubus villosus.}

Rust, Kuehneola albida (Kuehn) Magn. This forms much less conspicuous and injurious outbreaks than the orange rust which attacks the same hosts. The II stage of the fungus was found at Storrs on leaves of the cultivated blackberry, but was not very prominent on these, being much more luxuriant on the wild swamp blackberry. However, it sometimes proves an injurious pest, as Stone of Massachusetts (Ann. Rep. Hatch Exp. Stat. 9:74. I897) has reported a case in which considerable damage was done in 1894 to cultivated varieties in that state. The II or injurious stage shows as very small, yellowish-orange, dusty outbreaks on the under surface of the leaves. The final article of this Report contains further information concerning the fungus. 


\section{CHESTNUT, Castanea sativa americana.}

Chestnut Bark Disease, Diaporthe parasitica Murr. Plate XVIII, a. Mr. F. V. Stevens, Jr., tree warden of Stamford, informs the writer that the chestnut disease, which has proved so serious in the vicinity of New York City and on Long Island, has become common in the neighborhood of Stamford. He also reports having seen the trouble in one or two other places in the state. Dr. Murrill, of the New York Botanical Garden, has carried on extended investigations during the past three years, and finds that a particular fungus is responsible. for the injury. This fungus produces cankers in the bark, and in time becomes so general on an infected tree as often to kill it. While most injurious so far to the native chestnut, it also occurs on the chinquapin and the European chestnut, but has been found only occasionally on the Japanese.

Both Murrill and Metcalf, of the United States Department of Agriculture, who has also made a study of the trouble, take a rather alarming view of the danger to all chestnuts in infected regions. Mr. Metcalf (U. S. Dept. Agr. Bur. P1. Ind. Bull. I2 I, VI. I908) says: "Unless something now unforeseen occurs to check its spread, the complete destruction of the chestnut orchards and forests of the country, or at least the Atlantic States, is only a question of a few years' time." While the trouble is no doubt a serious one, we are inclined to believe that its power of spreading and the likelihood of its annihilating all the trees of infected regions, have been overemphasized. Spraying against the trouble seems not to have proved either practical or effective. Pruning off all diseased branches has not always been successful in freeing the trees of the disease, or if so, they have become re-infected through the wounds.

Whether or not the trouble is the same, serious injury to native chestnuts and chinquapins has been reported before from different parts of the United States. We quote the following from an article by $\mathrm{Mr}$. Jones, of Georgia, which appeared in the American Journal of Science and Arts, vol. I, page 450, in I846: "The present remarks are particularly directed to the death and disappearance of some of our trees and shrubs. The first that I will mention is the Castanea pumila, which is a tree from ten to thirty feet in height. In the year 1825 , during the months 
from June to September, I observed this tree dying when in full leaf and with fruit half matured. I examined numerous individuals, and could find no internal cause for their dying. I at first attributed it to the great fall of rain which took place in the year 1823 , for during the month of July of that year a considerable quantity of land, not subject to overflow, was covered with water for some time, and the highest lands were completely saturated. The latter part of 1824 was also very rainy. Knowing that this tree belongs in our highest and driest soils, I concluded that it was owing to a too moist state of the ground. But since that time I am convinced that there must be some other cause, for the tree continues still to die up to the year 1845 , and if the disease is not arrested, in a few years I fear it will be entirely exterminated."

Dr. Mohr, writing more recently, I90I, in Plant Life of Alabama, says concerning the chestnut in that state: "The chestnut, usually one of the most frequent trees of these forests, is at present rarely found in perfection. The older trees mostly show signs of decay, and the seedlings as well as the coppice growth proceeding from the stump, are more or less stunted. It is asserted by the old settlers that this tree is dying out all over the mountainous region, where at the beginning of the second half of the century it was still found abundant and in perfection."

\section{COW PEA, Vigna sinensis.}

LeAf Blight, Cercospora Dolichi E. \& E. This fungus forms reddish subcircular or angular spots, about one-eighth to onequarter of an inch in diameter, usually scattered over the leaves and showing through on both surfaces. With age these spots sometimes have a greyish center. By the aid of a hand lens the fruiting stage of the fungus can often be seen on the spots as an inconspicuous coating of very short olive-black threads. Two or three other species of Cercospora (C. cruenta Sacc., $C$. Vignae E. \& E., C. Vignae Racib.) have been described on species of Vigna, or Dolichos; as it is sometimes called, which possibly may not be distinct from this. On some of these spots a species of Alternaria occasionally occurs, but perhaps only as a saprophyte.

Leaf Spot, Amerosporium oeconomicum E. \& T. A second fungus frequently appears on the same leaves with the preceding, 
producing very similar spots. However, the latter can be distinguished in its mature state by having spots with a reddish border and whitish center in which the fruiting stage shows as minute black imbedded bodies. In the N. A. F. no. 2574, on Dolichos arvensis, Ellis \& Everhart issued a specimen which they named Amerosporium Dolichi E. \& E. n. s., which does not seem to be different from our species described by Ellis \& Tracy three years before (Journ. Myc. 4: I02. I888). These exsiccati specimens plainly show that the spores are septate (about three septa) when old, and the specimens collected in Connecticut also indicate that they would become septate with age. This may mean that the fungus belongs in a different genus, since the spores of Amerosporium are said to be continuous.

In the specimens collected at Storrs in September, besides the Cercospora and Amerosporium, the leaves also had numerous more or less elevated reddish spots or specks the size of a pinhead or less. While these may be the beginning of the fungous troubles already mentioned, they look very much like injuries caused by sucking insects. Altogether the spotting caused by these various agents becomes quite conspicuous, and causes considerable injury to the leaves.

CURRANT, Ribes rubrum.

BitTer Rot, Gloeosporium rufo-maculans (Berk.) Thuem. Plate XVIII, c. During the latter part of July, in a small plantation at Storrs, the white currant was found rather badly affected with a fungous trouble that caused the berries to gradually shrivel and dry up into wrinkled mummies. The fruiting stage of the fungus shows under a hand lens as minute black specks, frequently with a lighter center, but these may become obscured by the small masses of pinkish spores that ooze out on the surface. At the same place, but not necessarily on the same bushes, there was also found a small amount of anthracnose, Gloeosporium Ribis (Plate XVIII, b), that often attacks currant leaves. In passing it might be noted that Klebahn (Zeitschr. Pflanzenkr. 16: 65-83. 1906) has recently shown that this fungus is the conidial stage of Pseudopeziza Ribis $n$. $s$. that develops on the fallen leaves in the spring. At first it was believed that the fruit disease was also caused by this Gloeosporium, although it is not 
commonly reported on the fruit, Stewart, in Bulletin No. I99 of the N. Y. Exp. Station, being the only one known to the writer who has found it on the fruit and stems as well as on the leaves. Microscopic examination, however, showed that the spores from the berries and leaves were quite different in appearance. The spores from the leaves were chiefly $16-20 \mu$ by $5-6 \mu$, and decidedly curved, being usually bow-shaped and often tapering to the ends; while the spores from the fruit were straight, less tapering, and somewhat narrower, varying chiefly from $14-22 \mu$ by $4-5 \mu$. So similar are the spores to those of the bitter rot fungus, especially to grape rot mentioned in our last Report (1906, p. 3I4), that we have decided, at least for the present, to consider the fungus the same, though it has not before been reported on the currant as a host. We have found no other Gloeosporium mentioned as occurring on the fruit of currants, though Gloeosporium ribicolum E. \& E. was described on the fruit of Ribes sp. (cultivated gooseberry). A few days after collecting the fungus at Storrs, the white currants on the Experiment Station grounds at New Haven were examined, and the fruit of these was found to be somewhat similarly injured. Microscopic examination, however, showed that in this case the Gloeosporium present was different, the smaller spores varying chiefly from $7-15 \mu$ by $3-6 \mu$. As many of the shriveled berries showed no signs of this fungus, it is quite probable that it occurred here as a saprophyte, and the trouble was really due to some other cause, possibly the very dry weather. The spores of this fungus were similar to those of $G$. ribicolum, except slightly broader.

Powdery Mildew, Sphaerotheca mors-uvae (Schw.) B. \& C. Plate XIX. While the powdery mildew has been reported from Connecticut on the gooseberry, this is the first mention, so far as known, of its occurrence on the currant. Specimens were found in July on red currants in a nursery at Storrs, where it confined its attacks to the ends of the young branches and their leaves, the latter being checked in their development. At the same place the fungus occurred on the gooseberry, but limited its attacks here to the fruit. The dirty white or brownish mycelium forms a thickish felt (in which are imbedded the fruiting bodies as dark specks) on the affected parts, and is thus directly exposed to fungicides when applied. However, to secure good results, the 
treatment must be started before the appearance of the trouble, since the plants infected in this case had been sprayed, apparently tardily, with Bordeaux, with little effect.

\section{FALSE INDIGO, Baptisia ausiralis.}

Powdery Mildew, Erysiphe Polygoni DC. This fungus has been noted before from the state on several hosts, such as the columbine, crowfoot and pea, but this is the very first report, apparently from anywhere, of its occurrence on the above host. The mycelium forms a luxuriant growth on either side of the leaf and an abundance of the perithecia were developed. Altogether, it caused considerable disfigurement of the in fected plants, which were growing in a local nursery.

\section{FERN, Adiantum Farleyense.}

Leaf Scorch. Plate XX, a, gives a good idea of the appearance of this trouble of the Farleyense fern. It was first seen by the writer in the fall of 1902, in a Connecticut greenhouse, where it was quite troublesome. Complaint was made of it again in January, 1907, by Mr. A. N. Pierson, a large grower of ferns at Cromwell, who sent specimens for examination. The trouble shows on the leaves as prominent, often wedge-shaped, reddishbrown areas that extend inward from the clefts of the pinnae. These spots give a variegated appearance to the plants, which produce a less luxuriant growth, but otherwise appear in a healthy condition. A careful microscopical examination of the roots, stems and leaves showed no indication of any bacterial or fungous parasite. There seemed to be no unfavorable conditions of the soil to produce the injury. It appeared on the whole to be a physiological trouble. So far as the writer could determine, it seemed to be a leaf scorch, not necessarily entirely due to hot rays of the sun, but to loss of moisture from the leaves under unfavorable conditions, such as too dry an atmosphere, sudden changes of air moisture, etc. A somewhat similar trouble has been seen occasionally in nature where ferns suffered from lack of moisture. The Farleyense fern is very delicate, and, because of its very thin leaf tissues, is much more sensitive than other cultivated ferns to unfavorable conditions. The fact that 
the trouble seems to start near the veins, ard that under the microscope the stomates often show discoloration before the surrounding cells, indicate that it is a trouble connected with the inability to properly control transpiration of moisture. While no doubt it is a common trouble, and probably noted before in floral writings, the writer has seen no mention of it in the literature of plant diseases. Halsted (Ann. Rep. N. J. Exp. Stat. 14: 420. I894) describes and figures a somewhat similar trouble caused by a definite fungus (Phyllosticta Pteridis Hals.), and briefly states that unfavorable environment also often causes ferns to die and turn brown at their tips. Concerning the Farleyense trouble, Mr. Pierson wrote: "I do not think it is due to sun burn or scald, because the disease, which we have always called rust, is hardly noticeable in the summer time, but rather when the cold, damp weather comes on in the winter; particularly is it so this year. These very same plants that look so badly, with hardly a perfect leaf on them, will, by cutting the old leaves away, throw up perfect leaves in the spring, without a spot on them, and can be sold for decorative purposes." This last statement seems also to indicate that this trouble is a physiological rather than a parasitic one.

\section{HEMLOCK, Tsuga canadensis.}

Rust, Caeoma Abietis-canadensis Farl. This rust shows as small orange-yellow pustules on the leaves. Apparently it is never injurious to cultivated hemlocks, as it has only been found once, and then in very small amount, on a tree in a yard in Westville.

Rust, Peridermium Peckii Thuem. Plate XXIX, a. Another rust quite distinct from the preceding also occurs here on the hemlock. It forms small, cylindrical, white receptacles, usually in double rows, on the under surface of the leaves. In time these peridia rupture and discharge the orange-colored spores. The rust has been collected a number of times the past year, both on cultivated and native hemlocks, but never occurred in such abundance as to cause any noticeable injury, though the few infected leaves are shed prematurely. Both of these rusts are discussed further in the final article of this Report. 
HERBACEOUS PLANTS, Delphinium sp., Funkia sp., Pentstemon barbatus, Valeriana officinalis.

Stem Rot, Undet. sclerotial fungus. Plate XXI. A serious soil fungus was found last fall in a New Haven nursery doing considerable injury to a variety of herbaceous plants, especially to the Valeriana and Pentstemon mentioned above. The mycelium attacks the parts of the plant at or near the surface of the ground, frequently rotting off the stems. In the fall it forms subspherical reddish sclerotia both in the tissues and in the soil nearby. Pure cultures were obtained, and while the fungus grows luxuriantly, it has never produced a true spore stage. The sclerotia form as swellings at the tips of clustered threads, and are at first whitish, but soon turn reddish-brown on the outside. Their size depends somewhat on the character of the medium used in the cultures. Plate XXI, b, shows sclerotia on nutrient potato agar, which are quite similar to those found in nature, and others, grown in nutrient corn meal agar, which are much larger and more irregular. In artificial cultures made from the sclerotia these give rise to similar sclerotia, but what they will produce in the soil has not yet been determined. According to Professor Thaxter, they are probably the sclerotia of some hymenomycetous fungus.

JUNEBERRY, Amelanchier. canadensis.

Rust, Gymnosporangium clavipes C. \& P. Plate XX, b. The I stage (Roestelia aurantiaca $\mathrm{Pk}$.) of this fungus has often been seen on specimens of wild juneberry, but last July it was also found on cultivated specimens in the nursery at Storrs. It occurs most commonly on the fruit, the fringed white receptacles, containing bright orange-colored spores, often thickly covering the berries. The III, or mature stage, occurs on the cedar, so that the trouble is easily controlled by excluding this alternate host.

LAUREL, MT., Kalmia latifolia.

LeAf Spot, Septoria Kalmicola (Schw.) B. \& C. The native mountain laurel is often grown for ornament in Connecticut, and the last legislature made it the state flower. Any fungus causing injury to it thus becomes of interest. The leaf spot mentioned 
above is a very common trouble on both the wild and cultivated plants. Its chief injury consists in greatly marring the appearance of the leaves. The subcircular spots produced by it are scattered over the leaves, and reach a maximum size of about a quarter of an inch, except when closely placed, they may run together and form a more extended injury. They have a definite purplish border, with a greyish center on the upper surface in which the small black fruiting receptacles can be seen with the naked eye. Often on the same leaves other somewhat similar spots are present, but are distinguished by having a reddishbrown rather than a greyish center. The immature fungus found on these could not be determined, but the spots look like those of Phyllosticta latifoliae E. \& E.

\section{MLEADOWSWEET, Spiraea (Ulmaria) sp.}

Anthracnose, Cylindrosporium sp. We have not been able to determine specifically this leaf fungus; but, from lack of definite fungous walls in the imbedded receptacles, it seems to be a Cylindrosporium rather than a Septoria, though the spores are narrower than those of $C$. Filipendulae. A number of species belonging to these two genera have been described as having Spiraea for a host, and there seems to be some confusion regarding them. This particular fungus has spores more or less curved, with usually some indication of septa, often five when mature. The spores vary in size from $35-50 \mu$ by $2 \mu$. Frequently the spore masses can be seen with a hand lens as minute white tendrils that have oozed out on the upper surface of the leaves. The spots are purplish, most evident on the upper surface, rather thickly placed, and generally are one-eighth of an inch or less in diameter. This fungus causes considerable injury to certain of the cultivated varieties of Spiraea; the one mentioned here was collected in a New Haven nursery on plants labeled Ulmaria purpurea elegans.

\section{OAK, WHITE, Quercus alba.}

Anthracnose, Gloeosporium canadense E. \& E. This fungus injures the leaves, most frequently near the margins, where the tissues die and dry up into light brown areas of considerable extent. Isolated spots, surrounded by perfectly green tissue, 
also occur. The trouble is very similar to the leaf scorch of oak, and often one is not entirely sure, even after a microscopic examination, which is which. The specimens reported here were sent from New Canaan by Mr. A. L. Benedict, who complained of injury to his trees.

\section{PINE, SCOTCH, Pinus sylvestris.}

Rust, Peridermium pyriforme $\mathrm{Pk}$. Plate XXVIII. The writer has recently shown that this rust is merely the first stage of Cronartium Comptoniae Arth., which has the sweet fern for its alternate host. The first stage has been found in Connecticut on the pitch as well as the Scotch pine. The rust on the Scotch pine was first found by the State Forester, who had noticed for several years that a number of these young pines in the state plantation at Rainbow were attacked by some fungus. This rust occurs only on the stems, usually at the base of the young tree,

- and as its mycelium is perennial, appears year after year in the same specimen. It causes a slight swelling of the trunk, and considerable injury to the bark and young wood, so that badly infected young trees are no doubt sometimes killed. In time the spores are scattered, and all signs of the fruiting stage disappear, so that by the end of July the infected trees are not readily detected. The trouble should be easily controlled by destroying infected branches and young trees and keeping down the sweet fern in the neighborhood. This fungus is further discussed in the final article of the present Report.

\section{PINE, WHITE, Pinus Strobus.}

Pine Blight. Plate XXII. This so-called blight was one of the most conspicuous diseases of the year, since it occurred quite generally not only in Connecticut, but over most of New England. More complaints of the trouble, all after the middle of August, were received at the station than of any other for the year. Its widespread appearance caused general alarm and discussion, and an extended and intelligent account of it appeared in the Boston Transcript of August 20. The same, or a very similar trouble has been under observation for several years past by Professor Stone of the Massachusetts Experiment Station, who first noticed it after the severe winter of 1903-04. He attributes it to 
winter injury, and its prominence the past year to the unusually dry summer. In our last Report (1906, p. 320) we mentioned a case in this state which was also apparently due to winter injury. There is no question that the trouble, whether or not always due to the same causes, has been more prevalent this year than ever before.

The most serious complaints were from the northwestern part of the state, where many of the older trees were reported as seriously affected. The writer's observations were made after the first of August, chiefly on small trees from five to fifteen feet high in a Westville nursery and in the state plantation at Rainbow. We have seen no sign of the trouble in the nursery seedlings. In most of the cases examined the leaves were killed from their tips inward for about a third or two-thirds of their length, the dead tissues turning a reddish-brown color. Sometimes there was an inconspicuous yellowish spotting on the tissue below the dead area. This year's leaves were the most frequently injured, and in all cases were undersized, thus indicating the trouble at least began before the leaves reached maturity. In the fall often one or more of the leaves in a bundle dropped out, and no doubt all are shed prematurely. Occasionally a tree was seen with all the leaves dead, in which case there was no hope for it, as usually the roots were also dead. Most of the trees examined, however, showed no signs of injury to the trunk or root, such as a severe winter freeze might make; but the smallest fibrous roots were sometimes somewhat dried out, thus indicating possible suffering from lack of moisture.

Most persons have been inclined to consider this trouble the result of fungous attack. One firm claims to have sprayed trees with good results. This, if true, the writer believes to be due to stopping the transpiration of water by clogging the stomates, rather than to any fungicidal effect. We see absolutely no reason for believing the trouble due to a parasitic fungus on the leaves. The fungi found on the injured leaves were of the nature of saprophytes, being more or less tardy in their appearance. Then, too, the widespread injury to practically all of the leaves of the affected trees, while adjacent interlocking trees were often entirely free, is against any such theory. The dry season was also unfavorable for such a sudden and widespread injury 
by fungous agents. We have had seedlings for several months in the greenhouse with their leaves interlocked with leaves from diseased trees with no sign of contagion. Since the trouble is so general in its effect on the tree, a fungus, if the cause, would more naturally be found at work on the roots. As yet we have obtained no satisfactory evidence that a soil fungus is the cause of the trouble. In fact, the evidence in the main is against such a belief. We have seen some dead trees with a fungous growth on their roots and in the surrounding soil; and in one case young pines were planted in pots containing soil with such a fungus, but with no injury to the pines after several months' exposure. There seems to be no reason in the opinion of the entomologists who have examined the injured trees for believing that the trouble is caused by insects.

Everything considered, the trouble seems to be a physiological one, brought on by adverse conditions. In some cases winter injury alone probably accounts for it. In this state during the past year, it is apparently largely due to the drought; or possibly the late frosts of May II and 2I may have injured the protruding tips of the young leaves and thus have been altogether responsible for the unusual prominence of the trouble. The pine needles grow from the base, so that the exposed young tips could have been killed or injured and a growth still be made from the protected basal part. In the case of the sycamores, which we know suffered from these frosts, the whole of the young leaf was exposed, and so was entirely killed. In view of these possible and at the same time unusual causes, we do not look for the trouble to be so prominent the coming season as last year.

\section{POTATO, Solanum tuberosum.}

Internal Brown Spot. Plate XXIII, a. The writer first saw this trouble in Connecticut in potatoes that were imported from Scotland in 1906 for experimental purposes. It was especially bad in the Midlothian Early variety. The past year it was also found not uncommon in certain of Mr. East's numerous varieties, especially in those of European origin. Among the worst affected of the varieties were Sutton's Field Ash Leaf, Alderman, Harbinger; Royal Ash Leaf Kidney, Britannia, Snowball, and Early Maine, of which the last only is of American origin. A 
few Connecticut growers have complained of trouble similar to this, and Morse (5) also reports it from Maine in 1907.

The trouble is in no sense a true rot. The affected tubers may or may not show the disease on the outside. Usually, however, some indication of its presence is given by a slightly shrunken appearance and a reddish discoloration of the skin. When cut open, the tubers show a conspicuous reddish disease of the tissues. This may occur in isolated spots scattered through the healthy flesh, having no apparent connection with the exterior, or there may be a band starting from the exterior and progressing more or less deeply inward. Taken as a whole, the trouble most frequently starts at the stem end and works toward the bud end and inward. In the cases where the trouble shows as a band at the surface, it can scarcely be told from the blight disease caused by Phytophthora. In some of the worst affected European varieties the spotting finally runs all through the tuber, appearing much worse than that shown in the illustration. Often the spots have a watery appearance, especially in varieties poor in starch, but no evident wet rot develops from them.

Microscopic examination shows that the protoplasmic contents. of the cells in the injured areas are diseased and discolored reddish-brown. Often this gives an appearance as if the plasmodium of some extraneous organism were present. No evidence of fungous threads or bacteria was detected. Attempted cultures made from the diseased tissues uniformly gave no growth of any -kind, except in a few cases where outside contamination had occurred. Similar cultural attempts made by the writer (I) in Illinois some years ago, likewise indicated that the trouble was not of a parasitic nature, and Stewart of New York also failed to obtain any parasitic organism from the diseased tubers. All of the investigators in this country agree in considering it a physiological trouble, and to the writer it appears to be very much like the Baldwin Spot of apples. .

Poor soil, dry weather, lack of potash or lime, susceptibility of certain varieties, etc., all have been assigned as probable or partial causes. In this state last year the drought was certainly severe, but so far as observed by the writer, the trouble was conspicuous only in varieties poor in starch. Stewart (6), who made a study of the disease in New York in I895, showed that it was not prop- 
agated by diseased tubers, and others have had similar results. The trouble was particularly prominent in this country about I893-95, as it was then reported by the writer (I) in Illinois, Green (2) in Minnesota, Stewart (6) in New York, and the United States Department of Agriculture. It seems to be common in Europe, and according to Jones (4), it is not generally regarded there as a parasitic trouble. Sutton ( 7 ) notes its presence in England, where it is very likely to occur on light loams or sandy soils, when twenty to seventy per cent. of the tubers may be diseased. Helms (3) reported its presence in Australia in 1895 . The following are the references to this trouble that have been alluded to here:

I. Clinton, G. P. Interior Spotting. Ill. Agr. Exp. Stat. Bull. 40: I38-9. I895.

2. Green, S. B. Internal Brown Rot of Potatoes. Minn. Agr. Exp. Stat. Bull. 39: 212-3. Ibid., 45: 310. 1895.

3. Helms, R. Report on an Investigation into the Potato Diseases prevalent in the Clarence River District. Agr. Gaz. N. S. Wales 6: 328 . 1895 .

4 Jones, L. R. Internal Brown Spot. U. S. Dep. Agr. Bur. Pl. Ind. Bull. 87: I2-I3. I905.

5. Morse, W. J. Internal Brown Spot of the Tuber. Me. Agr. Exp. Stat. Bull. I49: 31S-2I. I907.

6. Stewart, F. C. Internal Browning of Potatoes. N. Y. Agr. Exp. Stat. Bull. IOI : 78-82. 1896.

7. Sutton, A. W. Internal Disease. Journ. Roy. Agr. Soc. Engl., III, 9: 599-600. 1898.

Scurf, Spondylocladinm atrovirens Harz. Plate XXIII, b-d. In the spring of 1907 this potato disease was first called to my attention by Mr. East, who noticed it on a few tubers among the many varieties to be tested that year by the station. It was also found not uncommon that fall on a still larger number of these same varieties. While not a serious potato trouble, it is interesting because it has not before been reported in this country. It has been known for some time in Europe, and apparently was introduced into Connecticut on imported varieties. On unwashed tubers the trouble does not show very plainly, but on perfectly clean ones it appears as a slightly sunken area, of greater or less extent, which has a darker brown color. It is not nearly so conspicuous or injurious as scab, though it finally causes the tubers to shrink somewhat over the affected areas, and may offer entrance for decay germs. 
The fungus that causes this trouble is usually evident, when tubers are kept for a time in a moist chamber, as a scanty growth of short, upright, blackish bristles, easily seen with a lens. These are the conidiophores, and bear irregular whorls of spores on their upper end (see illustration, Plate XXIII, c). The conidiophores are dark reddish-brown, often with a slightly swollen base, and taper somewhat toward their free extremity. They are septate $(6-16$ septa), and vary in length from $160-425 \mu$, and in width from 6 - I2 $\mu$. While stiff, and generally erect, they are sometimes somewhat bent or kneed, and rarely branched toward their base. They arise singly, or more than one, from a knot of fungous cells which infest the epidermal cells. The spores are reddish or greyish, but lighter colored than the conidiophores, and easily fall from them. They vary from oval to chiefly obclavate, and are $4-8$, usually 6 , celled. They are fastened to the conidiophore by the broader end, and are usually acute at the apex, but will occasionally be rounded at both ends. On falling off, they generally show the point of attachment as an evident dark ring at their base. They vary from $23-52 \mu$, chiefly $30-40 \mu$ in length, and from $6-9 \mu$ in greatest width. In germination they put forth a single tube at the pointed end.

This fungus was apparently first found and described in Vienna, Austria, by Harz, in I87I (Einige Neue Hyphomyceten: I29-30), Frank, in I897 (Kampfbuch gegen die Schädlinge unsere Feldfrüchte) and again in I898 (Ber. Deut. Bot. Ges. I6: 280-I) called attention to a new sterile fungus, named Phellomyces sclerotiophorus, which formed very minute dark colored sclerotia in the epidermal cells, and which he held responsible for a sort of dry rot of potatoes under some conditions. Johnson (Econ. Proc. Roy. Soc. Dublin I: I6I-6. I903) and Smith and Rea (Trans. Brit. Myc. Soc. 1903-04: 59-67) have also called attention to this Phellomyces causing injury to potatoes in Great Britain. In 1905 Appel and Laubert (Ber. Deut. Bot. Ges. 23: 2I 8-20) succeeded in getting these sterile sclerotia to produce a fruiting stage which they recognized to be the Spondylocladium atrovirens of Harz. In 1907 they gave a further account of the fungus in Arb. Kaiserl. Biol. Anst. Land. Fortw. 5: 435-4I.

In some of the specimens which we have seen, very small blackish spots or "sclerotia" occurred on the surface of the tubers apart 
from and with the fruiting stage of the Spondylocladium; these we have considered to be the Phellomyces sclerotiophorus of Frank. These sclerotia are composed of compacted colored cells of the fungus, which more or less completely fill the epidermal cells (see Plate XXIII, d). The mycelium of the fungus evidently at first does not penetrate very deeply into the tissues, and so forms only a superficial injury.

Saccardo (Syll. Fung. Io: 662) describes another species of Spondylocladium, S. abietinum (Zuk.) Sacc. on potato tubers, also from Vienna, Austria, that very probably is the same as this, though the spores are said to be only $3-4$ septate, but are 38 by $9 \mu$. The spores of our specimens are smaller than the measurements given by Appel and Laubert for S. atrovirens, but agree in the number of septa, while they agree in size with the other species, but not in the number of septa. Specimens were sent to Appel, who states that he is not yet sure whether these two species are distinct or not, though there seem to be at least two forms, one having larger spores than the other. If the species are distinct, our specimens apparently belong to the smaller spored species.

\section{ROSE, Rosa. sp.}

Rust, Phragmidium speciosum Fr. Sturgis, in his Report for 1893, p. 86, mentioned injury to cultivated roses by another species of rust, $P$. subcorticium, but this is the first note in the station's Reports of the above species. It was found on cultivated roses in Westville, causing considerable injury to the stems, to which it was limited. As usual, only the III stage appeared on the infected stems, forming small, hard, black pustules, uswally occurring in clusters.

\section{SWEET PEA, Lathyrus odoratus.}

Dampening OfF, Pythium sp., Rhizoctonia sp. During last July, when sweet peas were about one-third to one-half grown, occasional vines showed evidence of trouble by turning yellowish, wilting, and finally drying up entirely. An examination of such plants showed that they were more or less separated from their roots near the surface of the ground by a reddish-brown rot. Microscopic examination of the injured tissues revealed the 
presence of one or the other of the above fungi as the cause of injury. Although the trouble was quite common, usually enough plants escaped to make a fair stand. As manure encourages the growth of such fungi, it should be used with care, especially at the surface of the ground. The cold, backward spring was apparently largely responsible for the unusual amount of dampening off this year.

\section{SYCAMORE, Platanus occidentalis.}

- Frost Injury. One or both of the severe frosts of May I I and 2 I severely injured the unfolding leaves of the sycamore trees throughout the state, so that practically all of those out of the buds were killed outright. The injury was evident immediately afterward, but became even more conspicuous later, when the remaining leaves began to assume some size, through the very scanty foliage, which in many cases was confined entirely to the tops of the trees. While some trees had all their leaves killed, and so were destitute of foliage for a time, most of them finally put forth about one-fourth to one-half the normal foliage, but even then the injury was evident all summer. This injury to the sycamore was not limited to this state, since von Schrenk (Rept. Mo. Bot. Gard. I907: 8I-3) has published a short article in which he calls attention to similar injury extending from the Mississippi Valley eastward. The writer did not notice any serious damage to the leaves of other trees, but probably the sycamore leaves were the only ones ${ }^{\prime}$ just in the right condition for such an injury when the frosts came. Murrill (Journ. N. Y. Bot. Gard. 8: 157-61. J1. 1907), Lloyd (Plant World 10: 2 13. S. Ig07) and Halsted (Ann. Rep. N. J. Agr. Exp. Stat. I907:38I. I908) have made the mistake of attributing this trouble to the fungus Gloeosporium nervisequum, which frequently injures the foliage of sycamores.

\section{TOBACC0, Nicotiana Tabacum.}

Sumatra Disease, ?Bacterial. Shamel has previously called attention to this trouble in Bulletin $I_{5}$ o of this station. The seed from which the Sumatra tobacco was grown was imported by the United States government a few years ago. Last June Mr. Shamel showed the writer a small experimental seed bed at 
Granby in which most of the plants had been killed by this disease; the surviving plants had ceased to grow, at least for the time, and a few that were transferred to crocks in the greenhouse never made any further growth. The injury was not exactly like either the dampening off troubles or the root rot disease. So far as could be determined from this bed, the disease started in the roots, and was most manifest in the vicinity of the bundles, up which it developed a short distance above ground. The roots and the base of the stem, in time, were so severely injured that most of the plants succumbed. Those alive usually showed the lower leaves with a sickly, yellowish color, and within their tissues was sometimes found a Pythium-like fungus, which was apparently an after-comer. The disease appears, on the whole, like a bacterial trouble of the bundles, but specimens of the older plants were not seen to throw further light on the subject.

Concerning this trouble in the field, Mr. Shamel in his bulletin says: "A field was set out with plants grown from imported seed, which were attacked by a fungous root disease and all died with the exception of a few plants. These resistant or immune plants were found irregularly over the field, and produced ripe tobacco of excellent quality. All the other plants were completely destroyed, with the exception of one or two semi-resistant plants that produced a large amount of seed, but very few and extremely small leaves. The seed was saved separately from the resistant and semi-resistant plants, and sowed in separate sections of the seed beds. The resistant seeds produced perfectly resistant plants, both in the seed bed and in the field where the plants were destroyed the previous year. Most of the seedlings from the semi-resistant seed died in the seed bed. Enough were finally secured to set out one or two rows in the field. These plants grew slowly, some died, and none reached maturity, all having the characteristics of the diseased plants in roots, stem and leaves. Some of the resistant seed was sown on the seed bed where the diseased seedlings had been destroyed, and this immune seed produced perfectly resistant plants under these circumstances."

Mr. Shamel seems to think that our native varieties are not subject to this trouble, and so far it has not been found on them. 
Stevens (N. C. Exp. Stat. Bull. I88. I903), however, has described a bacterial wilt of tobacco from North Carolina that possibly may prove to be the same as this. Uyeda also has described a similar bacterial trouble from Japan, and Delacroix from France. All of these, however, describe it as a field disease, - and little or no mention is made of its injury in the seed bed.

\section{TOMATO, Lycopersicum esculentum.}

Chlorosis. Last fall in Westville the writer saw a large field of tomatoes in which many of the plants showed leaves more or less mottled with yellowish-green. This unhealthy coloring was quite similar to the injury that can be transferred to tomatoes from calicoed tobacco. On inquiry, it was found that the tomatoes had been severely injured by the late frosts of May, but had finally recovered and had borne a fair crop. It looked to the writer as if this chlorosis of the plant was one of the after effects of the frost, and was of the nature of the so-called calicoed tobacco, but whether or not it was infectious through the juice of the injured plant was not determined. Woods claims that a similar trouble in tomatoes can be produced by a very severe pruning back of the vines, and possibly the frost injury was in effect merely such a pruning.

\section{TRUMPET CREEPER, Tecoma radicans.}

Leaf Blight, Cercospora sordida Sacc. This fungus shows on the under surface of the leaves as small, angular, olive-brown patches, either distinct or more or less run together. The spore stage which forms these patches consists of short, dark, olivebrown conidiophores bearing lighter colored spores. The spores vary from linear to linear-obclavate, are smoky tinted, 4- I2 septate, straight or somewhat curved, and range in size from $40-120 \mu$ by $2.5-5.5 \mu$. The injury to the leaf first shows on the upper surface as a yellowish discoloration which in time may change to reddish-brown, but ordinarily it is not very severe. Two other species of Cercospora have been described from the United States on this same host, but it is doubtful if all three are distinct. 


\section{ROOT ROT OF TOBACCO-II.}

In the Report for I906 the writer gave a somewhat extended account of the fungus Thielavia basicola (B. \& Br.) Zopf, and the injury it caused to cultivated plants, especially to the tobacco in Connecticut. In this article is added such additional information as came to hand during the past season, when the investigation was brought to a close. Dr. E. A. Bessey, of the Government's Subtropical Laboratory in 'Florida, writes that he has found this fungus on the roots of tobacco sent from Cuba, on cultivated violets from the District of Columbia, on the garden pea in South Carolina, on sugar beets from Utah, and on various plants in Florida. Galloway, in his book on violet culture, also reports it as a serious pest on violet roots. No doubt, it is a common and widely distributed soil fungus, at least much more so than reports have hitherto indicated.

Cultures. During the past year and a half the fungus has been under observation in cultures with various media in an attempt to develop the ascospore stage. This has not been obtained, though the fungus was grown on tobacco roots on which this stage occurs in nature in Connecticut. Fresh tobacco roots containing the fungus were sent to Professor Thaxter, who tried to isolate the ascospores by the Barber method, and obtain cultures directly from them-our cultures having come originally from the endospores, or possibly from the chlamydospores-but he was not successful in obtaining such cultures. Professor Thaxter has, on the other hand, a culture of another species of Thielavia which forms the ascospores, but never the endospores and chlamydospores. These facts possibly may indicate that the ascospore stage has no relationship to our fungus, and that it occurs on the tobacco roots as a parasite of the fungus rather than as a stage of it. However, the mature stage of certain other fungi, the apple scab, for example, is rarely, if ever, obtained in artificial cultures, while the other stages readily grow there. For the present it is perhaps best to consider the ascospore form as the mature stage of the fungus with the understanding that further study is needed to positively prove this connection. 
Seed beds. There was more or less complaint of the root rot in the tobacco seed beds the past spring, especially in the neighborhood of Granby. Some growers lost their beds, and others gave them up because of previous injury, and made new ones. Where it can be done conveniently, this is perhaps the wisest thing to do. If it is of advantage to retain the old beds, our experiments have shown that they can be treated successfully with either formalin or steam, and the injury will be largely or entirely prevented.

Several beds were treated with formalin last fall and spring, all of which showed that the treatment had done no harm, and in most of them some benefit resulted even when the root rot or the dampening off troubles were not present to any injurious extent in the check beds. The two beds at Bridgewater, mentioned in our last Report, p. 329, which were treated in the fall of 1906 for the stem rot, did not give a fair idea of how effective this treatment would prove for this trouble, since no serious injury from the stem rot developed in the treated or untreated parts of the beds the next spring. In both cases, however, the plants upon the treated parts were a little more advanced than those on the untreated, and there were also fewer weeds and angle worms in them. In a bed treated for root rot at Poquonock in the fall, the soil had been covered with a layer of sand two or three inches deep just before the treatment, and this apparently interfered somewhat with the full action of the formalin on the infested soil beneath, since a little root rot was found the next spring in the treated part, though not as much as in the untreated. The injury in either case, however, was not severe, the sand apparently, when spaded in, having helped the mechanical character of the soil, or in some other way prevented as serious injury to the tobacco from the fungus as had occurred the year before.

The most extended experiments were made by the Director and the writer in a bed grown especially for the station by $\mathrm{Mr}$. E. S. Hale of Portland, and upon these we report more in detail. This bed, which was one that had been injured considerably by the root rot the year before, was ninety-one feet long by six feet wide. In the fall, before treatment, it had been manured and tilled in the usual way, and in the spring such com- 
mercial fertilizers as were needed were used. It was sown with sprouted tobacco seed April 25, covered with cloth, and watered as needed. The only difference in the treatment of the various plots into which the bed was divided was as follows:

(I) In the fall, November gth, a twenty-five foot plot was treated with formalin, strength I to Ioo water, this being sprinkled on at the rate of one gallon to each square foot.

(2) In the fall a seventeen foot plot was treated with steam by means of a steam rake whose teeth were pushed about eight inches into the soil. The rake was wide enough to take in the width of the bed, and two lengths made the seventeen feet. The rake was covered with sacks and boards to hold in the steam. The treatment with the first length was made for two and three-quarter hours, because of some difficulty with the steam. At the end of the treatment tests of the temperature of the soil midway between the teeth showed an average at two inches of $96^{\circ} \mathrm{C}$., at four inches of $99^{\circ} \mathrm{C}$., at eight inches, $97^{\circ} \mathrm{C}$., and at ten inches, $82^{\circ}$ C. Between the rake and the boards on the outside of the bed the temperature was not nearly so high. The second treatment was made only for one and one-half hours, and probably the temperature did not reach quite so high, but no difference in the plants was noticed on this account.

(3) In the fall a nine foot plot was treated with formalin, strength I to 200 of water, using one gallon to each square foot.

(4) In the spring, April I6th, a fourteen foot plot was treated with formalin, strength $I$ to Ioo, using two-thirds of a gallon to each square foot.

(5) After the plants were up, a ten foot plot was sprinkled with weak formalin water, about I to rooo or I200, nine times (May 3, I5, 22, June I, $8, I 2,15,20,25)$ instead of being watered, as was the rest of the bed on those dates.

(6) A sixteen foot plot was reserved as a check; that is, it had no untusual treatment.

The final results of these treatments, in general, were as follows:

(a) The steam heated plot (No. 2) produced the best stand, with plants most advanced, though at the time for pulling it had lost much of this lead over the formalin treated plot (No. I), which was next best, and had a fine stand of plants. The formalin treated plots (Nos. 3 and 4 ), though somewhat behind plots 2 and I, produced a good lot of plants. The formalin sprinkled plot (No. 5) and the check or untreated plot (No. 6) were both about the same, and made a very poor stand and growuth. The contrast between these two poorest plots and the two best at pulling time is shown by the illustrations in Plate XXIV. 
(b) Sprinkling with weak formalin (plot 5) evidently injured the plants, as the stand was very uneven, and the plants small at pulling time. This was possibly due to the large number of treatments, and began to show about the time of the third treatment, though by accident the first was about twice as strong as the others. Apparently the sprinkling method is not of much value.

(c) The steam treatment very materially reduced the number of weeds, and apparently the formalin treatment had somewhat similar effect. The formalin and steam both killed the angle worms, and the latter, undoubtedly, wire worms, insects, etc. The total number of weeds taken from each plot and the rate per square foot for each was as follows: Plot No. I, II59, a rate of 8 per square foot; plot No. 2, I04, or a rate of $\mathrm{I}$ per square foot; plot No. 3,606 , or a rate of II per square foot; plot No. 4,388 , or a rate of 5 per square foot; plot No. 5,885 , or a rate of 15 per square foot; plot No. 6, 3188, or a rate of 33 per square foot. The rate of the last two was raised considerably by the poor growth of the tobacco, which thus failed to crowd out the weeds; in plot 5 , this may have been offset by injury to the weeds from the formalin.

(d) The untreated plot (No. 6) had considerable root rot in it, but this was not so severe as to entirely rot off the roots of many of the plants, since these usually retained a firm hold on the ground. In the formalin plots (Nos. I, 3, 4) and the steam heated plot (No. 2) only a very little root rot was finally found, not enough to cause any harm whatever.

(e) We do not believe that the marked difference between these steam and formalin treated plots and the untreated plot was entirely due to the prevention of the root rot, as this did not seem so prominent as to have caused this difference. It is possible that part of the difference was due to a disturbance of the bacterial flora of the soil, in favor of the species more beneficial to plant growth, such as has been reported in Europe in the treatment of the soil of vineyards with carbon bisulphide.

Conclusions. From all of the experiments we have made during the past two years, we believe that the formalin treatment is a very efficient and convenient method of protecting tobacco beds against the root rot and possibly the dampening off trouble. 
The formalin is best applied in the fall, after the beds are prepared for seeding, but may also be used early in the spring, if the beds are thoroughly aired afterwards. Formalin, 40 per cent. strength, used at the rate of I to Ioo of water, should be gradually sprinkled on the beds, using about one gallon to each square foot of surface treated. The bed should then be covered for a day or two to keep in the fumes. The steam treatment is fully as effective against the root rot, and even more efficient in killing weed seeds, but is more cumbersome and expensive, especially if the necessary apparatus is not at hand. The soil in this case should be steamed for at least an hour after the apparatus is in good running order.

In the fields. The drought of the past summer had considerable effect on the growth of tobacco at that time, but the moist weather coming toward the end of August helped many of the fields to partially recover. Because of the drought the root rot fungus apparently was not so conspicuous in the fields as last year, though no doubt the injury it did cause was more or less obscured by the injury from the drought. As in the previous year, the tobacco in the region of Suffield, especially in certain fields, suffered severely from root rot or some other cause. From our examinations there, we are more convinced than before that the trouble is not alone caused by the root rot fungus, though this is the only agent of injury that we can be sure of so far. It is very probable, however, that in the worst affected fields such matters as fertilizers, drainage, poisoning of the land through continued use for tobacco, may have had as much or more to do with the failure of the crop than this fungus.

Our crock experiments (see Report of 1906, p. 362) with fertilizers, etc., in soil from two fields in Suffield that gave very poor crops in 1906, did not throw very much light on the subject except that those crocks treated with formalin gave by far the best plants all through the test. At first the best plants in all the crocks were apparently those whose roots were freest from root rot, but the single plants finally left in each crock at the end of the experiment did not show so much difference in the amount of fungus on their roots as they did in their vigor of growth. We have noticed in the fields, too, that it is often difficult to entirely explain the difference in size of individual 
mature plants by the amount of fungus on their roots. However, this possibly may be explained by the fact that the injury which counts most is that given to the young plant when some main or tap root is rotted off and thus stunts the growth, at least for the time, rather than a general, but not so severe, injury distributed over the root system, and which in mature plants might show as conspicuously as in the other case, so far as the total amount of root rot is concerned.

No field experiments were conducted directly by this station, but the writer had the privilege of seeing those made under Mr. Shamel's directions at Suffield with various fertilizers, etc. While there was some slight difference between these plots (most prominent in the plot where the ground had been treated with formalin, and in one of the fertilized plots), there did not seem to be sufficient difference to indicate any practical way of successfully treating infected fields. These plots were part of a field that had been in tobacco before, and the rows continued onto land that was new, or at least, not in tobacco the year before. The difference in the size of the tobacco on the new and the old land, in favor of the new land, was the striking thing to be seen here, rather than that due to any difference in the treatment. In other instances that we have known, the tobacco on the new land seemed to do much better than that on the adjacent old land.

Conclusions. There seems to be, so far as now known, no effective treatment for a field in which the tobacco has been gradually going backward in spite of good care. In such a case the best thing is rotation for a year or two. Of course, on many farms the land available for tobacco is no more than is needed, and this is one of the reasons why rotation is not more commonly practiced. In such instances the amount of injury the crop suffers will determine whether or not the farmer can afford to use this land for other purposes. We saw one field last year, however, where there was no question but that the owner would have saved money if he had not used it at all, and no doubt there were other cases of the same sort. 


\section{HETEROECIOUS RUSTS OF CONNECTICUT HAVING A PERIDERMIUM FOR THEIR AECIAL STAGE.}

GENERAL CHARACTER OF RUSTS.

Appearance. Rusts are among the most common and widely distributed forms of parasitic fungi. While it is difficult to describe their general appearance so that one unacquainted with the rusts can readily distinguish them from other fungi, still they do possess characters by which the expert readily recognizes these fungi with the naked eye. Perhaps to mention such common forms as the grain, asparagus, and chrysanthemum rusts, the cluster-cup of apple, and the cedar-apples of red cedar, is one of the best ways to describe them. In appearance they more nearly resemble the smuts than any other fungi, and in some cases are easily confused with these. In general their outbreaks occur scattered or clustered on the leaves or stems of plants (hosts), forming small roundish or linear spore clusters or sori. These sori, as a rule, are less dusty and more highly colored than the smuts. Early in the season the rusts often have a reddish, and later, a blackish color, as seen in the grain and asparagus rusts, due to the production of different stages.

Stages. The rusts are fungi that usually have more than one spore stage, in some cases having four different forms. The earliest stage, called the pycnium ( $\mathrm{O}$, spermagonium), is the most inconspicuous, and the one about which the least is known, for botanists are not yet certain whether it is a spore stage or the male element in sexual reproduction, and whether in either case it is now functional. It is generally associated with the next stage, often occurring on the upper side of the leaf, while the latter occurs on the lower, and is usually distinguished as minute blackish specks situated on discolored spots. (Plates XXVI, b; XXX, a.) The next, and generally considered the first spore stage, is called the aecium ( $\mathrm{I}$, aecidium, etc.). This usually has a distinct covering or cup-like receptacle called the peridium, which, when it opens, becomes toothed, fringed, or irregularly worn away, disclosing the enclosed mass of yellowish or orange-colored spores. The peridia in different species vary 
from the size of a small pinhead up to about one-third of an inch in diameter. (Plates XXVI; XXVIII, a-b.) The next stage, known as the uredinium (II, uredo-stage), usually forms numerous, small, naked outbreaks of reddish-brown spore masses on the surface of the leaves, etc. (Plates XXVII, a; XXVIII, c; $\mathrm{XXIX,b.)} \mathrm{It} \mathrm{is} \mathrm{the} \mathrm{stage} \mathrm{most} \mathrm{commonly} \mathrm{seen,} \mathrm{as} \mathrm{its} \mathrm{function} \mathrm{is}$ to spread the fungus over the infected plants and to new ones. The last stage, called the telium (III, teleuto-stage), is usually formed late in the season, and is the one that generally carries the fungus over the winter, so it is considered the mature stage. (Plates XXVII, b; XXVIII, d; XXIX, c.) The sori in this case may be developed externally on the plants or be imbedded in their tissues, and so the spores do not always form a dusty mass to be easily scattered, as in the uredinial stage. With the germination of the telial spores (usually forming in this process very temporary thin-walled secondary spores called sporidia) the rust may start anew the cycle of its life history on successfully infecting its proper host.

Heteroecism. It will be seen from the preceding account that rusts possess, in some cases, a complicated life history. The I, II and III stages are so different that they were considered by the early botanists as distinct genera (now known as form genera), and so they were frequently described under different specific names. When the life history of a rust is fully determined, all of its stages are then united under one name, the generic name being decided by its telial form. The relationships of the rusts are further complicated by the fact that, with some species, certain of their stages may occur on one plant and the others on an entirely different plant. This is known as heteroecism. In such cases there is no general rule by which a person can definitely determine. what hosts the different stages will occupy, though investigations are throwing considerable light on this matter. Therefore the life history of each species must be worked out by itself. Clues to the alternate host often may be obtained by closely watching the fungus in nature and determining what other related rusts with their hosts occur in the neighborhood of the one under observation. For instance, the farmers of England years ago noticed that the wheat rust was worst in the neighborhood of barberries having the cluster-cup rust; and from this clue De Bary, the great German mycologist, by infection 
experiments on these two hosts was the first to prove definitely their relationship and the phenomenon of heteroecism.

Kinds of aecia and their relationship. With the heteroecious rusts usually the $O$ and I stages occur on one host and the II and III on the alternate host. The use of the I stage is to carry the fungus to the second host, that of the II stage to spread it on this host, while the III stage carries it back to the first, usually early the next year. Now, the I stage, or aecium, may have the spores without a peridium (when it comes under the form genus Caeoma); the peridium may have the margin merely toothed (Aecidium); its margin may be more or less decidedly fringed (Roestelia); or the fragile peridium may break up rather indefinitely (Peridermium). The Caeomae species are not very common in this country, and their relationships have in but few cases been definitely worked out. From the investigations that have been made in Europe one may expect that most of them are stages of the Melampsora-like rusts. The species of the Aecidia are very numerous, and the American heteroecious forms have been found by Arthur and Kellerman to belong chiefly to the Pucciniae and Uromyces that inhabit grass-like plants. The American species of Roesteliae, which occur only on rosaceous hosts, through the studies of Farlow, Thaxter, Arthur and Kern, are now very completely connected with the species of Gymnosporangia, which occur only on cedar-like hosts.

Relationships of the Peridermia. The Peridermia, some thirty odd species of which Arthur and Kern (5) have described in their recent American monograph, limit their attacks to coniferous hosts. In this form genus the peridia generally extend prominently above the tissues of the host, the walls are white, very fragile, and separate in a rather indefinite fashion upon the wearing away of the aecia. All Peridermia, apparently, belong to heteroecious rusts, but so far the relationship of less than a dozen American ones to their telial stage is known. Added interest is given to the Peridermia because they are the aecial stages of at least seven telial genera, as now understood, namely, Calyptospora, Coleosporium, Cronartium, Melampsorella, Melampsoridium, Melampsoropsis, Pucciniastrum, and possibly Necium and Kuehneola (in case of $K$. albida). It is with the Connecticut species of these telial genera and their known or possible Peridermia that we are to deal especially in the present 
paper. So far, in America, Shear (16) has shown that Peridermium cerebrum on trunks of Pinus sps. belongs to Cronartium Quercus on Qucrcus sps.; Kellerman (13), that Peridermium Rostrupi on leaves of Pinus rigida is connected with Coleosporium Campanulae on Campanula sps.; and the writer $(6,7)$, that Peridcrmium acicolum on Pinus rigida belongs to Coleosporium Solidaginis on Solidago, etc., Pcridermium pyriforme on trunks of Pinus sps. to Cronartium Comptoniae on Comptonia asplenifolia, and Peridermium consimile on leaves of Picea nigra to Melampsoropsis Cassandrae on Cassandra calyculata. The probable relationship of several of our other species is known through the work of European investigators, especially that of Klebahn. Farlow (9, ro) and others have suggested possible relationships of still other species.

Injury. While rusts in general are among the most injurious fungi, the forms discussed here are none of them very serious pests, at least in Connecticut. In Europe more or less complaint has been made of certain of the Peridermia attacking forest trees. Stone, a few years ago, recorded injury to blackberries in Massachusetts by Kuehneola albida, so far found here only once on cultivated blackberries. The rust on the leaves of the pitch pine was very common in a forest reserved for landscape effect at South Manchester, and caused the owner some uneasiness lest it become of more serious trouble. A rust which was found on the trunks of the Scotch pine in the state plantation also would become a serious pest if more abundant, since its injury to the young tree is very considerable. While one or the other of the hosts of all of the forms discussed here are of some economic importance, so far the injury to them by their rusts has not been such as to attract any considerable attention. It is not, therefore, because we consider these rusts at present of great economic importance in the state that we have made a special study of them, but rather because of their very interesting problems of heteroecism and a desire to solve more completely their life histories and to awaken a more general interest in them.

Classification. Because of their variable number of stages and of the heteroecism of certain species, the classification of the rusts is more difficult than that of most fungi, and gives a basis for honest differences of opinion among investigators. Some botanists lay more stress on the host than others, thus greatly multiplying the 
number of species. A further source of trouble arises from the fact that morphologically similar rusts often infect entirely different, though closely related hosts, as proved by infection experiments. This gives rise to further confusion, since some botanists consider such rusts as distinct species, while others classify them as physiological species, or consider them merely as strains. These differences of opinion cause a grouping together of species and genera on the one hand, or to their splitting up on the other, according to the attitude of the investigator. 'In this paper we have used the nomenclature of Arthur (2), as given in his recent monograph, because he has made the most extended and thorough study of our American rusts; and, to avoid unnecessary confusion, we prefer to follow his work until further investigations shall have more definitely determined the nomenclature and relationships of the forms discussed.

Species considered. As stated before, we deal here only with Connecticut rusts supposed to have a Peridermium for their aecial stage. So far only four species of Peridermium ( $P$. acicolum, $P$. pyriforme, $P$. consimile, $P$. Peckii, Plate XXXII, I) have actually been found in the state. It is quite probable that other species exist here, since the search has extended only over a period of two years, and has not been made in the northwestern part of the state, where these species probably occur most abundantly. From their hosts and distribution, other species likely to occur here are $P$. Rostrupi on leaves of Pinus rigida, $P$. Laricis on leaves of Larix sps., $P$. cerebrum and $P$. globosum on branches of Pinus rigida, $P$. globosum and $P$. Strobi on branches of Pinus Strobus, $P$. conorum-Piceae on cones of Picea nigra, $P$. elatinum, which forms witches' brooms, and $P$. balsameum, which does not, on leaves of Abies balsamea. On the other hand, the uredinial or telial stages of thirteen species have been found in this state, namely, Coleosporimm Campanulae, $C$. Solidaginis, C. Vernoniae, Cronartium Comptoniae, Kuehneola (Chrysomyxa) albida, Melampsoridium Betulae, Melampsoropsis Cassandrae, M. Pyrolae, Necium Farlowii, Pucciniastrum Agrimoniae, $P$. minimum, $P$. pustulatum, $P$. Pyrolae. Besides these there are six to ten other species that possibly may be found here in time. See list at end of this article. A special discussion of those already found here follows. 
SPECIAL DISCUSSION OF CONNECTICUT SPECIES.

\section{Coleosporium Campanulae (Pers.) Lév. (I. Peridermium Rostrupi E. Fisch.)}

I. Plate XXV, a, (from Ohio Fungi I04). The aecial stage of this fungus has not yet been found in Connecticut. The fact that it occurs on the same host as Peridermium acicolum and is scarcely to be distinguished from the latter may indicate that it has been confused with this species. While the relationship between a Peridermium on pine leaves and a Coleosporium on Campanula was first shown by European investigators, Kellerman (13) was the first in this country to produce Coleosporium Campanulae from a Peridermium on Pinus rigida, collected in Ohio. Arthur and Kern (5, p. 416) later called the aecial stage Peridermium Rostrupi, after the European form, though previously it had not been considered distinct from our common $P$. acicolum.

II, III. Plate XXV, b-c. These stages have been found in Connecticut only once, in October, I907, on Campanula rapunculoides growing in a nursery at Westville. The II stage was common on the leaves, causing some injury, and the owner stated that he had noticed the rust on these plants for a few years past. The writer did not find the III stage on the plants outdoors, but it appeared later, after some of them were removed to the greenhouse for further observation. By the end of November the outdoor plants were entirely dead above ground. This shows that the fungus did not carry over the winter through the immature uredinia on the leaves, which in some plants escape winter injury. The III stage, of course, with all heteroecious rusts, is of use only in carrying the fungus to the alternate host, in this case, the leaves of Pinus rigida. There was little likelihood, however, that the Peridermium occurred on the pine trees in this vicinity, since these were watched rather closely without finding it. The question, then, as to how the fungus passes the winter and again appears on the Campanula is interesting. Of course it is barely possible that this is accomplished through an occasionally undeveloped infection on the underground perennial parts. As the uredinial stage is hardly to be distinguished from that of the Coleosporium on Solidago, and as the uredinia of the latter were common in this neighborhood, it occurred to the writer that possibly the rusts on these two hosts were not 
distinct, as supposed. The germination of the uredinial spores of the two (Plates XXXII, 2), however, was somewhat different, those from the Campanula sending out irregular and much more branched germ tubes than those from the Solidago. The uredinial spores from the Campanula, too, sown on Campanula, produced the II stage in about eleven days, but failed to infect Solidago rugosa and Aster sps., upon which they were also shown. A later attempt to infect the Campantila with spores of the Coleosporium from a species of Aster likewise failed. The evidence as a whole seems to indicate that these species are distinct, and so how Coleosporium Campanulae passes the winter in this nursery is left unsolved.

\section{Coleosporium Solidaginis (Schw.) Thuem. (I. Perider- mium acicolum Und. \& Earle.)}

I. Plate XXVI. The earlier writers in Europe, and even more recently in America, called the common forms of Peridermium on species of Pinus, Peridermium Pini, sometimes distinguishing the leaf form as acicola and the stem form as corticola. Later Fuckel called the corticolous form P. Pini and the leaf form $P$. oblongisporium, and more recently a number of other European species have been distinguished. Arthur and Kern, in their Peridermium paper, consider the American specimens on the leaves of Pinus rigida, which they call $P$. acicolum, distinct from the European species; P. oblongisporium, on Pinus sylvestris, and the writer follows their usage, though not entirely convinced that they may not be the same. The European Peridermium was long ago connected by Wolff with a Coleosporium on Senecio, and the writer (6) has recently connected the American Peridermium with a Coleosporium on Solidago. Though both rusts possess different alternate hosts, these hosts are related, and as the morphological characters of the various stages of the rusts are so similar, it may be merely a question of physiological, rather than true specific difference that distinguishes them. Solidago and Aster are very uncommon genera in Europe, and Senecio is not so common here as in Europe, while Pinus rigida is an American and Pinus sylvestris an European species. Thus the rusts, if the same, would of necessity have different hosts in the two countries. 
Peridermium acicolum was first called to the writer's attention in May, 1906, by Mr. Schults, a forester in Hartford, who found it very abundant on Pinus rigida in a private grove at South Manchester that was being developed for landscape purposes. The owner was afraid the rust would become a serious pest, and so Mr. Schults asked for information concerning spraying the trees to keep it in check. The writer advised against this, but recommended that a search be made for its alternate host, which at that time was not known to science, and that this, if found, be eradicated as a means for keeping the pine rust under control. An examination late in June, when the Peridermium on the pine was passing its prime, showed that Coleosporium Solidaginis on Solidago rugosa was just beginning to become prominent. This was the only rust present that could at all be connected with the Peridermium, and besides occurring on the above Solidago, it was found sparingly on two or three other species. The connection between the Peridermium and the Coleosporium was very plainly indicated by the fact that the Coleosporium on the Solidago only occurred prominently under the infected pine trees, and as the pines were mostly young, the branches reaching to the ground, several cases were found where infected branches interlocked with unusually badly infected plants of the Solidago. Upon our advice, these young pine trees were pruned of their branches for a distance of two to three feet up the trunk, and the goldenrod, especially beneath the trees, was mowed to the ground during the season. The next year an inspection failed to show any rust on the pines, except a small amount on one or two very small seedlings that were overtopped by some goldenrod. So this procedure seems to be an effectual method for controlling this rust. So far as was observed, the rust limited its attack to the limbs nearest the ground, and consequently was not found on the very large trees with no branches near their base. The young trees most badly infected were on low ground, with an abundance of infected goldenrod around them, so that conditions were unusually favorable for the development of the rust on both hosts.

Inoculation experiments in the greenhouse were made during 1906 and 1907 with spores of this Peridermium from different sources, and on three different occasions the Coleosporium was produced on plants of Solidago rugosa. The II stage of the 
Coleosporium generally showed inside of two weeks after the spores were placed on the leaves, and later in the season the III stage appeared in two cases. In van Tieghem cell tests of the spores their germination was never abundant, and in some cases entirely failed, though the spores were fresh. From these observations and experiments, there can be no question but that this Peridermium has for its alternate host in Connecticut Solidago rugosa, and presumably other species of Solidago and Aster on which the Coleosporium occurs. So far the attempts to infect the other species have not succeeded; but these were made only with one other species of Solidago and a species of Aster, and possibly not under favorable conditions. It is possible, however, that the Peridermium does not infect all of the hosts upon which the Coleosporium occurs, but that some of these may have become infected originally through the uredinial stage.

The infection of the pine leaves, so far as was determined, takes place in spring, and if then, only through the leaves of that year's growth. If this is correct, it is the year after infection before the aecial stage appears, as in all the cases examined the leaves of the present year's growth did not show the Peridermium. The other possibilities are that infection takes place in the late fall, or in the very early spring, before the leaves of the year appear. The first sign of the fungus was detected early in November on a few leaves which had fully developed pycnia, the aecia apparently following the next spring. The pycnia (O, Plate XXVI, b) are prominent, few in number, situated on a yellowish spot (not shown in the illustration), and open by a longitudinal slit.

While Arthur and Kern (5, p. 4I4) list only six collections of this Peridermium from the United States, one of which was from Connecticut, and limit it to a small area along the Atlantic Coast, this does not necessarily mean that the fungus is very rare, since collections have been made from five different localities in Connecticut alone during the past two years. These were all on the leaves of Pinus rigida, as follows: South Manchester, May 28, June 6, June 29, I906, May 29, I907; Rowayton, June 4, I906; Rainbow, June I5, I907; Storrs, July.22, I907; Union, August I, I907.

II, III. Plate XXVII. On the other hand, the Coleosporium is a very common rust, widely distributed over North America on a large number of species of Solidago, Aster, and a few other 
closely related genera. Arthur (2, p. 9I) lists over sixty of these hosts that have been reported so far. Even in Connecticut the Coleosporium is much more widely and commonly distributed than the Peridermium, as shown by the following collections made during the past two years: Aster cordifolius, Poquonock, II, July 20, III, Sept. 8, I906; A. diffusus, S. Manchester, II, Sept. 8, rgo6; $A$. paniculatus, Poquonock, II, Nov. 5, Ig06; $A$. vimineus, New Haven, II, Nov. 26, I907; Callistephus hortensis, Kent, II, Oct. 29, 1906, Storrs, II, Sept. 30, 1907, Westville, II, Aug. 28, I902, II, Oct. I7, I903, II, Oct. 25, I905 (Britton); Sericocarpus asteroides, Centerville, II, June 6, I907; Solidago caesia, Poquonock, II, Sept. 7, I907; S. canadensis, East Haven, II, Sept. 22, I877 (Herb. J. A. Allen), Kent, II, Sept. 29, I906, Poquonock, II, Sept. 8, 1906; S. juncea, Centerville, II, Sept. 25, I907; S. lanceolata, S. Manchester, II, June 29, I906; S. puberula, Woodbridge, III, Sept. I3, I879 (Herb. J. A. Allen); S. rugosa, Centerville, II, Sept. 25, I907, Fair Haven, II, Oct. 8, 1906, Kent, II, Sept. 29, I906, New Haven, II, Sept. 20, I906, S. Manchester, II, June 29, I906, II and III, Sept. 8, I906, Westville, II, Nov. 3, I906, II, Oct. I9, I907, West Willington, II and III, Sept. 28, I907; S. sempervirens, New London, II, Sept. I, 1905, Woodmont, II, Aug. I907. Besides the preceding hosts, Arthur (2, pp. 9I-2) lists the following from this state upon which the fungus has not been observed by the writer: Aster novae-angliae, Solidago serotina, and S. ulmifolia.

The data in the preceding paragraph show the second stage to be by far the most frequent, and that this occurs more commonly in the fall than at any other time of the year. A microscopic examination of the uredinial spores also showed that there is a marked variation, especially as regards the abundance and coarseness of the echinulations, on the different hosts. The extremes in this respect are certainly as great as those which exist between the typical uredinial spores of this and other closely related species. Just what this variation means, we are not prepared to state.

A very interesting question concerning the fungus is how it passes the winter. We have seen that the first stage on the pine has not been collected very frequently, and then only in a limited region along the Atlantic Coast, while the stages on the goldenrod, etc., are very widely distributed over the country, 
and frequently collected. That the I stage is no more necessary for the appearance of the Coleosporium than is the I stage for wheat rust, is made certain by the frequency with which the Coleosporium is collected in Illinois, where the Peridermium has never been found. Since the III stage can infect only the pine, how does the Coleosporium. carry over on the Solidago, etc., in regions where the Peridermium does not occur? These regions are often too remote for infection by wind-blown spores of the Peridermium, even if such were common enough for this method of infection, neither is it likely, in the writer's opinion, that such infection comes from the II stage gradually working northward from southern regions, where it may occur the year round.

The possibility of the mycelium of the fungus being perennial in the plants was not borne out by a microscopic examination of stems of infected specimens of Solidago rugosa. Badly infested specimens of these were also marked in the field, and after all their parts above ground were dead, their underground rootstocks were placed in crocks in the greenhouse. Half a dozen plants produced from these were kept under observation for nearly a year, and no rust ever appeared on them, so the mycelium is certainly not perennial. Of course it is barely possible in some cases, though this experiment seemed to show that it was not a common method, that a localized infection late in the fall might take place (by uredinial spores being: washed down to the partially developed underground rootstocks ) and thus carry the fungus over the winter.

In the writer's opinion, however, there is no question but that the fungus is commonly carried over the winter, in all parts of the country, by late fall infections of the II stage on the leaves which often occur in rosettes, especially in young plants, at the surface of the ground. We know that when more or less protected such leaves frequently survive the winter in Connecticut. Asters and goldenrod that are mowed late in the season send out great numbers of basal rosettes, and, in the fall as late as the first of December, the II stage often occurs as abundantly on these as at any time in the year. We have collected the II stage on such plants in December, January, February, March and April. Germination tests of the uredinial spores collected late in January gave as vigorous and abundant 
germinations as at any time of the year. No doubt some of these infections occur so late that the sori are not developed until spring, since by the first of April the mature sori found are not numerous. One of the earliest spring infections of Coleosporium we have found was on April 29th, on Solidago sp. and Sericocarpus asteroides, where the new sori occurred only on the lower leaves, indicating that these infections had come from sori or mycelia wintering over on the surviving basal leaves.

\section{Coleosporium Vernoniae B. \& C.}

We have never found this species in Connecticut, but Arthur (2, p. 89) lists a specimen on Vernonia noveboracensis from this state. It is a rather common fungus on species of Vernonia in the Middle West, where these hosts are more common than here. The I stage is not known, and so far, apparently, no suggestions have been made concerning it, though the connections of related species indicate that it is a Peridermium on the leaves of some species of Pinus.

\section{Cronartium Comptoniae Arth. (I. Periderminm pyriforme $\mathrm{Pk}$.)}

I. Plate XXVIII, a-b. Ever since proving the connection between the Peridermium on pine leaves and the Coleosporium on Solidago, we have been on the lookout for a Peridermium on the stems of pines to connect with the only species of Cronartium (on sweet fern) that occurs in this state, since the work of various investigators has shown that the corticolous forms of Peridermia occurring on pine are the aecial stages of Cronartia. Mr. Hawes, the state forester, gave the first clue to the occurrence of the Peridermium on pine trunks when, on questioning, he recalled that he had seen some fungus that worked on certain of the pine trees in the state plantation at Rainbow. He agreed to watch for this fungus, and early in June, I907, sent specimens of Pinus sylvestris that were badly infected with a Peridermium that proved to be $P$. pyriforme Peck. The writer visited the plantation June $I 5^{\text {th }}$ and found about a dozen trees, five or six years old, that were badly infected with the Peridermium. These trees were in a clearing near a small grove, but a careful search of this failed to show any rust on the sweet fern (Compionia asplenifolia) growing there, or the Peri- 
dermium on the native trees of Pinus rigida upon which $P$. pyriforme ordinarily occurs. As the rust had been noticed at least two or three years on the infected pines, and as they had been grown in seed beds, a mile or two away, very close to which the sweet fern occurred, there was no question but that they had been infected before transplanting while very young. A short time later the writer learned that this same Peridermium had been found at Storrs, on native specimens of Pinus rigida, by Mr. Graff, a botanical student, and on July 21st, through the kindness of Dr. Blakeslee and Dr. Thom, specimens were collected in this locality. On Aug. Ist, specimens were also found in the state forest at Union on the same host.

The Peridermium is perennial in the trunks of the infected host, and does considerable injury to the young specimens, stunting their growth, and probably, in severe cases, killing them. In all the specimens seen, the fungus occurred only on young trees, less than fifteen feet in height. In all of these it was confined to the lower branches, usually next the main trunk, and in the very young trees, to the base of the main trunk and its branches. It caused a slight swelling, and seemed to be confined chiefly to the bark and outer wood. When in its prime the Peridermium is conspicuous, the peridia being much larger than any of the other forms found here, and they are crowded together, encircling the infected stem. and extending up some distance upon it. The interlocking teeth or spiny processes (see illustration, Plate XXVIII, b) that show when the peridia break open, are also a distinguishing character. The orange spore mass is gradually emptied, and the peridia flake away, finally leaving few signs by which the infected trees can be detected. This Peridermium is found from the first of June until the last of July.

Arthur (4), in a recent paper, mentions receiving specimens of the Peridermium from Dr. Thom of Storrs, and noting the possible relationship to Cronartium Comptoniae, suggests inoculation experiments by those favorably situated to prove this relationship. Some time before, however, the writer had already proved this connection by indoor inoculation experiments in two different tests. In each case spores from the peridia found on Pinus sylvestris were sown on the leaves of Comptonia asplenifolia, and in about twelve days the uredinia began to 
appear. Spores sown on species of Solidago and Quercus produced no result. Curiously enough in several germination tests in water in van Tieghem cells, the spores failed entirely to germinate. From our experience with the spores of the different species of Peridermia, however, we have always found them difficult to germinate in this way. The relationship of the Peridermium and Cronartium was plainly indicated both at Storrs and Union, since the infected pitch pine trees were surrounded by sweet fern upon which the rust was common, while it was not found elsewhere in the neighborhood at that time. This, and our infection experiments, also show that the Peridermia on the pitch and Scotch pines are the same species.

II, III. Plate XXVIII, c-d. This Cronartium has been found along the Atlantic States from Canada to North Carolina, but only on the. sweet fern and a related species. In this state, the II stage begins to appear about the middle of July, while the telial stage can be looked for about the end of August. The uredinia show as very small, dusty, yellowish pustules on the under surface of the leaves, while the telia are slender, reddish, hair-like growths, more or less clustered into tufts, as shown somewhat poorly in the illustration. So far, in Connecticut, we have seen the Cronartium on the sweet fern only in the neighborhood of infected pine trees. This, and its somewhat limited distribution, indicate that the rust does not commonly carry over the winter on this host, and so would depend each year on renewed infection from the aecial stage. So far as we know, too, the leaves of the sweet fern do not survive the winter, so that the II stage would not be carried over on them.

This rust has been commonly known in this country as Cronartium asclepiadeum (Willd.) Fr., a species which occurs in Europe. This is probably the correct view rather than that of Arthur, who considers it as strictly an American species. The infection experiments made in Europe by Klebahn and others have shown that the aecial stage can produce the Cronartium on a number of hosts not very closely related, one of which is an African plant from a region in which the fungus never has been found. This wide range of hosts, and the facts that the different stages of the Cronartium asclepiadeum in Europe are at least similar in appearance to those of the American Cronartium, and that Pinus sylvestris is a host for the aecial stage in both places, all indicate 
the identity of the species. However, successful inoculation of one of the European telial hosts with the American Peridermium is needed to decide the matter finally.

\section{Kuehneola albida (Kuehn) Magn.}

The above rust is commonly known under the name Chrysomyxa albida Kuehn. There seems to be some doubt as to its exact systematic position, since some botanists think that it is more closely related to Phragmidium than to Chrysomyxa (Melampsoropsis of Arthur). The writer inclines to the Chrysomyxa relationship, since the telial spores are thin-walled, colorless, and septate like those of Chrysomyxa, and the uredinial stage is not provided with paraphyses, as are the uredinia of Phragmidia on Rubus species. Studies were made to determine its first stage, so that this question could be settled more definitely, but unfortunately the results were not conclusive. If closely related to Chrysomyxa, the I stage no doubt is some species of Peridermium (P. Peckii, for instance), while, if closely related to Phragmidium, such an aecial stage is improbable, and might be supplied, as has been suggested, by Uredo Muelleri. We give a discussion of these two fungi before proceeding to the known stages of the Kuehneola.

? I. Plate XXIX, a. Peridermium Peckii Thm. has for its host Tsuga canadensis, and is apparently confined to North America, while Kuehneola albida has a much wider distribution. The Peridermium occurs on the under side of the leaves in two parallel rows, one on either side of the midrib, and forms slender, white, fragile peridia that usually split into temporary filaments upon their dehiscence. Ordinarily this aecial stage does not occur abundantly, usually only one infected leaf showing on a branchlet. According to Arthur and Kern (5, p. 434), who report only seven collections, P. Peckii has so far been reported only from the Eastern United States. The writer has found this species, while not usually abundant, still not uncommon in Connecticut, the following specimens having been collected here: Coventry Lake, July 20, I907; Stafford Springs, July 3I, I907; Storrs, July 22, I907; Union, Aug. I, I907; Westville, July, I888 (Thaxter), July I2, 27 and 28, Aug. 4 , 1907. In some of these collections only a very few infected leaves were found, but at Storrs the fungus was very common 
on certain trees. In practically all of the cases the leaves near the ground were the ones infected, but on one very badly infested tree the fungus was found as high as twenty feet from the ground.

As soon as this Peridermium was found a search was commenced for the stages on the alternate host, but without finding anything suspicious until at Storrs the swamp blackberry (Rubus hispidus), underneath abundantly infected hemlock trees, was found infested with Kuehneola albida. Examples were seen here where the two hosts almost touched each other, each infected with its fungus, and in general the swamp blackberry had its rust only when situated beneath infected hemlock trees. A few days later, at Stafford Springs, another case was found where infected leaves of the hemlock were close to rusted leaves of the swamp blackberry, while other specimens of the blackberry further away were free. As no other rust was at any time found so situated as to suggest a probable relationship, the writer became convinced of the connection of these two.

Infection experiments in the greenhouse, using spores from this Peridermium on leaves of Rubus hispidus, were tried on three different occasions, but no infection resulted, except possibly in one case when one sorus of the II stage of this Kuehneola appeared about sixteen days afterward. As the plants used were recently transplanted, most of the leaves finally dropping off, this might explain the failure to infect the host; but on the other hand, as the plants came from an infected region, though from a spot apparently free from the rust, the single sorus that finally developed may not have come from the spores used, but from a previous outdoor infection.

The most unfavorable point against the relationship of Peridermium Peckii and Kuehneola albida, however, is that with this Peridermium on the hemlock leaves there occurs a pycnial stage, while with the Kuehneola on the Rubus host there is sometimes found a uredinial stage known as Uredo Muelleri also having pycnia. This Uredo is believed by some, though its exact relationship apparently has never been proved by cultures, to be merely the primary uredinium (II') of the Kuehneola. If it really is, then the Peridermium probably has no relationship to the Kuehneola, since no rust is known that has pycnia connected with more than one of its stages. From these considerations it 
readily appears that further infection experiments are necessary to determine the relationship, if any, of Peridermium Peckii, Uredo Muelleri, and Kuehneola albida. Farlow (ro, p. 72) has also suggested a possible relationship of $P$. Peckii to Calypiospora Goeppertiana; and it is barely possible, though not likely, that it is connected with the Necium discussed later.

II'. Plate XXIX, b. Uredo Muelleri Schroet. differs from the II stage of Kuehneola albida in having its sori in groups usually on the upper side of the leaves, a few large uredinia and pycnia occurring together there, while the smaller uredinia of Kuehneola occur scattered on the under side of the leaves and without pycnia. Mueller, who first described the species as Uredo aecidioides, according to Schroeter (Krypt. F1. Schl. III ${ }^{1}$ : 375 ) thought that it might possibly be the aecial stage of Chrysomyxa albida, since both were found together. That they have some relationship is further indicated by the fact that not only have they been found together in Europe and also in America, but on several different species of Rubus. In the specimens collected in Connecticut on Rubus hispidus, both at Storrs and Stafford Springs, this Uredo occurred on the same plants with the II, and III stages of Kuehneola albida. The two have also been found elsewhere in New England associated on this same host. Dietel (Hedw. 44: 122. 1905) has recently suggested that Uredo Muelleri, instead of being the aecial stage of Kuehneola albida, is a primary uredinial stage of it that merely functions as the aecial stage.

II, III. Plate XXIX, c. The II or uredinial stage of Kuchneola albida is the more common and injurious of these two stages. It has been reported on several species of Rubus from the United States, and extends over a wide district. While not a very common fungus, when it does occur it is often abundant. The sori are very small, and show as yellowish circular outbreaks scattered over the under side of the leaves. The telial sori often occur on the same leaves with these, but are easily distinguished by their white color. The telial spores found here last summer had all germinated before the middle of July. In the specimens first found on the swamp blackberry both of these stages occurred on the old leaves (the III being limited to these) that had lived over the winter, and as we have also found the II stage as late as November 3 oth, we have no doubt but that on 
this host the fungus carries over the winter through the uredinial stage, and so the I stage is not essential for its appearence the next year. The collections so far made in this state are as follows: Rubus hispidus, Storrs, II and III, July 22, II, Oct. I8, I907; Stafford Springs, II and III, July 3I, 1907; Westville, II, Nov. 30, 1907; Rubus villosus, Storrs, II, July 23, II, Sept. 30, 1907.

\section{Melampsoridium Betulae (Schum.) Arth.}

Plate XXXI, b. (From a specimen in Seym. Econ. Fungi $23 I, b)$. This is a fungus that is not very often collected in the United States, but apparently occurs as frequently in New England as anywhere. Though careful search was made for it in Connecticut the past season, it was not found. The writer, however, is indebted to Professor Farlow for specimens collected on September 20, 189o, by Setchell at Norwich, on Betula populifolia. Only the II stage occurs on these. While both the II and III stages have been found in the United States, the I stage has never been seen here. According to Klebahn (Zeitschr. Pflanzenkr. 9: I8. I899) this stage occurs on the leaves of Larix, and has been found in several places in Europe. A careful search for this [Peridermium Laricis (Kleb.) Arth. and Kern] on wild and cultivated larches in this state last year gave no evidence of its presence. Just how the fungus passes the winter in this country and reappears on the Betulae is unknown. As the leaves of the Betulae do not survive the winter, reinfection from the II stage on them is not probable. Though not known, possibly the uredinia sometimes occur on the young twigs, and by this means carry over the fungus.

\section{Melampsoropsis Cassandrae ( $\mathrm{Pk}$. \& Clint.) Arth.}

(I. Periderminm consimile Arth. \& Kern.)

I. Plate XXX, a. The writer (7) has recently shown the relationship of Peridermium consimile on Picea nigra to Melampsoropsis Cassandrae on Cassandra calyculata. Both of these fungi were found in Connecticut for the first time last year. The only locality in which the Peridermium was found was in a spruce swamp along the railroad just beyond West Willington toward Stafford Springs. When first seen there on July 3Ist, 
the aecia were just beginning to shed their spores, and when seen again on September 28th, they were far beyond their prime. The aecia occur irregularly in one or two rows on the leaves, usually four to eight on each leaf. The infected leaves are discolored yellowish, and look as if they would be shed prematurely, but there is no indication of a witches' broom formation. The peridia, as shown in the illustration, are somewhat flattened, and about as long as high. They break open irregularly at the top to shed the orange-colored spores, and then gradually wear away. A striking feature of this species is the very conspicuous reddishbrown pycnia, which show plainly in the illustration as the small black specks.

The only rust suitable for the alternate stages found in the vicinity of this Peridermium during the season was the II stage of Melampsoropsis Cassandrae on the leather leaf under the infected spruce trees. Specimens of the leather leaf from the edge of the swamp, away from the infected spruces, were collected and transplanted in crocks in the greenhouse. These were watched carefully, and two or three plants, upon which a sorus or two of the Melampsoropsis appeared, were discarded. Other specimens apparently entirely free from the rust were inoculated with the spores of the Peridermium, and about sixteen days later the uredinial sori appeared on a number of the plants. This experiment was repeated a short time later, using spores from leaves for a short time in a damp chamber, and the infection took place in this case in about eight days. Infection experiments with the spores on Rubus hispidus and Pyrola elliptica failed to produce anything. While necessity compelled the use of Cassandra calyculata from the infected locality, the results indicated that the sori obtained came from the Peridermium spores used in the experiments. It is hoped, however, to repeat the inoculations again the coming year with plants entirely above suspicion.

II. Plate XXX, b. The uredinia occur as minute orangeyellow dusty outbreaks on the under side of the leaves. So far we have been unable to find any suggestion of the telial stage on this host, though a careful search was made for it during July, September, October, January and February.* Arthur describes this stage, but apparently from other hosts. Last October the II stage was found on the leather leaf in Beaver Swamp, at

*See addenda, p. 396. 
Westville, and as no spruce trees are anywhere near, there is no doubt that the fungus can survive without the aid of the aecial stage. In January a careful examination of the plants in this locality was made, and a few old uredinia were found on the living leaves, which largely remain on the plants over the winter. Some of the branches, after the infected leaves were removed, were placed under a bell jar indoors, and a few new uredinia soon appeared, no doubt from nearly matured sori. No others showing during the next week, the branches were left undisturbed for about a month, when an examination revealed several hundred uredinia present. These observations show that the fungus can pass the winter, on the old but living leaves that adhere to the plants, through the more or less matured uredinia, or no doubt in some cases, when infection takes place late in the season, through localized mycelia which gives rise to the uredinia in the spring.

\section{Melampsoropsis Pyrolae (DC.) Arth.}

Plate XXXI, a. This is commonly known as Chrysomyxa Pyrolae, and occurs in the United States chiefly in the Northeastern States and the Rocky Mountains on various species of Pyrola. So far in this state only the II stage has been found, and this is striking when once detected, since the under surface of the infected leaves is thickly covered with brightly colored uredinia. The collections for this state are as follows: Pyrola elliptica, Storrs, May, I904 (Graff); Pyrola rotundifolia, Pine Rock in Westville, May, I894 (Sturgis, Fungi, Col. 1814); West Rock, I902 (Clinton); Vernon, May 25, I907 (Weatherby). No aecial stage has yet been discovered for this species. According to Arthur and Kern (5, p. 432), Rostrup has suggested that Peridermium conorum-Piccae (Reess) Arthur and Kern may have this connection, since both are found in somewhat the same localities in Europe and America. A search for this Peridermium failed to reveal its presence in Connecticut, though possibly it occurs in the northwestern part of the state since it has been found in New York and Northern New England. Apparently the aecial stage is not necessary for the appearance of the rust, as the leaves of the Pyrolae frequently live over the winter and could easily carry over the uredinial stage. 


\section{Necium Farlowii Arth.}

This species, found on hemlock, Tsuga canadensis, has recently been made the type of a new genus by Arthur (2, p. II4), who bases his description on material furnished by Farlow, and collected by Seymour at Chebacco Lake, Mass., and by Farlow at Lake Sunapee, N. H. Arthur describes only the telial stage, and characterizes the genus as having only telia and possibly pycnia. $\mathrm{He}$ neglects to state, however, that Seymour collected at the same time, and possibly on the same trees, a species of Caeoma which might very well be the aecium of this fungus. Farlow (9) was the first to call attention to these fungi. He says:"Besides our common Chrysomyxa on Pyrola, a species was found on Abies Canadensis at Chebacco Lake, Essex Co., Mass., by $\mathrm{Mr}$. A. B. Seymour, in June, I883. This is probably the same as Chrysomyra Abietis of Europe, although, as the spores were not quite ripe, one cannot be certain. If there is a difference, it is to be found in the fact that the teleutospores are arranged in threads, which branch less than the European forms. But at a later stage of development, this supposed difference might disappear. At the same time and place Mr. Seymour found another interesting species of Urediniae, also on Abies Canadensis, not on the same branches as the species last mentioned, nor on the same trees, as far as can now be ascertained. Spermagonia were abundant on both sides of the leaves, on whose under surface were elliptical or elongated sori of a pale yellow color, arranged in two rows parallel to the midrib. The spores were globose, or somewhat elliptical, about $13-17 \mu$ in length, and appeared to be borne in chains, composed of a small number of spores. It is possible that this form is Caeoma Abietis-pectinatae Reess, of which I have seen no specimens. From the description of Reess, however, this species has larger spores than ours, and no mention is made of spermagonia. It may be well to designate our form under the name Caeoma Abietis-Canadensis until more exact information can be obtained."

The writer is indebted to Professor Thaxter for a specimen of this Necium collected by him on the cones of hemlock at Hamden, Conn., July 18, I889, and for another on the branches and leaves from North Carolina. While these specimens show only the telium, Thaxter wrote on the label of the Hamden specimen, "teleutospores of Cảeoma on hemlock cones," and in 
a letter written to Professor Farlow, July I2, I890, said: "I sent you yesterday fresh cones with mature teleutospores, one having both Caeoma and teleuto forms side by side. I found a quantity of material at New Hartford, Conn., but a careful examination of the leaves on branches where the infected cones were hanging by dozens revealed nothing. The 'Chrysomyxa' which I formerly sent you from North Carolina on the same host occurred only on young shoots, running from them into the leaves. Though very common in North Carolina, I did not find it on the leaves of any but affected shoots. I find nothing of the sort here, though I have looked for these affected shoots, which are conspicuous. I have found the Caeoma on shoots, of which I sent you a specimen, twice only." The writer has never collected this Necium in Connecticut, though Thaxter found it not uncommon at the time of his collections, but has seen a specimen of Caeoma Abietis-canadensis found by Dr. Britton very sparingly in June, Igo6, on hemlock leaves in Westville.

Arthur describes the Necium as occurring on the leaves, while Thaxter's specimens show the telia on the cones and young stems as well, thus indicating that it is sometimes perennial. On the cones and twigs, at least, the spores seem to originate beneath the epidermal cells instead of in them, as stated by Arthur. The sori on these parts are also often crowded together so that the spores from a continuous layer (especially on the cone scales), across the entire microscopic section. (Plate XXXII, 5.) This gives them the general appearance of being an epidermal layer of the plant tissues, though they are quite unlike the true epidermal cells. The sori, where distinct, range from $60-120 \mu$ in depth by $70-300$ in length. The simple, slightly tinted oblong spores are very closely compacted together, so that in mature sori they are narrower and more elongated than in the immature. Frequently they are slightly broader and more deeply tinted at the apical end, and very rarely have a septum above their base. They seem to be somewhat larger than those on the leaves, as given by Arthur, since they vary from $40-85 \mu$ in length by $6-14 \mu$ in width, the shorter and broader often being immature. They arise from septate basal cells of about equal diameter, which in turn develop from the mycelial threads that ramify through the plant tissues beneath. In sections of the stem the mycelium shows very abundantly and no doubt is responsible 
for the distortion of the young stems, which are slightly swollen and sometimes more or less curved. The fungus gives a reddish tinge to both the infected stems and cones, due to the superficial colored sori.

While not exactly like Chrysomyxa Abietis, which has septate spores, and even less like Calyptospora Goeppertiana, this species has perhaps more the characters of the Melampsora-like genera, so everything considered, it will perhaps rest easiest for the time being in the new genus created for it by Arthur. While there is no positive proof that Caeoma Abietis-canadensis has any connection with the Necium, the fact that a Caeoma has been found on the leaves, cones and stems, and in some cases associated with the Necium, very strongly indicates a relationship. If this is so, or if Arthur is correct in believing that the Necium has no other stage, of course the fungus does not really come within the limits of this article. It is included here because of the possibility that it may have for its aecial stage some species of Peridermium. For example, Peridermium Peckii occurs on the same host, and there is a bare possibility that the two are connected, since Professor Farlow writes that he found them near together at Lake Sunapee.

\section{Io. Pucciniastrum Agrimoniae (Schw.) Tranz.}

Plate XXXI, c. So far no aecial stage has been found for this fungus, which in its uredinial stage is rather common in Europe and America. Presumably if it possesses an aecial stage, this is one of the Peridermia since, where known, species of this genus have such connection. The uredinia occur on the under side of the leaves of various species of Agrimonia, forming numerous, scattered, pale-orange or yellow, minute outbreaks, as shown in the illustration. The uredinia of this genus have a rather definite peridium, which opens by a pore, guarded by more or less differentiated neck cells. In this species the peridia are not sunken very deeply in the tissues, and are held in place by the overlapping epidermis. In general they are lenticular to subcircular in cross section, and vary from $90-180 \mu$ in height by I60- $360 \mu$ in width. The neck cells are somewhat differentiated, but are not nearly so characteristic as in some of the other species ( $P$. arcticum americanum, see Plate XXXII, 3 ), being somewhat larger, thicker walled, and more spore-like in appearance than the 
other peridial cells, which are frequently rather indistinct and semi-gelatinized. The spores are rather sparsely covered with inconspicuous echinulations, vary from ovoid to subspherical, occasionally flattened or more irregular, and are $15-20 \mu$, rarely $24 \mu$, in length.

The telia of this fungus were first described by Dietel (Hedw. 29: I52) in I890, but are not commonly recognized, probably because they develop late in the season, and in the specimens we have collected do not show to the naked eye. In cross sections of the leaf of one of the collections made on October I7, this stage was shown to be present. The sori occurred beneath the epidermal cells, and were characteristic of true Pucciniastrum telia; that is, in cross section the spores showed as twin cells, but when viewed from above, as four cells firmly bound together (see illustration, Plate XXXII, 4). Where the sori are abundant, the individuality of the cells is almost entirely lost by being crowded together. The compound spores vary from oval to subspherical, and are about $19-28 \mu$ in length.

\section{Pucciniastrum minimum (Schw.) Arth.}

Neither the aecial or telial stage is known for this fungus according to Arthur. We found its uredinal stage on cultivated Azalea sp., August 14th, I902, in a Westville nursery, where it was very abundant. No clue was obtained to its other stages, and as these plants were soon disposed of, it has not been seen since. The aecia show as very minute orange-yellow outbreaks on the under side of the leaves. The peridia are slightly imbedded in the tissues, are hemispherical to conical flattened, and about $70-85 \mu$ high by $140-180 \mu$ wide. The neck cells are thick-walled, and not especially marked or prominent. The spores are ellipsoidal or occasionally more elongate, minutely echinulate, and $16-25 \mu$ in length.

\section{Pucciniastrum pustulatum (Pers.) Diet.}

In Europe the above species has been connected by Klebahn (Zeitschr. Pflanzenkr. 9:22-6. I899) with a Peridermium on Abies pectinata, but so far the aecial stage has not been found in this country. Possibly Peridermium balsameum $\mathrm{Pk}$., a related species on Abies balsamea, is this stage, though according to Farlow (IO, p. 20) it has been conjectured that this Perider- 
mium belongs to the American species of the Calyptospora on Vaccinia. Blakeslee sent the writer, in August, I907, Peridermium balsameum from the Adirondacks, where the only suspicious alternate forms found were the II and III stages of Pucciniastrum arcticum var. americanum Farl. on Rubus strigosus. (Described in Rhodora I0: 13. Ja. I908.) Thus, while the specific ties of this Peridermium are doubtful, it seems certain that it is connected with some Pucciniastrum (in the wide sense, including Calyptospora).

The II and III stages of Pucciniastrum pustulatum occur on various species of Epilobium scattered over the United States. Only one collection, and then only of the II stage, has been made in this state, on Epilobium sp., at Hartford, Oct. 20th, 1902. The peridia seem to be composed of plant and fungous cells, and are hemispherical or decidedly flattened, slightly immersed in the tissues, and about 45 - II $5 \mu$ high by $165-300 \mu$ wide. The neck cells, while somewhat more prominent than the other peridial cells, have no especial markings, and seem to be rather fugacious.

\section{I3. Pucciniastrum Pyrolae (Pers.) Diet.}

This is another species of Pucciniastrum widely distributed over the United States, whose aecial stage is unknown, but which, like the others, is supposed to be a Peridermium. The only specimens collected in this state were of the II stage, found at Storrs, July 24, 1907, on Pyrola elliptica. This is a much less conspicuous fungus than the Melampsoropsis Pyrolae which occurs here on the same host. Apparently the fungus carries over the winter through the uredinia on infected leaves. While no clue to its aecial stage was obtained, it is not likely to be either Peridermium Peckii or $P$. balsameum, since infection experiments with these species on this host failed to give results.

\section{SPECIES NOT YET REPORTED BUT PROBABLY OCCURRING IN CONN.}

The following species have not yet been found in this state, but very probably will be collected here sometime as they have been listed from adjacent states.

I. Calyptospora columnaris (Alb. \& Schw.) Kuehn (C. Goeppertiana) on Vaccinium sps. (I. Peridermium columnare (Alb. \& Schw.) Schm. \& Kze. on Abies sps. Not yet 
reported in America. Peridermium Peckii and P. balsameum have been suggested as possibly belonging to this Calyptospora.)

2. Coleosporium Helianthi (Schw.) Arth. on Helianthus sps. (Peridermium unknown.)

3. Colcosporium Senecionis (Schum.) Fr. on Senecio sps. (I. Peridermium oblongisporium Fckl. on leaves of Pinus sylvestris. Not yet found in America.)

4. Cronartium Comandrae Pk. on Comandra umbellata. (Peridermium unknown.)

5. Cronartium ribicola Waldh. on Ribes sps. cult. (I. Peridermium Strobi Kleb. on branches of Pinus Strobus. Liable to be introduced on white pine imported from Europe.)

6. Melampsorclla elatina (Alb. \& Schw.) Arth. (M. Caryophyllacearum) on Caryophyllaceae. (I. Peridermium elatinum Alb. \& Schw., Schm. \& Kze. on Abies balsamea.)

7. Pucciniastrum arcticum americanum. Farl. on Rubus strigosus. See P1. XXXII, 3. (Peridermium unknown but possibly P. balsameum; see page 393.)

8. Pucciniastrum Myrtilli (Schum.) Arth. (P. Vacciniorum) on Gaylussacia sps. and Vaccinium sps. (Peridermium unknown.)

\section{LITERATURE.}

The following are a few of the American references relating to our Peridermia and their probable alternate stages:

I. Arthur, J. C. Peridermium on Pinus rigida. Journ. Myc. II: 52. Mr. 1905 .

Failed to infect leaves of Lobelia syphilitica with spores of above fungus.

2. Arthur, J. C. Uredinales. North Amer. Flora. 7: 85-123. Mr. 1907.

Gives within these pages the heteroecious rusts of N. A. having Peridermia for their aecial stage, describing all the stages so far as known.

3. Arthur, J. C. Cronartiun Quercus (Brond.) Schroet. Journ. Myc. I3: 194. S. 1907.

Produced above fungus on Quercus velutina, but not on Q. alba, by using spores of Periderminm cerebrum from Pinus virginiana.

4. Arthur, J. C. Peridermium pyriforme and its probable alternate host. Rhodora 9: 194-5. S. 1907.

Suggests from observations made by Dr. Thom of Conn., that the above is the aecial stage of Cronartium Comptoniae. 
5. Arthur, J. C. and Kern, F. D. North American species of Peridermium. Bull. Torr. Bot. Club 33: 403-38. Au. I906.

Give general discussion, keys, descriptions, synonyms, hosts, and distribution of thirty species.

6. Clinton, G. P. Periderminm acicolum, the aecial stage of Coleosporium Solidaginis. Science 25: 289-90. F. I907. (Also note in Ann. Rep. Conn. Agr. Exp. Stat. 1906: 320. My. 1907.)

Proves by observations and inoculation experiments the relationship of the above rusts.

7. Clinton, G. P. Notes on certain rusts with special reference to their Peridermial stages. Science 27: 340. F. I908.

Proves by infection experiments the relationships of Peridermium pyriforme to Cronartium Comptoniae and $P$. consimile to Melampsoropsis Cassandrae, and suggests possible relationship of P. Peckii to Chrysomyxa albida.

8. Farlow, W. G. Appalachia 3: 239-43. Ja. I884.

Gives notes on Peridermia of the White Mountains.

9. Farlow, W. G. Notes on some, species of Gymnosporangium and Chrysomyxa of the United States. Proc. Amer. Acad. Arts Sci. 20: 322-3. 1885 .

Gives notes on Chrysomyxa Ledi, II, III, and Uredo Ledicola, on Ledum, and suggests Peridermium (probably $P$. Abietinum) on Abies nigra may be associated with former; thinks Aecidium pseudo-columnare of Kuehn may be the same as $P$. balsameum of Peck; also gives notes on Chrysomyxa Abietis (?) and Caeoma Abietis-Canadensis.

I0. Farlow, W. G. Aecidium sps. Bibl. Ind. N. A. F. S. I905.

Gives bibliography of the species of Peridermium (under the form genus Aecidium) with notes upon the following: Aecidium Abietinum (p. 13), A. balsamenm (p. 20), A. carneum (p. 25), A. cerebrum (p. 27), A. conormm-Piceae (p. 35), A. decolorans (p. 38), A. deformans (p. 39), A. elatinum (p. 40), A. ornamentale (p. 7I), A. Peckii (p. 72), A. Pini (p. 75).

II. Farlow, W. G. and Seymour, A. B. Prov. Host Index Fungi U. S.: I58-I70. I89I.

List, under the various hosts, species of Peridermia that have been reported for the U. S.

12. Freeman, E. IM. Minnesota Plant Diseases: 275-7. J1. I905.

Gives notes on pine stem rust, leaf rust of pines (suggests relationship to rusts on asters and goldenrod), and witches' broom of balsam fir.

13. Kellerman, W. A. Pine rust, Peridermium Pini. Journ. Myc. Ir: 32. Ja. 1905 .

Sowed spores of "Peridermium Pini" obtained from Ohio on Campanula Americana outdoors and produced urediniospores, thus proving the fungus on the pine to be the aecial stage of Coleosporium Campanulae. 
14. Peck, C. H. Peridernium pyriforme Pk. Bull. Torr. Bot. Club 6: I3. F. 1875 .

Describes this as a new species on pine branches, probably from Newfield, N. J.

15. Seymour, A. B. Peridermium Pini Lév, var, acicolum Wallr. Eco. Fungi 223. I 893 .

States that this species on Pinus rigida is commonly associated with Cronartium on Myrica asplenifolia.

16. Shear, C. L. Peridermium cerebrum $\mathrm{Pk}$. and Cronartium Quercuum (Berk). Journ. Myc. 12: 89-92. My. I906.

Gives results of outdoor inoculation experiments by which the Peridermium is shown to be the aecial stage of the Cronartium; gives hosts and distribution of each.

17. Underwood, L. M. and Earle, F. S. Notes on pine-inhabiting species of Peridermium. Bull. Torr. Bot. Club 23: 400-5. O. I896.

Give notes on three species from Eastern U. S., and mention three others from the western part which they have not examined.

\section{ADDENDA.}

(I) See Kuehneola albida, p. 383. The writer is indebted to Professor Farlow for calling his attention to an infection experiment with this rust by Ernest Jacky, published in the Cent. Bak. Par. Infek. 18: 9I-3. February, 1907. This writer claims to have produced Uredo Muelleri on Rubus fruticosus from Phagmidium [Kuehneola] albidum on the same host. As this experiment was conducted in the woods merely by laying infected leaves on the plants, and as these leaves came from plants which also contained Uredo Muclleri at that time, there may be some question about his conclusion. In a late more careful experiment, using Uredo Muelleri he produced Uredo Muelleri, apparently as he claims.

(2) See Melampsoropsis Cassandrae, p. 386 . On May 4, 1908, just as this paper was going to press, the writer succeeded in finding the III stage of the above fungus on Cassandra calyculata, at Beaver Swamp, Westville, on the same plants that the II stage was found on during the previous fall and winter. The sori are small, about one-eighth of an inch or less in diameter, are situated on the under surface of the leaves (though also discoloring the upper surface) and show to the naked eye as slightly elevated, waxy, chestnut-red areas. These may be distinct or somewhat run together, and under a hand lens seem to consist of more minute divisions really caused by the leaf venations. The sori at this time were scarcely mature, but undoubtedly some of them would mature very shortly. Their season, apparently, is from May to June, which is the only time of the year I had not before looked for this fungus. 


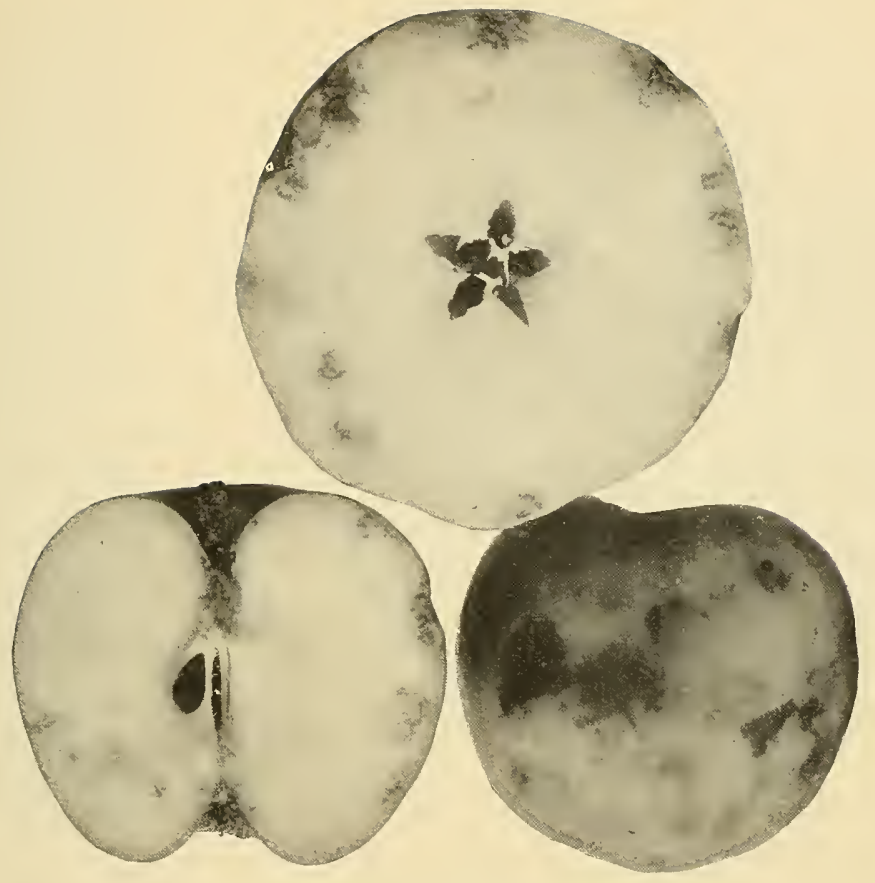

a. Baldwin Spot, p. 340 .
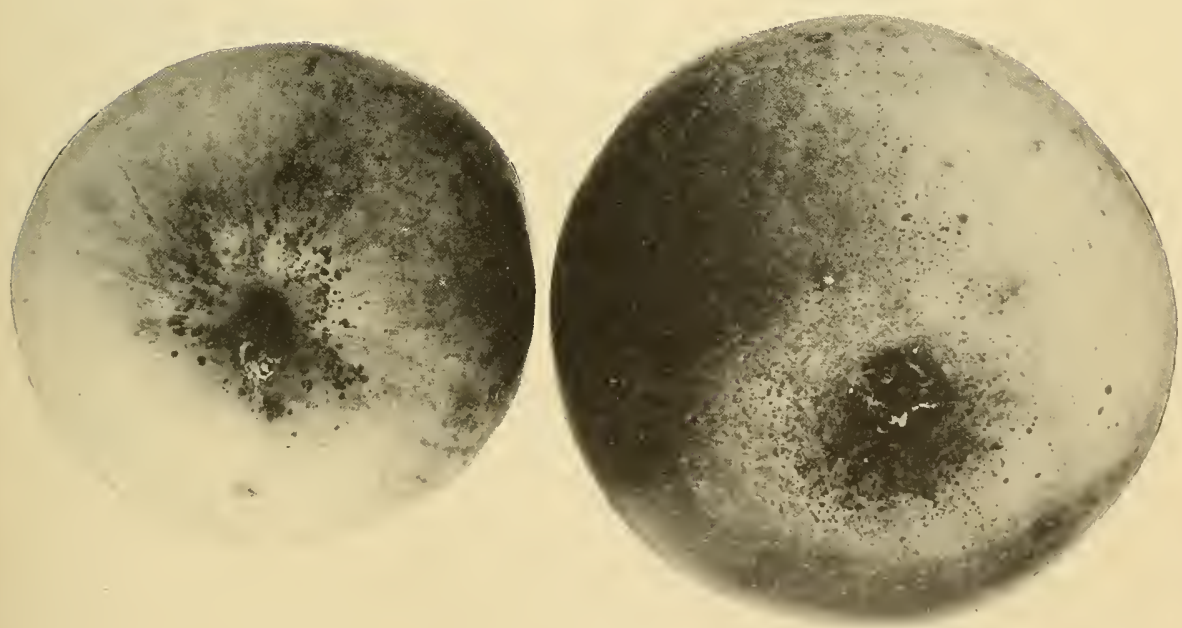

b. Spray Injury, p. 342 . 

PLATE XVIII.

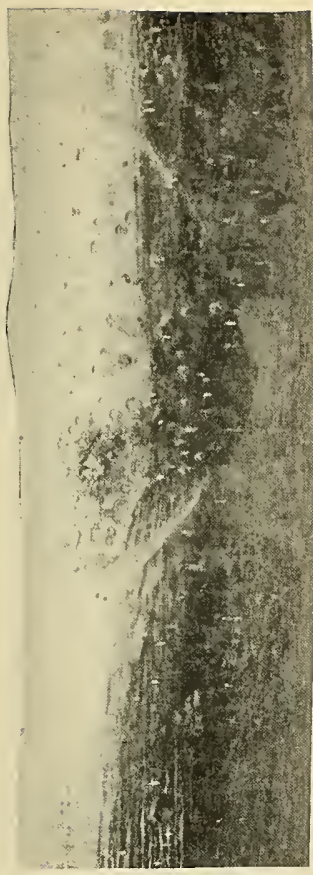

a. Chestnut Bark Disease, p. 345 .

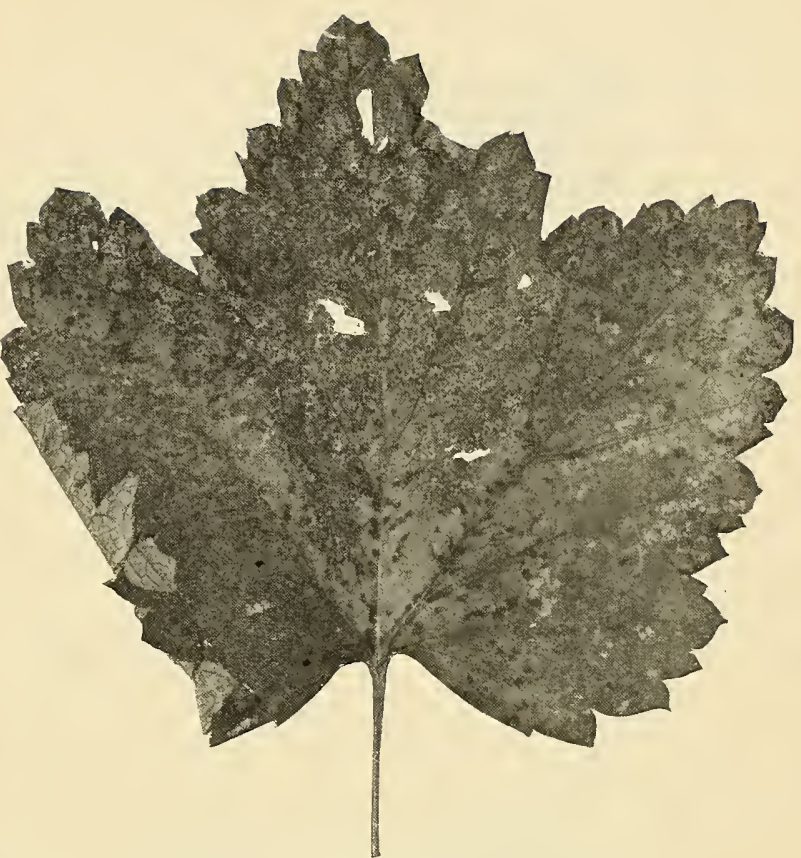

b. Anthracnose of Currant, p. 347 .

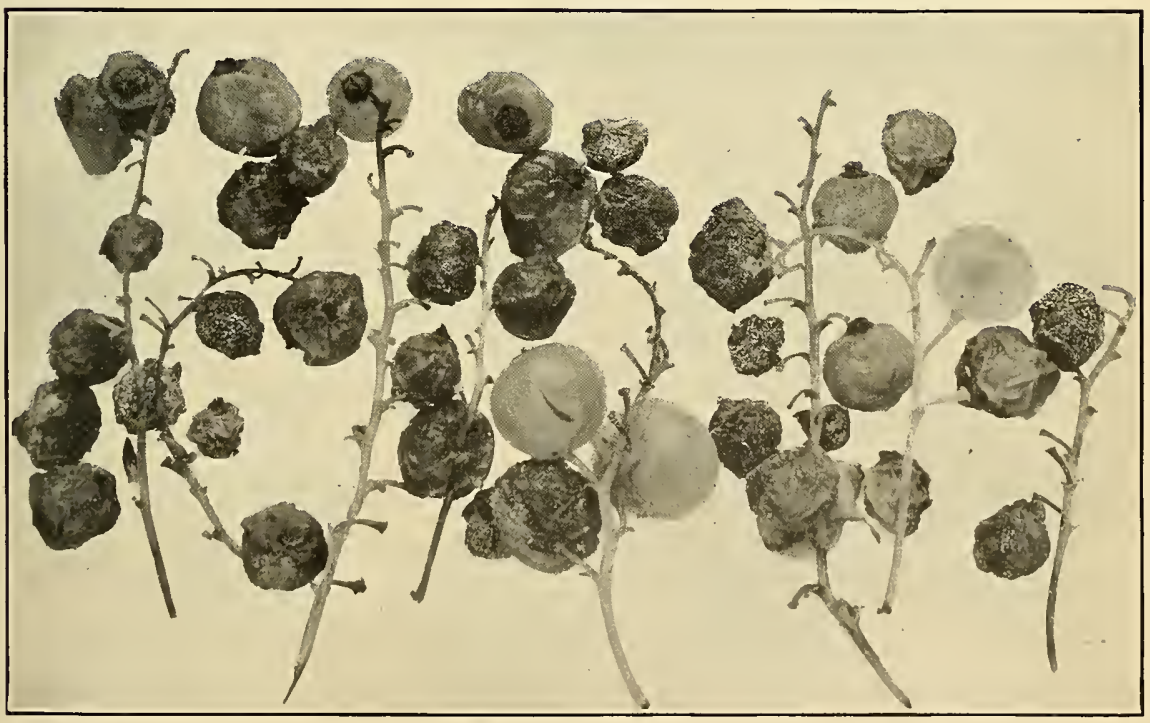

c. Bitter Rot of White Currants, p. 347 .

FUNGI OF CHESTNUT AND CURRANT. 



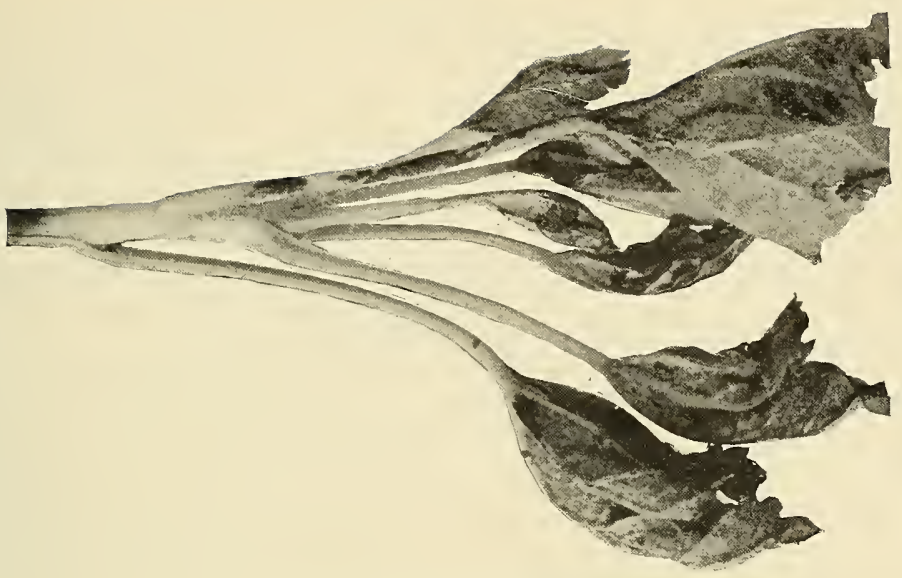

a. On young Currant shoot.
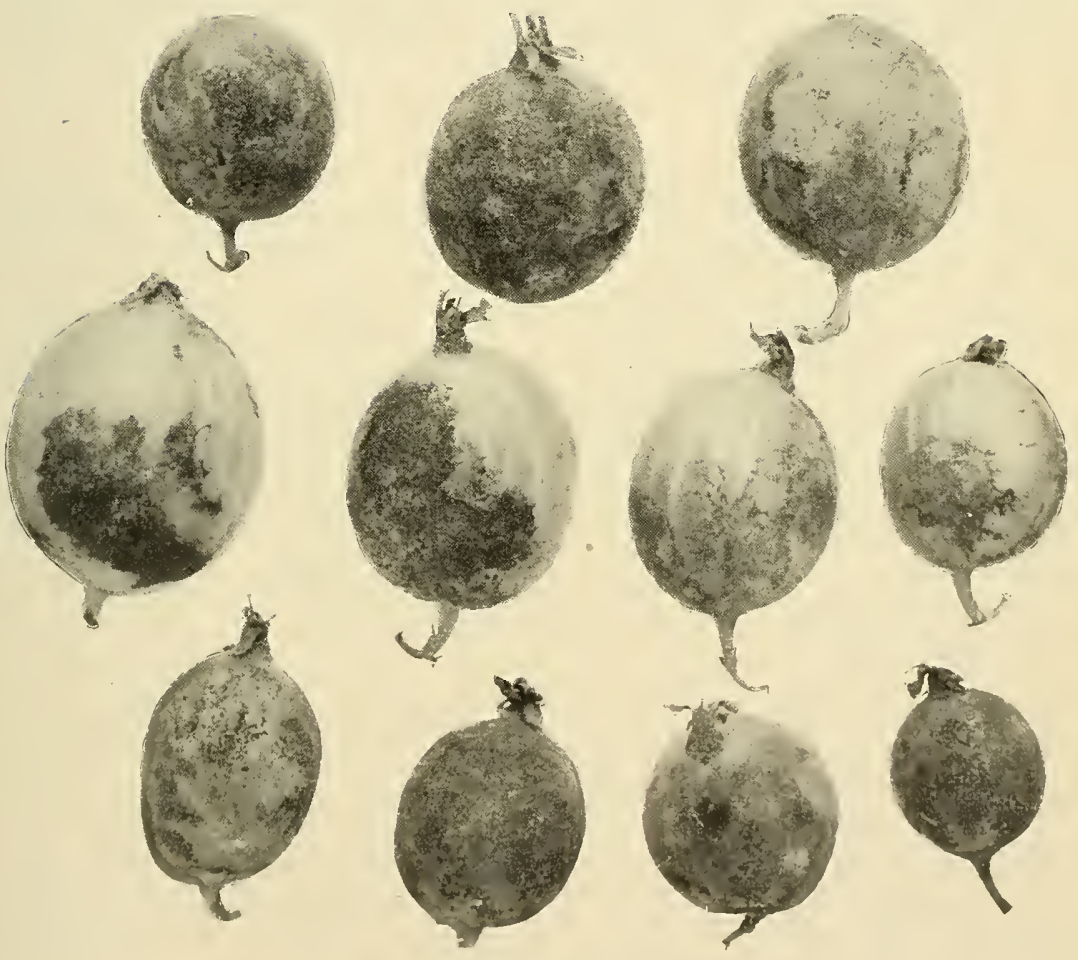

b. On fruit of Gooseberry. 

PLATE XX.

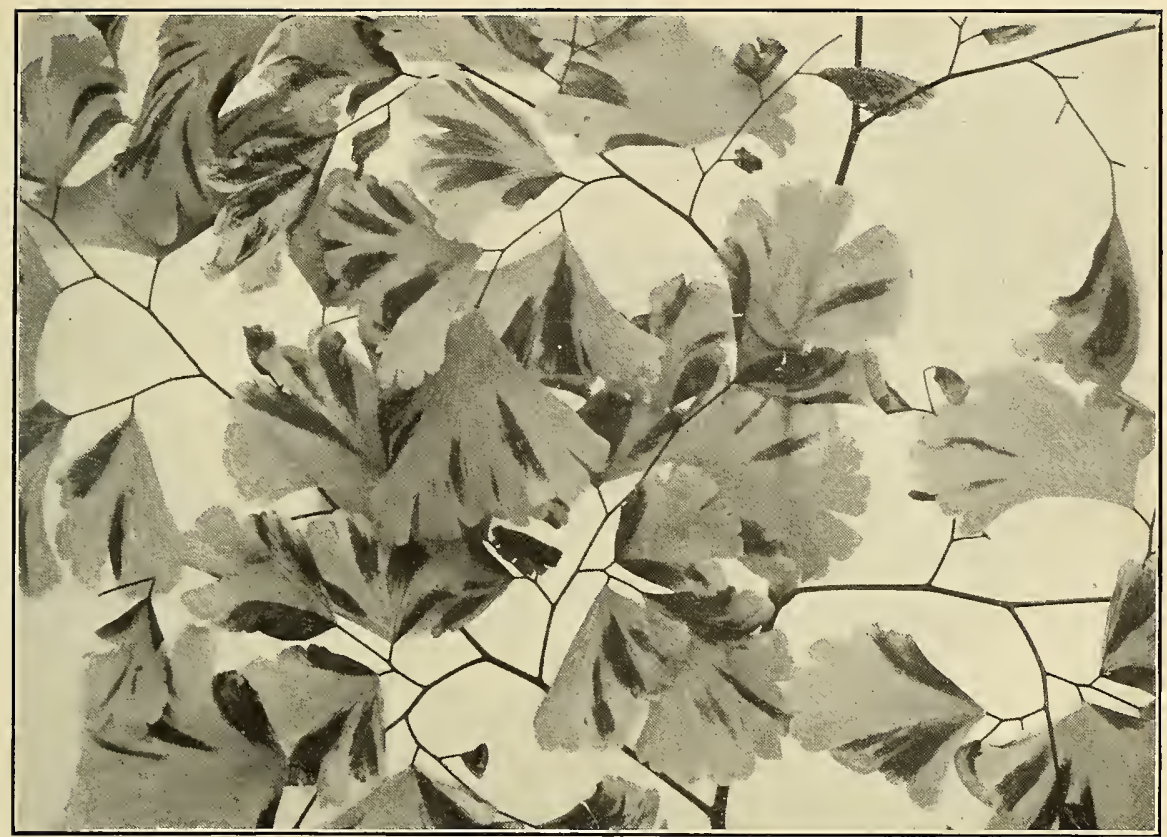

a. Leaf Scorch of Farleyense Fern, p. 349.

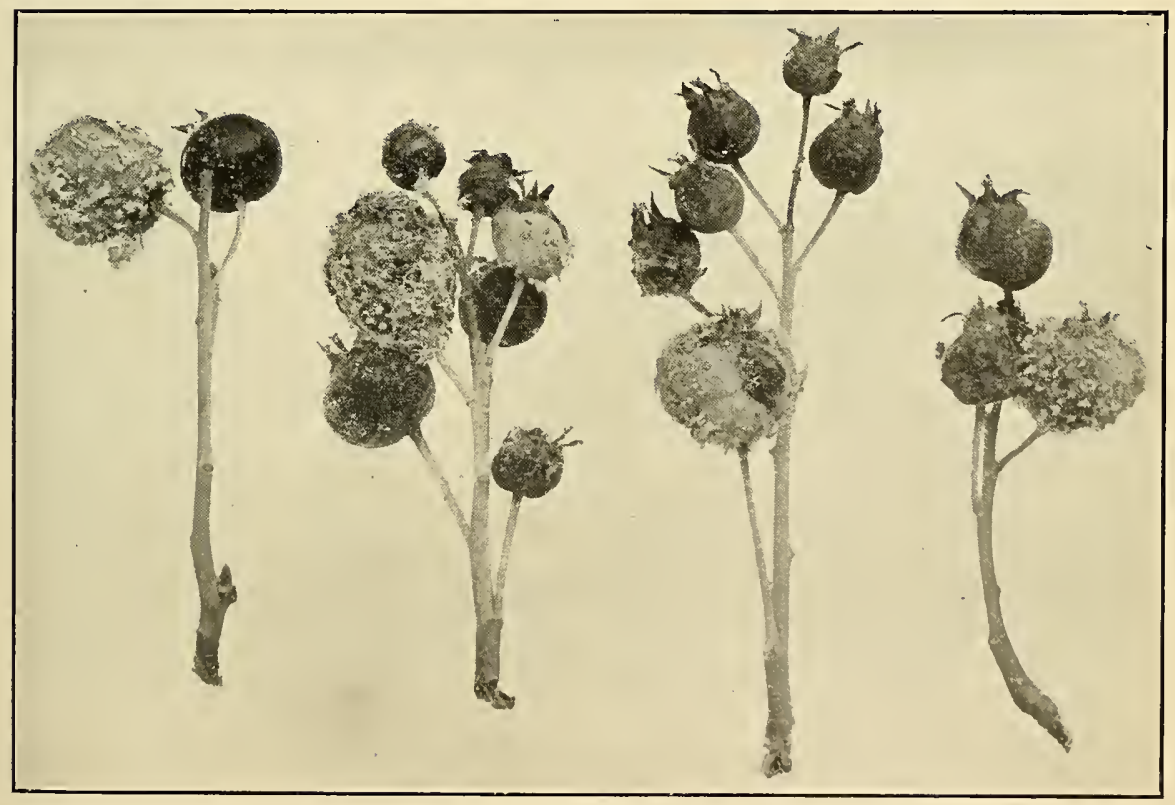

b. Rust of Juneberry, p. 35I.

DISEASES OF FERN AND JUNEBERRY. 



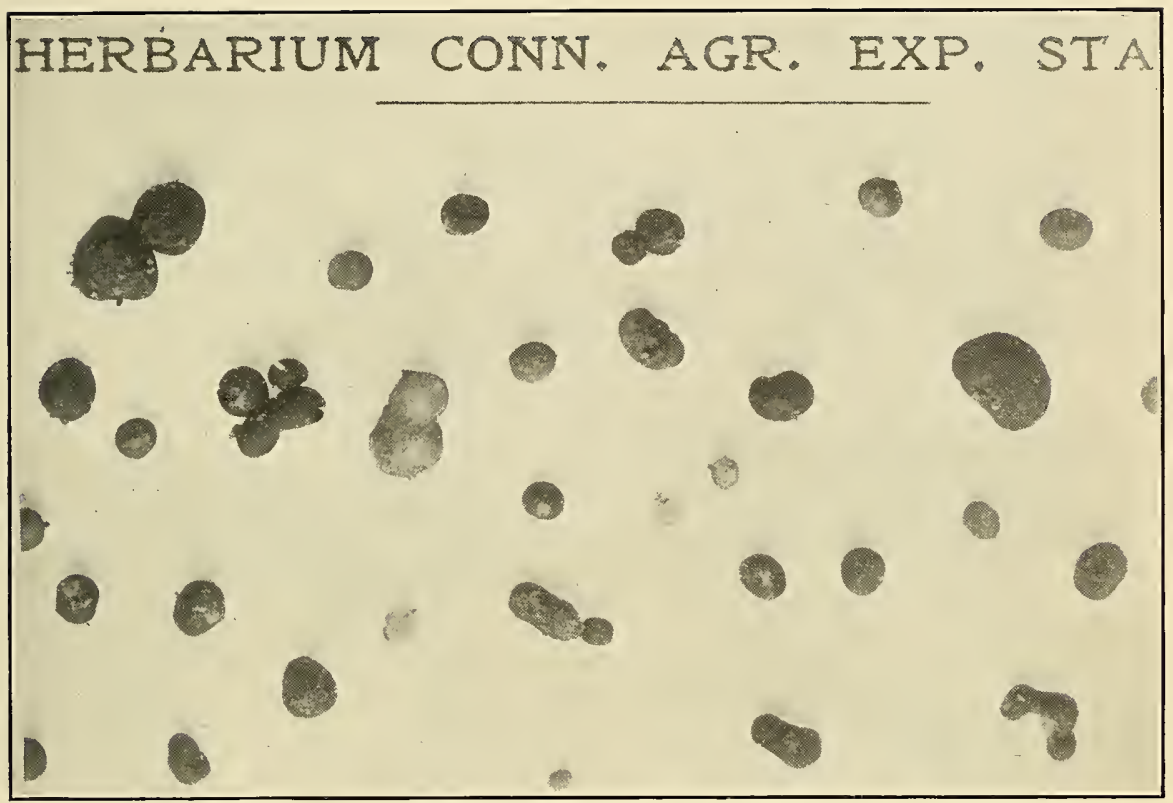

a. Sclerotia from the soil. $\times 2$.

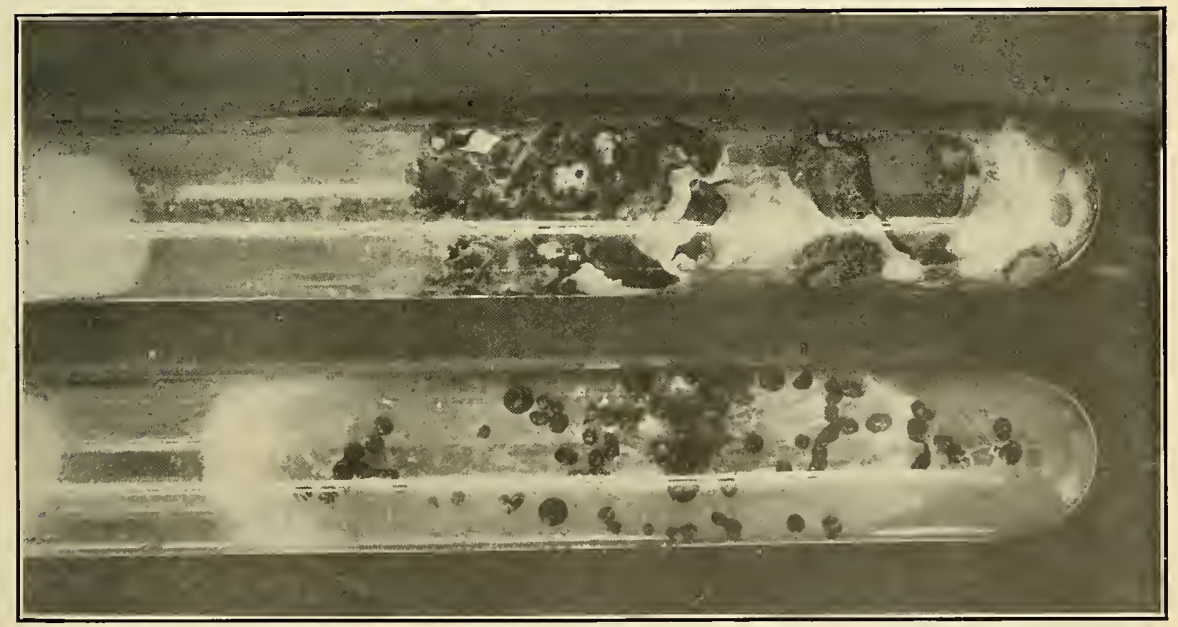

b. Artificial cultures on corn meal and agar.

STEM ROT FUNGUS OF HERBACEOUS PLANTS, p. $35 \mathrm{I}$. 



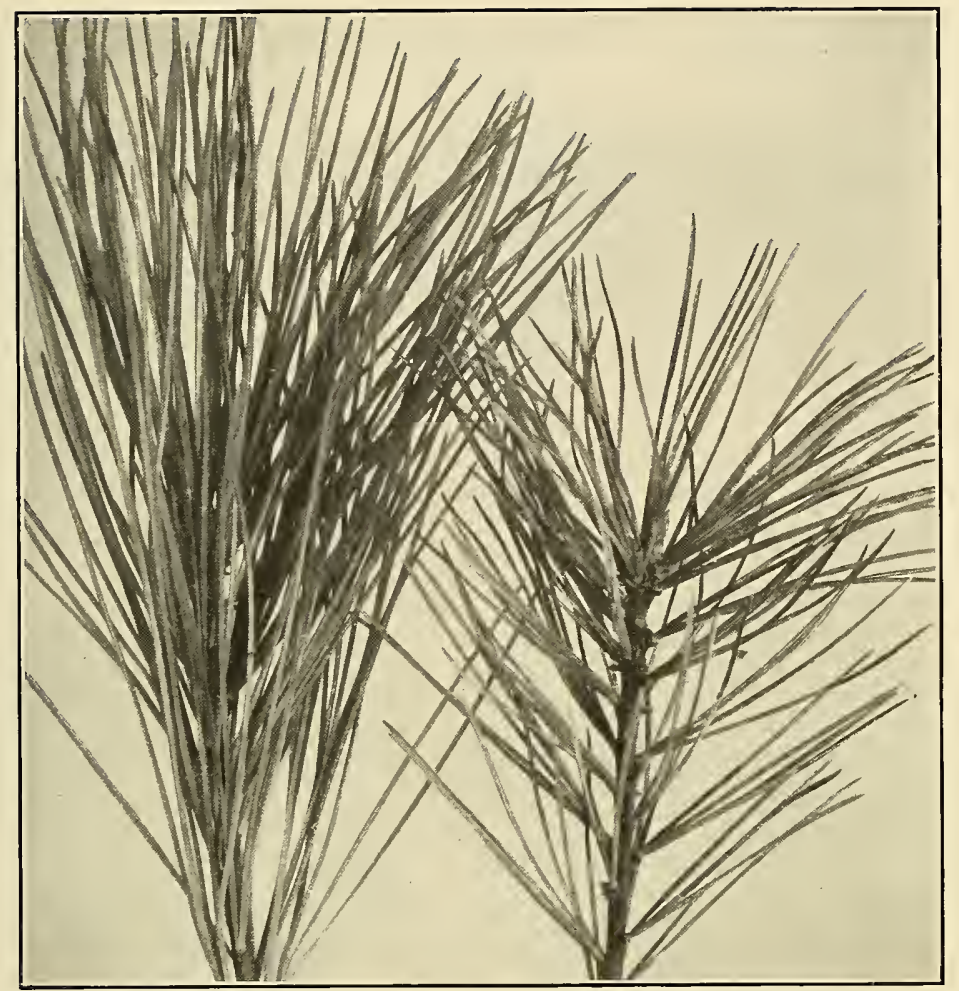

a. Showing effect on size of leaves.

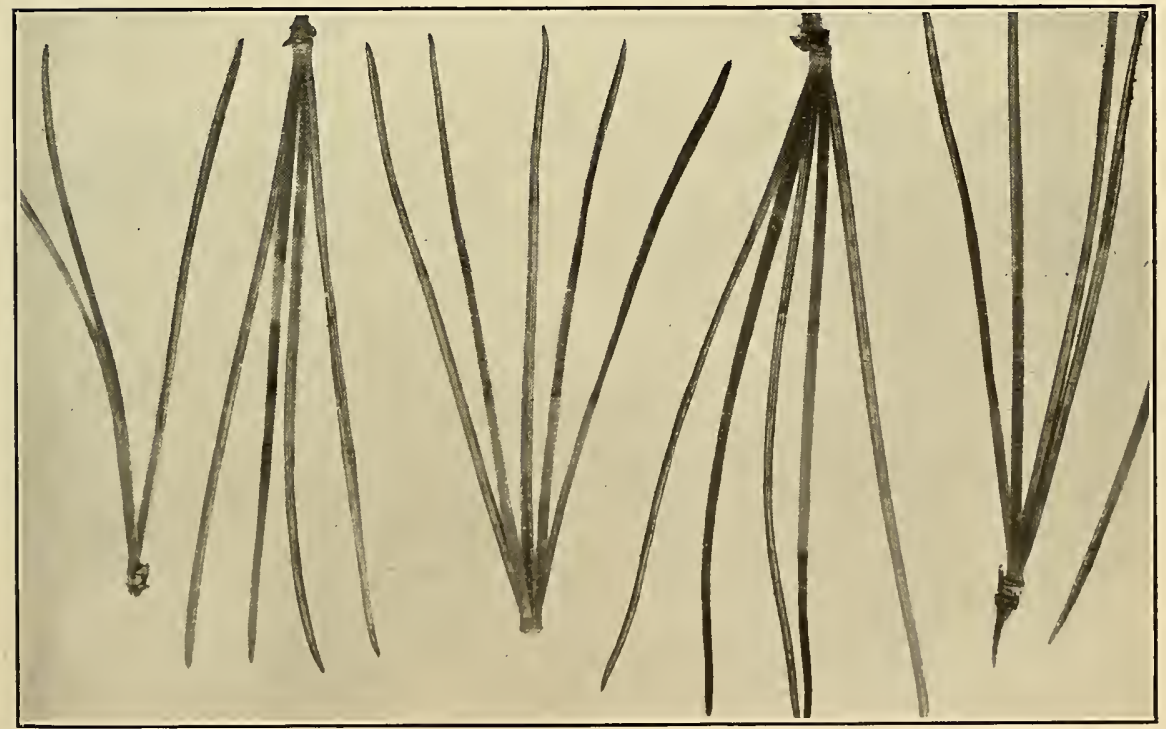

b. Showing injury to leaves. $\times 2$.

BLIGHT OF WHITE PINE, p. 353. 

PLATE XXIII.

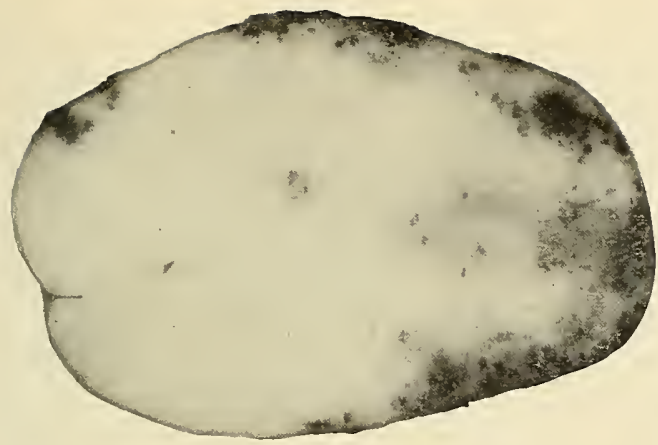

a. Internal Brown Spot, a physiological trouble, p. 355 .

b-d. Scurf, caused by Spondylocladium fungus, p. 357 .
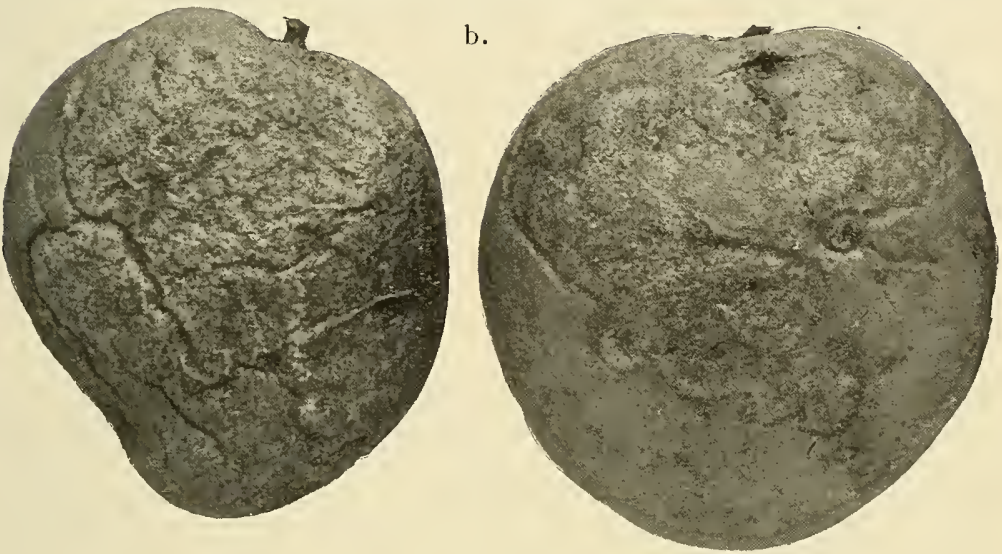

Surface of tubers greatly $x$.

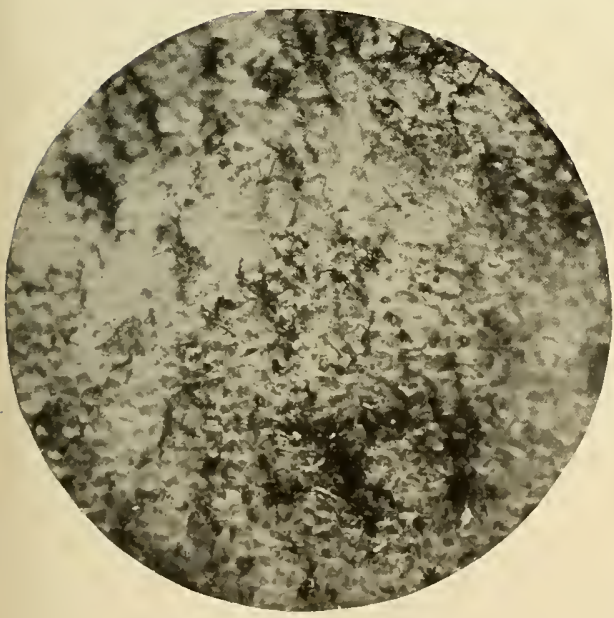

c. Spore stage.

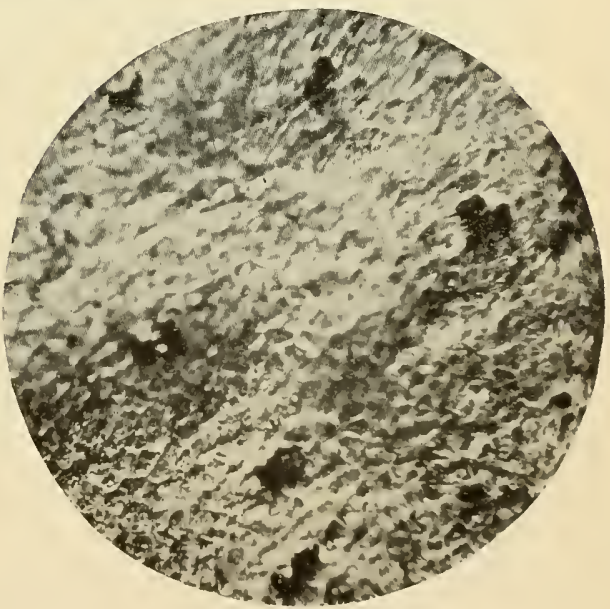

d. Sclerotia. 



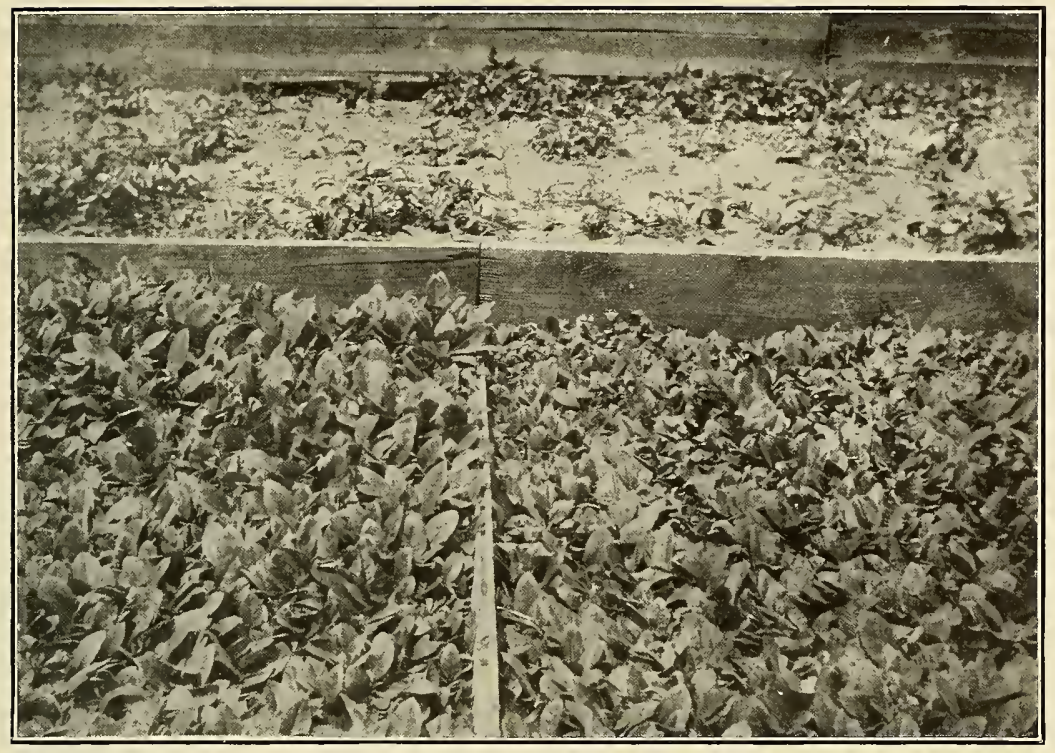
a. Formalin. (Plot I)
b. *Steam. (Plot 2)

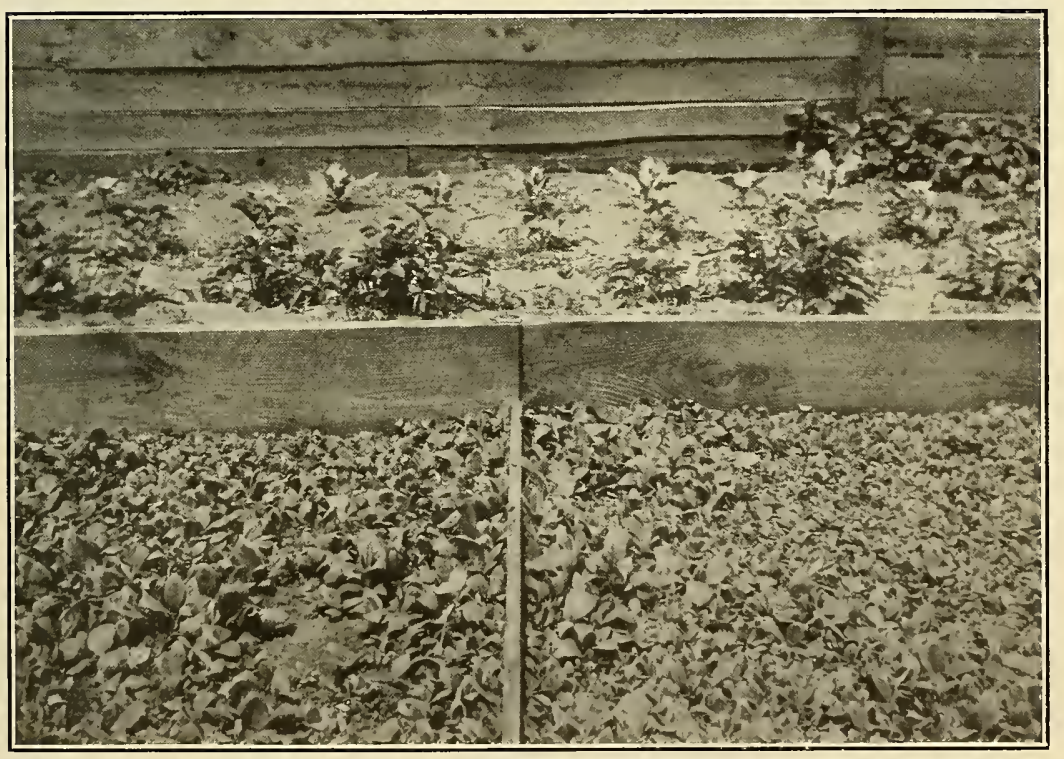

c. Weak formalin sprinkled. (Plot 5) d. Check, no treatment. (Plot 6)

(*Shortly before photographing, the best plants were pulled, so this should really sliow somewhat better than $a$.)

TREATMENT OF TOBACCO SEED BEDS FOR ROOT ROT, p. 365. 

PLATE XXV.

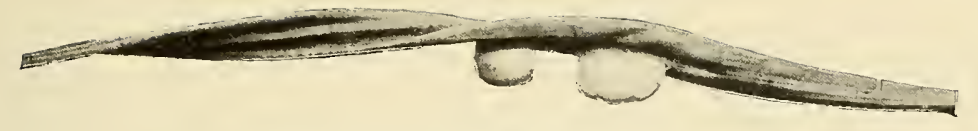

a. I on Pinus rigida. $\times 4$.
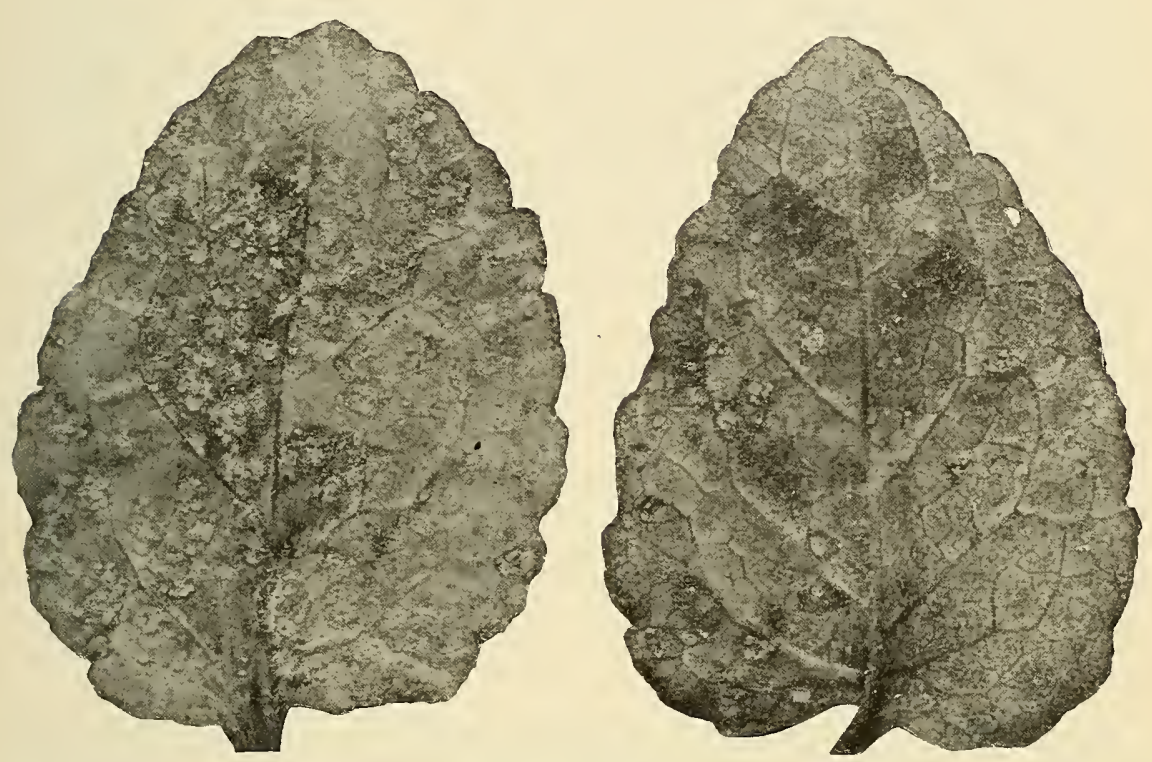

b. II on Campanula rapunculoides. $\times 2$.

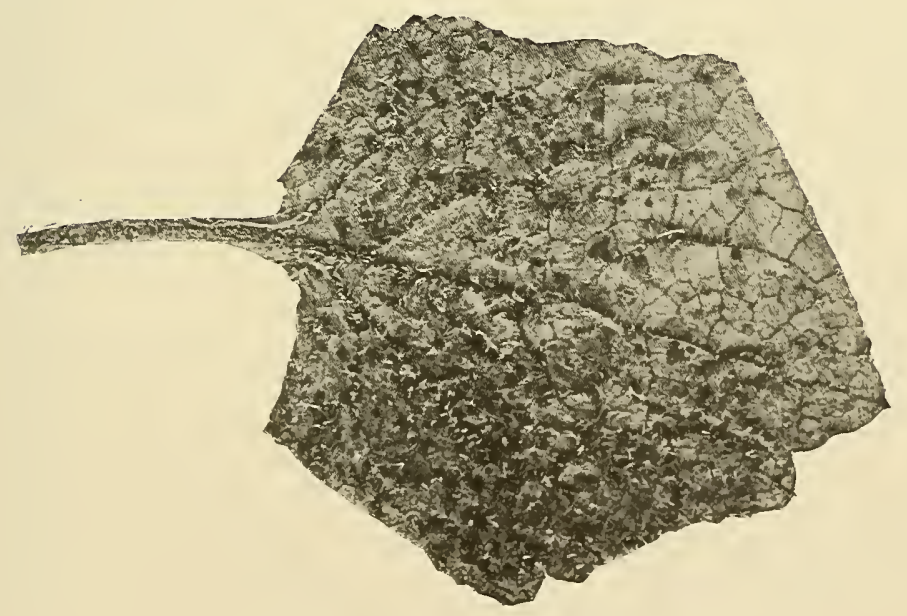

c. III on Campanula rapunculoides. $\times 4$.

1 (Peridermium Rostrupi), II, III STAGES OF Colcosporium Campanulae, 1. 374. 



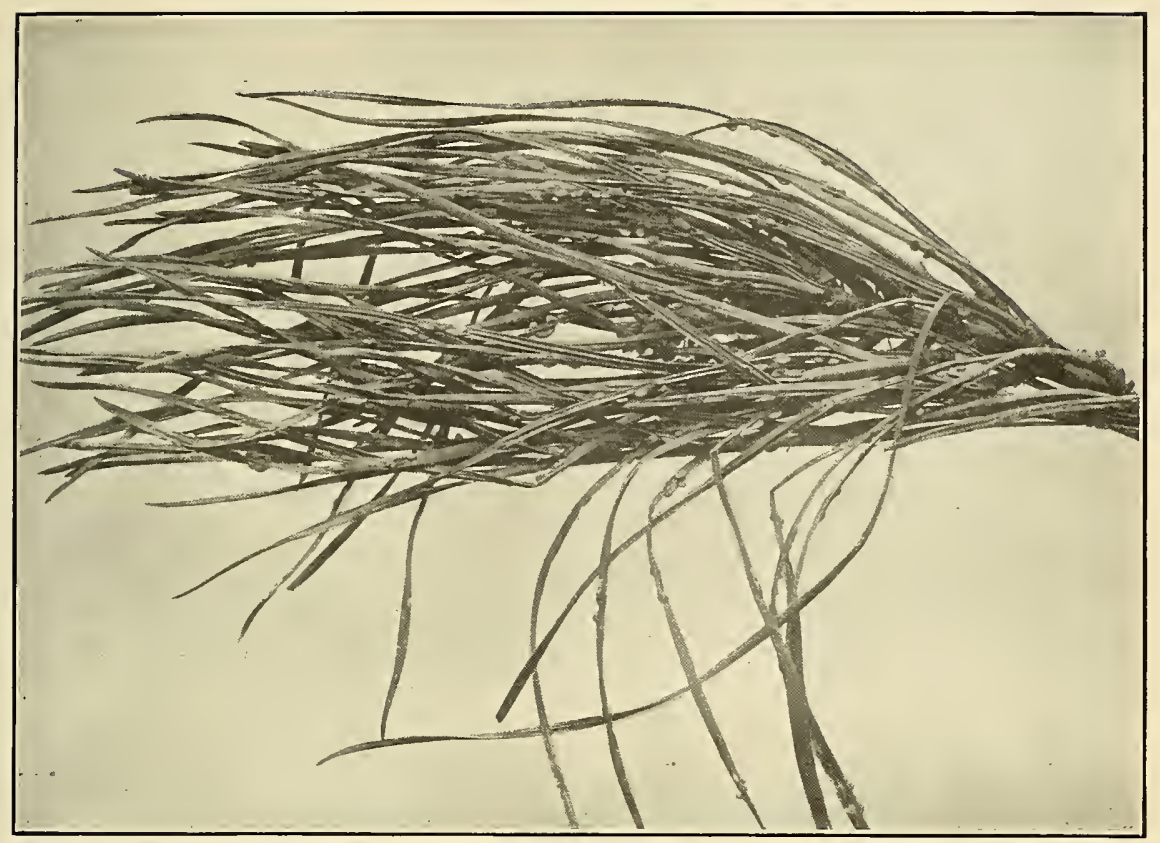

a. Showing a bunch of infected leaves natural size. I.

o.

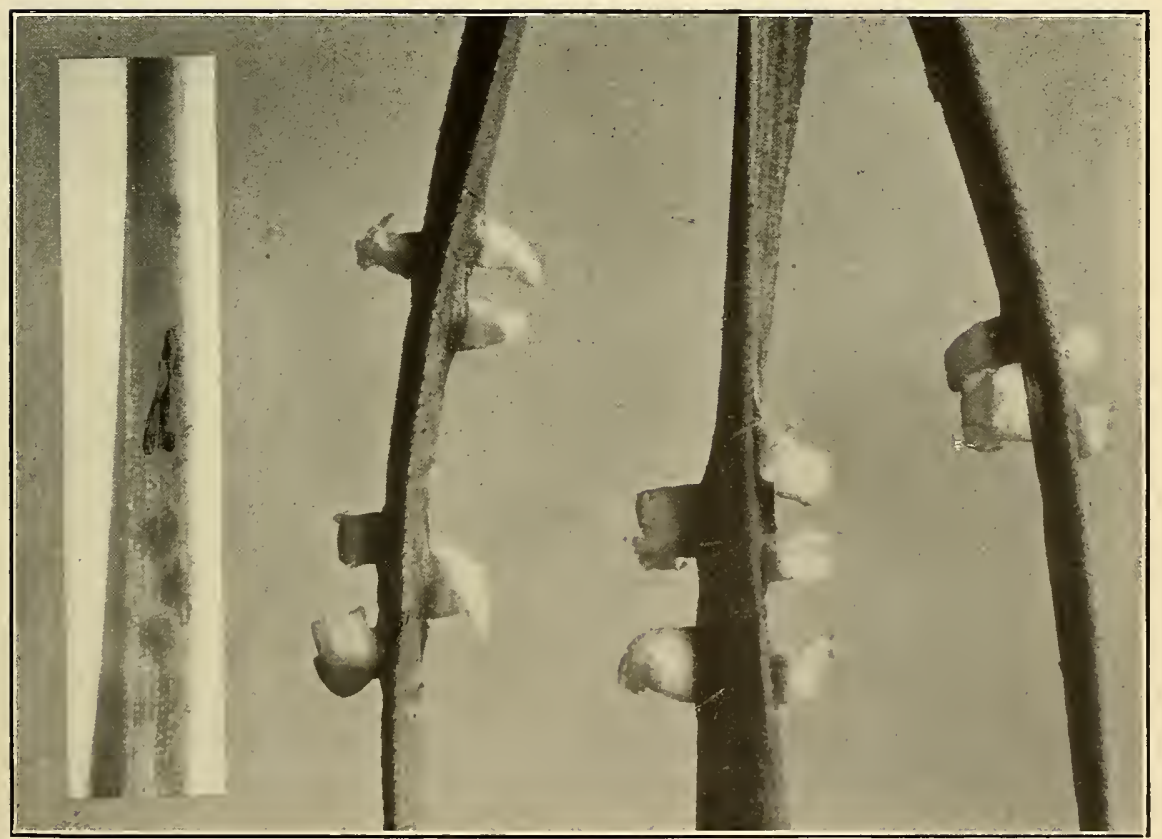

b. O, I on Pinus rigida. $\times 8$.

O, I (Peridermium acicolum), STAGES OF Coleosporium Solidagins, p. 375 . 



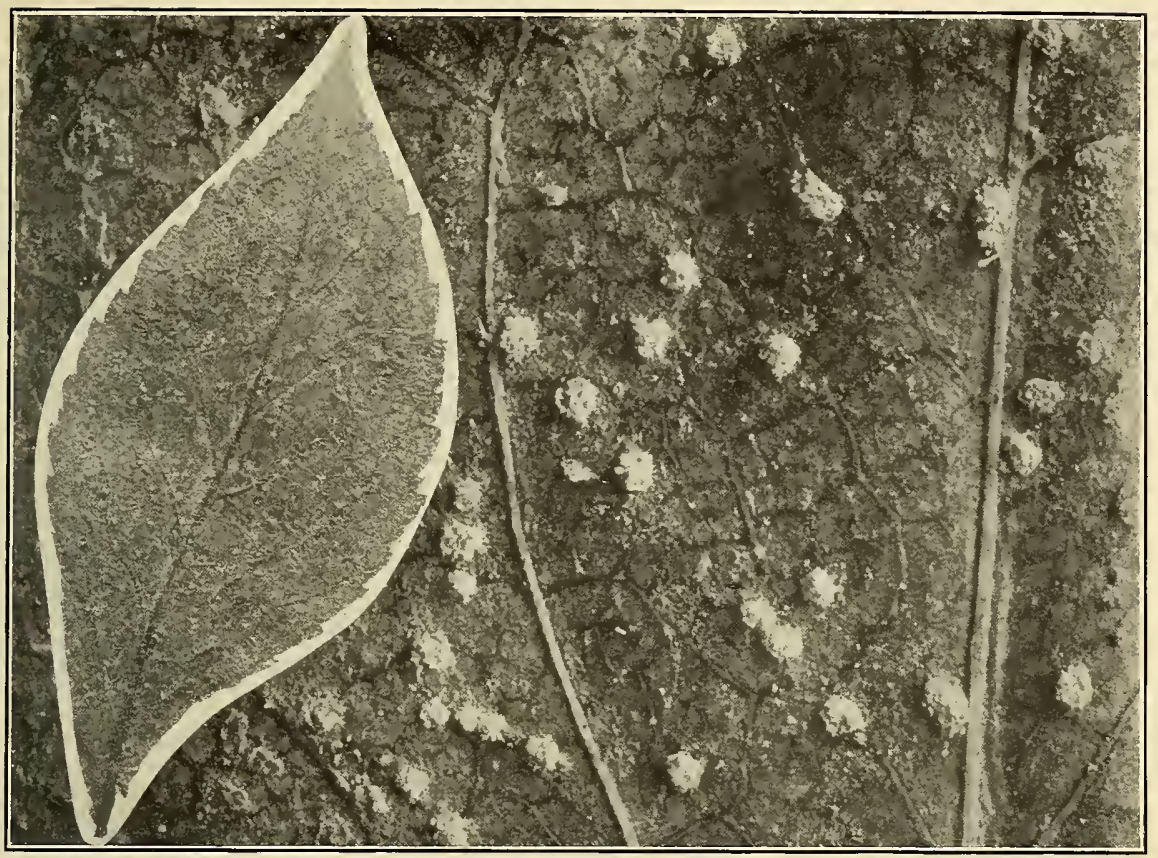

a. II on Solidago rugosa. Natural size and $\times 8$.

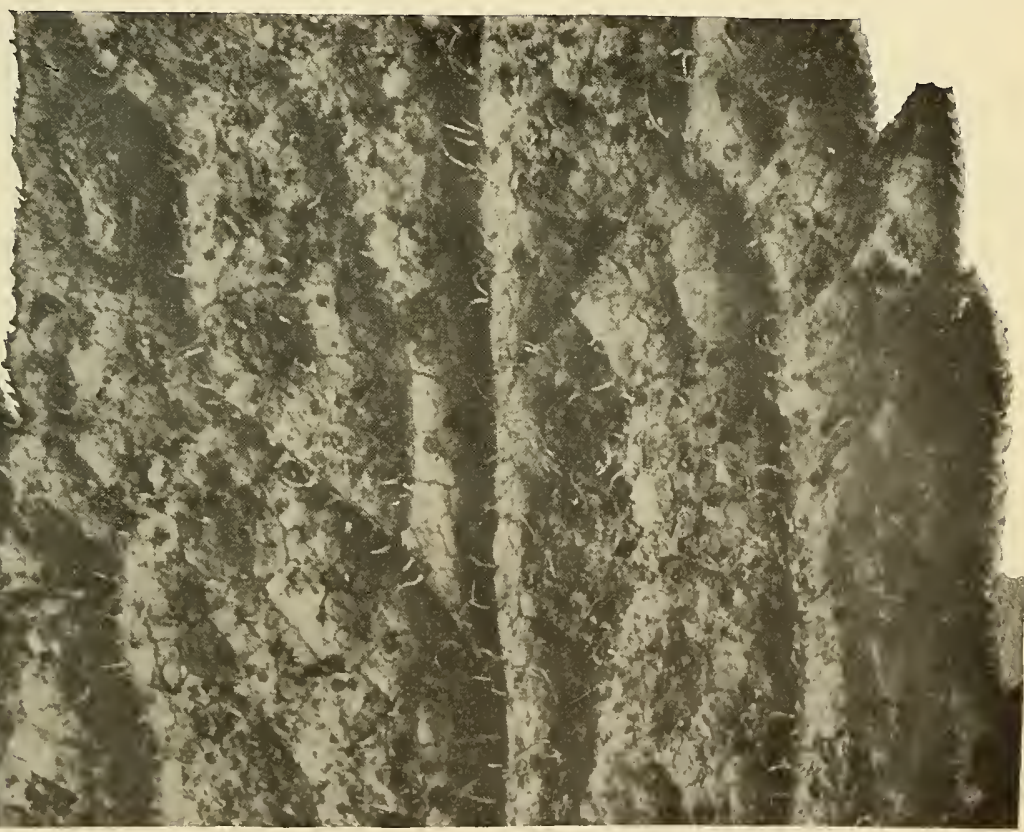

b. 1 II on Solidago rugosa. $\times 6$.

II, III STAGES OF Coleosporium Solidaginis, p. 377 . 

On Pinus sylvestris.

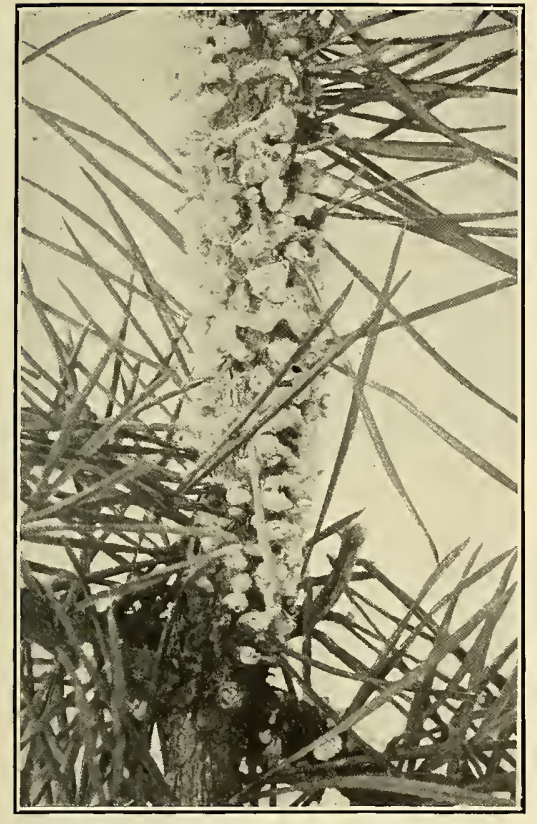

a. I natural size.

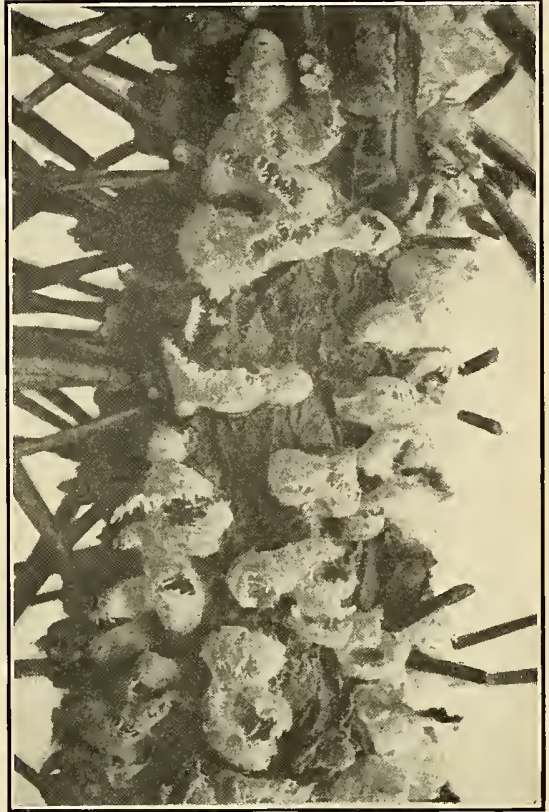

b. $\quad I \times 2$.

On Comptonia asplenifolia.

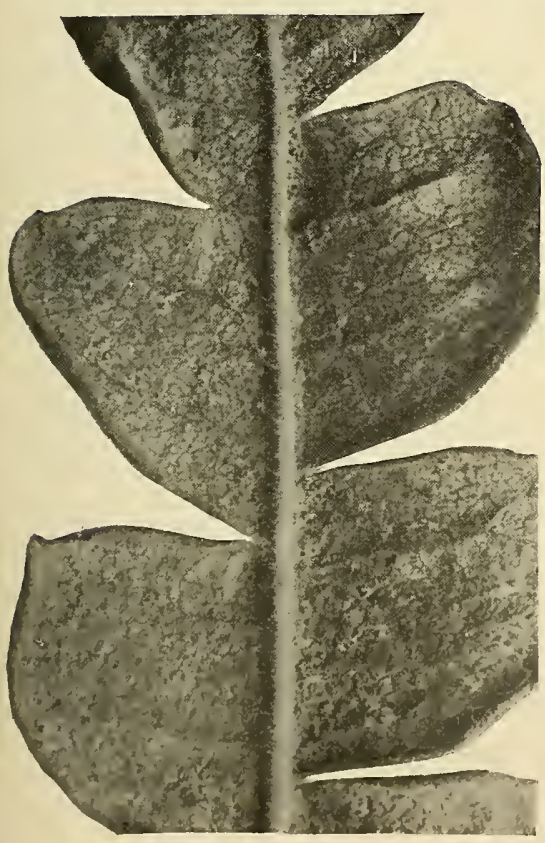

c. II $\times 4$.

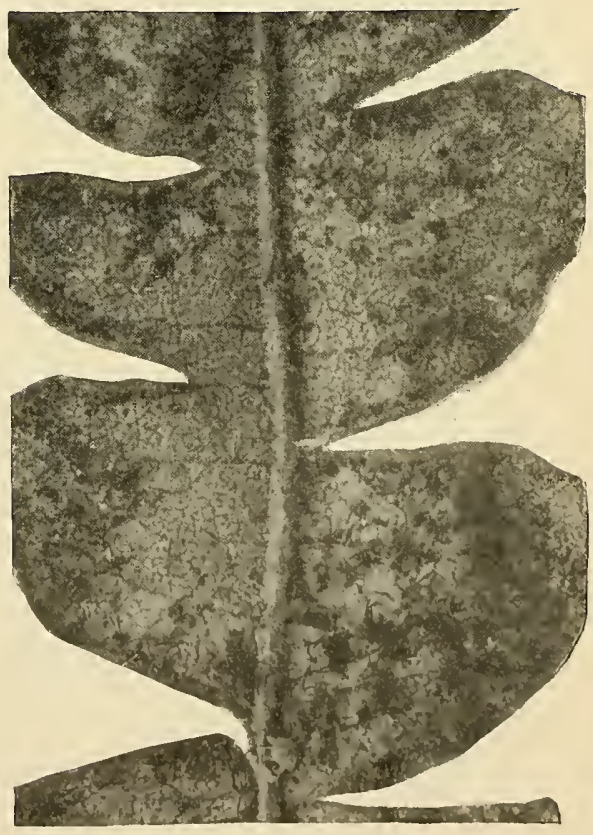

d. III $\times 4$.

I. (Peridermium pyriforme), II, III STAGES OF Cronartium Comptoniac, p. 38o. 

PLATE XXIX.

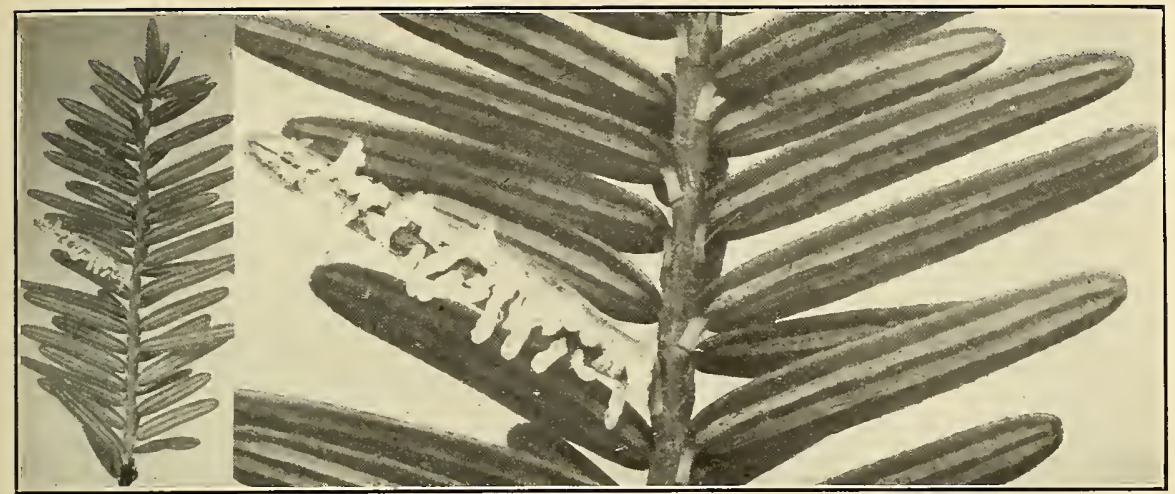

a. I Peridermium Peckii on Tsuga canadensis.

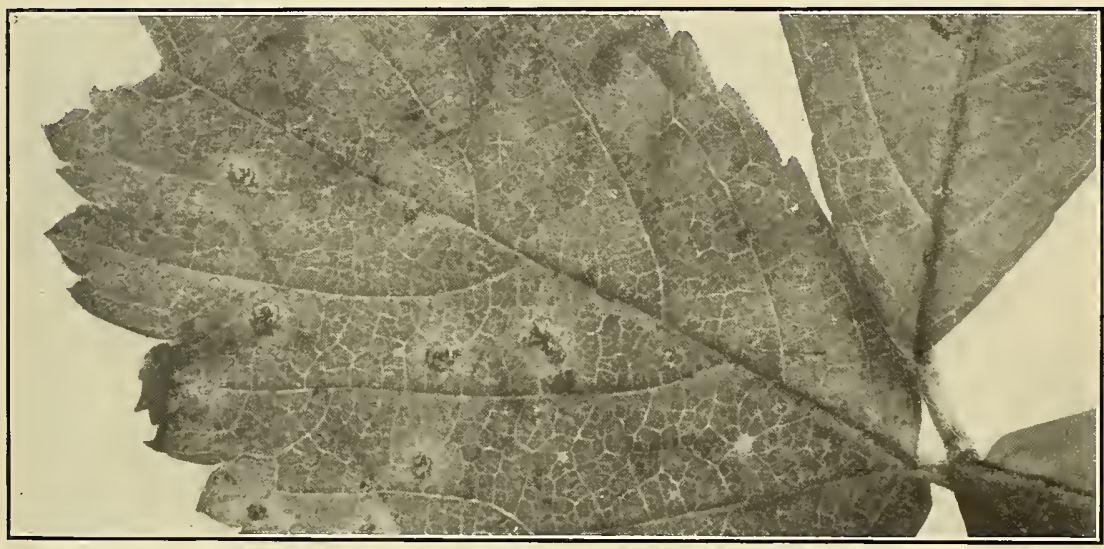

b. II' Uredo Muelleri on Rubus hispidus.

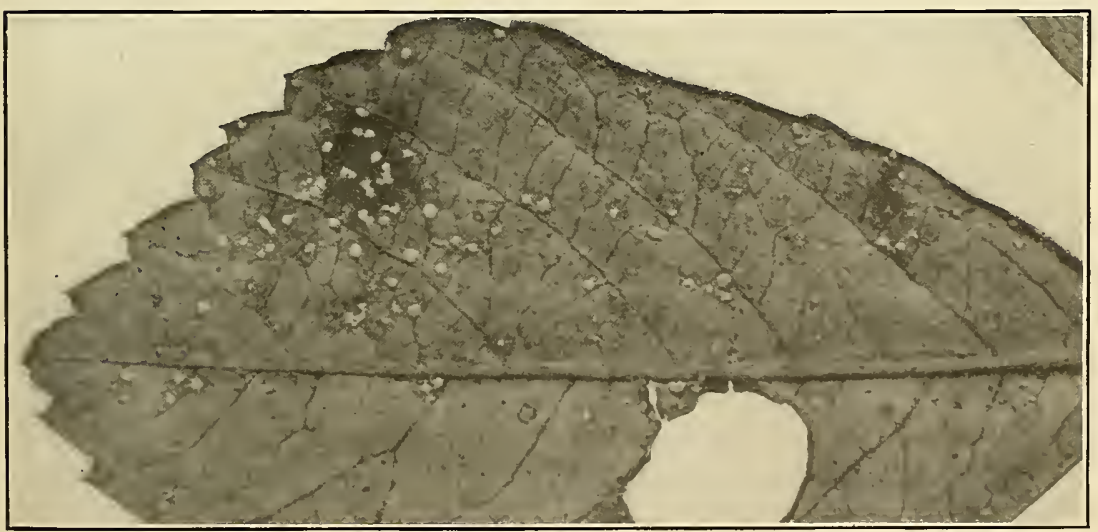

c. III Kuehneola albida on Rubus hispidus.

I, II', III STAGES $(\times 4)$ POSSIBLy OF THE SAME RUST, p. $38_{3}$. 

PLATE XXX.

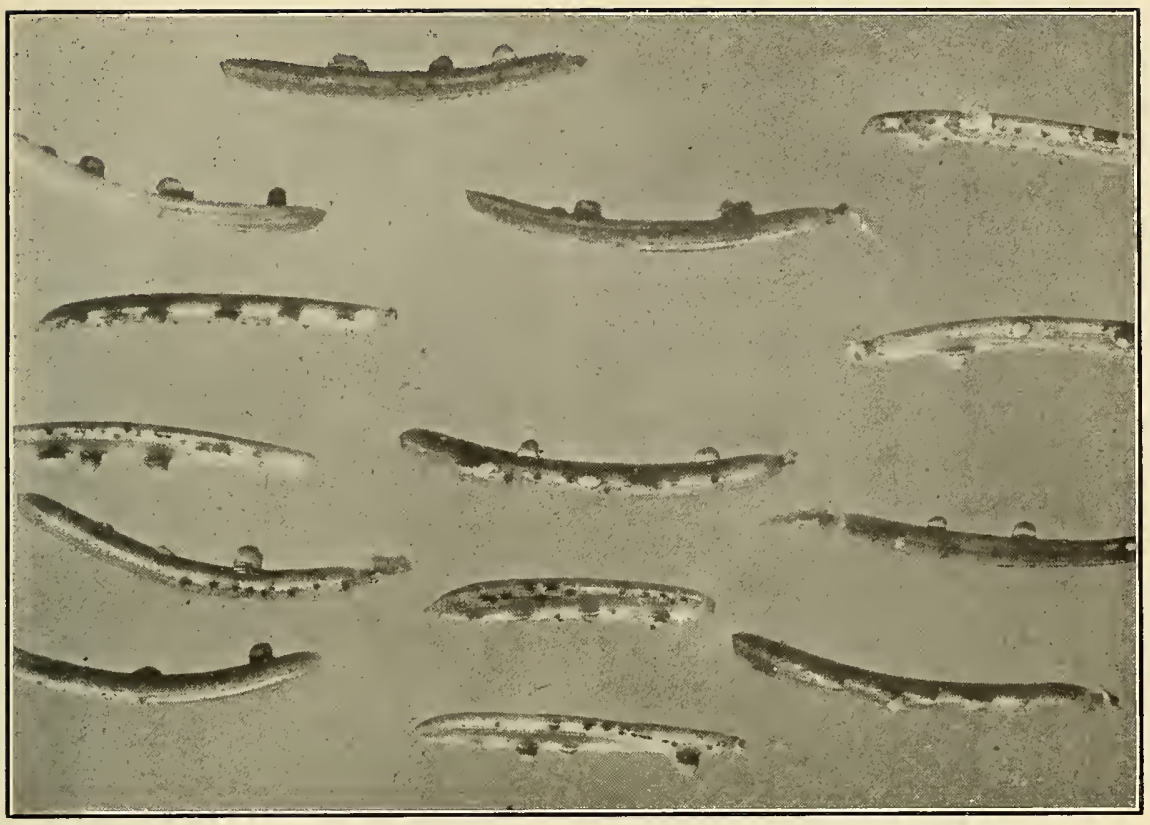

a. O, I on Picea nigra.

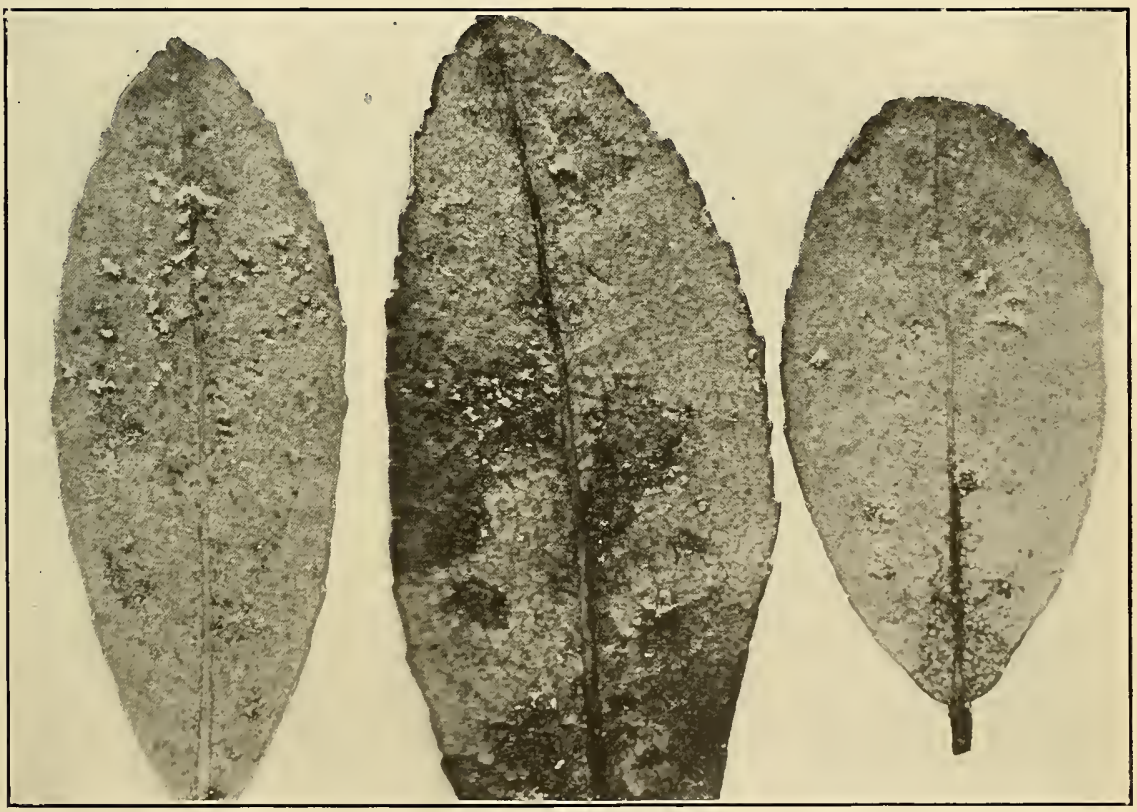

b. II on Cassandra calyculata.

0, I (Peridermium consimile), II STAGES $(\times 4)$ OF Melampsoropsis Cassandrac, p. 386. 

PLATE XXXI.

Melampsoropsis Pyrolae, p. 388.

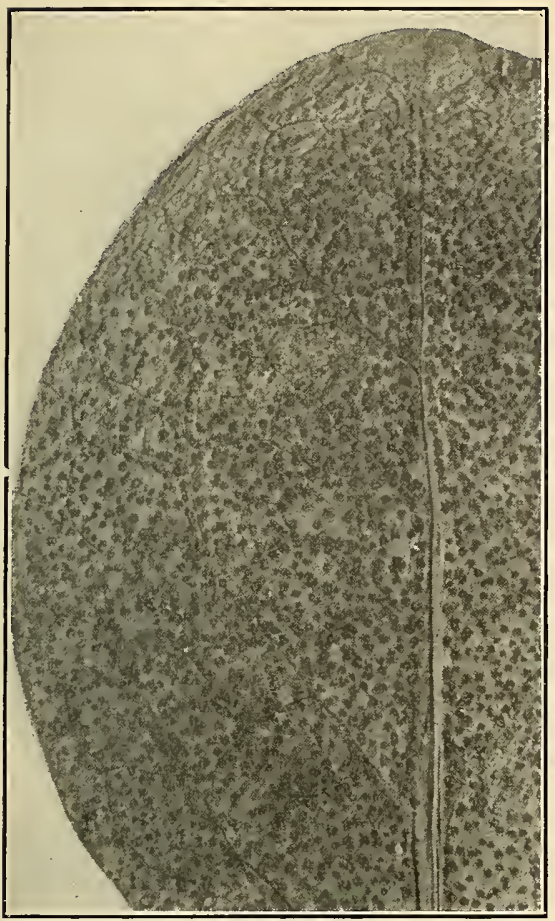

a. On Pyrola rotundifolia. $\times 4$.
Melampsoridium Betulae, p. 386.

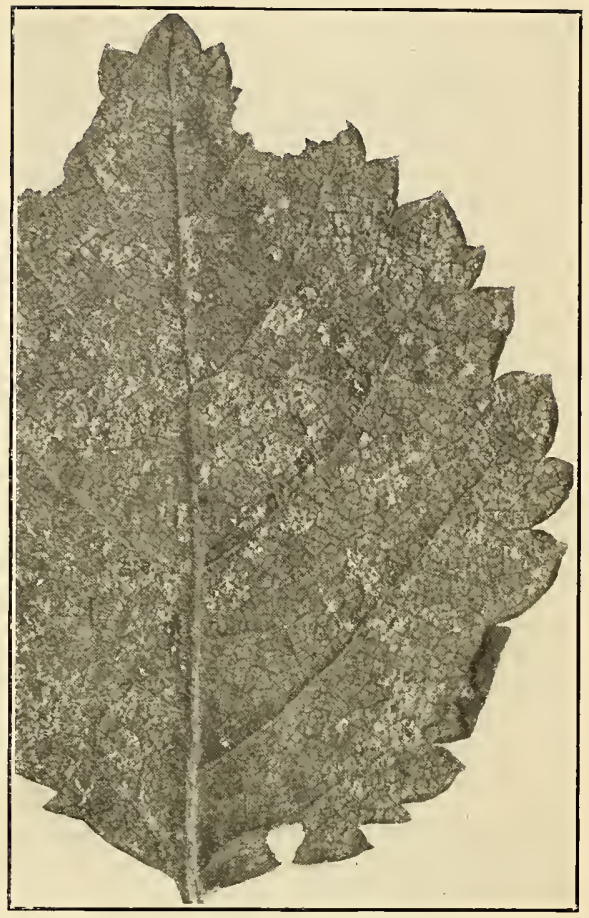

b. On Betula punila. $\times 2$.

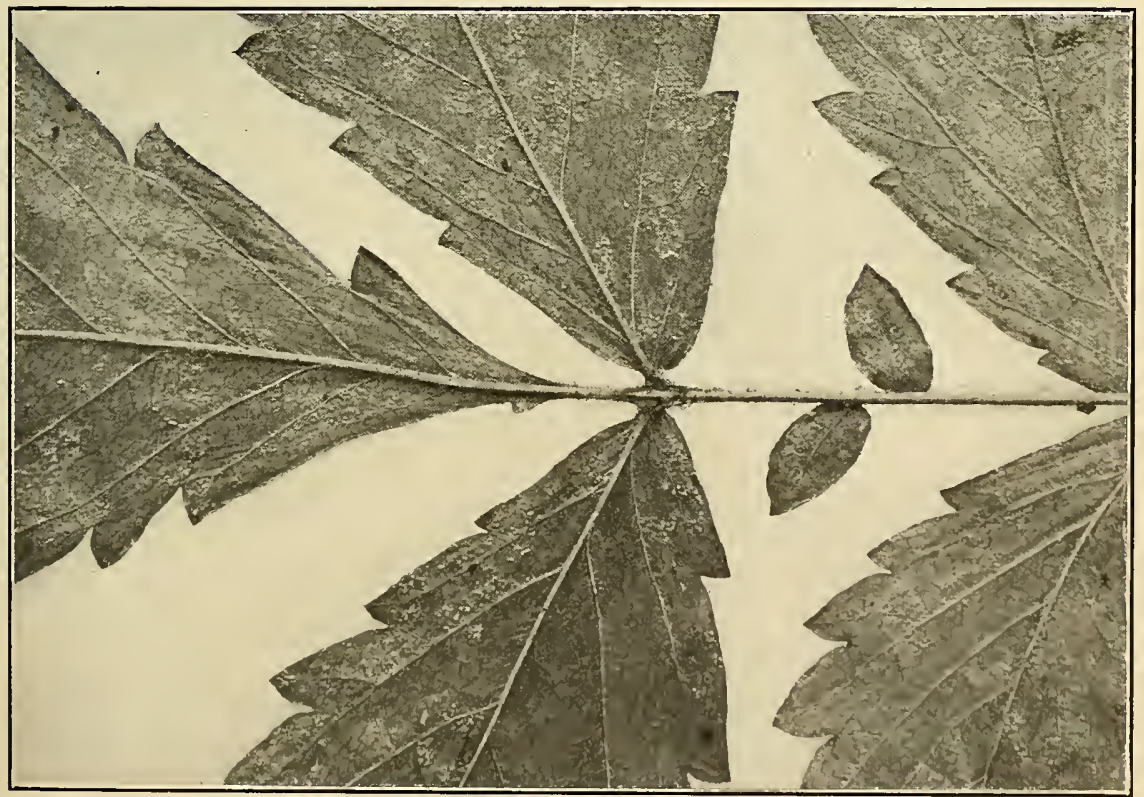

c. Pucciniastrum Agrimoniae on Agrimonia sp., p. 391. $\times 2$.

II STAGE OF THREE HETEROECIOUS RUSTS. 



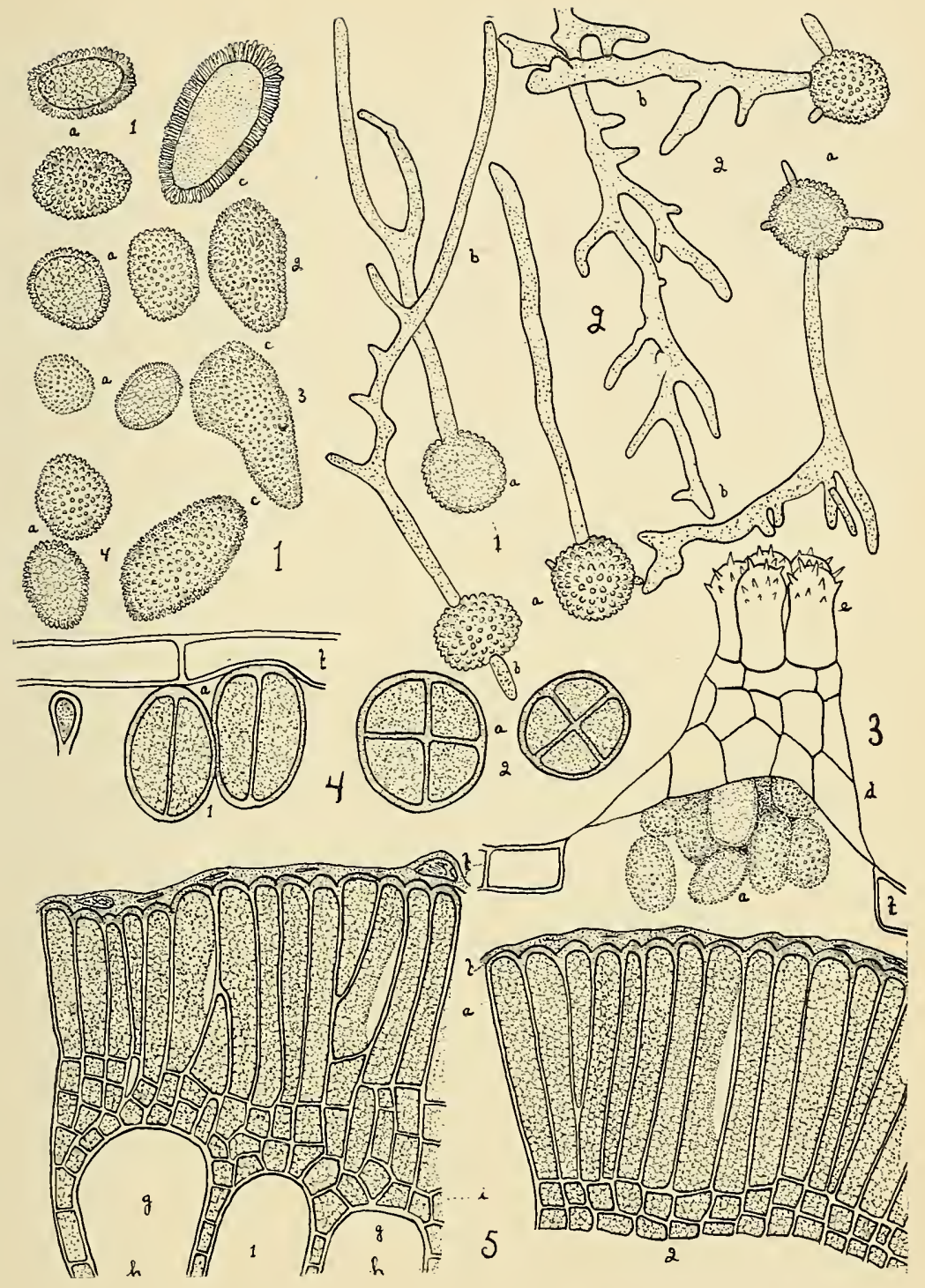

a. spores; b. germ tubes; c. peridial cells; d. peridium; e. neck cells of peridium; f. epidermal cells of host; g. parenchymatous cells of host; h. mycelium; i. fertile cells of mycelium. $\mathrm{I}^{1-4}$ (I) Periderminm acicolum; (2) P. pyriforme; (3) P. Peckii; (4) P. consimile. $2^{1-2}$ Germination of II spores of (1) Coleosporium Solidaginis and (2) C. Campanulae. 3. Partial section through peridium of Pucciniastrum arcticum var. americannm. $4^{1-2}$ Compound spores, III, of Pucciniastrum Agrimoniae, shown in longitudinal (I) and cross (2) section. $5^{12}$ Cross section through telia of Necium Farlowii on stem (I) and on cone (2). 



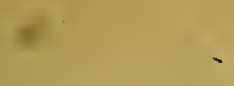

$=$

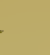

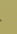





\title{
Ftate of Connecticut
}

\author{
REPORT
}

OF

\section{The Connecticut Agricultural Experiment Station}

REPORT OF THE STATION BOTANIST, 1908

G. P. CLINTON, SC.D.

BEING PART XII OF THE BIENNIAL REPORT OF 1907-1908 



\title{
CONNECTICUT
}

\section{AGRICULTURAL EXPERIMENT STATION}

\section{REPORT OF THE BOTANIST}

\author{
G. P. CLINTON, Sc.D.
}

I. Notes on Fungous Diseases, etc., for Igo8, . . . . . . . 849

A. General Notes on Diseases previously reported, . . . 849

B. New Observations on Diseases previously reported, . . 853

C. Diseases not previously reported, . . . . . . . . 858

II. Peach Yellows and so-called Yellows, . . . . . . . . 872

III. Chestnut Bark Disease, Diaporthe parasitica Murr., . . . . 879

IV. Artificial Cultures of Phytophthora, with special reference to oospores, . . . . . . . . . . . . . . . . . S9I 



\title{
PART XII.
}

\section{REPORT OF THE BOTANIST FOR Ig08.}

\author{
G. P. Clinton, Sc.D.
}

\section{NOTES ON FUNGOUS DISEASES, ETC., FOR Igo8.}

\section{A. GENERAL NOTES ON DISEASES PREVIOUSLY REPORTED.}

Weather conditions. The winter of 1907-08 was on the whole rather mild, so that no very general winter injury resulted to the shrubs and trees. During the latter part of January and in February, however, the cold was sufficient to kill a good many of the peach buds. Likewise, certain peach trees suffered somewhat from the collar girdle injury, which is described elsewhere.

The spring of 1908 was one of the earliest and driest that we have had in some years, the early vegetables being a week or two in advance of the average year, and considerably more than that as compared with the year of I907, which was unusually late.

The summer, like that of 1907 , was unusually dry, but differed in that the drought came in two periods. The first drought extended into the niddle of July. The latter part of that month and most of August were sufficiently moist for the needs of. vegetation in general; but the last of August and practically all of September were again free from rains. The splitting of the drought by the scattered rains during midsummer had the effect of keeping down drought injury much below that of 1907 , when the dry weather lasted from June until August.

While the drought did harm to certain of our crops, such as alfalfa, asparagus, potatoes and celery, on the other hand, some, like the peach, muskmelon and tobacco, were in the end benefited by the dry weather, especially by that of the late summer and fall. The comparatively dry weather of the growing season as a whole was sufficient to keep down most parasitic fungi, so that I908, like the past few years, was not one in which these pests (with a few exceptions) did any great injury to our cultivated plants. 
The fall frosts held off somewhat later than usual, the first one of consequence coming on October $\mathrm{I} 2 \mathrm{th}$, the slight frost of October $5^{\text {th }}$ merely injuring the cucurbits.

Market garden and other plants. There were a number of complaints of the premature yellowing and dying of alfalfa plants, these being affected sometimes in spots. While we did not have the opportunity of examining the plants in the fields, from the absence of any sure signs of fungous or insect attack on the specimens sent to the station, we were inclined to believe that the trouble was due to the dry weather. Certain weeds, such as the pigweed, often showed similar injury, due to the drought.

While the rust of asparagus was more common than usual, it did not do as much harm as the drought. Nearly all asparagus beds suffered from the dry weather, so that the tops were frequently dead early in September. Such injury from drought is likely to show itself the following spring in a lower yield of tips.

The anthracnose of string beans was conspicuous by its absence this year, and the downy mildew of the Lima beans only appeared at the very end of the season, when it was too late to do any harm.

The muskmelons were better this year than for some years past, in yield and especially in quality. Connecticut melons on the Boston market were unusually fine. This was due to the warm, dry weather which is so essential to this crop, and which also helped to keep down its fungous enemies. However, during the latter part of the season many of the vines were injured or prematurely killed by the attacks of the downy mildew and the leaf spot blights.

The blight, or downy mildew, of the potato, so far as the writer could discover from a careful search during the season, did not occur at all, it being the first time in seven years, at least, that it was not found. This meant that there was no injury by rot to the tubers. But while the potatoes escaped the blight, due to the dry season, from the same cause they suffered unusually from tip burn, so that practically all the vines, especially of the late varieties, were prematurely killed, and the yield very greatly reduced. In some fields the tubers were scarcely marketable. There was some $s c a b$, it being reported as quite bad in certain fields. 
The midsummer rains prevented much injury resulting from the drought to the tobacco fields, while the dry spell of the fall favored its harvest and curing in the barns. As a result the tobacco crop was unusually good. No complaint was made of serious root rot in the seed beds, and, so far as we have heard, the trouble in the fields, due to the Thielavia fungus and other causes, was not especially conspicuous in the Suffield region. In some fields there was more or less calico. (Plate LXVIb.) This is a trouble to which we have paid especial attention during the past two years, and we expect next year to give an account of these investigations.

Fruits and berries. While the apple crop was comparatively small and of rather poor quality, this was not due to any especial attacks from fungi. By far the most conspicuous apple fungus of the year was the leaf rust (Roestelia pirata). Conditions must have been unusually favorable in the spring for its spread from the "cedar apples," its winter stage on the red cedars, for it occurred on apple trees in some cases quite distant from any cedars. It was one of the fungi most frequently sent in for identification.

The peach apparently suffered more than any other fruit tree from fungous and physiological diseases the past year. While the $s c a b$ and brown rot were less noticeable than usual, the latter largely because of the favorable dry weather at harvest time, the bacterial spot was more common than at any time since we first called attention to it in I903. There was also considerable injury from collar girdle in some orchards. Yellows and so-called yellows were very prominent, especially in certain orchards. While the peach crop was not as large as some years, the quality was above the average.

With the quince, as with the apple, rust (Plate LX c) was unusually prevalent, especially in the vicinity of New Britain. The quince rust (Roestelia aurantiaca), however, generally attacks the fruit and the young stems, especially the fruit-spurs. Its mycelium in the stem, so far as we have been able to learn, is not perennial, so that infection each year depends upon the "cedar apple" stage. It forms elongated but quite fragile white peridia that rise above the infected parts and are filled with bright orange-colored spores. The half-tone shows a quince in which these peridia have worn off. 
Among the diseases of the small fruits, the downy mildew of the grape and the yellows of raspberries were the only ones to which our attention was called as being unusually common. We also noticed one case of leaf spot (Septoria Rubi) of raspberry which was as bad as any we have ever seen on this host.

Forest and shade trees. Because of the articles that have been written and the great damage it has caused, the chestmut bark disease is now attracting much more attention in this state than it has before. It is a question whether this trouble is on the increase or whether it is merely being reported in new localities because of the search that has been made for it. We treat of it more at length in a special paper later in this Report.

The fungus most frequently sent to the station for identification during the year was the black spot (Rhytisma acerinum) of the maple, and our own observation also showed that it was unusually common. This fungus is conspicuous because of the evident black spots, something like finger prints (see Plate LXIV a), that develop on the leaves. These are slightly elevated on the upper, and often concave on the lower surface, showing less prominently beneath. So far as known, this occurs only on the leaves and does not mature on them until the next spring. The evident method of combating it is to rake together and burn the leaves in the fall. While the cultivated cut-leaved variety of the soft maple is the one most commonly attacked, we have also found it on the soft and red maples.

The blight of white pine, which attracted so much attention last year, was very much less conspicuous this year and we received no complaints of it. Of course last year's leaves which were killed at the tips still showed the injury, and in some cases the leaves put out this year also showed the trouble somewhat. Early in the spring the Forester marked all of the injured young trees in a certain block at the state plantation at Rainbow. This block will be watched for a year or two to see if the trouble spreads and what its effect is on the trees already diseased. When examined last (fall, 1908), the trouble seemed not to have spread (at least to any extent) and the marked trees were improving, the leaves put out this year being usually in much better shape than those of last year. The results so far seem to confirm our statement made in the last Report, that this disease is not primarily due to fungous attack, as believed by some, but 
is rather the result of adverse weather conditions which culminated in the drought of last year.

The sycamore trees, which were severely injured last year by late frosts in May, just as the leaves were appearing, still show the effects by their scantier though healthy foliage. Some writers erroneously attributed this injury to the anthracnose.

\section{B. NEW OBSERVATIONS ON DISEASES PREVIOUSLY REPORTED.}

\section{APPLE, Pirus malus.}

Rust, Gymnosporangium macropus Lk. Plate LX a-b. The aecial stage of this fungus (Roestelia pirata), while common on apple leaves, has not before been reported on the fruit itself in this state. In the fall of $1907, \mathrm{Mr}$. A. B. Cook sent the first specimen that we have seen. The past year, because of the rust's unusual abundance, the fruit was also attacked more frequently than usual. On a roadside seedling near Meriden, in September, we found it quite abundant on the apples as well as on the leaves. The peridia on the fruit varied so in the character of their splitting open that we thought possibly. both of the species of Roestelia which occur here were present, though the spores seemed the same. Mr. Kern, however, to whom we sent the two specimens shown in the halftone, pronounced them the same.

The infected apples showed a progressive development of the mycelium, so that eventually the whole apple became involved. Cutting across one of these apples, the presence of the mycelium was shown by its endochrome, which gave an orange tint to the invaded tissues. This infected area was always evident at the surface, narrowing down, in wedge shape, toward the core in the cross section. Another peculiarity that, so far as we know, has not been described before, was the development of immature pycnia within these tissues; and, in the seed cavities of the core, the formation, in a number of cases, of perfectly mature peridia.

As these apples offered an easy method of obtaining tissue containing the mycelium of the fungus free from other germs, for artificial cultures, attempts were made to grow the fungus in this way on apple juice agar, but in none of the cultures did the fungus develop. However, so far none of the rusts have been grown in such artificial cultures. 


\section{AZALEA, Azalea sps.}

Rust, Pucciniastrum minimum (Schw.) Arth. In the Report of the station for 1903 , p. 306, we reported the uredinial stage of this fungus under the name Pucciniastrum Vacciniorum (Lk.) Diet., to which it has commonly been referred. Arthur in N. A. Flora $7^{2}$, p. 109, however, considers the rust on Azalea distinct from that on Vaccinium, and describes it under the name $P$. minimum, but states that the telial stage has never been reported. The past fall we again found this rust on Azalea nudiflora (and apparently other cultivated species) in the local nursery where it was seen before, and on specimens gathered the latter part of October we were able to find the telial stage. The sori of this stage are so inconspicuous that it is necessary to cut sections of the leaves in order to be sure of the presence of the spores. These compound spores are of the normal Pucciniastrum type, showing (when not too much crowded together) as four cells in surface view and two cells in longitudinal section. They occur, one or more, in the epidermal cells of the upper side of the leaves above the uredinial sori, but sometimes appear to be situated between the epidermal cells and the cuticle. They vary in size from $2 \mathrm{I}$ to $25 \mu$, in surface view, to 23 to $29 \mu$ in longitudinal section. Their walls are reddish-brown in color. So far nothing is known of the aecial stage of this fungus, which is supposed to occur on some coniferous host, and the collections made by us give no clue to this stage or its possible hosts, though we have looked for suspicious Peridermia on the Coniferae in that vicinity.

\section{GRAPE, Vitis sp.}

Downy Mildew, Plasmopara viticola (B. \& C.) Berl. \& De Toni. This fungus is not uncommon on the leaves and green fruit, but the past year for the first time we have found it here on the ripening fruit, causing the brown rot described by Scribner (Fungous Diseases of the Grape, etc., p. 48). In September specimens of rotting white grapes were sent to the station from Hartford by Mr. A. H. Newton. An examination showed that this fungus was responsible for the trouble, though the grapes were quickly infected by other fungi that fruited on them and so gave the appearance of being the primary cause of the rot. 
On the young green grapes the conidial stage is developed on the exterior, but with the brown rot of the ripening fruit neither this stage nor the oospores developed, though the specimens were examined in all stages of decay, for the latter, until the end of the season. The characteristic haustoria of the mycelium, however, easily distinguishes the fungus.

As the mycelium penetrates all through the tissue of the grape, attempts were made to secure artificial cultures of the fungus, as we have done with the downy mildews of the potato and Lima bean, by placing infected tissue in nutrient agar medium in sterilized test tubes. In this case we did not succeed, for all the grapes apparently were contaminated with other fungi that prevented the development of the mildew, or else crowded it out.

The past year a careful search of grape leaves from different sources late in the fall disclosed the presence of the oospores occasionally in these. Farlow years ago reported finding these spores, but they are rarely found except when a very careful search is made for them. There is no external indication on the leaf of their presence, and the only way to find them is to boil small fragments of the suspected leaves in potash, crushing the tissues so that they can be examined under the microscope, and then search until the oospores are discovered. We were most successful in finding them in the tissue next the larger veins, but did not find them on the twigs, though they have been reported on these in France.

Powdery Mildew, Uncinula necator (Schw.) Burr. Plate LXII c. During September an unusual appearance of this common fungus of the grape was found (in a single variety only, on the station grounds) where it produced small circular discolorations on the stems of this year's growth, as shown in the illustration. These reddish spots, about one-quarter inch in diameter, appeared to be made up of much smaller, closely placed dots. The fungus in its conidial stage occurred inconspicuously on these and in time disappeared, so that the cause of the injury would then have been difficult to determine. The mycelium of this fungus ordinarily develops externally on the host, sending only short branches, haustoria, into the tissues for nourishment, but in this case there is a possibility that the mycelium secured a firmer foothold in the plant, which might enable it to live over the winter there. 


\section{PEACH, Prumus Persica.}

Bacterial Spot, Pseudomonas Pruni Sm. Plate LXIX a. In the Station Report for I903, p. 337, the writer noted an unnamed bacterial disease of peach leaves from Pomfret, Connecticut, this apparently being the first mention of the disease in literature. In the Report for 1905, p. 273, a bacterial spot of plums, causing a purple-black spotting of the fruit, was described from specimens sent from Bridgeport. This was determined to be the bacterial disease of plum named by Erwin F. Smith Pseudomonas Pruni (now called Bacterium Pruni by Smith), and it was suggested by the writer that these two bacterial diseases might be caused by the same organism. Recently Rorer (Mycologia I: 23-7. I909) has practically demonstrated the identity of the two diseases. Rorer found the peach trouble quite common in Arkansas, where it occurred on the twigs and fruit as well as on the leaves. In this state, on the peach, we have found the disease only on the leaves, where it causes small reddish-brown spots which often fall out, producing shot holes, and when abundant, the premature yellowing and fall of the leaves. This year it was more abundant and injurious than we have seen it before. We also received for the first time specimens of diseased plum twigs from Sound View that possibly, were caused by this organism.

Collar Girdle and Root Injury. Plate LXVIII b-c. In a previous Report (I904, p. 323) we briefly mentioned winter injury of the roots of peach trees (Mr. Warner's of North Haven) caused by the severe winter of 1903-04. The winter of 1907-08 apparently caused more of this trouble-aggravated in part possibly by a weak condition of the trees due to the 1907 drought-than has yet been reported in the peach orchards of this state. The trouble was first called to the attention of the station by Mr. J. H. Hale, who asked for an investigation of the trouble. Mr. Hale wrote: "There has been a tremendous dying of peach trees around these parts the past two or three weeks, after they began to leaf out. Yesterday morning Albert Carini, who lives in the eastern part of South Glastonbury, came to me with a tale of practically six hundred dead and dying trees in an orchard that looked all right four or five days before." Other growers in the state lost occasional trees, but in few orchards was the injury so severe as in Mr. Carini's. 
In the absence of the writer Dr. Britton investigated this trouble, and we are indebted to him for the photographs and notes used here. The examination showed that the diseased trees had started to develop their foliage, but this soon turned yellow and dropped off before maturing. Some of the trees by June $2 \mathrm{~d}$ had dropped all of their foliage except small tufts at the end of the twigs, but the fruit still adhered. The trouble was found to be due to winter injury, which killed the roots and girdled the bark at the base of the tree, reaching above the ground two or three inches and forming the so-called "collar girdle." This bark could easily be peeled off, as shown in the illustration, Plate LXVIII $b$, and the demarcation between the injured and living bark was pronounced. Some indication of injury to the wood at the girdle was also shown by its brownish color. Some of the trees were dead only on one side, and in that case the roots were not all killed or the bark completely girdled; see Plate LXVIII c. The trouble at Mr. Carini's was chiefly on one variety, apparently a tender one, which had been bought for Elberta, but did not prove true to name.

This injury to peach trees is most likely to occur on places where the soil is not properly drained, or where the trees are exposed so that the snow is blown off from the ground around the trees. The snow acts as a mulch, and is of great value in protecting the roots and base of the tree. Cover crops or a vegetable mulch is of similar service where injury of this kind is likely to occur. Likewise, growers in this state have found it profitable, especially with young trees, to throw up the dirt around the base in the fall and then scrape it away again in spring.

\section{TOMAT0, Lycopersicum esculentum.}

Chlorosis (Infectious). Plate LXVIb. In the last Report ( 1907, p. 362) we mentioned a chlorosis trouble of tomatoes seen in the field and supposed to be due to the effects of frost, the plants having been injured by it in the spring. Whether or not this was the cause we cannot say positively, but attempts to produce this trouble in young greenhouse plants by exposing them to the cold so that they were more or less seriously injured were not successful. The past season we saw this trouble again in two or three different fields, and by using juice from these 
plants in one case were able to produce the same disease on healthy tomatoes, and also on tobacco. This shows that this tomato chlorosis is infectious and of the same nature as the calico of tobacco. In greenhouse experiments we have frequently pro-. duced chlorosis in tomatoes from juice from calicoed tobacco and then carried it back to the tobacco again from the tomato. In one of these experiments (see illustration) the effect on the tomato was to produce little visible calico, but rather a severe bacterial-like disease of the tomatoes. This possibly (though we hardly think so) was of the nature of a burn, since it was worse in plants sprinkled with water after handling them with the calicoed juice on the hands to produce the infection. However, we have at other times seen these small bacterial-like spots both on calicoed and healthy tomatoes.

\section{DISEASES NOT PREVIOUSLY REPORTED.}

ASPARAGUS, Asparagus officinalis.

Smoke (Gas) Injury. Early in October the writer was called to examine a field of asparagus claimed by the owner to have been seriously injured some time before (late August or September) by the smoke from an adjacent brick kiln. It seems that in muggy weather, when the wind was right, the smoke was sometimes swept down across the field for a time, and the tops were killed or severely injured. In the previous year such injury had resulted and the owner of the brick kiln had paid damages for the same. This year the owner of the kiln claimed that before the smoke was blown over the field the plants were as nearly dead as when seen later by the writer. Refusing to pay damages, he was sued.

After a careful examination, the writer came to the conclusion that while there was some slight indication of gas injury to the field (as shown by a streak through the center with more completely dead tops in an adjacent field), the main injury had not been caused by the smoke of this year. The asparagus tops in fields in the near vicinity and elsewhere were in no better shape than those here at this time, due to the severe droughts of the year. The asparagus in this field had been very severely ridged, even for a wet season, and so must have suffered during the present dry one, which no doubt was largely responsible for the 
dead roots rather than the gas. As the tops had been injured the year before by the gas, this no doubt weakened the plants and made them more susceptible to injury by the drought. This previous injury, however, had been settled for. It is generally understood that it is the sulphurous gas in the smoke that causes injury to vegetation under such conditions.

AZALEA, Azalea sps.

Powdery Mildew, Microsphaera Alni (Wallr.) Wint. The mildew on this host seemed to confine itself to the under surface of the leaves, forming there a more or less conspicuous white coating, with the perithecia scattered. See also New Jersey Tea.

\section{BALM, BEE, Monarda didyma.}

Rust, Puccinia Menthe Pers. This forms the II and III stages, frequently together, as light and dark, very small, dusty pustules, chiefly on the under side of the leaves, causing more or less spotting of the upper surface. It was found in a local nursery in September (rather abundant), on cultivated specimens of the above host and its variety alba. It is not an uncommon rust on some of the wild mints, especially the peppermint, Mentha piperita.

\section{BEANS, Phaseolus sps.}

Chlorosis (Infectious?). Plate LXI a. In the last Report of the station, I907, p. 343 , a chlorosis trouble of the Lima bean was described which did not seem to be infectious. (Plate LXI b of present report.) During September of the past year certain of the plants of both Lima and string beans on a market garden farm in Westville showed a chlorosis somewhat different from that noticed the year before, and which in general appearance resembled very closely the chlorosis (mosaic, or calico) troubles of tobacco, tomatoes and muskmelons $(q . v$.$) . The illus-$ tration gives a general idea of this trouble, the tissues around the veins showing usually the normal green, and those between a lighter green color, thus giving a mottled or mosaic effect. With the non-infectious chlorosis of the Lima bean mentioned above, the lighter green had more of yellowish cast, quite similar to insect or drought injury. Preliminary experiments in the green- 
house, using dried specimens of both Lima and string bean leaves three months old, soaked in water for a short time which was then applied to young Lima and string beans, were not successful in producing this disease, at least not very evidently. Neither did tobacco water from dried calicoed tobacco leaves produce it, though such water will easily produce calico in young tobacco plants. However, these experiments were not extended enough to say definitely that the disease is not infectious. Experiments with the fresh juice will be tried later, if possible, as we are strongly of the opinion that this is an infectious chlorosis.

\section{BEETS, Beta vulgaris.}

Drop Dampening-off, Sclerotinia Libertiana Fckl. The same fungus which caused the drop trouble of parsnips and lettuce $(q . v$.$) at Farnham's, also caused a serious dampening$ off of seedling beets (also somewhat, apparently, of lettuce, cabbage and radishes) in the hotbeds about the middle of March, 1909. So many of the seedling beets were dampened off that some of the frames had to be replanted, and in these the seedlings again dampened off, but not nearly so badly as at first. This indicates that the extra warm condition of the hotbeds soon after making was an important factor in the trouble. Also with the later planting the beds could be aired, when necessary, with less danger. Unlike the greenhouse conditions, where this fungus damaged the parsley and lettuce, there was seen little growth of the mycelium exposed on the soil, probably because there was little dying vegetation there for its development.

About the time of the second planting, a portion of the bed, under two frames at the end, was treated with formalin (at the rate of one part formalin to eighty parts of water, and used at the rate of two-thirds gallon per square foot of bed). The bed was left for five days to allow the fumes to escape, and seeded again with beets. In this treated soil by far the best stand anywhere on the beds was obtained and practically no dampening off occurred. The only check in this experiment was the adjacent frames, reseeded eleven days before, where the dampening off had made the rows quite irregular. One objection to treatment in this way is that the beds after being made must lie vacant a week before seeding in order to allow the fumes to escape. Whether or not the compost used over the manure could be 
treated some time before placing it in the beds, and the same results be obtained, can only be determined by experimentation. If so, then the beds could be seeded as soon after making as the temperature allowed.

CHRYSANTHEMUM (POMPON), Chrysanthemum indicum.

Rust, Puccinia Chrysanthemi Roze. We found this rust not uncommon on pompons, especially a variety called Sunset, last October, on outdoor plants in a local nursery; the rust, as on greenhouse chrysanthemums, formed only its uredinial stage. These uredinial sori, which occur on the under surface of the leaves, were, however, somewhat smaller than those on greenhouse varieties, but the spores did not appear to be different. The rust often kills the tissue so that variable-sized, reddishbrown spots show on both surfaces of the leaves.

\section{DAHLIA, Dahlia variabilis.}

Dry Weather Injury. During the past summer there were a number of complaints of injury to dahlias from some cause. In the vicinity of New Haven the writer observed that they did poorly, and the trouble apparently was noticed in other states than this. The trouble was something like the yellows of asters. The plants were more or less undersized, and the foliage (less luxuriant, somewhat misshapen, and turning yellowish at the margins) frequently slowly died. The plants also flowered much less than usual, and the flowers were of smaller size and often one-sided.

A careful examination of diseased plants sent by Mr. H. M. Robinson of Danbury, who complained that while the trouble showed somewhat in 1907 , it was much worse in 1908 , revealed no sign of any insect or fungus as the cause of the trouble. Cross sections of the stem under the microscope showed certain cells of the bark with discolored walls and contents shrunken; not infrequently lines of these injured cells extended out from the fibro-vascular bundles toward the surface of the stem. No signs of fungous threads were found as a cause of these diseased and dead cells. Everything taken into account, there seems to be no doubt that the trouble was a physiological one, due to the dry weather of the early part of the season, mention of which has 
already been made. Many of the ornamental plants suffered from this drought, but more or less recovered during the later, more moist weather. The injury to the dahlias, however, was sufficient to severely affect them, especially at the flowering period. Perhaps the injury may have been slightly accentuated by injury to the tubers from the drought of the previous season, in which case the plants the coming season may show the effect somewhat, even if it proves a favorable season.

DANDELION, Taraxacum officinale.

Leaf Spot, Ramularia Taraxaci Karst. This forms roundish spots, at first purplish but finally brownish, on the leaves, having fine concentric rings and often a purplish border. They vary in size from a pin head to nearly half an inch. While not uncommon on the wild dandelion, it does comparatively little harm to the cultivated plants, probably because these are renewed each year from the seed rather than grown continuously from the roots. There seems to be little or no reason for considering Peck's species, Ramularia lineola, distinct from this.

\section{GOURD, BOTTLE, Lagenaria vulgaris.}

Downy Mildew, Peronoplasmopora cubensis (B. \& C.) Clint. This mildew was seen for the first time last summer, in a Westville garden, on this host. It was likewise on the common gourd, Cucurbita Pepo. In both cases the fungus produced on the leaves numerous conspicuous reddish-brown spots about onequarter of an inch in diameter, which soon ran together. The fungus showed somewhat as a faint growth on the under surface. Although a careful search was made on these hosts, as well as on the numerous varieties of muskmelons in our experimental tests, throughout the entire season, we were still unable to discover the oospores, or winter stage, of this fungus.

\section{IARKSPUR, Delphinium sp.}

Bacterial Spot, Bacillus Delphini Sm. Plate LXIV c. While we have seen this disease before, we have paid no especial attention to it, thinking it probably due to injury by sucking insects. The past summer cultivated specimens of larkspur on the Experiment Station grounds showed the trouble quite promi- 
nently. It is chiefly a leaf injury, developing as purple-black, irregular spots (evident on both surfaces) which vary from those scarcely discernible up to a quarter of an inch in diameter, and where thickly placed, become more or less merged. An examination of the diseased tissue under the microscope showed the presence of plenty 'of bacteria. No cultures or inoculations were made, however. So far as the writer is aware, the only mention of a bacterial disease of this host is in a short note by Erwin F. Snith (Science I9: 4I7. I904), which is an abstract of a paper given before the A. A. A. S. A brief account of this disease and the organism causing it (which is named as a new species), is given there. Smith produced the disease on various varieties of Delphinium from pure cultures. In his Bacteria in Relation to Plant Disease, 1905, Smith also gives a photograph of diseased leaves.

\section{LETTUCE, Lactuca sativa.}

Drop, Sclerotinia Libertiana Fckl. Plate LXIII. While this fungus has been known for some time as a serious enemy of greenhouse lettuce, especially in the great Boston lettuce district (see Bull. 69, Mass. Agr. Exp. Station, by Stone and Smith), and no doubt has occasionally done injury to some extent in this state, we have not previously come across it. In Mr. Farnham's greenhouse, where parsley $(q . v$.) was injured by this fungus, that crop was followed by lettuce without changing the soil. While some damage resulted to the lettuce, the injury on the whole was not so great as one might expect, knowing that sometimes as high as ninety per cent. of the lettuce heads have been killed by this fungus in Massachusetts. However, before setting out the lettuce, all the refuse containing the fungus was removed from the soil; the lettuce was frequently cultivated to keep the fungus from developing on the surface of the soil, and greater care was taken with watering, especially during cloudy weather. Out of the whole, only about five per cent. of the lettuce heads were finally carried off by the drop.

A portion of the soil in this greenhouse shortly before the lettuce was set out was treated with formalin, rate of one part of formalin to one hundred of water. This was sprinkled over the soil gradually until there was used about three-fourths of a gallon per square foot. The ground was covered with canvas 
for a day and then aired for a week before setting the lettuce. This, however, did not prove long enough for the fumes to get out of the soil, although it was also lightly spaded three days before use, and as a result the lettuce began to wilt the next day, and in less than a week was all dead. We have used the soil in greenhouse benches inside of eight days after treatment, but as this bed was on the ground itself, it did not dry out so easily. So it is not wise to use the treated soil under ten days where plants are set out, or for a week where it is seeded. The second set of plants, put out a few days after the first were removed, started off very nicely, and eventually formed the finest looking lot of heads in the greenhouse. They had a finer green color, grew somewhat faster and more uniformly, and not a single one was lost.

Possibly where the sclerotia are present abundantly in the soil, the formalin treatment would not be so effective. Stone and Smith found that the use of hot water, heating the soil up to $176^{\circ}$ to $186^{\circ}$, was very beneficial in destroying the fungus and preventing subsequent trouble from the drop. Steam has also been used for the same purpose.

The trouble is called the drop because the fungus attacks the base of the leaves, rotting them there and causing them to fall over. This is shown very nicely by Plate LXIII c, which pictures a check and an inoculated plant. The inoculated plant had a small amount of the fungus from a pure culture placed on the base of the leaves that show the drop just two days before the photograph was taken; at the end of four days all of the leaves had fallen over, and by the end of the week the plant was entirely dead.

\section{LILY, COMMON WHITE, Lilium candidum.}

Bacterial Spot? Plate LXIV b. This disease was found on cultivated lilies during October in a local nursery. The oval spots are quite conspicuous, the largest varying from one-half inch to one inch in length. The greater portion of the spot is occupied by a semi-transparent portion in which the chlorophyll often entirely disappears, and surrounding this is a smaller purplish border. In dried specimens one can read print through the transparent portion if the leaf is placed on the page. The spots contain numerous bacteria, but also occasionally some 
mycelial threads of a fungus, though there was no sign of this fruiting on the exterior. As yet cultures and inoculations have not been made, so that it is not positively known that the disease is of bacterial origin, though from general appearances there seems to be little reason to disbelieve that it is such. So far, the writer has found in literature no mention of a similar trouble of lilies due to bacteria.

\section{MUSKMELON, Cucumis melo.}

Chlorosis (Infectious?). Plate LXI c. This physiological trouble was first seen the past summer on certain varieties of the muskmelons grown for the station by Mr. Frisbie of Southington. It appeared first and most prominently on the Extra Early Grand Rapids. In general, the appearance of the disease is very similar to the calico disease of tobacco, as the leaves are irregularly mottled with lighter and darker green areas, the darker green patches surrounding the larger veins, as shown in the illustration. The trouble is not severe enough to kill the tissue of the leaves, and therefore does not very seriously interfere with their normal functions. Mr. Frisbie said that he had observed this trouble before on muskmelons. So far as the writer is aware, it is not recorded in the literature of plant diseases on this host, though Selby of Ohio has briefly described the same or a very similar trouble on cucumbers (Ann. Rept. Ohio St. Hort. Soc. Ig02: Iog. 1903. Ibid. I903: 128. 1904). In Bull. Ohio Agr. Exp. Station 156 , p. 90, he says: "It seems now that we must class the mosaic disease of tobacco, the yellows of the peach, peach rosette, the mosaic disease of tomatoes, and the mosaic disease of forcing house cucumbers, which the writer has recently investigated at Ashtabula, Ohio, in one and the same group of maladies."

This disease is very similar in appearance to the calico of tobacco; and, as the melons were on land that had recently been in tobacco, it seemed quite likely that the disease was due to the same cause. In order to determine if it were infectious, the writer made a preliminary experiment in the field, similar to experiments that will produce the calico in tobacco. Some calicoed muskmelon leaves were crushed in the hands, and then seven healthy plants of different varieties at the end of the rows were handled, and bits of the crushed leaves left on them. Unfortunately, the plants were not examined until some three or four 
weeks later, when all of them showed more or less of the chlorosis, but as some of the neighboring untouched plants also showed the trouble it was impossible to say positively that the disease was induced by the touching in the experimental plants. Infection experiments will be tried again. The same, or a very similar trouble, was seen the past year on Lima and string beans and tomatoes, as well as on tobaceo.

\section{NEW JERSEY TEA, Ceanothus americanus.}

Powdery Mildew, Microsphaera Alni (Wallr.) Wint. Plate LXVI a. This mildew was found on French seedlings of the above host in a local nursery. There seemed to be considerable difference as to its abundance on the different plants. It forms a white coating on both the upper and lower surface of the leaves, but showing more prominently on the upper. Sometimes this coating entirely covers the surface of the leaf, as if painted over with a white paint. In such cases the perithecia often stand out quite plainly in small circular dark colonies about a quarter of an inch across, as shown in the illustration. This same mildew is common on this host here in its wild state. We have reported it before only on the lilac, but in this Report it is listed also on the azalea and the Pagoda tree, $q$. $v$. Its appearance on these different hosts varies somewhat.

\section{OAK, Quercus sp.}

Limb Gall (Bacterial?). Plate LXV a-b. For a long time the writer has observed galls on the limbs of various trees, such as the oak, hickory and maple, but has never definitely known the cause of these. They vary somewhat in size and duration on the different hosts, and may not, of course, all have the same causal agent, though their general character is the same. The general impression seems to be that these are the results of insect attack, but Dr. Britton states that the entomologists do not recognize them as such. The writer, in common with some other botanists, has believed that possibly they are the result of bacterial action, and since the researches of Smith and Townsend have shown that the galls of peach, etc., which in appearance have considerable in common with these galls, are due to bacteria, this belief has been strengthened. 
The past winter the Hartford Superintendent of Parks, Mr. G. A. Parker, sent the writer specimens of the gall on oak, from Keney Park. Mr. Parker stated that the trouble was first noticed several years ago on a single tree, and had since slowly spread over the tree and to two adjacent trees. An examination showed that the galls varied in size from that of a pea up to a small-sized pumpkin. There was no evidence of insect work on them, though other small galls on the twigs were of that nature. The galls in cross section (see illustration) showed that the swelling was due to an unusual enlargement of the wood (and to a less degree, of the bark), and exhibited a semi-radiating structure from a common center, with black spots showing frequently in the otherwise normally colored wood. The large galls were apparently some years old, and had increased in size each year. Some idea of their age could be obtained by cross sections, though the annual rings of growth were not very distinct. In the largest knots, not more than ten or twelve of these rings could be made out, but usually after four or five years the galls seem to stop growth and begin their gradual decay. The largest knots had ceased to grow; the bark and wood were both dead, and the former was more or less decayed also. On the whole, the oak galls attain a larger size and are more lasting than the hickory galls, which seem to be largely annual, and perpetuate the trouble by new galls at the margin of the old ones. The surface of the galls shows a corrugated and rougher character than the bark of the limbs on which they occur. Unlike the crown gall, these galls occur on the limbs high up in the tree.

The writer, early in March, made a number of inoculations in Lima bean agar with tissue from the interior of these galls, but obtained no growths. Perhaps such growths were prevented by the tannin-like substance that diffused from the tissues and discolored the medium for some distance around. Possibly cultures from new galls in the spring might give different results.

\section{OKRA, Hibiscus esculentus.}

Powdery Mildew, Erysiphe cichoracearum DC. This fungus forms a greyish-white, mealy, and rather inconspicuous growth, in spots, or eventually covering the whole surface, on the upper sides of the leaves, rarely forming a very slight growth 
on the under surface. Only the conidial stage was found, as is always the case on the squash, pumpkin, etc., and as this stage cannot be distinguished from that on those hosts, I have placed it under the same species. Apparently the powdery mildews do not occur commonly on the Malvaceae, as Farlow lists only one host in his Host Index, and Salmon, in his monograph, apparently only two. Neither gives this host. deThümen, however, judging from his description (Grev. 6: 102) described this fungus under the name Oidium Abelmoschi, having received it on this host from Egypt.

PAGODA TREE, Sophora japonica.

Powdery Mildew, Microsphaera Alni (Wallr.) Wint. This host is a small tree that comes from China and Japan and is occasionally grown for ornament here. The mildew, apparently, has not been reported on it before, at least this host is not in the host indexes of Farlow, Saccardo or Salmon, or in the'latter's Hosts of Japanese Mildews. It was found not uncommon in a local nursery, where, in September, it formed a grayish-white mealy growth, chiefly on the upper sides of the leaves, usually covering the entire surface of the leaflets. Very few perithecia were formed. See also New Jersey Tea.

\section{PARSLEY, Petroselinum sativum.}

Drop, Sclerotinia Libertiana Fckl. Plate LXIII. In February, 1909, Mr. A. N. Farnham, the market gardener of Westville, called my attention to an unusual trouble he was having with parsley in his greenhouse. The parsley was grown on the ground in rows, much after the manner of its cultivation in the field. As the soil is changed each year, hitherto no trouble had been had with soil fungi, but this year the soil had become infected in some manner, perhaps from the manure used, and this, with difficulty in properly regulating the watering at the time the plants were well covering the ground, started the drop fungus to work in good shape. This fungus develops its sterile mycelium as a white growth on the surface of the ground, especially on the decaying vegetation, and also works into the living stems and leaves, rotting them off. Occasionally it forms small, black, tuber-like bodies, called sclerotia (see artificial 
culture shown in Plate LXIII b), slightly embedded in these rotted stems. Where the soil is used year after year this trouble is likely to become increasingly serious, as these sclerotial bodies carry the fungus over from year to year, even if the soil thoroughly dries out in the summer time. While the fungus in this case injured the plants so severely as to make an uneven growth, killing them out entirely in spots, after the first cutting, by gathering up all the refuse containing the fungus, and by cultivating the ground frequently and using extra care in watering, the trouble was kept down so that the injury was considerably lessened in the second cutting. This same fungus is often quite injurious to greenhouse lettuce. A fuller description is given here under that host, as part of the house was afterwards planted to that crop.

\section{PEACH, Prunus Persica.}

Gummosis. Plate LXVIII a. The branches shown in the illustration were from a small orchard in Centerville in which a number of the trees developed this trouble. An examination of the orchard showed that the wood of most of these trees had been more or less severely winter injured a few years previously, and had not been pruned since to start new growth. Apparently the gummosis trouble was a secondary result of this winter injury, due possibly to bacteria or fungi that gained entrance to the branches because of their weak condition and produced diseased places in the bark, which cracked open and formed a deposit of gum around the wound. Gummosis has been attributed to a variety of causes, but we doubt if any particular organism, in the present case, was wholly responsible for the trouble.

Little Peach. At the annual meeting of the Connecticut Pomological Society at Hartford in February, I908, Mr. C. E. Lyman of Middlefield called attention to a trouble in his peach orchard which he took to be little peach. The past season this trouble has been definitely identified by Mr. M. B. Waite, of the United States Department of Agriculture, and has been noticed in other orchards, apparently more abundant than hitherto. As this trouble is said to be quite serious in Michigan, its appearance in this state is worthy of careful attention. Little peach was first investigated in Michigan, by Erwin F. Smith, who found the 
fibrous rootlets of the diseased trees more or less dried up. Mr. Waite holds that it is a trouble quite similar to the yellows and that it is contagious, so that infected trees should be promptly dug up and destroyed. By this means the trouble is said to be held in check in certain orchards in Michigan. The trees usually die quicker from little peach (about three years) than from the yellows.

Concerning this disease Waite (Rept. Conn. Pom. Soc. I908: 64) says: "The little peach resembles yellows in many respects, particularly in the foliage symptoms; and yet certain of its symptoms are exactly the opposite, namely, those of the fruit. Fruit on trees affected by little peach is undersized and belated in ripening. It is often a week, or two weeks or more belated. Its size may be only slightly reduced in mild cases, down to little tiny peaches less than three-fourths of an inch in diameter. Little peach trees rarely throw the wiry growth. I have only seen it produced where they were cut back, or on very vigorous young trees. It is rarely bushy and prominent, as in the case of the yellows. The foliage characters of the little peach are so nearly like peach yellows that when the fruit is absent and no wiry growth occurs, as is frequently the case on yellow trees, it is impossible to distinguish the two diseases."

The writer is inclined to believe that little peach, like much of our so-called yellows, is indirectly due to weather conditions, such as the droughts of 1907 and 1908, and possibly to winter injury. At least, it has shown up most prominently since the drought of 1907, and Smith's statement that the fibrous roots of the trees seem to be injured, goes along very well with the drought theory. See article relating to peach yellows and so-called yellows, later in this Report.

\section{POPPY, Papaver sp.}

Bacterial Spot? During the past two seasons the writer has noticed the leaves on poppies in his yard badly spotted from some cause. These spots are dark reddish-brown, somewhat watery, irregular, and about one to three millimeters in length, and usually are quite numerous. An examination of dried specimens, collected last fall, shows these diseased spots crowded with bacteria, which appear to be the cause of the trouble. So 
far no such bacterial disease of this host seems to have been described, so that before a positive statement can be given, cultures and inoculations will have to be made.

\section{RADISH, Raphanus sativus.}

Spindling. This is a trouble which sometimes appears in radishes grown in hotbeds, where they have not been watched closely enough after they germinated. The trouble is due to too great heat at this time, so that the radishes grow too rapidly, forming a long slender hypocotyl, often two or three inches above the ground. Such radishes are largely worthless, and are usually pulled up and the bed reseeded, as the bottoms of the small turnip-shaped radish will not form or will be irregular under such conditions. The way to prevent such trouble is not to use the beds too soon after making, and to watch them carefully to see that the temperature is properly controlled by ventilation, so that the radishes will not grow too rapidly for a time after they break through the ground.

\section{RHODODENDRON, Rhododendron maximum.}

LeAF Spot, Phyllosticta maxima E. \& E. This is found occasionally on leaves, forming reddish-brown areas (often grayish with flaking away of the epidermis) of greater or less extent, usually at the margins or tips. Other fungi sometimes occur on the spots, so possibly this is not entirely the cause of the trouble.

\section{SUNFLOWER, ORNAMENTAL, Helianthus multiflorus.}

Powdery Mildew, Erysiphe cichoracearum DC. This forms a whitish-gray, mealy coating over the upper surface of the leaves. On these specimens, collected on September i2th, the perithecia were not present.

Rust, Puccinia Helianthi Schw. This rust was found on the same specimens with the above mildew, but was confined chiefly to the under surface of the leaves, the II and III stages showing as numerous minute, dusty, reddish or blackish outbreaks. Apparently the rust has not been reported often on this host, though on the various wild species it is quite common. (See Report of I903, p. 36I.) 


\section{PEACH YELLOWS AND SO-CALLED YELLOWS}

General statement. During the seasons of 1907 and 1908 peach trees in Connecticut have shown an unusual amount of injury variously classed as yellows, so-called yellows, little peach, collar girdle, winter injury of wood, drought injury, leaf fall, gummosis, etc. Some persons have been inclined to lump these troubles largely into so-called "yellows," and others have made very nice distinctions, especially as to cause, apparently where such did not exist.

There is no question that there has been an unusual amount of typical yellows present, such as shown in Plate LXIX b (a photograph of a peach tree made by Dr. Britton in East Haven in I902), and there is likewise no question that much of the so-called yellows has not been typical. For instance, many of the trees cut down last fall as suffering from yellows bore a crop of peaches of good quality, and often with no indication of the red streaking in the interior which is taken to be one of the very first signs of this trouble. What the writer wishes to bring out in this article is that these various troubles are largely the result of the unusual weather conditions that have prevailed during the past seven years. That secondary causes, such as germs and enzyms, may have afterward entered into the problem and produced the various differences that show in different trees, is quite possible, but these alone we do not believe are to be held responsible. What have been these weather conditions and their effects, as shown by our observations covering this entire period, and of which there can be no question? They are as follows:

\section{Relation of Peach Troubles to Weather.}

Winter injury in I902. On December 9, 1902, after a very open fall in which late growing trees had no chance to properly mature their wood, there came a sudden drop to zero weather. As a result apple and peach trees in the nursery and those recently set out in the orchards had their wood prematurely killed or badly injured. Specimens were sent to the station by nurserymen immediately after this injury, and the writer also had abundant opportunity during the next two years to study such trees in the nurseries and orchards. Such trees showed the 
normally white wood darkened nearly or quite up to the bark, but when not too severely injured, the next year a small annual growth of white wood was formed around this. (See Plate X a, Rept. I903.) Trees suffered most that were set out in low places, and in the nurseries where the trees had been stimulated to late growth by forcing them with chemical fertilizers and late cultivation.

No one seemed to know much about such a trouble, even among the nurserymen; one firm built a large storage shed the next summer to avoid future trouble to the season's stock. Some of the least injured of these trees were sold the following year, but where complaint was made that they died, the nurserymen made good the loss. In other cases the young nursery trees were cut back near to the ground and a new trunk started. In some instances such trees had to be cut back again the next year because of further winter injury. We have seen two orchards set out by nurserymen from these twice winter-injured and cutback trees which the past year have gone with the so-called yellows. In one case the trees showed winter injury subsequent to setting the orchard, and in the other practically none. Now, we hold the winter injury, the severe pruning back, and the droughts of 1907 and 1908 as primarily responsible for the decline of these orchards, rather than yellows.

Severe vinter of 1903-04. The winter of 1903-04 did not find the trees so unprepared, because of an open fall, as the previous year, yet it was so unusually severe that even greater injury was done. This was especially true in the older orchards. Many trees were killed outright all over the state. Most frequently the injury showed in the wood, which was blackened to the snow line, while the bark and roots were uninjured. Severe injury. of course killed the cambium, and then the trees were past any help. This injured or prematurely killed wood undoubtedly set up unusual chemical activities that may have resulted in deleterious enzyms or other products that were carried in time to the new growth. Anyway, after some years I do not find that the sharp demarcation between the darkened winter-injured wood and the subsequent growth of normal white wood shows as plainly as it did at first.

In some places, often depending upon low elevation or exposure to moist winds, parts of, or even whole orchards, were 
so severely injured that they were taken up. Many of the trees least severely injured were severely pruned back and new growth started. The illustrations on Plate LXVII show two trees that were severely injured but not pruned back until the early spring of 1906; one of the trees failed to respond, but the other made in three years the vigorous growth shown in the illustration, and in 1908 bore a fine crop of fruit. Such trees, however, go much quicker than trees not injured, and where the injury was severe, even with the help of severe pruning, they have been dying from year to year, often from yellows or so-called yellows. No one has disputed the winter injury to the trees that were killed outright; but with the trees that have since gone into decline, the fact that they were thus handicapped has been overlooked by many who attribute this whole trouble to "yellows."

Subsequent winter injuries. Since the winter of 1903-04 (as, for instance, in I906), there has been some further injury, chiefly to the young twigs and buds, but nothing nearly so severe or unusual. During the winter of 1907-08, however, winter injury from collar girdle and root killing was unusually evident, especially where the ground was not properly drained or where there was no mulch of snow to protect the base of the trees and the roots.

Droughts of 1907 and I908. But while these subsequent winters have not been so severe, certain of the summers have been, especially the summers of 1907 and 1908 , when unusual droughts prevailed. In 1907 by far the most injury resulted, as the dry period lasted from June to August, when the rainfall was less than half that of the average year. In 1908 the drought was broken by rains in midsummer, which lessened the otherwise severer injury that would have resulted from the unusual early and late dry spells.

After the summer drought of 1907 , which at the time showed its effect on all vegetation, came the moist fall weather, and in many cases this set up a late growth of the dormant buds on the peaches. The yellow, curled leaves, due to the drought, and this premature fall growth of buds, were taken even by some experts to be the first symptoms of yellows. That such persons were mistaken in some cases, at least, was demonstrated with certain nursery trees showing these signs and pronounced typical yellows, by setting them out by themselves and keeping them 
under observation the following year, when all trace of the so-called yellows disappeared. Likewise certain orchards pronounced infected with yellows, the next year under special care showed decided improvement. There seems to be little doubt that these dry seasons injured the trees partly through the death of the fibrous rootlets. We know of one orchard planted with winter-injured stock and showing subsequent winter injury, situated on the top of a high, very rocky hill, where all attempts at cultivation merely increased the loss of water from the soil during the drought, and where the fibrous rootlets were killed or severely injured. No wonder this orchard has since disappeared because of the unfavorable environmental conditions that have surrounded it!

\section{Theories Concerning Yellows.}

Winter injury theory. Now from the above we do not wish it to be understood that we believe that the yellows never can occur on trees not injured by unfavorable weather conditions. It is past dispute that it can be budded into healthy trees, and there seems to be some reason for supposing that it is even contagious, though no positive proof of this seems to exist. What we do wish to offer is that seasonal injuries are the starting point and main factor of these so-called waves of yellows. This is no new theory. William Saunders, of the U. S. Department of Agriculture, writing to Penhallow in 1883 (Bull. Houghton Farm III, 3: 53) said: "About thirty years ago I came to the conclusion that this disease was one which originated from frost acting on the unripened wood. I have never known a tree to have the yellows when placed in conditions where the wood became thoroughly ripened before frost, a circumstance, as you are aware, which never occurs in the Northern States. Any application which will hasten ripening of the wood, will, therefore, have a tendency to ward off the conditions which make it possible for the tree to show yellows. This disease is to be seen on other plants which are similarly placed, and it was that observation which first led me to look for the cause of peach yellows in that direction."

In support of this connection between yellows and winter injury, we present the following points: (I) The apparent relation of the present unusual development of yellows, not only in 
Connecticut, but elsewhere, to the very severe and widespread winter injuries that have occurred to peaches since Ig02. (2) The fact that both winter injuries and yellows come in unusual severity at irregular periods, and the seeming fact that the waves of yellows gradually develop some time after these severe winters, often not reaching full development for some years. Besides the present case, there seems to have been some relation between the severe winter of $188 \mathrm{r}$ and the yellows that developed in New York, Connecticut and Delaware in the following years. (3) The apparent limitation of yellows to the northern part of the United States and the mountainous regions in the South, where winter injury occurs. (4) The fact that the peach is now a highly developed sensitive plant, as compared with its native condition, and is grown out of its natural climate, and so is more likely to succumb to unfavorable environment.

Potash theory. A second theory regarding the cause of yellows, not now held to any great extent, apparently, was that of soil exhaustion of the food elements necessary for the best development of the peach. Penhallow came to this conclusion, after a careful survey of the subject from all points of view, basing his belief largely on the chemical analyses of Dr. Goessman* of Massachusetts which showed a lack of potassium oxide in peach yellow fruit and wood. (Jenkins also later reported a similar result in this state.) Penhallow advocated fertilization with chemical fertilizers of which muriate of potash is a prominent constituent. The possible lack of potash in the diseased trees, the general need of fruits for this element, and its easy exhaustion from the soil, all are facts which are in favor of the use of potash fertilizers. Hale and others have found it of benefit, but Erwin F. Smith's extended experiments (U. S. Dept. Agr., Div. Veg. Path., Bull. 4. 1893) have shown that it is not a cure or preventive for yellows, and presumably its depletion in the soil is not the cause. Perhaps its value can be well summed up in the words of Hale (Rept. Conn. Bd. Agr., r891, p. 65), who said: "My own experience has been that trees fertilized with muriate of potash and given the same treatment as other trees to which it was not applied have been freer from the yellows, have lived longer and produced better fruit, although

\footnotetext{
* Smith in his paper (Bull. 4) reports analyses at variance ,with this idea.
} 
some of them have been diseased, than trees around which potash in that form was not used at all *** It is not a cure-all, but it is to a certain extent a check." A good illustration of the effect of a potash fertilizer on a peach orchard not in good shape was shown in the case of one of Mr. Lyman's orchards at Middlefield the past season. The year before, apparently due to the drought, the orchard was in such shape that an expert pronounced it an incipient case of yellows. Mr. Lyman gave it a treatment with saltpeter (potassium nitrate), with the result that the orchard last season took a decided step forward instead of backward. Of course if the trouble really was yellows, such improvement will probably prove of only temporary benefit.

Enzym theory. A third explanation of yellows has been that it is a physiological disease somewhat of the nature of indigestion, due to derangement of the chlorophyll of the leaves, as is seen in variegated plants. Such trouble is thought to be brought about by the presence of some deleterious enzym in the plant, and it is this enzym, when carried by budding from diseased to healthy stock, that causes the yellows to develop in the latter. Smith (U. S. Dept. Agr. Farmers' Bull. I7: Io. I894) and Woods (U. S. Dept. Agr., Bur. Pl. Ind. Bull. 18: 22. I902) were the first to present this or a similar theory, though they did not account for the origin of the deleterious enzym. This theory, modified by the belief that it is the unfavorable weather conditions (winter freezing and summer drought) that are directly responsible for the development of the injurious enzyms or toxins, is the theory held by the writer. (See also in Rept. Conn. Pom. Soc. I909, Report on Fungous Diseases for I908.)

Germ theory. The fourth prominent theory to account for yellows is the bacterial, or germ theory. This was probably first advanced by Burrill. Smith, in a recent conversation, and Waite (Rept. Conn. Pom. Soc., I908, p. 59), also, seem inclined to this view, though all admit that nothing definite has yet been found to support it. The chief point in its support is the supposed, but not definitely proven, contagious character of yellows.

\section{Preventive Measures.}

From the above consideration we may present the following precautionary measures for the guidance of Connecticut peach growers: 
(I) Location. Peach orchards should be planted only in the southern half of the state, preferably not too close to the Sound. Along the Connecticut Valley they may extend farther north than the center of the state. Low lands should be avoided, and as a rule only the higher hills selected, where the exposure is such as to avoid as much as possible moist winds in winter and early development of the buds in spring. Good drainage is necessary to avoid root injuries.

(2) Inspection. Only the best nursery stock should be used, free from all suspicion of winter injury or yellows. Winter injury can be told by the blackened wood. As it is not always possible to detect yellows in nursery trees, the young orchard should be watched during the first few years, in order to promptly remove any suspicious trees, for it is generally supposed that yellows is contagious. In the bearing orchards, also, any tree showing signs of yellows should be promptly cut down and burned. Such trees are of little value anyway, and it is best to be on the safe side of the question. Such is also the practice of good orchardists in the best peach-growing districts.

(3) Fertilization. As shown above, potash is a very necessary element for peach growing, and so fertilizers should be well supplied with it. Care, however, should be used not to force trees too much, especially with late applications of commercial fertilizers. This is especially true of sodium nitrate. Such trees are apt to go into the winter with the wood in an immature condition, and are then especially subject to winter injury.

(4) Cultivation. Good and frequent cultivation during the first of the season is very desirable, but after midsummer should be discontinued, since late cultivation, like late applications of fertilizers, may prevent proper maturity of the wood. Perhaps after cultivation is over it will be well in some cases to seed down the land with a quick-growing leguminous cover crop which can be plowed under the next spring. This will help to supply the nitrogen, and also give more or less protection against winter injury to the roots, especially where the snow blows off or is lacking. Green (Ohio Agr. Exp. Station Bull. 157. 1904) found in the study of winter injury to peach trees in Ohio that where the trees were mulched or protected by crimson clover, or other cover crops, root injury was much less. A mulch of earth thrown up around the younger trees in the fall and removed in the spring also seems to be of value in lessening collar girdle. 


\section{CHESTNUT BARK DISEASE, Diaporthe parasitica} Murr.

General-statement. In the Report for 1907 , p. 345, this serious trouble of chestnuts was briefly described. The writer first heard of the chestnut disease in 1905, through an article in a New York newspaper which discussed a serious disease of chestnuts in the Zoölogical Park. Specimens had been sent to the U. S. Department of Agriculture at Washington for identification and suggestions for control. Flora W. Patterson reported it as a species of Cytospora and suggested spraying with Bordeaux mixture.

A short time later, Dr. Murrill of the New York Botanical Garden, who has since made an extended study of the fungus and its havoc, sent the writer specimens of diseased chestnut bark for his opinion as to the cause. We reported the presence of a Cytospora, but from our experience with similar fungi at that time, stated that we believed it might be following winter injury to the trees rather than be the direct cause of the trouble. Dr. Murrill later found the Cytospora to be the conidial stage of an ascomycetous fungus which he described as a new species, Diaporthe parasitica. In his first articles Dr. Murrill noted that the trouble probably resulted in part from winter injury to the trees, but later he and all others who have written concerning the disease lay the responsibility entirely on the fungus.

Through the kindness of Dr. Murrill the writer has several times visited Bronx Park, where great damage was done, and has seen something of his experimental work with the fungus. Forest Park, Brooklyn, was also visited in the fall of 1908, and a number of localities in Fairfield and New Haven counties, this state, have been especially examined both by the writer and by Mr. Hawes. The writer has not aimed to make a special study of the particular fungus ordinarily associated with the trouble, as that has already been done very ably by Dr. Murrill (Jour. N. Y. Bot. Gard. 7: 143- 53 . Je. 1906. Ibid. 7: 203-rx. S. 1906. Ibid. 9: 23-30. F. 1908. Torreya 6: 186-9. S. 1906). However, our extended experience since 1902 with trees of all kinds which have shown various unusual troubles, due primarily to seasonal injuries, does not permit us to agree entirely with 
Dr. Murrill, and apparently Mr. Metcalf, that this trouble is due alone to the fungus Diaporthe parasitica.

Gencral character of the disease. In the vicinity of New York City the disease took chestnut trees of all ages, the large trees suffering as much as the younger trees or the sprouts. In most places there the trouble has now made a pretty clean sweep, so that few living, or at least healthy, chestnut trees are left. But as we come over into Connecticut, the injury gradually diminishes, being as yet serious only in Fairfield County, and growing less toward its northern and eastern borders. Here, though many large trees were killed, not all were taken, and as we go toward its outer limits the damage is only to the chestnut sprouts and small trees. In New Haven County it seems to be almost entirely the sprout growth that was injured.

Where large trees are infected, they begin to die from the top, and their decline is gradual, until the tree is killed to the base. Whether the roots of such trees are ultimately killed I do not know, but in one tree examined by the writer at Middlebury, while the trunk was dead to the ground, the main roots did not yet show injury. This at least proved that the tree was not dying as the result of root injury, unless possibly to the very small fibrous rootlets. Sometimes these dead trees show no fungus growth, but usually in time there can be found the characteristic orange or chestnut-brown pustules of this fungus breaking through the cracks of the rough bark, being developed gradually lower and lower down the tree. The tree dies because the bark and cambium are killed, but the fungus does not develop into the wood very deeply.

On the sprout growth and younger trees with smooth bark, however, the trouble shows much more plainly (see Plate LXII b) through cankered areas in the apparently healthy bark, and these frequently completely girdle the trunk or branches. In late fall and winter the fruiting stage of the fungus shows on these as small, reddish- or chestnut-brown cushions thickly breaking through the bark. It is these cankered areas on the smooth bark that afford the best evidence that the trouble is entirely due to the fungus. Such cankered spots, however, usually start from a winter-killed twig or other injury.

General distribution. The trouble has now made a nearly clean sweep of the chestnut trees in the New York City and 
Brooklyn parks. Dr. Murrill (Bull. N. Y. Bot. Gard. 6: I37. 23 Mr. I909) says concerning Bronx Park: "All of the chestnut trees on the grounds have either been killed or seriously damaged by it." Mr. J. J. Levison, arboriculturist of Brooklyn parks, writes concerning Prospect Park: "We have removed fourteen hundred chestnuts, practically all the trees of that species but six." He also reports (Mycologia I: 36. Ja. I909) concerning Forest Park that 16,695 chestnut trees were killed in $35^{\circ}$ acres of woodland there. About seven thousand of these were over one foot in diameter. Mr. John Mickleborough has also made a somewhat similar report (Conservation 14: 585-8. N. I908) concerning the condition of these two parks and elsewhere. He estimates the total damage in the eastern United States as at least ten million dollars.

Metcalf, of the U. S. Department of Agriculture (Bur. Pl. Ind. Bull. I2 $\mathrm{I}^{6}:$ F. I908), gives its distribution as follows: "The bark disease of the chestnut, caused by the fungus Diaporine parasitica Murrill, has spread rapidly over Long Island, where it was first observed, and is now reported from Connecticut, Massachusetts, Vermont, New York as far north as Poughkeepsie, New Jersey, Pennsylvania, and possibly Delaware." Murrill adds Maryland, and possibly Virginia and Washington, D. C., to the list.

Distribution in Connecticut. This trouble was first called to our attention in this state in the fall of 1907 by Mr. F. V. Stevens of Stamford, Fairfield County, and it is in this county, which is in the southwest part of the state, next New York and the Sound, where the chief injury has occurred. The disease has been found also in New Haven County, which is on the Sound next to Fairfield, but it occurs here only on the sprout growth, and not usually doing any serious damage as yet. Outside of these two counties we do not know of the presence of the disease, as determined by the examination of specimens, though inquiries have come concerning it from Willimantic and Pomfret Center, in Windham County.

Mr. Robert T. Morris (Conservation 15: 226. Ap. 1909) has recently called attention to the serious damage done near Stamford and Greenwich, and states that unless soon cut, the large trees will be of little value for lumber. Because of the 
glut on the market, they are of little or no value for cordwood at present.

In New Haven County the disease has been reported in the following places: In the vicinity of New Haven the writer has found only a few specimens, with no danige whatever; -at Morris Cove, in a low grove, one or two sprouts were found with large cankers in fruiting condition; in Westville, along Beaver Creek, a few small trees were found with small cankers in the otherwise healthy bark, but no fruiting pustules except in one case. These cankered spots were almost all on the south side of the trees.

W. A. Henry sent specimens from Wallingford, where he says that "many sprouts show the disease, though none are yet dead."

We are indebted to Newton J. Peck of Woodbridge for the specimen shown in the illustration, Plate LXII b. This was on an eight-year-old sprout tree. Mr. Peck says that only the sprout growth is affected in Woodbridge, and that he has noticed the trouble there for four or five years. With Mr. Filley, the acting Forester, we recently (April, I909) visited Mr. Peck's woods and also others in Woodbridge, and found considerable of the fungus present, but almost all of it on small sprout growth or small trees. We saw many cankers, often quite small, as yet showing no signs of the fungus; and by far the larger part of these were on the south or southwest side of the trees.

W. M. Shepardson of Middlebury reported the disease in that region, and the writer on a visit there found the fungus in two different woods. The situation here threw more light on the relation to weather conditions. On a dry hill on the Whittemore estate, many of the trees, oaks as well as chestnuts, showed that they were not in prime condition, especially their bark. Some few were dead, and others had dead bark on one side of the tree, but there was no evidence of the fungus. There is little question but that here the droughts of 1907 and 1908, especially of the former year, had seriously injured the trees. On a low spot in another grove, owned by Mr. Shepardson, over half the trees were injured or dead. While many of them showed characteristic Diaporthe cankers, others showed growths of different fungi, and some had no fungous growth at all! It looked to the writer as if winter injury and drought might just as well be 
given the responsibility for the trouble here as the bark disease fungus.

Mr. Hawley, of the Yale Forest School, has reported the fungus common in the woods of the Water Company near Ansonia. Dr. Graves, of the Yale Bot. Dept., found specimens near the North Branford line on the road to Twin Lakes. Mr. Metzger reports a few infected sprouts in his woods at Mt. Carmel. No doubt other infected regions occur besides.those given.

In Fairficld County, the writer has examined forests near Stamford and Danbury. At the former place, due to the kindness of F: V. Stevens, the writer and Mr. Hawes, in April, I908, got a very good idea of the damage done in one of the most seriously affected districts in the state. This examination gave the writer his first evidence of possible relation to winter injury. In one place chestnut sprouts showing signs of winter injury (indicated by blackened wood) were found on the border of an old orchard that also showed the same trouble. In cutting through the diseased sprouts, nearly all showed this dark wood back about four years, when the severe winter of 1903-04 did much damage to trees of all kinds. Of course it is not always possible after several years to distinguish between winter-injured wood and the normally colored heartwood, but in our opinion the dark color of the inner wood of the sprouts (see Plate LXII a) as seen almost everywhere is too close to and sharply marked off from the sapwood to be natural.

In order to determine if this disease was contagious, the writer had Mr. Hawes send Mr. Stevens one hundred small healthy chestnut trees from the state nursery at Rainbow. These were set out among the diseased trees late last spring. In a recent letter Mr. Stevens states that these trees as yet show no sign of the fungus, and are all living except a few that died when set out. $\mathrm{He}$ also writes regarding sprouts showing the disease: "All the sprouts from the cut of 1906 were very badly infected, in fact, seventy-five per cent. of the season's sprouts on our place and elsewhere in the near vicinity are a total loss, but I have not found a single sprout of the cutting of the winter of 1907 that shows the least infection, although I have spent considerable time looking over the woodlands in our section of the state." This condition might be explained by the fact that the drought of 1907 
was unusually hard on the sprout growth of that year, or possibly by the fact that the sprouts of 1908 have had only one season yet for infection, as compared with two for the others.

At Danbury the writer did not get into the worst infected woods, but the few diseased trees examined showed chiefly small, reddish-brown cankered spots on the smooth greenish bark, much like what winter injury will produce on pear and other fruit trees, and which Sorauer attributes to winter injury on various trees in Europe. These cankered spots usually had no fungous growth on them, and frequently were split through the center, but in some few cases the injury seemed to have been grown over. In one specimen brought back, that at the time was taken for the Diaporthe fungus, it was found on closer examination to be a species of Discomycetes, a species of Dermatea, as determined by E. J. Durand. The impression gained here was that these cankered spots might have resulted from winter injury, as they were most frequently found on the southwest side.

Mr. Hawes, in his recent forest survey of Fairfield County, had his assistants, Messrs. Moon and Hodgson, make notes in each town on the prevalence of the chestnut disease. I am indebted to Mr. Hawes for the following notes taken from their reports: "As I" (F. F. Moon) "came eastward from Stamford, where the effects were the worst, the number of infected trees decreased and the size and age as well. In the last three towns (Fairfield, Bridgeport, and Stratford) the infected trees seem to be almost wholly young sprouts along the road, while chestnut sprouts in the center of the stand seem to be free from the fungous disease." The record for the different towns in Fairfield County is as follows:

Bethel. "Disease spread over whole town and in a good many cases has done a good deal of damage."

Bridgeport. "A few cases of disease in open grown trees along road."

Brookfield. "Disease is scattered over town here and there, but not doing as much damage as further west."

Danbury. "The chestnut bark disease has spread from New York State into this town, all through its woodlands, and into adjoining towns. The affected trees are more numerous near the New York line, but they are in good numbers throughout the town. Upon examining a good many trees I find that most of the diseased branches and trees are discovered at a point near a wound, scar, or crack. In the crotch of two limbs which have slightly cracked apart seems to be a favorable place for the fungus to enter."

Darien. "The disease has its victims, but not over ten per cent. show the red branch of distress, and very few are killed." 
Easton. "Disease scattered lightly over most of the town."

Fairfield. "Only small per cent. of trees infected with chestnut bark disease."

Greenwich. "Disease has infected fully forty per cent. of the trees, but has not killed many in the town. Most of the trees have one or two branches affected, but as far as any serious injury is concerned it does not seem anywhere nearly so grave as in Stamford."

Huntington. "No chestnut bark disease reported."

Monroe. "Town at present is not badly infested by the disease except in south central portion, where there are a few very badly damaged sprout stands."

New Canaan. "Disease found here, but not over ten to fifteen per cent. of the trees are infected, and these only slightly, not many dead trees being seen."

New Fairfield. "A few chestnuts along western boundary are affected with the disease."

Newtown. "Bark disease has appeared only on scattered trees along western boundary. It is quite certain that the town will be infected badly with it next year if the present rate of spreading continues."

Norwalk. "Disease is found here, but not to such a great extent as further down the coast. It seems to diminish as one comes eastward. From ten to fifteen per cent. of trees infected. Few have been cut."

Redding. "Disease is spread over whole town, but is not so bad in eastern part."

Ridgefield. "Disease has spread over entire town, and in some cases the trees are infected quite badly, though only a few trees killed."

Sherman. "Chestnut bark disease appearing in western part of township."

Stamford. "Estimated that fifty to sixty per cent. of all chestnut trees in township are infected by chestnut bark disease, and probably five per cent. killed. Conditions especially bad in northern part of town."

Stratford. "No signs of any disease barring a few cases of Diaporthe, which seem to occur chiefly on roadside trees."

Trumbull. "Chestnut bark disease has not as yet done much damage. Only a few scattered trees noticed that were attacked by it."

Westport. "Trees infected by chestnut bark disease estimated at five to ten per cent."

Weston. "Chestnut bark disease is generally distributed over town."

Wilton. "The disease is found here but not so much of it as in Stamford. Not over fifteen per cent. of the trees infected, and not over two or three per cent. killed."

The fungous agent. Whether or not the fungus always develops its fruiting stage in the cankers the first year, I cannot state. If it does not, then this fungus, rather than winter injury, might explain the numerous cankers seen without any fruiting pustules whatever. On some, however, the small fruiting cushions or pustules, much like lenticels in appearance at first, are to be found developing during the summer, but apparently 
not before September does their spore stage appear to any extent. At first these pustules are light orange-brown, but by winter become dark chestnut-brown. They are composed of fungous threads and plant cells. The fungus has two spore stages, both of which develop in these pustules.

The Cytospora spore stage appears usually during the fall, and can be found more or less abundant until late spring. In cavities which appear in these pustules, certain slender fungous threads produce on their extremities very minute oblong spores in great abundance. These ooze to the surface, under moist conditions, as minute tendrils or globules. One can easily see that because of their enormous production, they would, when washed by rains over the tree, soon infect it badly, if entrance was readily gained; or if carried by insects, birds, or the wind to other trees, how the disease would rapidly spread.

Usually, along the latter part of December, the second or winter spore stage reaches its maturity. These spores are formed in special small spherical receptacles, to be made out with a hand lens, something like light-colored insect eggs, down in the tissue at the base of the pustule and around its margin. These spore receptacles open to the exterior by long slender necks that run from the receptacle through the pustule. These necks can be seen as small black specks on the surface, or in cross section of the pustule when in their prime. The receptacles are filled with spore sacs (or asci), and each sac has eight oval to oblong spores arranged within it, usually in a single row. These spores are hyaline, and are divided at the center (often slightly constricted there) by a cross wall into two cells. These spores are also shed out of the cushions during the late winter and early spring, so that finally the pustules gradually disappear, leaving small cavities in the bark.

With care, artificial cultures of the fungus can be obtained by taking tissue from the inside of cankers in the early stage of their development. Such cultures of the fungus on Lima bean agar at first show a growth of whitish threads, but with the development of the spore stage the growth gradually changes to a bright orange. The threads form a rather hard crust on the surface of the medium, and in this the Cytospora fruiting stage develops as numerous small elevations. The spores, after maturity, ooze out on the pustules as lemon-yellow drops, which 
later become light chestnut-brown in color. The asco-stage did not develop, and I believe Murrill has not obtained it in his cultures on various other media.

The writer has made no infection experiments. Murrill, however, found the fungus (in his inoculation tests) to be a wound parasite, but after it once gained entrance it killed the invaded tissues and eventually the young inoculated trees.

Relation to weather. From the preceding account one can readily see that the writer believes that the fungus alone is not entirely responsible for the havoc that has been wrought to the chestnut trees during the past few years. Winter injury in 1903-04, aggravated by the droughts, especially that of 1907, we believe to have been important factors in handicapping the trees so that the way was opened for further serious injury by the fungus. An account of the unusual weather conditions that have prevailed here since 1902 is given in the article relating to peach yellows and so-called yellows. We hold that these winter and drought injuries have affected chestnut trees as follows:

(I) Probably in some cases trees died outright from winter killing of the roots. In such cases no sprout growth would result.

(2) Serious injury occurred to the sapwood, changing it prematurely into heartwood, and thereby greatly reducing the capacity for carrying water to the leaves. Some sprouts, due to the droughts, now show only two annual rings of normal white wood, but most of them four or five, with a sharp demarcation between the white and colored wood indicating possible winter injury in 1903-04.

(3) Numerous cankered areas show in the smooth bark (often without any fruiting stage of the fungus on these sprouts), and in such cases these are chiefly on the south or southwest side of the trunk. These cankers often crack open, offering ready entrance for the fungus. Sometimes they heal over, or are not deep enough to cause subsequent injury.

(4) Numerous branches and twigs have been winter killed on otherwise healthy trees.

(5) Injury probably occurred to the fibrous rootlets from the droughts, especially on rocky knolls and hills, in 1907.

We give below briefly our reasons for believing that weather conditions are partially responsible for the chestnut disease. 
(I) The chestnut disease was first noticed soon after the winter of I903-04. Its appearance was sudden and widespread, and winter injuries rather than fungous troubles show up in this way. Since its appearance possibly it has spread further, but this may be more apparent than real, since discussion of the disease has caused persons to look for it in places where it was not looked for before.

(2) This trouble has gone over areas with greater total destructiveness than any purely fungous disease, especially of trees, that we have ever seen or heard of, and our experience has not been a limited one. We have known of winter injuries in peach orchards, however, just as severe, and both of these trees are here near their northern limit.

(3) The nature of the fungus is not such as to place it among the virulent parasitic forms. Murrill found it a wound parasite, and wound parasites are rarely, if ever, so aggressive as to totally destroy their hosts. We have seen cankers in apple trees produced, without doubt, by winter injury in 1903-04, very similar to the cankers of chestnut. On some of these cankers we found a Cytospora fungus which at first we thought might have caused them. We have also found Cytospora fungi on twigs of other trees killed by winter injury. The genus Diaporthe is made up almost entirely of saprophytic species, some of which occur on chestnut. We are not yet sure that Diaporthe parasitica has not been collected before under some other name. Professor Farlow calls our attention to the fact that it comes more naturally under the genus Endothia, and is closely related to E. gyrosa. In deThümen's Myc. Uni. No. 769 is a specimen under this name on Castanea vesca collected by Saccardo in Italy in 1876 , whose Cytospora stage (the only stage showing in our specimen) seems quite like that of our chestnut fungus. Rehm (Ann. Myc. 5: 2 Io. I907) has placed $D$. parasitica under the genus Valsonectria.

(4) The distribution of the injury shows that the vicinity of New York City was the center of the trouble, which gradually lessens in severity as we go away from there and the Sound, except perhaps, as it heads up the Hudson and Housatonic Rivers. Now this means either that the disease is spreading from this center, or that this region, due to soil or atmospheric conditions, sustained severer injury to the chestnuts during the severe winter of 1903-04. If due to the former, why, in so 
distant a locality as Woodbridge, New Haven County, where the disease has been known for four or five years (as long as in New York) has not the disease spread to the old chestnut trees and worked similar havoc?

(5) While of the forest trees the chestnut has suffered far more than others, especially in the regions indicated, yet in both Massachusetts and Connecticut during the past few years Dr. Stone, of the Amherst Experiment Station, and the writer, have had called to their attention numerous cases of trees killed or injured, as we believe, by the unfavorable weather conditions since 1902. Dr. Stone, in a recent letter, says: "All through this region the winter of $1903-04$ caused a great deal of injury to a large number of trees. The red maples have been dying by the hundreds here, due to root killing, and I have seen a great many oaks and large elms four or five feet in diameter injured at that time, although their death may not occur until three or four years afterward. It is interesting to note, in the diagnosis of trees, of which I do a great deal, that the injury can be traced backwards four or five years."

The writer has frequently called attention in his previous reports (Repts. 1903, pp. 280, 303, 324, 328, 34I, 35I ; I904, pp. $312,323,326,327$; 1906, pp. 310, 317, 320; I907, pp. 353, 360) to winter injuries of apple, grape, Koelreuteria, peach, privet, white pine, raspberry, and sycamore. In a number of cases these troubles were afterwards complicated with fungous growths that to those unacquainted with the conditions would lead them to believe the fungus the only cause of the trouble. The past year we have also seen numerous red maples, as mentioned by Stone, that seemed to be dying from the effects of winter and drought injuries. We do not include the elm here because it is difficult to determine whether or not the elm leaf beetle has been entirely responsible for the death of many of these trees which have died in recent years.

(6) As we showed in a previous article, chestnuts have been subject to severe injuries of unknown cause in the past, and have not been annihilated thereby. The cause of their dying was not made evident at the time.

Future outlook. If the chestnut disease is due alone to the Diaporthe fungus, as Murrill and others now believe, then it seems quite likely that Metcalf is correct in his statement that 
unless something intervenes, it means the destruction of all the chestnuts in the Atlantic States. But both Murrill and Metcalf are puzzled to explain the sudden and devastating attack of the fungus. The latter has suggested that possibly the fungus is an importation from Japan, and that, while it is comparatively harmless to the Japanese species, on our native species it found a host upon which it developed with unusual virulence. Murrill, however, has shown the writer a Japanese chestnut upon which the disease was as aggressive as on the native species. $\mathrm{He}$ thinks that the fungus is a native species that has by some means acquired unusual virulence. To the writer neither of these theories explains the situation so well as the winter-drought explanation, which is not entirely theoretical, at least.

It means much to the Connecticut owners of forest land whether or not this disease is due alone to the fungus or is due in part to seasonal injuries. In the former case they may expect that they are just beginning to see the results of a devastating agent. In the latter case, the writer believes that the trouble is now probably about at the height of its development, so that not much additional harm may be expected, especially if the following summer or two prove reasonably moist and the winters are normal. No efficacious treatment for the prevention of the trouble has yet been found, though spraying, pruning and burning of infected trees have been advocated. 


\section{ARTIFICIAL CULTURES OF PHYTOPHTHORA, WITH SPECIAL REFERENCE TO OOSPORES.}

\section{General Consideration.}

Previous work. The downy mildews (Peronosporales) have not, to the writer's knowledge, been grown in pure artificial cultures, with the exception of the genus Phytophthora. Matruchot and Molliard of France (Bull. Soc. Myc. Fr. 16: 209-IO. I900. Ann Myc. I : 540-3. I903) were the first to grow the potato blight fungus, Phytophthora infestans, in such cultures, and the writer (Ann. Rept. Conn. Exp. Station, I905: 3I7-2I) was the first one in this country to report somewhat similar results. Jones and Giddings of Vermont (Science 29: 27I. F. I909) have also in recent years been working along this line. J. van Breda de Haan (Mededeel. Uit's Lands. Plantentuim XV. 1896), according to Matruchot and Molliard, has made cultures of the mildew of tobacco, Phytophthora Nicotianae, but the writer has not seen this publication. The writer (loc. cit. p. 296), at the same time with his work on the potato mildew, also gave the results of artificial cultures of the Lima bean mildew, Phytophthora Phaseoli. These references apparently include most of the work that has been done along this line.

This method of attack admits of a more thorough study of the life history of these mildews. All of these fungi are supposed to possess two spore stages in their life cycle, one asexual spores, conidia, and the other sexual spores, called oogonia. The oogonia, however, are not usually produced very abundantly or frequently, and so are rarely found. In fact, for some of the species they have never been discovered. This has been the case with the potato mildew; and unfortunately the artificial cultures did not throw any further light on this stage, as none of the investigators obtained them. With the Lima bean, however, the writer, in his first investigations, obtained these spores somewhat in moderation in the artificial cultures. They had only recently been found in nature.

The results of the writer in obtaining the oospores of the Lima bean mildew in artificial cultures, but not those of the potato, together with other considerations, led him to advance the theory that with this group of fungi there might exist distinct 
sexual strains of mycelia. In this case it would be necessary to have both strains of mycelia present for the formation of the oospores. A somewhat similar condition had been recently found for certain species of the related group of Mucorales, by Blakeslee. In our work at that time this phase of the subject was tried to a limited extent with the few cultures on hand, but nothing very definite was determined.

In our previous cultural work the media found most successful for growing these fungi were living plugs of potato, cut by aseptic methods and placed on moist cotton in a sterilized test tube; living Lima beans, taken from unbroken pods in the same way; corn meal, mixed with water or various juices, etc.; and potato, or pumpkin juice, agar. While the fungi grew on these media, there were certain drawbacks for each that made it rather difficult to obtain pure cultures that were easily renewed and made vigorous growths.

Present work. Last fall we had opportunity to obtain further cultures of both the potato and the Lima bean mildews, and their investigation was again taken up with two points chiefly in view; viz., Ist, to obtain a perfectly satisfactory medium for their artificial culture, and $2 \mathrm{~d}$, to determine if they possess mycelia of distinct sexual strains. As another mildew, Phytophthora Thalictri, on Thalictrum, including its oospores, was found here, some attention was paid to this in the hope that it might throw some light on the latter problem. In fact, we have had for consideration all of the species of Phytophthora that are known to occur in the United States.

Altogether over a thousand cultures of the potato and Lima bean mildews have been made on various media. The general results are given under the following accounts of the fungi. By far the most satisfactory medium, however, is that described under Lima bean juice agar. With this medium one can grow either of these fungi, but especially the Lima bean mildew, almost as easily as any saprophytic fungus. They make a progressive growth on this medium which often covers the whole surface. With the Lima bean mildew this growth retains its vitality for some months, so that cultures are readily renewed at any time. With the potato mildew the mycelium does not live so long; so the cultures have to be renewed more frequently, every three or four weeks, and more care is needed in its renewal. 
As regards the sexual mycelia theory, we have worked from two points of attack. Our chief efforts have been with the downy mildew of the Lima bean, to lose the oospores. We have tried to accomplish this by Petrie dish separation cultures of the conidia, and by the use of very minute fragments of the mycelium from the edge of the cultures. We have not succeeded in a single instance in permanently doing away with the oospores by either of these methods, and in some cases we have tried both on the culture in liand. With unfavorable media one can temporarily prevent the formation of oospores, but these always readily develop when the transfer is made to a medium favorable for their growth. With the potato mildew, we have tried to produce the oospores by crossing the fungus with cultures from different sources. While we have had the fungus from only a few different localities, none of the crosses between these have given any indication of oospore formation. These results have thrown very considerable doubt upon the theory of sexual mycelia.

With the discovery of the oospores in both $P$. Phaseoli and $P$. Thalictri, their continued absence in $P$. infestans, especially when the theory of sexual mycelia does not seem to throw light on the subject, becomes a matter of still greater interest. In our previous report (p. 323) we gave some of the theories that have been advanced to explain their absence, of which one was that this species had lost the power to produce such bodies. Both Jones and the writer have found, under certain conditions, bodies in the cultures that possibly may indicate imperfect attempts on the part of the fungus to produce these spores. It is barely possible, with the continued renewal of the potato by the asexual method of propagating it by the tubers that the fungus has likewise been continually renewed asexually by its mycelium in these, and that both (the potato its seeds, and the fungus its oospores) have thus lost, at least largely, the power to reproduce themselves sexually. In this case one would probably find the oospores only where the fungus developed on the wild species of Solanum in its native habitat.

\section{Phytophthora Thalictri Wilson \& Davis.}

Distribution. This species was first described by Wilson (Bull. Torr. Bot. Club 34: 392. I907) from specimens col- 
lected by Davis in June, I907, on Thalictrum purpurascens, in Kenosha Co., Wisconsin. Dr. Davis informs the writer that he has since collected the fungus there and in another locality in the same state. On October 2, I908, at Centerville, and again on October Io, at Westville, the writer found this species on Thalictrum polygamum in Connecticut. These collections are apparently the only ones that have yet been made, but from its occurrence in both Wisconsin and Connecticut it seems very likely that careful search will reveal its presence in at least the intervening states.

Life history. Davis did not find the oospores, so Wilson described only the conidial stage. The mycelium causes black spots on the leaves, practically like those of $P$. infestans on the potato leaves. The conidiophores are produced only sparingly on the under surface of the leaves. The most important of the minor differences which Wilson gives as distinguishing this mildew from that of the potato are the shorter and more slender conidiophores (300-400 $\times 5-7 \mu$, with one or two branches), and slighter smaller and more elongated conidia (20-27 x I3-I7 $\mu$ ). The writer found the conidiophores varying from $250-500 \mu$, and with one to three branches, each bearing one to three conidial swellings.

The writer was fortunate in finding a few of the oospores which as yet had not been described. These were formed only rarely and in moderation in a few of the leaves found at the very end of the season. Their presence in the tissue could be determined only upon careful search with a microscope after boiling the leaf tissue in caustic potash and mashing it apart. Those seen by the writer did not differ very materially from the oospores of $P$. Phaseoli, so that we may expect those of $P$. infestans, when found, to be of similar character.

The oospores were not in all cases mature, but they seemed to have an oogonial wall somewhat more deeply tinted than those of $P$. Phascoli. So far as could be determined, the antheridia and oogonia were developed from different mycelial threads. The oogonia are chiefly subspherical, with moderately thin, reddish-brown tinted walls, loosely enveloping the oospore, and $25-33 \mu$ in diameter. The oospores are spherical, hyaline or slightly yellowish tinted, with medium thick and smooth wall $(3-4 \mu)$ and vary from 18.5 to $25 \mu$ in diameter. 
As the Thalictrum does not have any thickened tissues within which the mycelium penetrates, having so far been found only in the leaves, it was impossible to obtain artificial cultures of this fungus after the manner employed with the other two species.

Infection experiments. Since $P$. Thalictri resembles $P$. infestans so closely, the writer has thought that possibly they might not be distinct species. Worthington G. Smith (Diseases of Field and Garden Crops, p. 275-6) gives a list of different hosts of $P$. infestans which include even two Scrophulariaceae. Our specimens were found only at the end of a very dry season, and were not in very good shape for inoculation tests. At that time there were no living plants of potato available for experimentation. Tests of the spores on the cut surface of a potato and on leaves of a young greenhouse tomato failed to give any results. Some of the infected specimens of Thalictrum were taken up and placed in a moist atmosphere in the greenhouse, but the disease did not develop much further. The past spring, on some of the check plants of Thalictrum, developed prematurely in the greenhouse, the writer failed to produce infection with spores from artificial cultures of $P$. infestans, though these succeeded on the potato. While these experiments were perhaps not extended enough to speak positively, still they at least indicate that these fungi are distinct strains, if not distinct species.

\section{Phytophthora infestans (Mont.) DeBy.}

Life history. This phase of the subject, especially with reference to the conidial stage, has been so thoroughly presented by DeBary and others that we will not enter particularly upon it here. Some idea of the character of the conidial stage may be obtained from the photomicrographs shown in Plate LXXI. In our former article (p. 304) we made some observations upon the manner of primary infection in potato fields, which were somewhat different from the views formerly held. Such observations as we have been able to make since are still in favor of this view. If it could be proven that oospores develop in the decaying seed-tubers, this would further strengthen it. But so far we have never been able to positively identify oospores in the tubers under any conditions, though one often runs across 
suspicious looking bodies in some of the tubers in the last stages of their dry decay.

Upon its host in nature this fungus confines its mycelium largely to the intercellular spaces of the tissues. This necessitates special branches, or haustoria, for penetration into the cells for the food supply. The haustoria are lacking in the artificial cultures on agar medium. The mycelium in cultures on living potato plugs, while invading superficial tissues and cells, does not penetrate very deeply or set up a special decay. This certainly suggests that in nature much of the soft rot following attack of the tubers is due to bacterial action. Often this latter becomes so bad as to crowd out the original invader. The haustoria often seem to develop further in storage tubers, or at least their walls become thickened. This thickening possibly may be due to an envelope of the plant cellulose. When one sees two of these knobbed, thickened haustoria within a cell bending towards each other as if about to conjugate, the impression is gained that this may be the first step toward the formation of oospores. But, though we have examined these haustoria carefully, even after the infected tubers were planted, we have never seen any further development along this line.

Smith (loc. cit. p. 295) claimed to have discovered the oospores of the potato fungus. We have tried to obtain specimens of these from him and others, but have not succeeded. Smith wrote us in 1906: "No doubt you know that the oospores became a" kind of political subject-oospores of $P$. infestans or not oospores of P. infestans?; and I had no wish to go on. Botanists and popular writers followed what they took to be the safer authority, just as Saccardo has done; this is right enough in a way." Massee thinks that Smith's oospores were the chlamydospores of a Fusarium, as he writes me: "I have very carefully examined W. G. Smith's type slide preparation, and am positively certain that the so-called oospores are nothing more that the globose, thick-walled chlamydospores belonging to a Fusarium." From a study of Smith's drawings and an experience with the flora and fauna of decaying potatoes the writer is led to the conclusion that he did not find the oospores of P. infestans; or that, if he did, he also got other things mixed up with them. Our studies with the oospores of $P$. Phaseoli and $P$. Thalictri would also indicate that those described by him for $P$. infestans were too 
different to be such. Since his time others, as Smorawski, have described what they called immature oospores, but the general belief to-day is that these bodies have not been found.

Our culture work has thrown very little light on this subject. In some few of the earlier cultures we found occasional bodies that looked something like an attempt at oospore formation. Jones recently (loc. cit.) has further studied these bodies, and has succeeded in producing them in considerable numbers in a special potato juice gelatine medium. Our impression of those seen in our own cultures has been that they might be unusual mycelial branches produced under unfavorable conditions (presence of certain bacteria, etc.); and from what we have seen of Jones' cultures and slides, they resemble chlamydospores as much as oogonia. In our experience with the oospores of $P$. Phaseoli the oogonia were developed after rather than before the antheridia, and in Jones' cultures we saw no signs of antheridia. It is possible, however, if there really are sexual mycelia, that this was an attempt of the female strain to produce the oogonia; or, on the other hand, if this species has lost the power of producing oospores, such cultures might indicate strains in which this process had not entirely disappeared.

Cultural methods. In our previous report we described the method by which cultures are obtained from the mycelium of infected tubers by taking out this tissue by aseptic methods and inserting it on cultural media. The chief precautions which have to be observed are the use of tubers in which the infection is in its first stages and so has merely tinted the superficial tissue reddish-brown without any soft rot; also the sterilized knife used to take out the infected tissues should be allowed to cool so that the cut surface is not seared. It is best not to have liquid in the bottom of the agar culture, or if so, to insert the tissue above this, as the water may spread bacteria that may be included, and so spoil the culture. Out of such cultures, at least some with pure growths, or growths that permit of pure transfers, can be obtained.

The potato mildew forms its growth more in the air and less embedded in the medium than the Lima bean mildew. Likewise the mycelium loses its contents quicker, and so renewal from old cultures is often unsuccessful. A series of cultures on Lima bean juice agar, varying from 44 to 64 days old, failed to grow ; 
others, from 2 I to 34 days old, grew readily, and even in one case a culture 54 days old grew. It is best, however, to renew the cultures on this medium at least once every month. The mycelium in the air easily collapses, so that care has to be taken in making transfers; especially should the needle be completely cooled off before inserting. Both aerial and embedded material should be taken, preferably with a sharpened platinum wire, in these transfers.

Media. Of all the media tried the Lima bean juice agar gave by far the best results. The fungus on this, if properly started, formed a luxuriant growth in the air (see Plate LXX a) and usually a progressive growth, covering the surface of the agar. This medium likewise proved best for the Lima bean mildew, and as that mildew formed oospores unusually abundantly in it, it was thought that the potato mildew might make some effort in this direction, but there was no more indication of these bodies in this medium than in those in which the potato mildew grew poorly. The following notes give the result with the potato mildew on the various media tried.

Lima bean juice agar $(50+10+500)$. While the fungus grew readily on both the weak Lima and white bean agars (made from sliced beans and so not as nutritious as when ground), on the whole, the strong Lima bean agar, as given below, was the most satisfactory. It makes on this a luxuriant aerial growth of mycelium and conidiophores, that tends to cover the surface eventually. Conidia were produced in abundance, but no oospores or peculiar swollen mycelial branches. One or two drops of lactic acid added to it usually prevented the development of the fungus. See illustration in Plate LXX b A-B.

As this medium has proved by far the most satisfactory for this mildew and that of the Lima bean, as well as for certain other fungi, we give our method of making it. We used a $50+10+500$ formula; that is, 50 grms. of dried ground Lima beans, to grms. of agar-agar and $500 \mathrm{cc}$. of water. The beans are ground, as fine as possible with a fruit grinder, and then $50 \mathrm{grms}$. soaked one-half hour in tepid water (use as much water as necessary, but of course not to exceed $500 \mathrm{cc}$. finally) and then simmered slightly for another half-hour. Strain off liquid through fine wire strainer, add agar-agar (better dissolved in small amount of water) and water necessary to make $500 \mathrm{cc}$. of medium; heat long enough to thoroughly mix agar-agar and strain again through wire and fine cheese cloth into test tubes.

Corn meal juice agar $(50+10+500)$. This proved a far more satisfactory medium, as regards aerial growth, for this than for the Lima bean mildew. In general, it gave results about like those with potato juice agar; that is, a pure white, aerial growth around place of inoculation, but not generally progressive. There were no oospores, peculiar chlamydospore-like bodies, or unusual swellings of the mycelium. See Plate LXX b C. 
Potato juice agar $\left(150^{*}+10+500\right)$. This gives a localized but evident aerial growth, one-half to one inch in diameter around inoculation. Similar growths on pumpkin juice agar (see Plate XXV c, Report 1905) were obtained in 1905. Mycelium same as with corn meal agar. See Plate LXX b D.

Lima bean phaseolin agar; Nucleic acid peptone sugar agar; Phaseolin Pot. Phos. agar; sugar peptone water (see Lima bean mildew cultures) all proved unsatisfactory, as little or no growth resulted.

Lima bean juice gelatin $(50+50+500)$. Not extensively tried, but apparently about the same, or a little better, than next.

Potato juice gelatin $(150+50+500)$. Very poor medium, especially for aerial growth. In specially prepared potato juice gelatin in stab cultures, Jones succeeded with certain strains in getting the peculiar chlamydospore-like bodies (or immature oogonia?) spoken of earlier. In our cultures these did not appear as with him, though certain branches did produce unusual swellings that had a bacterial-like deposit around them.

Living plugs of potato, etc. As reported in 1905, living plugs of potato and of pumpkin, especially the former, offer a good medium for a (usually sparse) conidial growth of the fungus. These plugs should be on moist cotton. The growth does not cause any soft decay, though the superficial tissues often turn reddish-brown. The mycelium does not penetrate very deeply, but sometimes invades the cells. The haustoria are not formed so frequently as in nature. Jones found considerable difference in the growth on different varieties. This probably affords a means for testing resistance of varieties, but $I$ am under the impression that those showing most resistance will prove to be undesirable varieties, as the less starchy, soggy ones. (See I905 Report, Plate XXV a.)

Corn meal (moisten with water or potato juice). In my 1905 tests this proved the most satisfactory medium used, as when started it favored a luxuriant, progressive growth. The objection to it is that the corn meal dries out so that it is difficult to get cultures started, and the medium interferes somewhat with microscopic examination. (See I905 Report, Plate XXV b.)

Cross cultures. In order to test the mycelial sexual strain theory, the writer has from time to time inoculated the above media with this mildew from different sources. The Lima bean juice agar affords by far the best one for such tests, as it allows progressive growths. The usual method has been to inoculate the bottom of the tube with a culture from one source and above this-one-half to one inch-with a culture from a second source. With the Petrie dish (see Plate LXX a) three or four inoculations can be made if extreme care is used against contamination. Such cross inoculations have been made with cultures obtained from tubers from several sources in Connecticut, and one each from Maine, Long Island, Vermont and Holland, the writer being indebted to Jones for cultures from the last two sources.

* Took I50 grms. peeled potato, thinly sliced, soaked in tepid water, and then simmered for half-hour, and used juice from this. 
While these cultures have not been extended enough, perhaps, to speak positively, yet in none of them was there any indication of an unusual mycelial development or of the formation of oospores. We have noticed some difference in the vigor of these growths, as Plate LXX a shows, but this may be due to more material used in one inoculation than in another, or to the age of the cultures used, as a culture not frequently renewed tends to run out.

Hybrid? cultures. Blakeslee found that when certain distinct species of Mucoraceae were crossed with opposite strains there was an effort to form the sexual spores. As the Lima bean mildew cultures possessed both of these strains, if they exist, it was thought that cultures containing both $P$. infestans and $P$. Phaseoli might induce the former to make an attempt at oospore formation. Certain tubes, therefore, were inoculated with the Lima bean mildew below and the potato mildew above. Petrie dishes were also inoculated with the Lima bean mildew in the center and the potato mildew from several sources around this. Of course one would expect the Lima bean mildew to produce its oospores within the area covered by its own mycelium, but at the juncture of the area covered by the potato mildew one might look for attempted hybrid oospores if the same condition prevailed as with the mucors.

At first the writer was inclined to believe that such hybrid oospores did result. At the juncture of the cultures and within the area occupied by $P$. infestans occurred certain immature oogonia that were larger, somewhat thicker-walled, and of a darker reddish-brown tint than those produced by $P$. Phaseoli under ordinary conditions. One of these doubtful hybrid oogonia is shown in Plate LXXIV B. In all of these cultures there appeared in time mature oospores, more or less abundant, around, in and under the $P$. infestans colonies, but these were not different from the oospores of $P$. Phaseoli. Moreover, the renewal cultures made from the edge of the $P$. infestans colonies on the opposite side of the tube from the $P$. Phaseoli colony always gave what seemed to be pure growths of $P$. Phaseoli. These results apparently mean that the Lima bean mildew mycelium being more aggressive, penetrated into the potato mildew colony and, forming its oospores under somewhat unfavorable conditions (due to toxins in the medium produced by 
the growth of the former mildew), certain of these had been arrested or otherwise affected in their development, as sometimes occurs in unfavorable media. The potato mildew mycelium, being shorter lived, was entirely crowded out by the more aggressive Lima bean mildew when the renewals were made.

\section{Phytophthora Phaseoli Thaxt.}

Life history. In our previous report we gave rather complete details concerning the life history of this fungus. The general character of the mycelium, the conidia, and the conidiophores is shown by the photomicrographs of Plate LXXIII. Such information as has been gained during the present investigation has been chiefly concerning details in the development of the sexual spores. Due to improvement in cultural methods, we have been able to produce the oospores in great abundance in artificial cultures (see Plate LXXIV A). Usually it takes from six to ten days after the start of the culture before there are any very evident signs of these bodies, but with a favorable medium, such as strong Lima bean agar, they then develop very rapidly, so that practically full-grown oospores can be found in ten to fifteen days. If the culture gives a progressive growth, different stages may be found starting from the edge inward, the outermost growth, of course, being free from them. While the Lima bean juice agar gives by far the greatest development of oospores, it is not quite so favorable for their study, because of the usually abundant aerial growth, as corn meal juice agar. This latter medium gives a very scanty growth, there being practically no aerial development. The embedded threads are largely concerned in producing the oospores, which are very slowly developed, and in old cultures show all stages, most of them never reaching maturity.

The first step toward sexual reproduction seems to be the large, irregular swellings that develop in certain of the threads (see Plate LXXIV C). We have not been able to determine any fusion of the mycelial branches that proceeds or accompanies these swellings, but often they are more or less massed. Very frequently a terminal swelling develops a normal thread much like a germ-thread, into which the contents pass, and this may give rise to subsequent swellings. Such empty swellings in size 
and shape are often quite similar to the antheridia, and perhaps may be tentative antheridia that fail of full development because of lack of contact with tentative oogonial branches.

It is impossible in the majority of cases to determine whether the antheridium and the oogonium come from the same or from different mycelial branches. In quite a number of instances, however, we have been able to satisfy ourself that they originated on distinct branches (see Plate LXXIV J, $K$ ) and in some cases have traced these as independent for some distance. Of course such branches might originate finally from the same mycelium, but inasmuch as they remain independent as far as they can be traced, they admit of the possibility of distinct sexual mycelia. However, in a few cases (see Plate LXXIV H, I) we have seen them where they seemed to come from the same thread. Our results, in failing to permanently lose the oospores, would also indicate their final common origin.

In the development of the sexual stage, the antheridium is the first to appear, and is often apparently fully developed before there is much evidence of the oogonium (see Plates LXXIVE and LXXVA). Whether or not the peculiar swellings spoken of earlier develop into antheridia as a result of contact with certain other threads or swellings, it is difficult to determine, but it seems most probable (Plate LXXIVD). This potential oogonial thread, with or without a sivelling, becomes attached to the base of the antheridium and grows up along its surface toward the apex. Very often it can be seen when it has only partially covered the length of the antheridium, as shown in Plate LXXV B. For a long time it was difficult to decide whether or not these threads did not actually penetrate the antheridium and grow through it, and we are not yet certain that this does not sometimes occur. Certainly the optical effect is frequently that of an internal thread with its apical wall very thin as compared with the side walls, as shown in Plate LXXV A, $B$. In time, however, the oogonial thread reaches the top of the antheridium, and curving around its apex, begins to swell into the oogonium (Plates LXXIVE and LXXV C), which by this time is usually cut off from its basal thread by a septum. The various stages of its enlargement are shown in Plate LXXIV F, $\mathrm{G}, \mathrm{H}$. After the full size is reached the contents begin to be differentiated, marking off the oosphere (Plate LXXIV G, H). 
About this time fertilization by the antheridium usually takes place, but whether by means of a penetration tube or merely by a local opening where the walls of the two bodies are in contact, was not made out. If the oogonial thread really ever penetrates the antheridium, a union of certain of their protoplasmic contents no doubt takes place at that time.

After the demarcation of the oosphere by the thin wall, the subsequent evident change is in the gradual thickening of this wall until there is formed the fully developed oospore loosely enveloped by the oogonial sac (Plate LXXIV I-K). These oospores in cultures vary considerably in size (Plate LXXV D-G), and often there are a good many that never reach maturity. They are hyaline or slightly yellowish tinted. We have made no study of the cytological phenomena that accompany their formation, but the profusion with which they are developed in cultures should readily permit such study. We have not yet succeeded in germinating such spores, as they apparently require at least a winter's rest before this takes place.

Cultural metlods. The Lima bean mildew may be obtained in cultures by care in selecting beans from pods recently attacked. It is usually best to use pods showing a fresh and comparatively slight growth that has barely penetrated into the interior, using the beans beneath that show little or no sign of attack to the naked eye. Such beans, if transferred by aseptic means to test tubes containing moist cotton, will in time give an aerial growth that is frequently uncontaminated by other fungi or even by bacteria. From these pure cultures on Lima bean juice agar can be secured.

In my previous work, the cultures finally ran out, after two or three months. This was because of contamination, and the use of poor media for growth. In my recent work, by getting pure cultures to start with, and the use of a favorable medium for growth, I have had no trouble of this kind. In fact, the mildew grows as readily (perhaps a little more slowly) as most saprophytic forms, and is easily renewed by transfers. In these renewals, the needle should be cooled after flaming, and then a quantity of the mycelium and agar should be dug out and embedded in the base of the new tube. By such means cultures have been kept growing for over seven months and there seens to be no reason why they cannot be continued indefinitely. 
The mycelium of the Lima bean mildew lives in these cultures much longer than that of the potato mildew, probably because of a more embedded growth in the agar, due to the formation of oospores, and so the cultures are renewed much easier, and can be left without renewal for a longer time. A series of trials was made to determine how old a culture on Lima bean juice agar could be, and still retain its vitality. In the first test, ten cultures, varying from 28 to 43 days old, were used. These all grew readily. Renewals from the same cultures were made when they varied from 49 to 64 days old, again from these, when 65 to 95 days old, and still again, when 92 to I 36 days old; and every one, except two spoiled by bacteria, made fine vigorous growth, with oospores in abundance. Renewals from cultures older than I36 days have not been tried, but presumably would be successful. As the oospores did not germinate, the renewed growth was made from the mycelium, since the conidia were probably too old for germination in most cases.

Media. As with the potato mildew, the strong Lima bean juice agar forms by far the best medium for the growth of the Lima bean mildew. Not only did the conidial stage develop a more or less luxuriant aerial growth, but oospores were formed usually in great luxuriance (see Plate LXXIV A), at the surface and slightly embedded in the agar. Usually there is no indication to the naked eye whether or not oospores are produced in the cultures, but in this medium with certain old cultures, after the aerial growth had collapsed or when formed less abundantly than usual, their presence in great abundance could be told by two or three reddish-brown bands showing somewhat faintly toward the outer, thinner part of the culture. These darker bands contained more oospores than the intervening lighter ones. In general, the oospores were produced more abundantly in the more nutritious media; also the presence of acid limited or prevented their formation. The details of the growth of the fungus in different media is given in the following notes.

Lima bean juice agar $(50+10+500)$. While on this medium (Plate LXXII b B,C) the mildew formed a more or less vigorous aerial growth of mycelium and conidiospores, it was never quite so luxuriant as was the potato mildew. Oospores were always developed in abundance in the strong Lima bean agar, but were not so numerous in the weak Lima or white bean agar. A progressive growth of the fungus nearly always occurred on these media, often covering the surface. With the strong Lima bean agar, even when 
it was apparently made up under about the same conditions, there was noticed considerable difference in the growth of the fungus on it. This was probably due to slight variations in the medium (differences in cooking, sterilizing, etc.) rather than to the fungus, as it showed most strongly in sets of tubes made at different times. This variation showed in greater or less luxuriance of aerial growth, and in greater or less luxuriance of oospore production, and especially in the banded appearance already spoken of. This latter usually occurred where less luxuriant aerial but progressive embedded growth took place above the base of the tube. A cultural medium made from fresh green Lima beans did not prove any more satisfactory than from the dried beans. The addition of onehalf gram nucleic acid to weak Lima bean agar affected the growth somewhat unfavorably, often limiting it to a dense, white aerial development around the inoculation material. This was largely mycelium, as few conidia or conidiophores were formed, and oospore formation was almost, if not altogether, prohibited. One or two drops of lactic acid usually prevented any growth whatever. Powdered willow charcoal (one teaspoonful to $500 \mathrm{cc}$. of the medium) made a black background in striking contrast to the white aerial growth, but did not seem to affect particularly the development of the fungus. Cultures of the fungus grown on white bean juice agar failed to infect young white beans (always exempt in nature), though the young Lima beans inoculated at the same time were killed.

Corn meal juice agar $(50+10+500)$. This gave practically no aerial growth, and but a slight embedded growth, that spread slowly for a short distance from the point of inoculation. The production of oospores took place, and because these showed in all stages (many failing entirely to develop further) and with no aerial growth to bother, such cultures were well adapted to the microscopical study of the sexual organs, merely by mashing small pieces of the medium under a cover glass. Plate LXXII b E.

Potato juice agar $(150+10+500)$. The growth differed quite markedly from that of potato mildew on this medium, as there was no aerial development. The embedded growth was more evident than on the corn meal, and consisted of a rather matted development of mycelial threads, with very few conidiophores and conidia. Practically no oogonia were formed, and the few attempted did not produce oospores. The mycelium did not form irregular swellings so abundantly as usual, and so was more like that of $P$. infestans. Plate LXXII b D.

Sugar peptone agar $(4+2+10+500)$. The fungus failed to grow, or made only a slight growth around the inserted material, but with one-half gram of nucleic acid added, it made a somewhat more evident growth at the point of inoculation. Very few conidia were formed, and practically no mature oogonia. Phaseolin Pot. Phos. agar $(1 / 2+1 / 2+10+500)$ cultures practically failed to grow. Sugar peptone water $(4+2+500)$ failed entirely to grow.

Lima bean juice gelatin $(50+50+500)$. This is a poor medium, and usually only a slight aerial growth of mycelium and conidiophores with conidia takes place in surface cultures, and in stab cultures only a slight development of mycelium, with no chlamydospore-like bodies. No mature oospores occurred, and there were few attempts to start these, but the mycelium had more or less of the swellings. The walls of the imperfect oogonia were thicker and more strongly tinted than usual.

Potato juice gelatin $(150+50+500)$. Similar to, but even poorer than the preceding, but with no sign of oospore production and mycelium even with few swellings. Surface of medium in time 
becomes darkened in color, due to oxidation, and the conidia, conidiophores and mycelium take on this tint somewhat. There was no development of the peculiar chlamydospore-like bodies found by Jones with the potato mildew in his special preparation of this medium.

Ground Lima beans (with just water enough to keep moist after sterilization). Used both green and dried bears, and also green beans with the pods ground with them, but the addition of the latter proved of no particular value. The fungus formed a rather luxuriant, fluffy, aerial growth, composed of mycelium and conidiophores. Some oospores formed in time in the tissues. On the whole, not so convenient a medium for study as the agar mediun. Plate LXXII b A.

Living Lima beans. These were taken from the interior of unbroken pods by aseptic means, and placed in sterilized tubes on moist cotton, and then were inoculated. Or they were taken already inoculated from the infected pods. Sometimes an evident aerial growth of mycelium and conidiophores appeared on these, and sometimes, when the surface was unbroken, no external growth showed, though the seed coats were discolored by a reddish-brown dry rot. Oospores were formed more or less abundantly within the tissues.

Corn meal (with water enough to keep moist after sterilization). The fungus practically failed to grow in this medium. With our cultures in I905, when it was mixed with ground Lima beans and pods, etc., growths were obtained. The drying out of this medium in itself often prevents growth starting, and corn meal certainly is not so favorable for this as for the potato mildew.

Attempts to lose oospores. Our cultures of this fungus obtained last fall were from seven infected beans from the Experiment Station grounds and a market garden at Westville. These cultures have been continued distinct ever since. Our idea in connection with the sexual strain theory had been that possibly by obtaining cultures of the fungus early in the season, certain ones might be run across in which oospore production did not take place owing to the presence of only a single strain. Last year the mildew did not appear on the Lima bean until the very end of the season, our first cultures being obtained September 29th. The cultures from these seven beans all produced oospores. In fact, they have continued to do so ever since, except when grown under unfavorable conditions.

It being settled that both strains were present, if such existed, the next attempts were to get rid of one by means of the Petrie dish separation method with the conidia. It was found by Van Tiegham cell tests with nutrient agar medium that these spores did not usually germinate very readily, and when they did it was by means of germ tubes that did not make a very extended growth. However, in the poured Petrie dishes from the melted Lima bean agar tubes, having the introduced mass of spore- 
bearing mycelium shaken through them, it was found that usually numerous more or less isolated growths started up (see Plate LXXII a). These usually were so closely situated that they ran together, so that distinctly isolated colonies, presumably from a single spore, did not often occur after the first few days of growth. That these growths, at least sometimes, came from the germinating conidia rather than fragments of the mycelium, was shown on microscopic examination of the very young colonies. From the most isolated of these growths, and as early as possible, transfers were made to individual tubes. Petrie dish separation cultures were even made from these a second and a third time, but always with the result that the oospores eventually appeared if the medium used was a favorable one. In some cases where the medium was unfavorable, as potato juice agar, or where it was made acid, these oospores largely or entirely disappeared, but they always came back as abundantly as ever when transfers were made to strong Lima bean juice agar. These results are very strongly against the theory of distinct mycelial strains, the chief loophole being that the colonies were never from isolated spores, which seems quite improbable from the numerous transfers made from time to time.

The second method employed to get rid of the oospores was by means of transferring single isolated threads from the edge of the growth. This fungus does not afford a very good opportunity for such attempts. However, with the aid of a magnifier, one can sometimes get very small fragments from the mycelium that shows slightly embedded on the surface of the agar. Unless submerged hidden threads extended further than these visible ones, which seems improbable, it is certain that, in some of the numerous trials, fragments of a single thread were transferred. The results with these, however, were the same as with the ordinary renewals, namely, an abundance of oospores on the Lima bean juice agar. 

Apple, p. 853.

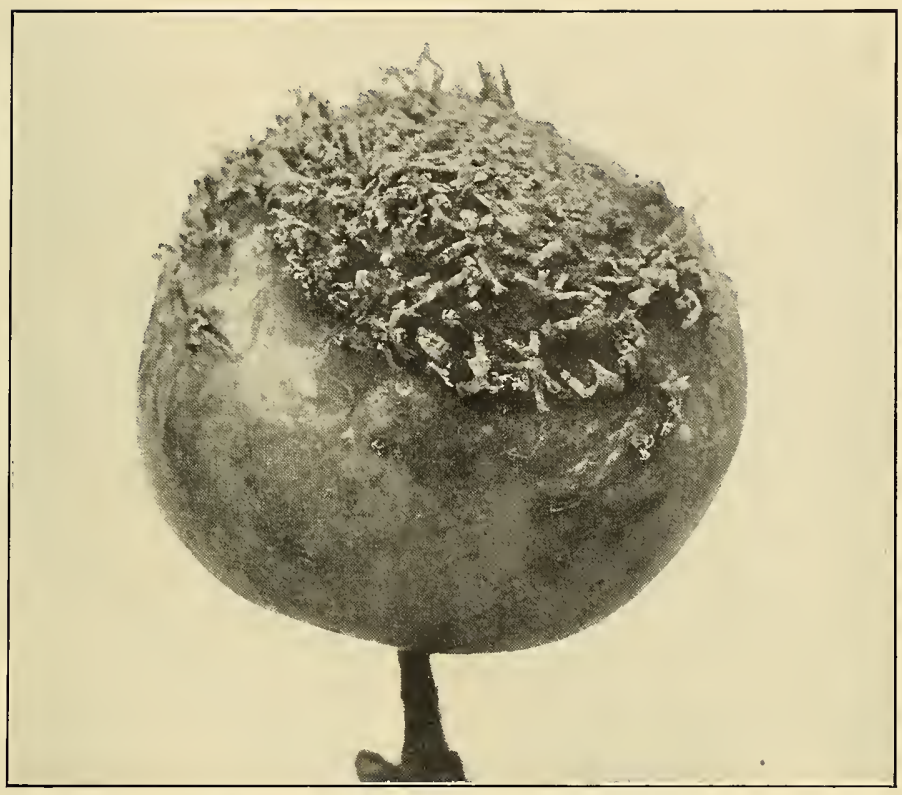

a. Showing peridia not spiit open. $\times 2$.

Quince, p. $85 \mathrm{I}$.

Apple, p. 853 .

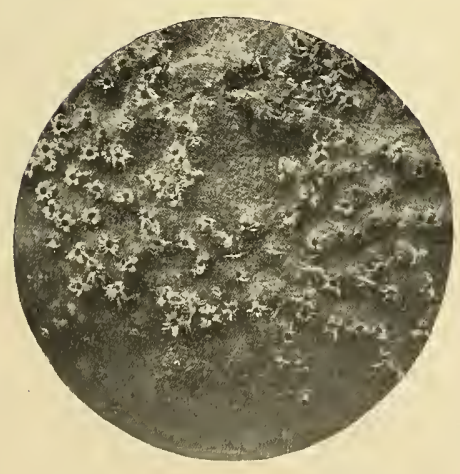

b. Peridia split open. $\times 2$.

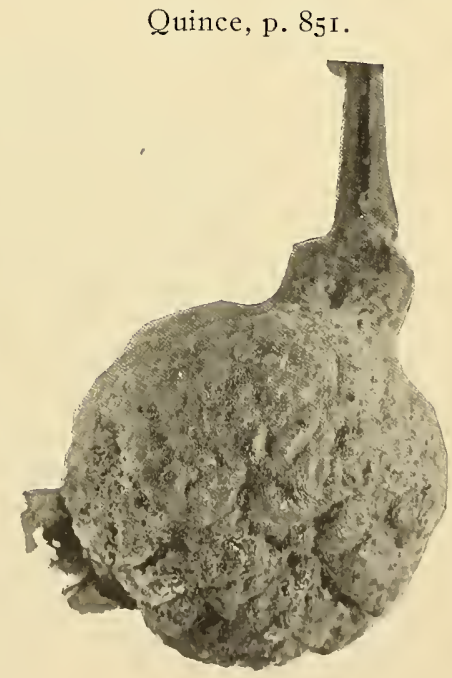

c. Peridia worn away.

RUSTS OF APPLE AND QUINCE. 

String Bean, p. 859 .

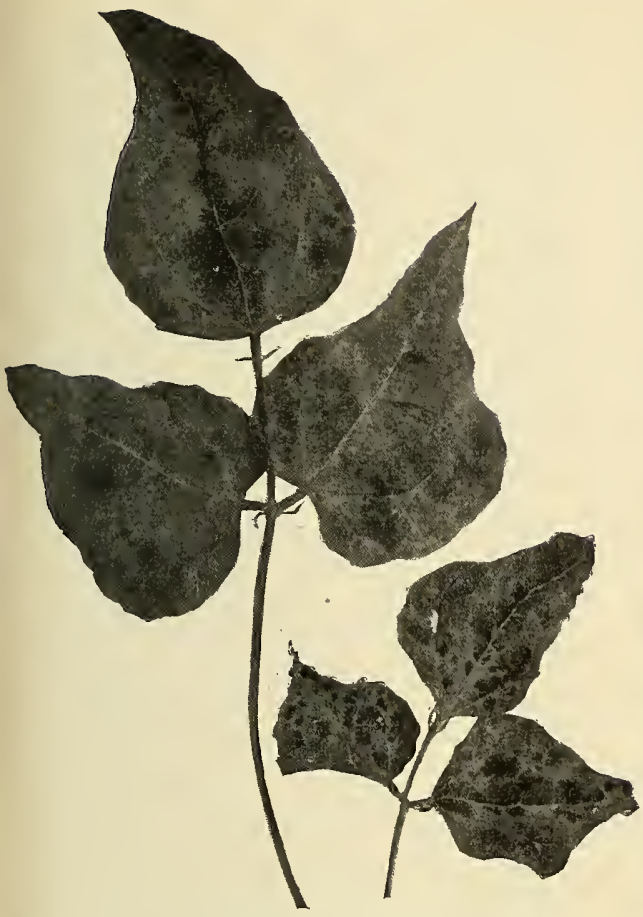

a. Chlorosis (infectious ?).
Lima Bean, p. 859.

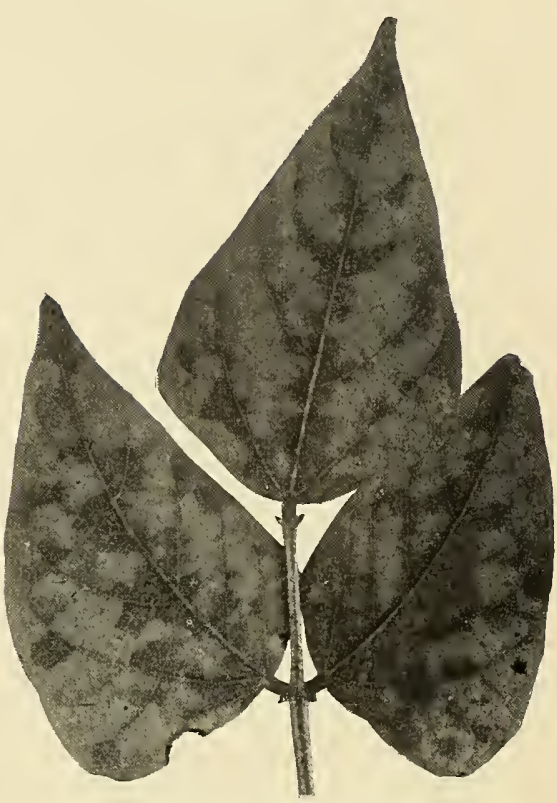

b. Chlorosis (non-infectious).

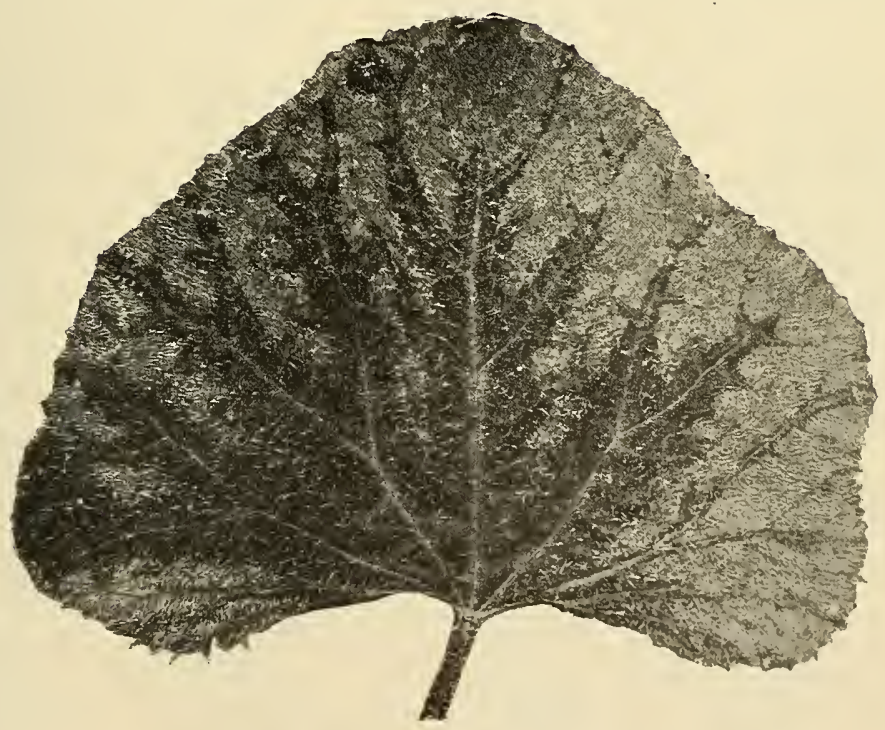

c. Chlorosis (iniectious ?) of Musk Melon, p. 865.

CHLOROSIS TROUBLES OF BEANS AND MUSK MELON. 



\section{Chestnut, p. 879 .}

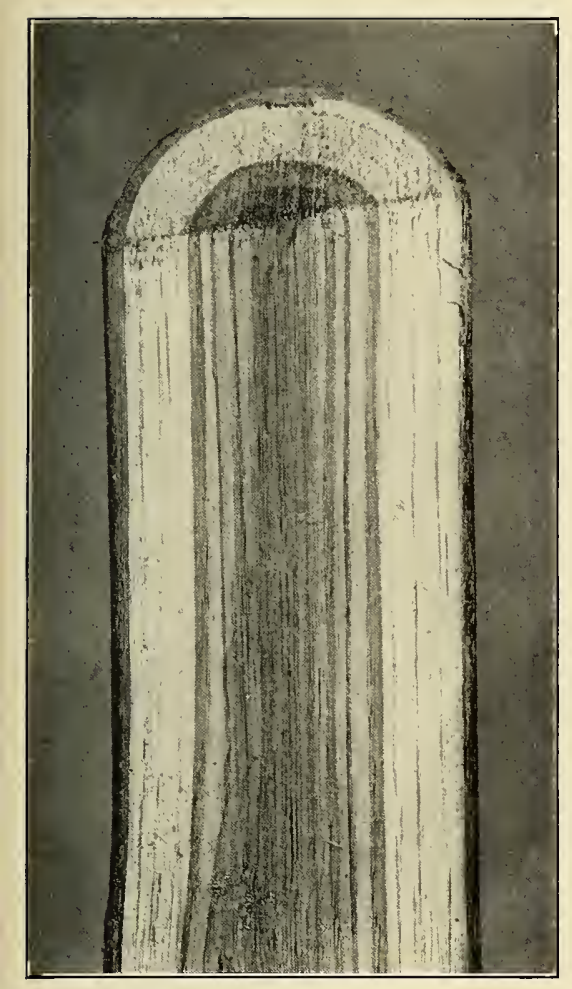

a. Winter injury of wood ?

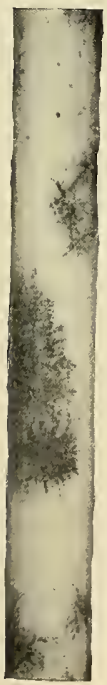

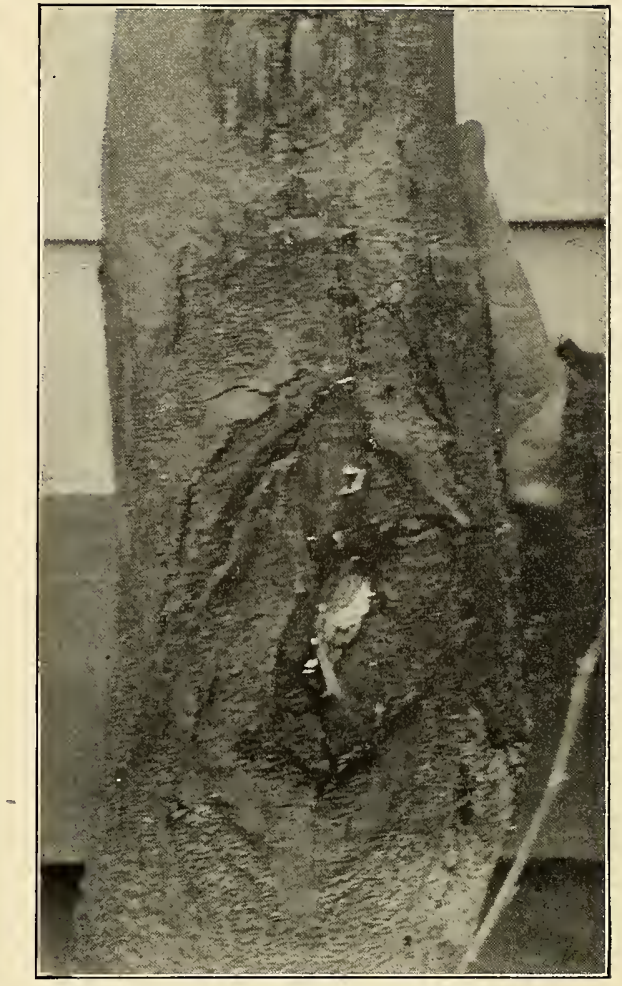

b. Diaporthe canker.
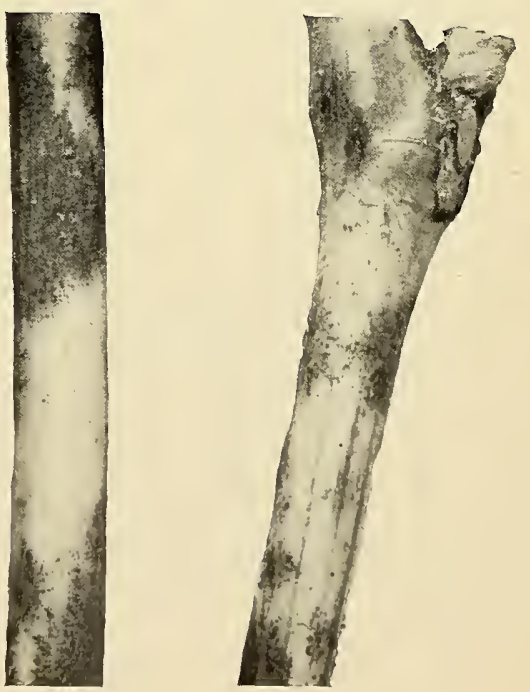

c. Powdery Mildew of Grape, p. 855. $\times 2$. 



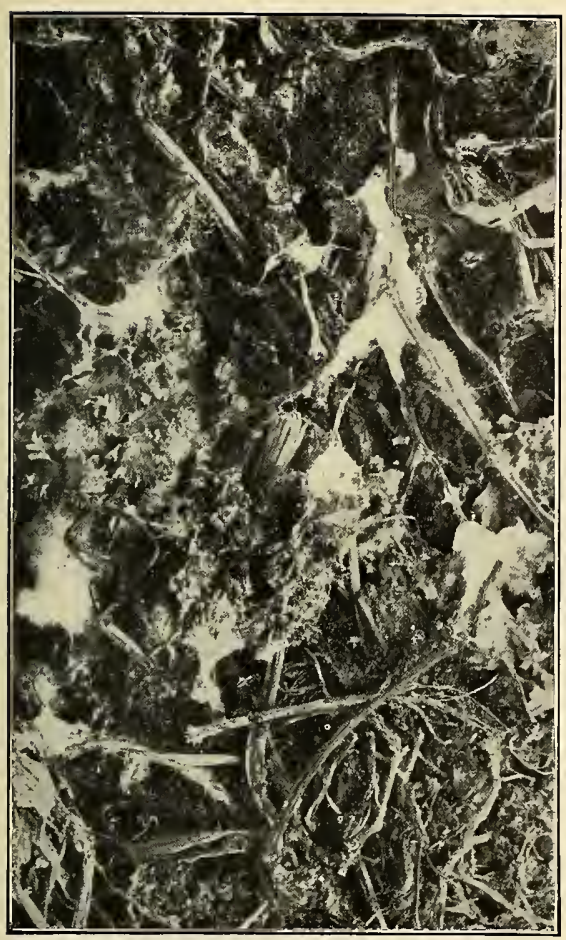

a. On parsley refuse, p. 868 .

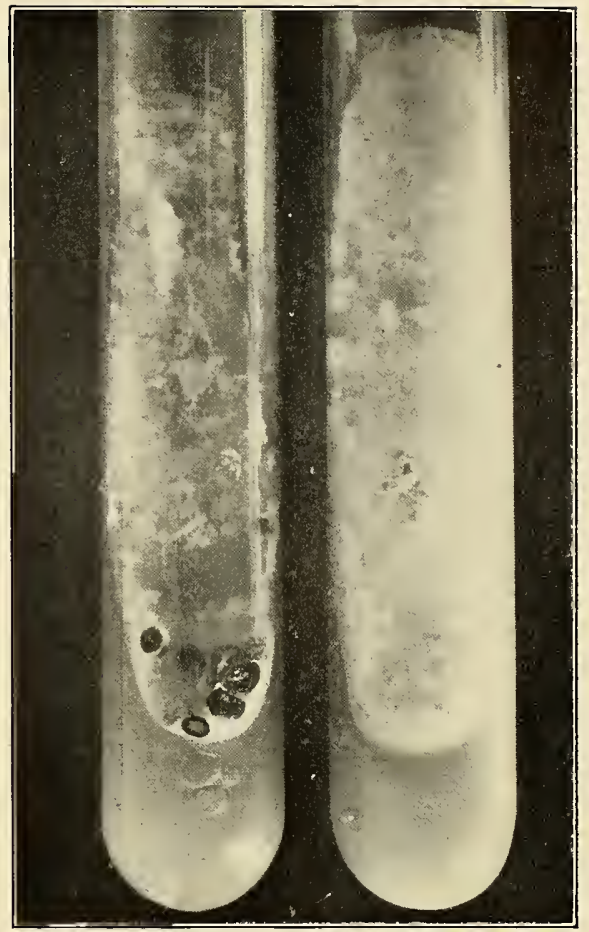

b. Artificial cultures, p. 869 .

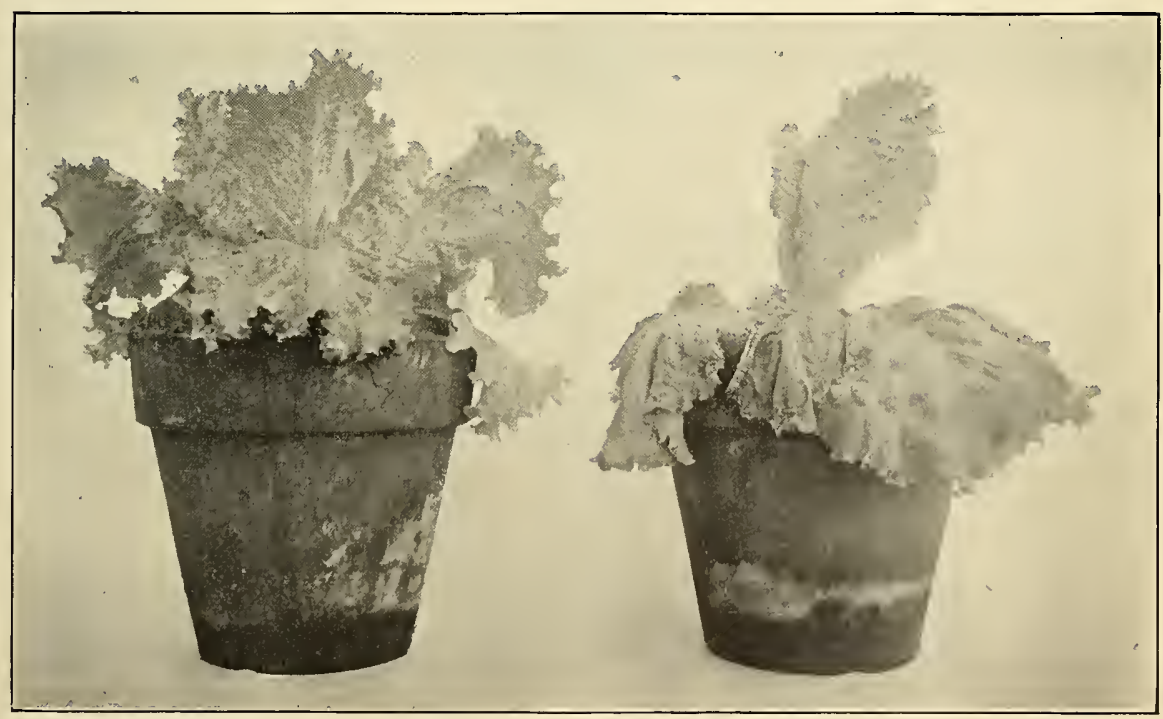

Check.

Inoculated.

c. Showing drop of lettuce leaves two days after inoculation, p. 864 .

DROP FUNGUS, Sclerotinia Libertiana, OF PARSLEY, LETTUCE, ETC. 



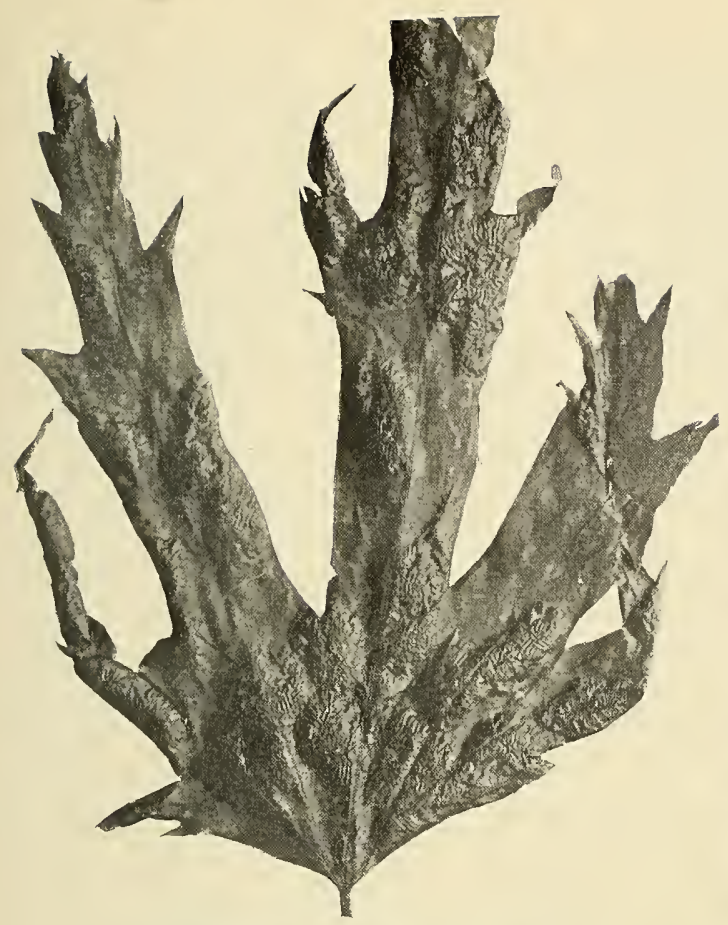

a. Black Śpot of Maple, p. 852.

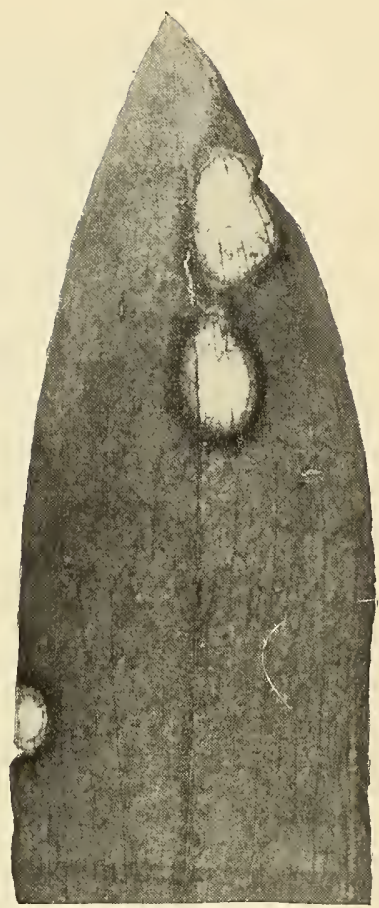

b. Bacterial Spot ? of Lily, p. 864 .

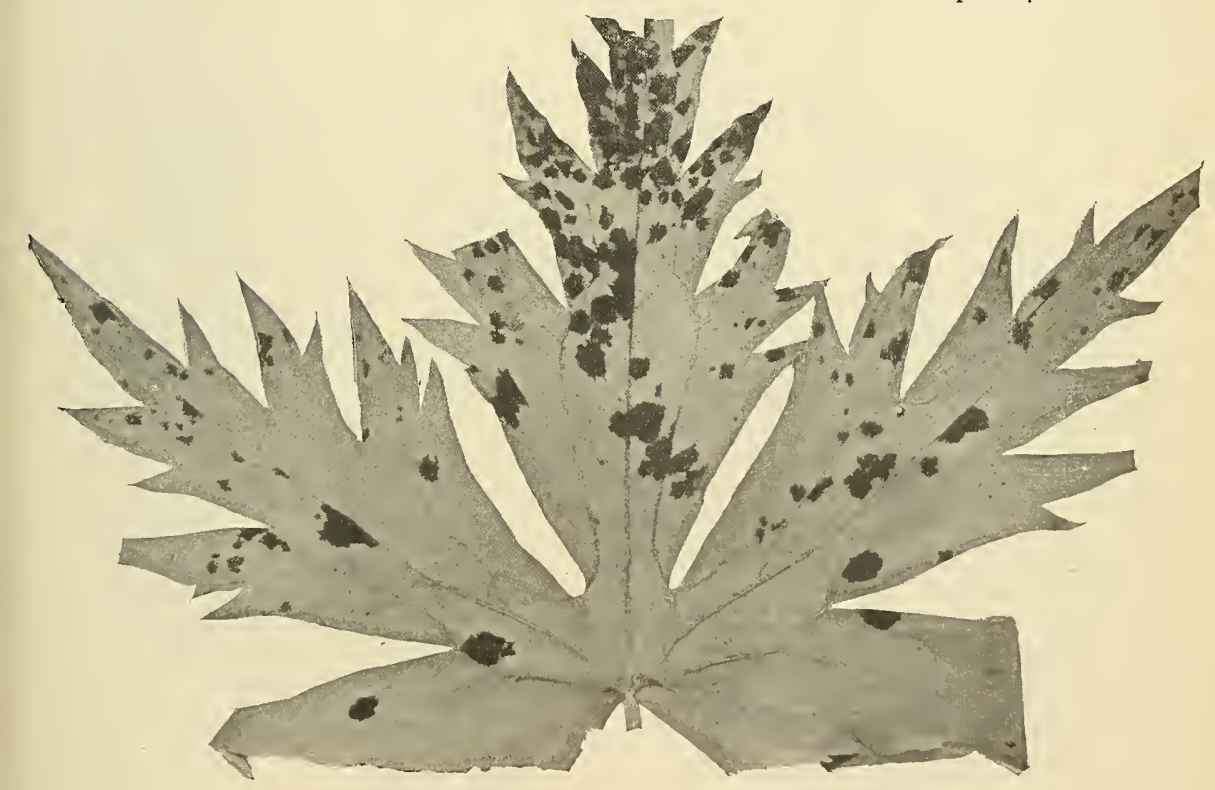

c. Bacterial Spot of Larkspur, p. 862.

DISEASES OF MAPLE, LILY AND LARKSPUR. 



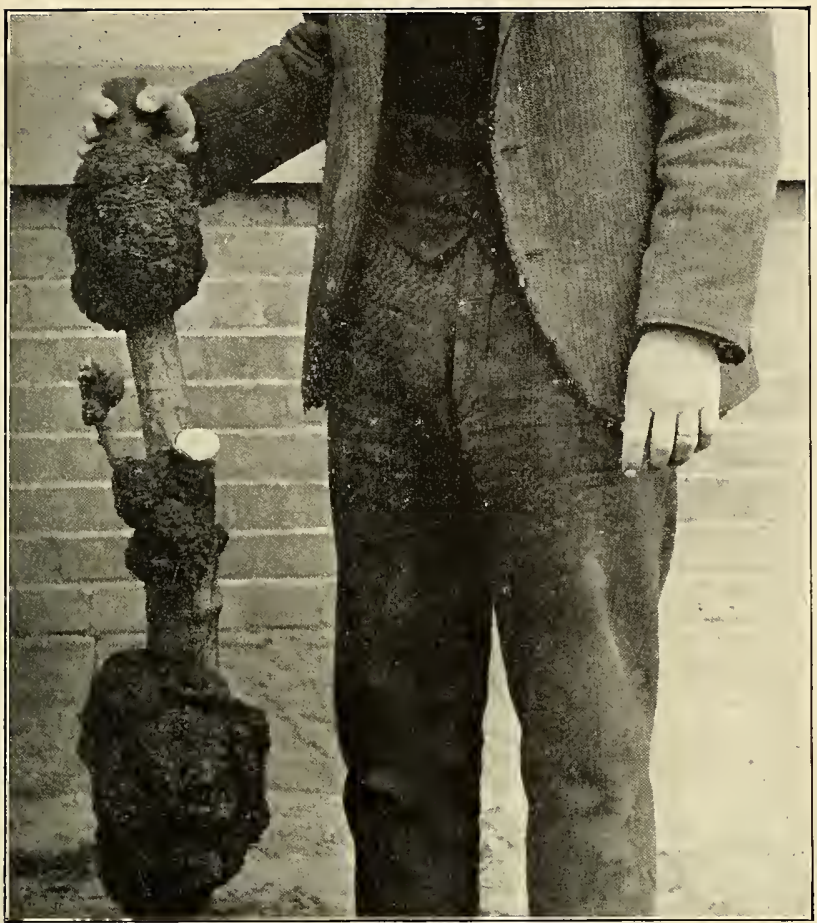

a. Showing large galls. Reduced.
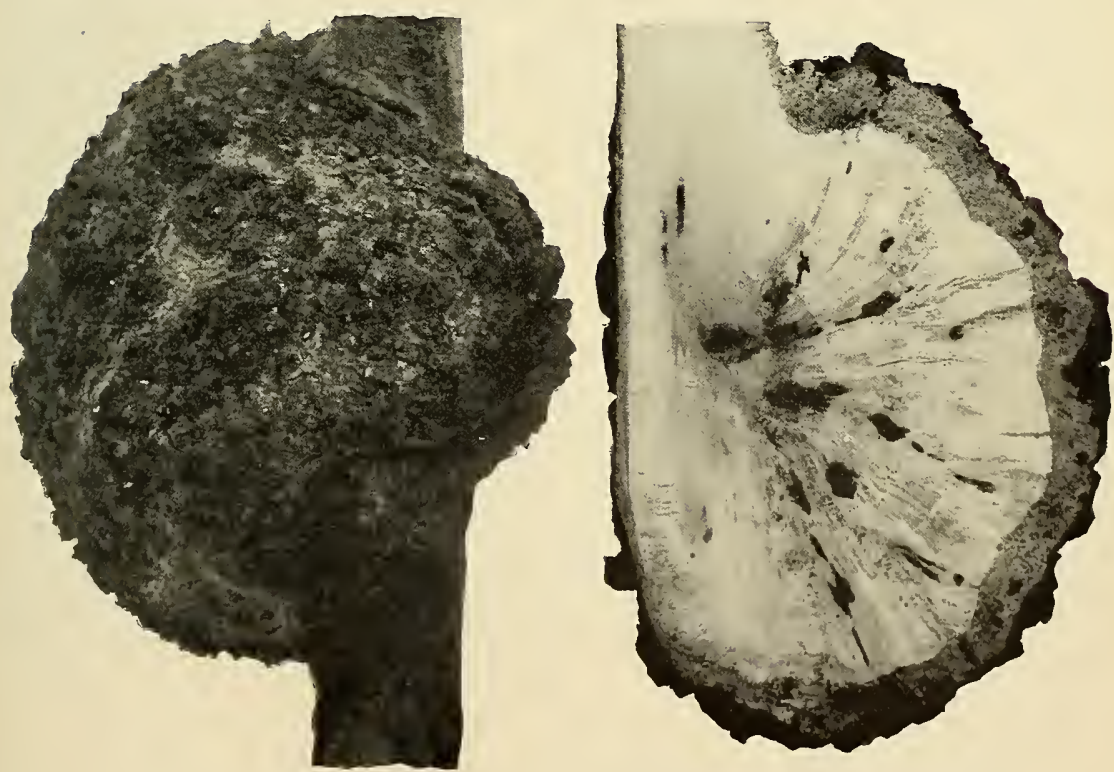

b. Showing structure of small galls. Natural size. 



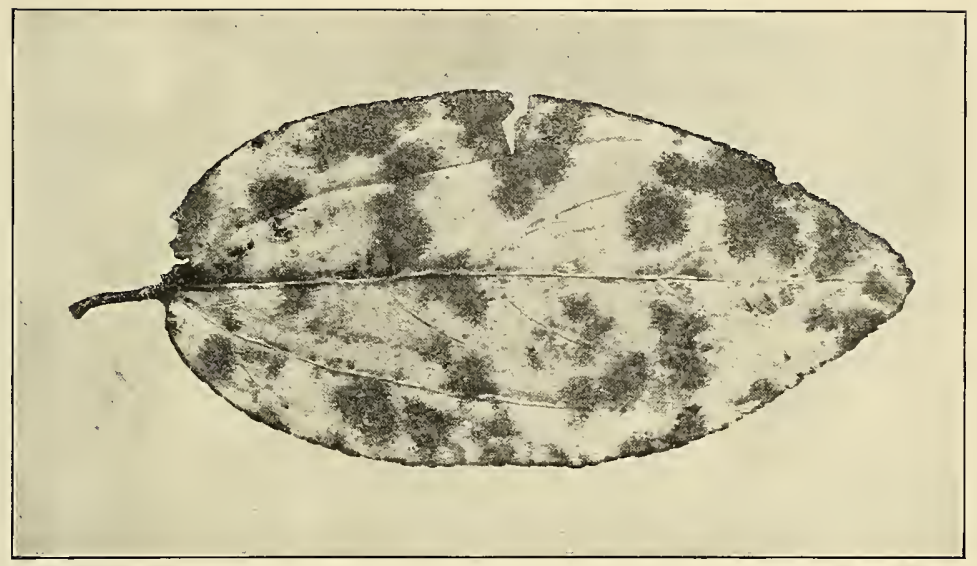

a. Powdery Mildew of New Jersey Tea, p. 866.

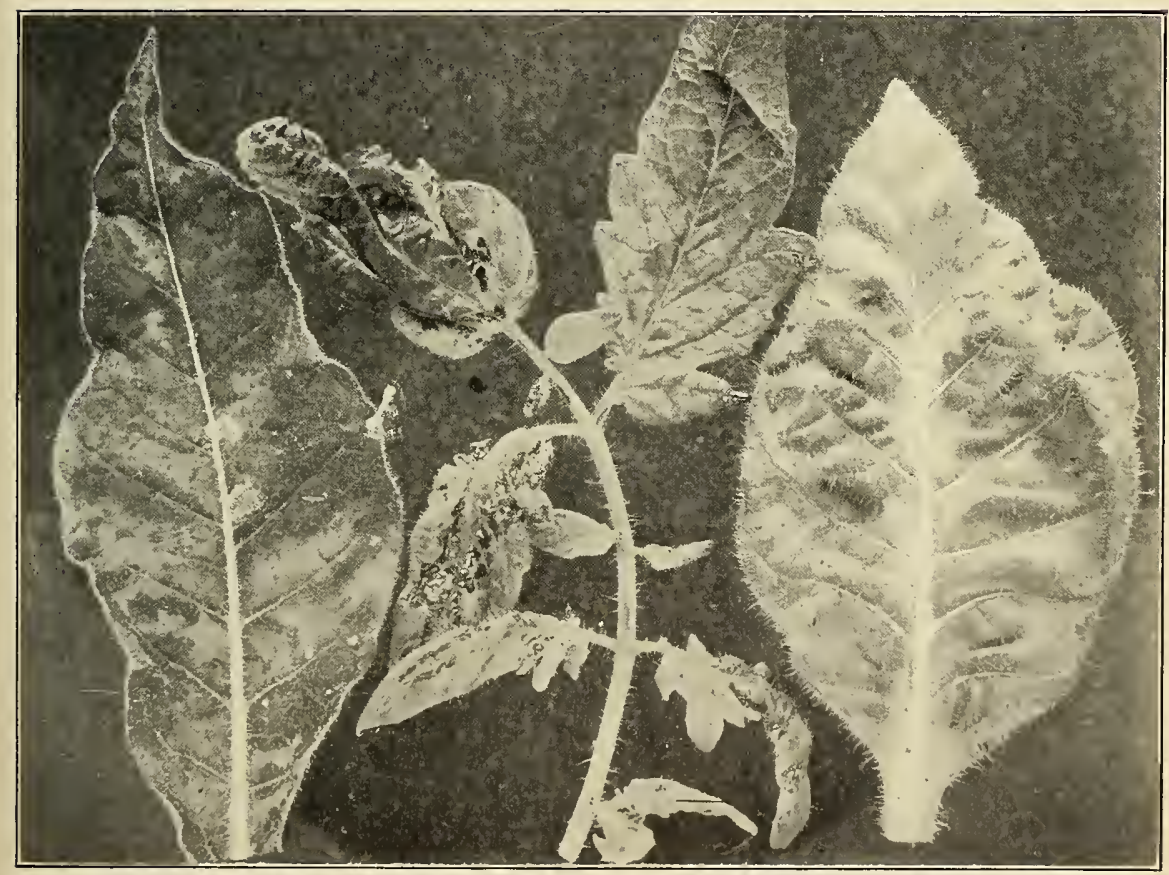

b. Calico from tobacco on tomato and then back to tobacco, p. 857 .

SOME DISEASES OF NEW JERSEY TEA, TOBACCO AND TOMATO. 



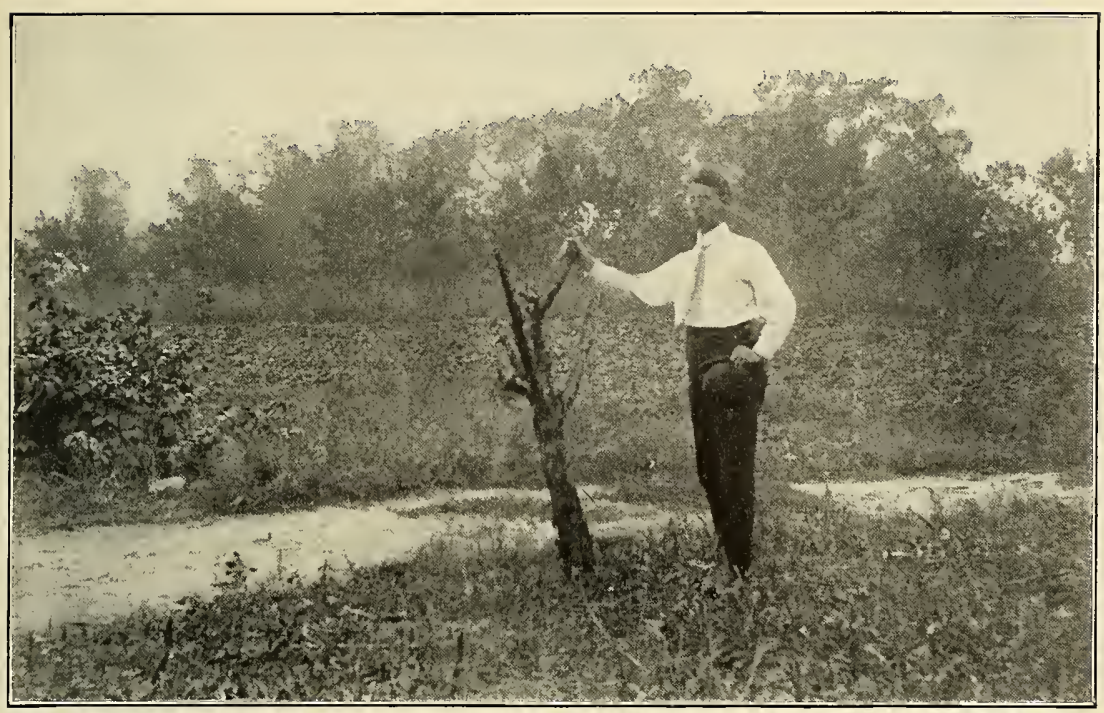

a. Showing manner of cutting back, spring of 1906 .

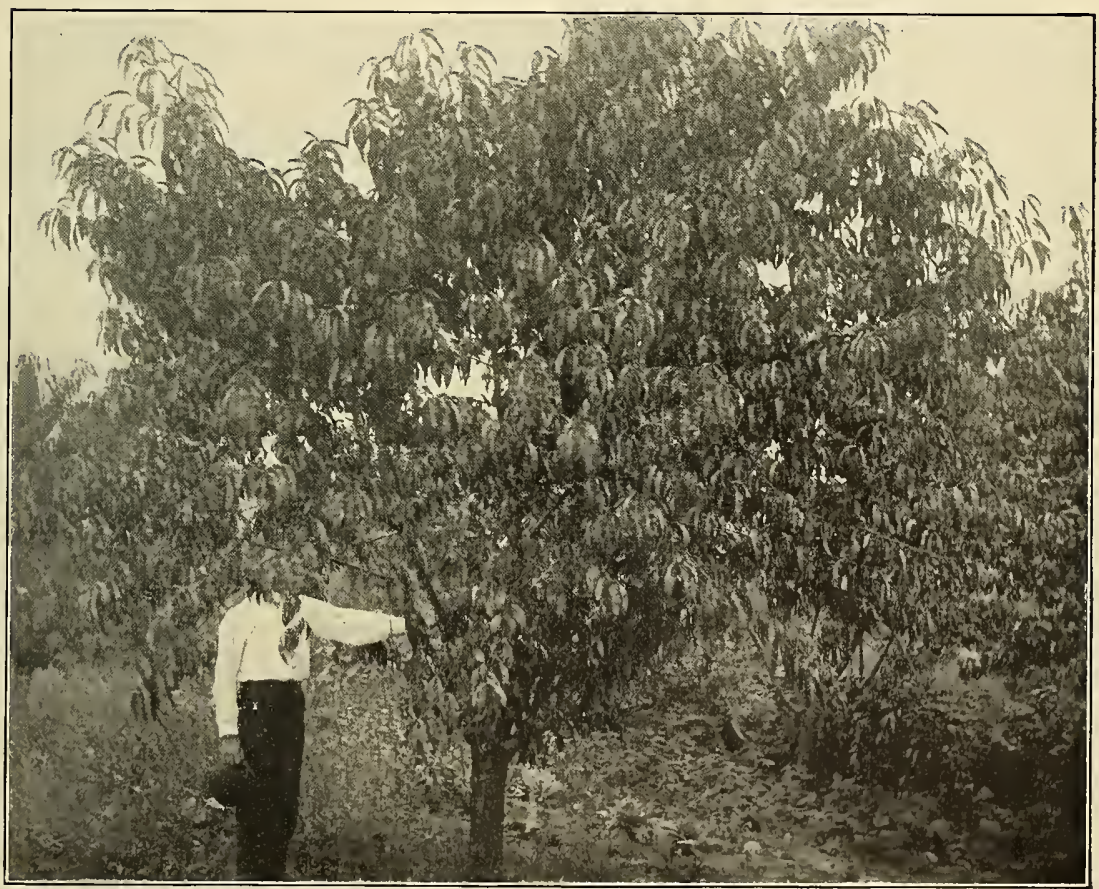

b. Showing growth made by fall of $\mathrm{igos}$.

PEACH TREES WINTER INJURED IN 1903-4, p. 874. 



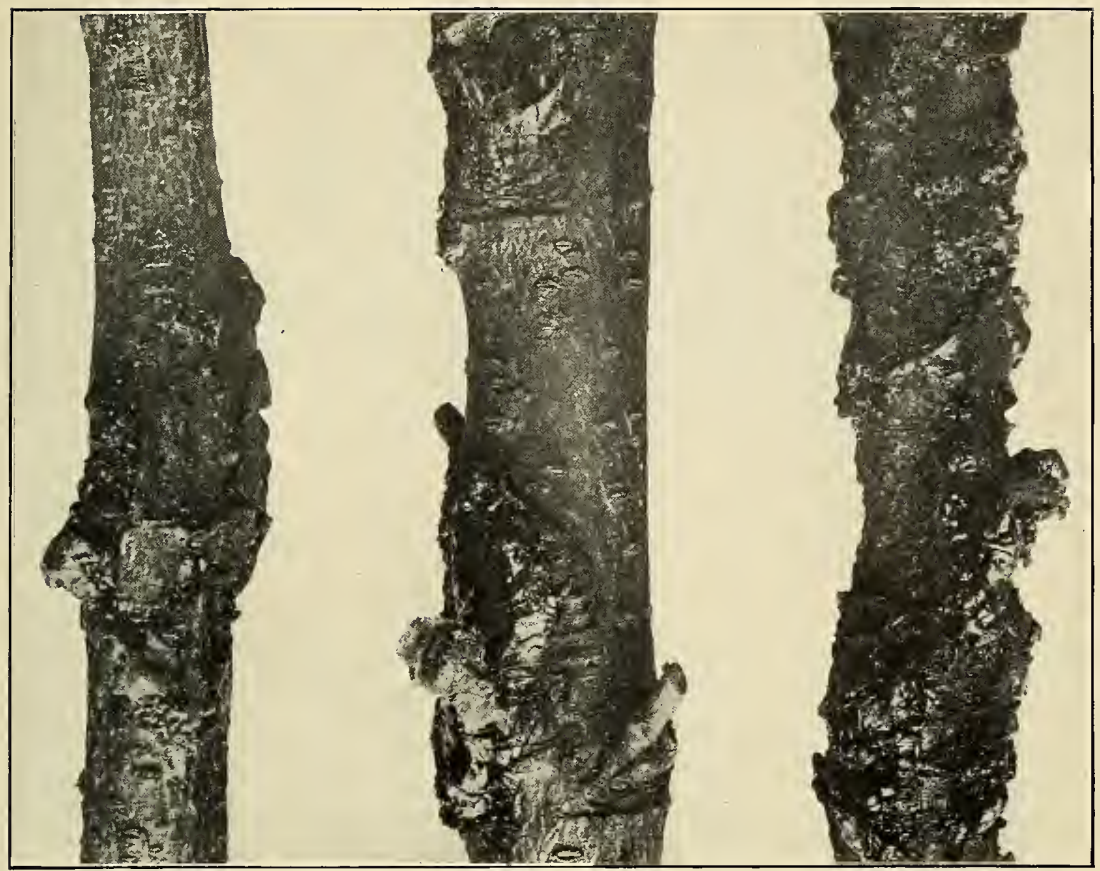

a. Gummosis, following winter injury, p. 869 .

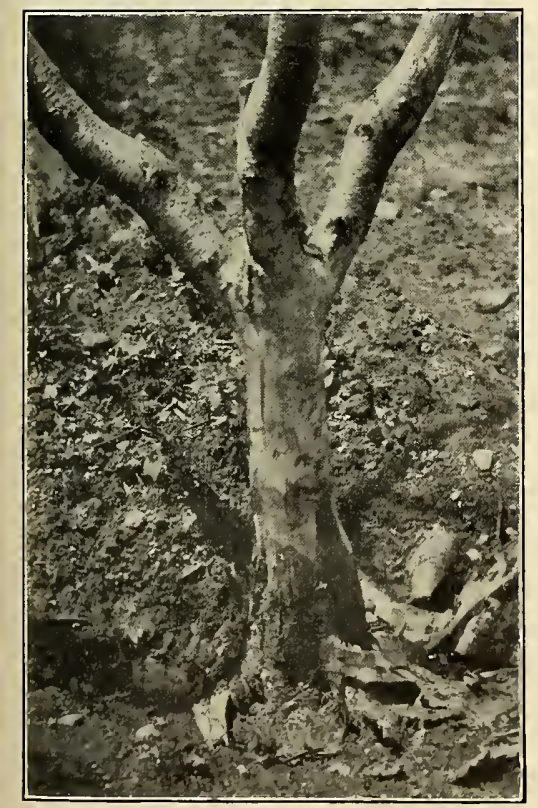

b. Collar Girdle with

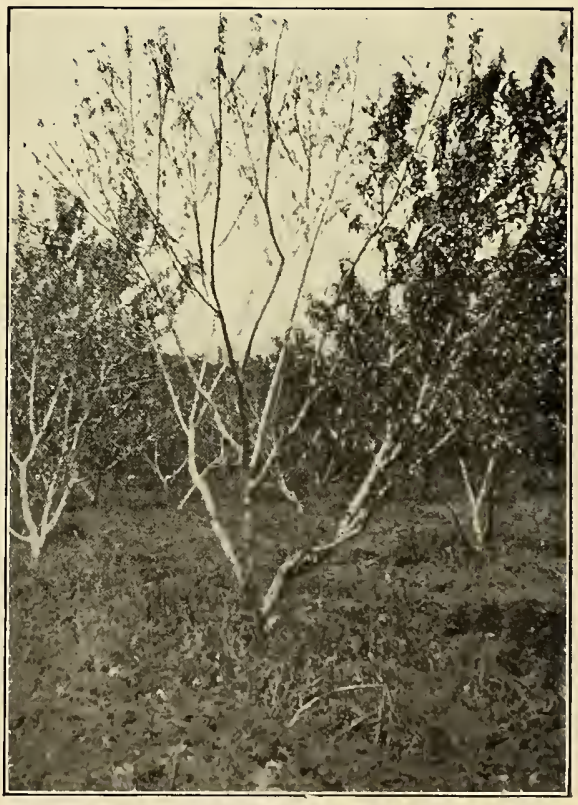

c. resulting death of tree; due to winter injury in $1907-8$, p. 856 . 



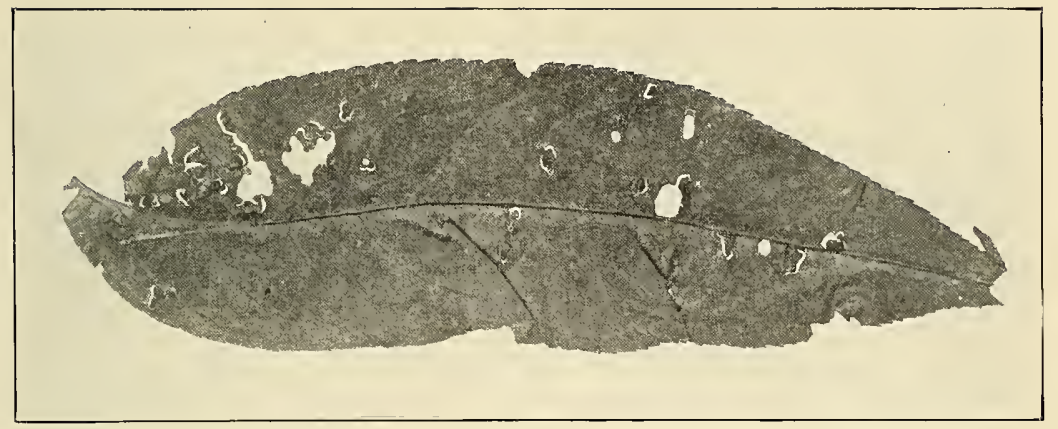

a. Bacterial Spot, showing shot hole effect, p. 856 .

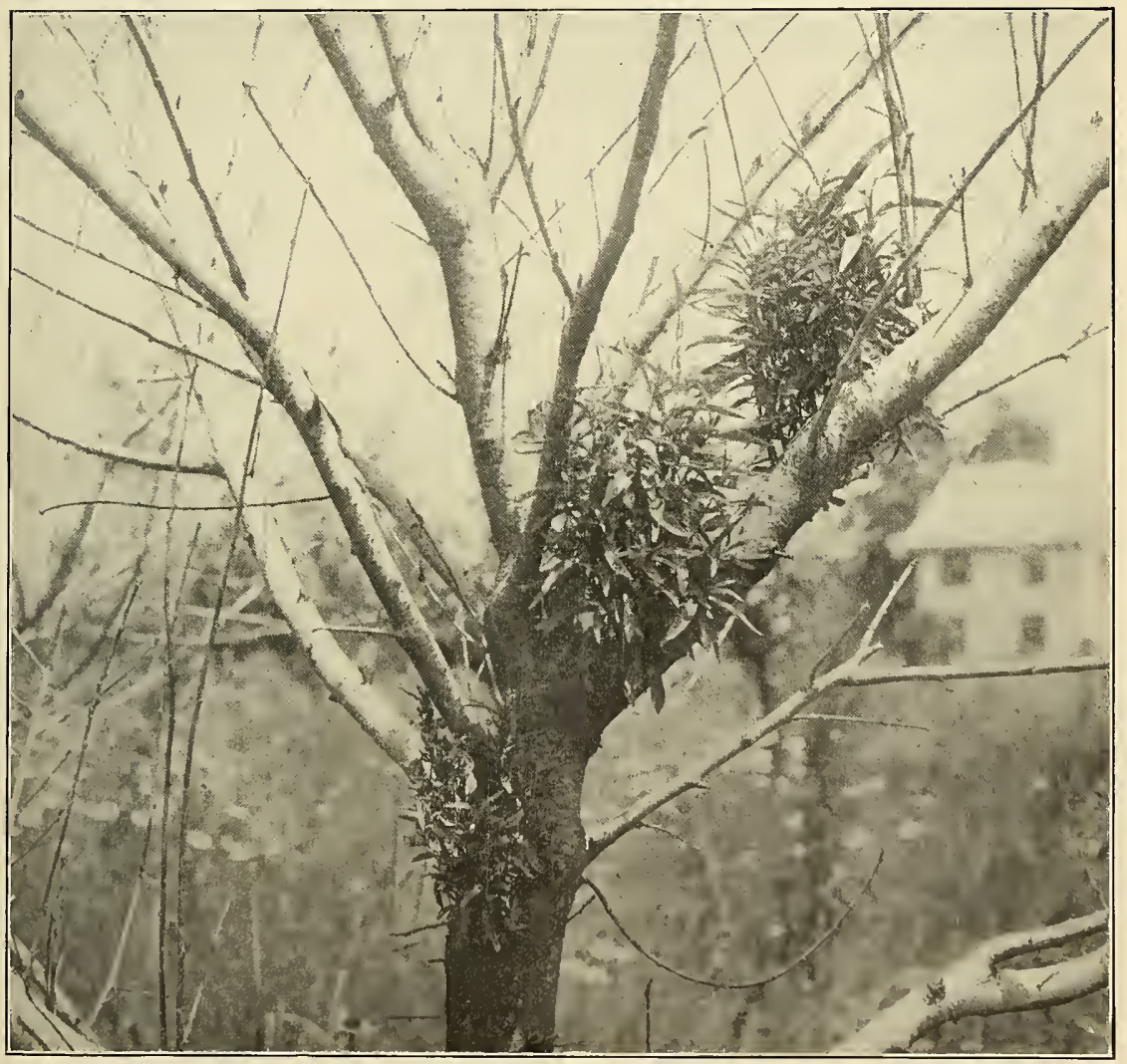

b. Last stage of Yellows, showing adventitious growths, p. 872 . 



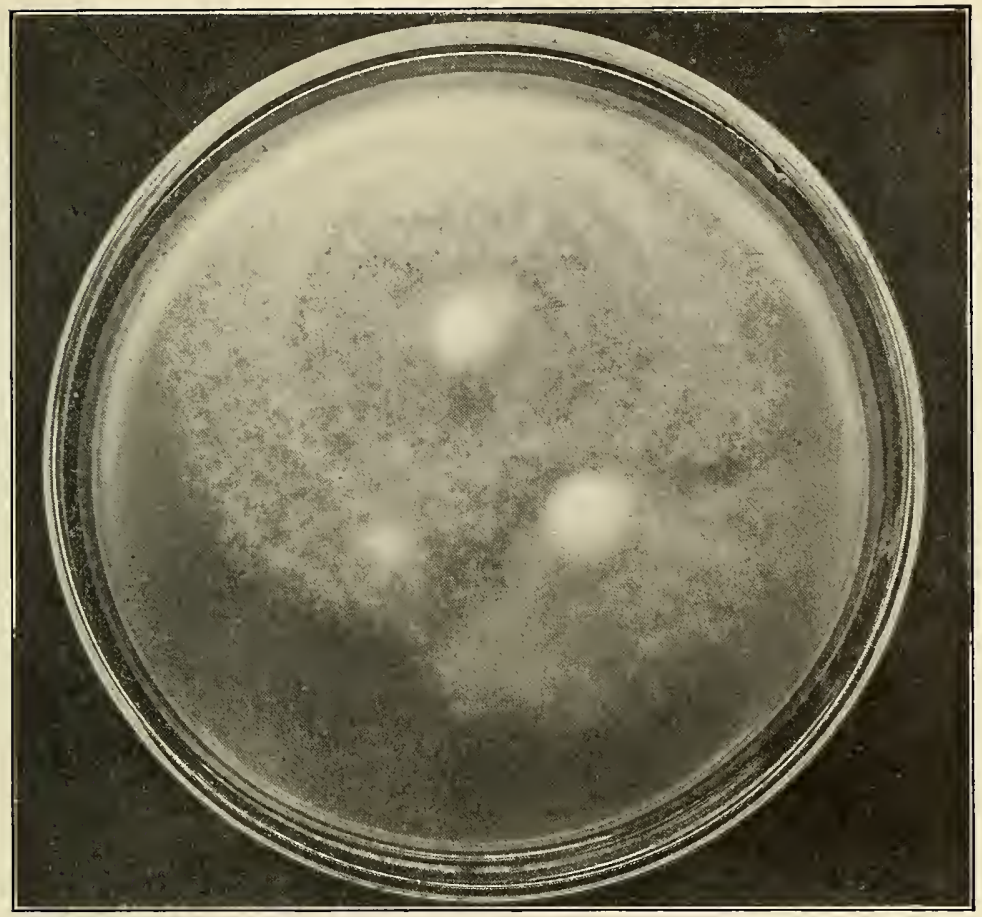

a. Petrie dish cross cultures from three sources, p. 899 .

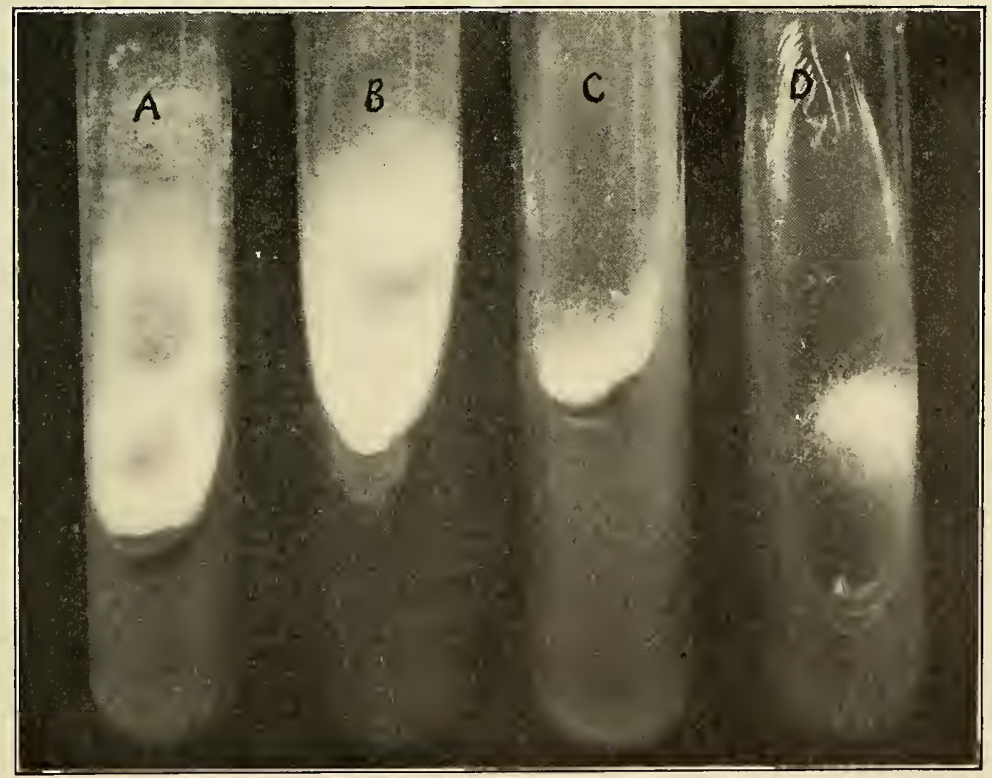

b. Growths on various media, p. 898 . 

PLATE LXXI.

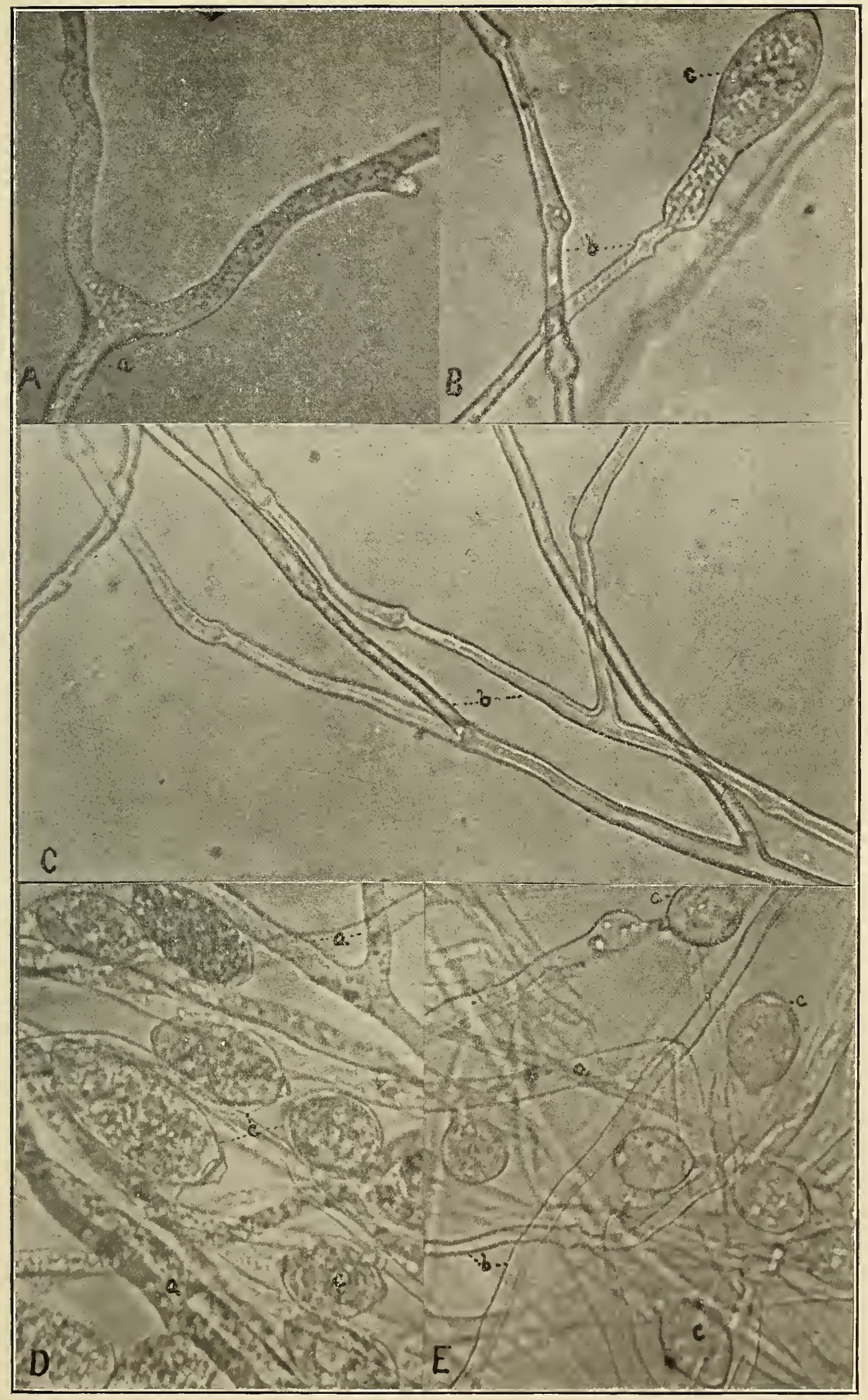

a. mycelium; b. conidiophores; c. conidia. $\times 600$ (about).

DETAILS OF CONIDIAL STAGE OF Phytophthora infestans, p. 895 . 



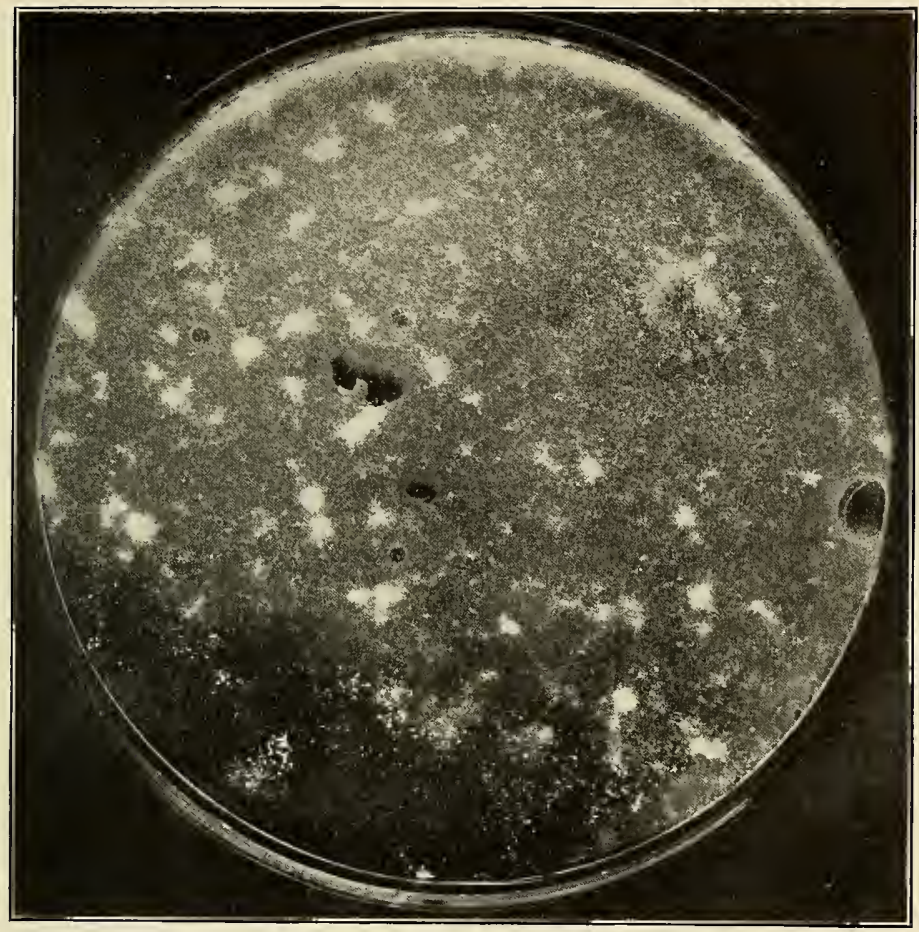

a. Petrie dish separation culture, p. 907.

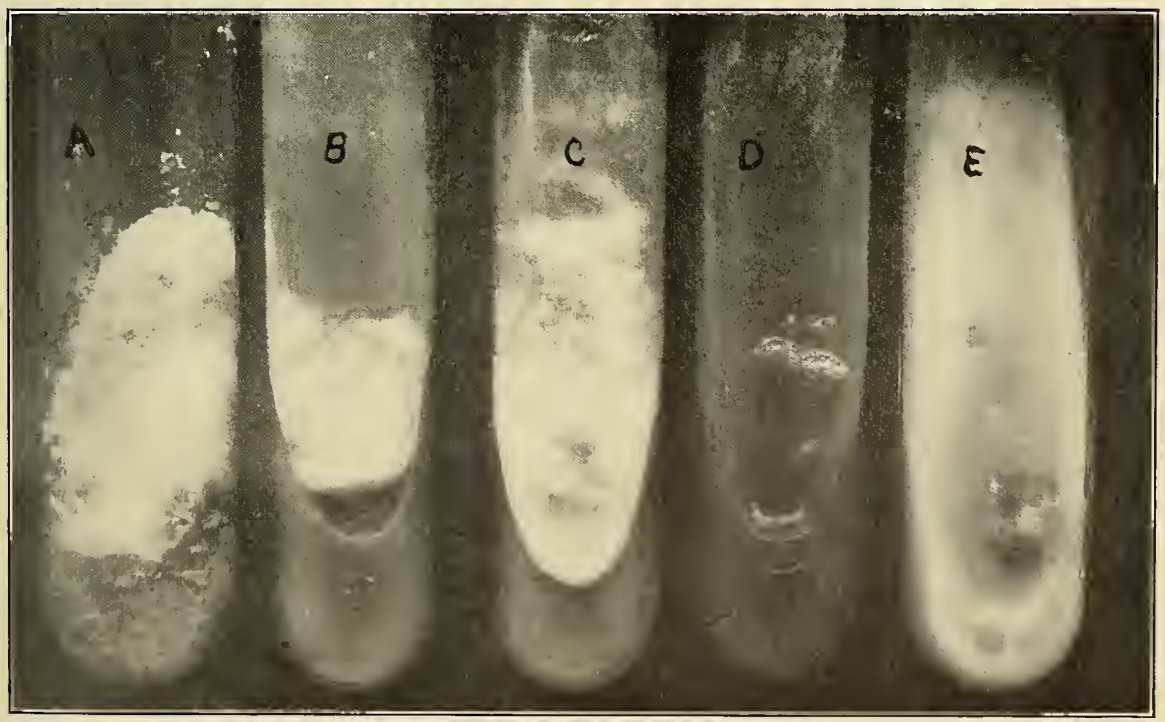

b. Growths on various media, p. 904 .

ARTIFICIAL CULTURES OF LIMA BEAN MILDEW, Phytophthora Phascoli. 



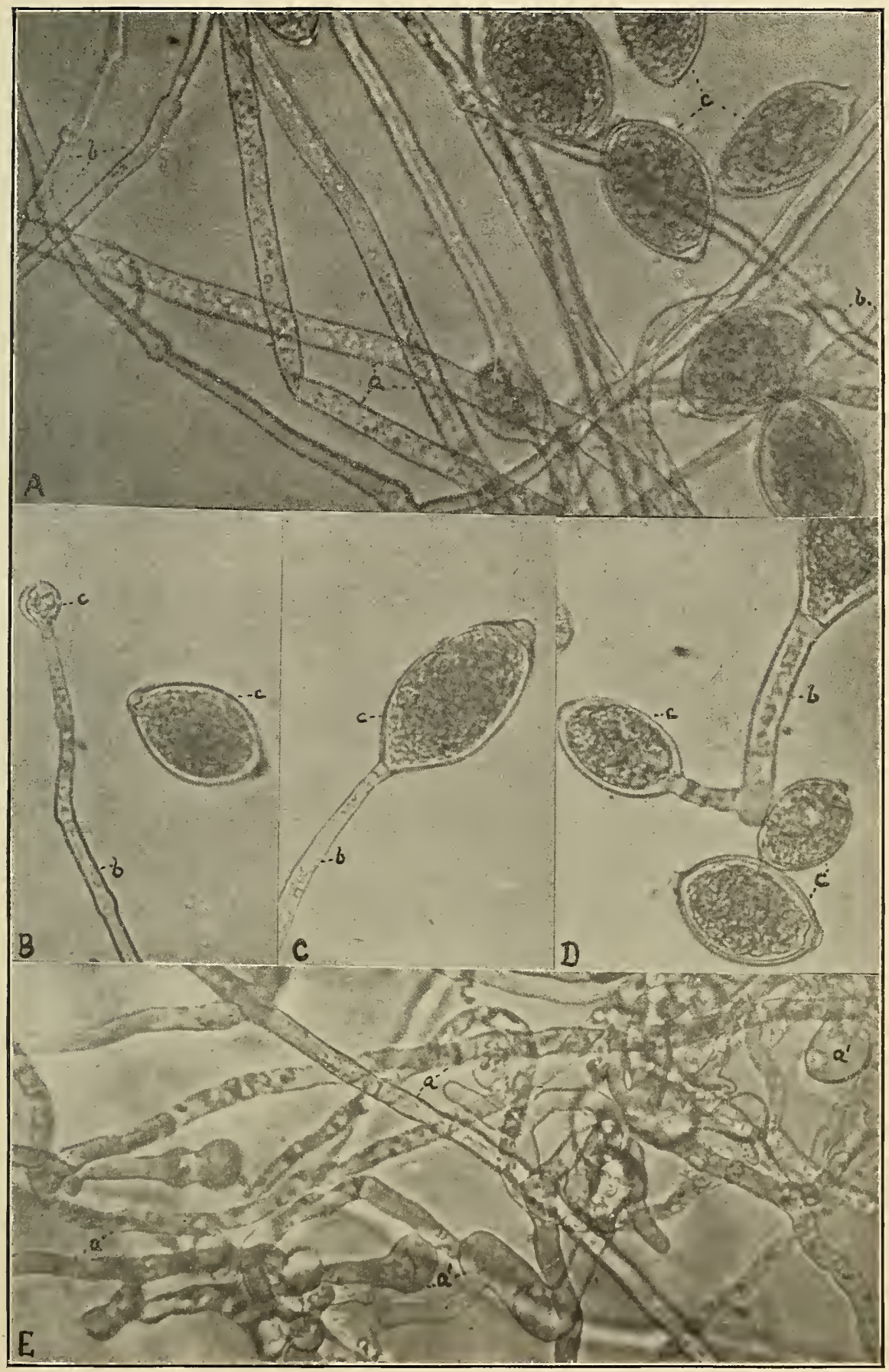

a. mycelium; a'. mycelial swellings; b. conidiophores; c. conidia. $\times 600$ (about). DETAILS OF CONIDIAL STAGE OF Phytophthora Phaseoli, p. 9or. 

PLATE LXXIV.

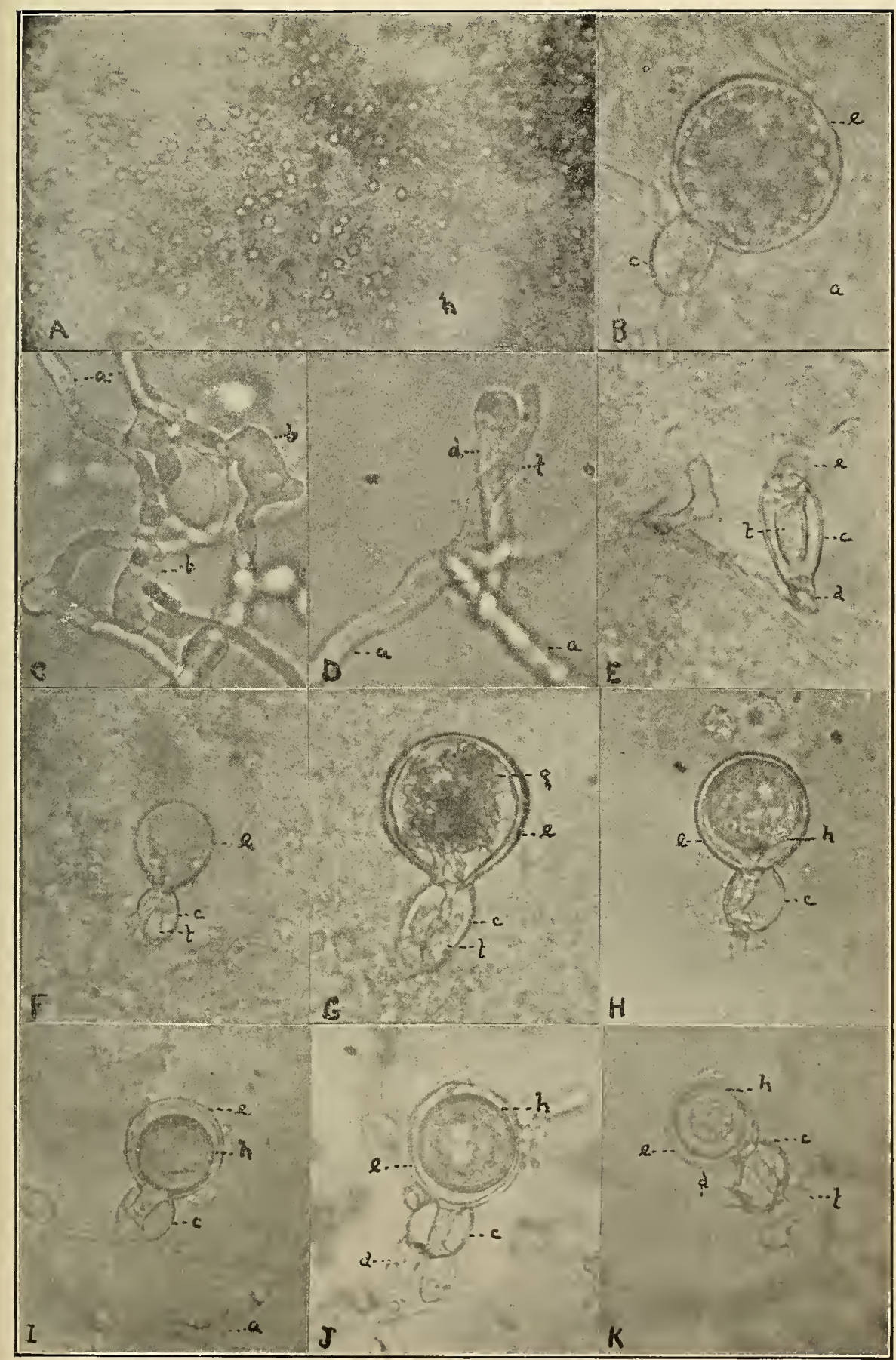

a. mycelium; b. potential antheridia ?; c. antheridia; d. antheridial threads; e. oogonia; f. oogonial threads; g. oosphere; h. oospores. $\times 600$ (about) except $\mathrm{A}$. 



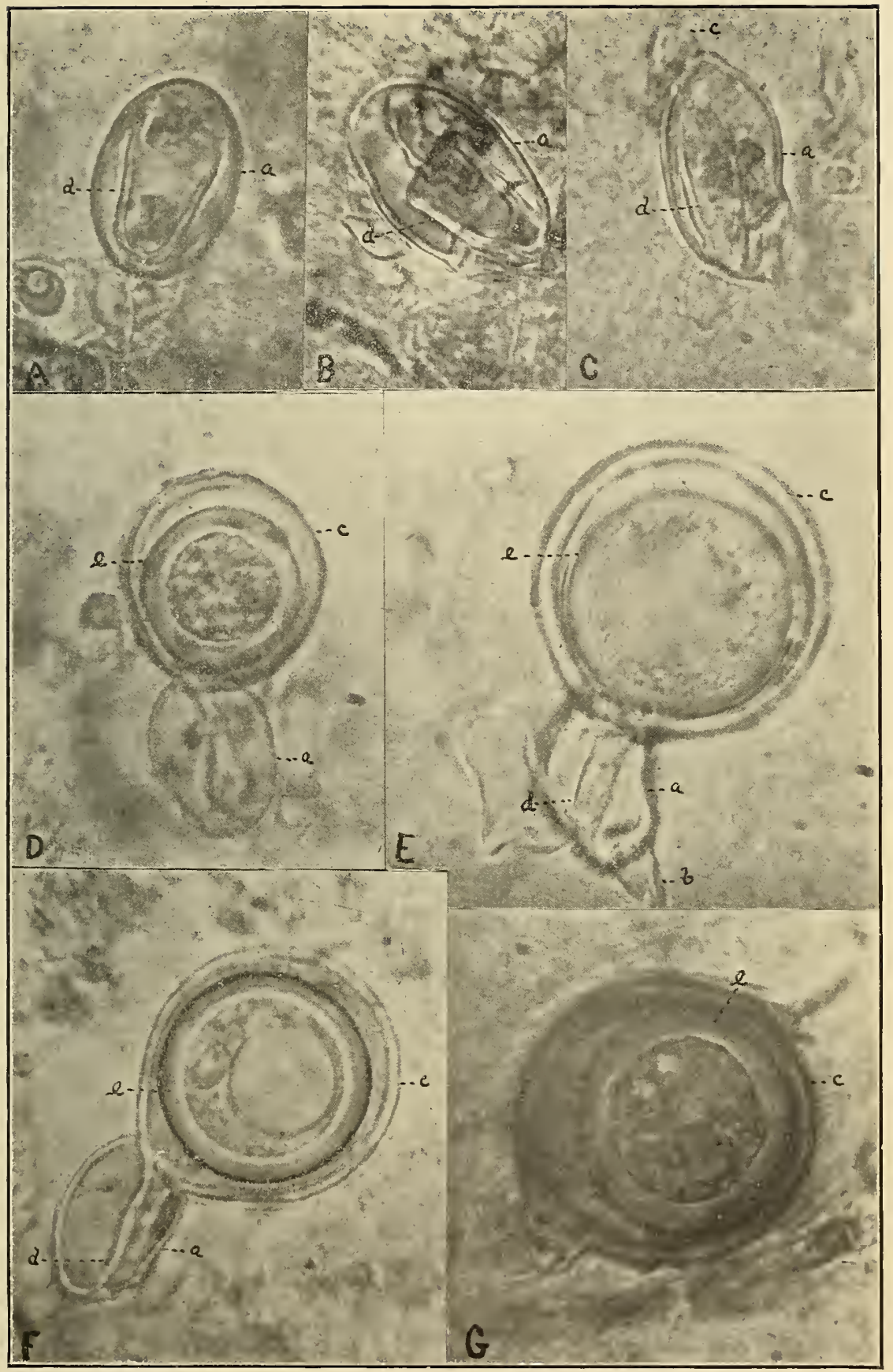

a. antheridia; b. antheridial threads; c. oogonia; d. oogonial threads; e. oospores. X I 200 (about); oil immersion; G. stained. 



\section{INDEX.}

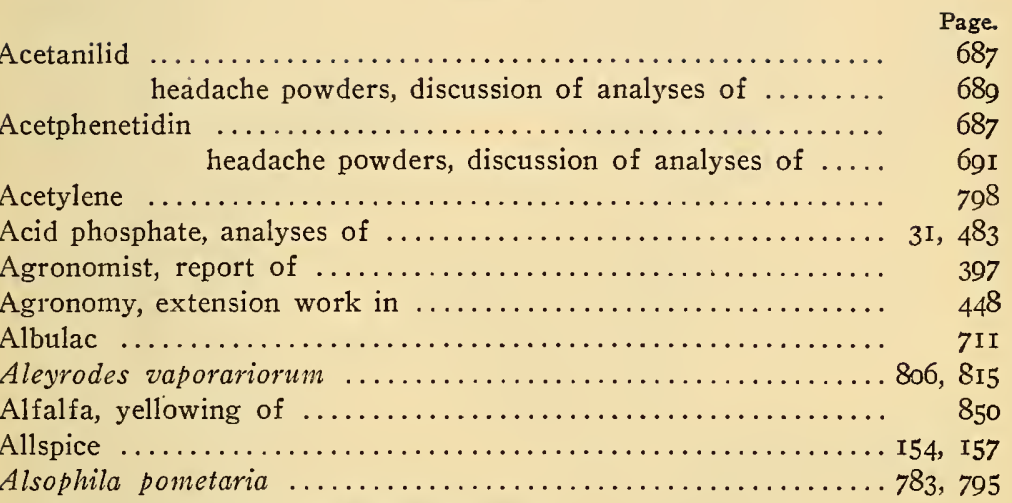

American Agricultural Chemical Co.:-

A. A. C. Co.'s Complete manure with Io\% potash $3,62,63,455,462$ Complete tobacco manure...3, I04, 105, 455, 558, 559 Grass and lawn top dressing. .3, 96, 97, 455, 544, 545 H. G. tobacco manure............ I, Io, 455,462 Southport XX special ................ 58, 59 Superphosphate $\ldots \ldots \ldots \ldots \ldots 3,68,69,455,520,52 \mathrm{I}$ Tobacco starter and grower...3, 88, 89, I00, IoI, 455 , $540,54 \mathrm{I}, 554,555$

Dry ground fish ........ $44,46,47,455,498,499$ Fine ground bone $\ldots \ldots \ldots \ldots 3,42,43,455,494,495$ Grass and oats fertilizer......3, 98, 99, 455, 554, 555 Acid phosphate $\ldots \ldots \ldots \ldots \ldots \ldots ., 32,33,455,462$ Castor pomace ............. 30, 455, 48I, 482 Muriate of potash .........3, 36, 37, 455, 488, 489 Nitrate of soda .............. I3, I4, 455, 465 Bradley's Complete manure for potatoes and vegetables...3, 86, 87, top dressing grass and
grain .....3, $86,87,455,540,54 \mathrm{I}$ Corn phosphate .............. 96, 97, 455, 550, 55 I Eclipse phosphate ........... 70, 7 I, 455, 524, 525 Farmers new method fertilizer....3, 66, 67, 455, 520, 521 Niagara phosphate ........... 72, 73, 455, 524, 525 Potato fertilizer $\ldots \ldots \ldots \ldots \ldots \ldots 3,92,93,455,550,55 \mathrm{I}$ manure $\ldots \ldots \ldots \ldots \ldots \ldots 3,90,9$ I, 455, 548, 549 
American Agricultural Chemical Co., cont'd-

Page.

Church's Fish and potash ............. 64, 65, 455, 522, 523

Crocker's Ammoniated corn phosphate .....3, 90, 91, 455, 548, 549

Potato, hop and tobacco fertilizer...3, 92, 93, 455, 548, 549

Darling's Blood, bone and potash....3, 60, 6I, 455, 5I 2,5 I $3,528,529$

Dissolved bone and potash..3, 62, 63, 455, 516, 517, 528, 529

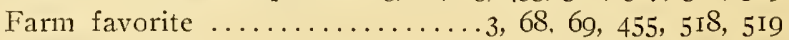

General fertilizer $\ldots \ldots \ldots \ldots \ldots . \ldots 3,72,73,455,524,525$

Potato manure $\ldots \ldots \ldots .3,88,89,455,544,545,554,555$

East India A. A. Ammoniated superphosphate 3, 66, 67, 455, 522, 523

Potato manure ........ 78, 79, 455, 540, 541, 542, 543

Great Eastern General .............. 70, 7I, 455, 516, 517

H. G. vegetable, vine and tobacco fer-

tilizer $\ldots \ldots \ldots \ldots \ldots \ldots .3,90,91,455,544,545$

Northern corn special.......3, 92, 93, 455, 546, 547

Packer's Union Animal corn fertilizer ......4. 92, 93, 456, 546, 547

Gardeners complete manure. $4,62,63,456,5$ I 4,5 I 5

Potato manure .........4, 88, 89,456, 542, 543

Universal fertilizer ......4, $70,7 \mathrm{I}, 456,520,52 \mathrm{I}$

Quinnipiac Climax phosphate .......... 72, 73, 456, 524, 525

Corn manure .............4, 90, 9I, 456, 552, 553

Market garden manure ........4, 56, 57, 456, 5IO, 5I I

Phosphate ............... 64, 65, 456, 518, 519

Potato manure .............4, 88, 89, 456, 542, 543

phosphate ...........4, 90, 9I, 456, 546, 547

Read's Practical potato special .........4, 98, 99, 456, 554, 555

Standard superphosphate $\ldots \ldots \ldots \ldots 4,70,71,456,524,525$

Vegetable and vine fertilizer.......4, 86, 87, 456, 546, 547

Wheeler's Bermuda onion grower $\ldots \ldots \ldots \ldots \ldots \ldots \ldots$, I00, I0I

Corn fertilizer $\ldots \ldots \ldots \ldots \ldots \ldots 4,98,99,456,552,553$

Havana tobacco grower 4, 100, IоI, 456, 531, 532, 536, 537

Potato manure ............. 94, 95, 456, 550, $55^{\mathrm{r}}$

Willianıs \& Clark's Americus Ammoniated bone super-

phosphate $4,68,69,456,522,523$

Corn phosphate ....4, 94, 95, 456,

$550,55 \mathrm{I}$

H. G. special fertilizer....4, 62, 63, $456,516,517$

Potato manure .....4, $94,95,456$,

548,549

Potato phosphate ....4, 94, 95, 456, 548, 549

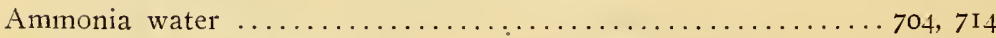

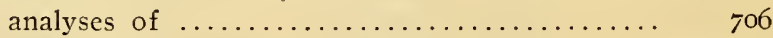

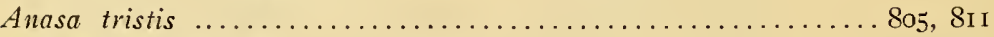

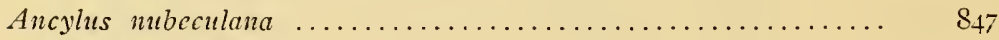

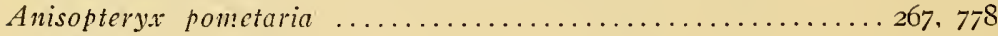

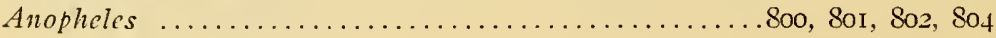


Anthonomus signatus ......................... 846

Anthracnose of meadowsweet .................... 352

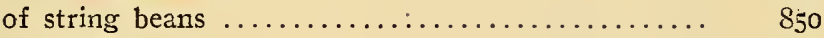

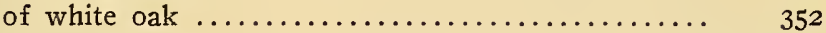

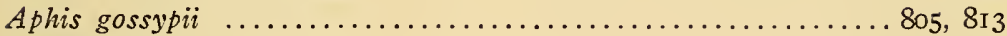

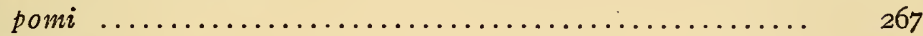

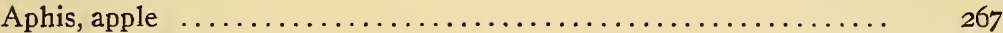

melon $\ldots \ldots \ldots \ldots \ldots \ldots \ldots \ldots \ldots \ldots \ldots \ldots \ldots \ldots . \ldots \ldots$ 805, 81 3

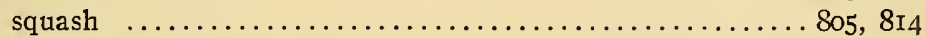

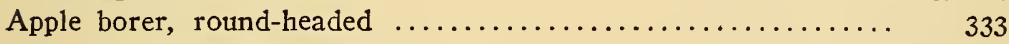

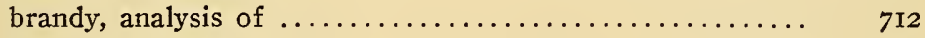

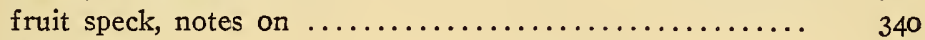

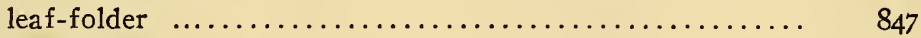

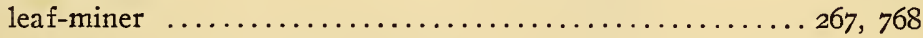

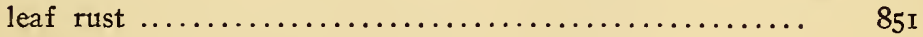

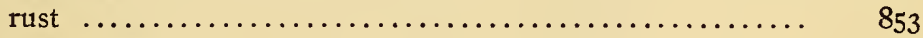

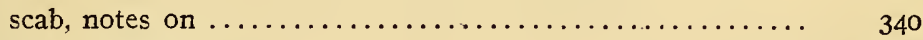

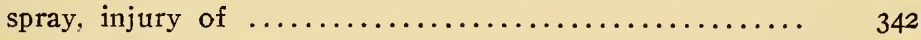

Armour Fertilizer Works :-

All soluble $\ldots \ldots \ldots \ldots \ldots \ldots \ldots \ldots \ldots \ldots \ldots \ldots 4,62,63,456,5$ I 8,5 I9

Ammoniated bone with potash .....4, 68, 69, 74, 75, 456, 522, 523

Bone, blood and potash $\ldots \ldots \ldots \ldots \ldots \ldots \ldots 4,58,59,456,5$ I 2,513

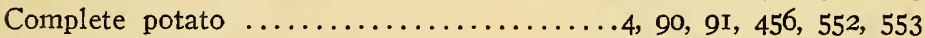

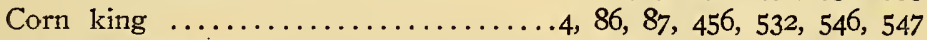

Fish and potash $\ldots \ldots \ldots \ldots \ldots \ldots \ldots \ldots \ldots, 60,6 \mathrm{r}, 456,522,523$

Fruit and root crop special $\ldots \ldots \ldots \ldots \ldots \ldots, 78,79,456,542,543$

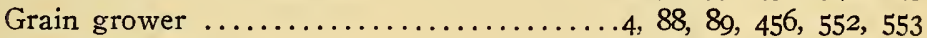

High grade potato ...............4, 82, 83, 456, 542, 543

Market garden $\ldots \ldots \ldots \ldots \ldots \ldots \ldots .48,59,74,75,456,514,5^{\mathrm{I} 5}$

Bone meal ....................4, 42, 43, 456, 494, 495

Artificial color in catsup ........................ 129

Ashes, analyses of lime-kiln .................. I 4, II5, 567,568

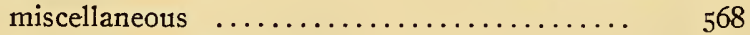

from household fires, composition of $\ldots \ldots \ldots \ldots \ldots \ldots . \ldots 6$

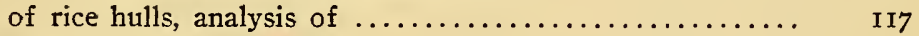

Asparagus, injury of, by smoke ................. 858

Assassin bug .............................. 822

"Available phosphoric acid," explanation of term .......... 33,483

Azalea, powdery mildew of $\ldots \ldots \ldots \ldots \ldots \ldots \ldots \ldots \ldots \ldots \ldots \ldots \ldots$

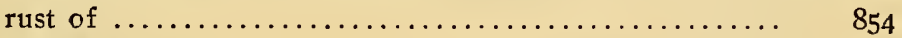

Bacillus Delphini ............................ 862

Bacterial spot of larkspur $\ldots \ldots \ldots \ldots \ldots \ldots \ldots \ldots \ldots \ldots \ldots \ldots \ldots$

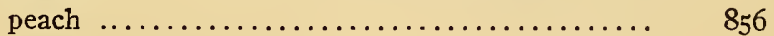

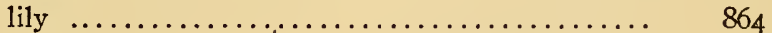

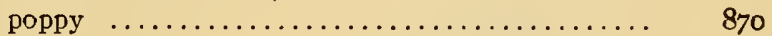

Bacterium pruni ............................. 856

tumefaciens ............................ 344 
Page,

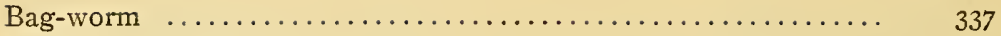

Baker, H. J., \& Bro.:-

Baker's Castor pomace ................. 30, 456, 48I, 482

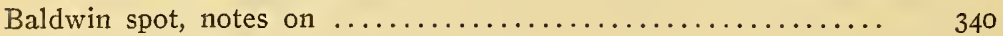

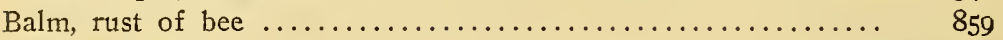

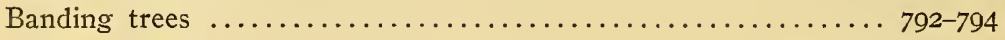

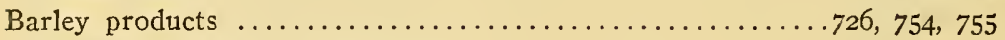

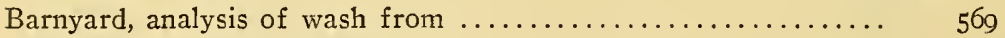

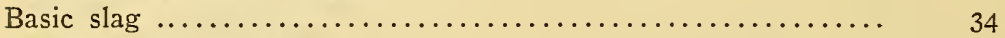

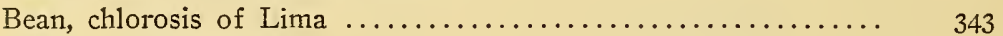

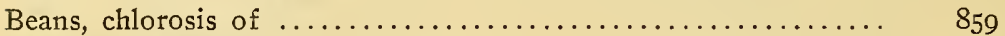

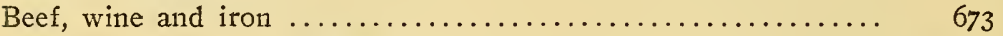

analyses of $\ldots \ldots \ldots \ldots \ldots \ldots \ldots \ldots \ldots, 676-679$

claims of manufacturers of ........... 682

discussion of analyses of $\ldots \ldots \ldots \ldots \ldots .680$

methods of analysis of $\ldots \ldots \ldots \ldots \ldots \ldots .685$

volume and selling price of $\ldots \ldots \ldots \ldots \ldots .675$

Beet pulp ......................................... 733

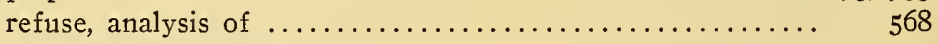

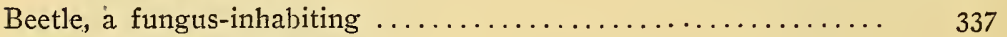

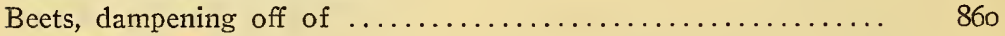

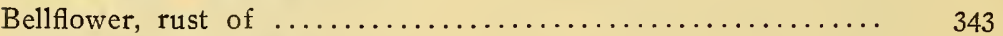

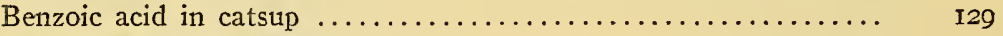

Berkshire Fertilizer Co.:-

Berkshire Ammoniated bone phosphate ....4, 72, 73, 456, 524, 525

Complete fertilizer .....4, 62, 63, 456, 514, 515, 516, 5I7

Grass special $\ldots \ldots \ldots \ldots \ldots \ldots .4,84,85,456,544,545$

Long Island special ...........56, 57, 456, 5I4, 5I5

Potato and vegetable phosphate ..4, 96, 97, 456, 550, 55I

Tobacco special ...4, 82, 83, 456, 530, 538, 539, 544, 545

Fine ground bone .........4, 4I, 42, 43, 456, 494, 495

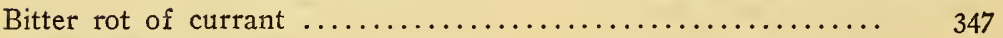

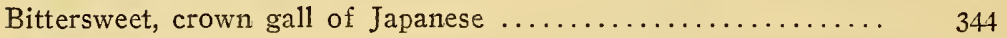

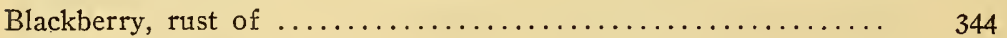

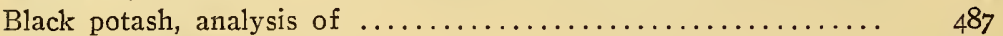

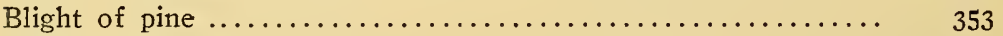

Board of control, report of $\ldots \ldots \ldots \ldots \ldots \ldots \ldots \ldots \ldots \ldots \ldots \ldots \ldots$ ix

Boardman, F. E. :-

Boardman's Complete fertilizer ........4, 56, 57, 456, 5I0, 5 II

Bohl, Valentine:-

Self-recommending fertilizer .........., 42, 43, 456, 494, 495

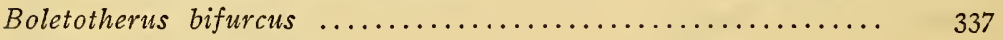

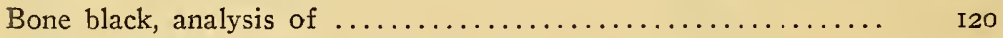

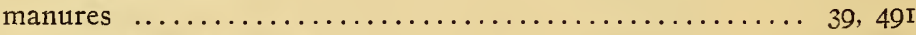

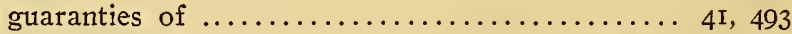

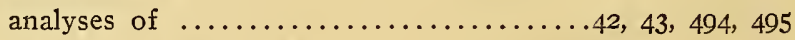

cost and valuation of $\ldots \ldots \ldots \ldots \ldots \ldots \ldots \ldots, 4 \mathbf{I}, 493$ 
Bone, method of valuation of 40, 493

Borax 710

Borer, maple 336

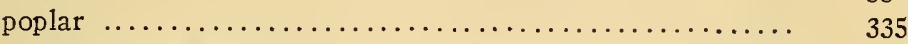

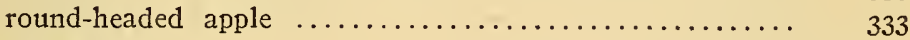

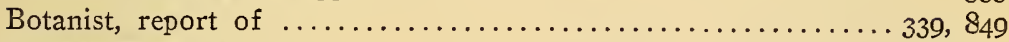
Bowker Fertilizer Co.:-

Castor pomace .................... 30, 456, 481, 482 Muriate of potash $\ldots \ldots \ldots \ldots \ldots \ldots \ldots \ldots .36,37,456,488,489$ Nitrate of soda $\ldots \ldots \ldots \ldots \ldots \ldots \ldots \ldots \ldots \ldots$, I3, I4, 456, 465 Bowker's Acid phosphate ............ 32, 33, 457, 483, 484 Complete alkaline tobacco grower .....4, I04, I05, 457, $55^{8}, 559$

Corn phosphate 4 , 100, I0I, $457,554,555$ Early potato manure $\ldots \ldots \ldots \ldots . .6,90,91,457,546,547$ Farm and garden phosphate ............. 72,73 Fine ground fish ........... 44, 47, 457, 498, 499 Fisherman's brand fish and potash $5,68,69,457,520,521$ Fresh ground bone ..........5, 42, 43, 457, 494, 495 Gloucester fish and potash ......5, 72, 73, 457, 526, 527 Hill and drill phosphate ........5, 66, 67, 457, 524, 525 Lawn and garden dressing ....5, I00, I0I, $457,554,555$ Market garden fertilizer .......5, 64, 65, 457, 520, 521 Middlesex special .................. 70 , 7 I Potato and vegetable fertilizer $\ldots .5,94,95,457,550,55$ I Potato and vegetable phosphate $\ldots 5,98,99,457,554,555$ Pure unleached Canada hard wood ashes ...5, II2, II3, $457,462,564,565$

Sure crop phosphate $\ldots \ldots \ldots \ldots .5,72,73,457,526,527$ Tobacco ash elements .......5, I04, 105, 457, 558, 559 starter $\ldots \ldots \ldots \ldots \ldots \ldots, 90,91,457,548,549$ XX bone ................ 42, 43, 457, 494, 495 Stockbridge Special complete manure for corn and grain $. .5,86,87$,

Special complete manure for potatoes and $457,540,54 \mathrm{I}$ vegetables $\ldots \ldots \ldots \ldots \ldots \ldots 5,88,89,457,540,54 \mathrm{I}$ Special complete manure for top dressing and for forcing $\ldots \ldots \ldots \ldots \ldots \ldots, 84,85,457,538,539$

Brainard, H. K. :-

Tobacco manure ..........5, 82, 83, 457, 538, 539

"High Grade" ........................... 56, 57

Brewers' grains, dried ..............177, 204, 205, 727, 754, 755

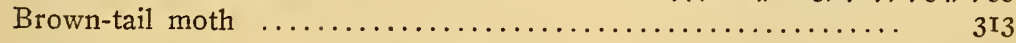

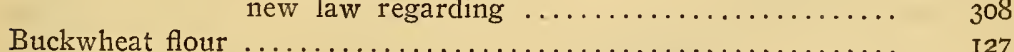


Buffalo Fertilizer Co. :-

Page.

Buffalo Tobacco producer ..........5, 78, 79, 100, I0I, 457, 462 Celery and potato special $\ldots \ldots 5,77,96,97$, roo, IOI, $457,540,54 \mathrm{I}$ Farmers' choice ............5, 48, 49, 50, 72, 73, 457, 5I4, 5I5 Fish guano $\ldots \ldots \ldots \ldots \ldots \ldots \ldots \ldots \ldots . \ldots \ldots, 70,71,457,512,513$ Garden truck ....................... 48, 49, 50,62, 63 H. G. manure (or fertilizer) ........ 100, I01, 457, 501, 512, 513 Ideal wheat and corn $\ldots \ldots \ldots \ldots \ldots 5,76,77,96,97,457,538,539$ Top dresser $\ldots \ldots \ldots \ldots \ldots \ldots, 48,49,66,67,72,73,457,510,5$ II Vegetable and potato $\ldots \ldots .5,76,77,94,95,98,99,457,538,539$ Bone meal .................. 4I, 42, 43, 457, 494, 495

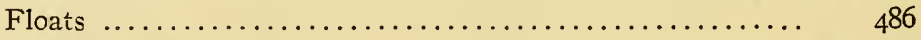

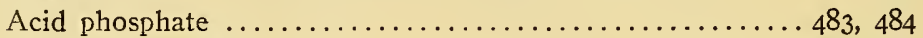

Muriate of potash $\ldots \ldots \ldots \ldots \ldots \ldots \ldots \ldots \ldots, 36,37,488,489$

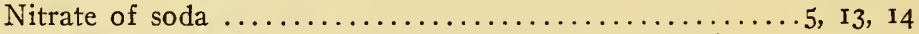

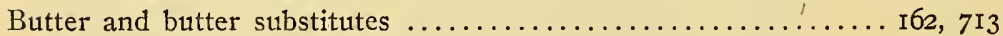

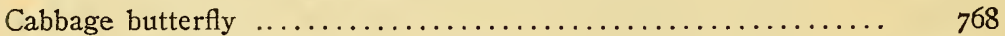

maggot, treatment to prevent $\ldots \ldots \ldots \ldots \ldots \ldots \ldots \ldots \ldots 832-837$

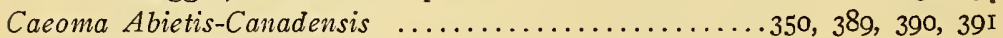

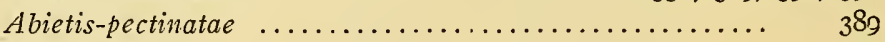

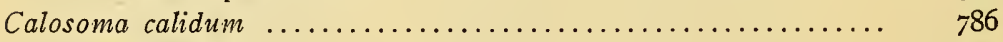

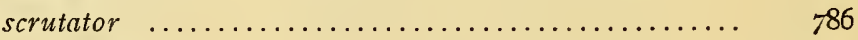

Calyptospora columnaris ........................... $39 \dot{3}$

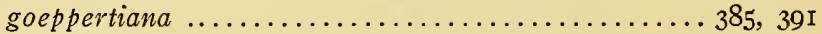

Canker worm .............................. 769,77796

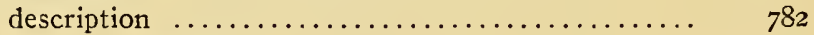

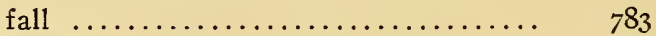

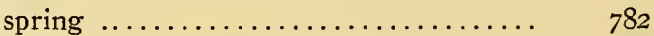

natural enemies ......................... $\quad 786$

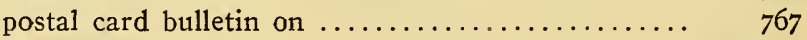

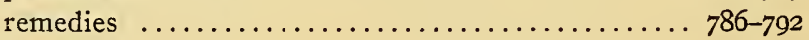

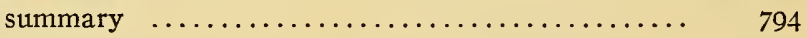

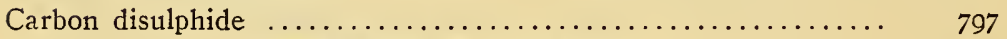

used against peach sawfly ............. 292

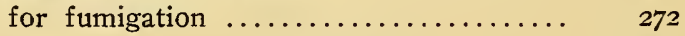

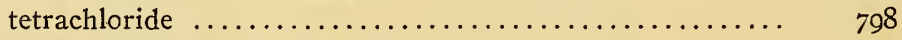

used for fumigation $\ldots \ldots \ldots \ldots \ldots \ldots \ldots \ldots, \quad 275$

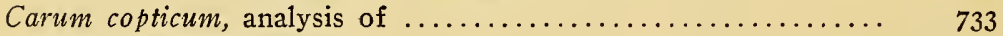

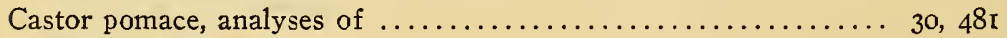

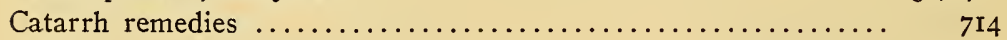

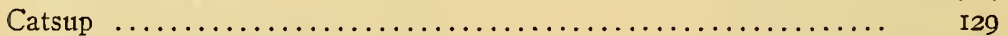

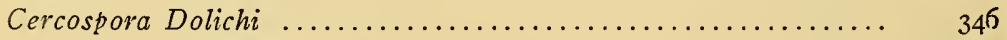

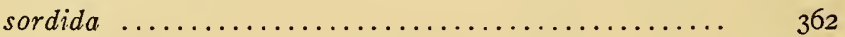

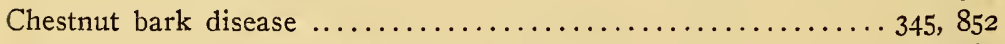

character of $\ldots \ldots \ldots \ldots \ldots \ldots \ldots \ldots \ldots . .6 \% \ldots$

distribution in Connecticut $\ldots \ldots \ldots \ldots \ldots . \quad 88 \mathrm{r}$

future outlook ............... 889 


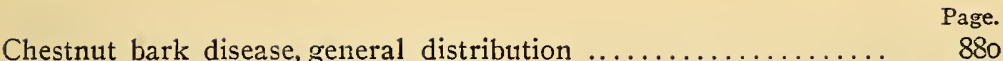

general statement concerning $\ldots \ldots \ldots \ldots \ldots \quad 879$

relation to weather $\ldots \ldots \ldots \ldots \ldots \ldots \ldots . \quad 887$

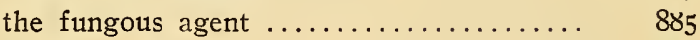

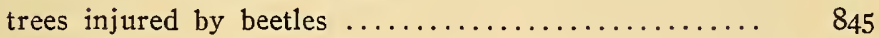

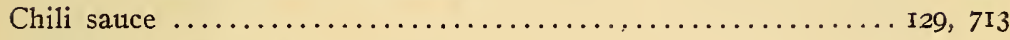

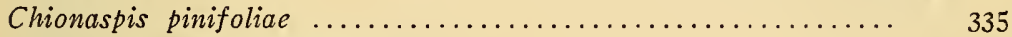

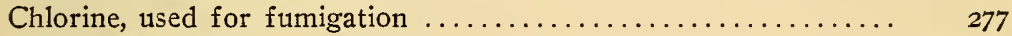

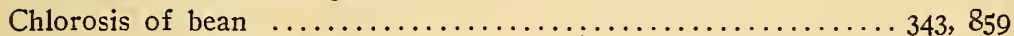

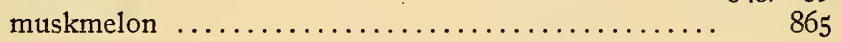

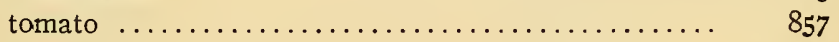

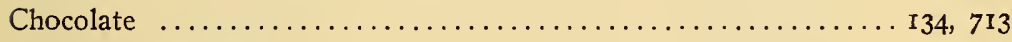

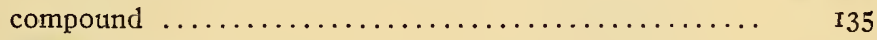

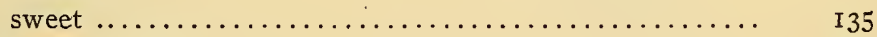

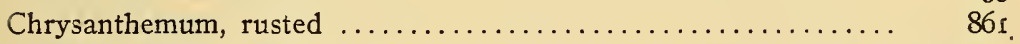

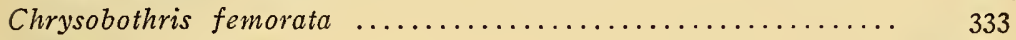

Chrysomyxa Abietis ............................... 39 I

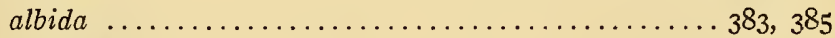

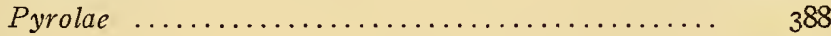

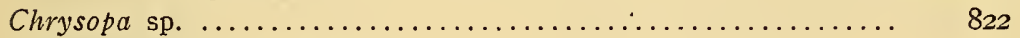

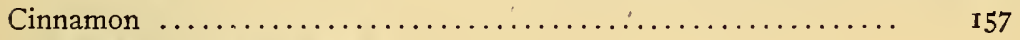

Clark Seed Co., Everett B.:-

Clark's Special mixture for general use $5,54,56,57,457,500,501$,

Special Io\% brand ...........60, 6I, 457, 510, 5I I, 526, 527

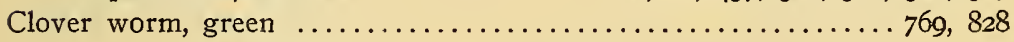

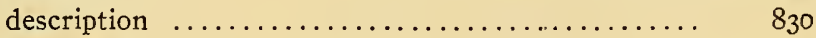

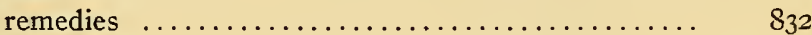

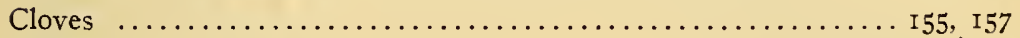

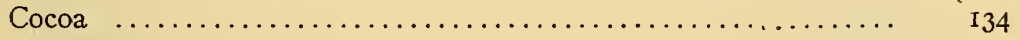

Coe-Mortimer Co.:-

Genuine Peruvian guano, Chincha grade 6, 60, 61, 457, 500, 508, 514,

$515,528,529$

Lobos grade ..............6, 60, 6I

Gold brand excelsior guano $\ldots \ldots \ldots \ldots .5,50,66,67,457,518,5$ I9

H. G. ammoniated bone superphosphate ....5, 70, 7I, 457, 516, 517

Peruvian market garden fertilizer ...........6, 48, 50, 68, 69

Peruvian tobacco fertilizer .............6, $75,84,85,88,89$

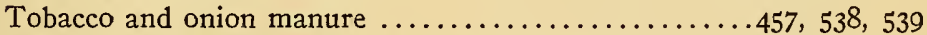

E. Frank Coe's Celebrated special potato fertilizer 5, 94, 95, 457,

536,537

New Englander corn and potato fertilizer 5, 98, 99,

$457,550,55$ 工

Peruvian vegetable grower $6,50,62,63,457,536$,

Red brand excelsior guano $5,48,50,64,65,458$, 
Coe-Mortimer Co., cont'd-

E. Frank Coe's XXX pure ground bone ...6, 42, 43, 458, 494, 495

H. G. sulphate of potash $\ldots \ldots \ldots \ldots \ldots \ldots \ldots \ldots \ldots \ldots 488,489$

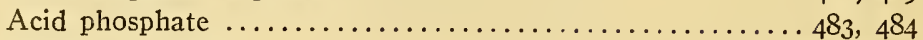

Muriate of potash .....................488, 489, 490

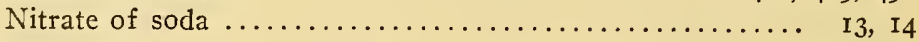

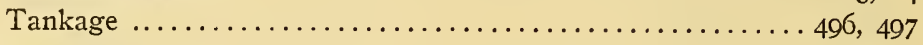

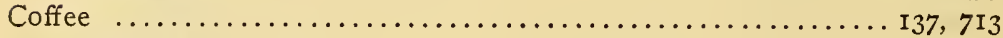

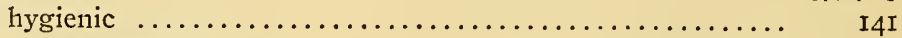

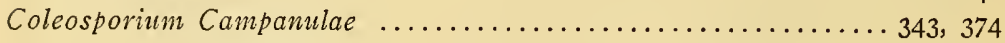

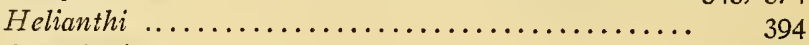

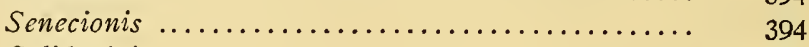

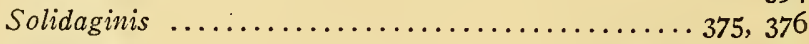

Vernoniae ......................... 380

Commercial feeds, average composition, digestibility and selling

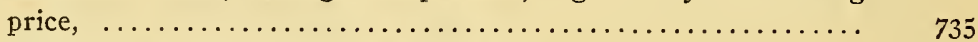

Commercial feeds, containing weed seeds $\ldots \ldots \ldots \ldots \ldots \ldots \ldots . \ldots \ldots 736$

Connecticut Fat Rendering and Fertilizing Corporation:-

Tankage ..................... 4I, 45, 458, 496, 497

Connecticut Valley Orchard Co.:-

C. V. O. Co.'s H. G. special ...6, 56, 57, 74, 75, 458, 508, 510, 5 II,

$526,527,528,529$

Contents, table of

Cooper's Glue Factory, Peter:-

Pure bone dust .................6, 42, 43, 458, 494, 495

Corn and oat feeds $\ldots \ldots \ldots \ldots \ldots \ldots \ldots \ldots . \ldots 178,204,205,728,754-757$

breeding at present in progress .................. 400

practical use of Mendelism in ............. 407

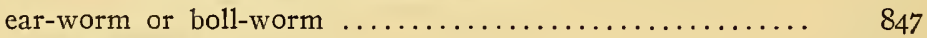

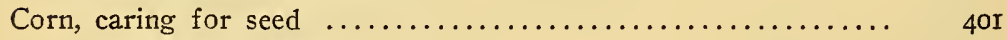

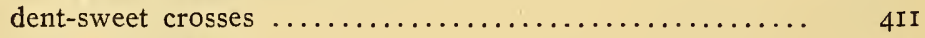

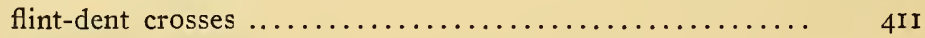

flint-sweet crosses $\ldots \ldots \ldots \ldots \ldots \ldots \ldots \ldots \ldots \ldots \ldots \ldots \ldots, \quad 4$ IIO

germination tests $\ldots \ldots \ldots \ldots \ldots \ldots \ldots \ldots \ldots \ldots \ldots \ldots \ldots, 403$

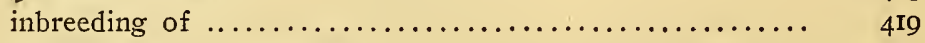

inheritance of characters in $\ldots \ldots \ldots \ldots \ldots \ldots \ldots \ldots \ldots, 407$

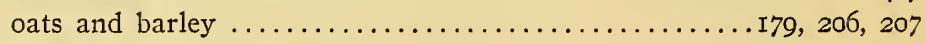

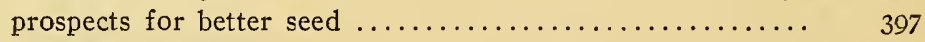

purple-white crosses $\ldots \ldots \ldots \ldots \ldots \ldots \ldots \ldots \ldots \ldots \ldots \ldots, 4$ 4I3

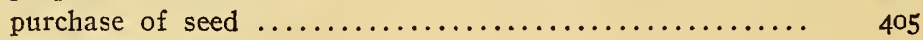

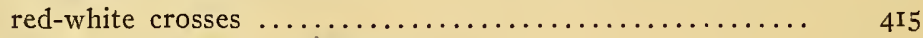

summary of law of inheritance $\ldots \ldots \ldots \ldots \ldots \ldots \ldots \ldots \ldots, 4 \mathrm{I} 6$

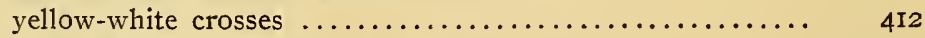

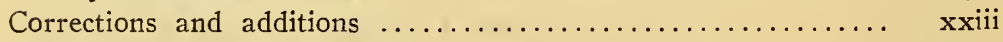

Cotton hull ashes, analyses of $\ldots \ldots \ldots \ldots \ldots \ldots \ldots \ldots \ldots \ldots$ I09, 560

"Cotton hulls," analyses of charred .................... IIo

Cotton seed meal .............I5, I69, I92, I93, 466, 717, 742, 743 
Cotton seed meal, composition and value of $\ldots \ldots \ldots \ldots \ldots \ldots$ I9, 469

guaranties .................... I8, 468

standard classification of $\ldots \ldots \ldots \ldots \ldots \ldots . \ldots \ldots, 467$

tables of analyses of $\ldots \ldots \ldots \ldots \ldots \ldots 22-29,470-480$

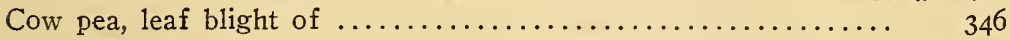

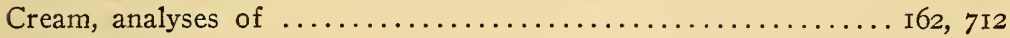

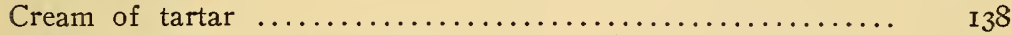

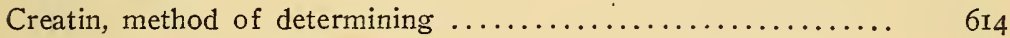

Creatinin, method of determining $\ldots \ldots \ldots \ldots \ldots \ldots \ldots \ldots \ldots .6 \ldots \ldots$

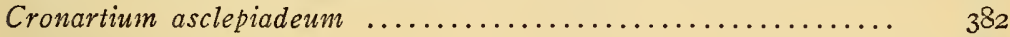

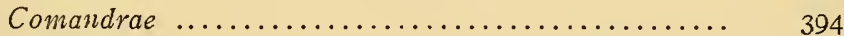

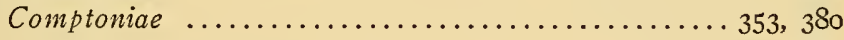

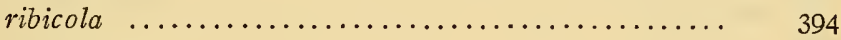

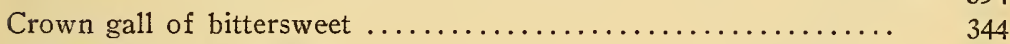

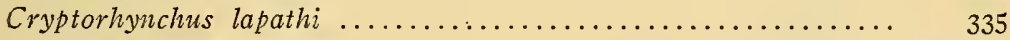

Cucumber beetle, striped $\ldots \ldots \ldots \ldots \ldots \ldots \ldots \ldots \ldots \ldots \ldots . \ldots \ldots, 807$

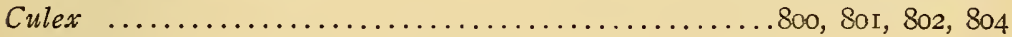

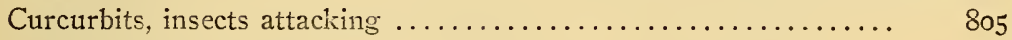

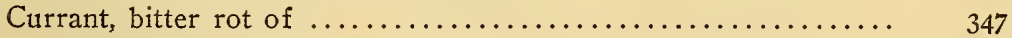

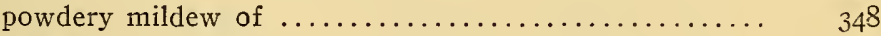

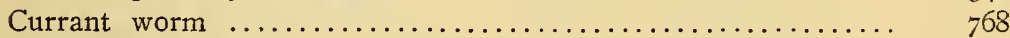

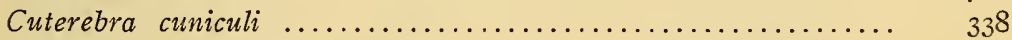

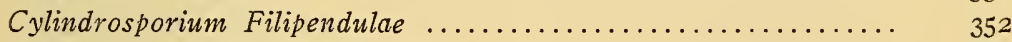

Dahlia, dry weather injury of $\ldots \ldots \ldots \ldots \ldots \ldots \ldots \ldots \ldots . \ldots \ldots \ldots$ 86.

Dairy and stock feeds, proprietary .......... $80,206-209,729,756-759$

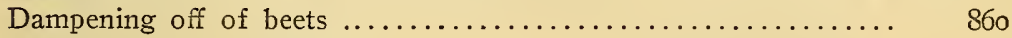

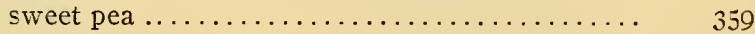

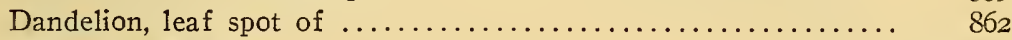

Dennis, George L. :-

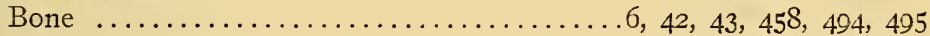

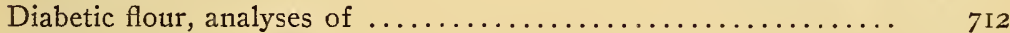

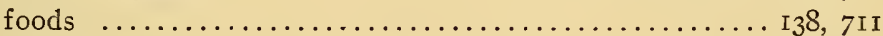

Diabrotica xii-punctata .................................... 805, 809

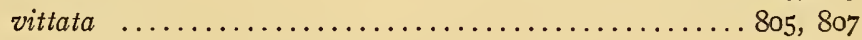

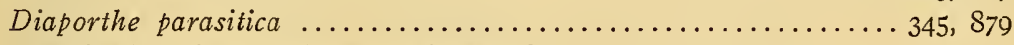

Dissolved rock phosphate, analyses of $\ldots \ldots \ldots \ldots \ldots \ldots \ldots \ldots \ldots \ldots \ldots, 483$

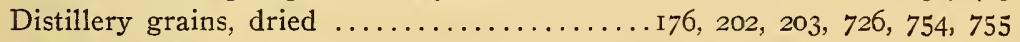

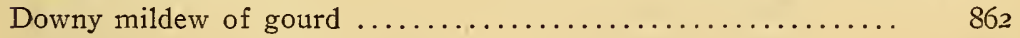

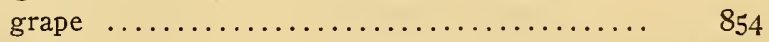

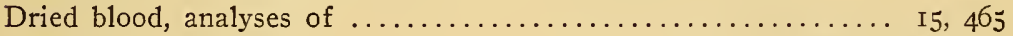

brewers' grains ................ $77,204,205,727,754,755$

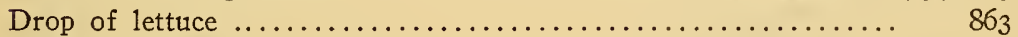

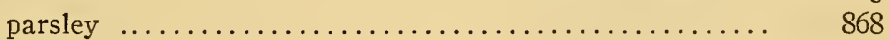

Drugs, summary of results of examination of $\ldots \ldots \ldots \ldots \ldots \ldots 7$ I5, 716

Eldredge, T. H.:-

Eldredge's Special fish and potash fertilizer 6, 70, $7 \mathrm{I}, 458,524,525$ superphosphate $\ldots \ldots \ldots 6,72,73,458,524,525$. 
Page.

Elm leaf beetle $337,767,769,815-828$

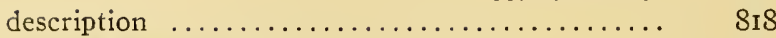

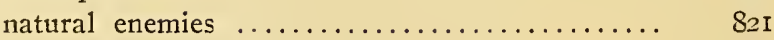

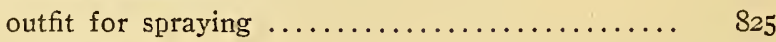

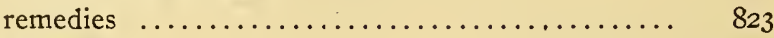

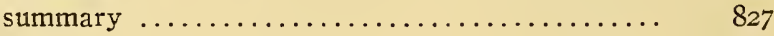

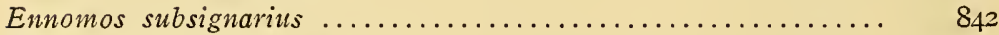

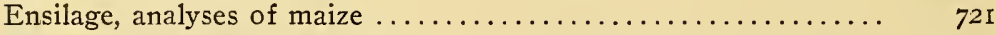

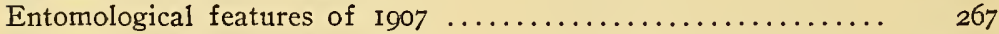

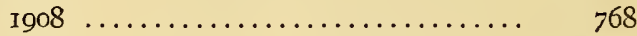

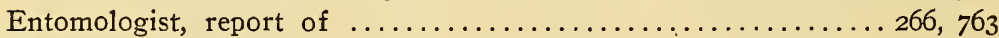

Epilachna borealis ...................................... Sio

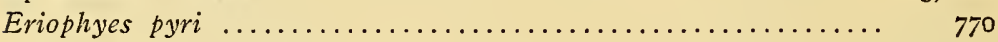

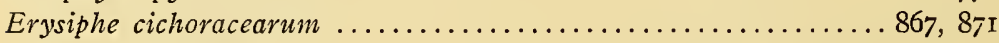

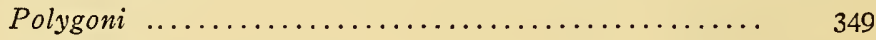

Essex Fertilizer Co. :-

Essex A I Superphosphate $\ldots \ldots \ldots \ldots \ldots \ldots \ldots \ldots \ldots, 72,73$

Complete, potatoes, roots and vegetables $8,80,8 \mathrm{I}, 458,530$,

Corn, grain and grass $\ldots \ldots \ldots \ldots 8,82,83,458,531,548,549$

Grass and top dressing $\ldots \ldots \ldots .8,80,8 \mathrm{I}, 458,532,550,55 \mathrm{I}$

Market garden and potato manure ...8, 92, 93, 458, 552, 553

Special tobacco manure $\ldots \ldots \ldots \ldots \ldots 8,78,79,458,540,54 \mathrm{I}$

Tobacco starter ...................... 90 , 91

and grower $\ldots \ldots \ldots \ldots \ldots \ldots 48,548,549$

XXX fish and potash .......... $64,65,458,520,521$

Dry ground fish .............. 44, 47, 458, 498, 499

Ground bone $\ldots \ldots \ldots \ldots \ldots \ldots \ldots \ldots \ldots \ldots \ldots 458,494,495$

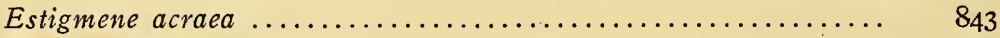

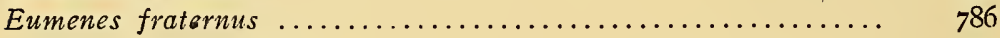

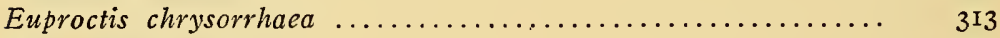

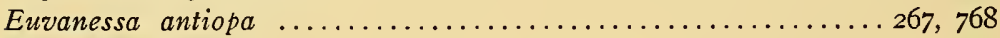

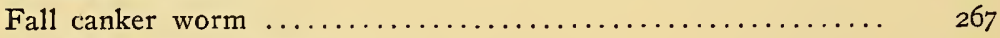

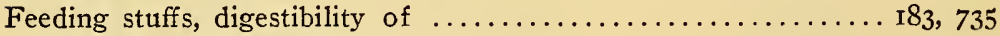

explanations of analyses of $\ldots \ldots \ldots \ldots \ldots \ldots \ldots . \quad 166$

law regulating sale of $\ldots \ldots \ldots \ldots \ldots \ldots \ldots \ldots \ldots, \quad 16_{5}$

sampling of commercial $\ldots \ldots \ldots \ldots \ldots \ldots \ldots \ldots, \quad \mathbf{1 6 6}$

uses of analyses of $\ldots \ldots \ldots \ldots \ldots \ldots \ldots \ldots \ldots, \quad 168$

weight of one quart of various $\ldots \ldots \ldots \ldots \ldots \ldots$ I89, 762

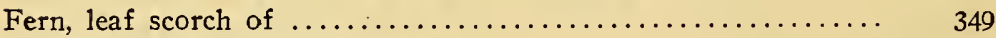

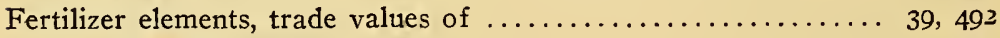

law, observance of $\ldots \ldots \ldots \ldots \ldots \ldots \ldots \ldots \ldots \ldots \ldots, 2,454$

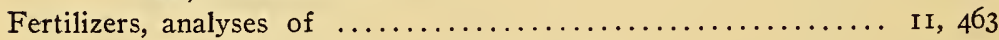

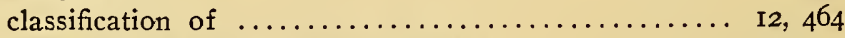

duties of manufacturers and dealers ............ I, 453

method of valuation of $\ldots \ldots \ldots \ldots \ldots \ldots \ldots \ldots \ldots \ldots \ldots \ldots \ldots, 491$

on which analysis fees have been paid, list of $\ldots \ldots \ldots \quad 3,455$ 
Fertilizers, sampling and collection of

selection and purchase of commercial ........... 52, 503

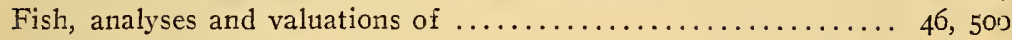
of dry ground $\ldots \ldots \ldots \ldots \ldots \ldots \ldots \ldots \ldots 4,47,496,499$

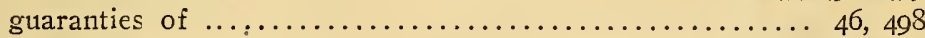

Flax feed and flax flakes .............

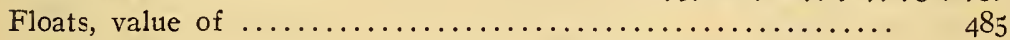

Food products, summary of results of examination of $\ldots \ldots \ldots 715,716$

work in $1907 \ldots \ldots \ldots \ldots \ldots \ldots \ldots \ldots \ldots \ldots$

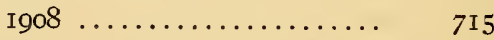

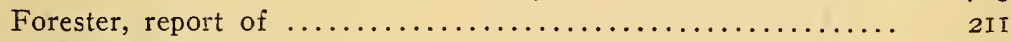

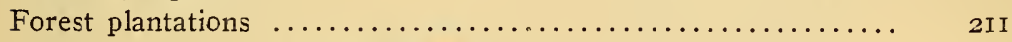

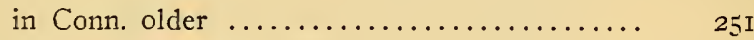

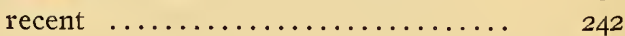

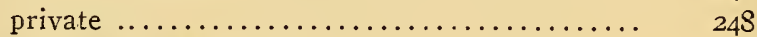

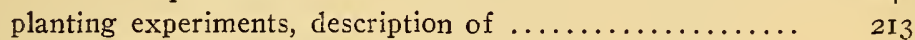

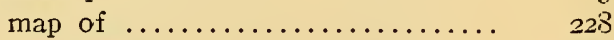

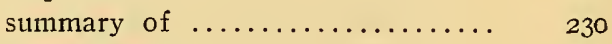

visitor's guide to $\ldots \ldots \ldots \ldots \ldots \ldots . \ldots \ldots$

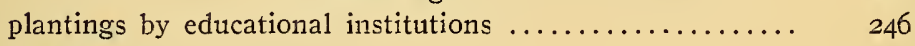

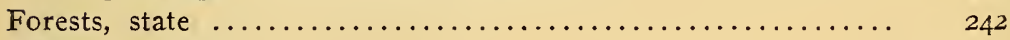

Frisbie, L. T., Co. :-

Frisbie's Fine bone meal ............6, 42, 43, 458, 494, 495

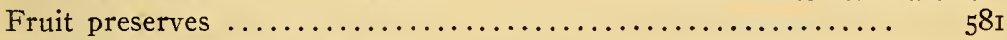

Fumigating nursery stock for San José scale ............. 796

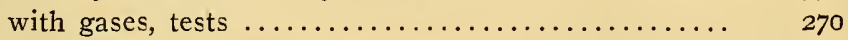

Fungous diseases, of 1907 , notes on $\ldots \ldots \ldots \ldots \ldots \ldots \ldots \ldots \ldots . \ldots \ldots$

of 1908 , notes on $\ldots \ldots \ldots \ldots \ldots \ldots \ldots \ldots \ldots . \ldots \ldots \ldots \ldots$

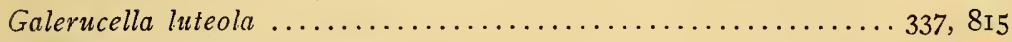

Gases for fumigation, tests of $\ldots \ldots \ldots \ldots \ldots \ldots \ldots \ldots \ldots \ldots \ldots \ldots \ldots \ldots \ldots \ldots \ldots$

Germofert Mfg. Co. :-

Germofert Patented fruit and flower fertilizer ......458, 534, 535

General fertilizer ................458, 5 I2, 5I3

Vegetable fertilizer ................458, 534, 535

Natural plant food ................... 528, 529

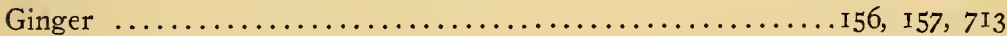

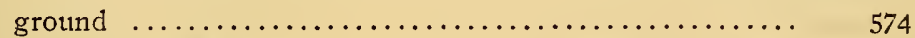

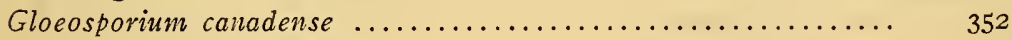

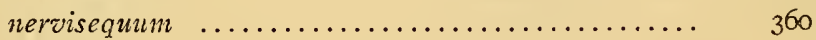

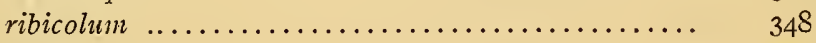

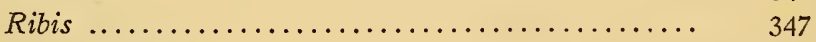

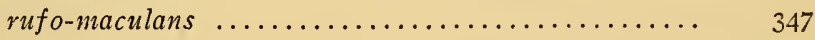

Gluten feed $\ldots \ldots \ldots \ldots \ldots \ldots \ldots \ldots \ldots \ldots \ldots$ I 72 , I98-20I, $722,748-751$

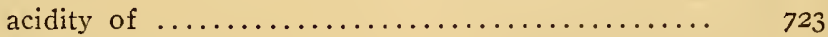

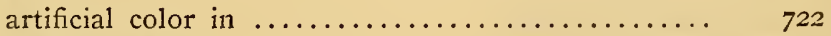

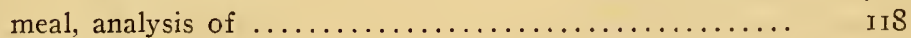

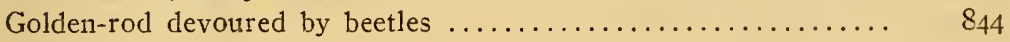


Goodsell, W. O.:-

Page.

Special grass mixture $\ldots \ldots \ldots \ldots \ldots \ldots \ldots \ldots \ldots 458,532,534,535$

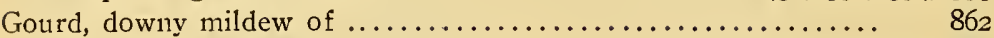

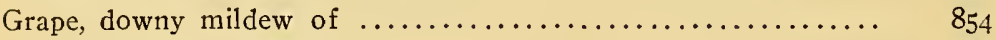

powdery mildew of $\ldots \ldots \ldots \ldots \ldots \ldots \ldots \ldots \ldots \ldots \ldots \ldots, \quad 855$

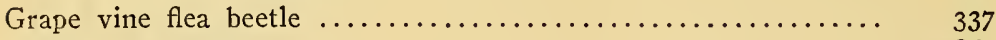

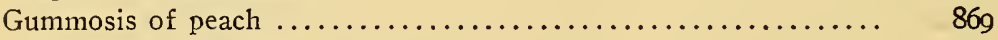

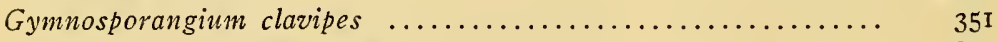

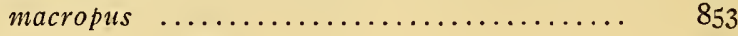

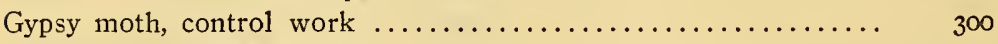

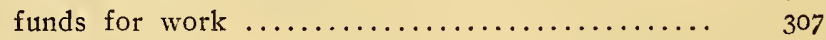

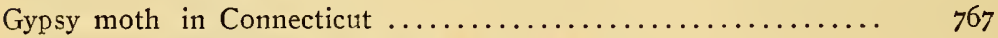

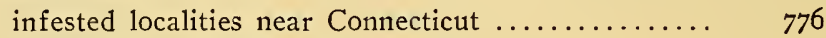

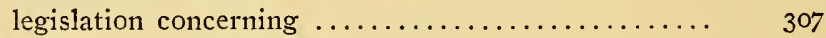

in other states $\ldots \ldots \ldots \ldots \ldots \ldots \ldots . .310$

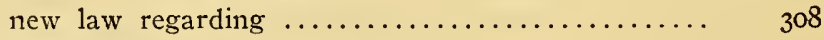

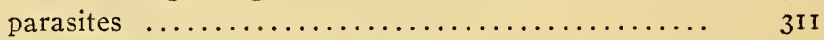

present condition at Stonington ............. 776

scouting for egg-masses-Eastern Connecticut ..... 774

Hartford ............. 774

New Haven to Hartford $\quad \mathbf{7 7 5}$

Stonington $\ldots \ldots \ldots \ldots \ldots . \quad 773$

statistics ........................ 306

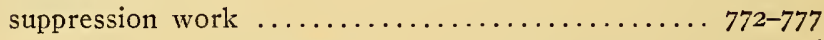

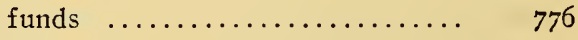

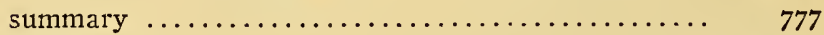

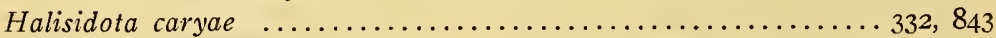

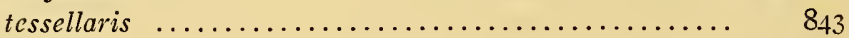

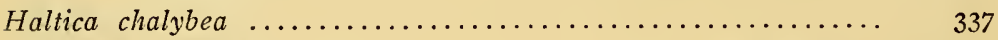

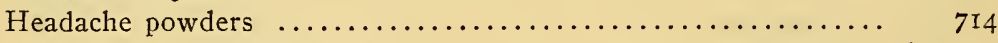

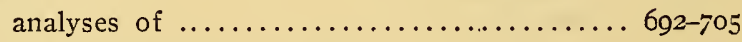

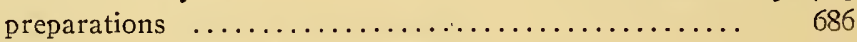

methods of analysis of $\ldots \ldots \ldots \ldots \ldots .688$

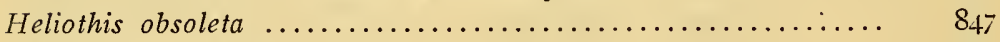

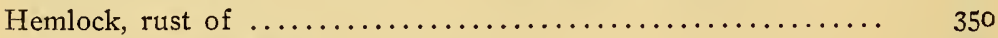

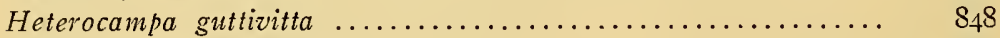

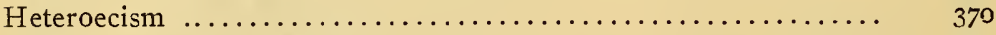

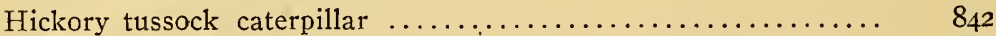

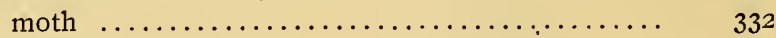

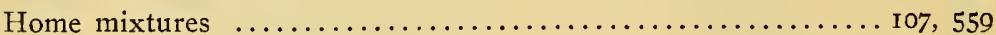

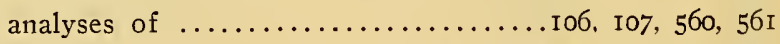

Hominy feed $\ldots \ldots \ldots \ldots \ldots \ldots \ldots \ldots \ldots \ldots \ldots$ I $74,200-203,725,750-753$

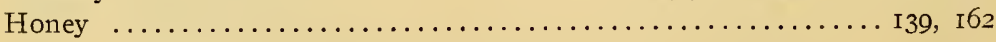

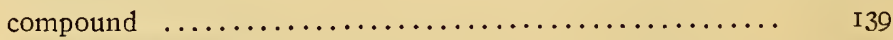

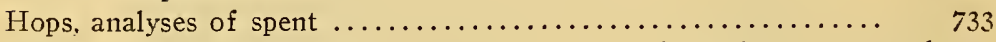

Horse feeds, proprietary ............. $80,206,207,729,756,757$

"Humus Fertilizer," analysis of $\ldots \ldots \ldots \ldots \ldots \ldots \ldots \ldots \ldots \ldots . \quad 570$ 
Hydrocyanic acid gas, used for fumigating

Ichneumon utilis

"I. M. P. Plant Food," analysis of ................... II

Indigo, powdery mildew of false $\ldots \ldots \ldots \ldots \ldots \ldots \ldots \ldots \ldots \ldots . \ldots \ldots \ldots$

Infant and invalid foods, methods of analysis of $\ldots . \ldots . \ldots .601$

tables of analyses of $\ldots \ldots \ldots \ldots \ldots 602-605$

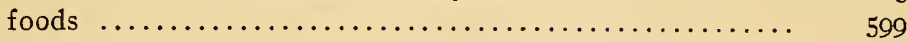

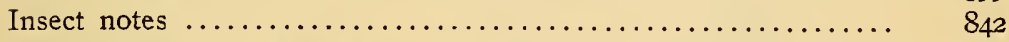

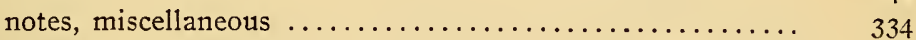

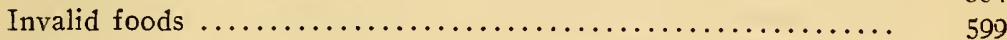

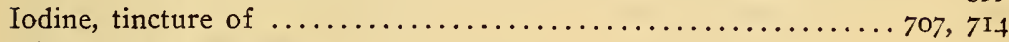

Ithycerus noveboracensis $\ldots \ldots \ldots \ldots \ldots \ldots \ldots \ldots \ldots \ldots \ldots \ldots \ldots \ldots \ldots \ldots, \quad 845$

James, Ernest L. :-

James' Bone phosphate ............6, 74, 75, 458, 526, 527

Ground bone $\ldots \ldots \ldots \ldots \ldots \ldots \ldots \ldots, 42,43,458,494,495$

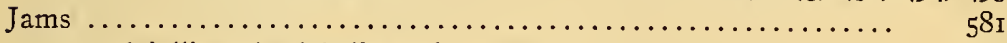

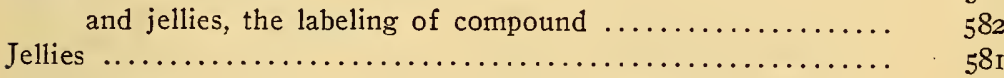

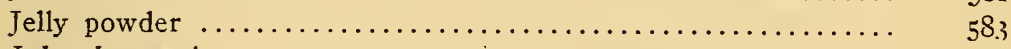

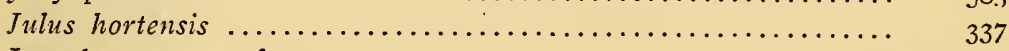

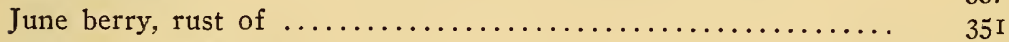

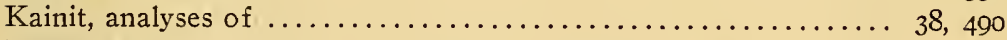

Kelsey, E. R. :

Bone, fish and potash ..6, 56, 57, 74, 75, 458, 509, 510, 5II, 526, 527

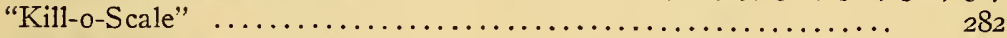

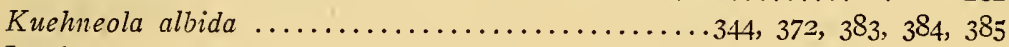

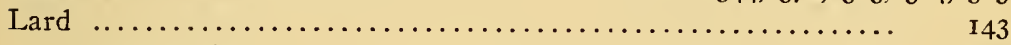

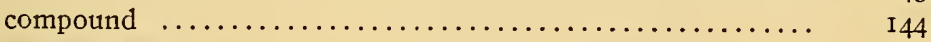

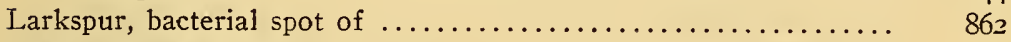

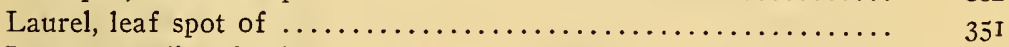

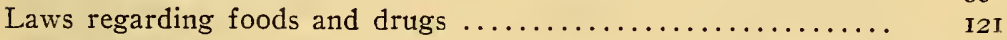

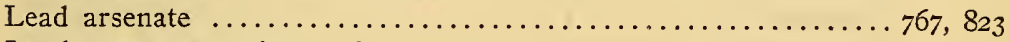

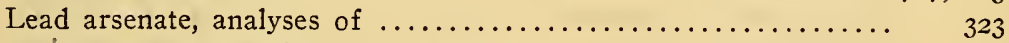

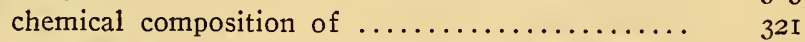

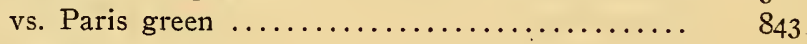

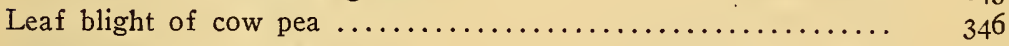

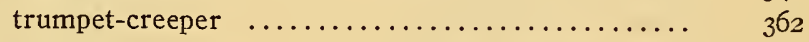

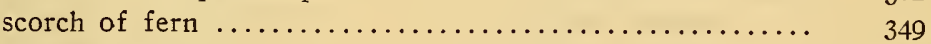

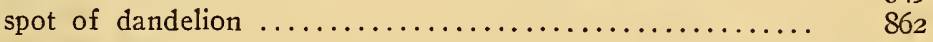

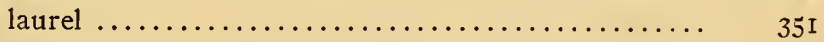

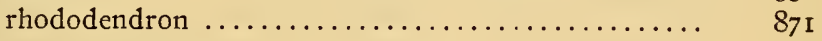

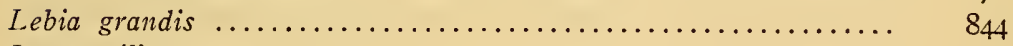

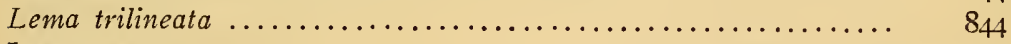

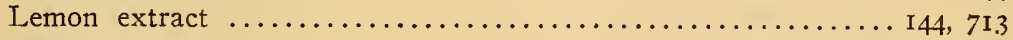

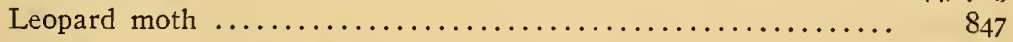

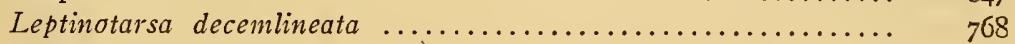

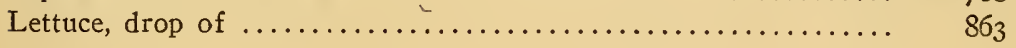


Liebig process for meat extract $\ldots \ldots \ldots \ldots \ldots \ldots \ldots \ldots \ldots \ldots . \ldots \ldots 6 . \ldots \ldots$

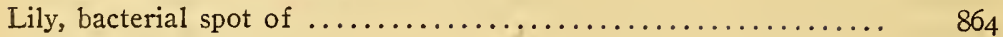

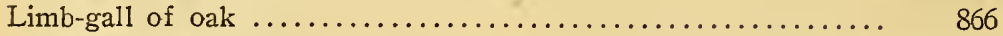

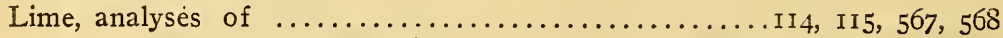

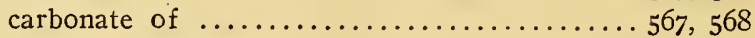

Lime and sulphur washes, various kinds .............. 840

Linseed meal ..................170, 192, 193, 718, 742, 743

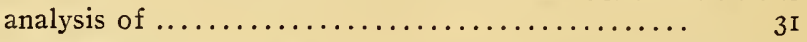

Lister's Agricultural Chemical Works:-

Lister's Ammoniated dissolved bone phosphate 6, 64, 65, 458, 514, 515 Potato manure ........6, 82, 83, 458, 530, 53I, 538, 539

Special corn ..........6, 86, 87, 458, 552, 553, 554, 555 potato $\ldots \ldots \ldots \ldots \ldots \ldots \ldots \ldots, 6,86,87,458,462$ tobacco $\ldots \ldots \ldots \ldots \ldots 6,96,97,458,531,544,545$ Standard pure bone superphosphate of lime $6,62,63,458$, 516,517

Success fertilizer ............6, 66, 67, 458, 522, 523 Animal bone and potash $\ldots \ldots \ldots \ldots \ldots \ldots \ldots 458,524,525$ Bone meal ........................6, 42, 43 Celebrated ground bone acidulated ........458, 494, 495

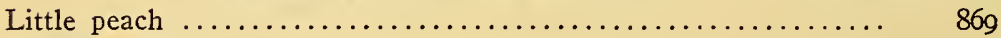

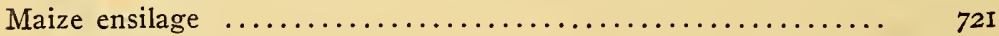

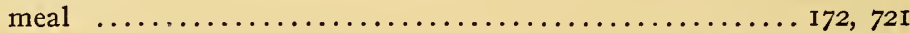

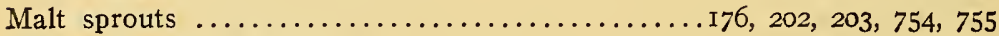

Manchester, E., \& Sons:-

Manchester's formula ...........6, 56, $57,459,500,5$ IO, 5II

Manure, analysis of shredded $\ldots \ldots \ldots \ldots \ldots \ldots \ldots \ldots \ldots \ldots$ I 6

Mapes F. \& P. G. Co.:-

Average soil complete manure ........6, 58, 59, 459, 514, 515

Cereal brand $\ldots \ldots \ldots \ldots \ldots \ldots \ldots \ldots \ldots \ldots .6,98,99,459,554,555$

Complete manure "A" brand ..........6, 70, 7I, 459, 522, 523

Corn manure ...................6, 92, 93, 459, 552, 553

Economical potato manure ...........6, 84, 85, 459, 544, 545

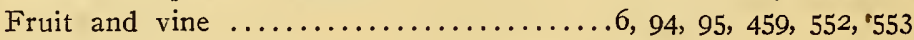

Potato manure .................. 86, 87, 459, 542, 543

Seeding down manure ...............6, 80, 81, 459, 536, 537

Tobacco ash constituents ...........6, I04, I05, 459, 558, 559 manure, wrapper brand .......6, 104, 105, 459, 558, 559 starter, improved ............6, 84, 85, 459, 558, 559

Top dresser, improved, full strength ......7, 56, 57, 459, 5I0, 5 I I half " $\quad \ldots \ldots .7,66,67,459,516,5$ I7

Vegetable manure, or complete manure for light soils $7,60,61,459$,

Dissolved bone $\ldots \ldots \ldots \ldots \ldots \ldots \ldots \ldots \ldots, 56,57,459,512,5$ I 3

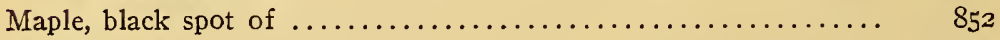

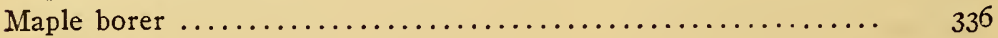

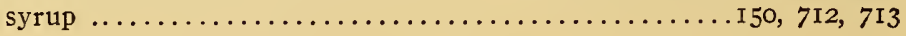


Marine mud, analysis of

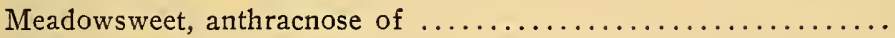

analyses of fluid ...................... 642

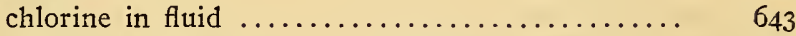

claims of manufacturers of fluid ........... 647 discussion of claims of the manufacturers of .... 634

fluid

fluid, statement of brands found pure, misbranded

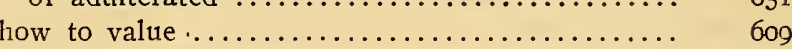

methods of analysis of $\ldots \ldots \ldots \ldots \ldots \ldots \ldots \ldots .6 \ldots \ldots$

net weight and selling price of $\ldots \ldots \ldots \ldots \ldots \ldots .6 \ldots \ldots$

nitrogenous constituents of fluid ............. 644

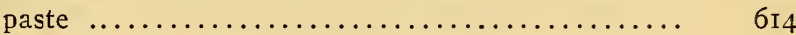

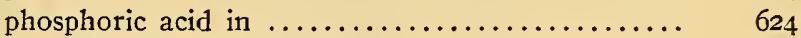

physiological effect of $\ldots \ldots \ldots \ldots \ldots \ldots \ldots \ldots, 607$

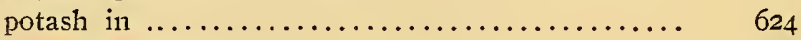

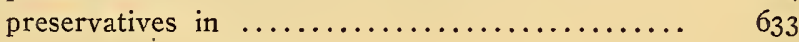

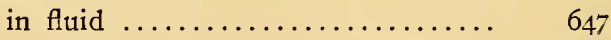

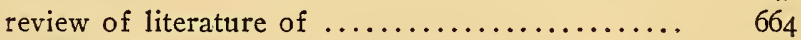

sodium chlorid in ...................... 622

standards of composition of ............... 609

statement of brands found pure, misbranded or adulterated .......................... 639

table of chemical analyses of $\ldots \ldots \ldots \ldots \ldots \ldots 6$ 6I8-62I

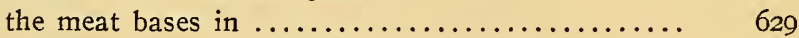

fluid $\ldots \ldots \ldots \ldots \ldots \ldots \ldots \ldots \ldots \ldots \ldots \ldots \ldots \ldots \ldots$

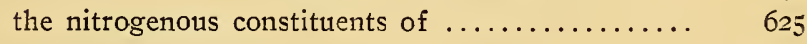

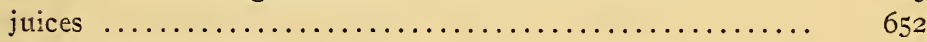

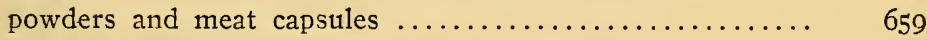

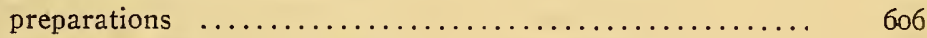

fluid proprietary $\ldots \ldots \ldots \ldots \ldots \ldots \ldots \ldots \ldots, 655$

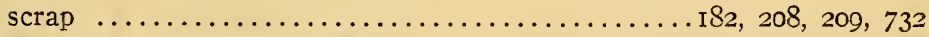

Melampsorella Caryophyllaceum $\ldots \ldots \ldots \ldots \ldots \ldots \ldots \ldots \ldots \ldots . \ldots . \ldots \ldots$

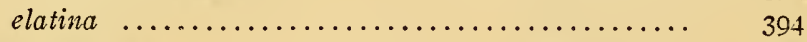

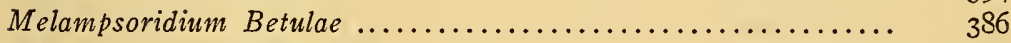

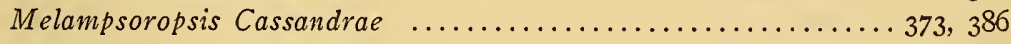

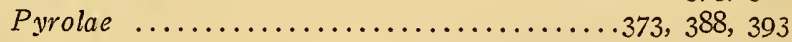

Melittia satyriniformis ....................... 805,805

Mendelism in corn breeding, practical use of .............. 406

Mendel's law of inheritance ........................ 408

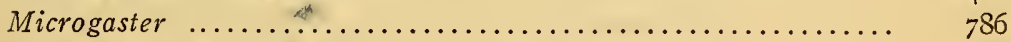

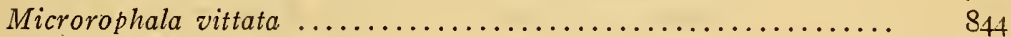

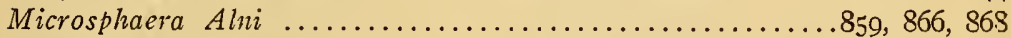

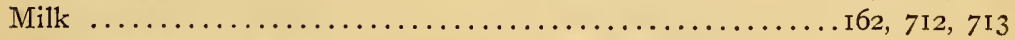

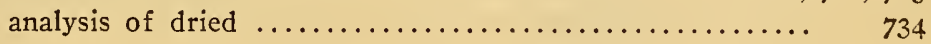


Page.

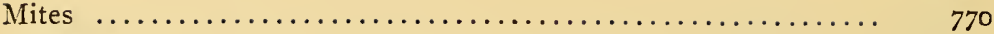

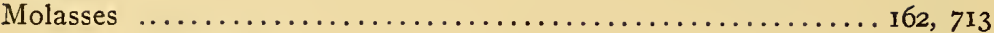

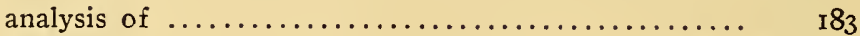

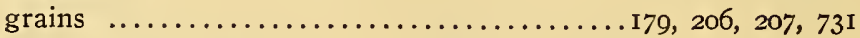

Monophadnoides rubi ............................ 846

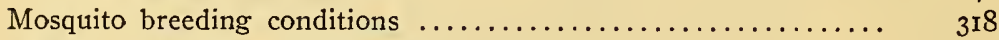

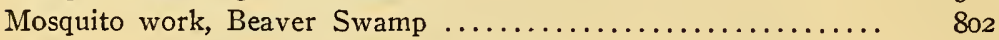

East Haven rifle range $\ldots \ldots \ldots \ldots \ldots \ldots \ldots \ldots . . . \ldots$

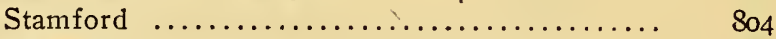

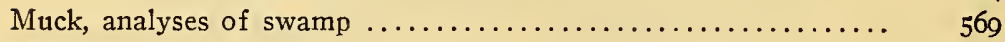

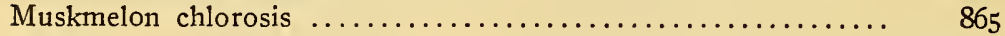

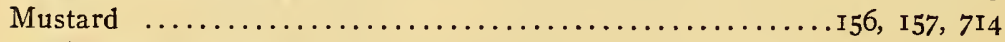

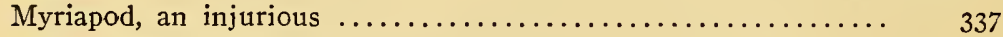

National Fertilizer Co. :-

Chittenden's Ammoniated bone phosphate .....7, I0, 459, 526, 527

Complete fertilizer ........... $62,63,459,518,519$ tobacco $\ldots \ldots \ldots \ldots \ldots \ldots ., 84,85$, IO0, IOI

Connecticut Valley tobacco grower ...7, 104, 105, 459, 558,559

starter $\ldots \ldots 7,80,8 \mathrm{I}, 459$, 536,537

Fish and potash $\ldots \ldots \ldots \ldots \ldots 7,60,61,459,518,519$ Formula "A" $\ldots \ldots \ldots \ldots \ldots \ldots 7,56.57,459,512,513$

"B" $\ldots \ldots \ldots \ldots \ldots \ldots \ldots 7,58,59,459,462$

H. G. special tobacco fertilizer ....7, 77, 80, 8I, 459, 536,537

Market garden fertilizer .....7, 64, 65, 459, 518, 519 Potato phosphate $\ldots \ldots \ldots \ldots \ldots 7,86,87,459,540,54 \mathrm{I}$ special $\ldots \ldots \ldots \ldots \ldots \ldots \ldots \ldots .459,546,547$

Tobacco special with carbonate of potash ..7, 104, 105, $459,558,559$

XXX fish and potash $\ldots \ldots \ldots .7,56,57,459,514,515$

Soluble bone and potash $\ldots \ldots .7,70,71,459,526,527$

Nitrate of soda ........................ $3,14,459,465$

Dried blood ................................. ${ }_{46} 66$

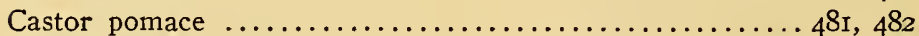

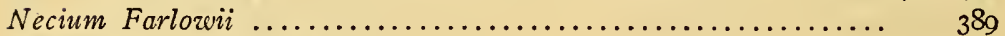

Nectarophora cucurbitae $\ldots \ldots \ldots \ldots \ldots \ldots \ldots \ldots \ldots \ldots \ldots \ldots . \ldots \ldots, 8 \ldots \ldots$

New England Fertilizer Co.:-

New England Corn and grain fertilizer ...7, 100, I0r, 459, 554, 555 H. G. potato fertilizer ...... $88,89,459,546,547$ Perfect tobacco grower ...7, 104, 105, 459, 540, 54I Potato fertilizer .......... $96,97,459,554,555$ Superphosphate $\ldots \ldots \ldots \ldots \ldots 7,64,65,459,518,519$ Ground bone $\ldots \ldots \ldots \ldots \ldots \ldots 7,42,43,459,494,495$ Muriate of potash $\ldots \ldots \ldots \ldots \ldots \ldots \ldots 488,489$ Tankage $\ldots \ldots \ldots \ldots \ldots \ldots \ldots \ldots \ldots \ldots \ldots \ldots, 496 \ldots \ldots$ 
New Jersey tea, powdery mildew of $\ldots \ldots \ldots \ldots \ldots \ldots \ldots \ldots . . . \ldots 66$

Niantic Menhaden Oil \& Guano Co.:-

Bone, fish and potash ....................459, 514, 515

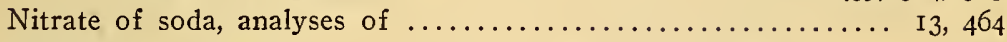

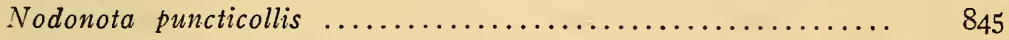

North Western Fertilizing Co.:-

North Western Bone, fish and potash ...........459, 518, 519

Empire special manure $\ldots \ldots 7,58,59,459,5$ I0, 5 II

Market garden phosphate ..7, 60, 6I, 459, 518, 519

Superphosphate .........7,60, 6I, 459, 5I4, 5I5

I0\% manure ........... $7,56,57,459,5$ I0, 5 II

Io\% potato fertilizer $\ldots \ldots 7,92,93,459,550,551$

Universal fertilizer $\ldots \ldots \ldots \ldots \ldots \ldots 459,5$ I8, 519

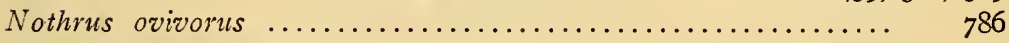

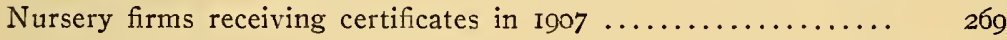

$1908 \ldots \ldots \ldots \ldots \ldots \ldots \ldots \ldots \ldots \ldots \ldots, 771$

inspection $\ldots \ldots \ldots \ldots \ldots \ldots \ldots \ldots \ldots \ldots \ldots \ldots \ldots \ldots, 765,770$

Oak, anthracnose of white $\ldots \ldots \ldots \ldots \ldots \ldots \ldots \ldots \ldots \ldots \ldots \ldots, \quad 352$

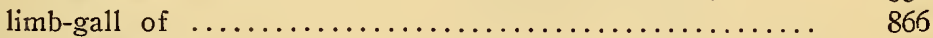

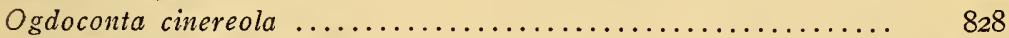

Ohio Farmers Potato and Tobacco Special ...............77, 92, 93

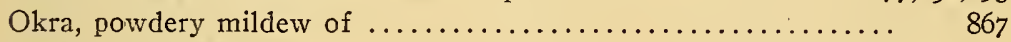

Olds \& Whipple:-

O. \& W.'s Complete tobacco fertilizer ...7, I04, I05, 460, 558, 559 Corn and potato fertilizer $7,82,83$, I00, I0I, 460,536 ,

Fish and potash ...............460, 5I6, $5 \mathrm{I} 7$

Grass fertilizer ............ 82, 83, 460, 540, 54I

H. G. potato fertilizer ........ $82,83,460,536,537$

Special phosphate $\ldots \ldots \ldots \ldots \ldots .7,62,63,460,5$ I0, 5 II

Dry ground fish .................460, 498, 499

Grey pomace $\ldots \ldots \ldots \ldots \ldots \ldots \ldots \ldots 7,30,460,481,482$

Vegetable potash ............... I08, 460, 487

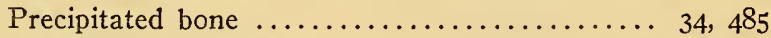

Carbonate of potash $\ldots \ldots \ldots \ldots \ldots \ldots \ldots \ldots 486,487$

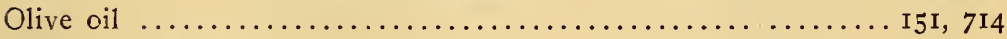

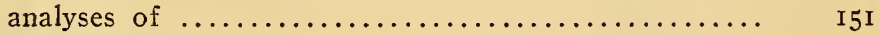

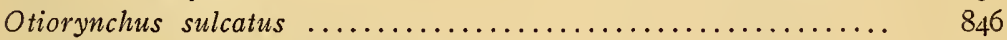

Pagoda tree, powdery mildew of $\ldots \ldots \ldots \ldots \ldots \ldots \ldots \ldots \ldots . \ldots \ldots$

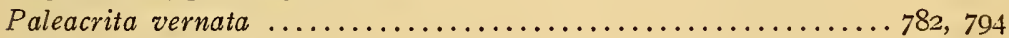

Pamphilius persicum .............................. 285, 767

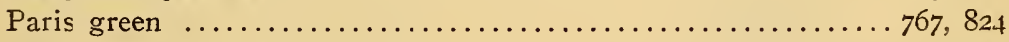

analyses of $\ldots \ldots \ldots \ldots \ldots \ldots \ldots \ldots \ldots \ldots \ldots \ldots \ldots \ldots \ldots \ldots \ldots \ldots \ldots \ldots \ldots, 328$

chemical composition of $\ldots \ldots \ldots \ldots \ldots \ldots \ldots \ldots \ldots \ldots \ldots \ldots \ldots \ldots$

Parmenter \& Polsey Fertilizer Co. :-

"A. A." brand $\ldots \ldots \ldots \ldots \ldots \ldots \ldots \ldots \ldots \ldots \ldots, 58,59,460,462$

Plymouth Rock brand $\ldots \ldots \ldots \ldots \ldots \ldots \ldots 7,64,65,460,516,517$ 
Parmenter \& Polsey Fertilizer Co., cont'd-

Special potato fertilizer $\ldots \ldots \ldots \ldots \ldots \ldots \ldots \ldots, 88,89,460,462$

Star Brand ........................... 10

P. \& P. Potato fertilizer ............7, 98, 99, 460, 552, 553

Ground bone .............. 42, 43, 460, 494, 495

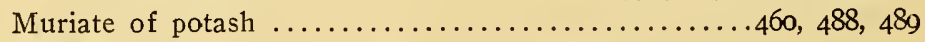

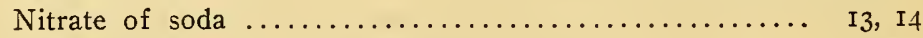

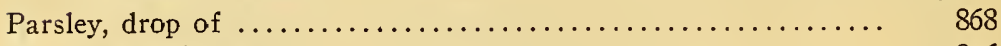

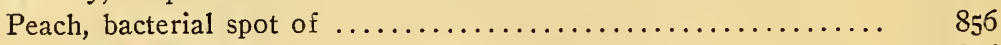

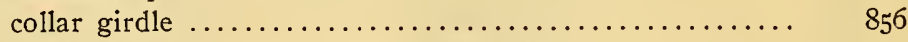

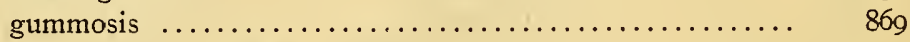

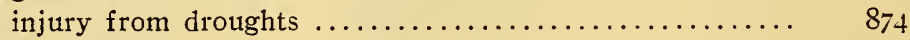

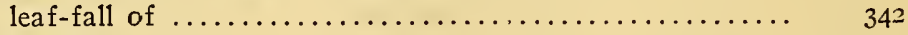

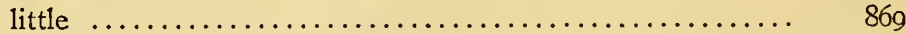

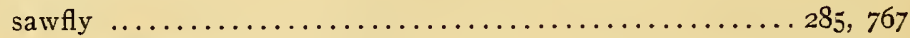

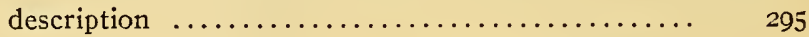

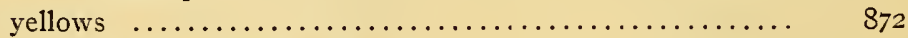

preventive measures $\ldots \ldots \ldots \ldots \ldots \ldots \ldots \ldots \ldots . \ldots \ldots \ldots \ldots \ldots \ldots$

theories concerning $\ldots \ldots \ldots \ldots \ldots \ldots \ldots \ldots \ldots, \quad 875$

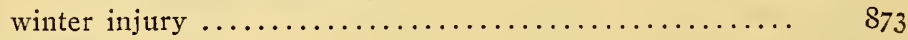

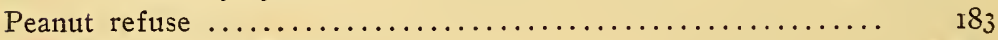

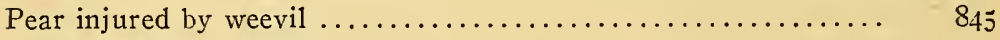

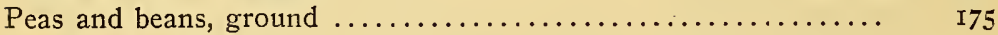

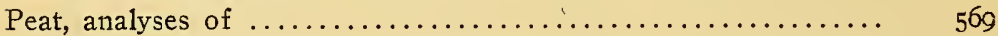

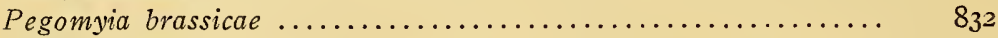

Pepper, black ......................... I54, I55, I57, 7 I 3

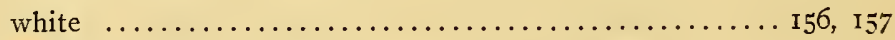

Percentage difference, explanation of $\ldots \ldots \ldots \ldots \ldots \ldots \ldots \ldots \ldots$ I, 502

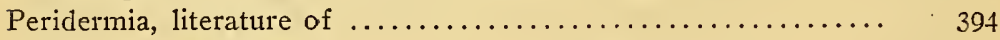

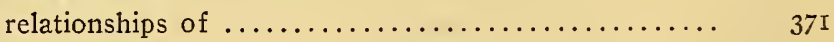

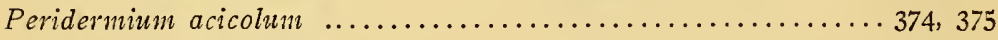

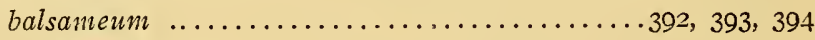

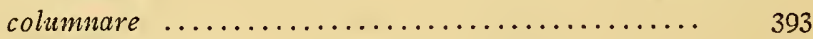

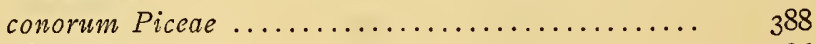

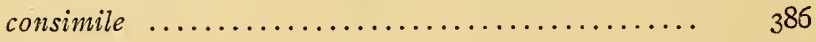

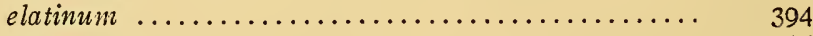

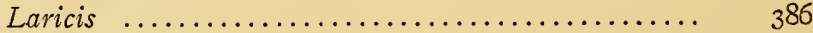

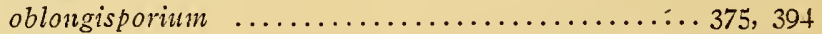

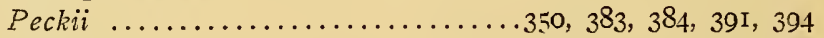

Pini ............................... 375

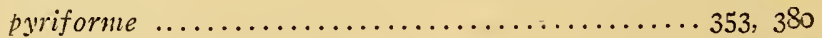

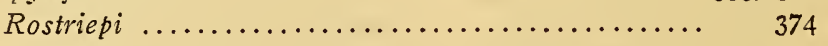

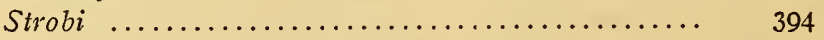

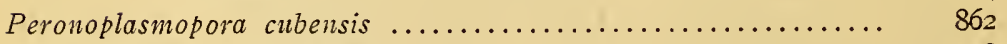

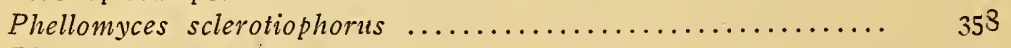

Phragmidium speciosum .......................... 359

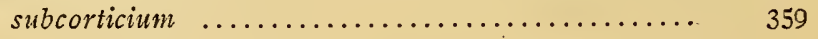




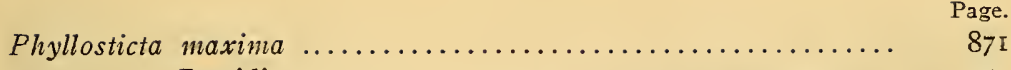

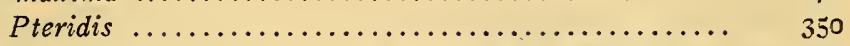

Phytophthora, artificial cultures of with reference to oospores ... 89 I

Phytophthora infestans ..................891, 893, 894, 895, 900

cross-cultures .................. 899

cultural methods .................. 897

hybrid (?) cultures $\ldots \ldots \ldots \ldots \ldots \ldots \ldots . \quad 900$

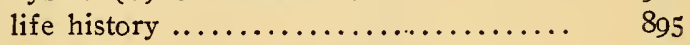

media $\ldots \ldots \ldots \ldots \ldots \ldots \ldots \ldots \ldots . \ldots \ldots \ldots$

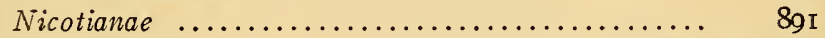

Phaseoli ..................89r, 893, 894, 900, 90r

attempts to lose oospores ........... 906

cultural methods ................. 903

life history $\ldots \ldots \ldots \ldots \ldots \ldots \ldots \ldots \ldots$ gor

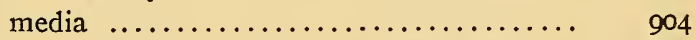

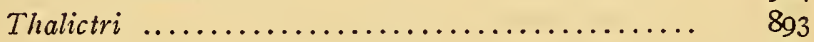

infection experiments $\ldots \ldots \ldots \ldots \ldots \ldots . \quad 895$

life history $\ldots \ldots \ldots \ldots \ldots \ldots \ldots \ldots \ldots . .6 \% \ldots$

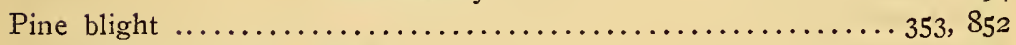

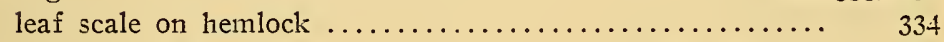

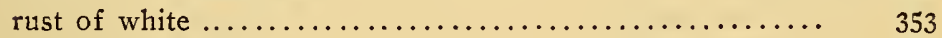

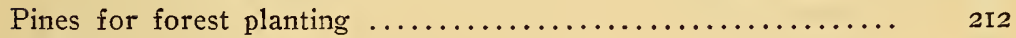

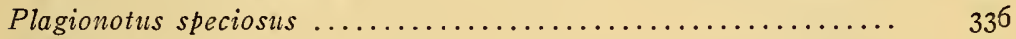

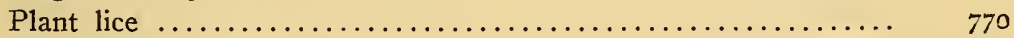

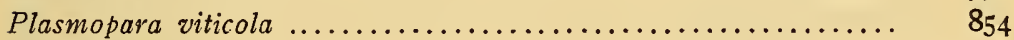

Plathypena scabra ............................... 769,828

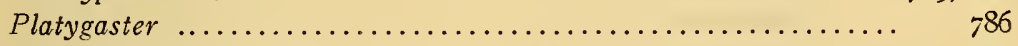

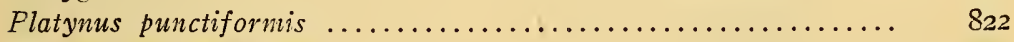

Podisus maculiventris (spinosus) $\ldots \ldots \ldots \ldots \ldots \ldots \ldots \ldots \ldots, 869,822$

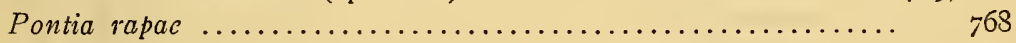

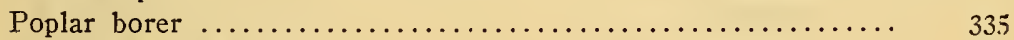

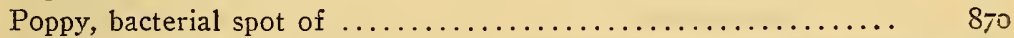

Potash, analyses of carbonate of $\ldots \ldots \ldots \ldots \ldots \ldots \ldots \ldots \ldots \ldots \ldots \ldots, 486$

double sulphate of $\ldots \ldots \ldots \ldots \ldots \ldots 35,36,488-490$

high grade sulphate of $\ldots \ldots \ldots \ldots . \ldots 35,36,487,488$

muriate of $\ldots \ldots \ldots \ldots \ldots \ldots \ldots \ldots . \ldots \ldots 6-38,488-490$

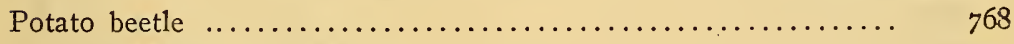

breeding, some essential points in ............... 429

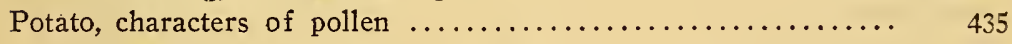

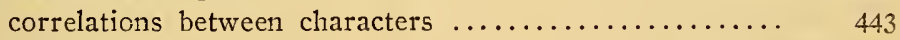

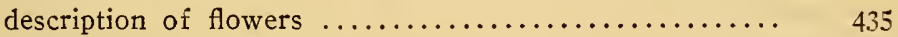

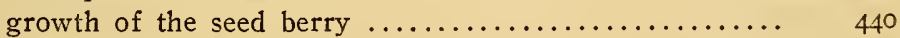

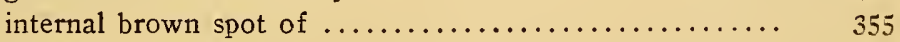

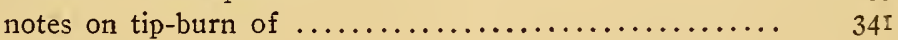

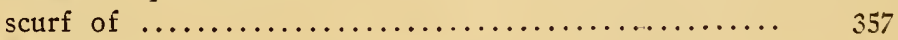

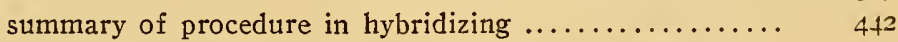

variety variation in flowering $\ldots \ldots \ldots \ldots \ldots \ldots \ldots \ldots, \quad 430$ 


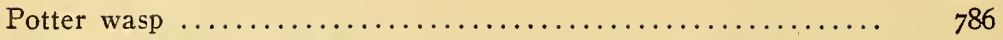

Poultry feeds, proprietary $\ldots \ldots \ldots \ldots \ldots \ldots$ ISI, 208, 209, 73I, 760, 761

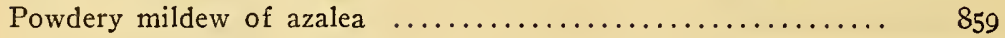

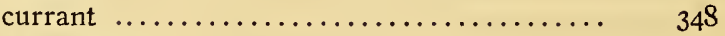

false indigo $\ldots \ldots \ldots \ldots \ldots \ldots \ldots \ldots \ldots \ldots, \quad 349$

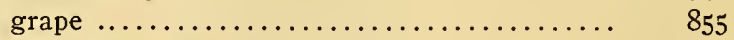

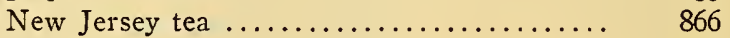

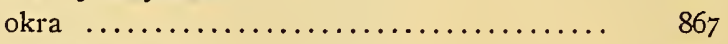

pagoda tree $\ldots \ldots \ldots \ldots \ldots \ldots \ldots \ldots \ldots \ldots . \ldots \ldots . \ldots \ldots$

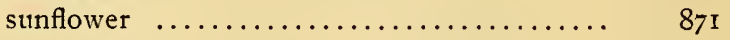

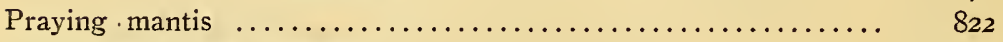

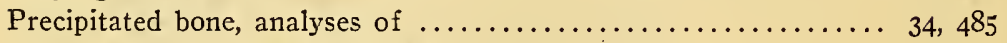

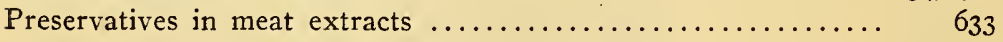

fluid meat extract $\ldots \ldots \ldots \ldots \ldots \ldots \ldots \ldots \ldots \ldots \ldots \ldots \ldots \ldots \ldots \ldots$

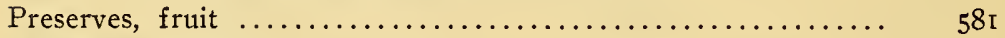

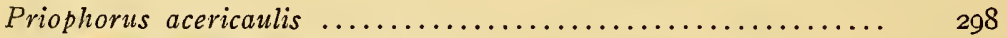

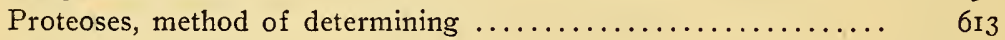

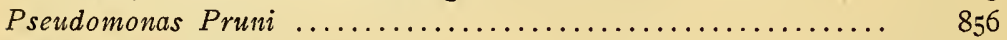

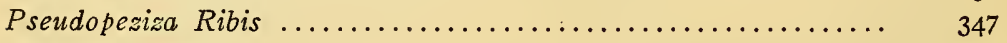

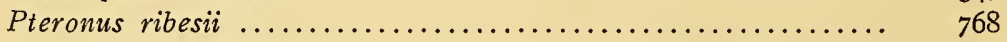

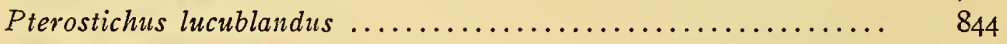

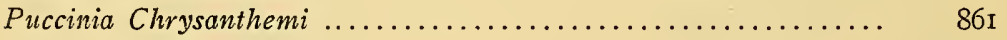

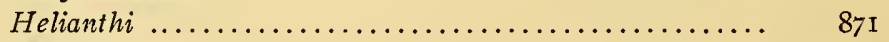

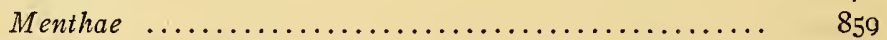

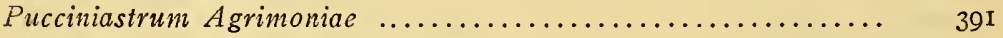

arcticum americanum .................... 39. 393, 394

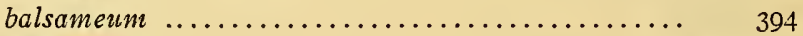

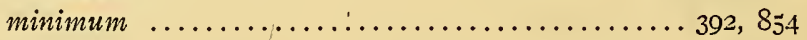

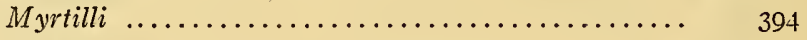

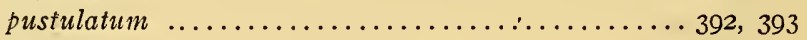

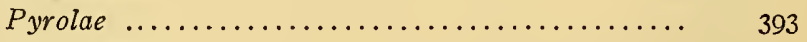

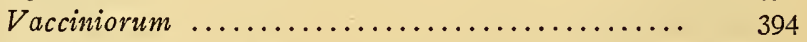

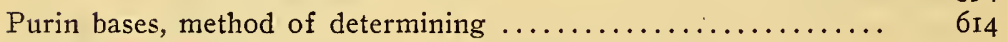

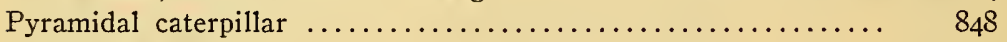

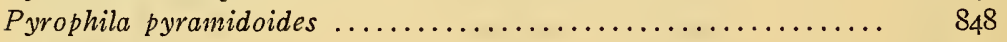

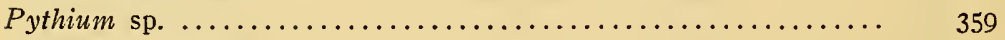

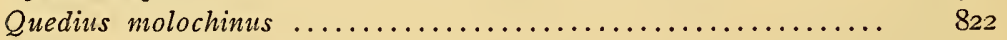

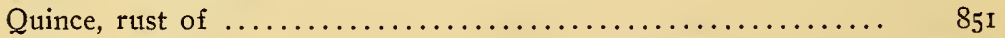

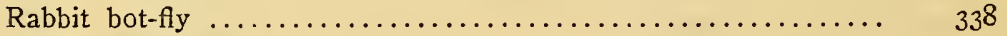

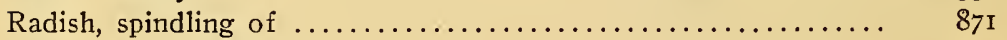

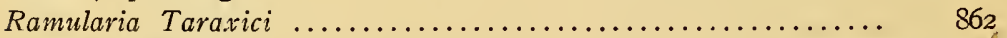

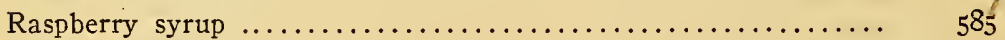

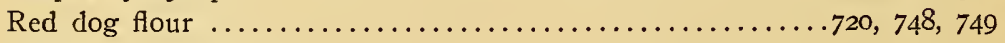

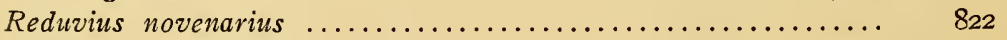

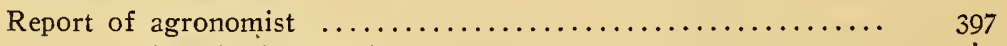

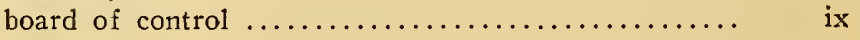

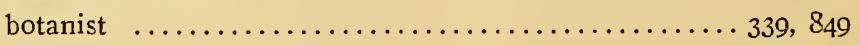


Report of entomologist 266,763

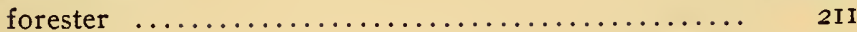

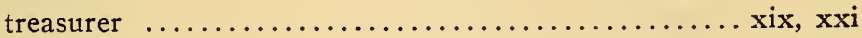

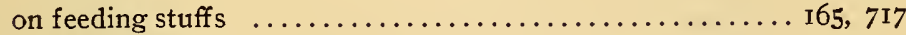

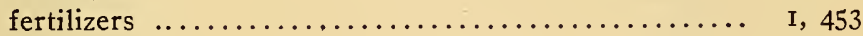

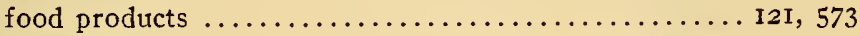

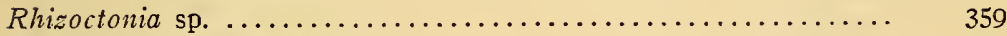

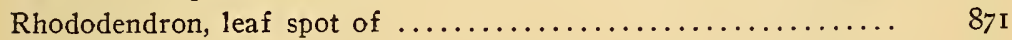

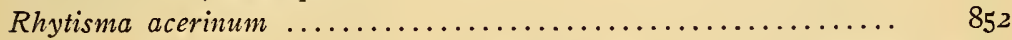

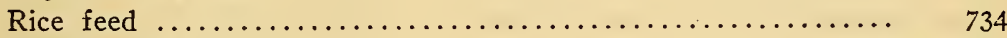

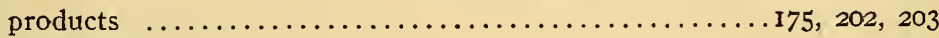

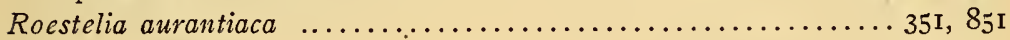
pirata ............................... 85 I, 853

Rogers \& Hubbard Co.:-

Hubbard's Complete phosphate .........7, 68, 69, 460, 520, 52I Fertilizer for oats and top dressing $7,78,79,460,535$,

Grass and grain fertilizer ......8, 80, 8I, 460, 540, 54I Market garden fertilizer ............. 58,59 Potato phosphate ...........8, 86, $87,460,538,539$ Soluble corn and general crops manure $8,62,63,460$, 5 I6, 517 potato manure ........8, 80, 81, 460, 534, 535 tobacco manure .......8, 80, 8I, $460,534,535$ Pure raw knuckle bone flour ....8, 42, 43, 460, 494, 495 Rogers Mfg. Co.:-

Strictly pure fine bone $\ldots \ldots \ldots \ldots 8,42,43,460,494,495$

All round fertilizer $\ldots \ldots \ldots \ldots .8,48,64,65,68,69,460,522,523$

Corn and onion $\ldots \ldots \ldots \ldots \ldots \ldots, 78,79,460,531,532,536,537$

Fish and potash $\ldots \ldots \ldots \ldots \ldots \ldots \ldots 8,66,67,460,500,518,519$

Grass and grain .................. $78,79,460,534,535$

H. G. soluble tobacco .........8, 78, 79, I00, IOI, 460, 534, 535

Oats and top dressing ......8, 78, 79, I00, Іог, 460, 529, 534, 535

Potato and vegetable ...............8, 88, 89, 460, 538, 539

Tobacco and potato ................8, 82, 83,460, 534, 53.5

grower $\ldots \ldots \ldots \ldots \ldots \ldots \ldots .8,80,8 \mathrm{I}, 460,530,534,535$

starter $\ldots \ldots \ldots \ldots \ldots \ldots \ldots \ldots \ldots, 84,85,460,544,545$

Fine ground bone $\ldots \ldots \ldots \ldots \ldots \ldots \ldots \ldots . .4,42,43,460,494,495$

Knuckle bone flour ................8, 42, 43, 460, 494, 495

Black potash $\ldots \ldots \ldots \ldots \ldots \ldots \ldots \ldots \ldots \ldots \ldots \ldots \ldots \ldots .{ }_{4} 87$

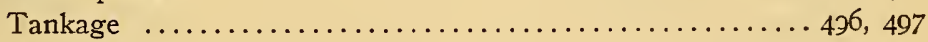

Root rot of tobacco ............................. 363

method of sterilizing seed beds $\ldots \ldots \ldots \ldots \ldots \quad 364$

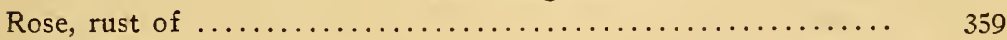

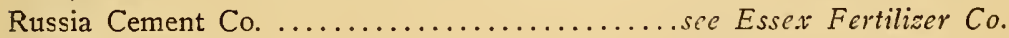

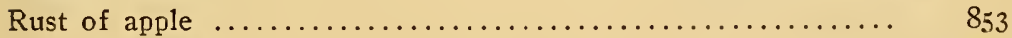

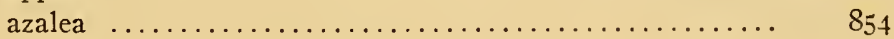


Page.

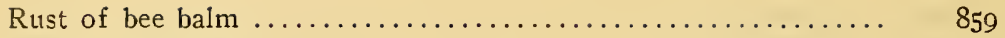

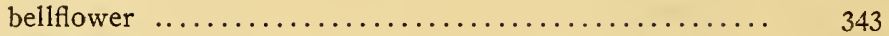

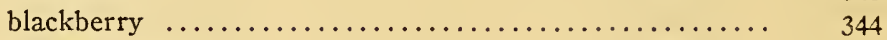

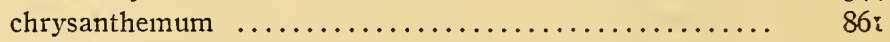

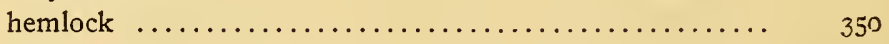

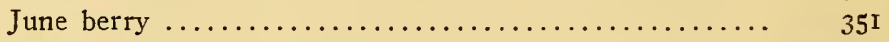

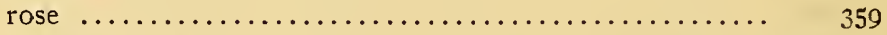

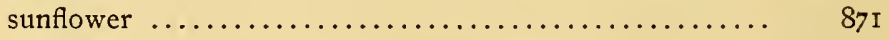

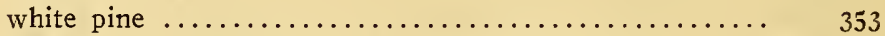

Rusts, Heteroecious of Connecticut having a peridermium ...... 369

Rye products $\ldots \ldots \ldots \ldots \ldots \ldots \ldots \ldots \ldots \ldots \ldots \ldots$.74, 202, 203, 726, 752-755

Salt, Cerebos .................................. 595

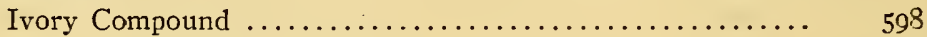

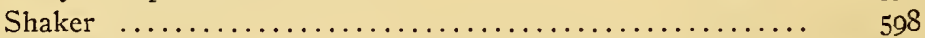

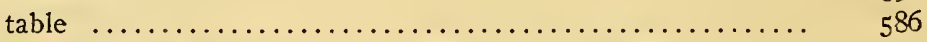

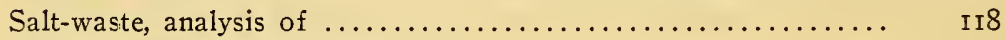

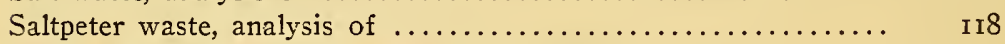

Sanderson Fertilizer \& Chemical Co.:-

Atlantic Coast bone, fish and potash .....8, 66, 67, 460, 522, 523

Sandersoṇ's Corn superphosphate ........8, 94, 95, 460, 546, 547

Formula A ............ 6 , 60, 6I, 460, 512, 513

B for tobacco $8,82,83,84,85$, 100, Ior, 460 ,

$538,539,554,555$

Potato manure ............ $86,97,460,544,545$

Special with 10\% potash ...8, 50, 68, 69, 460, 512, 513

Top dressing for grass and grains $8,84,85,460,546$,

547

Fine ground bone $\ldots \ldots \ldots \ldots .8,42,43,460,494,495$ fish $\ldots \ldots \ldots \ldots \ldots, 46,47,460,498,499$

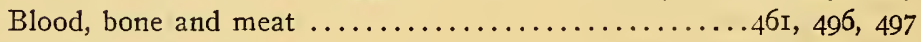

Acid phosphate ......................... 46 I, 483, 484

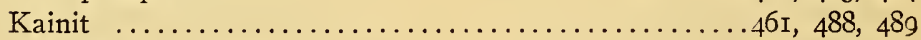

Muriate of potash ............... 36, 37, 46I, 488, 489

Nitrate of soda .................... I3, I4, 46r, $46_{5}$

Sulphate of potash ............... $36,37,46 \mathrm{I}, 488,489$

Special mixture No. I $\ldots \ldots \ldots \ldots \ldots \ldots \ldots \ldots \ldots 526,527,528,529$

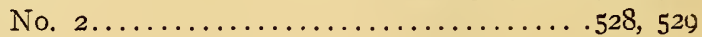

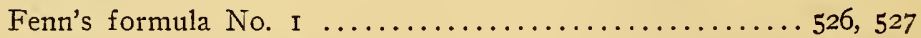

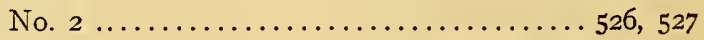

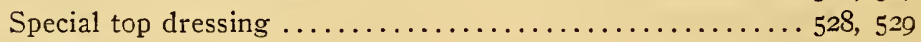

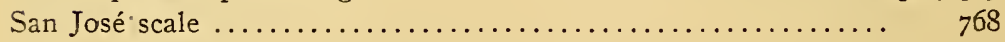

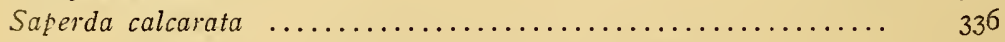

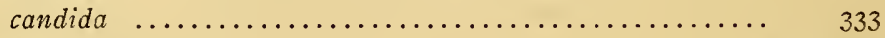

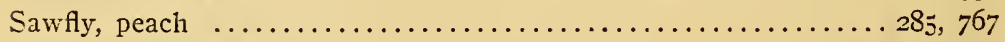

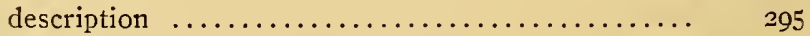

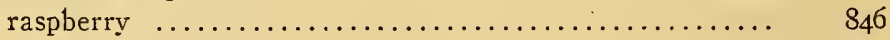

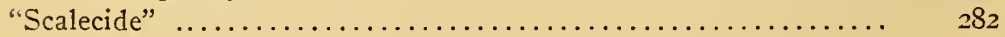


Sclerotinia Libertiana $.860,863,868$

Screenings, botanical analysis of $\ldots \ldots \ldots \ldots \ldots \ldots \ldots \ldots \ldots$ I 82

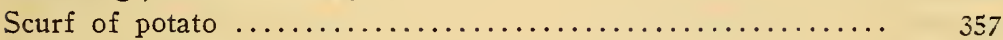

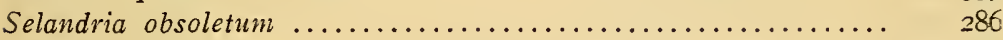

Separator skim milk ........................... I62

Septoria Kalmicola ................................ 35 I

Shay, C. M., Fertilizer Co.:-

Shay's Corn fertilizer ............ $78,79,461,532,546,547$

Grass and lawn $\ldots \ldots \ldots \ldots \ldots \ldots . .6,78,79,461,534,535$

Potato $\ldots \ldots \ldots \ldots \ldots \ldots \ldots \ldots 8,78,79,461,509,534,535$

Pure ground bone ............ 42, 43, 46I, 494, 495

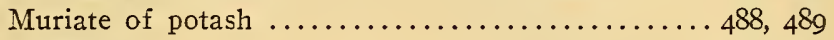

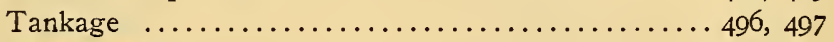

Sheep manure, analyses of $\ldots \ldots \ldots \ldots \ldots \ldots \ldots \ldots \ldots \ldots \ldots \ldots \ldots \ldots \ldots \ldots$ II 4 II6

Shoemaker, M. L., \& Co. :-

"Swift-Sure" Guano for truck, corn and onions 9, 82, 83, 46r, 536,

Superphosphate for general use 9, 58, 59, 46I, 5I0, 5 II potatoes ..9, 82, 83, 46I, 536, 537

Bone meal .............9, 42, 43, 46r, 494, 495

Snow-white linden moth ......................... 842

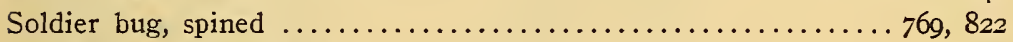

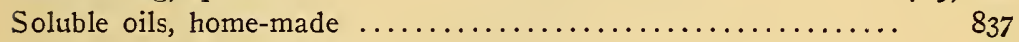

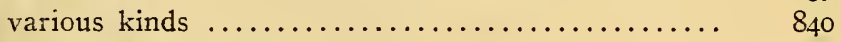

"Soluble oils," spraying tests with $\ldots \ldots \ldots \ldots \ldots \ldots \ldots \ldots \ldots \ldots .282$

Southern corn root-worm ........................ 805, 809

Special manures .............................. 74, 528

cost and valuation of $\ldots \ldots \ldots \ldots \ldots \ldots \ldots \ldots, 77,532$

guaranties of $\ldots \ldots \ldots \ldots \ldots \ldots \ldots \ldots \ldots \ldots, 76,532$

tables of analyses of $\ldots \ldots \ldots \ldots \ldots \ldots .78$-10I, $534-555$

Sphaerotheca mors-iuvae ........................... 348

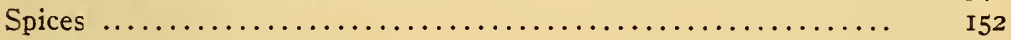

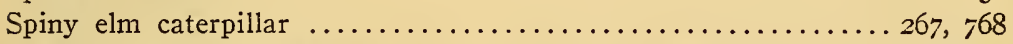

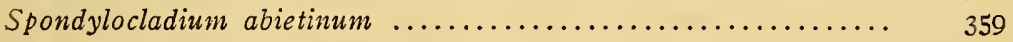

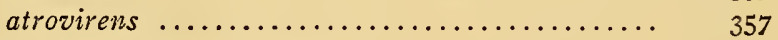

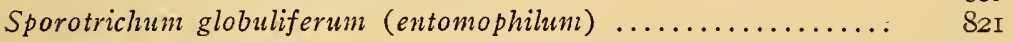

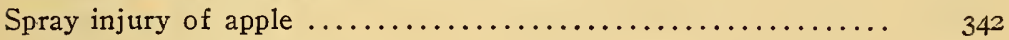

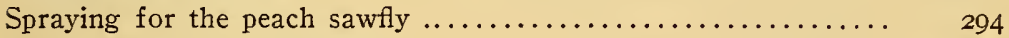

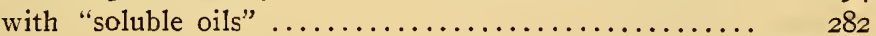

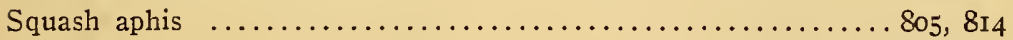

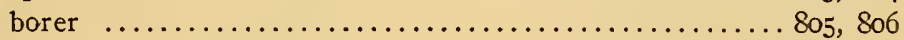

bug $\ldots \ldots \ldots \ldots \ldots \ldots \ldots \ldots \ldots \ldots \ldots \ldots \ldots \ldots \ldots \ldots \ldots \ldots \ldots, 8 \ldots \ldots \ldots$

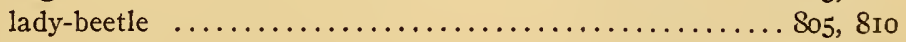

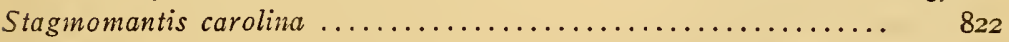

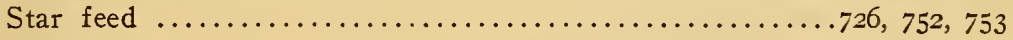

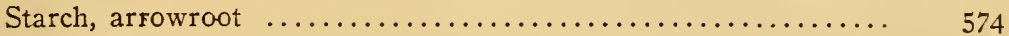

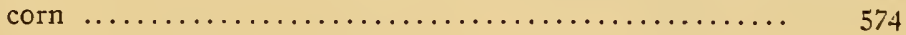


Starch, potato

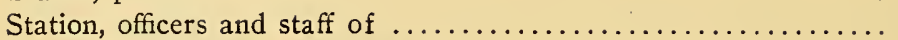

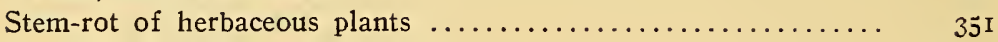

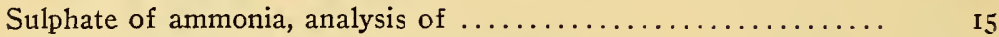

Sulphuretted hydrogen, used for fumigation $\ldots \ldots \ldots \ldots \ldots \ldots \ldots . \ldots \ldots$

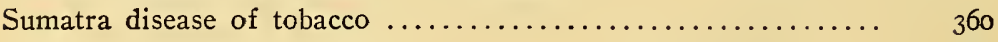

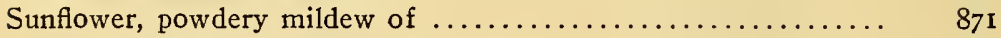

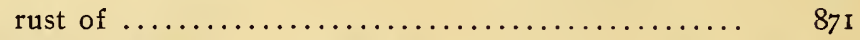

Superphosphates, analyses of nitrogenous $\ldots \ldots \ldots \ldots \ldots .56-75,510-529$

cost and valuation of nitrogenous .......... 50, $50 \mathrm{I}$

guaranties of nitrogenous $\ldots \ldots \ldots \ldots \ldots \ldots \ldots 49,501$

nitrogenous $\ldots \ldots \ldots \ldots \ldots \ldots \ldots \ldots \ldots \ldots \ldots, 46,500$

Sweet pea, dampening off $\ldots \ldots \ldots \ldots \ldots \ldots \ldots \ldots \ldots \ldots \ldots \ldots . . \ldots \ldots$

Swift's Lowell Fertilizer Co.:-
Swift's Lowell Animal brand 9, 66, 67, 68, 69, 46I, 509, 514, 515,

Bone fertilizer .........9, 98, 99, 461, 524, 525

Dissolved bone and potash 9, 70, 7I, 46I, 520, 52I

Empress brand ..........9, 98, 99, 46r, 524, 525

Market garden manure 9, 60, 6I, 46I, 50I, 512, 5I3

Perfect tobacco grower ...9, 104, 105, 46r, 542, 543

Potato manure ......9, 76, 96, 97, 46I, 552, 553

phosphate $9,76,80,8 \mathrm{I}, 92,93,46 \mathrm{I}, 542,543$

Special grass mixture .....9, 82, 83, 46I, 540, 54I vegetable manure .........9, $77,90,9 \mathrm{I}$

Ground bone $\ldots \ldots \ldots \ldots \ldots 9,42,43,46 \mathrm{I}, 494,495$

Tobacco manure $\ldots \ldots \ldots \ldots \ldots \ldots \ldots \ldots \ldots . \ldots \ldots$ r, 538,539

Acid phosphate $\ldots \ldots \ldots \ldots \ldots \ldots \ldots \ldots \ldots .9,32,33,46 \mathrm{r}, 483,484$

Muriate of potash ................ 36, 37, 46r, 488, 489

Nitrate of soda $\ldots \ldots \ldots \ldots \ldots \ldots \ldots \ldots \ldots \ldots, 13$, I4 461,465

Dried blood $\ldots \ldots \ldots \ldots \ldots \ldots \ldots \ldots \ldots \ldots \ldots \ldots \ldots \ldots \ldots \ldots \ldots \ldots \ldots \ldots \ldots \ldots$

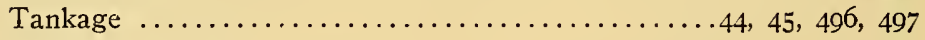

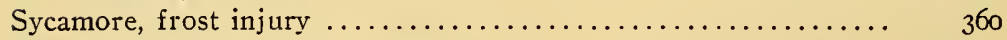

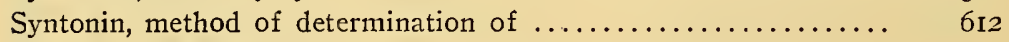

Table of contents $\ldots \ldots \ldots \ldots \ldots \ldots \ldots \ldots \ldots \ldots \ldots \ldots \ldots \ldots \ldots \ldots \ldots \ldots, \quad v$

Tables showing results of fumigating with gases ...274, 276, 278, 279, 28I

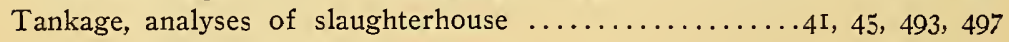

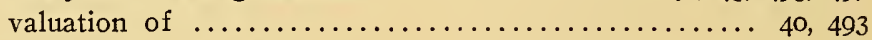

"Target Brand Scale Destroyer" ..................... ${ }_{282}$

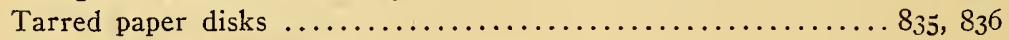

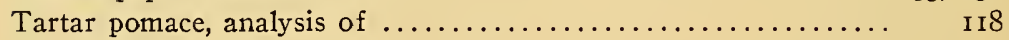

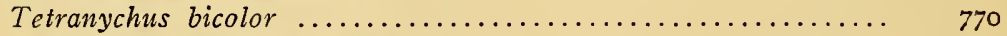

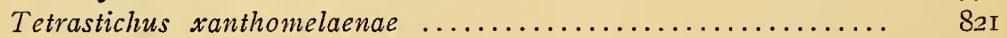

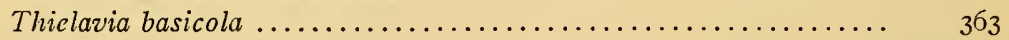

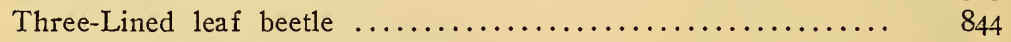

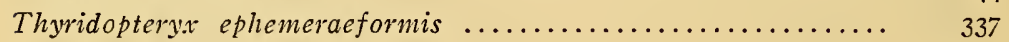

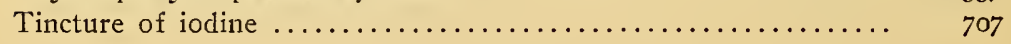


Tischeria malifoliella ........................................... 768

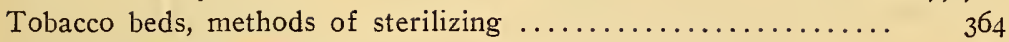

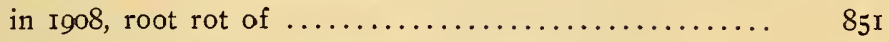

manures containing potash as carbonate $\ldots \ldots \ldots \ldots \ldots$ I02, 556

guaranties ........................ 557

tables of analyses of $\ldots \ldots \ldots \ldots \ldots \ldots \ldots \ldots \ldots \ldots \ldots \ldots \ldots \ldots \ldots \ldots \ldots \ldots \ldots \ldots \ldots \ldots \ldots \ldots \ldots$
of $\ldots \ldots \ldots \ldots \ldots \ldots$

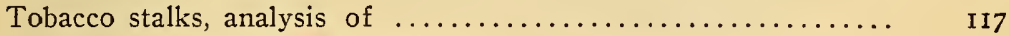

analyses of ashes of $\ldots \ldots \ldots \ldots \ldots \ldots \ldots \ldots \ldots$ II

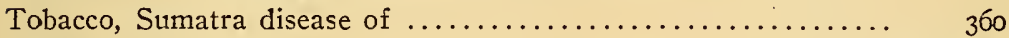

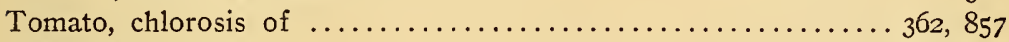

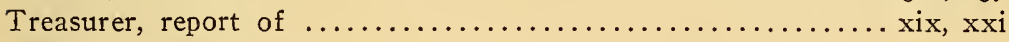

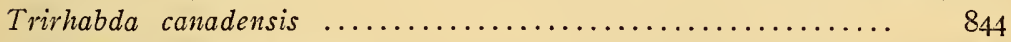

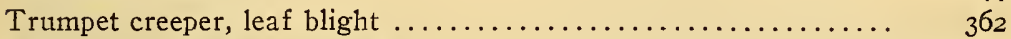

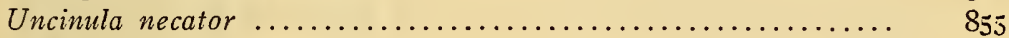

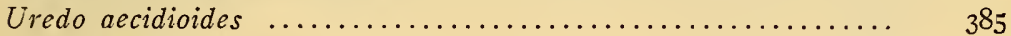

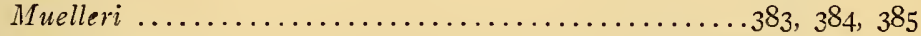

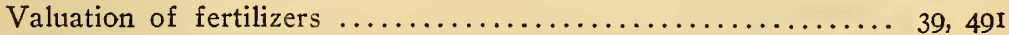

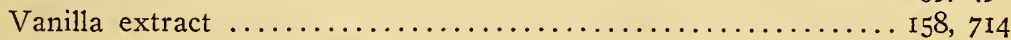

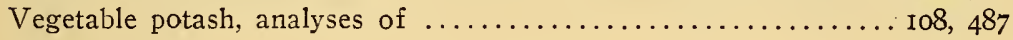

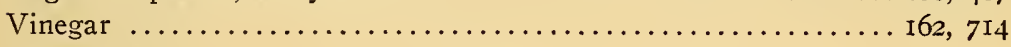

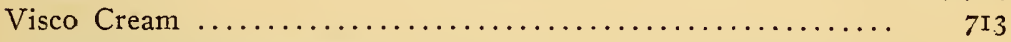

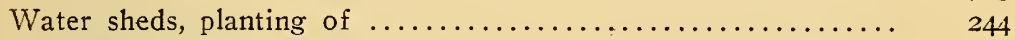

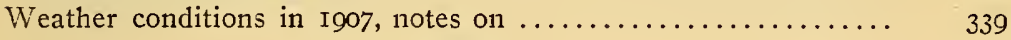

Igo8, notes on $\ldots \ldots \ldots \ldots \ldots \ldots \ldots \ldots . .649$

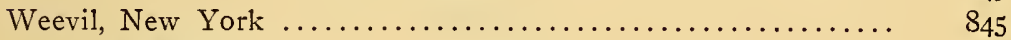

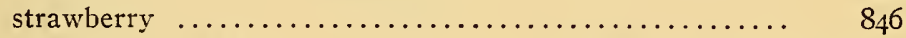

Wheat and corn-cob feeds ............

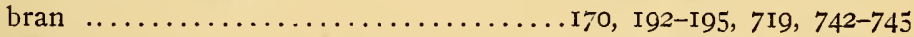

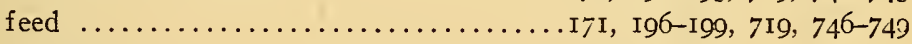

middlings $\ldots \ldots \ldots \ldots \ldots \ldots \ldots \ldots \ldots \ldots$ I 7 I, I94-197, 7I9, 744-747

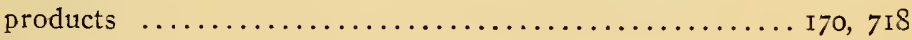

Wheeler Bros. :-

Wheeler's Special potato .................461, 536, 537

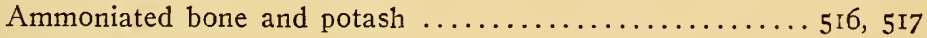

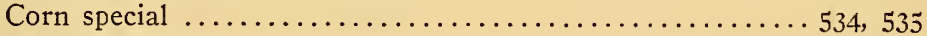

White fly, greenhouse $\ldots \ldots \ldots \ldots \ldots \ldots \ldots \ldots \ldots \ldots \ldots$ 806, 8I 5

Wilcox Fertilizer Co. :-

Wilcox's Complete bone superphosphate ...9, 58, 59, 46I, 5I6, $5 \mathrm{I} 7$

Fish and potash $\ldots \ldots \ldots \ldots \ldots \ldots 9,64,65,461,512,513$

Grass fertilizer ............9, 82, 83, 46r, 536, 537

H. G. fish and potash .........9, 56, 57, 46I, 5I0, 5 II

tobacco special .......9, 74, 78, 79, 46r, 536, 537

Potato fertilizer ............9, 86, 87, 46I, 548, 549 onion and vegetable manure $9,80,81,46 \mathrm{I}, 536$,

Special superphosphate $\ldots \ldots \ldots \ldots 9,62,63,461,520,521$ 
Wilcox Fertilizer Co., cont'd-

Wilcox's Dry ground fish

.9, 44, 47, 46I, 498, 499

Pure ground bone

$9,42,43,46 \mathrm{I}, 494,495$

Acid phosphate

$9,3 \mathrm{I}, 32,46 \mathrm{I}, 483,484$

Muriate of potash

$9,36,37,38,46 \mathrm{I}, 488,489$

Nitrate of soda

$9,13,14,46 \mathrm{I}, 465$

H. G. sulphate of potash ..........9, 36, 37, 488, 489

Special mixture No. I $\ldots \ldots \ldots \ldots \ldots \ldots \ldots \ldots 526,527$

No. $2 \ldots \ldots \ldots \ldots \ldots \ldots \ldots \ldots . \ldots \ldots, 526,527$

Willow curculio

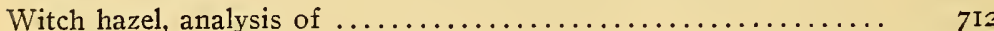

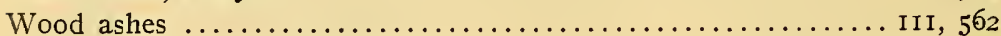
tables of analyses of $\ldots \ldots \ldots \ldots \ldots \ldots \ldots$ II2, II $3,564,565$

Woodruff, S. D., \& Sons :-

Woodruff's Home mixture .......9, 46, 48, 56, 57, 46I, 510, 5 II

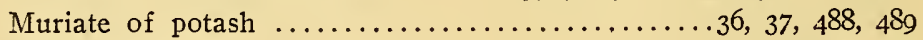

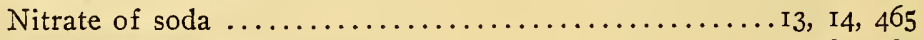

Acid phosphate ............................ 483, 484

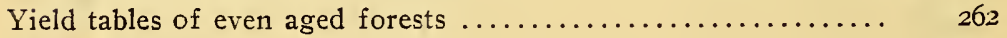

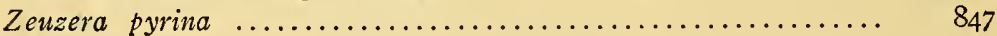




\section{Itate of Connecticut PUBLIC DOCUMENT No. 24}

Thirty-first and Thirty-second Annual Reports

OF

The Connecticut Agricultural Experiment Station

Being the biennial report for the two years ended 0ctober 31 , 1908

PRINTED BY ORDER OF THE LEGISLATURE

HARTFORD

Published by the State

I 908 
PUBLICATION

APPROVED BY

THE BOARD OF CONTROL. 


\section{CONNECTICUT AGRICULTURAL BXPERIMENT STAPION.}

\section{OFFIOFRS AND STAFE'.}

\section{BOARD OF CONTROL.}

His Excellency, Roldin S. Woodruff, Ex officio, President.

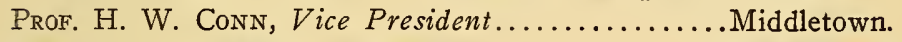

Pror. W. H. Brewer, Secretary................... Hew Haven.

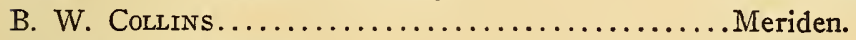

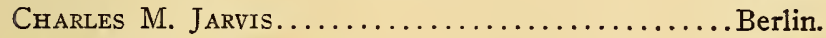

Frank $H$. Stadtmueller....................... Elmwood.

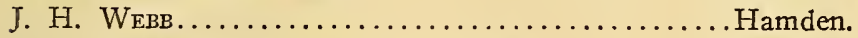

E. H. Jenkins, Director and Treasurer............New Haven.

\section{STATION STAFF.}

Chemists.

Analytical Laboratory.

JoHn P. Street, M.S., Chemist in Charge.

E. Monroe Bailey, M.S.

C. A. Brautlecht, Ph.B.

C. B. MORRISON, B.S.

Clarence W. Rodman, B.S.

Laboratory for the Study of Proteids.

T. B. Osborne, Pн.D., Chemist in Charge.

Botanist.

G. P. Clinton, S.D.

Entomologist.

W. E. Britton, Ph.D.

Assistant in Entomology.

B. H. WAlden, B.Agr.

Forester.

Austin F. Hawes, M.F.

Agronomist.

Edward M. EAst, Ph.D.

Seed Testing.

MARY H. JAGGER.

Stenographers and Clerks.

Miss V. E. Cole.

Miss L. M. Brautlecht.

Miss E. B. Whittlesey.

Mrss C. A. BotsFord.

In charge of Buildings and Grounds.

WILLIAM VEITCH.

Laboratory Helper. Hugo LANGe.

Sampling Agent.

V. L. Churchill, New Haven. 



\section{TABLE OF CONTENTS.}

PAGE.

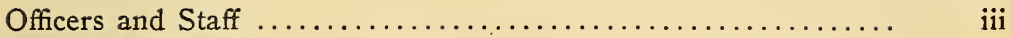

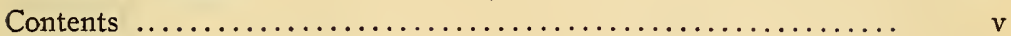

Report of Board of Control .......................... ix

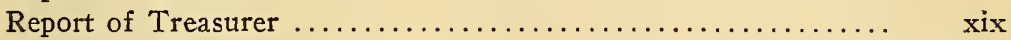

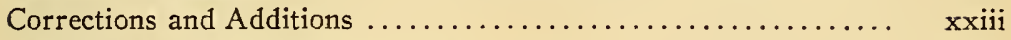

Report on Commercial Fertilizers ................... I, 453

Duties of Manufacturers and Dealers ............... I, 453

Observance of the Fertilizer Law $\ldots \ldots \ldots \ldots \ldots \ldots \ldots \ldots \ldots, 2,454$

Sampling and Collection of Fertilizers .............. 10, 462

Raw Materials chiefly valuable for Nitrogen ........ I3-31, 464-482

Raw Materials chiefly valuable for Phosphoric Acid ..3I-34, 483-486

Raw Materials of High Grade containing Potash ...35-38, 486-49I

Raw Materials containing Nitrogen and Phosphoric

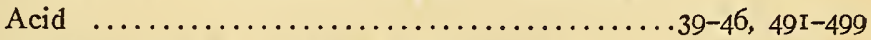

Nitrogenous Superphosphates and Guanos ......46-74, 500-528

Special Manures .....................74-106, 528-559

Home Mixtures .................... 106-108, 559-560

Ashes, Cotton Hull and Wood ...............108-114, 560-567

Lime and Lime-Kiln Ashes ...............II4-II5, 567-568

Various Manurial Wastes ................II4-120, 568-570

Report on Food Products (See also below, p. 573 et seq.) ....... I2I

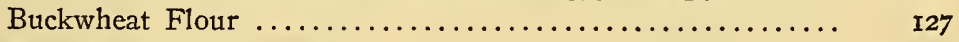

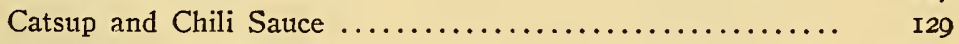

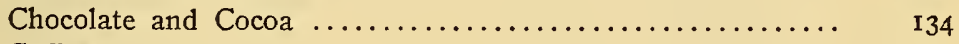

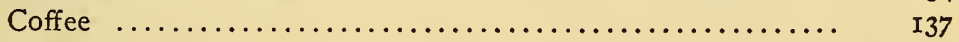

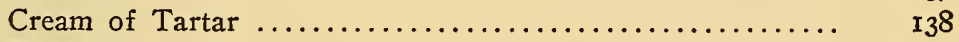

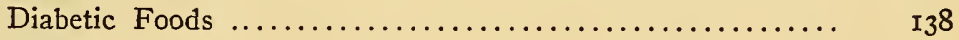

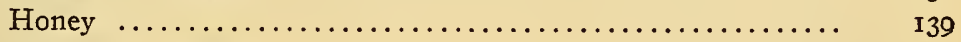

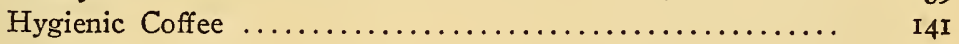

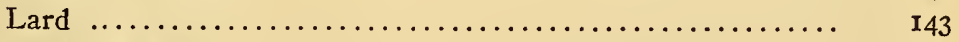

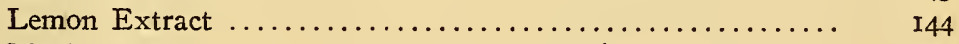

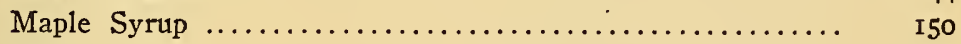

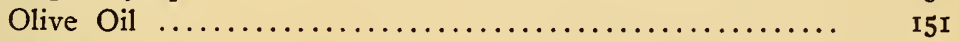

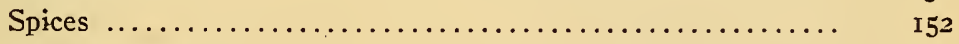

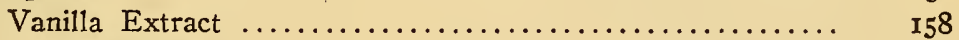

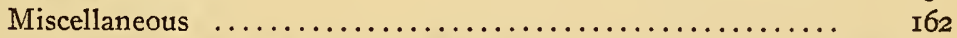

Samples sent by Dairy Commissioner .............. 162, 713

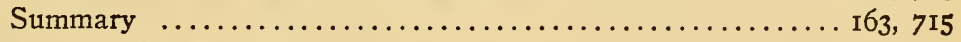

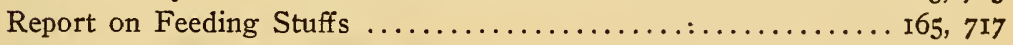

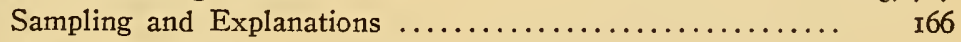

Uses of Analyses ............................ I68 
Report on Feeding Stuffs, cont'd-

PAGE.

Oil Seed Products ..................... $169-170,717-718$

Wheat Products ...............................

Corn Products ........................

Rye Products ............................ 174, 726

Buckwheat, Rice and Miscellaneous Products .......... 175, 726

Barley Products ........................

Various Mixed Feeds ................... 178-179, 727-728

Proprietary Horse Feeds ...................... 180, 729

Proprietary Dairy and Stock Feeds ............... I80, 729

Proprietary Poultry Feeds ..................... I8r, 73I

Miscellaneous Feeds ......................... I83, 732

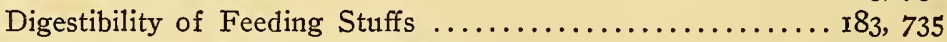

Regarding the Purchase of Feeds ................. 185, 735

Weight of One Quart of Various Feeds .............. 189, 762

Commercial Feeds containing Weed Seeds ............. 736

Analyses of Feeds .......................

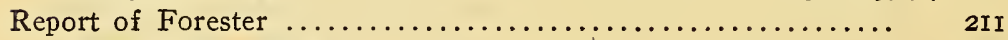

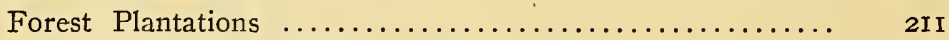

Description of Forest Planting Experiments ............ 213

Summary of Results .......................... 230

Recent Plantations in Connecticut .................. 242

Plantations in State Forests ................ 242

Planting Water Sheds $\ldots \ldots \ldots \ldots \ldots \ldots \ldots \ldots \ldots \ldots .244$

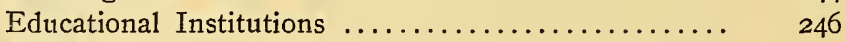

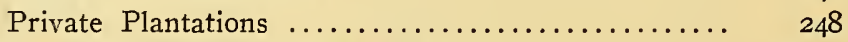

Older Forest Plantations in Connecticut .............. 25I

Yield Tables of Even Aged Forests in Europe ........... 262

Report of Entomologist (See also below, p. 763) ............ 266

Nursery Inspection $\ldots \ldots \ldots \ldots \ldots \ldots \ldots \ldots \ldots \ldots \ldots \ldots \ldots \ldots, 770$

Tests of Gases for Fumigating Stock ............. 270, 796

Spraying Tests with Soluble Oils .................. 282

The Peach Sawfly ............................ $\quad 285$

Progress of Work in Controlling the Gypsy Moth ...... 300, 772

The Brown Tail Moth ......................... 3 I 3

Mosquito Studies ................................. 800

The Chemical Composition of Lead Arsenate and Paris Green $32 \mathrm{I}$

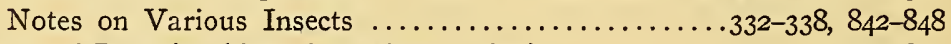

Report of Botanist (See also below, p. 850) ................ 339, 849

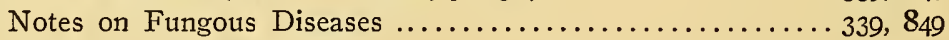

Root Rot of Tobacco ......................... 363

Heteroecious Rusts of Connecticut ................ 369

Report of Agronomist ......................... 397

The Prospect of Better Seed Corn in Connecticut ......... 397

Practical Use of Mendelism in Corn Breeding ........... 406

Inbreeding in Corn ........................... 4 I9

Some Essential Points in Potato Breeding ............. 429

Extension Work in Agronomy ................... 448 


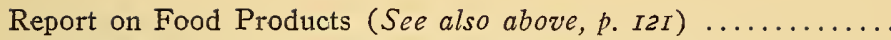

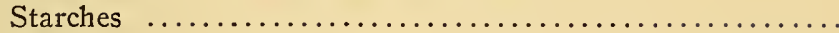

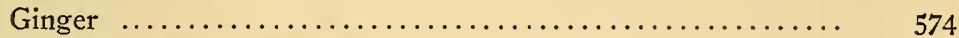

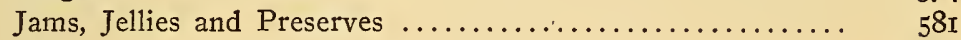

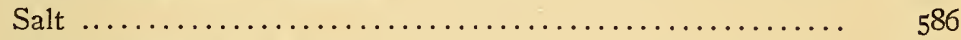

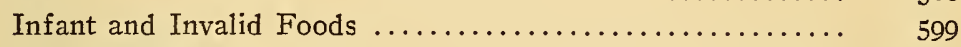

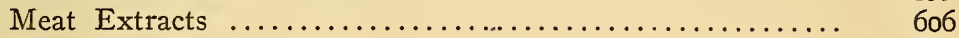

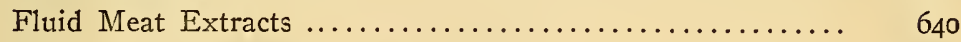

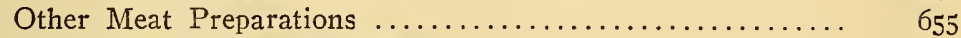

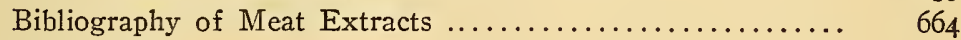

Report on Drugs :

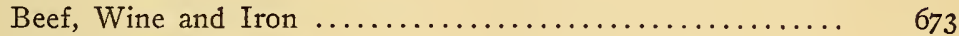

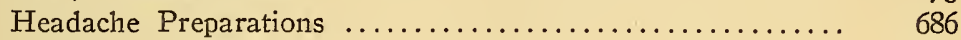

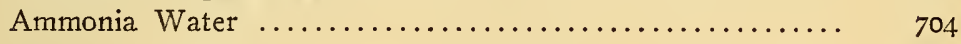

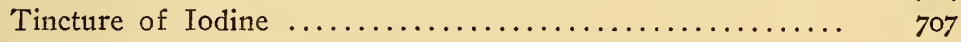

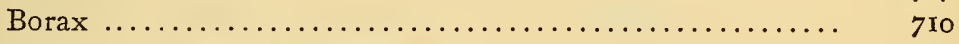

Miscellaneous Foods and Drugs ..................... 7II

Foods and Drugs Examined for the Dairy Commissioner .... 7 I 3

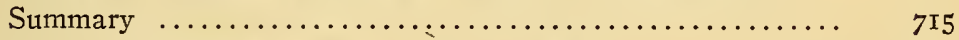

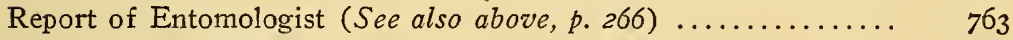

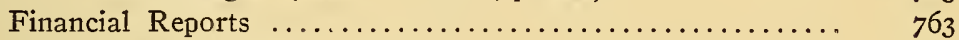

Entomological Features of $1908 \ldots \ldots \ldots \ldots \ldots \ldots \ldots \ldots \ldots \ldots \ldots$

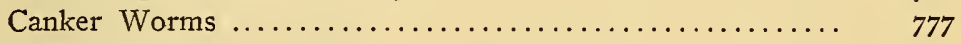

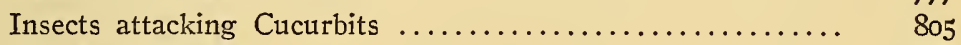

Elm Leaf Beetle ............................. 8I5

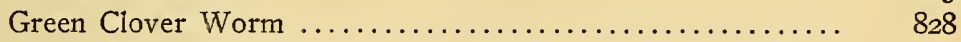

Treatment of Cabbage Plants to Prevent Injury by Cabbage

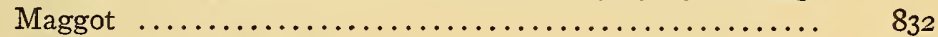

Soluble Oils, home-made ....................... 837

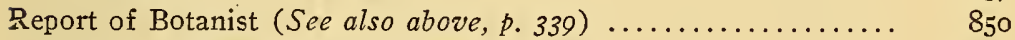

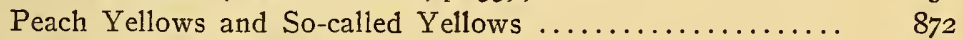

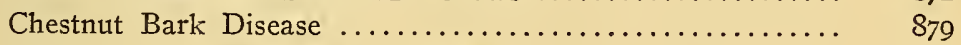

Artificial Cultures of Phytophthora .................... $89 \mathrm{I}$ 



\section{REPORT OF THE BOARD OF CONTROL}

OF THE

\section{CONNECTICUT AGRICULTURAL EXPERIMENT STATION.}

To His Excellency, Rollin S. Woodruff, Governor of Connecticut:

The Board of Control of the Connecticut Agricultural Experiment Station, as required by law, herewith submits its report for the two years ending November Ist, Igo8.

Professor Wilbur Olin Atwater, of Wesleyan University, died in Middletown, Conn., September 22d, I907.

The members of the Board of Control of the Connecticut Agricultural Experiment Station, with this notice of his death, desire also to record their appreciation of the great work which Professor Atwater did for the cause of Agricultural Research, both in Connecticut and in the country at large. Active and helpful in encouraging an interest in the subject and in urging the establishment of an Agricultural Experiment Station in Connecticut, he became Director in the first Station established on this continent, in 1875 , and his influence contributed very largely to the successful establishment of agricultural experiment stations in other states.

He was also for fourteen years Director of the Storrs Station.

After the United States Department of Agriculture had been created and when the office of Experiment Stations was organized within it, Professor Atwater was appointed its first director, which office he held for three years and did much in shaping its policy and work.

For nearly twenty-seven years and until his last illness, he was a valued member of this Board, contributing to the management of its affairs the faithfulness, experience and good sense which had made him so successful in his other work.

Edwin Hoyt, a member of the Board of Control of this Station continuously since its incorporation in 1877 , died at his home in New Canaan, on April I7th, I908.

Born in 1832 , educated in the schools of his native town, he spent a year in further study at the Potter School, at Niagara Falls, and a winter at the Sheffield Scientific School of Yale University, and in 1856 entered the nursery business established by his father, and continued in it until his death. 
The nursery became the largest in New England, and Mr. Hoyt became known throughout the country as an expert nurseryman and orchardist. He was a member and an officer in the State Grange, the State Pomological Society, and other agricultural organizations, both state and national, and his papers presented at meetings of such bodies were always concise, convincing, and valued as the opinion of a disinterested and honest expert.

In his native town he was a prominent worker in the cause of temperance, a member of the Congregational Church, and an office holder in it for more than forty years, and interested in every movement for the advancement of his town and the welfare of its citizens.

He had represented his town in the General Assembly, and at the time of his death was President of the First National Bank of New Canaan.

In all the relations of life he showed himself scrupulously honest, generous and broad-minded, a lover of righteousness and a hater of iniquity.

The members of this Board desire to place on record their appreciation of the long, faithful and valuable service which $\mathrm{Mr}$. Hoyt rendered to the Agricultural Station. His interest in it and his services for it began while it was still only talked of as a possibility, and continued as long as he lived.

The General Assembly, by joint resolution approved May Ist, 1907, accepted the provisions of the so-called Adams Act of the Congress of the United States and directed that one-half of the fund appropriated by this act should be given to this Station and one-half to the Storrs Station.

An act of the last General Assembly concerning Printing, Chapter I33, limits the edition of the Station report to 12,000 copies, the number of pages to 400 , and provides that it shall be issued biennially. Authority is, however, given to the State Board of Control to limit the number of copies printed and to permit the printing of a larger number of pages of such reports as were made biennial by this act. The Board has authorized the printing of ten thousand copies of the report, not to exceed 900 pages, at the state expense, and allows it to be issued in parts as the material is prepared, so as to place the results of the work before the public as soon as they are ready.

A third act of the Assembly affecting this Station is the Food and Drug Law, Chapter 255, which is quite like the National Law, and charges this Station with the examination of drugs as well as food products, but makes no appropriation for the drug work. The Station, however, has been able to do something in the examination of drugs. 
Mr. F. H. Stadtmueller, of Elmwood, was appointed a member of this Board to fill the unexpired term of Mr. Hoyt.

On May Ist, I907, Dr. A. L. Winton, chemist in charge of the analytical laboratory, after twenty-three years of most valuable service to this Station, resigned to accept the position of chief of the United States Food and Drug Laboratory in Chicago.

On September Ist, 1907, Mr. E. J. Shanley resigned his position as chemist, to take a similar position in the Chicago Food and Drug Laboratory.

On October Ist, I907, Dr. Kate G. Barber, the Station microscopist, resigned to take a similar position in the Bureau of Chemistry of the United States Department of Agriculture at Washington.

Mr. John Phillips Street, a graduate of Rutgers College, and for eighteen years connected with the New Jersey Station, was appointed to succeed Dr. Winton, on May Ist, I907.

Mr. C. B. Morrison, a graduate of the Rhode Island Agricultural College, and employed at the time by the Sewage Purification Department of the City of Providence, R. I., was engaged as chemist in September, 1907, and in November, 1907, Mr. Harry R. Stevens, a graduate of the University of Vermont, was also added to the staff as chemist, but was obliged to resign in May, I908, on account of ill health.

Mr. K. G. Mackenzie, a graduate of Yale University; also served the Station as chemist for five months in I908.

Mr. C. A. Brautlecht, a graduate of the Sheffield School of Yale University, was appointed to the Station staff as chemist in April, I908.

In January, I908, Miss Mary H. Jagger was employed to attend to the work of seed testing.

In October of the same year Mr. Clarence Rodman, a graduate of the University of Pennsylvania, and employed at the time as a chemist in the Philadelphia Water Works, was engaged as chemist.

During the summer months of 1907 and 1908, Mr. Paul Graff was employed to put in order and arrange the additions to the herbarium which are noticed later in this report.

Messrs. F. F. Moon and Allen Hodgson, during the same time, assisted Mr. Hawes in the forest survey of the state. 
Six hundred and fifty-one analyses of fertilizers were made in I907, including all of the two hundred and seventy-nine brands registered for sale in the state, and the results published with appropriate discussion as Part I of the biennial report.

In 1908 six hundred and thirty-one fertilizer analyses were made, and the results are already in type.

In I907 fifteen hundred and ninety-four food products were examined with reference to adulteration and all cases of adulteration reported to the dairy commissioner, with whom rests the enforcement of the law. A full report on all the samples was issued as Part II of the report.

In 1908 ten hundred and seventy-four analyses of foods, and four hundred and four of drugs were made and reported to the commissioner as before. The results are nearly ready for printing.

Two hundred and thirty-seven samples of feeding stuffs, including nearly if not quite all the brands sold in Connecticut, were analyzed in 1907, and the results published and discussed in Part III of the report. In Igo8 about the same number have been collected and are now being examined.

Examinations and analyses have been made of all the brands of arsenical insecticides which could be found in the state, twentythree in number, and the restults printed in Bulletin 157 .

As usual, a good deal of miscellaneous analytical work has been done, and also work in testing and improving analytical methods.

One hundred and fifty-four pieces of measuring apparatus for the Babcock test have been tested for creameries and individuals. Nine pieces were condemned as inaccurate.

The work done during 1907 and 1908 in the laboratory for protein research, supported in part by the Carnegie Institution and in part by the Adams fund, may be summarized as follows:

A full report on the Chemistry of Protein of the Wheat Kernel has been made and published by the Carnegie Institution as Publication 84 .

A new substance, a dipeptide of proline and phenylalanine, has been isolated from one of the wheat proteins. This substance is important, not only in connection with the structure of wheat protein, but in connection with the chemistry of proteins in general. 
Quantitative determinations have been made of the proportions of decomposition products yielded by a considerable number of vegetable proteins, and the results have been published.

Similar determinations have been made in a number of animal food substances to compare with the others, and to determine whether or not wide differences in decomposition products existed between animal food substances similar to those in vegetable proteins.

The extended study of the determination of the different forms of nitrogen in a. large number of vegetable and animal proteins has been finished.

Experiments with the nucleic acid of wheat have settled an important point in the chemistry of this class of substances which has been the subject of much controversy.

The results of the work of this laboratory have been given in twenty-one papers published in scientific journals.

During 1907 and 1908 the entomological department has spent much effort in subduing the gipsy moth at Stonington, the only place in the state where it has been found. The infested area has been isolated as well as could be by the destruction of shrubs and bushes on all sides of it, and has been made considerably smaller, and within the area all larvae, pupae and egg masses discoverable by men working from November, 1906, to September, 1908, have been destroyed. Fourteen thousand trees were banded and inspected daily during the caterpillar season of each year, and fifty-five hundred caterpillars, two hundred pupae, and one hundred and forty-one newly laid egg masses were destroyed.

By act approved June 5th, 1907, the General Assembly of 1907 appropriated \$1,000 for fighting the gipsy moth, and provided that the State Board of Control might supply additional funds to the amount of $\$ 10,000$, if, in their judgment, it should be necessary. Five thousand dollars have been spent from this appropriation, one hundred dollars supplied by the State Board of Agriculture, and $\$ 1,513.34$ from the regular state appropriation for the entomologist.

A new orchard pest, the peach saw-fly, which proved to be a new species, was studied, and its life history determined and described. It was very abundant in the peach orchards of one sections of the state, and threatened great injury. Under the direction of the entomologist spraying with arsenate of lead controlled the pest perfectly. 
Experiments on the effectiveness of the fumigation of nursery stock with five different gases have been concluded.

Tests of remedies against the cabbage maggot and squash borer have been completed on the Station grounds at Mt. Carmel.

Examinations of localities where mosquitoes breed have been made, particularly at Beaver Swamp, New Haven, infected with the malaria-bearing mosquito, and by request of health officers, at the state rifle range, East Haven, and in the region about Stamford.

A paper on the Orthoptera of the state has been prepared for the Natural History Survey by Mr. B. H. Walden, and a general introduction to the insects of the state by Dr. Britton.

The insect collection now contains nearly 3,500 species, and over 30,000 specimens.

Ninety-two nurseries and seventy orchards and gardens have been inspected, and 338 samples of insects identified in answer to inquiries.

Four papers on entomological subjects have been prepared for scientific journals or reports.

The work of the agronomist, in large part supported by the Adams fund for scientific research, may be summarized as follows:

Dr. East has finished a preliminary study of the factors involved in the improvement of the potato, the relation of physical and chemical characters to quality, and the amount of fluctuation of these characters, a work begun at the University of Illinois, in I90I, completed here, offered as a thesis for the doctorate degree, and published by the Illinois Station as Bulletin I27.

A study of the physiology of the production of seed and of the difficulties attending hybridization in the potato, in which over seven hundred varieties have been under observation, has been finished and the results published.

In a study of inheritance of fluctuations within a bud propagating line (potatoes), using the nitrogen fluctuation for the observed character, the second generation has been grown.

The crosses between varieties of potatoes made in 1907 were grown in 1908, in order to study the inheritance of different unit characters.

In a study of the graft hybrids in potatoes it has been shown that no transference of coloring matter can be made, and certain errors in published work on the subject have been explained. 
Some interesting results on bud variation have been obtained which offered a new explanation for the phenomenon.

The experiment at Elmwood in increasing by selection the protein content of a variety of corn has been continued. At the station at Granby several hundred crosses of corn have been made to determine the inheritance of various characters, and the second generation of several previous crosses have been grown, as well as the third generation of certain inbred varieties.

The coöperative tests in corn breeding, started in 1905, have, in 1908 , been left entirely to the coöperators.

In studying the laws of inheritance with tobacco, which is a plant better suited to the purpose than any other of economic value grown here, I25 varieties have been grown for classification, for observation as to commercially desirable kinds, and, chiefly, to obtain varieties with different unit characters to use in heredity experiments.

In the greenhouse an experiment with tomatoes is in progress to determine whether it is possible by abnormal treatment of the developing seed to change in any way the usual characters of the offspring. The question is one of great economic importance.

Field, laboratory, and pot experiments have been made to test the availability of potassium in fine ground feldspar, so far without decisive results.

On the Station farm land the study of soil needs and improvement by rotations, cover crops, green manures and fertilizers has been continued with observations on fall and spring seeding with clover, together with experiments in spraying and other means of combating insect and fungus attacks; the latter under the direction of the entomologist and botanist.

Four papers on the subject of Dr. East's work have been read at meetings of specialists or published in scientific journals.

The botanist, Dr. Clinton, was absent on leave for two months in Igo8, to do some preliminary work on the inoculation of the brown tail moth with the Empusa disease for the State of Massachusetts. This was done at Harvard University under the direction of Prof. Thaxter, formerly botanist of this Station.

Besides study and observation on the fungous troubles of crops in all parts of the state, collecting and arranging additions to the herbarium, and conducting experiments on the Station experi- 
ment land and in the greenhouse, the study of the botanist during the last two years has been chiefly on the following subjects:

I. The "Calico" disease of tobacco and chlorosis in other plants.

2. The downy mildew of Connecticut. (For the State Natural History Survey of the state.)

3. A study of roo varieties of muskmelons, especially regarding their resistance to blight and adaptability to Connecticut conditions.

4. The root rot of tobacco.

5. Certain Peridermia and their telial stage.

6. Potato blight.

On the Station's experimental forest the forester has continued experiments on the economic planting of white pine, and on different methods of seeding and planting forest trees, on fertilizing young trees by growing cow peas, on the progress of the white pine disease, and the best treatment of the pine weevil.

The forest nursery contains about 950,000 seedling trees, mostly one-year-olds, and 300,000 seedlings in addition have been sold at cost to landowners.

Four acres of pine growth 30 years old have been bought in Enfield for experiments in thinning.

The increased interest in forest planting is shown by the facts that about 100,000 forest trees were planted in the state in 1906, 350,000 in 1907 , and 600,000 in the present year.

A number of landowners in marketing their mature lumber are doing the work by improvement thinnings planned by the Station forester.

As state forester, Mr. Hawes has carried on improvement thinning and planting work both at the Portland and Union forests. A tract of I30 acres of waste land frequently burned over has been bought for a state forest in Simsbury, and 20,000 trees already planted.

The fire warden service has been greatly improved and a pamphlet of instructions to fire wardens, containing also a list of wardens with telephone calls of those who have them, has been distributed.

In 1908, alone, the wardens reported ${ }^{5} 6$ fires, burning over Io,807 acres, of which 6,100 were sprout and timber land. 568 
cords of cut wood were destroyed. I,347 men were employed in fighting fire, and the total amount paid them by state, county, and town was about $\$ 9.00$ per fire.

In Simsbury, alone, a single patrol during the danger season of April and May put out 35 fires before any considerable damage was done.

A forest survey has been made of Litchfield and Fairfield counties, and in coöperation with the Yale Forest School of New Haven County, estimating the quantity and kind of the standing timber. All wood lots of over ten acres are plotted on topographic sheets. The map is completed and the report prepared on the wood supplies and wood industries of these counties.

Miss Jagger has made five hundred and thirty-five examinations of seeds, a part on samples sent by seedsmen and buyers, and a part bought by our sampling agent in different parts of the state.

Twenty-eight thoroughbred Guernsey cows and twenty-nine Jerseys have been tested for advanced registry by monthly determinations of production of milk and of butter-fat. The tests of twelve Guernseys and ten Jerseys have been finished, and eleven were withdrawn before the year's test was finished.

At present seventeen Guernseys and eighteen Jerseys are being tested.

Within the period covered by this report the Station has acquired by purchase for its collections several hundred species of European fungi, and the herbarium of J. N. Bishop, of Plainville, containing between two and three thousand specimens.

Dr. W. A. Murrill, of the New York Botanical Garden, has given the Station one hundred specimens of the common Polyporei.

Mr. James Shepard, of New Britain, has given the Station the herbarium of his daughter, recently deceased, Miss Celia Antoinette Shepard, containing one thousand or more species, chiefly from Connecticut, but including many from other states and foreign countries.

Prof. S. W. Johnson, formerly director of this Station, has given, conditionally, to its library five hundred bound volumes and many pamphlets from his valuable agricultural library. These include sets of a number of valuable journals, almost impossible to get now from book dealers, and works on scientific 
XVIii CONNECTICUT EXPERIMENT STATION REPORT, I9O7-I9O8.

agriculture which represent its history and development from the early years of the last century.

Members of the staff have made addresses at one hundred and six institutes, grange meetings, and other agricultural gatherings.

The Station has coöperated with the United States Department of Agriculture in tobacco breeding work and in a study of the improvement of sweet corn by selection of seed.

In the two years the Station has published one report of four hundred and twenty-three pages, with thirty-three plates, and onehalf its biennial report of four hundred and fifty-three pages, with forty-seven plates. It has also issued six bulletins aggregating one hundred and forty-one pages, with nine plates and figures, and four bulletins of immediate information, aggregating twenty-three pages and nine figures. The editions range from eight thousand to ten thousand copies.

In the two years fourteen thousand three hundred and fortytwo letters and manuscript reports have been written and mailed from the Station.

All of which is respectfully submitted.

(Signed)

William H. Brewer, Secretary.

New Haven, Conn., November I, Ig08. 


\section{REPORT OF THE TREASURER, 1907}

E. H. Jenkins, in account with The Connecticut Agricultural Experiment Station for the fiscal year ending September 30, I907.

RECEIPTS.

Balance on hand, October I, I906:

Analysis Fees ............... \$522.15

Insect Pest Appropriation ......... 650.00

State Appropriation, Agriculture ............\$10,000.00

$\$ \mathrm{I}, \mathrm{I} 72 . \mathrm{I}_{5}$

State Appropriation, Food $\ldots \ldots \ldots \ldots \ldots \ldots \ldots \ldots$ 2,500.00

State Appropriation, Insect Pest ............. 3,000.00

State Appropriation, Gypsy Moth ........... 2,500.00

United States Appropriation, Hatch .......... 7,500.00

United States Appropriation, Adams ........... 3,750.00

Analysis Fees ........................ 2,900.00

Miscellaneous Receipts ................... 46.45

From the Lockwood Estate .............. I0,800.0n

Total

Disbursements.

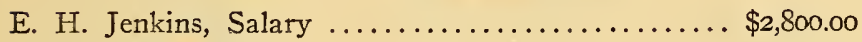

W. H. Brewer; " $\ldots \ldots \ldots \ldots \ldots \ldots \ldots \ldots \ldots \ldots$ I00.00

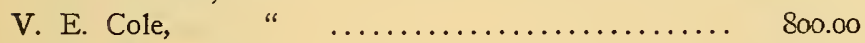

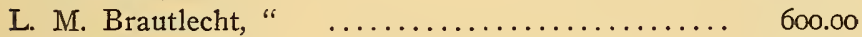

A. L. Winton, "

J. P. Street, " "

T. B. Osborne, "

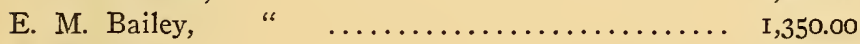

Kate Barber, " $\quad \ldots \ldots \ldots \ldots \ldots \ldots \ldots \ldots \ldots \ldots$ 1,066.66

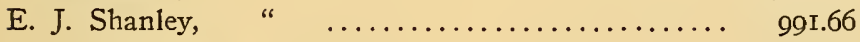

C. B. Morrison, " $\ldots \ldots \ldots \ldots \ldots \ldots \ldots \ldots \ldots \ldots$ I8.75

W. E. Britton, " $\ldots \ldots \ldots \ldots \ldots \ldots \ldots \ldots \ldots \ldots$ I,700.00

G. P. Clinton, " $\ldots \ldots \ldots \ldots \ldots \ldots \ldots \ldots \ldots \ldots$ 2,000.60

A. F. Hawes, " " $\ldots \ldots \ldots \ldots \ldots \ldots \ldots \ldots \ldots$ I,291.66

E. M. East, “ $\quad \ldots \ldots \ldots \ldots \ldots \ldots \ldots \ldots \ldots$ I,700.00

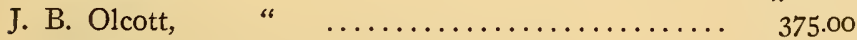

H. Lange, . "

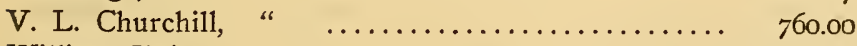

William Veitch, " $\ldots \ldots \ldots \ldots \ldots \ldots \ldots \ldots \ldots \ldots, 633.33$

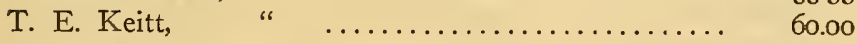

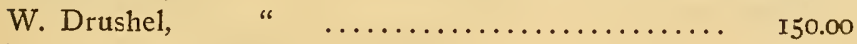

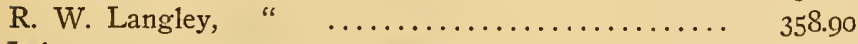

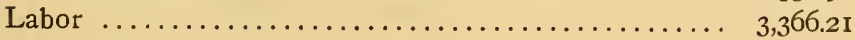

Publications $\ldots \ldots \ldots \ldots \ldots \ldots \ldots \ldots \ldots \ldots \ldots \ldots . \quad 583.29$ 


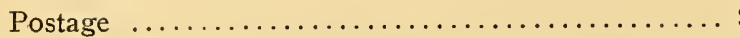

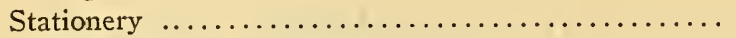

Telephone and Telegraph $\ldots \ldots \ldots \ldots \ldots \ldots \ldots \ldots \ldots$

Freight and Express $\ldots \ldots \ldots \ldots \ldots \ldots \ldots \ldots \ldots \ldots \ldots$

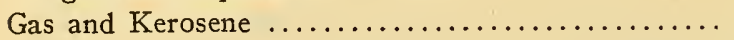

Coal

Water

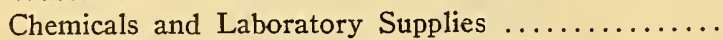

Agricultural and Horticultural Supplies ...........

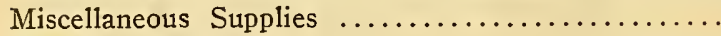

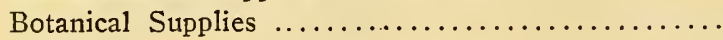

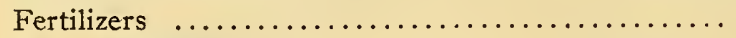

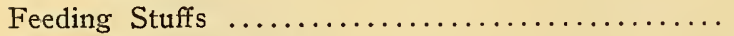

Library and Periodicals..$\ldots \ldots \ldots \ldots \ldots \ldots \ldots$

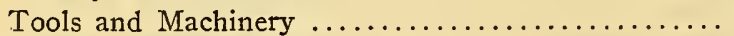

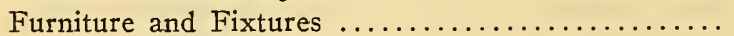

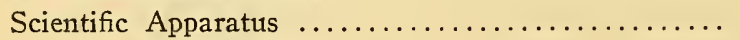

Traveling by the Board $\ldots \ldots \ldots \ldots \ldots \ldots \ldots \ldots \ldots$

Traveling by the Staff $\ldots \ldots \ldots \ldots \ldots \ldots \ldots \ldots$

Traveling in connection with Adams Fund Investigations

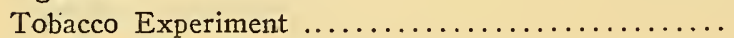

Fertilizer Sampling $\ldots \ldots \ldots \ldots \ldots \ldots \ldots \ldots \ldots \ldots$

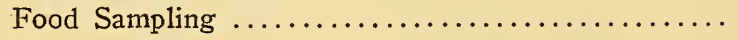

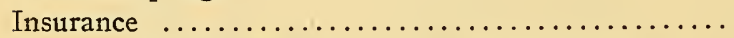

Insect Pest Appropriation to State Entomologist ....

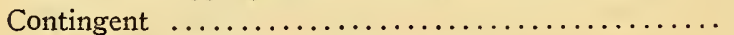

Forestry and Lockwood Expenses .....................

Gypsy Moth Appropriation to State Entomologist ...

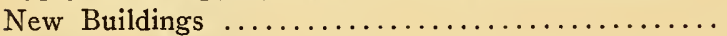

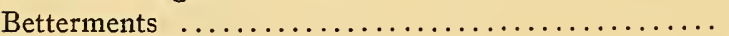

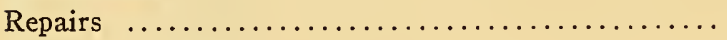

Rental of Land ..................... $\quad 120.00$

Balance on hand, October I, I907:

$\begin{array}{lrr}\text { Analysis Fees ..................... } & \$ 307.79 \\ \text { State Agricultural Appropriation } \ldots \ldots . & 502.82\end{array}$

Total
$\$ 160.45$

283.94

211.65

149.98

$329.2 \mathrm{I}$

I,302.05

I 57.39

I,I94.35

33I.I7

250.26

72.20

255.29

I 18.53

594.68

300.74

I 37.40

82.33

79.40

623.19

I78.76

75.30

206.27

$34 \mathrm{I} .2 \mathrm{I}$

28.20

$3,650.00$

I93.45

$2,256.85$

$2,500.00$

88.12

I I 5.27

698.22

$\$ 43,357.99$

8 ro.6r

$\$ 44,168.60$

New Haven, Conn., November 5, 1907.

This Certifies that we have examined the accounts of $E$. H. Jenkins, Treasurer of The Connecticut Agricultural Experiment Station, for the year ending September 30, I907, compared the same with the vouchers therefor and found them correct.

William P. BaIley, EDWARD S. Roberts, Auditors of Public Accounts. 


\section{REPORT OF THE TREASURER, 1908}

E. H. Jenkins, in account with The Connecticut Agricultural Experiment Station for the fiscal year ending September 30, Igo8.

\section{RECEIPTS.}

Balance on hand, October I, 1907:

Analysis Fees ............... \$307.79

State Agricultural Appropriation ..... 502.82

State Appropriation, Agriculture ...........\$10,000.00

$\$ 810.61$

State Appropriation, Food ................ 2,500.00

State Appropriation; Insect Pest .............. 3,000.00

State Appropriation, Gypsy Moth ........... 2,500.00

United States Appropriation, Hatch .......... 7,500.00

United States Appropriation, Adams ......... 4,750.00

Analysis Fees ....................... 8,799.98

Sale of Tobacco ..................... 65.97

Sale of Farm Products $\ldots \ldots \ldots \ldots \ldots \ldots \ldots \ldots \ldots . \quad 228.25$

Miscellaneous Receipts .................. 433.52

From the Lockwood Estate .............. 9,177.40

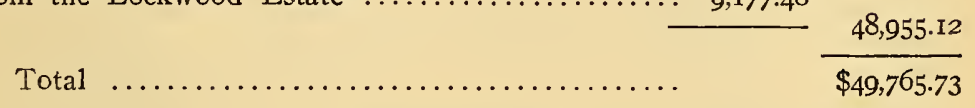

Disbursements.

E. H. Jenkins, Salary $\ldots \ldots \ldots \ldots \ldots \ldots \ldots \ldots \ldots \ldots \ldots 2,800.00$

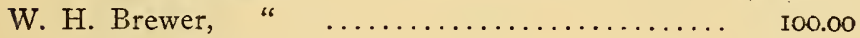

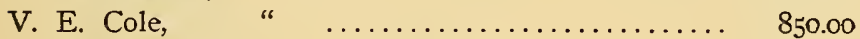

L. M. Brautlecht, " $\ldots \ldots \ldots \ldots \ldots \ldots \ldots \ldots \ldots .6 \% \ldots$

J. P. Street, " " $\ldots \ldots \ldots \ldots \ldots \ldots \ldots \ldots \ldots \ldots 2,2,500.00$

T. B. Osborne, " $\quad \ldots \ldots \ldots \ldots \ldots \ldots \ldots \ldots \ldots \ldots, 2,200.00$

E. M. Bailey, " $\ldots \ldots \ldots \ldots \ldots \ldots \ldots \ldots \ldots$ I, 550.00

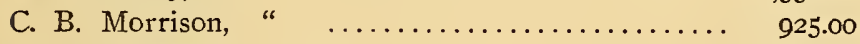

H. R. Stevens, “ $\ldots \ldots \ldots \ldots \ldots \ldots \ldots \ldots \ldots \ldots$. 500.00

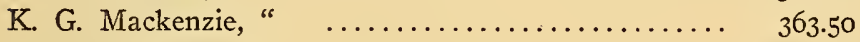

C. A. Brautlecht, " $\ldots \ldots \ldots \ldots \ldots \ldots \ldots \ldots \ldots \ldots .450 .00$

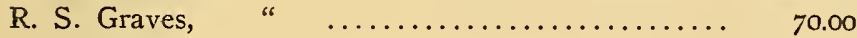

W. E. Britton, " $\quad \ldots \ldots \ldots \ldots \ldots \ldots \ldots \ldots \ldots \ldots 2,000.00$

G. P. Clinton, " $\quad \ldots \ldots \ldots \ldots \ldots \ldots \ldots \ldots \ldots \ldots$ I,833.32

A. F. Hawes, " $\quad \ldots \ldots \ldots \ldots \ldots \ldots \ldots \ldots \ldots \ldots$ I,800.00

E. M. East, " $\quad \ldots \ldots \ldots \ldots \ldots \ldots \ldots \ldots \ldots$ I,900.00

J. B. Olcott, " " $\ldots \ldots \ldots \ldots \ldots \ldots \ldots \ldots \ldots \ldots 200.00$

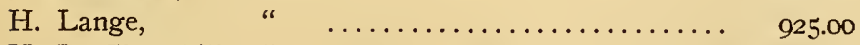

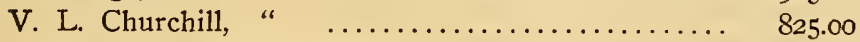

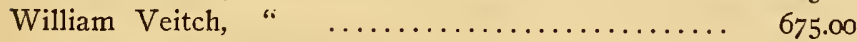

H. W. Kiley (Labor) $\ldots \ldots \ldots \ldots \ldots \ldots \ldots \ldots \ldots \ldots, 728.00$

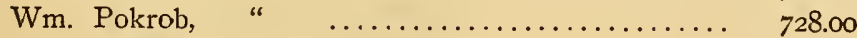

C. D. Hubbell, “ $\ldots \ldots \ldots \ldots \ldots \ldots \ldots \ldots \ldots, \quad 728.00$ 
M. Howley (Labor) . ................... \$280.00

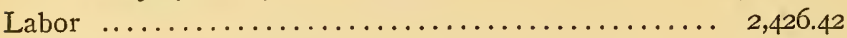

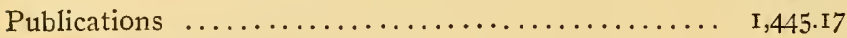

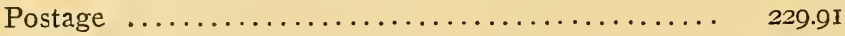

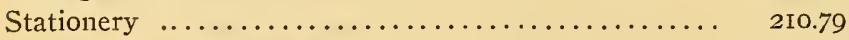

Telephone and Telegraph .................. $\quad \mathbf{1 4 4 . 9 2}$

Freight and Express .................... $\quad$ I28.49

Gas and Kerosene ...................... $\quad 428.36$

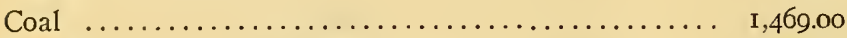

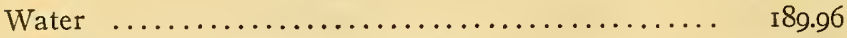

Chemicals and Laboratory Supplies ............ I,283.56

Agricultural and Horticultural Supplies ........ 209.9I

Miscellaneous Supplies .................... $\quad$ I64.42

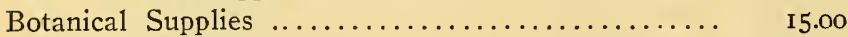

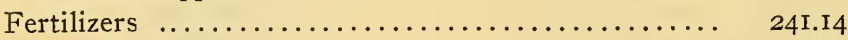

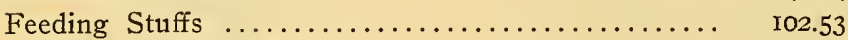

Library and Periodicals .................. 612.28

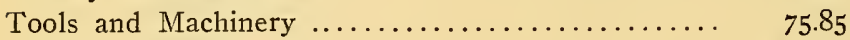

Furniture and Fixtures ................... ${ }_{462.63}$

Scientific Apparatus ..................... 85.47

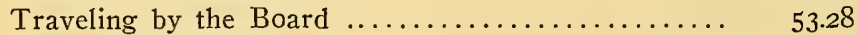

Traveling by the Staff $\ldots \ldots \ldots \ldots \ldots \ldots \ldots \ldots$ I,I 49.18

Traveling in connection with Adams Fund Investi-

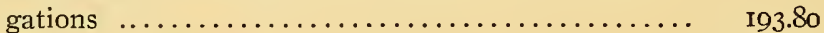

Tobacco Experiment .................... I,272.47

Fertilizer Sampling ......................... I64.10

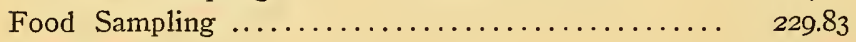

Insurance $\ldots \ldots \ldots \ldots \ldots \ldots \ldots \ldots \ldots \ldots \ldots \ldots . \quad 275.25$

Insect Pest Appropriation to State Entomologist ... 3, 3,000.00

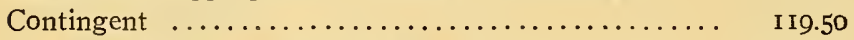

Forestry and Lockwood Expenses ............ I,899.88

Gypsy Moth Appropriation to State Entomologist .. 2,500.00

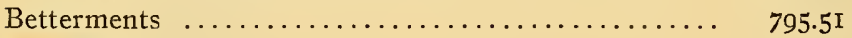

Repairs ......................... I,4I2.90

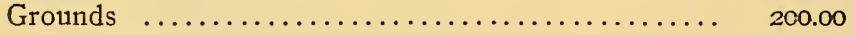

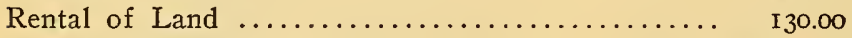

Analysis

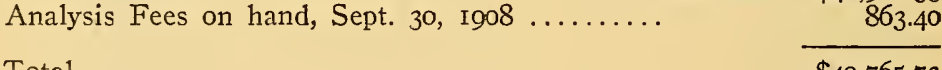

Tota1

$\$ 49,765.73$

New Haven, Conn., October I4, I908.

This Certifies that we have examined the accounts of E. H. Jenkins, Treasurer of The Connecticut Agricultural Experiment Station, for the year ending September 30, I908, have compared the same with the vouchers therefor and found them correct.

William P. Batley,

EDWARD S. ROBERTS,

Auditors of Public Accounts. 


\section{CORRECTIONS AND ADDITIONS.}

Bulletin I63, page I3. Second paragraph from bottom. The Stearns Lime Co. offer water-slaked lime at $\$ 5.00$ in bulk, $\$ 6.00$ in bags, and delivered about $\$ 7.25$. This makes the cost of pure lime and magnesia 60 cents per 100 pounds, instead of 73 , as given in the Bulletin.

Report, page 4, twentieth line, strike out "Wheeler's Havana Tobacco Grower."

page II, sixteenth line from the bottom, for 652 read 651 .

pages $56,60,74$. The fertilizer bearing the name of E. B. Clark Co., Milford, Conn., is made by that firm at its works at Communipaw, N. J. On pages 56,60 and 74 of the Report it is stated that the fertilizer is "made for" E. B. Clark Co. This is an error.

pages 56 and 57. The price of Olds and Whipple's Home Mixture is $\$ 38.00$ per ton, instead of $\$ 28.00$, as given in the table. The percentage difference is I3.I.

page II5. Lime-Kiln Ashes, last line, under I8944, for "IO3" read 54; for "IOI" read 39.

page II9. The statement that the I. M. P. Plant Food contains essentially 55 per cent. of nitrate of potash and 45 per cent. of phosphate of soda is incorrect. It consists essentially of phosphate and nitrates of the alkalies. A more particular statement is not justified by the figures.

page 27I, second line from top, for "weight" read weigh.

page 5Io. The cost price of Manchester's Formula, No. 20767, is $\$ 30.00$ per ton, instead of $\$ 32.00$, and the percentage difference 4.4 , instead of II.3.

page 528 , last line of table, the dealer's price is $\$ 45.00$ and the calculated valuation $\$ 34.56$.

page 534, note, read 530 instead of 529 .

page 725 , last paragraph. The Hominy Feed sold by M. F. Barringer, Philadelphia, was shipped with a guaranty of composition, as required by law.

page 727, second paragraph. After One ex, strike out AI. The manufacturer states that the One ex is the lowest grade of distillers' grains and the mark AI had never been used in connection with it.

The feed represented by sample 207 ro was not made by the Biles Co.

To the explanation regarding Dried Distillery Grains on pages I76 and 726 may be added the following note regarding the several kinds of distillery grains sold by the J. W. Biles Co. : 
Four ex is the product of alcohol distilleries, consisting of 88 to 90 per cent. of corn residues with Io to I2 per cent. of "small grains," chiefly malted barley, with a few oats coming as an unavoidable mixture in the barley.

Two ex, the product of Bourbon whiskey distilleries, contains 60 to 80 per cent. of corn residues and 20 to 40 per cent. residues of "small grains," chiefly rye and malted barley, with a few oats.

Rye grains, the product of rye whiskey distilleries, may consist wholly of rye residues, or of rye and malted barley, with a few oats, or they may have a large admixture of corn.

One ex grains are from vinegar and yeast factories, containing about 50 to 60 per cent. of corn residues and 40 to 50 per cent. of "small grains."

page 729, after the words, "Biles' Union Grains contain," insert cotton seed meal. The manufacturers state that the oat product is very small in quantity and comes entirely from the oats which all malted barley contains as an accidental mixture, the ingredients of the mixture being distillery grains, linseed and cotton seed meal, hominy feed, wheat middlings and bran and barley malt sprouts.

page 777, last line, for "Ridley" read Riley. 




\section{Ftate of Connecticut}

\section{REPORT}

OF

The Connecticut Agricultural Experiment Station

REPORT OF THE STATION BOTANIST, 1909-1910

G. P. CLINTON, SC.D.

BEING PART X OF THE BIENNIAL REPORT OF 1909-1910 



\section{CONNECTICUT}

\section{AGRICULTURAL EXPERIMENT STATION}

\section{REPORT·OF THE BOTANIST \\ 1909 and 1910}

\section{G. P. CLINTON, Sc.D.}

I. Notes on Plant Diseases of Connecticut, . . . . . . . . 713

A. Diseases in Relation to Weather in 1909 and I9Io, . . . 7I 3

B. New Observations on Diseases Previously Reported, . . 7 I6

C. Diseases or Hosts Not Previously Reported, . . . . . 723

II. Spraying Potatoes in Dry Seasons, . . . . . . . . . . . 739

III. Oöspores of Potato Blight, Phytophthora infestans, . . . . 753 



\title{
PART X.
}

\section{REPORT OF THE BOTANIST FOR 1909 AND 1910.}

\author{
G. P. Clinton, Sc.D.
}

\section{NOTES ON PLANT DISEASES OF CONNECTICUT.}

A. DiSEASES IN RELATION TO WEATHER IN IgOg AND IgIO.

Weather Conditions in I909. The winter of Ig08-og was not especially severe, so that trees did not show any unusual injury, except from a couple of ice storms in February, Igog. These storms so heavily coated the limbs that considerable damage resulted, especially to shade and forest trees in the northern half of the state, where the storm was more severe. The spring of 1909 was rather wet and backward, so that such fungous troubles as peach leaf curl, apple scab, etc., that gain their foothold at this time of the year, were unusually prominent.

The summer, however, especially in July and August, like the two preceding seasons, was one of drought, but it was broken in August by rains that prevented serious damage to miost of the crops. The late fall proved to be very dry. The first killing frost did not occur until October $\mathrm{I}_{3}$.

Diseases Prevalent in I909. The following troubles were conspicuous or unusually injurious during this season. Apple: Black Rot (Leaf Spot form), Rust, Scab, and Spray Injury (Bordeaux). Ash: Rust. Chestnut: Bark Disease. Egg Plant: Wilt (Fusarium?). Elm: Leaf Spot. Muskmelon: Leaf Mold, Anthracnose. Peach: Brown Rot (spring form on twigs, etc.), Leaf Curl. Plum: Black Knot. Potatoes: Tip Burn, Scab. Quince: Leaf Blight. Rose: Rust. Spinach: Leaf Mold. Strawberries: Powdery Mildew, Winter Injury (root killing). Tobacco: Calico.

Of the above diseases the leaf spot of elm, which was quite serious in some places, is discussed later in this Report (p. 717). 
The winter seemed in some way to have weakened the spinach crop in the vicinity of Greens Farms, for there were reports that several of the crops there failed because of the subsequent action of the leaf mold fungus described in the Report for 1905, page 275. Mr. Joseph Adams, writing of this trouble, said: "I have a patch of spinach (sown last September in connection with Mr. L. P. Wakeman), which is practically worthless from a black spot which covers the leaves. This is the worst I ever saw. This piece contains about an acre, and we have another piece that is not quite as bad." This fungus was identified by us previously as Heterosporium variable Cke., and Professor Thaxter, who examined these later specimens, writes that it was also described by Cooke as Cladosporium subnodosum (see Grev. I7:67. I889).

Specimens of strawberry plants were received about the middle of June, both from Essex and Naugatuck, with complaints that some trouble was killing off certain fields in those places. Examination revealed no fungus or insect as responsible, but showed that the rootlets were dead, while the crowns were still alive. This was a trouble similar to that seen once before, and discussed in the Report for 1905, page 276. Apparently there was enough life and food in the crowns to put forth leaves in the spring, but with the approach of warm weather these suddenly died off from lack of moisture, etc. The trouble seems to be due to winter injury of the roots, which had either suffered from drought the previous year or else had not been properly protected by snow or mulch during the winter.

Weather Conditions in IOIO. The winter of I909-IO was not especially severe on the whole, though one or two quite cold spells were recorded in January. March proved to be unusually warm and open, and the spring started early, but afterwards cool, rainy weather in May kept back the vegetation so that, as in the preceding spring, it was somewhat backward, and developed an unusual amount of spring fungous troubles. There were two very late frosts, in May and early June, that did more or less injury to fruit blossoms in certain parts of the state, especially cherries, apples and strawberries, and also killed or injured the foliage on certain shrubs, etc., especially in low places. At Windsor we saw small scrub oaks whose leaves were all killed as if by fire. Some injury to coniferous plants was also observed, and no doubt much of the russeting 
of apples, so common this year, was traceable in part to these frosts.

Again the summer proved to be one of drought, thus making four years in succession that may be so classed. However, like the preceding one, it was temporarily broken in midsummer by rains that saved most of the crops from serious injury, though potatoes, especially early varieties, were a very light crop. The fall months were unusually dry, and this late drought was not broken until late in December, so that a water famine threatened many communities. As in the preceding year, the first fall frost was delayed until the middle of October, thus favoring the late crops.

Diseases Prevalent in I9IO. Among the most conspicuous diseases of the year may be mentioned the following. Apple: Rust, Scab, Frost and Spray Injury. Cherry and Plum: Black Knot. Chestnut: Bark Disease, Drought Injury. Corn: Smut. Hollyhock: Rust. Maple: Leaf Scorch. Muskmelon: Mildew Blight. Peach: Leaf Curl, Brown Rot (chiefly spring infection of twigs, etc.). Pear: Scab. Pines: Pine-Sweetfern Rust. Potatoes: Rot (Blight), Tip Burn. Rye and Barley: Powdery Mildew. Quince: Rust. Sycamore: Anthracnose.

Concerning the spray and frost injury of apples, there appears a discussion in Part VII of this Report. There was more peach leaf curl than we have seen before in this state, and while the wet spring favored twig infection with brown rot, this did little harm to the mature fruit except during a wet week in September, when some injury was done to certain varieties in the vicinity of Wallingford. Potatoes suffered most from tip burn, but the rains came so that blight developed slightly on the late varieties and caused some rot of the tubers for the first time in several years. Blight, in late August and early September, carried off many of the melon fields that had not been sprayed.

The effect of successive droughts of the past four years has begun to be manifest on our shade and forest trees, so that an unusually large number of them are dying. This is especially true of the chestnuts, where the blight fungus plays a very important part on these weakened trees.

On the whole, I909 and I9I0, because of their dry summers, were not years in which fungi became especially troublesome, 
except those starting during the wet springs. In Parts $\mathrm{B}$ and $\mathrm{C}$ of this paper we discuss certain diseases that are new to the state, or concerning which special information was obtained.

\section{B. NEW OBSERVATIONS ON DISEASES PREVIOUSLY REPORTED.}

\section{APPLE, Pyrus Malus.}

Spray Injury. Both during 1909 and rgio there was considerable injury resulting from spraying apples in this state with Bordeaux mixture. As previously reported, this injury was of the nature of leaf spotting and fruit russeting. Experiments conducted in I9IO with different fungicides to replace Bordeaux, because of this tendency to injure, showed that there was danger of serious leaf spotting and subsequent fall with "One for All" (rate 5 or 6 lbs. to 50 gallons of water), and also with "Sulfocide" (rate I to 200) when either Paris green or arsenate of lead was used with it, though the injury with Paris green when lime was added was lessened. Even without these insecticides, this strength of "Sulfocide" sometimes produces more or less leaf spotting. Some leaf injury was also caused by Bogart's "Sulphur Compound" used at the rate of $I \frac{1}{2}$ to 50 . Practically no russeting or leaf spotting was produced by any of the straight commercial lime-sulphur sprays, with arsenate of lead added, even at the rate of $I I / 2$ to 50 , except what occasionally occurred in the shape of sun scald on the most exposed side of the fruit. While this rarely occurred, when it did it produced rather serious injury. On the whole, the straight commercial lime-sulphur sprays were the most satisfactory as regards least spray injury. For further information, see Part VII of this Report.

\section{CHESTNUT, Castanea dentata.}

Chestnut Bark Disease, Diaporthe parasitica Murr. In our Report for 1908, page 879, we gave an account of this trouble. At that time it had been reported in every one of the twenty-three towns of Fairfield County, and in eight towns in New Haven County, making thirty-one towns altogether. At the time of writing this article (March 20, I9II), its known distribution is as follows: Fairfield County, twenty-three towns; New Haven County, twenty-one towns; Litchfield County, 
fourteen towns; Hartford County, seven towns; Middlesex County, two towns; Tolland County, three towns; Windham County, one town; New London County, one town. This makes a total of seventy-two towns, of which only seven are east of the Connecticut River. We have no doubt that a more thorough survey of that region would reveal its presence, in an inconspicuous way, in quite a few more towns.

This increased distribution in the last three years may indicate that the disease has spread to those new localities, or it may mean that a more thorough search has revealed its presence, and that it has also become more prominent because of the four years of drought that have occurred, beginning with 1907. There are those who believe, however, that unfavorable weather conditions have nothing to do with the prominence of this disease, which they suspect to be a recent importation into this country from Japan. If this theory is true, then we are just beginning to feel the effects of its devastation in this state. Personally, we have not yet found convincing proofs to cause us to change our views expressed in the above-mentioned Report. These views, briefly given, are (I) that the fungus is a native, weak parasite, usually very inconspicuous in its damage, and therefore rarely noticed; and (2) that the unusual winter of 1904, by severely injuring chestnut trees, gave it a chance to spring into unusual and sudden prominence, which it has since maintained and even increased by reason of four successive years of drought, that have injured not only chestnuts, but many other trees.

We do not, and never have, questioned its seriousness. Trees that have been marked in two localities by the botanical and the forestry departments have uniformly showed injury greatly in excess of that indicated when first examined. If our theory is correct, we do believe, however, with the return of several normally wet years the trouble will gradually grow less rather than more conspicuous as it should if weakened vitality of the trees has nothing to do with its development.

\section{ELM, Ulmus americana.}

Leaf Spot, Gnomonia Ulmea (Schw.) Thuem. Plate XXXIV. During the summer of Igog several complaints came to the station of elm trees shedding their leaves where the elm leaf 
beetle had not been at work. The most serious injury seemed to occur in the vicinity of Chapinville. At the request of $\mathrm{Mr}$. Walter Angus, manager of the Scoville estate at that place, $\mathrm{Mr}$. Walden first visited there in August, and as he found no insect responsible for the trouble the writer made an investigation early in September to determine if a fungus was the cause of it. By July, or earlier, some of the trees had almost entirely shed their leaves, and later put forth a new crop, and these, when examined by the writer, were quite free from fungous attack. Other trees, however, not originally so severely injured, showed the leaves quite badly infected with the above fungus, and these had been shedding their leaves more or less during the season. Where the defoliation had been rather severe, the young branchlets of the season had also frequently fallen off. While the fungus was present on some trees more than on others, and while some of the fallen leaves showed no sign of the fungus, it seemed quite evident, after a careful examination, that this fungus was primarily responsible for the trouble, but that drought had helped to exaggerate it. The illustration shows the condition as regards foliage of one of the trees photographed by Mr. Walden in August.

The fungus produces very numerous, small, black eruptions on the upper surface of the leaves, and these often merge more or less in small groups. In time the specimens show a whitish or grayish margin around these black cushions, due to the wearing away of the epidermis. We have been unable to find any fruiting stage in any of the specimens we have gathered in different years, as the only known stage produces its ascospores on the fallen leaves the subsequent spring. Infection seems to take place only early in the season, since the trees early denuded did not have their second crop of leaves attacked to any extent. Apparently the weather conditions in the spring determine the character and amount of infection, and these conditions seem to have been unusually favorable in I909. In I9IO, on the same estate in Chapinville, the fungus did practically no harm, though the trees bore a smaller crop of leaves, due to the shedding of the small twigs the previous year and to the death of others that were severely injured.

Spraying the unfolding leaves with Bordeaux would probably control this trouble, though the uncertainty of its appearance would make such a treatment rarely practical. 
This fungus was placed by Ellis under the genus Dothidella as D. Ulmea (Schw.) E. \& E. It is, however, quite distinct in its microscopic appearance, as Ellis states, from Dothidella Ulmi (Duv.) Wint., although the two have ascospores very similar. The latter fungus has its perithecia embedded in a distinct black stroma, and the necks open on the upper surface of the leaves. The former, by the crowding of the perithecia together, has something of the appearance of an imperfect stroma, while the perithecia open on the under surface of the leaves mature their asci later, and apparently have no other stage connected with them.

HEMLOCK, Tsuga canadensis.

Hemlock-Heath Rust, Pucciniastrum Myrtilli (Schum.) Arth. (I. Peridermium Peckii Thuem.) The I stage of this fungus (see Report 1907, pp. 350, 383), which is not uncommon, though rarely abundant, in this state on hemlock, has now been connected by us, through artificial infections, with the II and III stage of the above Pucciniastrum, which we found in I9Io for the first time on various species of blueberry and huckleberry. Pucciniastrum minimum on cultivated azaleas, also found here (see Reports 1907, p. 392 and 1908, p. 854), is probably not distinct from this Pucciniastrum.

PEACH, Prunus Persica.

Spray Injury. Sturgis (Report I900, p. 219) has recorded spray injury to the foliage of peach by Bordeaux and other fungicides used in his experiments to prevent peach rot and scab. He found potassium sulphide to be about the least injurious fungicide when used at the rate of $\mathrm{x} 1 \mathrm{~b}$. to 50 gallons of water. In our experiments with spraying peaches in I9Io, this strength was used, and very little injury, except shot-holes in a few of the leaves, resulted. However, when arsenate of lead (rate of $3 \mathrm{lbs}$. to 50 gallons potassium sulphide) or Paris green ( $\mathrm{I}$ lb. to IOO) was added, the most serious injury resulted. Not only were the leaves badly injured by shot-holes, but in time they all fell off. Many of the young twigs were also badly spotted (purplish spots much like those produced by the scab fungus), ard some were killed. A few young trees were so severely injured that they finally died. 
Very similar results were obtained when either of these insecticides was used with "Sulfocide." This spray, even when used without them, at a rate of I to 200 produced more or less injury, and even some on young trees at I to 400 . With both potassium sulphide and "Sulfocide" the injury resulting from the addition of the poisons was due to the production of a soluble arsenate which burned the tissues.

\section{PINE, WHITE, Pinus Strobus.}

So-called "Blight." In our Report for 1907, page 353, we described the white pine "blight," which was general that year not only in Connecticut but all over New England. We took the view that it was a physiological trouble due to adverse weather conditions (such as winter, drought, and frost injuries), though there were those who believed that it was of a contagious nature, due to fungous attack. We now have data at hand to prove that we were correct. In general this disease becomes evident by the leaves being killed to a greater or less extent from their tip downward, the dead portion turning reddish brown, and also by the undersized leaves, which remain bunched, due to the failure of the branches to lengthen out.

That the disease is not contagious was suggested strongly in our previous studies, since leaves on one tree may all be badly affected while those of an adjacent tree show no signs of the trouble. This noncontagious nature has been clearly proved by observations made in the station's forest plantation on a lot of white pine trees eight years old, in I9IO, from planting. At our request the forester, Mr. Hawes, early in the spring of Igo8 had all the diseased trees of this plot marked by permanent stakes. There were one hundred and twenty-four of these so marked, but it seems quite likely that some few that showed the disease slightly at the time were not included. We examined them that fall, and found that their condition on the whole seemed somewhat improved, and that there was no general increase of the trouble, though some trees that had not been marked showed signs of the disease. In July, I909, and again in November, I9IO, careful examinations were made of the plot, and the condition of each diseased tree noted. The comparative condition of these trees as regards foliage is shown in the following table: 


\begin{tabular}{|c|c|c|c|c|c|c|}
\hline $\begin{array}{c}\text { Date of } \\
\text { Examination }\end{array}$ & $\begin{array}{l}\text { Diseased, but } \\
\text { not marked } \\
\text { in } 1908\end{array}$ & Dead & $\begin{array}{l}\text { Nor } \\
\text { Improved }\end{array}$ & Improved & Cured & Total \\
\hline July, Igog-.... & 24 & 5 & 54 & $3^{8}$ & $2 I$ & 142 \\
\hline Jov., I9IO _... & I8 & 6 & 9 & 65 & 44 & $I_{42}$ \\
\hline
\end{tabular}

This shows that there has been gradual improvement since the trouble first showed in 1907 , and that there has been practically no subsequent spreading of the trouble. That is, in I9Io there were only eighteen trees showing the disease, among the 3,000 to 3,200 in the plot, that did not show it in the spring of Igo8. Of these eighteen, at least thirteen were included as questionable; that is, there was not positive evidence that it was this trouble, as the leaves were only slightly affected. No doubt, too, some of these were trees that were not marked originally because they were not badly injured. It is also quite probable that some were trees whose leaves were injured by the frosts of I9IO, of which we shall speak later, as the injured leaves were often largely on lower branches. Finally, there was no relationship in position between these trees and those badly diseased.

Concerning the effect of the so-called "blight" on the subsequent growth of the trees, we may state that those that were very badly injured have either died, or remained so stunted in growth that their subsequent usefulness is quite doubtful. Others that were rather severely injured have made some growth, and their foliage condition, especially as to color, has improved considerably, though the leaves often remain more or less stunted and bunched. Those least injured have recovered their normal leaf appearance, but are still somewhat backward in their growth. Some few seem to have almost entirely recovered from the effects, and are scarcely to be distinguished in size and appearance from the surrounding trees that were not injured.

Concerning the cause of the sudden appearance of this "blight" in 1907, we are now quite convinced that it was due to the severe frosts that occurred on May II and $2 \mathrm{I}$ of that year. We mentioned these as a possible cause in our previous Report, but at that time we had no proof as to their connection, as the "blight" was not called especially to our attention until August. In I9Io, however, we saw the same trouble produced on certain pines by the late frosts of May and June of that year. Soon after these frosts we found the leaves of scrub 
oaks in certain regions entirely killed by the frosts, just as had been the case with the leaves of sycamore trees in 1907. In I9IO, however, the frosts were much more local in their effects, and in a given region often killed the leaves only on the lower trees and the shrubs, especially those in low places. Shortly after the last of these frosts we visited the white pine plantations on the Whittemore estate at Middlebury, and here we found not only small oaks and other trees in low spots with injured foliage, but also the young pines in these low places showed "blight" injury on the tips of their leaves. Often a difference of only a few feet in the level of the ground on which these stood determined whether or not they were injured.

We have also noted elsewhere in this Report injury by these frosts to pine seedlings in the seed beds. Whether or not a pine tree is injured by the late frosts seems to be determined by the state of development of the foliage at the time, as well as by the lay of the land and the character of the frost. Previous to 1907 we had some few complaints of pine "blight," which we may attribute to winter injury of the roots, and no doubt drought or other injury to the roots, if severe, produces a similar effect. Hartig, in his Diseases of Trees, English ed., p. II I, notes a similar "blight" trouble in Europe, due to frost and drought injury.

PLUM, Prunus sp.

Bacterial Spot, Pseudomonas Pruni Sm. This has been reported here before on peach, causing spots on the leaves, and on the plum, causing large black spots on the fruit. In July, I9IO, it was seen at the Ives farm, Meriden, for the first time causing a shot-hole spotting of plum leaves, similar to that not uncommon on the peach.

\section{SPRUCE, NORWAY, Picea excelsa.}

Smoke Injury. During the summer of I9IO the writer saw young spruce trees at East Rock Park, New Haven, that had been injured by smoke from a brick kiln about half a mile distant. The injury occurred suddenly on a day when the atmospheric conditions were just right for blowing the smoke among the trees. The young leaves of this year were killed and subsequently dropped off, but those of the previous'year were 
not injured. Some other conifers were also slightly injured, but the deciduous trees escaped injury, though in the vicinity of the kiln the maples and other trees are sometimes injured. Previous smoke injury, complicated with drought injury, to asparagus fields in the vicinity of this kiln, was mentioned in our Report for I908, page 858 , and similar injury is claimed to have been caused again this year.

\section{DISEASES OR HOSTS NOT PREVIOUSLY REPORTED.}

APPLE, Pyrus Malus.

Fruit Spot, Cylindrosporinm Pomi Brooks. Plate XXXIII a. In our Reports for 1905, page 264, and 1907, page 340, we described a fruit speck of apples that formed small, brownish, spots in the skin of apples, being especially prominent after storage. Cultures proved this trouble to be of fungous origin, but as these cultures did not produce a fruiting stage of the fungus, we were not sure of its identity.

More recent study has shown that there are three fungi that occur in fruit spots or specks of apples. One of these is the black rot fungus, Sphaeropsis Malorum, which is more commonly known not as a spot trouble, but as a general rot of the fruit, especially on summer and fall varieties following insect injury. This fungus is the one that we have most commonly isolated from the fruit specks of market apples. Ordinarily it does not fruit in the culture media on which we have grown it, and so it was probably largely responsible for the fruit speck we describe in the above reports, though Cylindrosporium Pomi was possibly present in some cases. Besides the black rot, we have also occasionally isolated a species of Alternaria which seems to be responsible for speck injury, though we have as yet made no inoculation tests to prove this.

The third fruit spot, which we have seen frequently on the fruit before it was gathered from the trees, as well as afterwards, is that caused by Cylindrosporium Pomi, which was described a few years ago as a new species by Brooks, who found it responsible for a serious spotting of apples in New Hampshire. This fruit spot on the market apples is usually very difficult to distinguish from that of the black rot. Perhaps the black rot fungus 
may finally crowd it out in many cases. However, on certain light skinned varieties, especially seedlings, it shows in the summer as small spots in the skin having a decidedly pinkish or reddish purple color. We have seen roadside seedlings made very conspicuous by it in late fall. In storage the color of the spots is darker. So far we have not seen the fungus in fruit on these superficial spots, and ordinarily they do not seem to reach any considerable size, except perhaps when developed further by the presence of the black rot fungus. In one instance we isolated this Cylindrosporium from market quinces, a new host, and we have frequently seen similar spots, showing no fruiting fungus, on quinces before and after picking.

On our oat juice agar medium the fungus forms a large; yeastlike, pinkish colony with no aerial growth, but producing an abundance of spores. With age it turns a darker color, sometimes black, though in such cases it may be due to the presence of another fungus frequently associated with it, which we have isolated, but whose identity has not yet been determined.

\section{AZALEA, Rhododendron indicum.}

Pocket CurL, Exobasidium Vaccinii (Fckl.) Wor. Plate XXXIII b. Galls and hypertrophy caused by this or closely related species are not uncommon in this state on various wild species of the heath family, but this fungus on a cultivated species was called to our attention for the first time in the fall of 1909. Specimens of the above azalea, purchased a few months previously for a private greenhouse, were very badly injured. These plants were apparently infected when purchased, having been grown out of doors in a neighboring state, but did not show the trouble at that time. The disease appeared on the leaves, usually involving the apical part and causing a decided thickening of the tissues. This infected part covered more or less of the leaf, which often became decidedly concavo-convex, as shown in the illustration. The infected tissues were quite sharply marked off from the healthy part, both by their distortion and by their whitish color, being eventually covered by a mealy coating of spores, etc.

Cultures were made, and a fungus obtained that seems to be a conidial stage of this fungus, though its identity has not been thoroughly established. 
The question whether or not the various forms of Exobasidium found on the different genera of the heaths are distinct or not has not been definitely decided. Often their macroscopic appearance on different hosts is quite distinct, but as Richards (Bot. Gaz. 2I: IOI. I896) succeeded in producing the ordinary leaf form from spores of the unusual large bladder form on a different host, it looks to the writer as if these differences were largely due to the age or parts of the host infected. Shirai has described two species of Exobasidium on Rhododendron indicum, to one of which our fungus possibly may belong if they are really distinct, though the spore measurements do not seem to agree entirely.

\section{CELERIAC, Apium graveolens var. rapaceum.}

Leaf Blight, Cercospora Apii Fr. We have reported before, on celeriac, the leaf spot due to Septoria, but not this fungus. Both produce brownish or grayish spots of considerable size on the leaves, often causing them to turn yellow and die prematurely. They are often found associated, the Cercospora being distinguished by its minute threads arising from the surface of the leaves, while the Septoria forms small, embedded, black specks.

\section{CHESTNUT, Castanea sps.}

Chestnut Bark Disease, Diaporthe parasitica Murr. Specimens of this serious disease of our native chestnuts have been collected on the Japanese chestnut, Castanea japonica, in a local nursery. Dr. R. T. Morris, who grows a large number of varieties of chestnuts on his Stamford farm, also reports (Conn. Farmer, March II, I9I I, p. 2) that, besides the Japanese species, the European species, Castanea sativa, and the American Chinquapin, Castanea pumila, have been more or less subject to this blight at this place. See page $7 I 6$ of this Report.

\section{CHESTNUT, Castanea dentata.}

Powdery Mildew, Microsphara Alni (Wallr.) Wint. We have not reported this host because we have found the mildew on it previously only in the woods, but in September, I907, it was observed on cultivated trees in a small nursery at Storrs. It forms evident, mealy, whitish growths, in which the perithecia 
are embedded as small black specks, chiefly on the upper surface of the leaves. It is not an important disease of this host.

\section{CHIVES, Allium Schonoprasum.}

Rust, Puccinia Porri (Sow.) Wint. This rust was collected by Dr. Britton during June, I9Io, on chives in his garden in Westville, where it was doing considerable injury to the plants. Both the II and III stages were present, the former showing as minute, reddish, dusty pustules, and the latter as black, granular ones, more permanently covered by the epidermis. The leaves, when fairly abundantly infected, turned yellow and died prematurely. I have not seen any account of injury by this rust to cultivated species of Allium in this country, though in Europe it is not uncommon. Worthington Smith, in his Diseases of Field and Garden, page 39, mentions it, under the name Puccinia mixta Fckl., as causing serious injury to a crop of chives in England. There is more or less difficulty in deciding the proper genus of this fungus, since the telial spores in some specimens on certain hosts are almost or entirely single-celled, and so properly come under the genus Uromyces; other specimens show these spores largely two-celled, and so place it more properly under the genus Puccinia. Our specimens run more nearly to the former type, as not over one or two per cent. of the spores are two-celled. Winter considered the two as a single species, and we have followed him. Other writers place the single-celled form under Uromyces ambiguus (DC.) Fckl., and the form with most of its spores two-celled under Puccinia Porri, as given here. The rust on chives in Europe is generally reported under this latter name. Our specimens, however, have fewer two-celled spores than those we have seen from Europe on the same host. Puccinia Allii (DC.) Rud., also on species of Allium, is quite a different fungus.

\section{CORNFLOWER, Centaurea Cyanus.}

Rust, Puccinia Cyani (Sch1.) Pass. Both the II and III stages of this rust were found, causing severe injury to the cornflowers in the writer's garden during the summer of I909. The sori, while numerous, form rather inconspicuous, dusty outbreaks on both surfaces of the leaves and on the stems 
Apparently this fungus has rarely been reported in this country. Another rust, $P$. Centaurece DC., also occurs on other species of Centaurea both here and in Europe. Both of these species have frequently been grouped with other Puccinias, the species here reported being usually placed under $P$. suaveolens, along with the rust on Cnicus now commonly known by that name.

\section{ELM, Ulmus sp.}

Anthracnose, Septogloum Ulmi (Fr.) Br. and Cav. This fungus was found on an escaped seedling of Ulmus campestris (apparently) along the roadside in Centerville. It produces numerous, minute, at first yellowish but finally reddish-brown spots on the upper surface of the leaves, while below the fruiting stage shows as minute, glistening, yellowish globules.

The fungus has usually been reported as Phleospora Ulmi (Fr.) Wallr., but the writer agrees with Briosi and Cavara that it belongs more properly under the above genus. Cylindrosporium ulmicolum E11. and Ev. possibly is not distinct from this species, as its description is very similar. This Septogloum is thought by some writers to be the spermagonial and Piggotia astroidea $\mathrm{B}$. and $\mathrm{Br}$., the pycnidial stage of Dothidella Ulmi (Duv.) Wint. [Phyllachora Ulmi (Duv.) Fckl.], though neither of these two stages were found associated with our specimens. The asco stage of Dothidella Ulmi, while not uncommon in Europe, does not seem to have been reported in this country except the doubtful specimen sent by Torrey to Schweinitz.

\section{GOOSEBERRY, Ribes sp.}

Rust, EEcidium Grossularice (Pers.) Schum. This rust was found on the leaves of a species of gooseberry, apparently escaped from cultivation, in the woods of an abandoned farm belonging to the water company at Ansonia. The fungus forms rather small clusters of cup-shaped fruiting bodies on the under surface of the leaves, producing discolored spots above. It is probably connected with some species of Puccinia on Carex as its mature stage, as has been found to be the case with several European forms on Ribes sp. We have never seen this Ecidium causing much harm to its hosts, and it seems to occur chiefly on the wild species. 
HORSECHESTNUT, Esculus sps.

Powdery Mildew, Uncinula flexuosa $\mathrm{Pk}$. This mildew was found on a species of EEsculus with colored blossoms, on an estate at Chapinville in the fall of Igog. The conidial stage formed a conspicuous whitish coating on the upper surface of the leaves, while the perithecia were less prominent, though abundant, on the lower surface. The fungus has not been reported by us before, though Thaxter collected it in New Haven in I888 on another cultivated species, Esculus Hippocastanum.

\section{MONKSHOOD, Aconitum Fischeri.}

Stem Rot, ? Hypochnus sp. In our Report for 1907, page 35I, we described this stem rot, which was found on a variety of herbaceous plants in a local nursery. This year it was sent to us from Westbrook, where it was injuring specimens of larkspur, one of the hosts reported before. Since our first report we have also found it on monkshood, in the same nursery where it was found originally. So far we have been unable to identify the fungus, as our cultures form only the sclerotial stage-small, reddish, usually subspherical bodies about 2 to $5 \mathrm{~mm}$. in diameter. We have a similar fungus from potato stems, forming considerable small sclerotia, that was given to us by Morse of the Maine Station. While in Japan, we saw in Professor Hori's laboratory artificial cultures of a number of these sclerotial fungi, which he had described as species of Hypochnus, though we are not sure of this identification from what we have learned concerning them.

\section{PINE, Pinus sps.}

Pine-Oak Rust, Cronartium Quercus (Brond.) Schræt. (I. Peridermium cerebrum $\mathrm{Pk}$.) On specimens of jack pine, Pinus Banksiana, in the nursery of the station forest plantation at Rainbow in the spring of I9Io, Mr. Filley, and later the writer, collected the I stage of this fungus. These seedlings were about four years old, and had been brought in Igos from Michigan, where no doubt they were originally infected, as this fungus in none of its stages has ever before been found in this state. The fungus on the pine forms conspicuous 
swellings, usually globular in shape, and in early spring the fruiting stage shows under the denuding bark as orange-colored, dusty spore masses, with the peridia rarely forming distinct cups, as in the next species. The II and III stages occur on species of oak. So far as could be seen, these did not appear on the oaks in the vicinity, and as all the infected pines were destroyed, it is not likely to become established there. Infection experiments made in the laboratory from the I stage, however, produced the III stage only very readily on seedlings of both red and white oaks. So far this fungus has not done much damage elsewhere on either host. See Plate XXXVI b.

Pine-Sweetfern Rust, Cronartium Comptonice Arth. (I. Peridermium pyriforme $\mathrm{Pk}$.) In the Report of 1907 , page 380 , the writer reported the I stage of this rust on both Pinus rigida and $P$. sylvestris from this state. It had become established on the latter host in the station forest plantation at Rainbow. In. I9Io it was found there also on Pinus rigida, $P$. austriaca, and $P$. maritima. It was also found in its II and III stages on the sweetfern, to which it had spread since its introduction. Apparently most of these pines had become infected in their nursery beds at Poquonock before transplanting here some years ago, as thousands of seedlings of Pinus rigida grown from the first in their vicinity showed practically no infection. The specimens of $P$. maritima, however, had become infected there in their seed bed, yet we could find no infected sweetfern in their immediate vicinity this year. In order to prevent further spread of the rust, all infected pines were destroyed or the infected branches cut off, and the forester had all the sweetfern in the vicinity mowed off. Most of the pines, having the fungus on their main trunk, were of little value. Where infection takes place after the pines are a few years old, the damage is not likely to be nearly so severe as when it takes place in the seed bed. See Plate XXXVI c.

\section{PINE, WHITE, Pinus Strobus.}

Drought Injury. In the fall of I909, Mr. Spring noticed a few spots in one of the seed beds at the station forest plantation where the white pine had been entirely killed out for the space of a few inches. Specimens of these and some of the adjacent living pines were brought to the writer at the time for examina- 
tion. On the stems of the dead pines, and also somewhat on the living ones, was a conspicuous felt of mycelium of a hymenomycetous fungus which Professor E. A. Burt determined as Coniophora byssoidea (Pers.) Fr. At first we thought that this fungus was responsible for the death of the seedlings, but we were unable to find any account of injury caused by it elsewhere. A bunch of these young pines was kept in a crock in the greenhouse for several months, and there was no indication that the fungus injured the healthy young pines on which it originally occurred, or that it spread further. The fungus evidently ran up on the stems merely as a saprophyte, from various leaves on the ground on which it also occurred. The pines in the seed beds were probably killed by the drought, which was so severe in I909, and the dead and injured seedlings offered a better condition for the development of the fungus than the surrounding mulch of leaves, as Professor Burt states that out of nine specimens in his herbarium seven are on pine and two on spruce. See Plate XXXV a.

Frost Injury. Plate XXXV b. In examining the seed beds of white pines at the station plantation at Rainbow in the fall of I9I0, the writer found small spots scattered in the beds where the leaves of this year's growth had been killed. The injury was evidently caused by the late frosts of May and June of that year, as these had killed the leaves of the scrub oaks in this vicinity, as observed at the time. The young pines had developed their terminal branches an inch or two in length, and these had been severely injured or killed by the frost on both the one- and two-year-old seedlings. The leaves of the previous year remained uninjured. Afterwards these injured pines put out several lateral buds from or below the injured tip, but even as late as November I, when seen by the writer, these had not usually attained a length of half an inch. This injury had severely stunted the growth of the plants during the season, as is indicated by the photograph, which shows one of the uninjured plants, besides several of the injured ones of the same age. A few seedlings of Pinus montana were also injured, but not so extensively as were those of the white pine.

Pine-Currant Rust, Cronartium ribicola Waldh. (I. Peridermium Strobi Kleb.) Plate XXXVI a. In our article on Heterœcious Rusts of Connecticut, published in the Report for 1907, 
page 374 , we mentioned this rust as one likely to be brought into this state on imported white pine seedlings from Europe. Its introduction really occurred sooner than was anticipated. Mr. F. A. Metzger first found specimens on a lot of three-yearold seedlings from Germany that had been imported by our State Forester for Mr. C. F. Street, and planted at Wilton. Mr. Metzger, who was employed to set them out, found in the Io,000 seedlings from fifty to one hundred that were infected with the rust. He brought specimens to the station the last of April, I909, but as the writer was in Japan at that time, nothing further was done.

In the meantime Messrs. Metcalf and Spaulding, of the U. S. Department of Agriculture, who had been looking up infected seedlings in other states, came to this state about the middle of June, and with the forester examined the plantations of the New Haven Water Company at West Haven and the Ansonia Water Company near Ansonia, and found a few very suspicious specimens at these places. Arrangements were made soon afterward by which Mr. Spaulding and Mr. Graves for the Government and the botanical department for the station undertook during July to go over the plantations in the state where white pine seedlings had been imported from Europe, and inspect them for this rust, and to destroy any infected seedlings, if found, and any wild gooseberries or currants in their vicinity, as the II and III stages occur on the latter as alternate hosts. It was really then too late in the season to find the fungus on the pines, except far past its prime. However, twenty-four plantations, including about 580,000 seedlings, were inspected, and very suspicious or positively identified infected specimens were found at two additional places; viz., at the Plant estate plantation at East Lyme and at the Groton Water Company plantation at Poquonock. In none of the five places where signs of the pine rust were found were more than a dozen specimens seen, except at the Street plantation, where the diseased plants were noticed as they were being set out. A descriptive letter concerning the rust and its reputation was sent to all those who had ised imported seedlings.

In I9IO the botanical and forestry departments of the station undertook to again go over these and other plantations, beginning early in the season, as soon as the rust ordinarily makes its 
appearance. During May and June four inspectors visited twenty-six plantations, inspecting about 425,000 seedlings, and made very careful examinations for the rust, in many cases examining every individual seedling. In spite of this thorough examination, not a single rusted plant was found! No doubt the severe drought of the preceding year had killed off those seedlings weakened by the rust, if such existed. Of course it is possible that examination another year might reveal a few rusted plants, as it is usual for the seedlings to go one or possibly more years after infection, before the æcial stage of the rust appears on them.

During the years 1907, I908 and 1909, there were imported into the state, chiefly from Germany, under the supervision of the station's forestry department, about 640,000 white pine seedlings, which were set out in fifty-five different localities, and private individuals have imported at least 100,000 more. All of these seedlings, except about 95,000 set out mostly in small lots in twenty different localities, have now been inspected once or twice for the rust. No doubt, too, at the time they were set out the men would have discarded any specimens showing evidence of the rust. In all of the plantations examined, watch was kept for any signs of currants or gooseberries in the vicinity of the pines, and these were destroyed when found. Fortunately, species of Ribes in a wild or escaped state are comparatively rare here, so that even if this rust occurred on the pines, it would be much more difficult for it to pass to these hosts than in some of the more northern states where they are more frequent. In I9IO the station did not import any white pines because of the danger of bringing in this rust, and only one lot, to our knowledge, was imported by others. Examination of these showed no signs of the rust. From now on it is probable that most of the seedlings set out will be native grown stock, as plenty of this seems to be in evidence at fair prices. There does not seem to be much likelihood, therefore, that the rust will obtain a foothold in the state, though watch will still be kept for it. Anyone finding suspicious specimens should send them to the station for examination.

Infected white pine seedlings, out of the season when the fruiting stage appears, may be recognized in a general way 
by the somewhat fusiform swollen stems and by the bunching of the leaves, shown by the halftones in Plate XXXVIa. Not all swellings of the stem, however, are due to rust, as insect and other injuries may produce such distortions in young seedlings. During the months of May and June the fruiting stage shows on the swollen stems as small, white, oblong blisters that upon rupture reveal an orange mass of spores. These gradually wear away, and then positive evidence of infection is more or less difficult. The mycelium remains in the infected tissues, gradually spreading to the new growth, and renews its fruiting stage each spring, unless the death of the host intervenes. The spores produced on the pine do not spread the disease to other pines, but develop two other spore stages on both gooseberries and currants, the last stage carrying the fungus back to the pines.

Many writers consider this rust as a very serious menace to white pines. The writer is not so much afraid of it in this state because of the scarcity of the alternative hosts, and also because it looks to him as if most of the damage comes from the use of infected seedlings, which we should be able to largely eliminate here. Such infection as might occur after the pines once got a good start in the forests we are inclined to believe would be rare, and not nearly so injurious to the host. We have heard of one large importer of white pines who intends also to import a large number of currant bushes for commercial purposes. Such a condition offers a chance for the rust to do considerable harm if it once gets started in either of his plantations.

The native pine-sweetfern rust, which we describe elsewhere, seems to us to be just as virulent as this rust, and one much more likely to spread generally here, on account of the frequency of its alternate host, the sweetfern. Yet, with the exception of the plantation at Rainbow, where pines were infected in the seed beds, we have seen and heard of no damage by this rust. This rust does not occur on the white pine, though it has several other species for its hosts.

\section{PRIVET, Ligustrum vulgare.}

Anthracnose, Glocosporium cingulatum Atk.' Mr. Coe, of the Elm City Nursery Company, first called the writer's attention 
to this disease on a variety of privet called italicum, which was imported from France in the spring previous to our examination in the fall of I9IO. The fungus causes diseased areas on the stem and branches, which are not very conspicuous, being slightly sunken and a different color, but when these cankers entirely girdle the branches, the leaves and finally the whole branch above die, and the trouble becomes very evident. The injury at this place was quite noticeable, through the dead branches and one or two dead bushes, but probably the shock of transplanting may have weakened the plants so that the trouble was more conspicuous than it would be under more favorable conditions for the host.

When Atkinson originally described this fungus (Bull. 49, Cornell Exp. Sta.) in I892, he said nothing about the injury to the host, and we have seen no reference where it is said to have caused conspicuous injury, though it seems to be capable of it. Atkinson obtained cultures of the fungus, described the conidial stage, and suggested that it had a mature stage, which his student, Miss Stoneman, later depscribed (Bot. Gaz. 26: IOI. I898) as belonging to the genus Gnomoniopsis, now known as Glomerella.

Cultures of the fungus were easily obtained by the writer from the cankers, and these produced both the conidial and the asco stages. Miss Stoneman notes the presence in the cultures of setre connected with the conidial stage, but did not find these on the host. The writer, however, found some of these setæ with the conidial stage on the host.

\section{RASPBERRY, Rubus strigosus.}

Rust, Puccinastrum arcticum var. americanum Farl. This rust, which was described a few years ago by Professor Farlow (Rhodora I0: I3. 1908), has ordinarily been confused with the uredo stage of Kueneola albida, as, like that species, it forms very small orange outbreaks on the under side of the leaves. Microscopically, however, the two are quite distinct. The uredo stage was sent to the writer from Stamford in September, I9o9, on cultivated raspberry, this being the first time it has been found in the state. It apparently did little harm to its host. The æcial stage is unknown, though it may be Peridermium balsameum on the balsam fir. 


\section{RYE, Secale cereale.}

PoWDERy MILDEw, Erysiphe graminis DC. In our Report for 1903 we listed the conidial stage of this mildew on cultivated barley. In I9lo specimens on rye were received from J. F. Shepard, of New Haven, and others were collected by the writer at the station farm at Centerville, these being the first collections on this host in the state. In the latter locality the perithecial stage was very conspicuous and abundant on rye, but on barley was practically absent. Considerable injury was caused to both these hosts through severe infection of the leaves, which died prematurely. Apparently the season was favorable for an unusual development of the fungus. It forms an evident grayish felt in small clusters, thickly covering the leaves, and the perithecia, when produced, show as small but evident black specks embedded in this. As usual with this species, none of the asci matured their spores on the living plants.

\section{SQUASH, Cucurbita Pepo.}

Chlorosis. In previous Reports we have mentioned chlorosis troubles of Lima and string beans, muskmelon, tobacco and tomato. Of these so far we have been able to prove only those of tobacco and tomato to be infectious, that is, capable of producing the trouble in healthy plants when juice from the chlorosis plants is placed on the young leaves. In June, I9ro, we saw plants of summer squash in cold frames at the Farnham farm in Westville that were subject to a chlorosis trouble, though from its appearance it did not impress us as being of an infectious nature. The leaves were quite prominently streaked with irregular areas of lighter yellowish-green, the normal green color remaining more commonly around the veins. The cause of the trouble was not determined, though possibly too much manure in the beds may have had something to do with it.

\section{SWEET PEA, Lathyrus odoratus.}

Powdery Mildew, Erysiphe Polygoni DC. Previous to this we have reported in this state only one trouble of the sweet pea; viz., a rot disease. This powdery mildew forms a mealy, whitish growth on the leaves through the production of its conidial stage, but the perithecial stage was not found. Apparently the 
mildew is not a conspicuous parasite of the sweet pea, as it is not listed on this host in the more prominent works on the mildews. The absence of the mature stage renders its determination somewhat doubtful, but as the conidial stage agrees with the above species, and as this has been reported on several other species of Lathyrus, it is more likely to be this than any other species.

WALNUT, ENGLISH, Juglans regia.

White Mold, Microstroma Juglandis (Ber.) Sacc. We have reported this fungus before on cultivated specimens of our native butternut. It was sent to the writer in July, I909, by Dr. R. T. Morris on the variety Kaghazi of the English walnut, grown on his farm at Stamford. While this fungus forms conspicuous white patches on the under sides of the leaves, it is not usually a very serious pest.

\section{WHEAT, Triticum vulgare.}

Stinking Smut, Tilletia fœtens (B. and C.) Trel. Very little wheat is grown in this state at the present time, so that this smut has not been collected here in the fields. However, it is of economic importance in another way. At least four times during the last few years samples of commercial wheat feeds, usually in the shape of middlings, have been sent to the station for examination because animals refused to eat the feed. Two of these samples have come from feed men and two from farmers. A microscopical examination in each case has shown the presence of the spores of the stinking smut. In a sample recently received from $\mathrm{Mr}$. $\mathrm{R}$. A. Jones of Bethlehem, the smut spores were unusually abundant. Mr. Jones said that the middlings had been fed to hogs, that it made them sick, and that some of them refused to eat more. After changing to other food the hogs got over their trouble.

Feeds that contain these spores indicate not only that they are made from middlings, but from badly smutted or injured wheat, which would be of no value for flour. Whether or not the smut spores are themselves the injurious principle might be questioned, but there seems to be no question, if they are not, that the action of this fungus, or its opening the way for 
bacteria to act, produces in the plant tissues deleterious products that injure or render dangerous their use for feeding purposes.

Tubeuf, in the English edition of his Diseases of Plants, page 306, says concerning Tilletia Tritici (a very closely related smut, also found in grain in this country): "The smut also possesses poisonous properties which make flour contaminated with it dangerous to human beings and the straw or chaff injurious to cattle.... The symptoms in the few cases of disease observed do not agree very closely. A paralyzing effect on the centers of deglutition and the spinal cord seem to be regularly present. As a result one generally finds a continuous chewing movement of the jaws and a flow of saliva, also lameness, staggering, and falling. Cattle, sheep, swine and horses are all liable to attack."

McAlpine, in his Smuts of Australia, page 8I, records a case in which six hundred and fifty Leghorns dropped in a few days from a daily average of one hundred eggs to sixteen when they were fed on smutted wheat, and when this was stopped and clean wheat substituted, they regained in three weeks an average daily yield of eighty eggs. He also records an experiment with pigeons in which one pair was fed smutted wheat for twentytwo weeks, while the other pair was fed sound wheat. The doves fed good wheat laid seven eggs during this period, while the others laid only two. Both pairs of pigeons at the start were in good plumage, and the pair fed on good wheat retained the good plumage and was fat at the end of the experiment, while the other pair was in poor condition, with the feathers all standing out.

While writing on this subject of deleterious animal foods, we might mention that we have also occasionally had whole oats sent in that horses refused to eat. We have never found any fungus that might be the cause of a musty condition of these oats. It has been thought that in these cases the oats were bleached by some sulphur process, and that this had left them unpalatable to the horses. We have also recently heard of a case where certain farmers last year purchased oats for feeding purposes, and as they looked plump and white they were also used for seed. None of the fields sowed with these oats came up, and as they were to serve as a cover crop for grass seed, the latter also failed. It seems quite probable that 
738 CONNECTICUT EXPERIMENT STATION REPORT, IgO9-IgIO.

these oats had been sulphured, and their vitality entirely destroyed. Seed at all suspicious should be sent to the station to have its germination tested.

We have also had one or two cases called to our attention recently where animals have been made sick and some have died from eating silage. In such cases the silage had not been properly made and had become moldy, and the fungous growths no doubt had produced poisonous products in the decomposition of the silage. Similar troubles have been noticed elsewhere from feeding moldy silage (see Pammel's Manual of Poisonous Plants, p. 24). 


\section{SPRAYING POTATOES IN DRY SEASONS.}

\section{General Considerations.}

Object. In our Report for 1904, page 363 , we gave the results of spraying potatoes during the three wet years, 1902 to I904, when blight was unusually severe in this state. The sprayed parts of these fields showed increased yields, varying from 18 up to 108 per cent., according to the season, thoroughness of the spraying, etc. During these experiments certain points came up for consideration upon which we had no data to base conclusions. For example: (I) Would manure tend to increase the amount of rot in a field badly blighted over the amount of rot in the same field in which a commercial fertilizer was used? (2) Would the use of the same land for two or three years in succession tend to increase the amount of rot in the successive crops, other things being the same; and would blight tend to appear earlier in such a field? (3) Would ridging the rows help to prevent the blight spores from being washed down to the tubers, and so decrease the per cent. of rot as compared with level culture under the same conditions?

In order to answer the above questions, the writer started a series of experiments in 1906, which were carried on for the four years ending in 1909. Unfortunately for the primary objects of the experiments, these years proved to be ones in which blight did very little harm in this state. In fact, in three of these years we were unable to find any of the blight fungus on potatoes in this experimental field, and in the other year it was so scarce as to cause practically no harm. However, while the main objects of the experiments remained unanswered, we still obtained data regarding spraying in dry seasons, also some data regarding scab, which we present in this paper.

Conditions of Experimentation. The experiments were carried on each year on the same plot of ground; viz., two-thirds of an acre of level, uniform, light loam, with a very leachy subsoil, at the station's temporary experimental farm leased of Mr. Webb at Centerville. This land had not been cultivated or fertilized for some years before our experiments began, and so was in very poor shape for growing crops of any kind. Amount of yield, however, except in a comparative way, was not contemplated in these experiments. 
The land was divided into plots as follows: The east half each year was fertilized with manure at the rate of sixteen to eighteen tons per acre, while the west half received about the equivalent of the nitrogen in the manure in the shape of two applications of nitrate of soda (rate of $450 \mathrm{lbs}$. per acre). Each half received the same amount of muriate of potash (rate of $300 \mathrm{lbs}$. the first and second years, and 450 lbs. the other two years, per acre) and bone meal (rate of $200 \mathrm{lbs}$. per acre each year). As the manure had also some phosphorus and potash in it, this naturally gave that half of the field a somewhat better fertilization than the half on which sodium nitrate was used, and as a matter of fact it showed this each year in a more luxuriant growth and a larger yield.

Running crosswise of the manured and sodium nitrate halves, the field was divided into halves, one of which received level culture and the other modified ridge culture. This ridged half was really cultivated the same as the level until the first to the middle of July, when, during the last two cultivations, the potatoes were ridged by the shovel cultivators as much as possible, and in some seasons hilled further with a hoe. In order to bring the tubers in the level culture near the ground and those in the ridged culture as deep as possible, the former were planted only three or four inches deep, while the latter were planted five to seven inches. Ordinary cultivation, not averaging once a week, was given the whole field. Some hand work with the hoe was also given. Each year the halves given level and ridged culture were reversed, so that any inequality of land might be cancelled.

The central halves of the ridged and level cultivated rows were sprayed with Bordeaux mixture (4-4-50 formula), leaving similar unsiprayed rows on either side. Usually about three sprayings with Bordeaux were given, and as these were made by hand, they were very thorough. The first spraying was generally given about the middle of July, and the last about the first of September. All the potatoes were sprayed for insects, either with Paris green or with arsenate of lead, so as to make conditions the same so far as insect injury was concerned.

These treatments divided the field into eight equal areas, each receiving some different point of treatment, as follows: (I) sprayed, manured, ridged; (2) unsprayed, manured, ridged; 
(3) sprayed, sodium nitrate, ridged; (4) unsprayed, sodium nitrate, ridged; (5) sprayed, manured, level; (6) unsprayed, manured, level; (7) sprayed, sodium nitrate, level; unsprayed, sodium nitrate, level.

The potatoes were dug in October, after all the vines were dead, and comparative yields determined by taking the counts and weights from fifty-foot lengths in two separate rows of each plot for comparison, but the figures given in the tables are for the combined one hundred feet. To avoid any unevenness due to the difference in the land, the sprayed and unsprayed rows, which otherwise received the same treatment, were always taken as near together as possible.

Results. Sprayed versus Unsprayed. In the four years, out of the forty-four comparisons of fifty feet of sprayed vines with the corresponding unsprayed vines, the sprayed lots in every case except three gave a greater yield. In these three exceptions the average of the two tests of fifty feet of sprayed vines in each case was greater than the corresponding average of the two fifty feet of unsprayed vines, so that it can be stated that during the four years' tests the sprayed lots invariably gave a higher yield than the unsprayed. Table I gives the averages for the four years of these sprayed and unsprayed potatoes, and from this we find that the average increase of all the sprayed vines over unsprayed vines was about 32 per cent. The increased yield of the sprayed over the unsprayed by years was as follows: In I906, 30 per cent. ; in 1907, 24 per cent. ; in 1908, I7 per cent.; in I909, 53 per cent. Plate XXXVII b shows the comparative yields in 1906 on the sodium nitrate half (I) sprayed, ridged; (2) unsprayed, ridged; (3) sprayed, level; (4) unsprayed, level. As shown in our previous experiments, the increased yield of the potatoes was not only due to increased numbers of marketable tubers, but also to increased weight of the tubers, especially the larger ones.

In every one of these years, the spraying, theoretically, more than paid for itself, despite the fact that none were blight years. Stewart, in the 1906 Report of the Geneva, N. Y., Experiment Station, shows that out of fourteen coöperative experiments with farmers in different parts of the state in 1905, it cost from $\$ 2.44$ to $\$ 6.84$ per acre to make the sprayings, or an average cost for all of $\$ 4.25$ per acre. We think that in this state, to be on the safe side, we may estimate the cost, including bother, of spraying 
at $\$ 10.00$ per acre. It often requires more time to cart water and make up the mixture than it does to apply it. If the spraying is done by hand, it also costs more than when done with spraying machines, but a more thorough job can be done in this way with three sprayings than with five by any power sprayer we have seen. Taking the cost of spraying then, at $\$ 10.00$ per acre, and the average yield of an unsprayed field in this state at the conservative figure of I 30 bushels per acre, we find that the lowest increase in yield due to spraying, namely, I7 per cent., means 22 bushels, and the highest increase, 53 per cent., means 69 bushels. At the very low price of fifty cents per bushel, the lowest increase would mean \$1 I.00, or one dollar net profit, and the highest, $\$ 34.50$, or $\$ 24.50$ profit. We have made these estimates especially conservative by taking comparatively low yields and a high cost of spraying per acre. Years when blight really did harm in the fields would of course make the gains very considerably greater, if the spraying were well done.

The question naturally comes up, why did the sprayed potatoes give this increased yield over the unsprayed if there was no particular injury caused by the late blight fungus? Some little benefit was no doubt derived from the prevention of the early blight, but this must have been scarcely appreciable because this fungus was not at all conspicuous these years. Again, some very small benefit may have been due to lessening insect attack, since potatoes sprayed with both Bordeaux and Paris green keep off the insects somewhat better than where sprayed only with Paris green. This is especially true as regards the potato flea beetle. But here again the gain was of a very minor kind. Ordinarily botanists have explained this increase as due to some stimulative effect the Bordeaux mixture has on the chlorophyll of the potato leaves in increasing starch production. Personally, the writer believes that the results are largely due to conservation of moisture in the leaves in dry seasons by clogging up the stomata and water pores with the sediment of the spray. The reasons for this belief are (I) that the potato leaves, through their numerous stomata and terminal water pores, lose water very easily, and are especially susceptible to what is known as tip burn in dry seasons; (2) that the unsprayed vines uniformly suffered earlier and more severely from tip burn than the sprayed, which were green for about two weeks after the unsprayed were dead; (3) that in 
I9I0, which was a season like the preceding years, except with a little injury from blight at the very end of the season, spraying with "Sulphocide" and commercial lime-sulphur, sprays with comparatively little sediment, did not prolong the life of the vines or give increased yield, while spraying with Bordeaux mixture did.

Results: Ridged versus Level Culture. As to the primary object of these two methods of culture, we have very little data, since there was practically no rot in the potatoes during the four years. We hope to continue the experiment until seasons favorable for rot shall give us data on this subject. That there is some basis for the belief that ridging will be of help in lessening the rot was shown in our experiments in I9Io in another field, where the ridged rows, both sprayed and unsprayed, gave practically no rot against a small per cent. in the level rows. This was especially true of the unsprayed level rows, which gave about nine per cent. of tubers rotted against only one-half per cent. in the sprayed level rows, though the blight appeared on the foliage only in a small way toward the end of the season.

While our data are not very enlightening on this point, still the experiments do show results along a related line, namely, that the ridging did not materially lessen the yield. There are those in this state who advocate level culture because of the supposed increased yield over ridging, and if this is so, then any increased yield due to prevention of rot in the ridged potatoes might be more than outbalanced by the increased yield due to level culture, especially taking the yields year after year, many of which show no rot. However, with our modified ridged culture (as explained previously) we do not find in averaging the four years that the ridged potatoes gave any very materially smaller crop than the level, since the average of the latter was only about 6 per cent. higher than the former, and to offset this, the I9IO crop in a different field slightly favored the ridged. Taking the yields by years, the level culture gave slightly better crops in 1906, 1907, and 1908 , and the ridged in 1909 and 19Io. As these last four years were chiefly drought years, the test was even more severe than it would be in wet seasons. Likewise, the data that we obtained in some coöperative experiments with farmers in 1906 did not seem to show that the ridged potatoes were at a disadvantage, judging from the yields given and the general opinion of the growers where no measurements were taken. 
In connection with the spraying, it may be noted that the averdge for the four years gave a slightly greater proportional increase in the sprayed ridged over the unsprayed ridged than was given by the sprayed level over the unsprayed level, on both the manured and the sodium nitrate plots, though in two of these years (1907 and 1909) the proportional increase was greater for the level. This perhaps may be explained by the unsprayed ridged potatoes suffering on the whole slightly more from the droughts.

Results: Manure versus Sodium Nitrate. Here again we did not get any data relative to whether or not manure increased the amount of rot in fields in blight seasons. From our correspondence with farmers, they seemed to favor the opinion that manured fields rot worse than those where chemical fertilizers only are used. While we did not get data on the blight, we did obtain data regarding scab and the use of manure, which we will mention later.

Of course the manured half of the field each year gave a greater yieid than the sodium nitrate half, since it was better fertilized. The average increase for the four years of the manured over the sodium nitrate was about 47 per cent. There is no doubt that manure is a very good fertilizer for potatoes, but at the same time there is greater danger of injury from scab and apparently from rot with its use. The most sensible way to use manure seems to be either in a heavy application on corn the previous year, using only a commercial fertilizer the same year with the potatoes, or at least to put it on the land and plow it in the preceding fall rather than in the spring just before planting the potatoes, as was done in our experiments. As regards spraying, the sodium nitrate sprayed rows uniformly gave a higher per cent. of increase over the checks, either ridged or level, than did the sprayed manure rows over the unsprayed checks. We are not sure of the reason for this, unless it was because the manured rows suffered earlier and more severely from the drought. Our manured plot also had more weeds than the sodium nitrate plot.

Results: Scab. These experiments showed very strikingly how the continued use of the same land for potatoes greatly increases the amount of scab. Even if it were of no benefit in the prevention of rot, rotation certainly is of value in lessening scab. The first year the potatoes were on the land the per cent. of scab was so 
small that it was not determined. It certainly was below 5 per cent., and probably not over I per cent. The second year, I907, the scabby tubers had increased to 22 per cent., in 1908 to 47 per cent. (the same potatoes in our general rotation fields this year gave only about I per cent. scabby), and in Igog to 63 per cent. The last two years the scab was so bad as to seriously affect the market value of the potatoes. The scab on the manured half was more serious than on the sodium nitrate half, since the average scab for the three years 1907 to 1909 for the former was 48 per cent., while on the latter it was only 33 per cent. As regards level and ridged rows, there was more scab in 1907 and

Table I.-Spraying Experiments-Average, 1906, 1907, ig08 and 1909.

\begin{tabular}{|c|c|c|c|c|c|c|c|c|c|c|}
\hline \multirow{2}{*}{ Treatment } & \multicolumn{2}{|c|}{ Very large } & \multicolumn{2}{|c|}{$\begin{array}{l}\text { Large to } \\
\text { mecium }\end{array}$} & \multicolumn{2}{|c|}{$\underset{\text { small }}{\text { Medium to }}$} & \multicolumn{2}{|c|}{$\begin{array}{c}\text { Total } \\
\text { marketable }\end{array}$} & \multicolumn{2}{|c|}{ Very small } \\
\hline & No. & Wt. & No. & Wt. & No. & Wt.. & No. & $\mathrm{Wt}_{\mathrm{t}}$ & No. & wt. \\
\hline (I) Sprayed, Manured, Ridged & 2 & 2 & 77 & 25 & I6I & 25 & 240 & 52 & 82 & 3 \\
\hline (2) Unsprayed, Manured, Ridged & 0 & 0 & 61 & 19 & I4I & $2 \mathrm{I}$ & 202 & 39 & 74 & 3 \\
\hline (3) Sprayed, Sod. Nitrate, Ridged . & 3 & $21 / 2$ & 64 & 20 & 102 & I4 & I 70 & 36 & 40 & I \\
\hline (4) Unsprayed, Sod. Nitrate, Ridged .... & 0 & 0 & 50 & I4 & 90 & I2 & 140 & 25 & 45 & 2 \\
\hline (5) Sprayed, Manured, Level & 2 & I $1 / 4$ & 78 & 25 & 183 & 27 & 264 & 54 & I I9 & 4 \\
\hline (6) Unsprayed, Manured, Level & I & I & 68 & 18 & I68 & 22 & 236 & 43 & I5 I & 5 \\
\hline (7) Sprayed, Sod. Nitrate, Level ... & 0 & 0 & 66 & 20 & I $3 \mathrm{I}$ & I 7 & I97 & $3^{8}$ & $7+$ & 2 \\
\hline (8) Unsprayed, Sod. Nitrate, Level . & 0 & 0 & 45 & 13 & I I6 & I 5 & 162 & 28 & So & 3 \\
\hline Average-Sprayed & I & I & 71 & 23 & I44 & $2 \mathrm{I}$ & 217 & 45 & 77 & 3 \\
\hline Average-Unsprayed ... & 0 & $\mathrm{o}$ & 56 & I6 & 68 & ${ }^{17} 7$ & 185 & 34 & 87 & 3 \\
\hline
\end{tabular}

I909 in the ridged rows and less in I908, and in the average for the three years the ridged ran slightly higher, though whether this means anything or not we do not know. As the level and ridged halves were alternated each year, this shows that it was the same side of the land that each time gave the most scab, and so the nature of the land rather than the manner of cultivation may have been the determining factor. It is certain, however, that the level rows suffered much more from sun scald.

\section{Details of Experiments in I906.}

Treatment. May' 2: Planted with Carmen No. 3. June 2f: Sprayed all with Paris green. July 6: Gave second spraying with Paris green. July 16 : Gave first spraying with Bordeatux mixture (4-4-50) by hand. Used Paris green in Bordeaux, and gave un- 
sprayed half the third treatment with Paris green, as bugs were unusually bad. Also gave first ridging to ridged half about this time. July 24: Gave final ridging. July 27: Made second treatment with Bordeaux. August 8: No blight, but a little early blight and considerable tip burn, especially on unsprayed vines. August II: Gave third spraying with Bordeaux. Found a very few blight leaves on unsprayed vines. August 26: Difference between sprayed and unsprayed vines quite marked in favor of former, due to tip burn and insect injury. September 6: Unsprayed vines fully two-thirds dead from tip burn, while on the sprayed not one-half the leaves were dead. Gave two rows only

Table II.-Spraying Experiments in i 906.

\begin{tabular}{|c|c|c|c|c|c|c|c|c|c|c|c|}
\hline \multirow{2}{*}{ Treatment } & \multicolumn{2}{|c|}{ Very large } & \multicolumn{2}{|c|}{$\begin{array}{l}\text { Large to } \\
\text { medium }\end{array}$} & \multicolumn{2}{|c|}{$\underset{\text { small }}{\text { Medium to }}$} & \multicolumn{2}{|c|}{$\begin{array}{c}\text { Total } \\
\text { marketable }\end{array}$} & \multicolumn{2}{|c|}{ Very small } & \multirow{2}{*}{$\begin{array}{l}\text { Rot } \\
\text { No. }\end{array}$} \\
\hline & No. & Wt. & No. & Wt. & No. & Wt. & No. & Wt. & No. & Wt. & \\
\hline 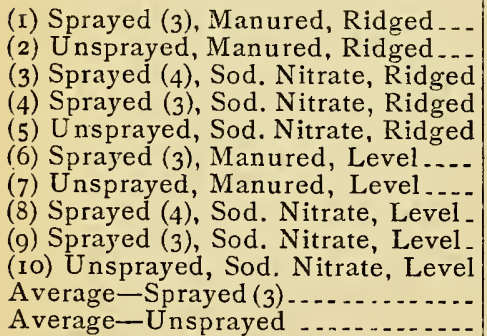 & $\begin{array}{l}5 \\
0 \\
2 \\
5 \\
0 \\
8 \\
3 \\
2 \\
0 \\
0 \\
3 \\
\mathrm{I}\end{array}$ & $\begin{array}{l}33 / 4 \\
0 \\
11 / 2 \\
31 / 2 \\
0 \\
5 \\
21 / 2 \\
11 / 2 \\
0 \\
0 \\
3 \\
1\end{array}$ & $\begin{array}{l}\text { I } 54 \\
\text { I } 25 \\
\text { I67 } \\
\text { I } 22 \\
\text { I03 } \\
\text { I } 7 \\
\text { I } 40 \\
\text { I } 59 \\
\text { I } 46 \\
\text { I02 } \\
\text { I } 48 \\
\text { I } 17\end{array}$ & $\begin{array}{l}43 \\
321 / 4 \\
453 / 4 \\
323 / 4 \\
25 \\
5 \mathrm{I} \\
27 \mathrm{I} / 2 \\
4 \mathrm{I} \\
42 \mathrm{I} / 4 \\
291 / 4 \\
42 \\
28\end{array}$ & $\begin{array}{l}159 \\
140 \\
106 \\
134 \\
109 \\
166 \\
201 \\
158 \\
143 \\
164 \\
150 \\
153\end{array}$ & $\begin{array}{l}181 / 2 \\
141 / 4 \\
121 / 4 \\
143 / 4 \\
101 / 2 \\
191 / 2 \\
203 / 4 \\
161 / 2 \\
161 / 2 \\
173 / 4 \\
17 \\
16\end{array}$ & $\begin{array}{l}318 \\
265 \\
273 \\
26 \mathrm{r} \\
2 \mathrm{I} 2 \\
345 \\
344 \\
318 \\
289 \\
266 \\
303 \\
272\end{array}$ & $\begin{array}{l}65 \mathrm{I} / 4 \\
46 \mathrm{I} / 2 \\
59 \mathrm{I} / 2 \\
5 \mathrm{I} \\
35 \mathrm{I} / 2 \\
75 \mathrm{I} / 2 \\
603 / 4 \\
59 \\
583 / 4 \\
47 \\
6 \mathrm{I} \\
47\end{array}$ & $\begin{array}{l}28 \\
22 \\
15 \\
16 \\
22 \\
35 \\
29 \\
24 \\
21 \\
26 \\
25 \\
25\end{array}$ & $\begin{array}{l}1 / 4 \\
1 / 4 \\
1 / 5 \\
1 / 5 \\
1 / 4 \\
1 / 3 \\
1 / 3 \\
1 / 4 \\
1 / 4 \\
1 / 4 \\
1 / 4 \\
1 / 4\end{array}$ & $\begin{array}{r}2 \\
\text { I4 } \\
5 \\
\text { I } \\
\text { I } \\
0 \\
4 \\
2 \\
0 \\
5 \\
\text { I } \\
6\end{array}$ \\
\hline
\end{tabular}

a fourth treatment, as vines were too far gone and blight was doing no particular harm.

Results: It is a question whether the fourth treatment did much good, though in the ridged rows it gave a better yield than the ridged row sprayed only three times. There was more rot this year than any other, yet not enough to do any harm. Besides the evident difference in the life of the vines, the yield also showed a corresponding difference in favor of the sprayed rows. The sprayed (3) manured ridged lot gave a 40 per cent. increased yield over the unsprayed manured ridged, as compared with 24 per cent. increase for the sprayed manured level over their unsprayed rows; the sprayed sodium nitrate ridged gave 43 per cent. increase over the unsprayed sodium nitrate ridged, while the sprayed sodium nitrate level gave 25 per cent. increase over the 
unsprayed check rows. The average of all the sprayed rows over the unsprayed was about 30 per cent., or the second best results of the four years' test. The details of yields are given in Table II.

\section{Details of Experiments in 1907.}

Treatment. On May I planted Green Mountain variety. July 3: Gave first application to all rows of insecticide, as bugs were late in starting this year. July 8: Gave first ridging to ridged half. July I6: Gave first spraying with Bordeaux, and used

Table III.-Spraying Experiments in 1907.

(I) Sprayed (3), Manured, Ridged

(2) Sprayed (2), Manured, Ridged

(3) Unsprayed, Manured, Ridged

(4) Sprayed (3), Sod. Nitrate,

(5) Sprayed (2), Sod. Nitrate,

(6) Unsprayed, Sod. Nitrate,

(7) Sprayed (3), Manured, Level.

(8) Sprayed (2), Manured, Level

(9) Unsprayed, Manured, Level.

(I0) Sprayed (3), Sod. Nitrate,

(I I) Sprayed (2), Sod. Nitrate,

Level .....................

(12) Unsprayed, Sod. Nitrate, Level

A verage-Sprayed (3)

Average-Unsprayed ...........

\begin{tabular}{|c|c|c|c|c|c|c|c|c|c|c|c|}
\hline \multicolumn{2}{|c|}{ Very large } & \multicolumn{2}{|c|}{$\begin{array}{l}\text { Large to } \\
\text { medium }\end{array}$} & \multicolumn{2}{|c|}{$\begin{array}{c}\text { Medium to } \\
\text { small }\end{array}$} & \multicolumn{2}{|c|}{$\begin{array}{c}\text { Total } \\
\text { marketable }\end{array}$} & \multicolumn{2}{|c|}{ Very small } & \multirow{2}{*}{$\begin{array}{l}\text { Rot } \\
\text { No. }\end{array}$} & \multirow{2}{*}{$\begin{array}{l}\text { Scab } \\
\text { Per } \\
\text { Cent }\end{array}$} \\
\hline No. & Wt. & No. & Wt. & No. & Wt. & No. & Wt. & No. & Wt. & & \\
\hline 0 & 0 & I9 & 7 & 143 & $2 \mathrm{I} \mathrm{I} / 2$ & 162 & $28 \mathrm{r} / 2$ & I64 & $63 / 4$ & 0 & 34 \\
\hline 0 & 0 & 20 & $71 / 2$ & 140 & $211 / 2$ & I6o & 29 & 130 & $5 \%$ & 0 & $4 \mathrm{I}$ \\
\hline 0 & o & 21 & $63 / 4$ & II 2 & 17 & I33 & $233 / 4$ & 97 & $4 / / 4$ & 0 & 32 \\
\hline 0 & 0 & 24 & 7 & 93 & $121 / 2$ & II 7 & $191 / 2$ & 87 & $23 / 4$ & 0 & IO \\
\hline 0 & 0 & 33 & Io & $9^{6}$ & $131 / 2$ & 129 & $23 \% / 2$ & 68 & $21 / 4$ & o & I6 \\
\hline 0 & 0 & I9 & $51 / 2$ & $9^{2}$ & $121 / 2$ & I I I & I8 & $9 \mathrm{I}$ & $41 / 4$ & o & 35 \\
\hline o & 0 & 13 & $41 / 2$ & 162 & $25 \mathrm{I} / 2$ & I 75 & 30 & 162 & $61 / 2$ & 0 & 19 \\
\hline 0 & 0 & 22 & $81 / 2$ & I 55 & $25 \mathrm{I} / 4$ & I 77 & $333 / 4$ & 130 & $53 / 4$ & 0 & I6 \\
\hline 0 & o & 9 & $33 / 4$ & 127 & I $93 / 4$ & I 36 & $231 / 2$ & 262 & I0 & 0 & 18 \\
\hline 0 & 0 & 28 & $83 / 4$ & II 7 & I4 & I 45 & $223 / 4$ & 122 & $31 / 2$ & 0 & I4 \\
\hline o & 0 & IO & $33 / 4$ & II 8 & I $81 / 2$ & I28 & $22 \frac{1}{4}$ & 148 & $51 / 2$ & 0 & 10 \\
\hline 0 & 0 & 7 & $2 \pi / 4$ & IO2 & $15 \frac{1}{2}$ & IO9 & $173 / 4$ & 149 & $61 / 4$ & o & I6 \\
\hline 0 & 0 & $2 \mathrm{I}$ & 7 & 128 & I9 & 149 & 26 & I 28 & 5 & o & 20 \\
\hline 0 & 0 & I4 & 5 & 108 & I6 & I22 & $2 \mathrm{I}$ & 150 & 6 & 0 & 25 \\
\hline
\end{tabular}

insecticide with it and alone on unsprayed vines. July I9: Gave final ridging and cultivation of potatoes. August 5: Made second spraying with Bordeaux. No signs of blight, but tip burn bad, especially on unsprayed potatoes, and showed more with those on manured rows than on sodium nitrate rows. September 6: Gave third spraying to six rows only (three ridged and three level), as it was rather late to do much good. No signs of blight this season. Unsprayed vines with level culture more uniformly dead than the unsprayed ridged. Sprayed rows still showing consider- 
able percentage of green leaves, especially on sodium nitrate part, but difference not so marked as in previous year.

Results. On account of drought, the yield this year was considerably less than any of the other years. The third spraying was too late to do any good at all. If the first spraying had been made about the first of July and the third the last of August, the results would have been better. The sprayed (3) manured ridged rows gave an increase of 20 per cent. over the unsprayed manured ridged portion, while this was increased to 27 per cent. on the sprayed manured level over the corresponding unsprayed portion. The sprayed (3) sodium nitrate ridged rows gave only 8 per cent. increase (30 per cent. in the case of those sprayed twice) over the unsprayed, while the sprayed ( 3 ) sodium nitrate level gave 28 per cent. over the unsprayed portion. The average increase of all the sprayed over the unsprayed was 24 per cent. Table III shows details of yields.

\section{Details of Experiments in 1908.}

Treatment. On April 29, planted Green Mountain variety. July 5 to ro: Gave first ridging. Vines were sprayed twice with arsenate of lead for bugs, which were not bad this year. July I7: Gave first spraying with Bordeaux. This was rather late, as the tip burn was already evident, especially on manured half. July 27: Gave second spraying with Bordeaux. Sodium nitrate half with less tip burn than the manured half, and sprayed vines somewhat better than unsprayed. August I3: Gave third spraying with Bordeaux. Very little early, and no late blight. Sprayed rows somewhat better than unsprayed. September II: Vines nearly all dead except a few scattered ones. Sprayed vines showed less difference over unsprayed this year than any other, due no doubt to the fact that drought was bad and the first spraying was not given until tip burn began to show its effects, on the vines. No blight at all.

Results: The spraying this year gave the least results of any year, showing only an average increase of 17 per cent. over the unsprayed. Had the first spraying been made earlier, there would no doubt have been less injury from tip burn, with a consequent increase in yield. As the drought affected the manured rows most, the increased yield due to spraying was least in these. The sprayed manured ridged gave 12 per cent. increase over the 
unsprayed, while the sprayed manured level gave only 5 per cent. increase over the unsprayed part. On the other hand, the sprayed sodium nitrate ridged gave 46 per cent. increase over the unsprayed rows, while the sprayed sodium nitrate level gave 20 per cent. increase over the unsprayed portion. See Table IV.

Table IV.-Spraying Experiments in rgos.

\begin{tabular}{|c|c|c|c|c|c|c|c|c|c|c|c|c|}
\hline \multirow{2}{*}{ Treatment } & \multicolumn{2}{|c|}{ Very large } & \multicolumn{2}{|c|}{$\begin{array}{l}\text { Large to } \\
\text { medium }\end{array}$} & \multicolumn{2}{|c|}{$\begin{array}{c}\text { Medium } \\
\text { small }\end{array}$} & \multicolumn{2}{|c|}{$\begin{array}{c}\text { Total } \\
\text { marketable }\end{array}$} & \multicolumn{2}{|c|}{ Very small } & \multirow{2}{*}{$\begin{array}{l}\text { Rot } \\
\text { No. }\end{array}$} & \multirow{2}{*}{$\begin{array}{l}\text { Scab } \\
\text { Per } \\
\text { Cent }\end{array}$} \\
\hline & No. & Wt. & No. & Wt. & No. & Wt. & No. & Wt. & No. & wt. & & \\
\hline 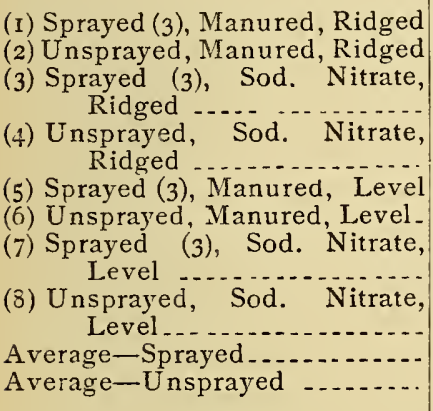 & $\begin{array}{l}0 \\
0 \\
0\end{array}$ & $\begin{array}{c}\mathrm{I} \\
0 \\
3 / 4 \\
0 \\
0 \\
0 \\
0\end{array}$ & $\begin{array}{l}71 \\
56 \\
6 I \\
44 \\
69 \\
77\end{array}$ & $\begin{array}{l}233 / 4 \\
201 / 4 \\
2 \mathrm{I} 3 / 4 \\
\\
\mathrm{I} 3 \mathrm{y} / 4 \\
24 \mathrm{I} / 2 \\
24 \\
\mathrm{I} 2 \mathrm{I} / 2\end{array}$ & $\begin{array}{l}\text { I28 } \\
\text { I } 26 \\
75 \\
67 \\
163 \\
158 \\
120\end{array}$ & $\begin{array}{l}20 \mathrm{I} / 2 \\
2 \mathrm{O}^{1} / 4 \\
\mathrm{II} \mathrm{I} / 2 \\
\mathrm{IO} \\
23 \mathrm{I} / 2 \\
2 \mathrm{I} 3 / 4 \\
\mathrm{I} 7 \mathrm{7} / 4\end{array}$ & $\begin{array}{l}200 \\
\text { I } 82 \\
\\
\text { I37 } \\
\text { II I } \\
232 \\
235 \\
160\end{array}$ & $\begin{array}{l}45 \mathrm{I} / 4 \\
40 \mathrm{I} / 2 \\
34 \\
23 \mathrm{I} / 4 \\
48 \\
45^{3} / 4 \\
293 / 4\end{array}$ & $\begin{array}{r}55 \\
\text { I03 } \\
31 \\
39 \\
\text { I08 } \\
\text { r } 74 \\
76\end{array}$ & $\begin{array}{l}21 / 4 \\
33 / 4 \\
11 / 4 \\
11 / 2 \\
31 / 4 \\
51 / 4 \\
23 / 4\end{array}$ & $\begin{array}{l}0 \\
0 \\
0\end{array}$ & $\begin{array}{r}58 \\
46 \\
\\
29\end{array}$ \\
\hline
\end{tabular}

Details of Experiments in I909.

Treatment. Used Green Mountain variety this year, not planting until May II, as the season was late. Gave all a couple of sprayings with arsenate of lead for bugs on June 24 and July 7 . About the middle of July gave first ridging, and the final one on July 27, when first treatment with Bordeaux was also made. August 9: Made second spraying with Bordeaux. September 2: Gave third spraying with Bordeaux. Sprayed rows now much greener than unsprayed, especially those ridged, as the vines in the unsprayed ridged rows were all dead from tip burn. September 28: Vines all dead except one here and there. No late blight, and very little early blight. Practically all of premature dying due to tip burn.

Results. The spraying this year gave the best results of any of the four, since the average increased yield was 53 per cent. The yields this year were better than any other year except 1906. The sprayed manured ridged gave an increase of 45 per cent. over 
the unsprayed manured ridged, while the sprayed manured level gave 48 per cent. over the unsprayed check. On the other hand, the sprayed sodium nitrate ridged gave 60 per cent., and the sprayed sodium nitrate level 79 per cent. over their unsprayed checks, the last being the greatest increased yield due to spraying obtained in any of the experiments during the four years. See Table V.

Table V.-Spraying Experiments in I 909.

\begin{tabular}{|c|c|c|c|c|c|c|c|c|c|c|c|c|}
\hline \multirow{2}{*}{ Treatment } & \multicolumn{2}{|c|}{ Very large } & \multicolumn{2}{|c|}{$\begin{array}{l}\text { Large to } \\
\text { medium }\end{array}$} & \multicolumn{2}{|c|}{$\underset{\text { small }}{\text { Medium to }}$} & \multicolumn{2}{|c|}{$\begin{array}{c}\text { Total } \\
\text { marketable }\end{array}$} & \multicolumn{2}{|c|}{ Very small } & \multirow{2}{*}{\begin{tabular}{|l} 
Rot \\
No.
\end{tabular}} & \multirow{2}{*}{$\begin{array}{l}\text { Scab } \\
\text { Per } \\
\text { Cent. }\end{array}$} \\
\hline & No. & Wt. & No. & $\mathrm{W}_{\mathrm{t}}$. & No. & Wt. & No. & Wt. & No. & Wt. & & \\
\hline 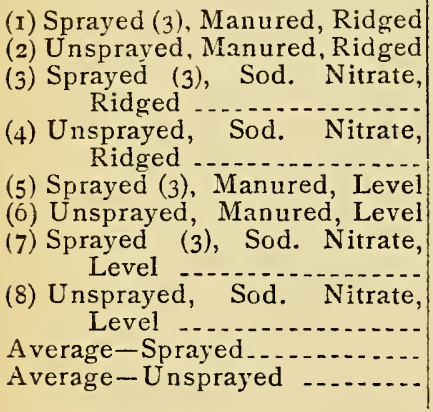 & $\begin{array}{l}0 \\
0 \\
0\end{array}$ & \begin{tabular}{l|}
$31 / 2$ \\
0 \\
$41 / 2$ \\
0 \\
0 \\
0 \\
0 \\
0 \\
2 \\
0
\end{tabular} & $\begin{array}{l}64 \\
44 \\
50 \\
34 \\
6 \text { I } \\
46 \\
51 \\
59 \\
56 \\
38\end{array}$ & $\begin{array}{l}\text { I I I } 1 / 2 \\
22 \\
\text { I6 } \\
\text { I } 81 / 2 \\
9 \\
91 \\
\text { I } 3\end{array}$ & $\begin{array}{r}91 \\
242 \\
184 \\
\\
145 \\
108 \\
177 \\
142\end{array}$ & $\left\{\begin{array}{l}391 / 2 \\
311 / 2 \\
171 / 2\end{array}\right.$ & $\begin{array}{r}125 \\
303 \\
230 \\
196 \\
137 \\
235 \\
180\end{array}$ & $\begin{array}{l}25 \\
6 \mathrm{r} 1 / 2 \\
4 \mathrm{I} 1 / 2\end{array}$ & $\begin{array}{r}79 \\
73 \\
28 \\
28 \\
173 \\
139 \\
78\end{array}$ & $\begin{array}{l}11 / 4 \\
51 / 2 \\
53 / 4\end{array}$ & $\begin{array}{l}0 \\
\text { I } \\
\text { O }\end{array}$ & $\begin{array}{l}67 \\
60 \\
65\end{array}$ \\
\hline
\end{tabular}

\section{Recommendations.}

(I) Seed. The blight fungus carries over in the tubers, and the infected ones may be recognized in the spring by the slightly sunken, often pitted, reddish-brown, superficial dry rot. While the use of such tubers is not advisable, still blight may do much harm in a field in which the seed tubers were perfectly free from the fungus. As to varieties, we know of no good standard variety grown in this state that is not subject to blight of the vines and rot of the tubers, though there may be more variation in the latter respect than in the former. Such varieties as have been found by experiment to possess more or less resistance to either blight of the foliage or rot of the tubers seem to have it at the expense of quality of tubers. However, this is a subject for further investigation, and probably offers greater possibilities than have yet been developed. 
(2) Planting. For early varieties early planting, in order to mature them as soon as possible to escape injury by blight or drought in midsummer, is no doubt advisable. But for late varieties we rather favor only medium early planting, say the last of April to the first week of May, because if planted too early, late potatoes suffer more in the years of drought than if planted later, since they are usually so far matured that a dry July or August will kill them, while the later planted fields, especially if sprayed, will manage to pull through until the moist fall season, and so really have a longer period of growth. We recommend that the seed be planted fairly deep, five to seven inches, to develop the tubers in the ground as deeply as possible as a protection against rot and sun scald.

(3) Rotation. We advise rotation, having potatoes on a different piece of land each year. A four years' rotation, such as the following, is not bad for this state: (I) Corn. (2) Potatoes. (3) Rye. (4) Leguminous crop (sow in fall with the rye, or the following spring). Growing potatoes on the same land two or more years in succession increases scab and possibly in favorable seasons an earlier appearance of blight and greater rot, though so far as the blight is concerned this is largely conjecture.

(4) Fertilization. Manure plowed into the land in spring just before planting the potatoes increases the amount of scab and possibly the amount of rot in blight seasons. If a heavy coat of manure was used with the corn the previous year, commercial fertilizers only may be used with the potatoes. Or if manure is used, plow it in the preceding fall. Horse manure is probably the least objectionable. The following home-mixed fertilizer (per acre), recommended by Dr. Jenkins, seems to merit extended use in this state: Nitrate of soda, I50 lbs.; muriate of potash, 200 lbs.; acid phosphate, 400 lbs.; tankage, 350 lbs.

(5) Cultivation. We recommend a thorough cultivation, to conserve the moisture, in the nature of a combined level-ridge culture. That is, give the vines thorough level culture up to the last two cultivations, and then begin sometime early in July to ridge up the rows with the shovel cultivators, moderately at first, and as much as possible the second time. After both of these ridgings, mulch up the soil between the ridges by shallow cultivation as much as possible without pulling down the ridges, so as to hold in the moisture. This ridging, we think, protects the tubers 
more against rot, by burying them deeper under the soil, so that the blight spores are not washed down to them so easily. It also gives better ventilation to the vines, by allowing water on the foliage to dry off quicker, and by holding the vines erect and off the ground makes spraying easier and more effective.

(6) Spraying. As year after year, wet or dry, we have got increased yields due to spraying potatoes with Bordeaux mixture (4-4-50), we recommend the spraying as a yearly feature in growing late potatoes in this state. The spraying should be done thoroughly, whether by hand or by power, which means that it will take from two to three barrels of the mixture per acre. With the ordinary horse-power sprayers using fixed nozzles, it is necessary to go over the rows twice, in opposite directions, at each spraying, in order to properly coat the vines. The first spraying should be given about the first of July, and if desired, an insecticide, either Paris green, rate of $1 / 2 \mathrm{lb}$., or arsenate of lead, rate of 3 lbs., to 50 gallons of Bordeaux, may be added. We do not believe from our trials with various other sprays that there is anything as good for potatoes as the home-made liquid Bordeaux mixture.

For the late blight alone, the middle of July is early enough for the first spraying, but we advise the first of July, since better results against tip burn and early blight may be expected, and then, too, by the middle of July it is more difficult to reach the lower parts of the vines when a luxuriant growth has been made. The number of times of spraying will depend upon the weather and the manner of spraying. When it is done with leads of hose by men on the ground, only three or four sprayings are necessary. When stationary nozzles attached to the back of the wagon are used, whether the power is furnished by hand or by horse, it will take from four to seven sprayings, depending on the weather, to do good work. In any case it is essential that the vines be kept covered with spray up to the time of their death, otherwise the blight may develop slowly on the green foliage in the fall, and while doing no harm in preventing tuber formation, may work great havoc by rotting the tubers already formed by the spores washing down on them. See Plate XXXVII a. 


\section{OÖSPORES OF POTATO BLIGHT, Phytophthora infestans.}

Importance. Very few fungi have caused the serious and widespread injury that in certain seasons has been wrought by the potato blight. So great was this damage in Europe about I845, that three governments appointed commissions to investigate the trouble and determine surely the cause, as there was considerable difference of opinion on this latter point. In North America the blight was very destructive at the same time. Thoreau, in his book "The Maine Woods," written about 1846 , says: "The potato rot had found him out here, too, the previous year, and got half or two-thirds of his crop, though the seed was of his own raising." A similar condition existed in Canada, as shown by a letter written in $x 844$ to Dr. Bellingham of Dublin (see Berkeley in Journ. Hort. Soc. London I : I I. I846), which reads as follows:

During the months of July and August we had repeated and heavy showers, with oppressive heat and an atmosphere strongly charged with electricity. Toward the close of the month of August I observed the leaves to be marked with black spots, as if ink had been sprinkled over them. They began to wither, emitting a peculiar offensive odor; and before a fortnight the field, which had been singularly luxuriant and almost rank, became arid and dried $u p$, as if by a severe frost. I had the potatoes dug out during the month of September, when about two-thirds were either positively rotten, partially decayed and swarming with worms, or spotted with brownish colored patches, resembling flesh that had been frost-bitten. These parts were soft to the touch, and upon the decayed potatoes I observed a whitish substance like mould.

Concerning the condition at this time in Europe, Berkeley, in the article mentioned above, writes: "Few subjects have attracted more attention, or have been more variously canvassed than the malady with which potatoes have been almost universally visited during the autumn of 1845 ." Since that great outbreak, which resulted in famine in Ireland, the blight has been frequently reported in the potato districts of the cooler temperate regions, but only under special conditions of moisture, such as rainy or foggy weather of some duration in July and August, has it developed in epidemics of widespread and unusual importance. 
When the writer first came to this station in 1902, the potato blight was at the height of one of its periods of destructiveness. In that year the injury resulted largely from the very premature killing of the vines, some fields going down in a week during the latter part of July. In I903 the vines were killed somewhat prematurely, and there was serious rotting of the tubers. This tuber rot was even more serious in 1904, being in fact more destructive in this respect than in any other of the ten years in which we have gathered data. Correspondence at the time with farmers over the state brought out the following items: J. B. Gelston, East Haddam,- "almost a total failure"; Vine Hill Farm, Elmwood,-_"lost about sixty per cent. of crop"; W. S. Thomas, Groton,-- "saved about one-third of crop"; W. S. Lee, Hanover,- "I probably lost three-fourths of my crop"; W. M. Shepardson, Middlebury,- "about one-half crop rotted"; E. Healey, Mystic,- "I think three-fourths rotted before they were dug"; C. M. Ladd, North Franklin,- "estimated two-thirds crop rotted." Since that year there has been comparatively little injury in the state from blight, especially during the dry years from I907 to 1909. In I9Io some little rot started, but the vines were too far gone from tip burn before the appearance of the blight for it to get a good start.

With the reappearance of a season having a wet or muggy July and August, we may expect further outbreaks of this trouble. The work of this and other stations, however, has shown that much of the injury may be prevented by spraying and other protective measures, and that an increased yield even may be expected by spraying in seasons with practically no blight. (See preceding article, also our Report for I904, p. 363.) This part of our object in studying potato blight has been largely accomplished.

Historical Interest. Another feature of potato blight that is of especial interest is its historical importance from a botanical standpoint. Some idea of the early study made of it is well illustrated by the following extract, published in 1846 in The Amer. Journ. Sci. and Arts, vol. 2, page 28I, and written by J. P. Norton:

Little has as yet been done on any organized plan in this country (United States). In Europe the case has been very different. In Holland and Belgium a committee was first appointed to collect facts calculated to 
throw light on the nature of the disease. In one of the Dutch provinces, Groningen, a separate commission was appointed for the same purpose. In Germany, Liebig, among others, has turned his attention to the potato, and has lately published some observations on its nitrogenous constituents. A number of the French philosophers, both alone, and under the auspices of the Central Society of Agriculture, have also attended to the subject. M. Payen has lately published three or four reports containing the results of elaborate microscopic and chemical researches. The English government sent a commission to Ireland of three distinguished scientific men, with directions to obtain as much information as possible on the nature and extent of the disease. In Scotland originated the most extended schemes of all. The subject was taken up in its several branches, as it is connected with botany, meteorology, entomology, and chemistry. Each branch was referred to a competent person, and the investigation is still in progress.

Object of Investigation. Many investigators since have made careful studies of the life history of this fungus. Considerable interest was excited by the Smith-De Bary controversy concerning its disputed winter spore stage, known as oöspores. It is upon this point that the writer has become especially interested by reason of several years' study of the fungus in artificial cultures. Our object was to secure these oöspores in cultures through the use of special strains of the fungus or by particularly favorable cultural media, since in our first cultures no indication of their existence was revealed. In. this respect we have finally been successful, though their abundant production has not yet been accomplished. We have made a special study of cultural media, environmental conditions, etc., in the hope that some light might also be thrown on the related question why certain stages of a fungus, usually the conidial ones, are grown readily in artificial cultures, while other stages, usually the mature one, rarely if ever appear, though not uncommon in nature. We cannot say that we have yet accomplished much in this direction, though. it often takes tedious preliminary work of seemingly little importance to lead up to the final successful results.

Previous Work by Others. We have referred to the SmithDe Bary controversy, carried on in the seventies over the socalled oöspores of potato blight. The former claimed to have found these sexual spores in old leaves and tubers injured by the blight fungus. The latter, a more careful investigator, failed to find any oöspores of this nature that he could connect with the blight fungus, and he threw so much doubt on the conclu- 
sions of Smith that botanists generally have. regarded that the existence of these oöspores has not been proven. Since that time other investigators have claimed, on a few occasions, to have found bodies like immature oöspores. The writer has found various suspicious bodies in the leaves and tubers of infected plants, but has never been convinced of their real nature. Some of these bodies are much like oöspores in appearance, but in our experience they have never been so abundant or typical as to convince us of their connection with the blight fungus. Plate XXXIX G-I shows some of these bodies which are easily distinguished from the true potato oöspores shown above.

Two French investigators, Matruchot and Molliard, were apparently the first to grow the blight fungus in artificial cultures. Their reports were made in 1900 and 1903 . They were not successful in gaining any light concerning the oöspores from their cultures.

In 1904 the writer first made artificial cultures of the blight fungus, and about this time Jones and his assistants at the University of Vermont took up the study of the fungus in the same manner. The results of their work have not been published in detail, though the main points have been presented in two papers before our botanical societies, and brief abstracts of these have appeared in Science. In their work, so far as published, they have had more success than the writer, up to the present investigation, in obtaining curious, immature, and apparently somewhat abnormal bodies, apparently of an oögonial nature, but whose exact identity was left in doubt, since there were no signs of antheridia or of oöspores. The writer previously has been inclined to call these bodies chlamydospores. From the results of our present investigations we believe that they are essentially abnormally and imperfectly developed oögonia (possibly functioning as chlamydospores) due to lack of fertilization by normal antheridia.

Previous Work by the Writer. The results of our previous work with the blight fungus in artificial cultures have been presented in the Reports of this station for 1905 (p. 304) and IgoS (p. 89I). In these investigations, while we occasionally obtained swollen and differentiated threads in the cultures, we were unable to produce these at will, or to further their development, so their nature was largely a matter of speculation. Jones and 
his assistants in the meantime had been much more successful with the development of these bodies, but with culture media much less suited to the vigorous development of the fungus. Our efforts, however, were rewarded at the time by learning how to best obtain cultures of the fungus, and what media were best suited to its luxuriant development. In this respect we believe our cultures have proven better than any of those yet attempted. The Lima bean juice agar described in our Report for 1908 was up to that time the most satisfactory of these media. It has been by continued efforts to develop a specially favorable medium that, for the greater part, we have finally accomplished the desired results.

\section{Present Investigations.}

Nature of Work. We shall give in the following pages the general results of our recent endeavors to produce the oöspores of Phytophthora infestans in artificial cultures. A short preliminary account of this work has recently appeared in Science, vol. XXXIII, p. 744. We wish here to acknowledge indebtedness to our assistant, Mr. E. M. Stoddard, who has made most of these cultures under our direction, and has been very helpful in determining the results thus obtained, since it has required hundreds of cultures, and the examination of these several times, to obtain the required data. The main lines of procedure have been to secure favorable strains of the fungus for the work, and to induce these strains to produce oöspores by means of favorable media or special environment. We shall discuss these points in detail in the following paragraphs.

Strains. The cultures used in our previous work were lost or allowed to die out from time to time, so that these reported here are from different sources, except the one from Holland. These strains, besides representing a variation in origin, also present different lengths of time of growth in artificial cultures. For example, we have continuously grown the Holland strain, A, for over two years, and we do not know how much longer Professor Jones had it in culture; while the E strain has been cultivated less than two months. There seems to be no diminution in the vigor of their growth under continued artificial cultivation, though we do not know whether or not their power of infecting potato plants has declined. They all still retain this 
power, however, as determined by recent tests. These strains are designated by letters, A, B, C, etc., as a matter of easy identification. They have exhibited some slight variation in the luxuriance of their mycelial and conidial development, and even more in the matter of oöspore production. A short description of their source of origin, development, etc., follows :

Strain A. This was obtained about February, 1909, from Jones, who isolated it from tubers grown in Holland. From this culture we have grown at least twenty-two generations, represented by many cultures under varying conditions. It has formed a very fair growth on suitable media, though it is the least vigorous now of any of the strains. It was the first in which we noticed the appearance of imperfect oögonial formation, though this was perhaps more owing to the medium employed than the strain, since the $B$ strain soon afterwards gave even better results in the same medium. It now stands about fourth in the matter of oöspore production, being less variable than $\mathrm{D}$, but the oöspores produced are never very abundant, and are usually imperfect.

Strain B. This culture was isolated by the writer in November, 1909, from tubers furnished by Mr. Ellicott Curtis, and grown at Bantam, Conn., that year. His crop had been sprayed during the season and kept green until late in the fall, when the rains washed off the spray, and the blight got a foothold too late to injure the vines much, but enough to thoroughly infect the tubers, which were dug very late, and found to be badly rotted. We have grown this strain for at least nineteen generations, perhaps in more cultures and under more different conditions than any of the other strains. It makes a good vigorous growth, perhaps the best of any, though not always the most luxuriant. On the whole, the best results in oöspore production have been obtained with it. The most perfect oögonia, antheridia and oöspores have also been found in cultures of this strain.

Strain C. Cultures of this strain were obtained by the writer in January, I9I0, from infected tubers purchased at a Westville grocery, and probably grown either in Maine or Long Island. About fifteen generations have been grown in cultures after the manner of $A$ and B. For a long time this strain gave no indication of oögonial formation, though grown continuously on the medium most favorable for that purpose. About the tenth generation immature oögonia were first noticed, and succeeding generations developed these better and more abundantly, until finally antheridia also began to appear, and somewhat rarely, mature oöspores. At present it ranks about third as regards oögonial development. It ranks high in conidial production.

Strain D. This strain was separated by the writer in October, I9Io, from the descendants of diseased tubers obtained from Mr. Curtis (see Strain B) and grown in IgIo on our experimental farm at Centerville. It has the general characteristics of $B$, and has given some cultures with a good development of oögonia, antheridia and mature oöspores, but as 
yet it seems much more variable than $B$ in this respect, and so not to be depended on, though it has not been in culture nearly so long, as it has been carried through only seven generations. However, it now stands about second in oöspore production.

Strain E. Mr. Stoddard obtained this strain in February, I9II, from Maine grown tubers purchased at a local grocery. As yet it has not been thoroughly tested, as comparatively few cultures have been made, represented by only three generations, but in these oögonial production has not made its appearance even in a slight way.

Media. Synthetic media, because of known composition, offer the best means for determining the cause of oöspore production, if such depends on some particular chemical substance or element. Yet such media, especially when in liquid form, are not as favorable for general growth of fungi as media containing vegetable nutrients whose ingredients are quite complex and whose exact chemical nature cannot be determined. Consequently, we have not used synthetic media except in the sense that certain substances of known composition have been added to our vegetable media to determine their individual effect. Potassium and phosphorus are more or less fixed in literature as having importance in vegetable reproduction, and yet we have not in any way by the addition of potassium phosphate increased oöspore production in our cultures. Likewise, toxic or stimulative substances have an influence on vegetative growth, yet such substances as we have tried in a small way, copper sulphate, chloroform, ether, etc., have given no response in increased oöspore production.

Various Media. Most of our cultures have been on vegetable media, usually in combination with agar-agar. We have tried some few liquid media, but they have shown no special advantage, such as might be expected from the supposed relationship of Phytophthora and Pythium, and the reported favorable development of the oöspores of the latter in liquids. Likewise, we have not found gelatine a favorable medium in what little use we have made of it, though this was used largely by Jones in his cultures. In our work, besides various agar-agar media, we have tried a considerable variety of substances and combinations. We have used living aseptic vegetable tissues and quite a number of sterilized ones, either in whole or ground condition. We have also used filter paper soaked with nutrient liquid. Taking into consideration all of the various media, and their modifica- 
tions, we have tried about seventy-five different combinations in over $\mathrm{I}, 200$ cultures.

Most Favorable Media. Out of all these combinations, three media stand out as being especially favorable for the growth of the fungus. Of these the Lima bean juice agar was described in a previous paper. (Report, I908, p. 898.) This has never given us mature oöspores, and immature ones only once. A second very favorable medium for aërial growth of the fungus, perhaps the most favorable of any we have used, is a "combination medium" consisting of the following ingredients, ground to powder in a food-chopper: Lima beans, 15 grms.; oats, 25 grms.; peanuts, Io grms.; potato, I5 grms.; sweet corn, IO grms.; wheat, 10 grms.; with agar, Io grms., and water, $500 \mathrm{cc}$. This, however, has shown no special virtue so far as oöspore production is concerned. Potato juice agar gives a fair mycelial growth of the fungus, but not as luxuriant or vigorous as the other two media mentioned here. It needs to be used for the best development somewhat stronger than we first tried it, and we are now using at least 300 grms. of the sliced tubers to $500 \mathrm{cc}$. of medium. But potato juice agar, like the preceding, has so far been of no value in producing oöspores. The one medium that has stood alone so far as production of oöspores is concerned is our oat juice agar. Without this, apparently, we would never have produced perfect oöspores in cultures.

Oat Juice Agar. We have varied somewhat from time to time in the manner of making this, but in order to have as uniform a product as possible, we have finally adopted the following method: Fifty grms. of ground oats, such as are ordinarily fed to horses, are stirred into about 300 to $350 \mathrm{cc}$. of water, and steam from an autoclave, by means of glass and rubber tubing connected with the stopcock, is run into this in a covered dish for half an hour. This cooks the material without burning and at a uniform temperature. The coarse sediment of the oats is then strained off through an ordinary fine wire strainer, and Io grms. agar is added to the liquid, which is again treated to the steam for half an hour to thoroughly melt the agar. Some water passes over with the stream during these cookings, so that what little, if any, is needed to bring it up to the required $500 \mathrm{cc}$. is added after the whole is drained into a graduated cyclinder. After the added water is uniformly distributed by repouring, the 
medium is placed in the test tubes and these are sterilized in the autoclave for fifteen minutes under 7 to Io lbs. pressure.

Chemistry of Oats. We are not sure what particular ingredient of oats, if any, is responsible for stimulating oögonial development in the oat juice agar. Chemical analyses of oats show that they have higher percentages of ash, fat, and lecithin than the other cereals. Taking the ash content, however, it seems that this higher per cent. is due largely to silica, so that the percentages of phosphorus and potash are even lower than in most of the other cereals, as well as in beans, though perhaps higher than in potatoes. So these constituents of the ash are apparently not the favorable factors. While the licithin is higher than in the other cereals and potatoes, it is lower than in beans. On the other hand, the fat is considerably higher than in the beans, or any other cereal except corn, which it slightly exceeds.

Lecithin is phosphorized fat (contains fatty acids, cholin and esters of phosphoric acid), and is more soluble than ordinary fat, being the form in which it is said by some to be digested. According to Loew*: "By the transformation of fatty matter into lecithin the higher fatty acids are offered to the protoplasm in a soluble form, and after being oxidized, other molecules of fatty acids may enter into the place of the former, and thus the same molecules of the glycerol-phosphoric acid can serve repeatedly as vehicles for the oxidation of fatty acids." In this manner the amount of lecithin really available in the oats, because of the much higher per cent. of fat, may greatly exceed that of the bean. Lecithin also, according to Loew, has considerable therapeutic value in cases of nervous debility, and is a high constituent of the nervous system (and it is also a prominent constituent of the spermatozoa of animals), and this might explain its value in stimulating the potato blight to sexual reproduction, especially in its effect on the antheridia, which seem to have most nearly disappeared.

Fat alone, possibly because not available for the fungus, does not explain the production of these oöspores, since corn, though but little lower than oats in its fatty content, did not stimulate their production. Likewise peanuts, very high in fat and probably higher in lecithin, failed to even produce a mycelial growth of this fungus, though several other fungi grew rather vigor-

*Bull. 45 Bur. P1. Ind. U. S. Dept. Agr. 
ously in the peanut juice agar. The fat is so evident in this medium that it shows plainly, even when only 25 grms. of ground peanuts are used per $500 \mathrm{cc}$. of medium, which is not the case with our oat juice agar. While the comparatively high per cent. of fat in oats, and the possibility of its easy conversion into lecithin, might explain the phenomenon of oöspore production in the potato blight fungus, we have no sure proof that this is so. In any case the fungus seems to "feel its oats" more or less.

Likewise, this oat medium seems to stimulate ordinary spore production with some other fungi. For example, Monochetia Desmazierii fruits abundantly in it, whereas it does not fruit at all, or very little, on several other media in which we have grown it. We have also several times had the sclerotia of Sclerotinia Libertiana attempt to form its asco stage in this medium, by developing long stalks which just fail to expand and develop the terminal fruiting cups. Several other fungi also produce in this medium a more luxurious fruiting condition than they do in the other media in which we have grown them.

Environmental Factors. Having secured this favorable medium and using the various strains at hand, we have attempted to determine if certain changes in the medium or its surroundings might not act more favorably on oöspore production. We will briefly discuss these factors in the following paragraphs. In summary, however, it may be stated that we have not found any very decidedly favorable factors, though there seem to be "tendencies" in certain directions, and that as yet we fail to uniformly insure or gradually increase oöspore production by taking advantage of these apparently favorable conditions.

Acid versus Alkaline Media. As made up by us, oat juice agar takes about I $5 \mathrm{cc}$. of $\frac{\mathrm{N}}{\mathrm{IO}} \mathrm{NaOH}$ to neutralize $250 \mathrm{cc}$. of the natural medium, as determined by the phenolphthalein test. In order to test the effect of acid, neutral, and alkaline oat agar the following strengths were made at different times and the potato blight fungus grown in them: (I) 15 cc. acid (natural medium); (2) 5 cc. acid (used ro cc. of $\frac{\mathrm{N}}{\mathrm{IO}} \mathrm{NaOH}$ to neutralize 250 cc. of medium); (3) neutral (used I $_{5}$ cc. of $\frac{\mathrm{N}}{\mathrm{IO}} \mathrm{NaOH}$, 
etc.); (4) 5 cc. alkaline (used 20 cc. of $\frac{\mathrm{N}}{\mathrm{IO}} \mathrm{NaOH}$, etc.) ;

I5 cc. alkaline (used $30 \mathrm{cc}$. of $\frac{\mathrm{N}}{\mathrm{IO}} \mathrm{NaOH}$, etc.) The strains A to $\mathrm{D}$ acted somewhat differently on these five strengths, ${ }^{*}$ but as a rule vigorous mycelial growth occurred only on the ${ }_{5} 5 \mathrm{cc}$. and $5 \mathrm{cc}$. acid, and practically no growth on the $5 \mathrm{cc}$. and $\mathrm{I} 5 \mathrm{cc}$. alkaline tubes. However, by gradually acclimating the various strains through the different strengths from the natural I $5 \mathrm{cc}$. acid, they were all finally brought so that they would grow more or less on the $15 \mathrm{cc}$. alkaline tubes.

As regards oöspores, they formed less abundantly and more imperfectly on the alkaline tubes than they did on the acid tubes. On the whole, perhaps the $5 \mathrm{cc}$. acid tubes gave the best results, though in some of the comparative tests the $15 \mathrm{cc}$. acid and the neutral media did as well or even better. We had thought that perhaps a slightly alkaline medium would favor oöspore production, since in previous work with the Lima bean mildew ( $P$. Phaseoli) we had found that by making the medium slightly more acid we had first cut off oöspore production, then conidial, and finally the mycelial development itself, and our first results with the potato blight seemed to indicate that a neutral or less acid medium than the natural oat juice agar favored better oöspore development. Out of the total of our experimentations, however, we can only say that alkaline oats agar is apparently less rather than more favorable, and that between neutrality and I5 cc. acidity is the best condition for oöspore production as far as this particular factor is concerned.

Light and Darkness. Some investigators have found that light favored spore germination in the smuts. We tried strong light, partial and total darkness, to see if light or its absence had any effect on oöspore production. Cuitures kept in a jar exposed to full light of a north window made a less vigorous growth than those kept in an adjacent jar entirely protected from the light, while neither did quite as well as the cultures kept under our usual conditions of partially diffused light (in the same room in a glass front cupboard in open tin cans, for

*For instance, one tube of $\mathrm{C}$ grew fairly well on the $\mathrm{I}_{5} \mathrm{cc}$. alkaline tube when transferred directly from the $15 \mathrm{cc}$. acid tube. 
convenience in holding them). Neither did those cultures exposed to the stronger light or those in total darkness show an increase in oöspore production, as the difference, if any, wàs in favor of our ordinary conditions of partially diffused light.

Temperature. The fact that ordinarily we have found the oöspores of $P$. Phaseoli on beans in the fall, about the time of the first frosts, indicated, as is the case with many other fungi which develop their mature stage in late fall or early spring, that cold is an important factor in the production of the sexual stage. Our experiments along this line, however, gave no indication that oöspore production in the potato blight could be stimulated in this manner. Comparative tests were made, and repeated with similar results, under four different conditions of temperature, the temperatures being taken three times a day during the duration of the tests. (I) Cultures were kept in an incubator varying from 29 to $33^{\circ} \mathrm{C}$, and averaging $32.6^{\circ}$. (2) In another incubator they were kept at a temperature of 24 to $27^{\circ}$ and averaging $24.6^{\circ}$. (3) Check cultures were kept under our ordinary room conditions of 16 to $22^{\circ}$, averaging I9. $4^{\circ}$. (4) Cultures were kept in a box connected with an indirect ventilator to the outside of the building, in which the temperature ranged from 1.5 to $20^{\circ}$, averaging $14.5^{\circ}$.

The results of these tests showed that the fungus failed to grow at all in the higher temperatures of the incubators. The best growth was made under our ordinary room conditions, where the temperature averaged $19.4^{\circ}$. The cultures that were kept in the low and quite variable temperature, averaging only $14.5^{\circ}$, did very well and made fair growths despite these conditions. It would seem that the best temperature conditions for mycelial growth of the fungus were between 15 and $20^{\circ}$.

These temperature tests agree with the general prevalence of the disease in our more northern temperate regions, and its most severe outbreaks in seasons that are slightly below the average in temperature as well as above it in moisture. However, in spite of the great variability with those cultures grown under the colder conditions, there was no indication of increased vigor in oöspore production. In fact, these tubes did no better, if as well as the check tubes, under our ordinary temperature conditions. Low temperature, then, does not seem to be the factor determining oöspore production in this case. 
Air. So far as we have seen, oöspore production takes place in the medium slightly below or at the surface of the agar. In fact, this, as well as most other fungi when grown on agar media, makes only a slight invasion into the medium itself. Jones, in his experiments with this fungus, however, seems to have used stab cultures to a very-large extent, and here the oöspore-like bodies were produced deep in the medium, away from the air. We have not used stab cultures largely, but so far as we have tried them we have not obtained oöspores as abundantly or as perfectly developed as in the ordinary agar slant tubes. Jones, however, used gelatine in the place of agar. We have not used this in our work nearly so much as the agar, but so far as we have tried it we have not found it as desirable as agar. It would seem from our work that the exclusion of the air by stab cultures in gelatine media was not necessarily a favorable factor in oöspore production, and that Jones got his results in spite of, rather than because of, this condition. Possibly the strains he used were the real factors in his partial success.

Moisture. Moisture seems to be a very important factor in the spread of the potato blight fungus, since infected leaves of a plant, if kept in a dry atmosphere, develop the disease no further. Likewise, in cultures there seem to be certain conditions of moisture most favorable for success, but here excessive moisture is as unfavorable as too little moisture. Cultures inoculated into the base of a tube containing water do not do so well as those inoculated above and kept free from the water. Likewise, as a general rule, cultures inoculated toward the base of a tube do better than those inoculated in the drier upper edge. We have had the best results by inoculating the tubes at the base, if not bothered by water there, inserting a small amount of the medium with the fungus, and slightly imbedding this into the agar.

The chief difference in a tube seems to come in the production of the oöspores, which if present are most likely to be found in the upper and drier part of the tube. Whether the passing of the fungus from the more moist lower portion into the upper and drier portion (dries out quicker because thinner) explains this we do not know. We do know that the use of either a more or less dilute agar (we ordinarily use $10 \mathrm{grm}$. to $500 \mathrm{cc}$. of water) does not increase oöspore production to any appre- 
ciable degree. We have tried rolled tubes in a few cases, inoculating them at the base. These dry out much quicker than the ordinary slant tube, but we cannot say that they gave us any very unusual results. We have also tried running the water, when present in the base of the tubes, over the growth occasionally, and have pulled off the aerial growth every few days, but neither of these methods gave us unusual results as regards the oöspores. We have also tried growing the fungus in Petrie dishes, which offer a difference in moisture conditions, but our luck here has been no better than with the tubes.

While speaking of the Petrie dish cultures we might mention that we devised methods by which, with temporary slips of paraffined paper, we could pour a plate containing from two to four different kinds of media. Inoculating these at the center, the fungus gradually spreads out over these different media; or by a special contrivance it can be made to pass successively from one kind to another. But these variations have not given any particularly favorable results in oöspore production.

Clear versus Sedimentary Media. Besides stab cultures in a gelatine medium, a third factor in which Jones' methods have differed from ours has been his use of a clear or filtered medium, while we have largely used sedimentary media, in which only the coarser food particles have been filtered off. That his use of filtered media does not explain his partial success in imperfect oöspore production seems apparent, since we failed in our previous experiments to obtain oöspores under conditions employed by him, so far as the use of stab cultures in a filtered, potato juice gelatine goes. So it must be some other factor than this that gave him oögonia where we failed to obtain them. In fact, we have found with our oat juice agar that the sediment in the medium favors rather than retards oöspore production.

On several occasions we have placed a batch of hot oat agar in a centrifuge and whirled it in the machine for ten to fifteen minutes, until it hardened, when we have been able to cut off the upper perfectly clear portion from the lower portion containing the extra sediment. Comparative cultures made in tubes of the clear and sedimentary portions have always shown that the fungus makes a much weaker growth in the former, and so far no signs of oöspore formation have been found in it, while in the sedimentary tubes the mycelial growth and oöspore 
production remain about the same as in our ordinary tubes, from which they differ only in a little more sediment. Tubes made from oats in which none of the coarse sediment is removed also act about the same as our ordinary tubes with only the finer sediment present. Since it might be that the clear tubes were very deficient in soluble food matter, we have made cultures in which the ground oats were soaked over night in water, protected from bacterial action by chloroform, and then used. this for making the oat juice agar. The clear and sedimentary portions of such a medium, separated in a similar manner in the centrifuge, showed no different results than before on inoculation with the fungus. It seems from these experiments quite evident that the fungus gets from the solid food particles in the sediment something favorable not only for more vigorous mycelial development, but also for inciting moderate oöspore production. Whether or not it is the fat, which might be held in greater amount in the sediment, we have not determined.

Variability of Oöspore Production. Despite the fact that oat juice agar will usually produce oöspores with most of our strains, while Lima bean juice agar practically fails to do so, there still remains much to be desired in stability and productiveness of oöspore formation in this favorable medium. In fact, we are never sure even now when we make a culture from a very good tube as regards oöspores that its descendant tube will be equally good. While our success in obtaining oöspores to-day is much greater than it was over a year ago, when they first began to appear, it is only in looking back over this long period that we notice improvement, since cultures made a month or two ago may have been even better than those of recent date.

Variability in the Same Tube. Just what causes this variability of oöspore production we do not know, since it manifests itself even in the same tube. We have mentioned before that ordinarily we are more likely to find the oöspores at the top of the culture than anywhere else. We may take out for microscopic examination small pieces of the medium from several different places, and find no oöspores, or only a few, and then we may strike a spot where they are rather common. This may be due to the fact that localized portions of the mycelium are concerned in their production, and that these are scattered. We have some evidence in favor of this view in the oöspore pro- 
duction of $P$. Phaseoli, where we find oöspores more abundant in some places than in others, and occasionally we find them developed in more or less luxuriant bands, so evident as to be detected by the naked eye. Yet with this species it is rare that they do not occur very abundantly in every slide made from the surface of an oat agar tube; while the opposite condition is more likely to be true of the potato blight. Perhaps this restriction and scarcity in the case of the potato blight is due to their development in certain spots where the available food, especially in the sediment, is most abundant.

Variability in Different Tubes. We have also found that cultures made from the same source into tubes of the same batch of the medium may vary considerably. Perhaps variation in different batches of the same medium might be accounted for by some very slight variation in the manner of making, but we would hardly expect this to hold true in the same batch unless it was some variation in the settling of the sediment, too slight to be detected by the eye.

We have tried to increase oöspore production by propagating from tubes showing the greatest luxuriance in their development. While there seems to be something in this, still on the whole we have no very clear proof of it. Perhaps one difficulty in the way is that in these renewals we are never sure that we have used a portion of the culture that was richest in oöspore production, since it is usually impossible to detect their presence with a hand lens in our uncleared media. With Jones' cleared gelatine media, however, this method of renewal was more feasible, as the oöspore groups were quite evident with a hand lens, and this may account for such success as he has attained by his continued use of these oögonial groups.

Age of Cultures as Regards Oöspore Production. As a usual thing, with our oat juice agar cultures we can find immature oöspores in the tubes, if such appear at all, two weeks after inoculation. With P. Phaseoli mature oöspores are usually quite abundant by this time. In order to be sure, however, we have usually examined the tubes again about a month after inoculation, as the oöspores are then frequently more mature and abundant. One of the very best tubes produced showed about a hundred oöspores, in different stages of development, on a single slide from it. Ordinarily, however, the number of 
oöspores does not run over from six to twenty on a slide, and most of these are imperfect. A slide that will give two or three oögonia from which mature oöspores can be crushed out is considered a good one. Most of the oögonia fail entirely to mature, apparently through lack of fertilization. Those that reach maturity with a perfect oöspore usually have attached a well-developed antheridium. Whether or not we can develop oöspore production to the luxuriance which is the usual thing with $P$. Phaseoli in both Lima bean and oat juice agar, time only will tell. What we are sure of so far is that we have produced perfectly matured oögonia with normal and apparently functional antheridia, and that the oögonia in such cases have often contained mature and apparently functional oöspores. As yet we have not germinated these oöspores, but this is equally true of those of $P$. Phaseoli, as it apparently takes an exposure to winter conditions to bring about germination.

Microscopic Characters of the Oöspores. We have not been able to follow the different steps in the development of these oöspores as closely as in the bean Phytophthora because of their comparative scarcity. In general the oögonium develops as a much more prominent factor than the antheridium, since the latter is so frequently missing. Then, too, the oögonium seems to be able to attain a much more advanced stage of development independent of any fertilization than does $P$. Phaseoli, if we can judge by the size and condition of the oögonium in the latter when the antheridium first appears. The oögonia of the potato fungus (see Plate XXXVIII) first made their appearance in our cultures as swollen terminal threads, cut off from the normal mycelium by a septum. Not infrequently, by bifucation of the mycelial thread, there were two of these swollen bodies together. The terminal portion of these swollen threads gradually assumes a globular shape and is cut off from the rest of the thread. In the meantime the swollen thread, especially its spherical tip, becomes more or less deeply tinted. The wall is thickened by the deposition on the outside of the original coat of a more or less irregular, thick, reddish-brown coat (see Plate XXXVIII J). The protoplasmic contents of the oögonium may now begin to contract into the oösphere. If no antheridium is present, however, this seems to be as far as the development toward an oöspore proceeds, and this is the fate of most of the oögonia. 
When an antheridium is present (see Plate XXXIX), it is very similar to those of $P$. Phaseoli. We have not yet been able to detect antheridia in their younger stages, having seen them only when they were practically mature, and the ooggonium is then well along in its development. With P. Phaseoli we found that the antheridium was matured, as to size and general appearance at least, when the oögonium was just beginning to develop. (See Report, 1908, Plate LXXIV E.) Perhaps a similar condition would exist with the potato fungus if the antheridia were produced as abundantly. The presence of the antheridium further stimulates, apparently through fertilization, the protoplasmic contents into forming a definite spherical oöspore with a thin limiting cell wall, which gradually thickens until there is formed a perfectly normal oöspore. Plate XXXIX $F$ shows an oögonium crushed open to reveal more plainly its enclosed oöspore, well filled with protoplasmic contents. In this case the oögonium, antheridium and oöspore are certainly as perfect as any of those ever produced by $P$. Phaseoli (see Plate XL A-C).

The thick, colored, outer wall of the oögonium sometimes becomes so opaque (see Plate XXXIX D) as to hide all signs of its oöspore. This outer coat is also quite variable in thickness and in the irregularity of its markings. Apparently the medium in which it is grown has some effect on the irregularity of the markings as Jones got some apparently quite abnormal sculpturing on those grown in his potato gelatine medium. Then, too. the outer wall is somewhat brittle, and, when slightly crushed under a slide, the thick walled oögonia appear more irregular than they really are. If these oögonia were produced in the plant tissues we doubt if the outer wall would be as thick, or present as great irregularities of surface as it does in the artificial cultures. Some of the oögonia, however, are very nearly smooth, and some have rather thin walls or thin places.

The oöspores have a medium to rather thick wall when mature. This wall is smooth and hyaline, though in some cases we have seen a slight tint and some unevenness of surface. Those we have measured vary from 24 to $35 \mu$ in diameter. The oögonia vary from $34 \mu$ to $50 \mu$, mostly 38 to $42 \mu$, depending somewhat on the thickness and irregularity of their outer coat. The antheridia are usually somewhat irregular-oval in shape, vary 
in size usually from $\mathrm{I} 4-25 \times \mathrm{I} 2-\mathrm{I} 8 \mu$, and, like $P$. Phaseoli, often show the superimposed oögonial thread (see Plate XXXIX D-F). We have not been able to trace the point of origin of antheridium and oögonium, but they seem to come from separate threads, and perhaps it is the contact of these threads that stimulates the beginning of their development, as seems to be the case with $P$. Phaseoli.

Hybrids. In our Report for 1908, page 900, we described attempts to produce hybrid oöspores of $P$. infestans and $P$. Phaseoli by inoculating a tube of Lima bean juice agar above with the former and below with the latter fungus. At first we were inclined to believe that such a hybrid resulted, as in, around, and below the $P$. infestans colony there were developed numerous oöspores. As these did not differ essentially from those of $P$. Phaseoli, however, we finally came to the conclusion that they all belonged to the latter fungus.

When, however, in our present work we tried this same crossing on oat juice agar, the results were entirely different, since we obtained ooggonia, usually only in the vicinity of the $P$. infestans colony, which were entirely different from the normal oögonia of $P$. Phaseoli that were produced abundantly all through the culture. These different oögonia were of the $P$. infestans type, which at that time we were just beginning to get in a small way in our pure cultures of P. infestans on oat juice agar, and they differed in that they usually produced mature oöspores, and were far more abundant than we have ever obtained them in pure cultures of P. infestans. Plate XL shows, in the upper row, the oögonia of $P$. Phaseoli as grown in Lima bean juice agar; the second row shows these $P$. Phaseoli oögonia as grown in a cross culture in oat juice agar with $P$. infestans; while the two lower rows show the hybrid $P$. infestans oögonia as appearing in the same culture with those of $P$. Phaseoli shown in the row above. These photomicrographs easily convince one that the hybrid oögonia are of an entirely different type from those of $P$. Phaseoli, and that they closely resemble those of $P$. infestans, as shown in Plate XXXIX A-F.

As stated before, they differ from those of $P$. infestans in their greater abundance and more perfect development, especially of the oöspores. They also differ, perhaps, in not being so deeply tinted, and there are some that seem to grade into 
$P$. Phaseoli, or at least are not very different from those of that species, as the oögonial walls are only slightly tinted and thickened. In one of these cross cultures we measured fifteen oögonia and oöspores each of $P$. Phaseoli and the hybrid $P$. infestans, and found that in the former the ooggonia varied from 24 to $34 \mu$, averaging $29 \mu$, and the oöspores from 18 to $26 \mu$ averaging $22.5 \mu$, while the oögonia of the latter varied from 34 to $47 \mu$, averaging $40 \mu$, and the oöspores from 25 to $35 \mu$, averaging $30 \mu$. These hybrids, then, are about the same size as the uncrossed oögonia and oöspores of $P$. infestans when fully matured.

We have crossed most of the strains of $P$. infestans with $P$. Phaseoli on two different occasions. Some of these cross cultures have been much better than others as regards production of the hybrid oöspores. We have continued these hybrids in renewal cultures in some cases through six generations. Plate $\mathrm{XL}, \mathrm{L}$, shows one of these oöspores in the fifth renewal from the original cross. It does not look essentially different from the original hybrids, as its lighter color is not lighter than some that were produced in the original crosses. Now in these renewal cultures from the original cross, the oöspores are not descendants of the hybrid oöspores, since these never germinate in the cultures, but apparently are merely new crosses each time, and so are produced only by the conveyance of the mycelia of both species, which became closely mixed in the original culture. All of the renewal cultures produce an abundance of the normal oöspores of $P$. Phaseoli, and those cultures which produce few or none of the hybrid oöspores are therefore ones in which the $P$. infestans mycelium has been largely or entirely crowded out by that of $P$. Phaseoli.

Of course there are those who may think that these oöspores are not hybrids, but true oöspores of $P$. infestans which have been stimulated to oöspore production in some way by the presence of $P$. Phaseoli, just as the oat juice agar has stimulated this production to a less degree. We do not believe this to be the case, however. The potato blight has evidently lost its power of antheridial development much more completely than it has its oögonial development. The history of all our cultures shows this to be so. In these cross cultures, the antheridia of $P$. Phaseoli take the place of the missing ones of 
$P$. infestans when situated more favorably to the potato oögonia or ooggonial threads than they are to their own. Naturally they are more favorably situated on the whole to their own than they are to those of the potato, and so the hybrids are much fewer in number.

Not only has $P$. infestans been crossed with $P$. Phaseoli, but also with $P$. cactorum. Our results in crossing with the latter, however, have not been nearly so satisfactory, as comparatively few hybrids were found in the cultures, and only where the $\mathrm{B}$ and the $\mathrm{D}$ strains were used. We think that this is probably due as much to mechanical difficulties in having the antheridia of $P$. cactorum free to fertilize the oögonia of $P$. infestans, as to physiological incompatibility. Our cultures of $P$. cactorum on oat juice agar run almost entirely to oöspore production, with little or no aërial growth of mycelium and conidiophores. This makes it probable that the antheridia are much more favorably situated to fertilize their own oögonia than those of $P$. infestans, so that the chances of crossing are thereby greatly lessened. Those hybrids that were formed were of the potato type, but were not nearly so deeply tinted as those obtained with the bean Phytophthora, being more of a golden than a chestnut brown. Photomicrographs of the normal oöspores of $P$. cactorum in a cross culture with $P$. infestans are shown in Plate XXXIX J while $\mathrm{K}$ of the same plate shows one of the hybrid oöspores. Four of the hybrids had oögonia varying from 35 to $40 \mu$, and oöspores from 25 to $28 \mu$, while the variation of $P$. cactorum in the same culture was 20 to $35 \mu$ for the oögonia and 18 to $28 \mu$ for the oöspores. The oögonia and oöspores of $P$. cactorum are very similar to those of $P$. Phaseoli, being hyaline, smooth, and moderately thin-walled. Sometimes the oögonia of both these species become slightly tinted.

Theories. At one time we suggested as a reason for the absence of the oöspores of potato blight in nature and cultures that there might be male and female mycelial strains and that oöspore production could therefore take place only when these occurred together. So far as our culture work has gone with both $P$. Phaseoli and $P$. infestans, this theory does not seem to hold good, as we explained in our last Report.

The more probable theory is that the potato blight fungus has, at least in most instances, lost its power of sexual repro- 
duction to $a^{*}$ large degree. This is shown by failure to produce oöspores in media in which both $P$. Phaseoli and $P$. cactorum produce them abundantly. It is further shown by oat juice agar stimulating the production of oögonia in varying degrees from imperfect to fully matured specimens, and by the varying response of different strains of the fungus to this favorable medium.

That the absense of oöspore production is due more largely to the absense or loss of vigor of the male than the female factor, is shown by the appearance of oögonia in cultures more frequently than of antheridia, their evident attempt to form oöspores in the absence of the latter, and their success when normal antheridia do appear. Likewise, the ease with which $P$. infestans crosses with $P$. Phaseoli seems to be due to the vigorous antheridia of the latter species.

It is perhaps idle to speculate as to how this loss of sexual vigor came about, though it may be due to the same cause that has induced the decline of sexual reproduction in the potato itself. Very rarely do the blossoms of the potato set seeds, apparently due largely to the sterility of the pollen. Varieties long propagated seem to have lost the power of seed production more completely than those recently originated, especially if the latter are from a cross with a species nearer the wild condition. This loss of sexual vigor is explained, at least in part, by the continued propagation of our cultivated varieties by the asexual tubers. As the potato blight, so far as is known in nature, carries over from one season to another only through the vegetative mycelium in the tubers, it may be that continued asexual propagation of the fungus in this manner has also resulted in its loss of sexual vigor, especially of the antheridia. 


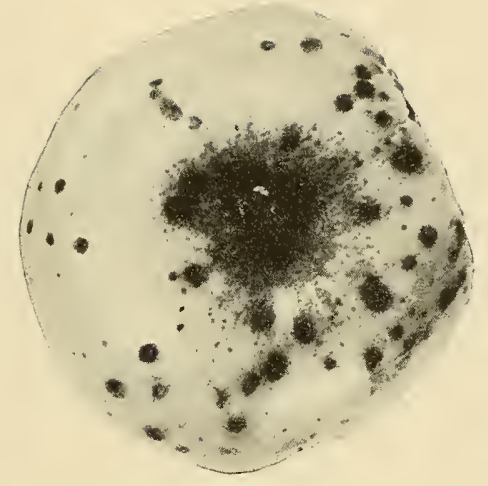

a. Fruit Spot of Apple, p. 723.

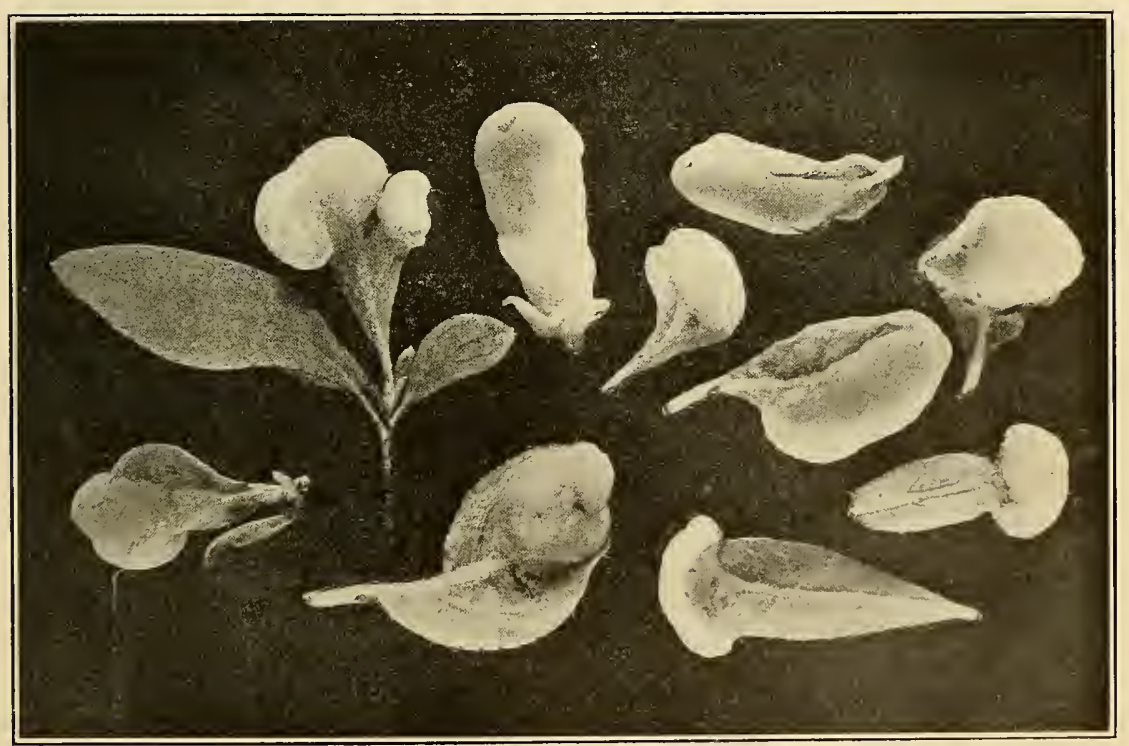

b. Pocket Curl of Azalea, p. 724.

FUNGI OF APPLE AND AZALEA. 



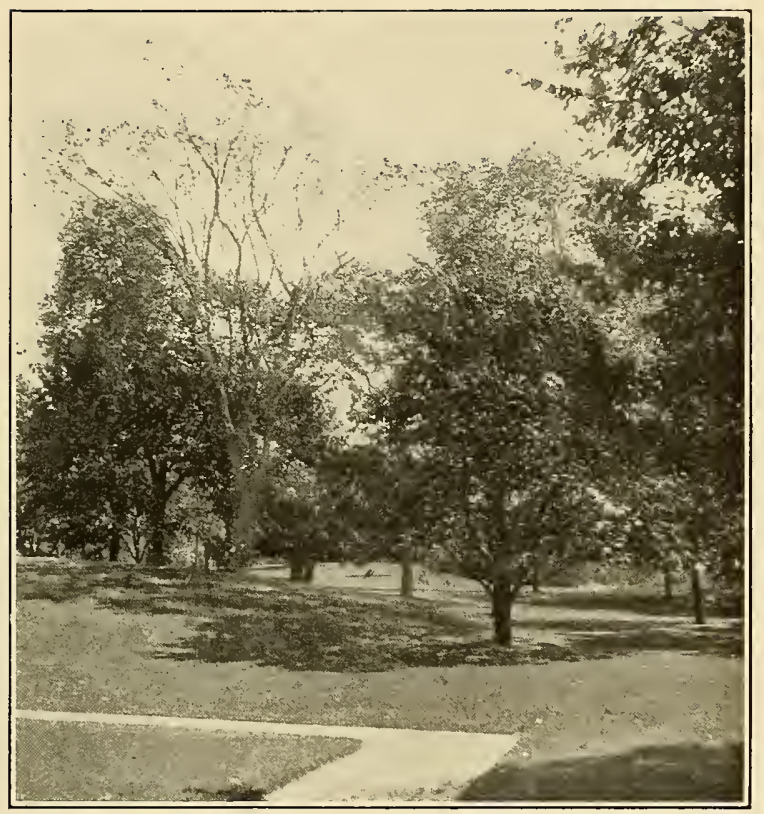

a. Showing an elm defoliated in mid-summer.
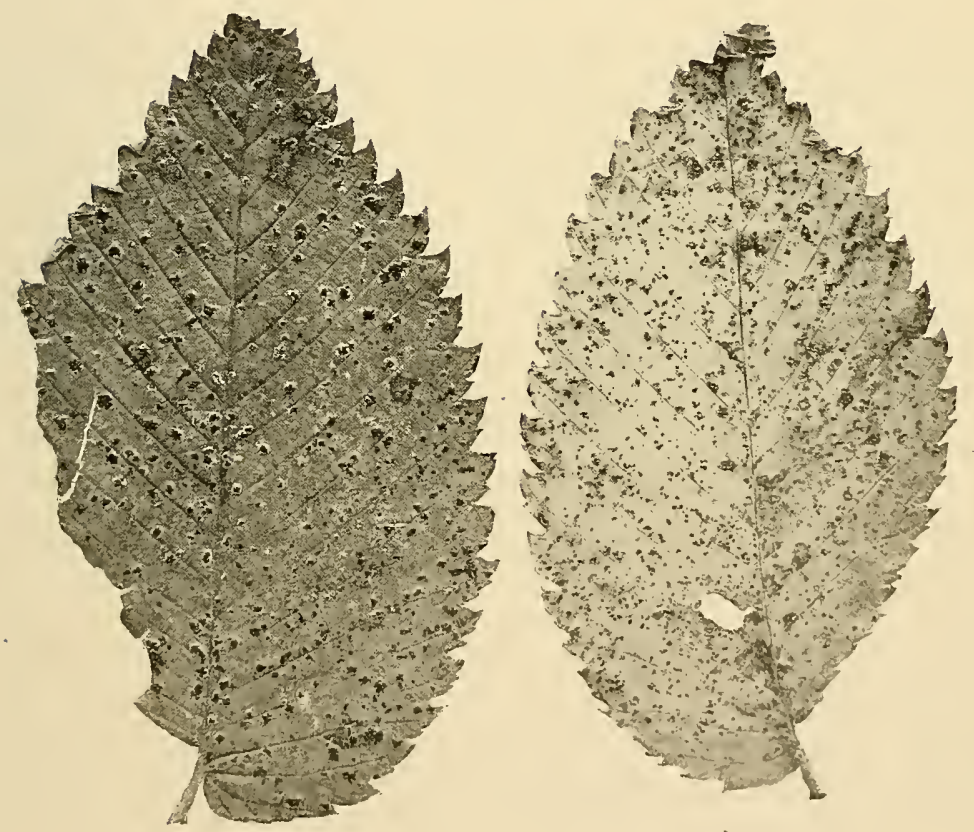

b. Appearance of fungus on the leares. 



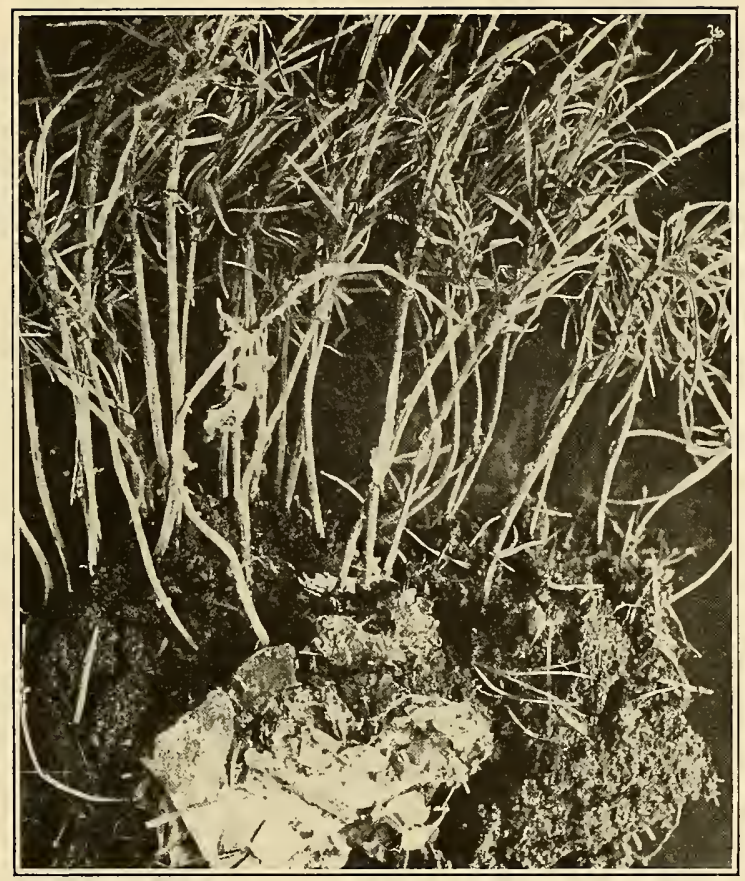

a. Drought injury, followed by fungus, p. 729 .

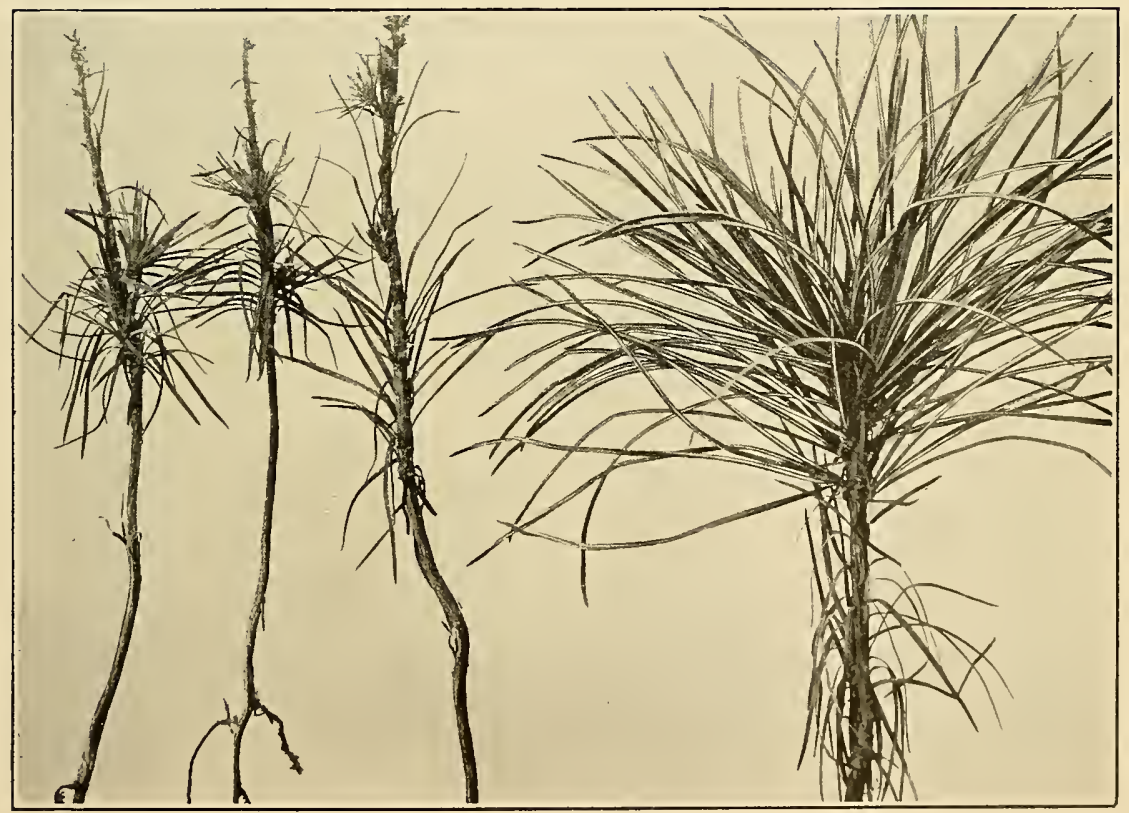

b. Frost injury, p. 730 . Tealthy. 



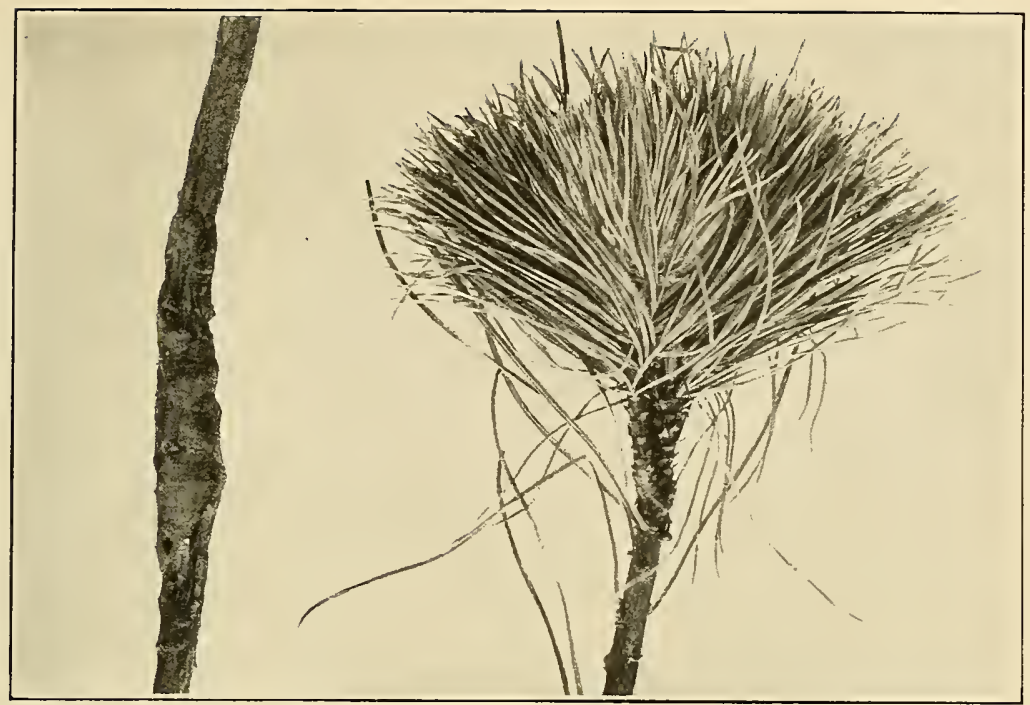

a. Pine-Currant Rust, p. 730.

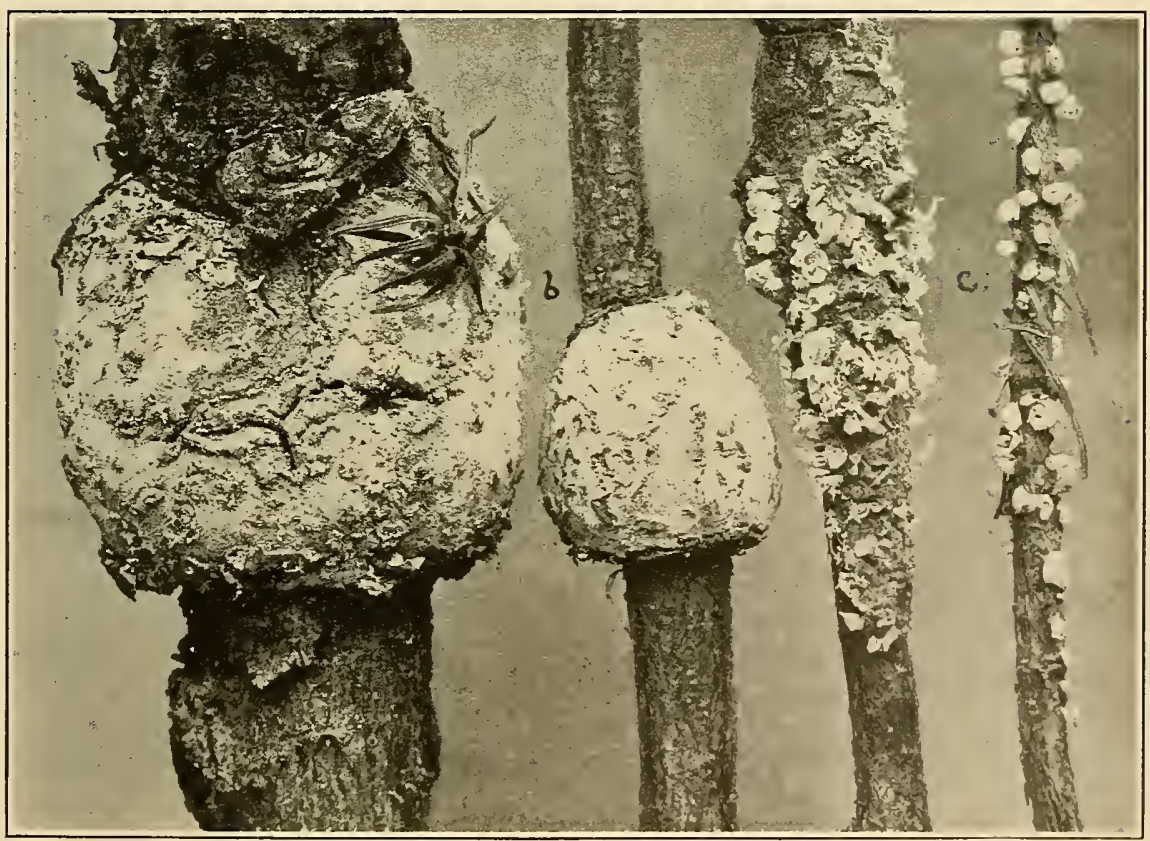

b. Pine-Oak Rust, p. 728. c. Pine-Sweetfern Rust, p. 729. 



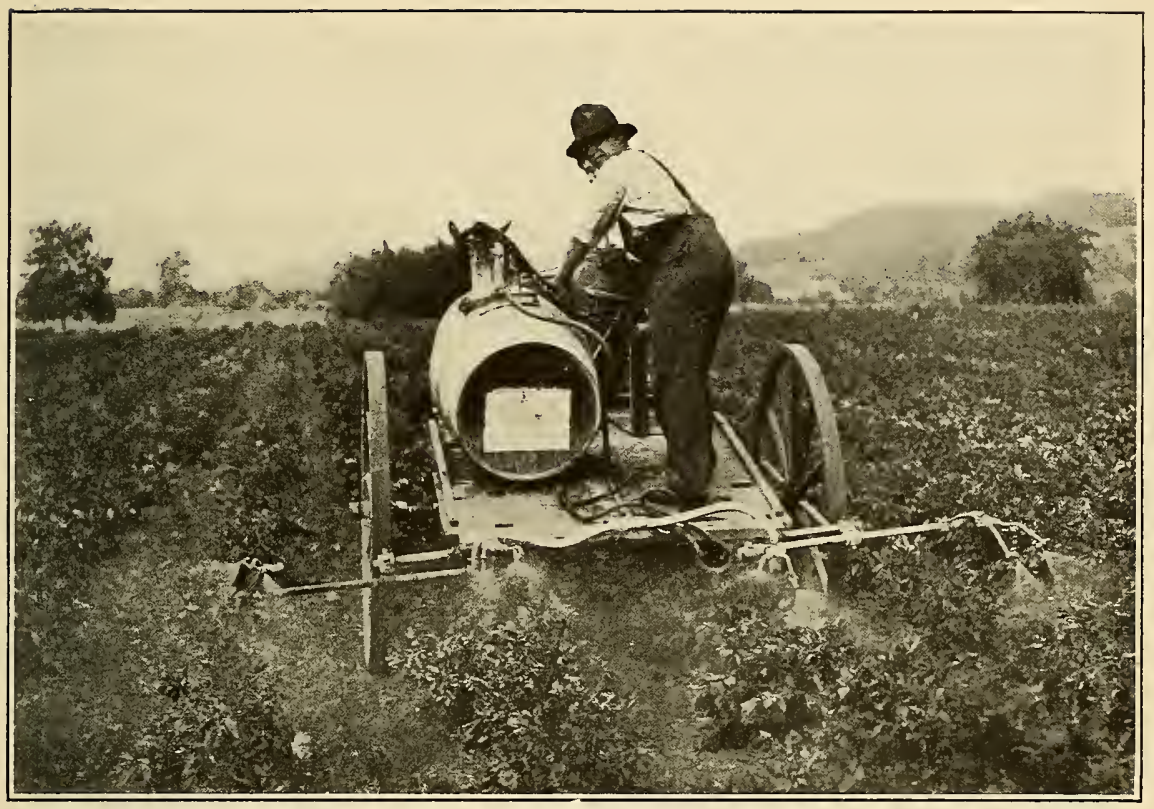

a. Spraying by hand with stationary nozzels.

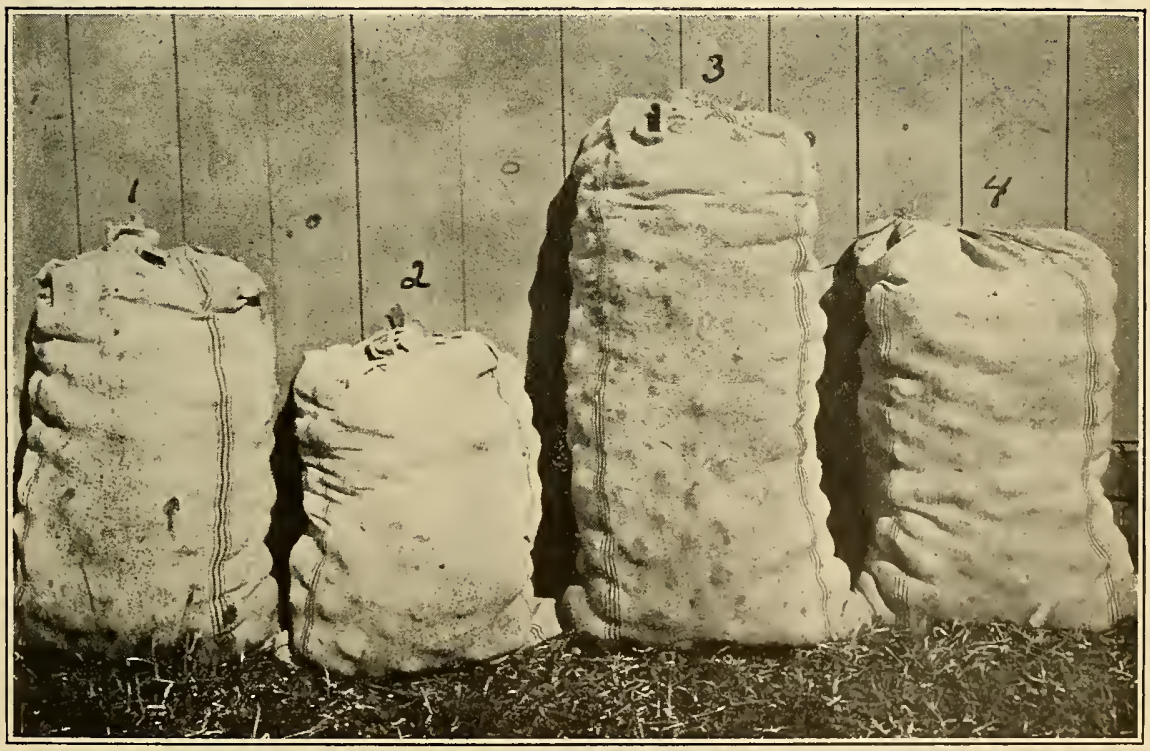

b. Comparative yields from sprayed $(\mathrm{I}, 3)$ and unsprayed $(2,4)$ vines, $\mathrm{p} .74 \mathrm{I}$. 



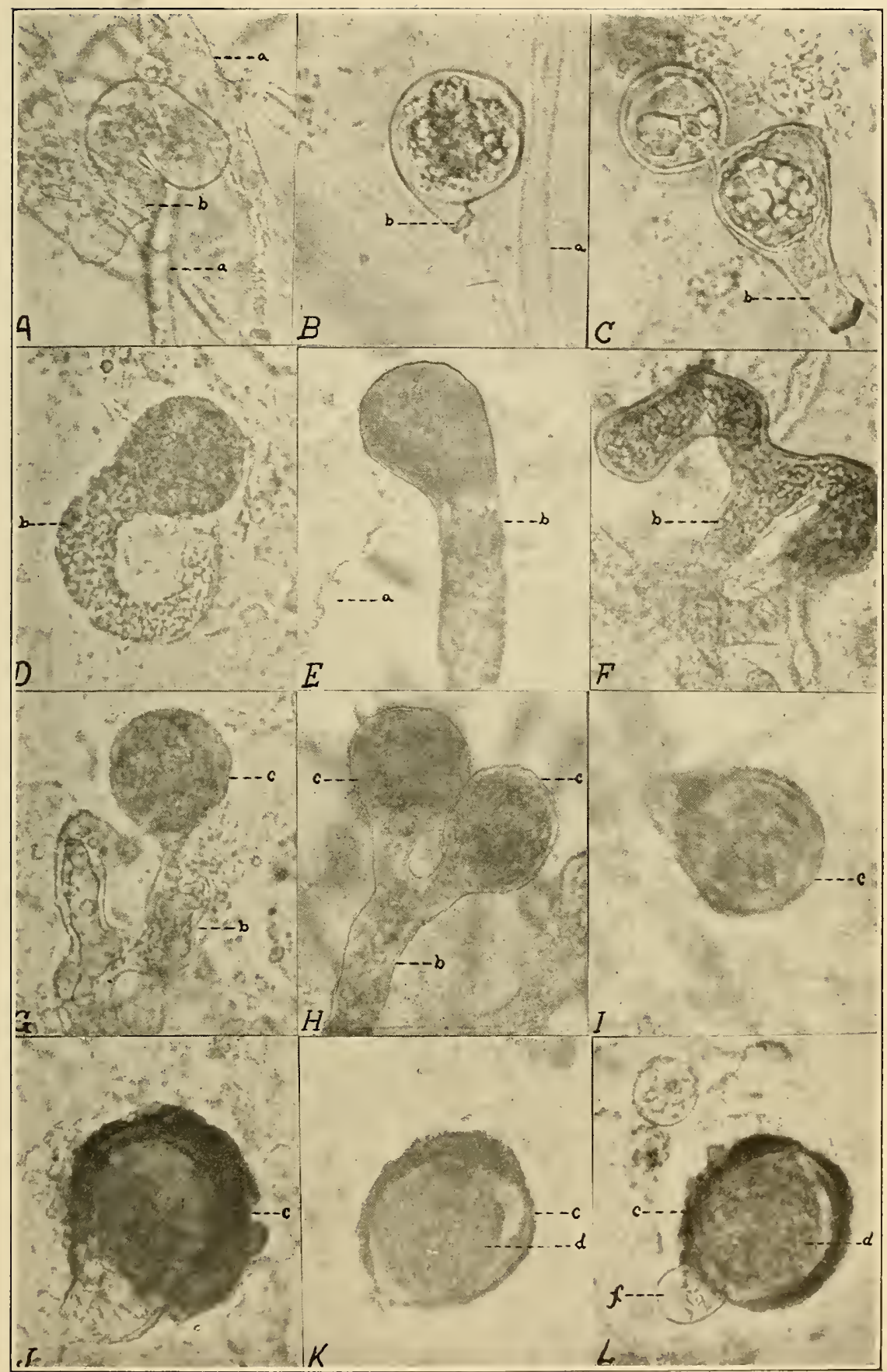

a. mycelium; b. oögonial thread; c. oögonium ; d. ö̈sphere; c. ö̈spore; f. antheridium. 



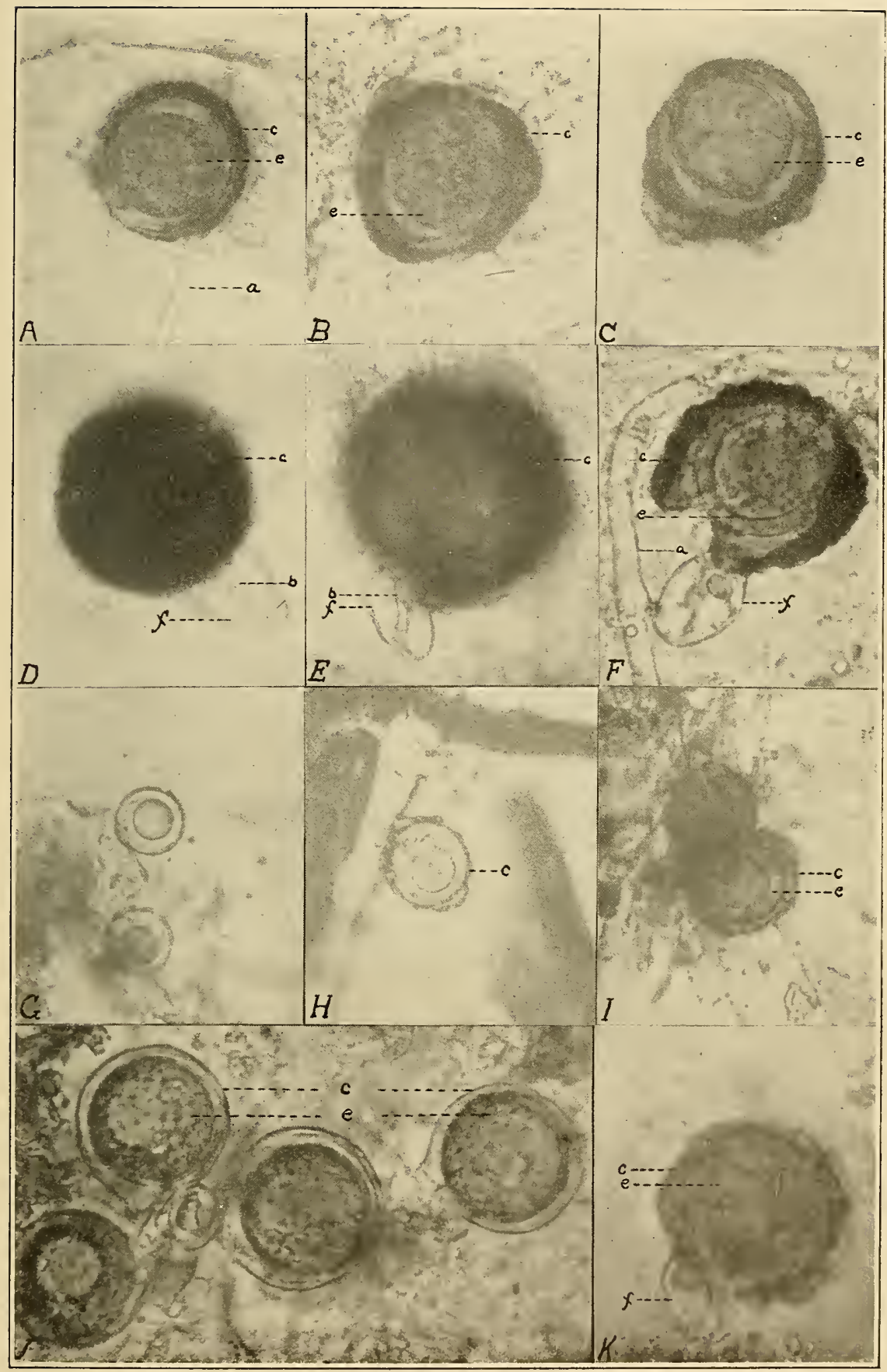

A-F. Mature oögonia, oöspores and antheridia of $P$. infestans, p. 770.

G-I. Oögonia-like bodies found in blighted leaves and tubers of potatoes, $p .756$.

J. Oïgonia of $P$. cactormm and K, hybrid of this and I'. infestans, p. 773.

OÖGONIA, OÖSPORES, ANTHERIDIA OF PHYTOPHTHORA sps, etc. 



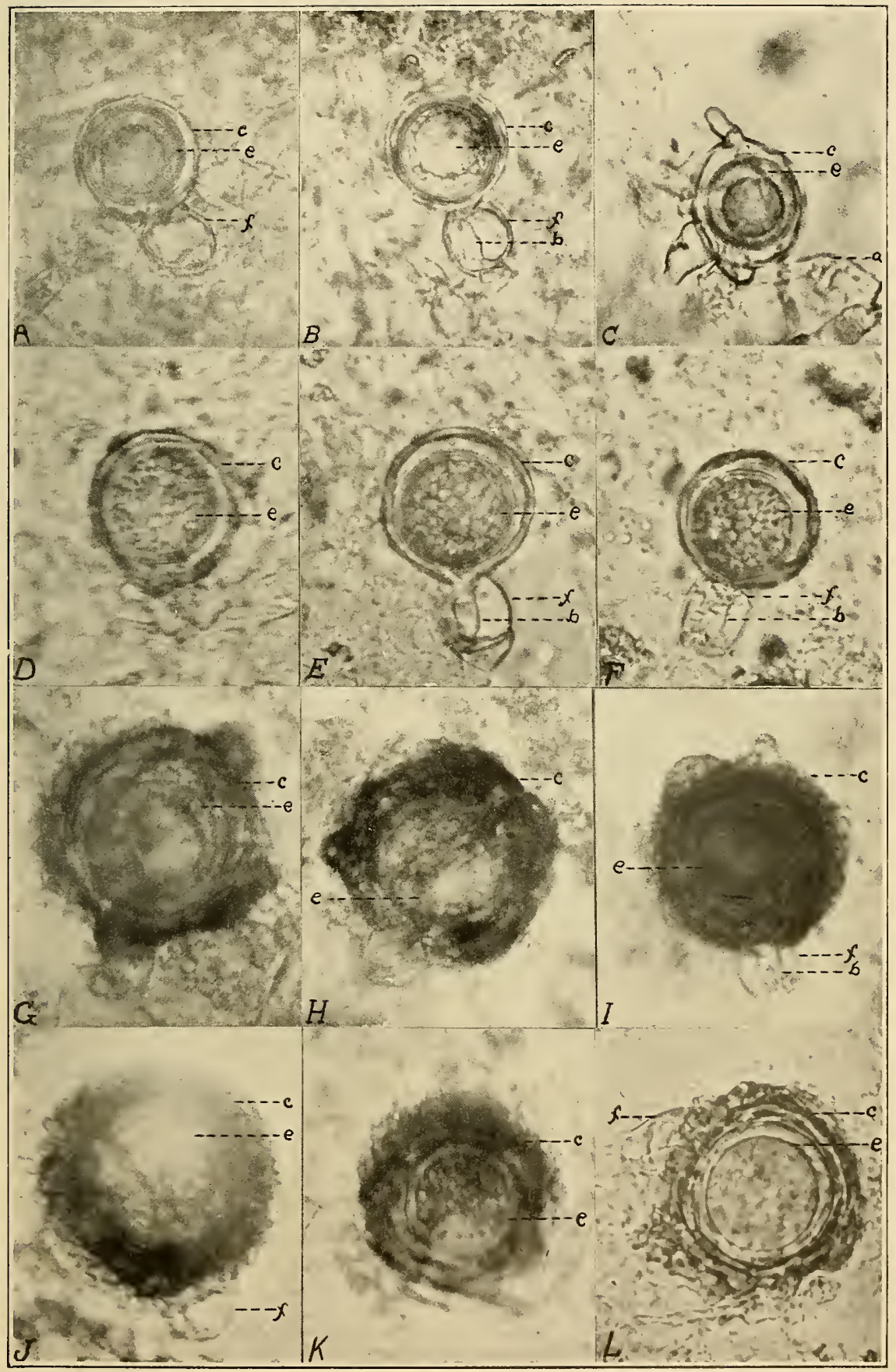

A-C, P. Phaseoli grown in Lima bean agar. D-F, P. Phaseoli grown in same tube of oat agar with $P$. infestans. G-L, Hybrids produced by fertilizing $P$ '. infestans ö̈gonia with antheridia of $P$. Phaseoli, p. 77r. 

$-$

-

- 






